\title{
Prehistoric Archeology and Paleoenvironments in Hidalgo and Willacy Counties, South Texas: Results of the Phase II Excavations
}

C. Britt Bousman

Department of Anthropology, Texas State University

Steve A. Tomka

Raba Kistner

Gail L. Bailey

Prewitt and Associates, Inc.

Follow this and additional works at: https://scholarworks.sfasu.edu/ita

Part of the American Material Culture Commons, Archaeological Anthropology Commons, Environmental Studies Commons, Other American Studies Commons, Other Arts and Humanities Commons, Other History of Art, Architecture, and Archaeology Commons, and the United States History Commons

Tell us how this article helped you.

This Article is brought to you for free and open access by the Center for Regional Heritage Research at SFA ScholarWorks. It has been accepted for inclusion in Index of Texas Archaeology: Open Access Gray Literature from the Lone Star State by an authorized editor of SFA ScholarWorks. For more information, please contact cdsscholarworks@sfasu.edu. 
Prehistoric Archeology and Paleoenvironments in Hidalgo and Willacy Counties, South Texas: Results of the Phase II Excavations

\section{Creative Commons License}

\section{c) (1)@ $\Theta$}

This work is licensed under a Creative Commons Attribution-NonCommercial-No Derivative Works 4.0 International License. 
PREHISTORIC ARCHEOLOGY AND PALEOENVIRONMENTS IN HIDALGO AND WILLACY COUNTIES, SOUTH TEXAS:

RESULTS OF THE PHASE II TEST EXCAVATIONS

by

C. Britt Bousman

Steve A. Tomka

and

Gail L. Bailey

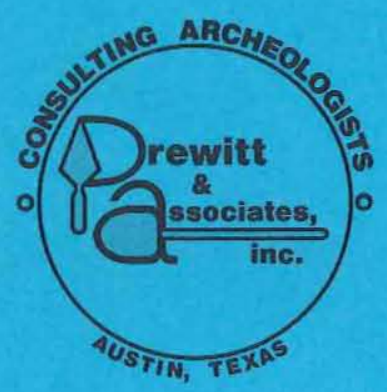

REPORTS OF INVESTIGATIONS, NUMBER 76

TEXAS ANTIQUITIES COMMITTEE PERMIT NUMBER 784 


\title{
PREHISTORIC ARCHEOLOGY AND PALEOENVIRONMENTS IN HIIDALGO AND WILLACY COUNTIES, SOUTH TEXAS: RESULTS OF THE PHASE II TEST EXCAVATIONS
}

by

\author{
C. Britt Bousman \\ Steve A. Tomka \\ and \\ Gail L. Bailey \\ with Contributions by \\ Charles D. Frederick \\ James T. Abbott \\ Colin M. Garvey \\ and \\ J. Michael Quigg
}

Co-Principal Investigators: C. Britt Bousman and Elton R. Prewitt

REPORTS OF INVESTIGATIONS, NUMBER 76

Prewitt and Associates, Inc.

Consulting Archeologists

Austin, Texas

December 1990 


\section{TABLE OF CONTENTS}

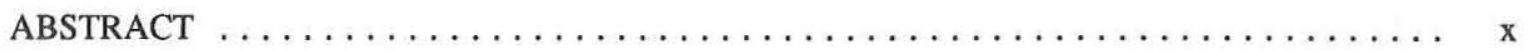

ACKNOWLEDGMENTS $\ldots \ldots \ldots \ldots \ldots \ldots \ldots \ldots \ldots \ldots \ldots \ldots \ldots \ldots \ldots \ldots \ldots \ldots \ldots \ldots \ldots$

CHAPTER 1: INTRODUCTION

C. Britt Bousman and Gail L. Bailey $\ldots \ldots \ldots \ldots \ldots \ldots \ldots \ldots \ldots \ldots$

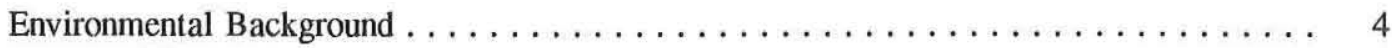

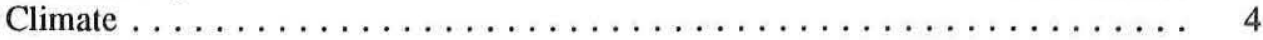

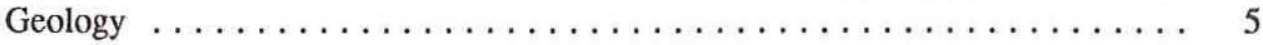

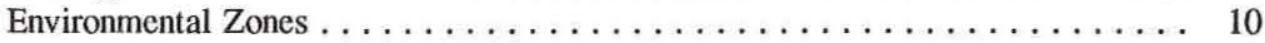

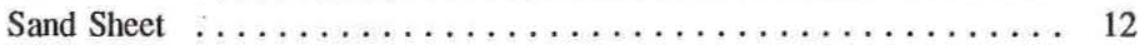

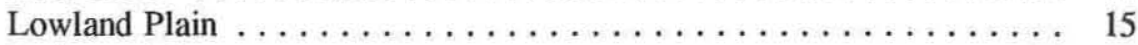

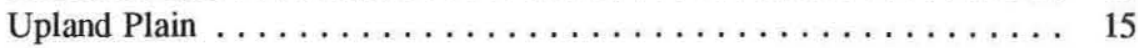

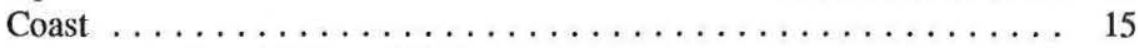

Rio Grande Floodplain and Delta $\ldots \ldots \ldots \ldots \ldots \ldots \ldots \ldots \ldots$

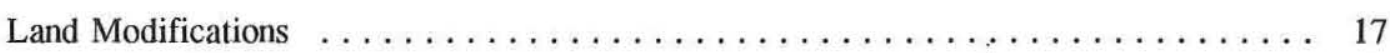

CHAPTER 2: ARCHEOLOGICAL BACKGROUND

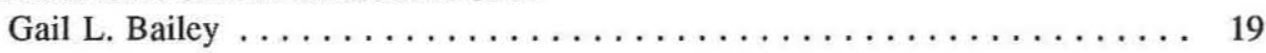

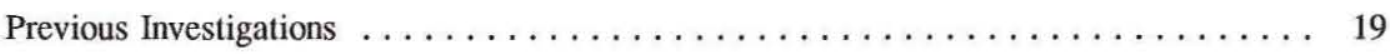

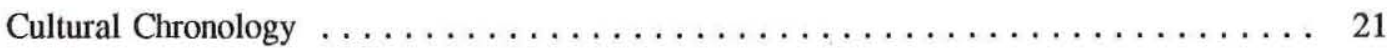

CHAPTER 3: MODELS OF LATE HOLOCENE HUMAN ADAPTATION IN THE LOWER RIO GRANDE VALLEY

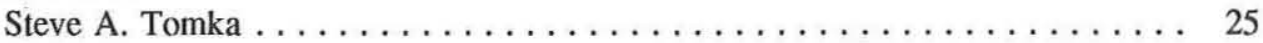

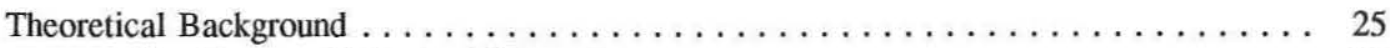

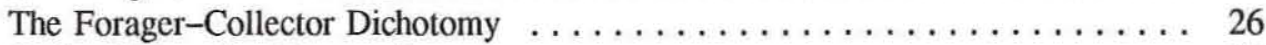

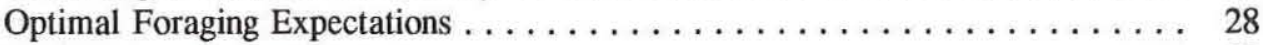

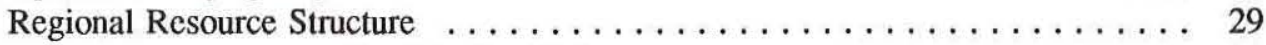

Ethnohistoric Resource Exploitation Patterns $\ldots \ldots \ldots \ldots \ldots \ldots \ldots \ldots \ldots$

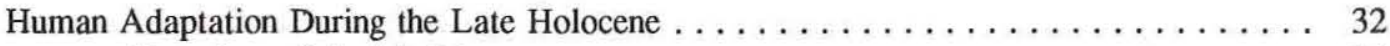

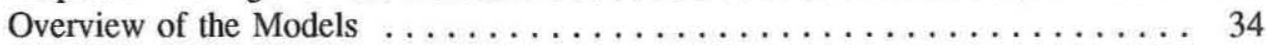

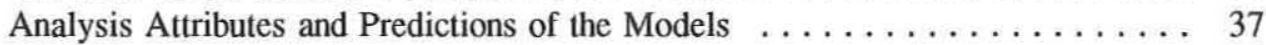

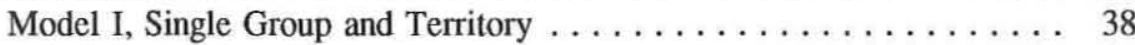

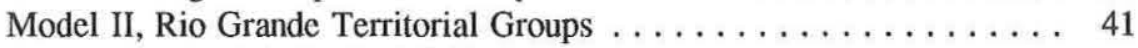

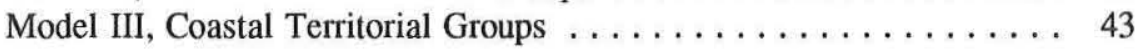

CHAPTER 4: OBJECTIVES AND METHODS

Gail L. Bailey and C. Britt Bousman $\ldots \ldots \ldots \ldots \ldots \ldots \ldots \ldots \ldots \ldots$

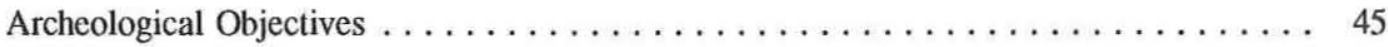

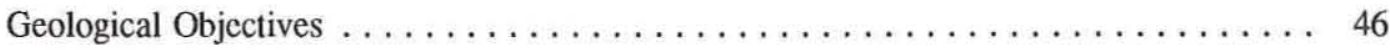

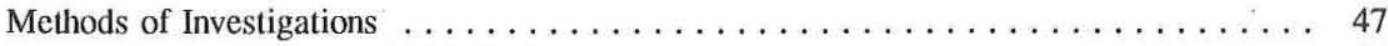

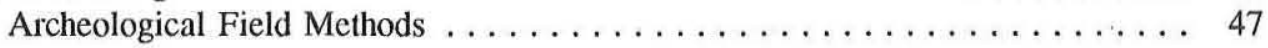

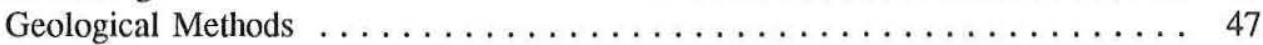

Laboratory Processing Methods $\ldots \ldots \ldots \ldots \ldots \ldots \ldots \ldots \ldots \ldots \ldots \ldots \ldots \ldots \ldots \ldots$

Evaluation of the Methodology $\ldots \ldots \ldots \ldots \ldots \ldots \ldots \ldots \ldots \ldots \ldots \ldots \ldots$ 
CHAPTER 5: SITE DESCRIPTIONS

Gail L. Bailey and C. Britt Bousman $\ldots \ldots \ldots \ldots \ldots \ldots \ldots \ldots \ldots \ldots \ldots \ldots \ldots \ldots \ldots \ldots$

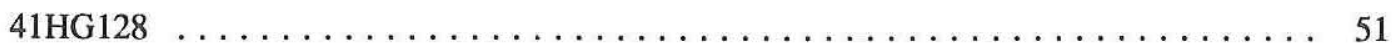

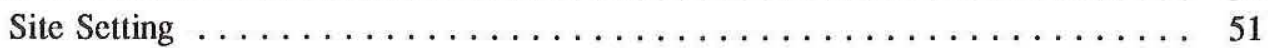

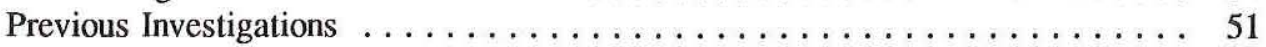

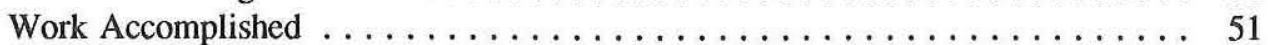

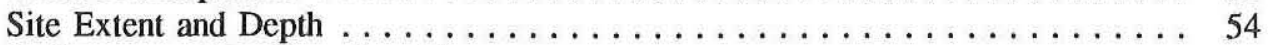

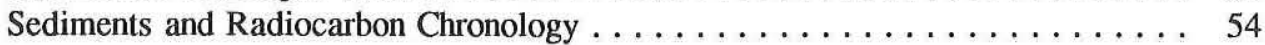

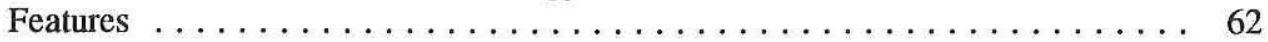

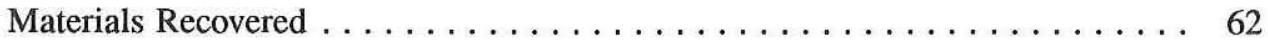

Discussion . . . . . . . . . . . . . . 62

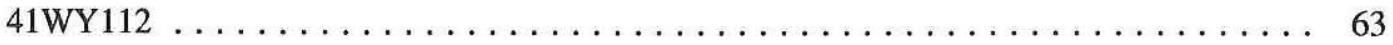

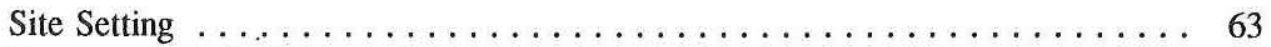

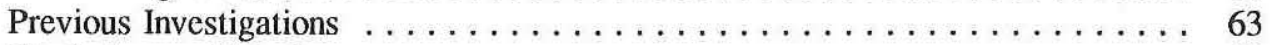

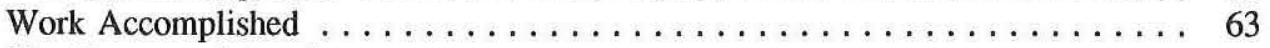

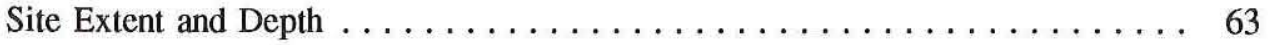

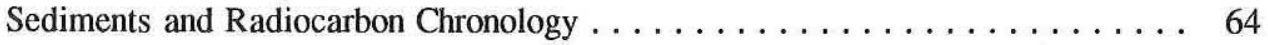

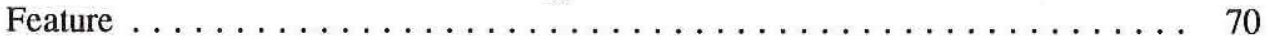

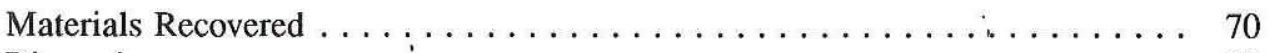

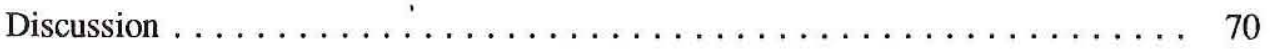

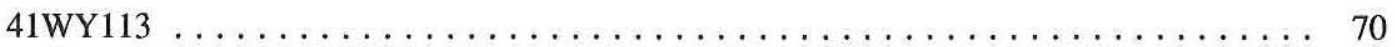

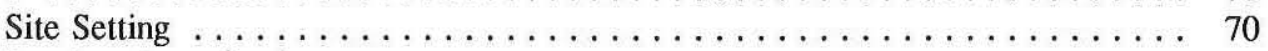

Previous Investigations $\ldots \ldots \ldots \ldots \ldots \ldots \ldots \ldots \ldots \ldots \ldots \ldots \ldots \ldots$

Work Accomplished $\ldots \ldots \ldots \ldots \ldots \ldots \ldots \ldots \ldots \ldots \ldots \ldots \ldots \ldots \ldots \ldots$

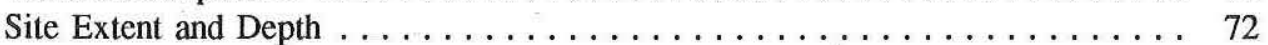

Sediments and Radiocarbon Chronology . . . . . . . . . . . . . . . . . . . 74

Features . . . . . . . . . . . . . . . . . . . . . . . 77

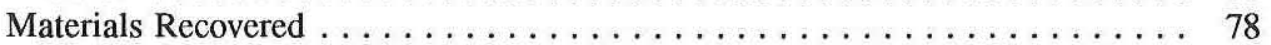

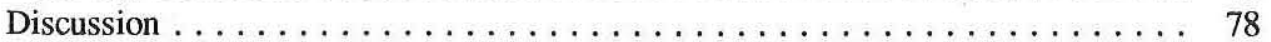

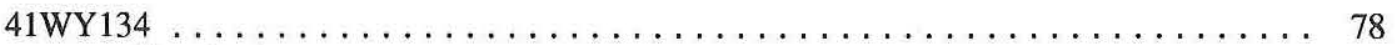

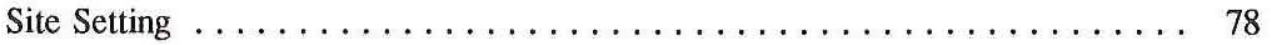

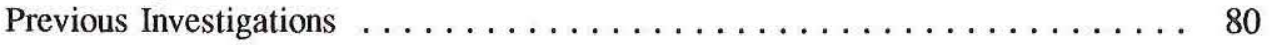

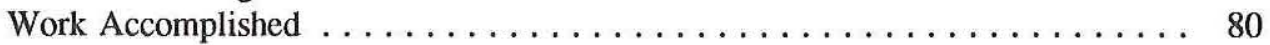

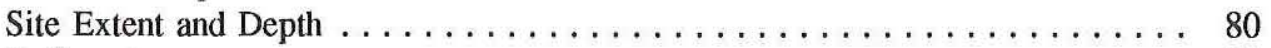

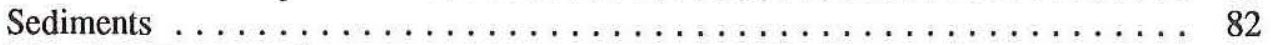

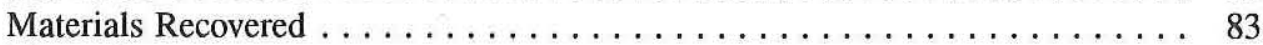

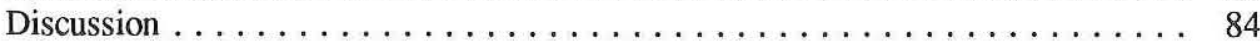

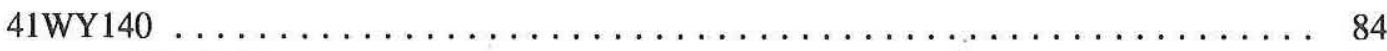

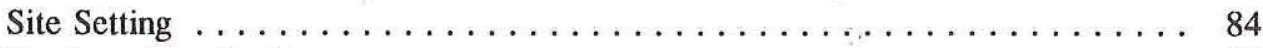

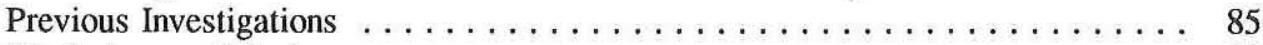

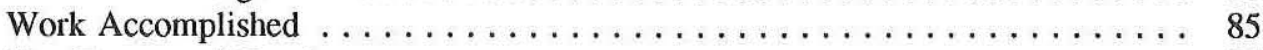

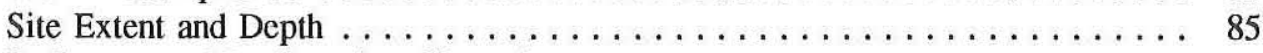

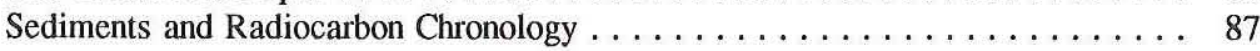

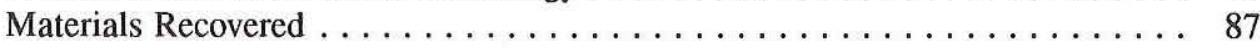

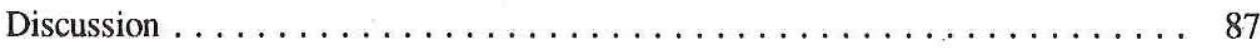

CHAPTER 6: PALEOENVIRONMENTS AND HUMAN DIETS

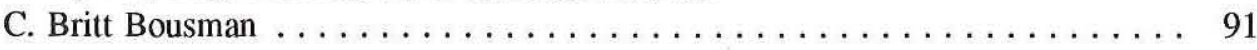

Late Pleistocene and Holocene Paleoenvironmental Change $\ldots \ldots \ldots \ldots \ldots \ldots \ldots$. 91

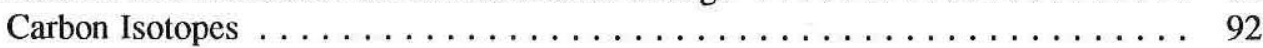

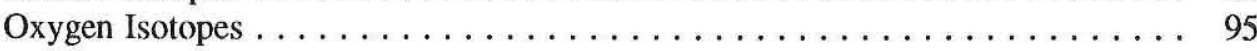

Faunal Remains . . . . . . . . . . . . . . . . . . . . . . . . 98 


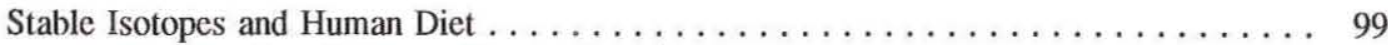

Radiocarbon Dates on Human Bone $\ldots \ldots \ldots \ldots \ldots \ldots \ldots \ldots \ldots \ldots$

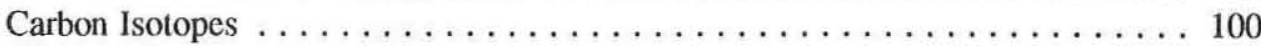

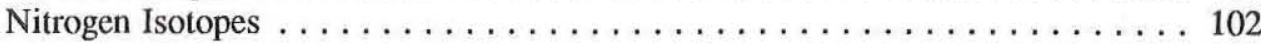

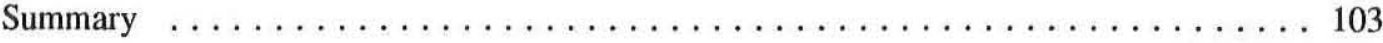

CHAPTER 7: TESTING THE HUNTER-GATHERER MOBILITY AND TERRITORIAL MODELS FOR THE LOWER RIO GRANDE VALLEY

Steve A. Tomka and C. Britt Bousman . . . . . . . . . . . . 105

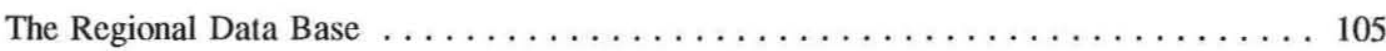

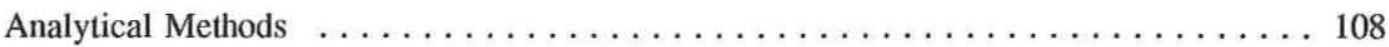

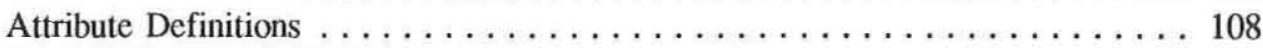

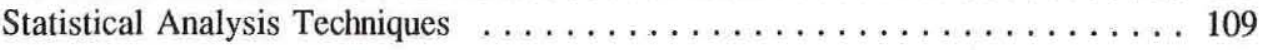

Discussion of Results . . . . . . . . . . . . . . . . . . . . . . . . . 114

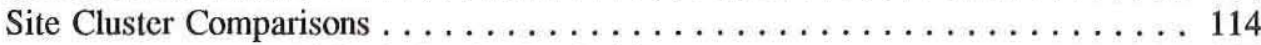

Frequency of Early Reduction Debitage $\ldots \ldots \ldots \ldots \ldots \ldots \ldots \ldots 115$

Debitage Size Frequencies . . . . . . . . . . . . . . . . 120

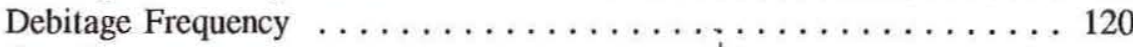

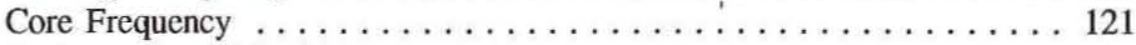

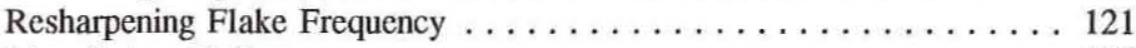

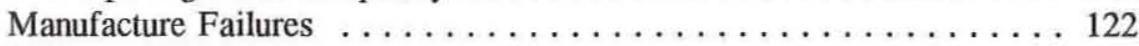

Exhausted Tool Frequencies . . . . . . . . . . . . . 122

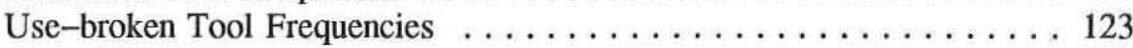

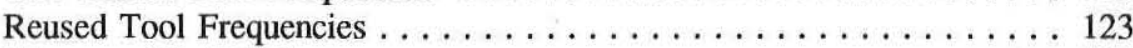

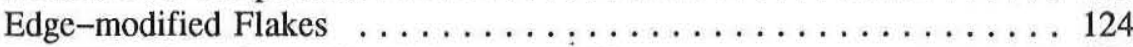

Mean Number of Working Edges per Uniface $\ldots \ldots \ldots \ldots \ldots \ldots 124$

Mean Number of Utilized Edges per Edge-modified Flake . . . . . . 124

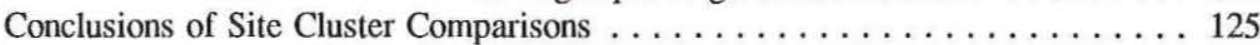

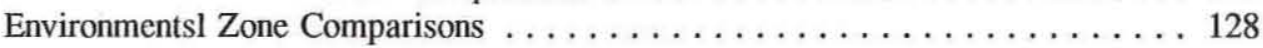

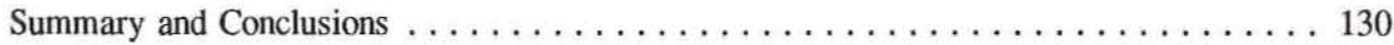

CHAPTER 8: CONCLUSIONS AND SITE ASSESSMENTS

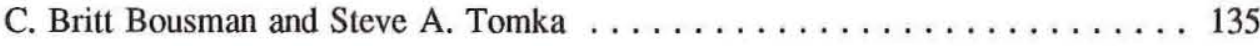

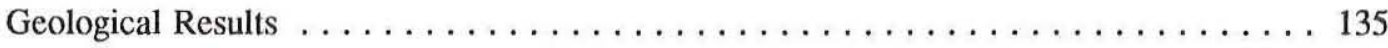

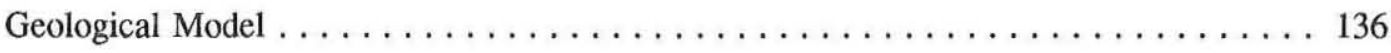

Archeological Results $\ldots \ldots \ldots \ldots \ldots \ldots \ldots \ldots \ldots \ldots \ldots \ldots \ldots \ldots \ldots \ldots \ldots \ldots \ldots$

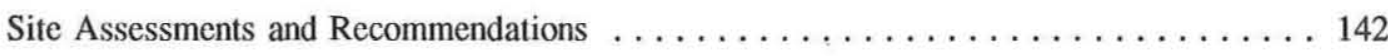

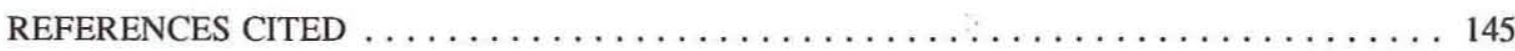

APPENDIX A: Materials Recovered

Gail L. Bailey, Steve A. Tomka, and C. Britt Bousman . . . . . . . . . 165

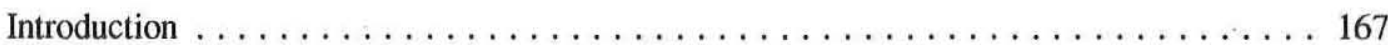

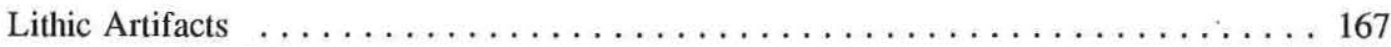

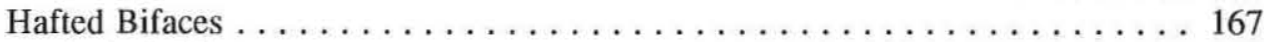

Nonhafted Bifaces . . . . . . . . . . . . . . . . . . . 169

Miscellaneous Biface Fragments . . . . . . . . . . . . . . . . 169

Edge-modified Flake . . . . . . . . . . . . . . . . . . . . . . . 169

Tested Cobble . . . . . . . . . . . . . . . . . . . . . . . . . . . . . 169

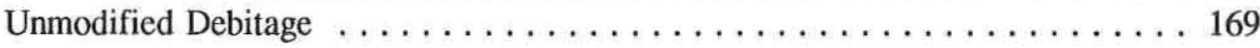




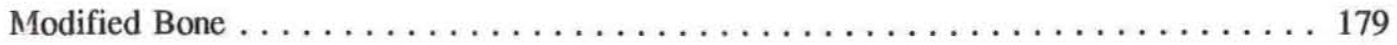

Ceramic Sherd from 41 HG128 . . . . . . . . . . . . . . . . . . . . 179

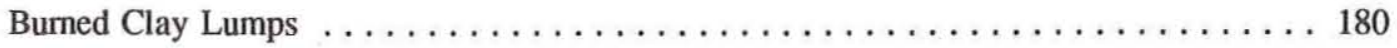

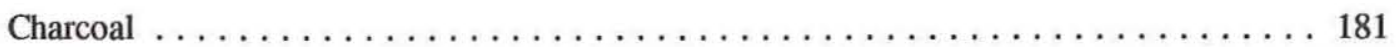

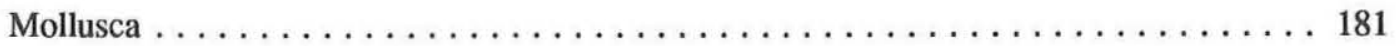

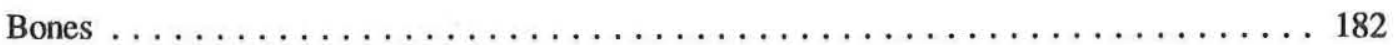

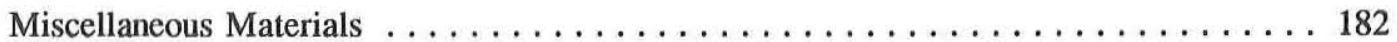

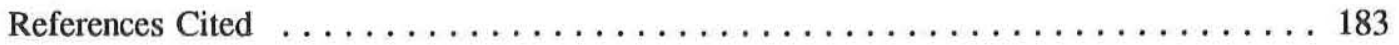

APPENDIX B: Magnetic Investigations at Sites 41WY112 and 41WY113

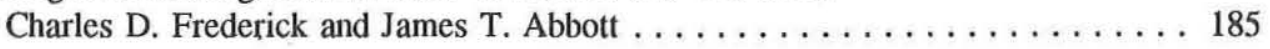

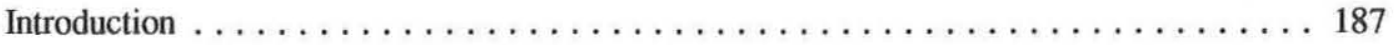

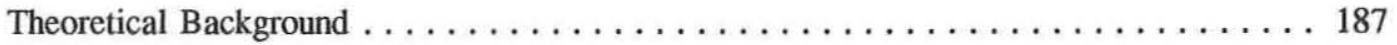

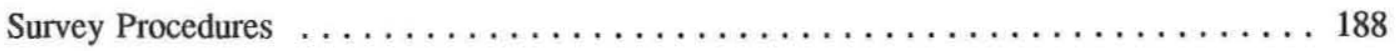

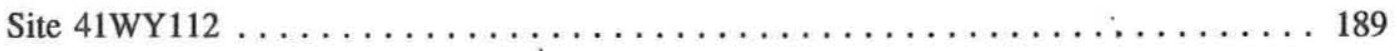

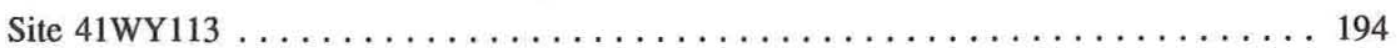

Conclusions . . . . . . . . . . . . . . . . . . . . . . . . . . . . . . . . . . 194

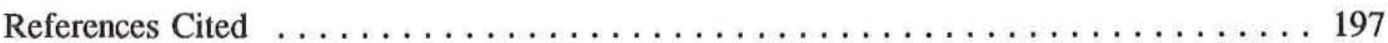

APPENDIX C: Geological Profile Descriptions

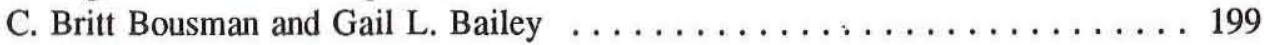

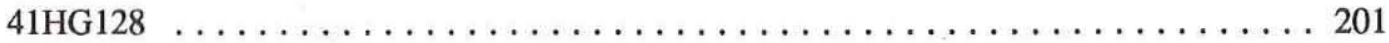

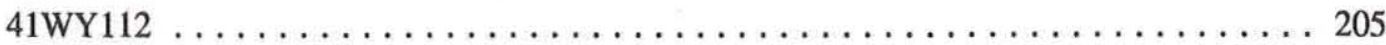

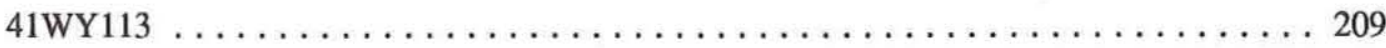

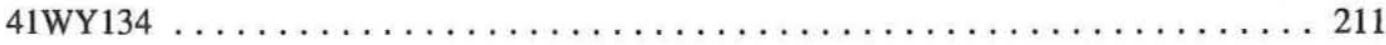

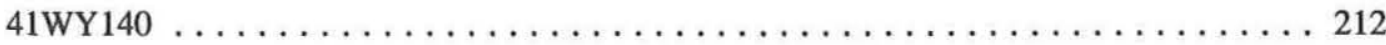

APPENDIX D: Radiocarbon Dating

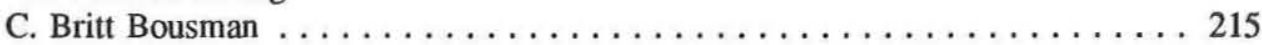

APPENDIX E: Application and Comparison of Two Water Pump Systems

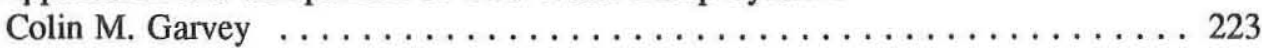

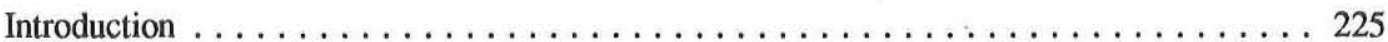

The Agricultural Pump or Positive Displacement Roller Spray Pump . . . . . . . . . 225

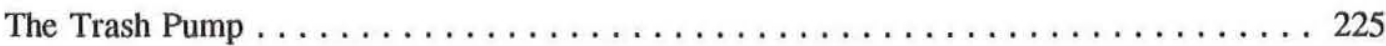

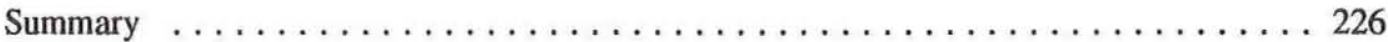

APPENDIX F: Archeological Reconnaissance of Realigned Segment of the Mission-Lateral, Hidalgo County, Texas

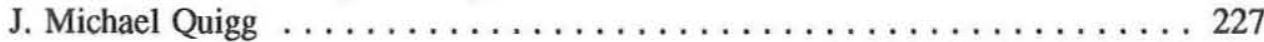

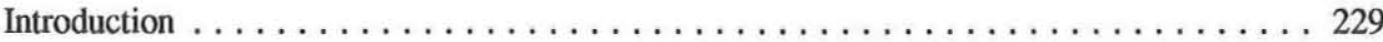

Methods, Results, and Recommendations . . . . . . . . . . . . . . . . 229

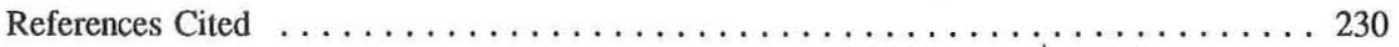




\section{LIST OF FIGURES}

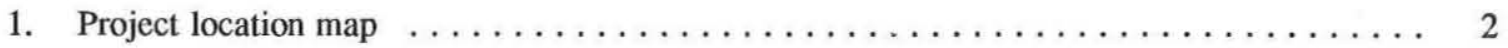

2. Average monthly high temperatures at five weather stations in the region $\ldots \ldots \ldots \ldots$

3. Five-year moving averages of South Texas drought index, $1900-1983 \ldots \ldots \ldots \ldots$

4. Mean monthly rainfall for five weather stations in the region $\ldots \ldots \ldots \ldots \ldots \ldots \ldots$

5. Bedrock geological formations in the Lower Rio Grande Valley region $\ldots \ldots \ldots \ldots \ldots .8$

6. Sea level changes in the last 150,000 years $\ldots \ldots \ldots \ldots \ldots \ldots \ldots \ldots \ldots \ldots$

7. Gulf basin sea level changes as indicated by freshwater- and saltwaterassociated deposits in the last 16,000 years $\ldots \ldots \ldots \ldots \ldots \ldots \ldots \ldots \ldots \ldots$

8. Abandoned Rio Grande channels and blowout depressions $\ldots \ldots \ldots \ldots \ldots \ldots \ldots \ldots \ldots 11$

9. Map of the environmental zones in the lower Rio Grande Valley $\ldots \ldots \ldots \ldots \ldots \ldots$

10. Photograph of active dune and stabilized dune in southern sand sheet $\ldots \ldots \ldots \ldots \ldots$

11. Aerial photograph of small blowout surrounded by natural vegetation $\ldots \ldots \ldots \ldots \ldots$

12. Aerial photograph showing modern land-clearing activities $\ldots \ldots \ldots \ldots \ldots \ldots \ldots \ldots$

13. Regional environmental zones and hypothesized land-use models $\ldots \ldots \ldots \ldots \ldots \ldots \ldots$

14. Photograph showing water-screening system at $41 \mathrm{WY} 112 \ldots \ldots \ldots \ldots \ldots \ldots \ldots \ldots$

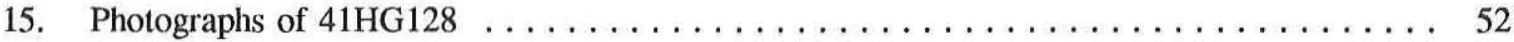

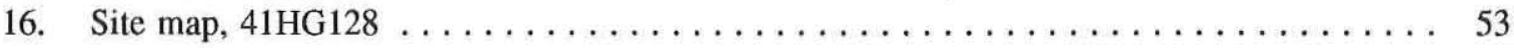

17. Distribution of soils and blowout depressions at $41 \mathrm{HG} 128 \ldots \ldots \ldots \ldots \ldots \ldots \ldots \ldots$

18. Selected geological profiles of backhoe trenches and test units at $41 \mathrm{HG} 128 \ldots \ldots \ldots 7$

19. Geological profile of Test Unit 5 , $41 \mathrm{HG} 128 \ldots \ldots \ldots \ldots \ldots \ldots \ldots \ldots \ldots \ldots \ldots \ldots \ldots \ldots$

20. Geological profile of Test Unit 6,41 HG128 $\ldots \ldots \ldots \ldots \ldots \ldots \ldots \ldots \ldots \ldots \ldots$

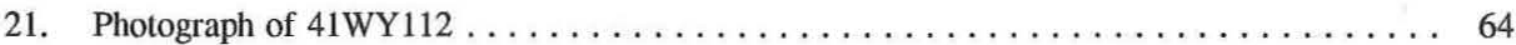

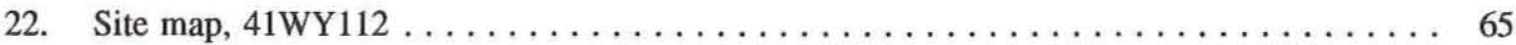

23. Distribution of soils and blowout depressions at 41 WY $112 \ldots \ldots \ldots \ldots \ldots \ldots \ldots \ldots$

24. Selected geological profiles of backhoe trenches and test units at $41 \mathrm{WY} 112 \ldots \ldots \ldots 6$

25. Photograph of Feature 1 road surface in Test Unit 5,41 WY112 $\ldots \ldots \ldots \ldots \ldots \ldots \ldots .71$

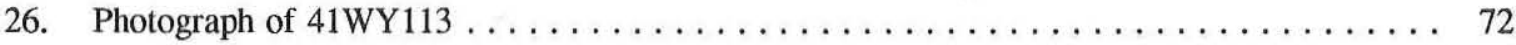

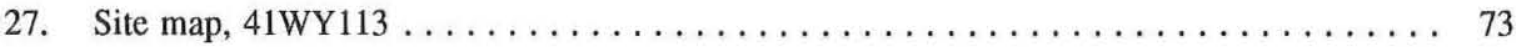

28. Distribution of soils and blowout depressions at $41 \mathrm{WY} 113 \ldots \ldots \ldots \ldots \ldots \ldots \ldots$

29. Selected geological profiles of backhoe trenches and test units at $41 \mathrm{WY} 113 \ldots \ldots \ldots$

30. Geological profile of Feature 1, Test Unit 2, 41WY113 $\ldots \ldots \ldots \ldots \ldots \ldots \ldots$

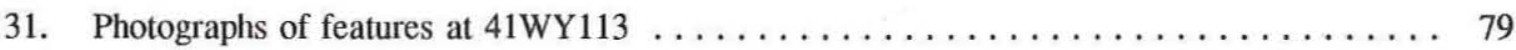

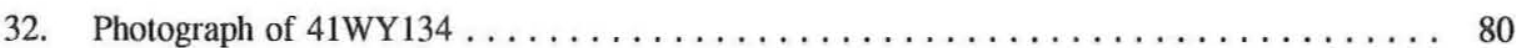

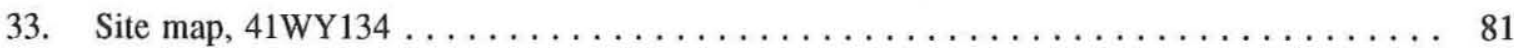

34. Distribution of soils and blowout depressions at 41 WY $134 \ldots \ldots \ldots \ldots \ldots \ldots \ldots$ 
35. Selected geological profiles of backhoe trenches and test unit at $41 \mathrm{WY} 134 \ldots \ldots \ldots 4$

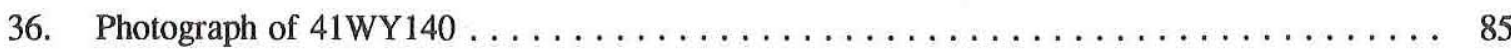

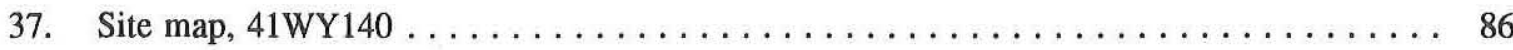

38. Distribution of soils and blowout depressions at $41 \mathrm{WY} 140 \ldots \ldots \ldots \ldots \ldots \ldots$

39. Selected geological profiles of backhoe trenches at $41 \mathrm{WY} 140 \ldots \ldots \ldots \ldots \ldots$

40. Linear regression of $\delta^{13} \mathrm{C}$ in nonfreezing soil carbonates and percent of $\mathrm{C}_{3}$ biomass $\ldots \ldots 94$

41. Estimates of $\mathrm{C}_{3}$ plant percentages for humate and pedogenic carbonate samples $\ldots \ldots \ldots 95$

42. Linear regression between ${ }^{18} \mathrm{O} /{ }^{16} \mathrm{O}$ ratios in soil carbonates and associated meteoric water . . 96

43. Linear regression between ${ }^{18} \mathrm{O} /{ }^{16} \mathrm{O}$ ratios in local meteoric water

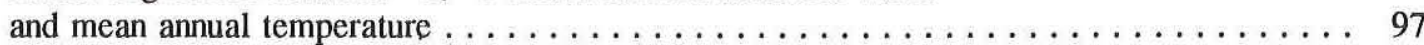

44. Estimates of $\mathrm{C}_{3}$ plants and temperature using oxygen and carbon stable isotopes from carbonates $\ldots \ldots \ldots \ldots \ldots \ldots \ldots \ldots \ldots \ldots$

45. Soil humate and human stable carbon isotope ratios $\ldots \ldots \ldots \ldots \ldots \ldots \ldots \ldots \ldots$

46. Site clusters and hunter-gatherer mobility/territorial models $\ldots \ldots \ldots \ldots \ldots \ldots \ldots \ldots$

47. Observed values versus expected values by site cluster for analyzed

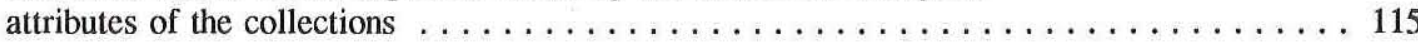

48. Observed distribution of artifact frequencies by environmental zone . . . . . . . . . . 129

49. Distribution of all known sites and sites with marine shells, obsidian, and ceramics $\ldots \ldots 132$

50. South Texas physiographic features and some of the major archeological projects . . . . 137

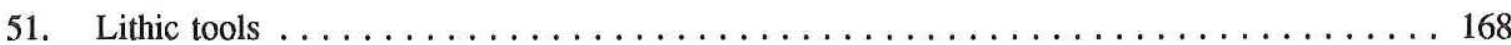

52. Modified bone from $41 \mathrm{WY} 113 \ldots \ldots \ldots \ldots \ldots \ldots \ldots \ldots \ldots \ldots$

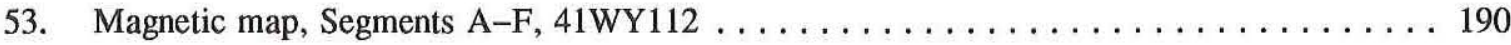

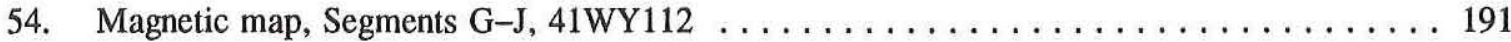

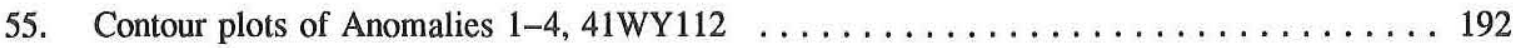

56. Contour plots of Anomalies $5-7,41 \mathrm{WY} 112 \ldots \ldots \ldots \ldots \ldots \ldots \ldots \ldots \ldots \ldots \ldots \ldots \ldots$

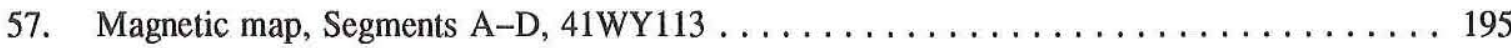

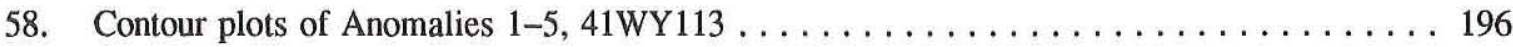

59. Percent variation between uncorrected and corrected radiocarbon dates $\ldots \ldots \ldots \ldots \ldots 220$

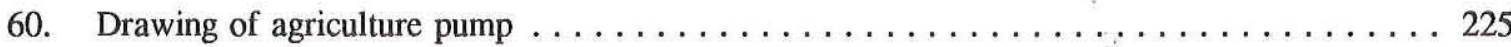

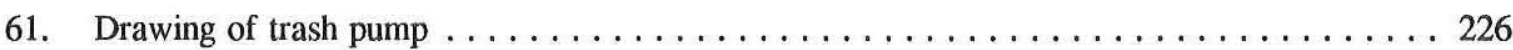

62. Section of USGS 7.5' Alton and Edinburg, Texas quadrangles showing survey area . . . . . 229 


\section{LIST OF TABLES}

1. Correlation of environmental zones between present and previous projects $\ldots \ldots \ldots \ldots 14$

2. Publications and technical reports on the Rio Grande Delta $\ldots \ldots \ldots \ldots \ldots \ldots \ldots \ldots$

3. Summary of ethnohistoric groups, names, and locations $\ldots \ldots \ldots \ldots \ldots \ldots \ldots \ldots \ldots$

4. Lithic assemblage predictions, Model I $\ldots \ldots \ldots \ldots \ldots \ldots \ldots \ldots \ldots \ldots \ldots \ldots \ldots \ldots \ldots \ldots \ldots$

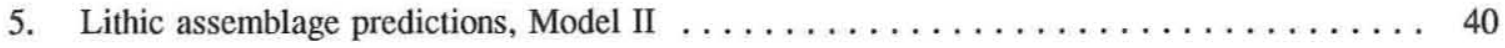

6. Lithic assemblage predictions, Model III $\ldots \ldots \ldots \ldots \ldots \ldots \ldots \ldots \ldots \ldots \ldots \ldots$. 41

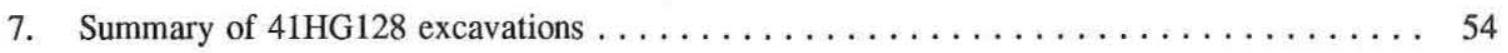

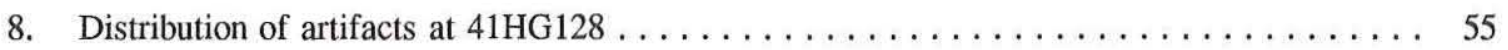

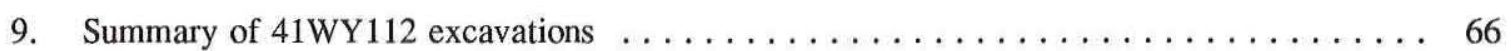

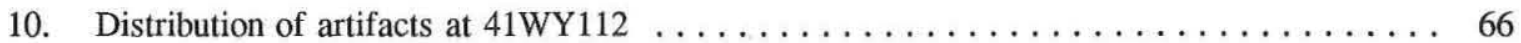

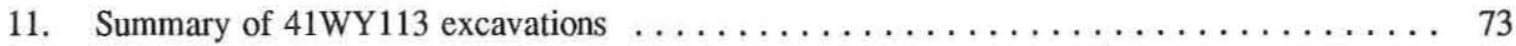

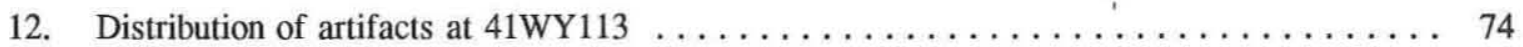

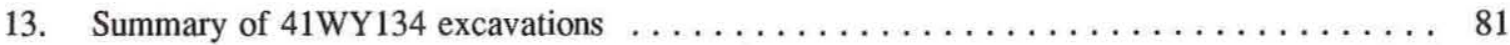

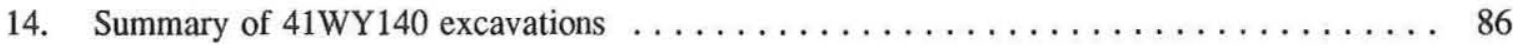

15. Classification of sites by site cluster and environmental zone $\ldots \ldots \ldots \ldots \ldots \ldots \ldots$

16. Analytical categories by site cluster and environmental zone $\ldots \ldots \ldots \ldots \ldots \ldots \ldots \ldots$

17. Comparison of observed standardized deviates with Model I predictions $\ldots \ldots \ldots \ldots 116$

18. Comparison of observed standardized deviates with Model II predictions $\ldots \ldots \ldots \ldots \ldots 118$

19. Comparison of observed standardized deviates with Model III predictions . . . . . . . . . 119

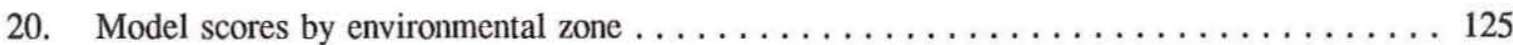

21. Factor analysis of artifact categories $\ldots \ldots \ldots \ldots \ldots \ldots \ldots \ldots \ldots \ldots \ldots \ldots \ldots \ldots \ldots \ldots$

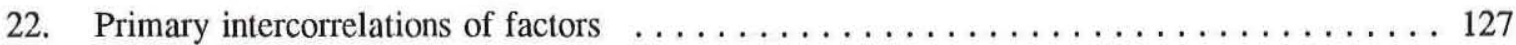

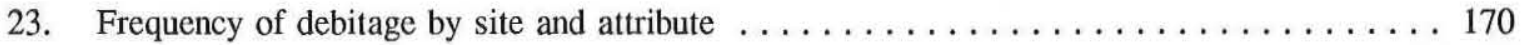

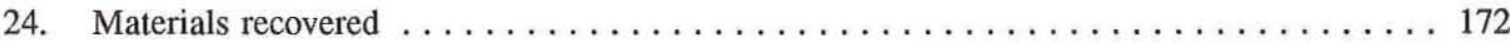

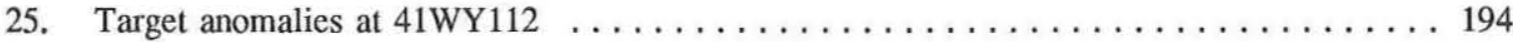

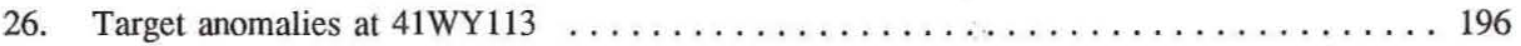

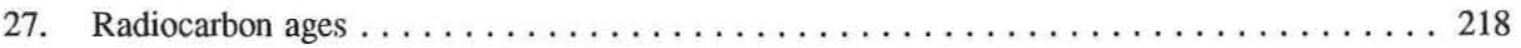




\begin{abstract}
In May 1989 through July 1989, archeological and geomorphological investigations were conducted at five prehistoric archeological sites impacted by drainage ditch construction in Hidalgo and Willacy counties. These investigations were sponsored by Hidalgo County Drainage District No. 1 and Willacy County Drainage District No. 1 as part of a continuing program of cultural resources studies along the drainage ditch construction right-of-way. One site, 41WY140, is situated on a low rise adjacent to a main channel of the ditch and lacks sufficient Holocene sediments to contain archeological materials in good context. However, a tortoise, cf. Gopherus hexagonatus, was recovered, and the inorganic fraction was assayed by radiocarbon to $9360 \pm 415$ B.P. If correct, this date indicates that these now-extinct tortoises could have been coeval with Paleoindian occupations in South Texas. The other four sites are in or on the edges of small deflationary basins. Based on the radiocarbon chronology obtained from these sites, soils formed on many of the deflationary basins during the late Pleistocene. Between ca. 12,000 B.P. and 5000 B.P., these soils were removed by wind erosion, and in the last 5,000 years, a modern soil formed. At all sites, this modern soil has been disturbed by historic farming, land clearing, and ditch construction. The prehistoric archeological remains at 41HG128, 41WY112, 41WY113, and 41WY134 are sparse, reflecting a continuing record of nonintensive use by mobile hunter-gatherers. In order to assess the National Register eligibility of individual sites, three models of hunter-gatherer resource and territorial exploitation patterns were developed and a preliminary test of these models was conducted with the regional archeological data base. The first model assumes unrestricted access to all major resource areas in the region; the second model assumes that prehistoric territories focused on resources along the Rio Grande floodplain; and the third model assumes that hunter-gatherer territories were organized in response to coastal resources. The results of the test were inconclusive, but important exploitation patterns were recognized and invalid assumptions of the models identified. In light of the recovered materials from the sites, the analysis of the regional data base, and the assessment of the models, none of the five sites reported here are judged eligible for listing on the National Register of Historic Places, and no further work at these sites is recommended.
\end{abstract}




\section{ACKNOWLEDGMENTS}

Many people contributed to the completion of this project. Vona Walker, Director of the Hidalgo County Right of Way Department, and Jim Riggan, Director of the Willacy County Drainage District No. 1, helped in many ways including providing the earth-moving machinery and machine operators used in fieldwork. Jim Riggan is also thanked for taking the primary author on an aerial reconnaissance of the project area and region in his private plane. Rick Olvera, a Willacy County Drainage District backhoe operator, was especially helpful and knowledgeable about the area and the details of ditch construction and maintenance.

The field crew consisted of Gail Bailey, project archeologist; Colin Garvey, assistant archeologist; and Karl Kibler, Dan Lauterbur, Jeff McCulloch, and Joe Sanchez, crewmembers. Their perseverance through hot weather, hard dirt, and few artifacts is a testament to their professionalism and dedication. Their contribution is greatly appreciated. The proton magnetometer survey was conducted by Charles Frederick with assistance from Jeff McCulloch. The geoarcheology was undertaken by Britt Bousman, and Karl Kibler assisted in the field.

Thanks are due to Carolyn Good, Galveston District, U.S. Army Corps of Engineers, for allowing radiocarbon dating and stable isotope analysis of human remains collected from 41 WY50 and 41WY67 during previous Corps sponsored projects. Dr. Thomas Hester, Dr. Darrell Creel, and Joseph Powell provided ready access to materials housed at the Texas Archeological Research Laboratory, The University of Texas at Austin.

A number of individuals contributed to the success of this report by acting as sounding boards for ideas and/or providing information; these individuals are Dr. Michael B. Collins, J. Michael Quigg, Dr. Rolfe D. Mandel, Robert J. Mallouf, Dr. Joe Saunders, Dr. Grant D. Hall, and Michael D. Blum. The reader should not, however, attribute blame to them for misinterpretations. In addition, we would like to thank the Coastal Palaver for allowing us to present a synopsis of the research design at their Fall 1989 meeting and greatly appreciate the interaction and discussion generated within that group.

The staff at Prewitt and Associates, Inc. has provided able assistance through all phases of these investigations. More specifically, Jerrilyn McLerran has been the logic board through which all our ideas, and worse yet, our grammar had to pass. She is to be commended for her diligence and attention to detail. This report would have been considerably less intelligible without her editorial efforts. Sandra Hannum and Colin Garvey, assisted by Karen Gardner, have skillfully produced the maps and graphs that, as always, make the written word understandable at a glance. Ellen Atha drew the artifact illustrations, and our only wish was that we had recovered more artifacts for her to draw. Laboratory processing was directed by Jeanine McDonald with Karen Gardner assisting, and J. Michael Quigg assisted the faunal analysis. Finally, thanks are due to Ross C. Fields and Elton Prewitt for their sage advice at all levels of this project and report preparation. 



\section{INTRODUCTION}

by C. Britt Bousman and Gail L. Bailey

This report presents the findings from archeological investigations of the following five prehistoric sites in Hidalgo and Willacy counties in the Lower Rio Grande Valley of South Texas: 41HG128, 41WY112, 41WY113, 41WY134, and 41WY140. These sites are along the Hidalgo-Willacy Drainage Ditch, a manmade river system constructed by Hidalgo County Drainage District No. 1 and Willacy County Drainage District No. 1, that drains hurricane-delivered floodwaters from an enormous area in these two counties (Fig. 1). These five sites were originally reported in 1987 and recommended for Phase II test excavations at that time (Hall et al. 1987). One of the sites is located in eastern Hidalgo County, while the remaining four are in central and western Willacy County. The present field investigations, which began in May and continued through June of 1989, were conducted by Prewitt and Associates, Inc. under contract with Hidalgo County Drainage District No. 1 and Willacy County Drainage District No. 1.

Hidalgo County Drainage District No. 1 and Willacy County Drainage District No. 1 sponsored the archeological testing reported herein as part of an ongoing program of cultural resource mitigation along the drainage ditch. These current investigations were conducted under the regulations of the State of Texas Antiquities Code (Texas Natural Resource Code of 1977, Title 9, Chapter 191, VTCS 6145-9) with Texas Antiquities Committee Permit No. 784, and under the special conditions of U.S. Army Corps of Engineers Permit No. 11374 issued by the
Galveston District Office. The cultural resources are considered under the provisions of 33 CFR 325 , Appendix C; 36 CFR 800; and 36 CFR 36. Authorizing legislation includes the National Historic Preservation Act of 1966, P.L. 89-665, P.L. 96-515 (as amended), Executive Order 11593 (Protection and Enhancement of the Cultural Environment 1971), and the Archeological and Historical Preservation Act of 1974, P.L. 93-291 (as amended).

Twelve cultural resource investigations have been conducted in conjunction with the Hidalgo and Willacy counties drainage ditch project. The first, sponsored by the U.S. Army Corps of Engineers, Galveston District, was a controlled sample survey of the region carried out in 1976 by the Office of the State Archeologist, Texas Historical Commission (Mallouf et al. 1977), as a preliminary assessment of the archeological resources. Forty-nine sites were recorded, and the sparse nature of the archeological remains was noted. This initial assessment could be used for planning more extensive and efficient cultural resource investigations along the ditch rightof-way.

Prewitt and Associates, Inc. has conducted all remaining cultural resource investigations associated with the drainage ditch, beginning in 1980 with two projects, one sponsored by the Corps of Engineers and the second sponsored by the county drainage districts. This resulted in the survey and assessment of archeological sites discovered along various sections of the planned ditch right-of-way (Day et al. 1981). These investigations were founded on 


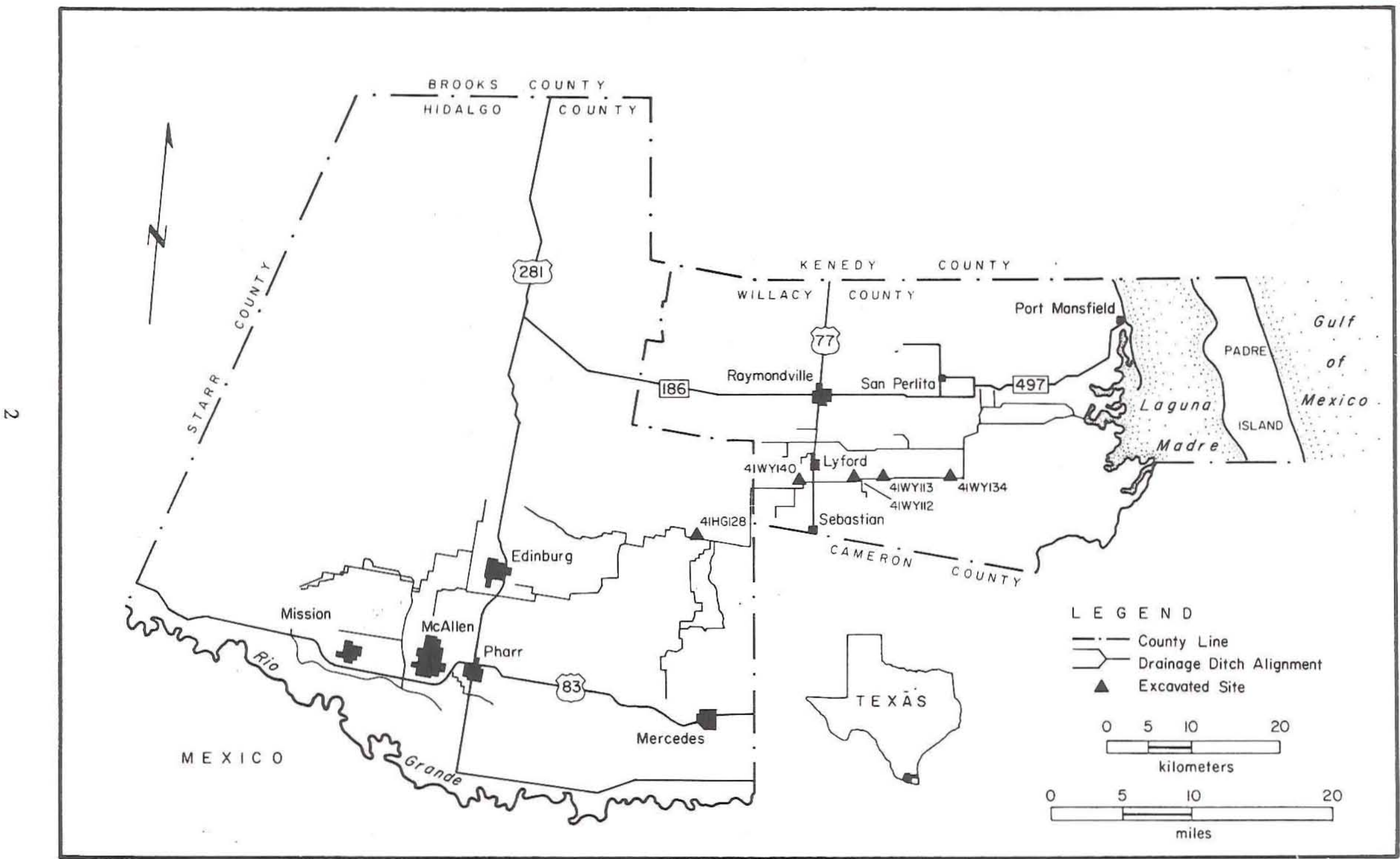

Figure 1. Project location map. 
a simple predictive model (i.e., sites would be located adjacent to water resources and often on adjacent elevated landforms) and utilized sophisticated analyses of aerial photographs and topographic maps to identify the locations of small deflationary playas with a higher probability of associated sites. Fifty-three sites were discovered, and two sites, $41 \mathrm{WY} 50$ and 41WY60, were selected for limited testing. A burial was recovered from the testing of $41 \mathrm{WY} 50$ and was dated by radiocarbon. Two additional sites on the North Ditch in eastern Willacy County were in immediate danger of destruction by the excavation of the ditch, and these were recommended for National Register testing. Soon thereafter, these two prehistoric sites, 41WY71 and 41WY72, were investigated (Day 1981). Site 41 WY72 was judged eligible for listing on the National Register of Historic Places, resulting in its preservation by alteration of the route of the drainage ditch (Day 1981). In 1981, the districts began a monitoring program for sites disturbed by construction on the North Ditch, but this did not result in efficient or reliable field assessments of buried sites in the region due to the sparseness of the remains. In 1982, Willacy County Drainage District No. 1 funded an archeological survey along the Lyford Drain, resulting in the discovery of an additional ten sites and National Register testing of a single prehistoric site, 41WY84 (MercadoAllinger 1983). Site 41 WY84 was judged ineligible for listing on the National Register.

In November 1985, the excavated segments of the drainage ditch were surveyed and nineteen archeological sites were discovered in the eroding banks of the ditch. Many of these sites had not been visible before ditch construction, and many could only be discovered after rain washed spoil off of the excavated ditch slopes. Thus, surveying after construction actually increased site visibility and the discovery rate of the region's thinly distributed archeological resources.

In 1986, systematic surface survey again resumed, with reconnaissance of existing channel segments allowing an assessment of buried archeological remains (Hall et al. 1987). Forty-three archeological sites were recorded, and geomorphological and paleontological investigations were initiated. Twenty-two Pleistocene faunal localities were located and seven extinct tortoise remains (Gopherus hexagonatus) were recovered but without any evidence of human associations. In addition, one archeological site, the Sardinas Resaca Site (41HG118), was mitigated and radiocarbon dates obtained. Finally, an eroding burial was excavated from the ditch bank at 41WY113.

Hall et al. (1987) summarize all Phase I investigations and provide recommendations for the 158 cultural resources (118 sites and 35 isolated artifacts) discovered up to that time. They (Hall et al. 1987:76-77) identified 27 sites for National Register testing, 9 of which were identified by Corps sponsored investigations in 1980 . The remaining 18 sites were recorded by investigations sponsored by the county drainage districts, and Hall et al. (1987:77) recommended that a sample of 7 be selected for National Register Testing in the Phase II portion of the project. Since the 1986 work, two small surveys have recorded two archeological sites (Quigg et al. 1989; Quigg, Appendix F, this report). The 1988 work plan guiding the current investigations recommended that only five sites receive Phase II testing and that two sites be reserved for future Phase II testing-level investigations. The sites recommended for testing were 41HG128, 41WY112, 41WY113, 41WY134, and 41WY140 (see Chapter 4 for selection criteria).

In 1986, a technical proposal (Prewitt and Associates, Inc. 1986) was submitted for archeological investigations along the Hidalgo-Willacy Drainage Ditch. This proposal identified four major goals and provided a theoretical model of hunter-gatherer mobility and territorial organization. The four major goals were to develop the ethnohistorical, archeologi$\mathrm{cal}$, and paleoenvironmental records, and then, with this data base, develop a synthesis of prehistoric occupations. Past and recent ethnohistorical research (Ruecking 1953, 1955; Salinas 1986; Campbell 1988) has provided a detailed ethnohistorical record and no further primary research is necessary. However, the archeological and paleoenvironmental records still require attention.

The 1988 work plan (Prewitt and Associates, Inc. 1988) for these Phase II investigations outlined many of the limitations in the regional archeological record and suggested a broad-based strategy utilizing a number of analytical techniques. During excavation it became clear that the archeological sites lacked the temporal, stratigraphic, and chronological resolution to justify such a broad-based approach. Thus, a number of analytical methods were not employed, including analyses of pollen and molluscan fauna, proton magnetometer surveys of all sites, use-wear 
and residue analyses on stone tools, and trace element analysis of ceramics. A series of analyses were judiciously selected that were less inhibited by the lack of resolution; these included stable isotope analysis of radiocarbon-dated human remains, soil humates, and pedogenic calcium carbonates. In addition, attention was focused on the regional archeological record, most of which had been amassed by the twelve projects associated with the drainage ditch but had never been synthesized.

Guiding this preliminary regional synthesis was the 1986 research design that had been incorporated into the 1988 work plan. The research design proposed alternative models of hunter-gatherer seasonal transhumance along the lower coast based on earlier hypotheses by Hester (1981) and research by Aten (1983). These models provided a theoretical framework into which regional synthesis could best fit. In the current investigations, these models have been expanded and tested, representing a first step toward achieving a new synthesis of the prehistoric record in the Lower Rio Grande Valley.

This report consists of eight chapters and six appendixes. Chapter 1 provides introductory information and background environmental data pertinent to the project. Chapter 2 presents the archeological background and discusses the previous archeological work in the region, highlighting the problems of prehistoric culture chronologies in southern Texas. Chapter 3 is a theoretical research design that develops models of hunter-gatherer resource use, mobility, and territoriality, and presents the archeological predictions of these models. Chapter 4 presents the field and laboratory objectives and methods used on this project. Site descriptions constitute Chapter 5 , and the basic site data are presented there. Chapter 6 discusses the isotopic results in terms of paleoenvironments and paleodiets. The models outlined in Chapter 3 are tested in Chapter 7, and a preliminary synthesis is offered on hunter-gatherer adaptations in the Lower Rio Grande Valley. Chapter 8 presents the substantive conclusions reached by this work, the assessments of the individual sites in terms of National Register eligibility, and the recommendations for future work at these sites. The first appendix provides detailed descriptions of the diagnostic artifacts recovered by this project. Appendix B discusses the results of a proton magnetometer survey of two sites. Appendix C presents detailed profile descriptions of geological backhoe trenches and selected test units.
Appendix D presents and discusses the radiocarbon dates obtained on this project and provides tree-ringcalibrated ages. Appendix E discusses the unique and advantageous water-screening system used on this project, and Appendix F reports the findings of a small survey conducted by Prewitt and Associates, Inc. during April of 1989.

\section{ENVIRONMENTAL BACKGROUND}

This section describes the environment of the project area, providing necessary background information. It presents a general picture of the regional geology that allows the specific geological findings to be placed in a broader framework. It also outlines the climatic and botanic parameters that constitute the foundation of the hunter-gatherer models discussed in Chapters 3 and 7.

\section{Climate}

The Lower Rio Grande Valley region is warm and is classified as subtropical (Bomar 1983). Given its proximity to the Gulf of Mexico, the region receives surprisingly little precipitation. Temperature extremes become more marked and rainfall decreases away from the coast. The flow of the upper level jet streams controls the movement and juxtaposition of four air masses--maritime polar (Pacific), continental Arctic, continental tropical, and maritime tropical-that create weather patterns in South Texas (Bomar 1983:28-37). Because the polar jet stream loops farther south during the winter, maritime polar (cool-wet) and continental Arctic (cold-dry) fronts occasionally penetrate as far south as the Lower Rio Grande Valley. These fronts normally are accompanied by rain as cold and warm moist air masses meet. The distance from the Arctic and the proximity of the Gulf of Mexico, however, limit the number of freezes to one or two days per year near the coast and slightly more often farther inland. During the warmer months, the polar jet stream migrates farther north and the subtropical jet stream blows in from the southwest steering the warm dry continental tropical air masses over the region, causing the unusually dry conditions near the Gulf in South Texas.

Average monthly high temperature readings taken for the period 1951-1980 at five stations in the region provide a picture of seasonal and spatial variability (Fig. 2). Throughout the region, winter 


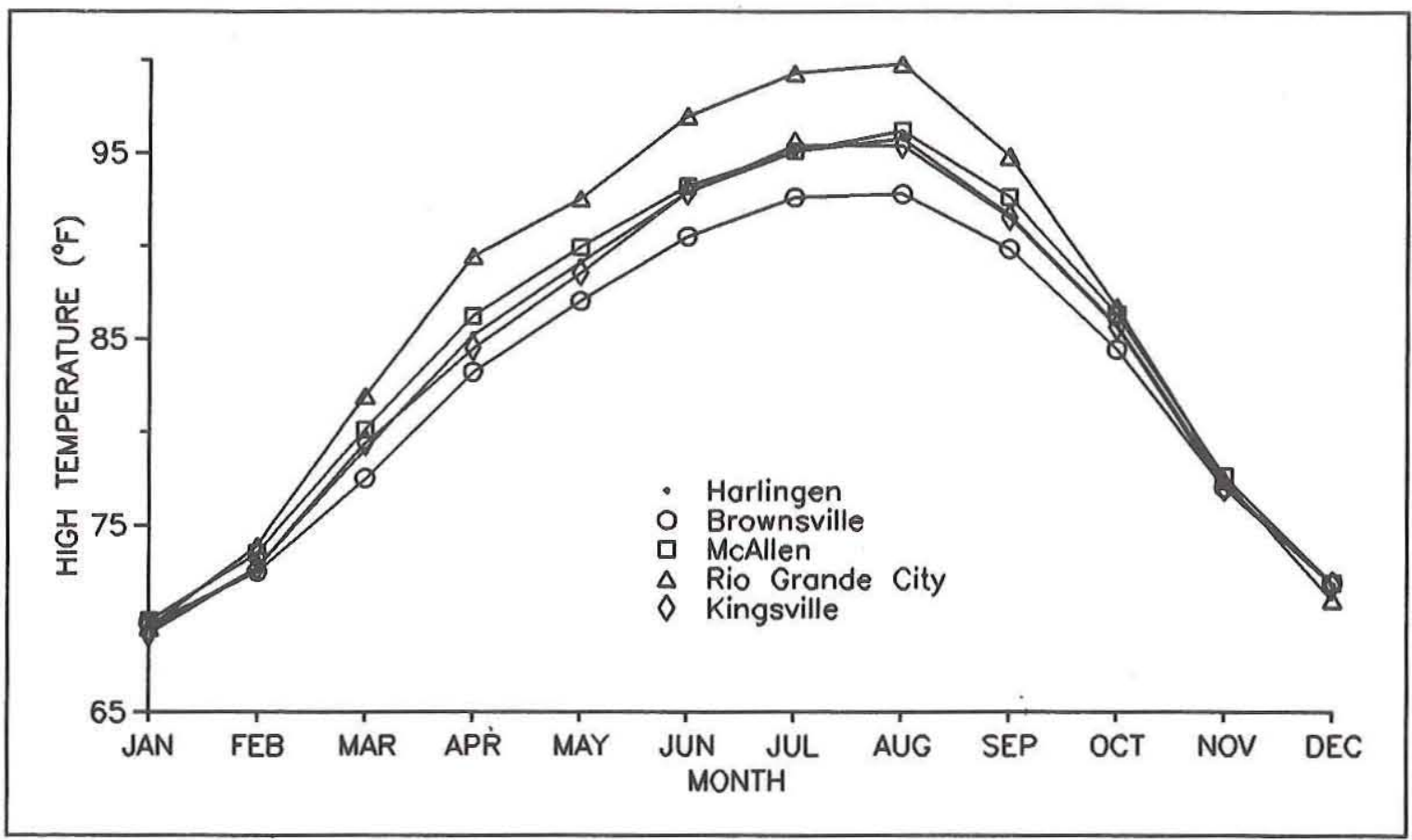

Figure 2. Average monthly high temperatures at five weather stations in the region (data from Bomar 1983:215216).

temperatures are warm; as noted above, cold fronts are few. As the seasons progress, spatial differences become more marked with August showing the greatest spatial variability. Summer temperatures are cooler near the coast and progressively warmer inland. While it is well known that temperatures decrease with increasing elevation, the average normal lapse rate cannot account for this regional temperature difference; rather, it is due to the sea breezes that normally influence temperatures within 10-15 miles $(25-40 \mathrm{~km})$ of the coast (Bomar 1983:184).

The regional average yearly rainfall is approximately $635 \mathrm{~mm}$ ( 25 inches), falling within a semiarid climatic classification; however, the atmosphere is often very humid because of the proximity of the Gulf of Mexico (Norwine and Bingham 1986). The low precipitation is aggravated by a high potential evapotranspiration rate of $1525 \mathrm{~mm}$ (60 inches) per year. Precipitation is highly variable (coefficient of variation $=35$ ), and years with normal rainfall (i.e., within $10 \%$ of the average) occurred only $30 \%$ of the time between 1900 and 1983 (Norwine and Bingham 1986:3-6). Drought cycles with irregular intervals characterize the twentieth-century rainfall record (Fig. 3) and probably existed throughout the past. One factor in the irregularity in the dry-wet cycles must be the occurrence of hurricanes, which are related to nonlocal forcing mechanisms. It is self-evident that hurricanes do not occur during major droughts, and their absence is a factor in the longevity of drought conditions in South Texas. For example, no hurricanes hit the South Texas coast between 1947 and 1960 (Brown et al. 1980:27), and this spans the period of the worst drought on record in South Texas.

The seasonal distribution of rainfall is bimodal with the greatest peak in September, which is the height of the hurricane season, and a smaller peak in May or June (Fig. 4). Rainfall is low from the beginning of November through April. Precipitation tends to show a spatial pattern with rainfall decreasing from the northeast to the southwest.

\section{Geology}

The bedrock geology in the Lower Rio Grande Valley is characterized by alluvial and deltaic deposits. Wind has eroded these to form extensive eolian deposits throughout much of the region, 


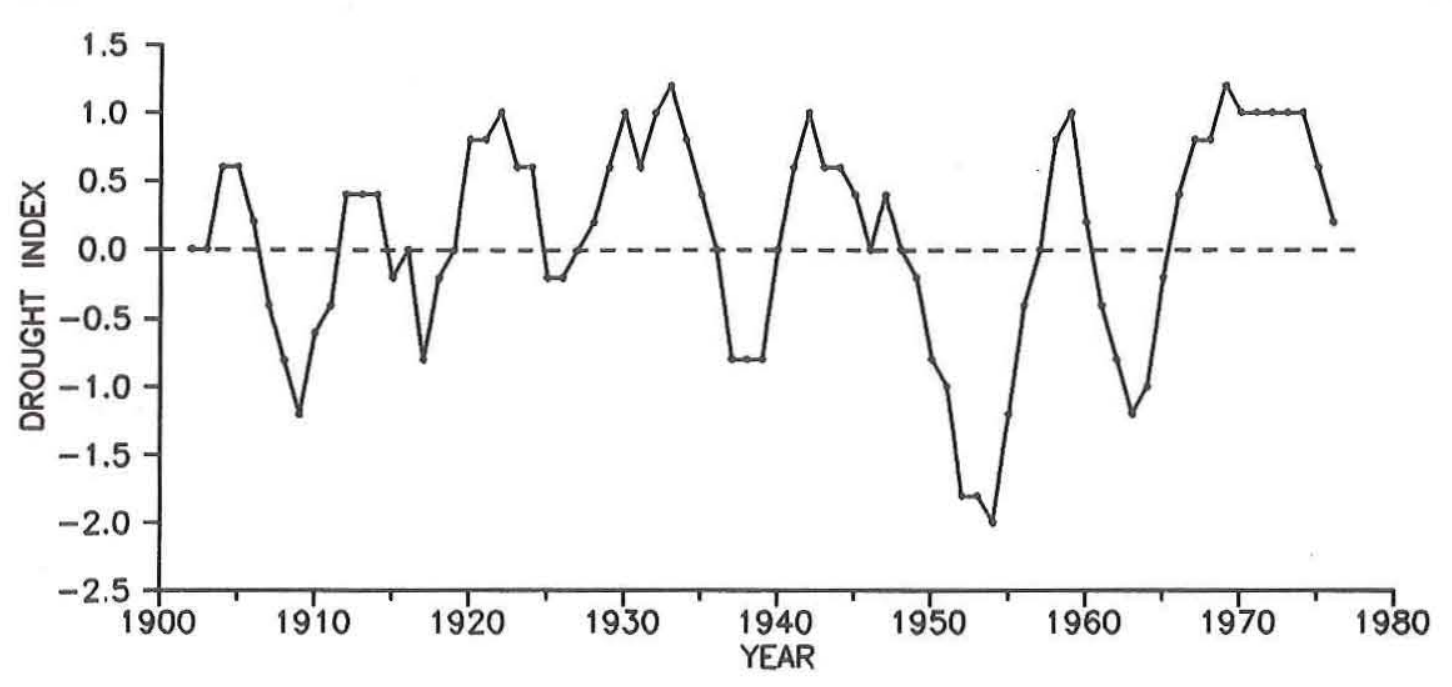

Figure 3. Five-year moving averages of South Texas drought index, 1900-1983 (data from Norwine and Bingham 1986:5-10).

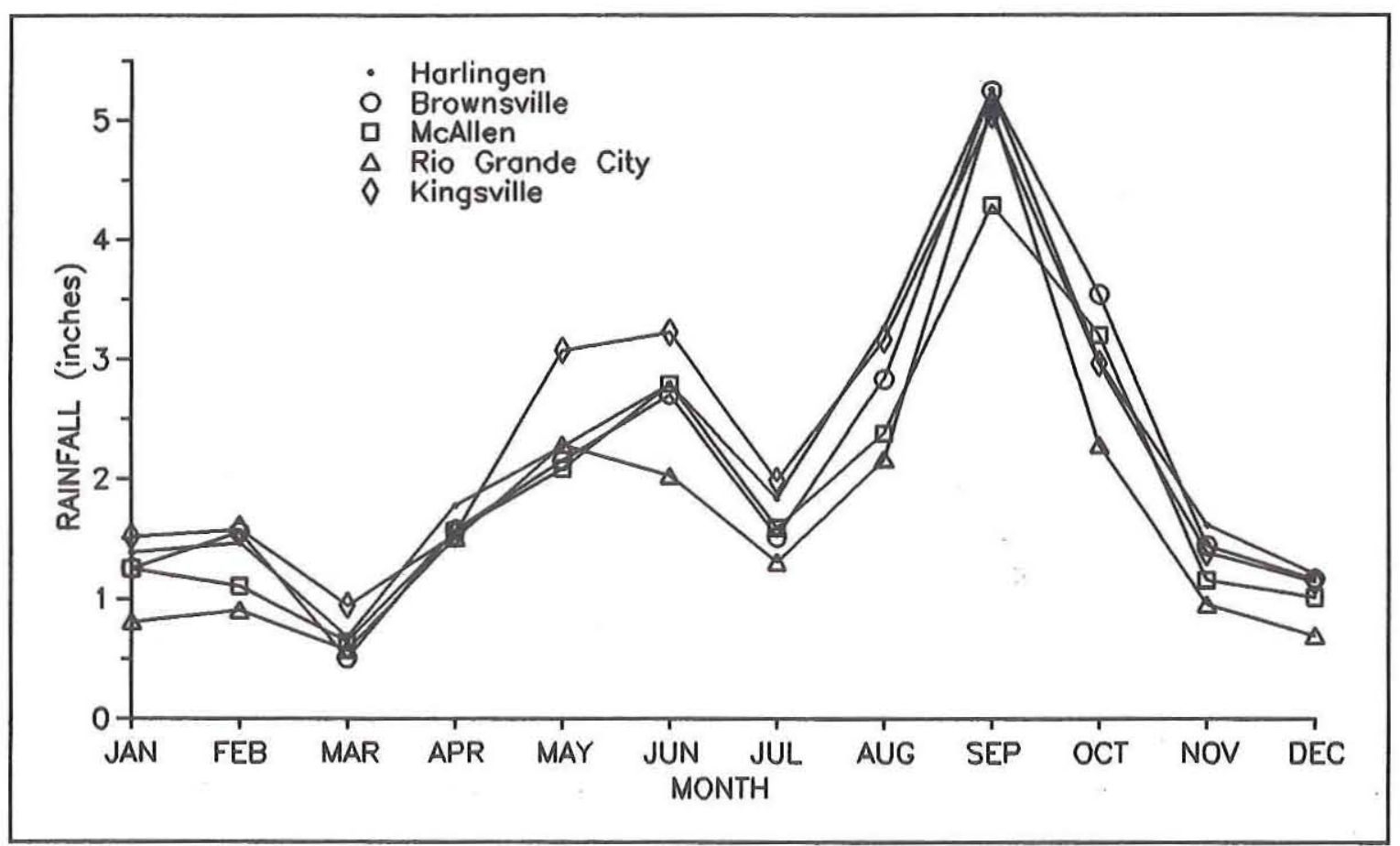

Figure 4. Mean monthly rainfall for five weather stations in the region (data from Bomar 1983:221-222). 
especially in the northern part of Willacy County and most of Kenedy County. Surface bedrock deposits are youngest in the east and become progressively older to the west. Figure 5 shows the distribution of bedrock formations in the project area.

Bedrock deposits in the western portion of the project area consist of the Goliad Formation. These are Pliocene fluvial deposits consisting of clays, sands, marls, and gravels. The only known source of knappable lithic materials in the project area occurs in the Goliad Formation as river gravels near La Joya. Other sources, as yet undiscovered, probably occur in this deposit. The Goliad Formation extends from La Joya in the far southwest corner of the region to La Sal Vieja, a natural salt lake in an internally draining basin in western Willacy County.

A thin band of the Lissie Formation occurs along the eastern edge of the Goliad Formation in southeastern and eastern Hidalgo County. It is a prograding delta deposit that probably was deposited during a high sea stand in the Pleistocene, but it is undated by chronometric methods. The sediments consist of clays, silts, sands, and gravels, although no knappable lithic sources are known from the Lissie Formation. One site investigated during this project occurs on this formation.

Most of the sites investigated during this project occur on the Beaumont Formation. The Beaumont Formation is the most recent Pleistocene formation and is a deltaic deposit preserving many channel meander scars on its surface. It is undated on the lower Texas coast, but the majority of the deposits probably date to the last interglacial period between 132,000 and 120,000 years ago, or possibly as late as 83,000 B.P. For deposition to have occurred at that elevation, sea level must have been above or at least near its present elevation. Chappell and Shackleton's (1986) recent study of global sea level changes in the last 150,000 years suggests that sea levels have been at least $12 \mathrm{~m}$ below the modern sea level over the last 112,000 years (Fig. 6), and in the last 80,000 years, sea levels were at least $27 \mathrm{~m}$ below modem levels. On the upper Texas coast, Aronow (Birdseye and Aronow 1988:7) has radiocarbon dated seven marine shells from the Beaumont Formation at the Rose City Sand Pit. All but one are infinite dates, and the one finite date is 35,300 B.P. According to Chappell and Shackleton (1986:139), at 35,000 B.P. sea level was $65 \mathrm{~m}$ below the modern level, and it is difficult to accept this one finite radiocarbon date from the Rose City Sand Pit as an accurate age estimate for the majority of the Beaumont Formation.

At the beginning of the last glacial period when sea levels initially dropped, the Rio Grande began to cut down, and deposition of the Beaumont Formation, at least as a delta deposit, ceased. It is possible that limited alluvial deposition did occur during the last glaciation, but at the peak of the Last Glacial Maximum only 18,000 years ago, sea level was $150 \mathrm{~m}(492 \mathrm{ft})$ below the present level, and the shoreline was some $150-175 \mathrm{~km}(60-70 \mathrm{mi})$ east of the present coast. The inland fluvial erosion that must have been stimulated by this dramatic drop in base level would have removed much of the previous alluvial deposits in the active Rio Grande Valley, and this partially may account for the lack of deposits dating to the last glacial period. It is possible that alluvial deposits dating between 18,000 and 10,000 B.P. are present along the Rio Grande; similar-age deposits, the Deweyville Terraces, are known from the upper Texas coast and the lower Trinity River (Aten 1983:110-115). Such deposits have not been identified yet in South Texas, although the Rio Grande terrace deposits in the western portion of the region may date to this period.

Frazier (1974:2) has mapped a number of linear sand bodies offshore in the shallow portion of the Gulf (upper $180 \mathrm{~m}$ ). These are most certainly barrier island deposits, but as sea level rise was so rapid after the Last Glacial Maximum and barrier islands would have had too little time to form, these probably date to the period between the Last Interglacial and the Last Glacial Maximum (i.e., 112,00030,000 B.P.). During the period of initial human habitation of the area, these relict barrier islands would have been exposed in a similar manner to the present-day Ingleside Barrier Island/Strandplain deposits farther up the coast (Price 1933; Birdseye and Aronow 1988).

At the end of the Pleistocene, sea levels rose rapidly; submerged freshwater and saltwater deposits in the Gulf provide measurements of sea level rise for the end of the Pleistocene and the Holocene periods (Frazier 1974; Brown et al. 1980; Pearson et al. 1986; Prewitt and Paine 1987). This rise was not continuous, but experienced dips at ca. 12,000 and 8200 B.P. (Fig. 7). By ca. 7000 B.P., sea levels were established near modern levels; however, minor fluctuations have occurred since that time. Evidence of a maximum height of $1.5 \mathrm{~m}$ above current mean 


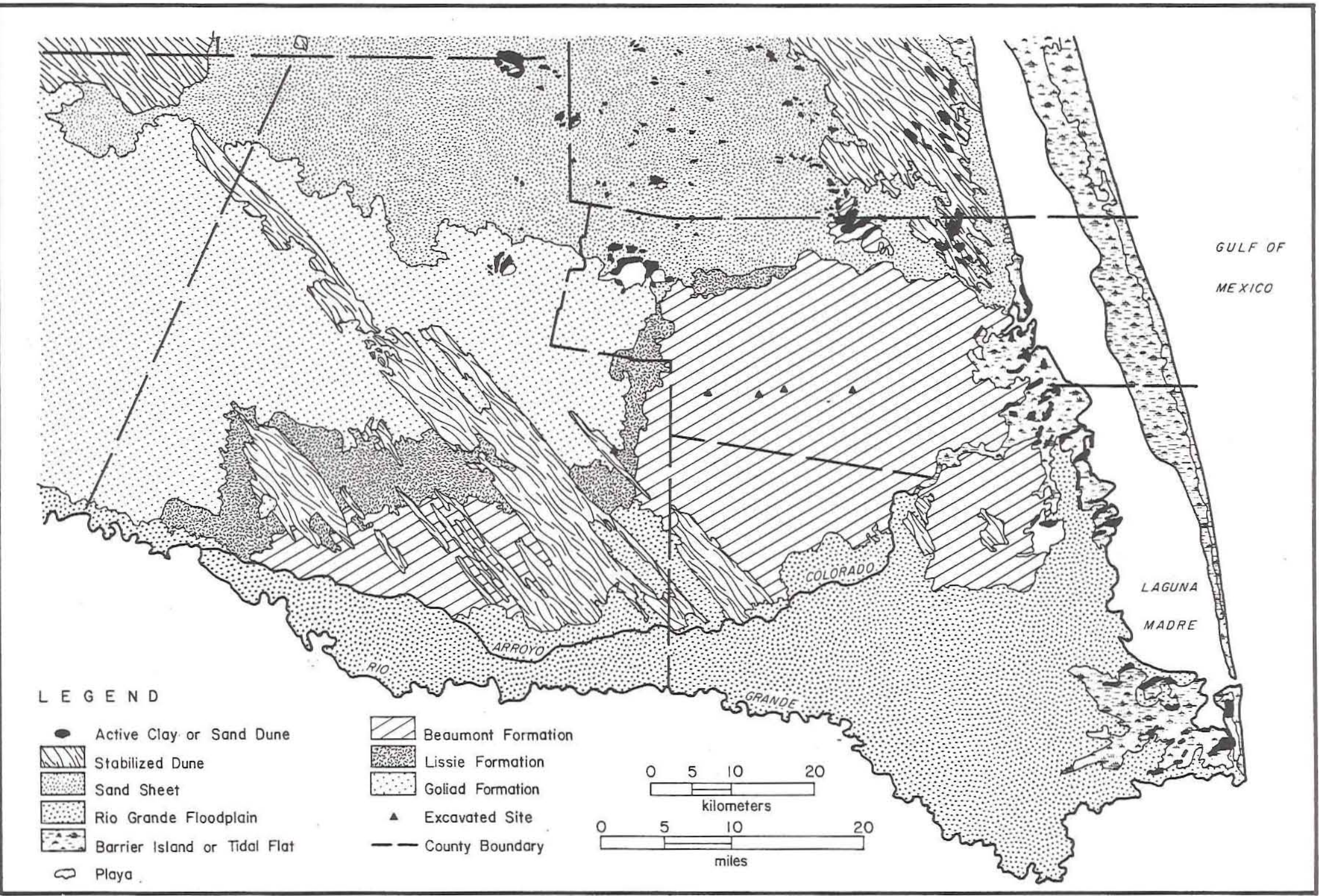

Figure 5. Bedrock geological formations in the Lower Rio Grande Valley region (after Bureau of Economic Geology 1976). 


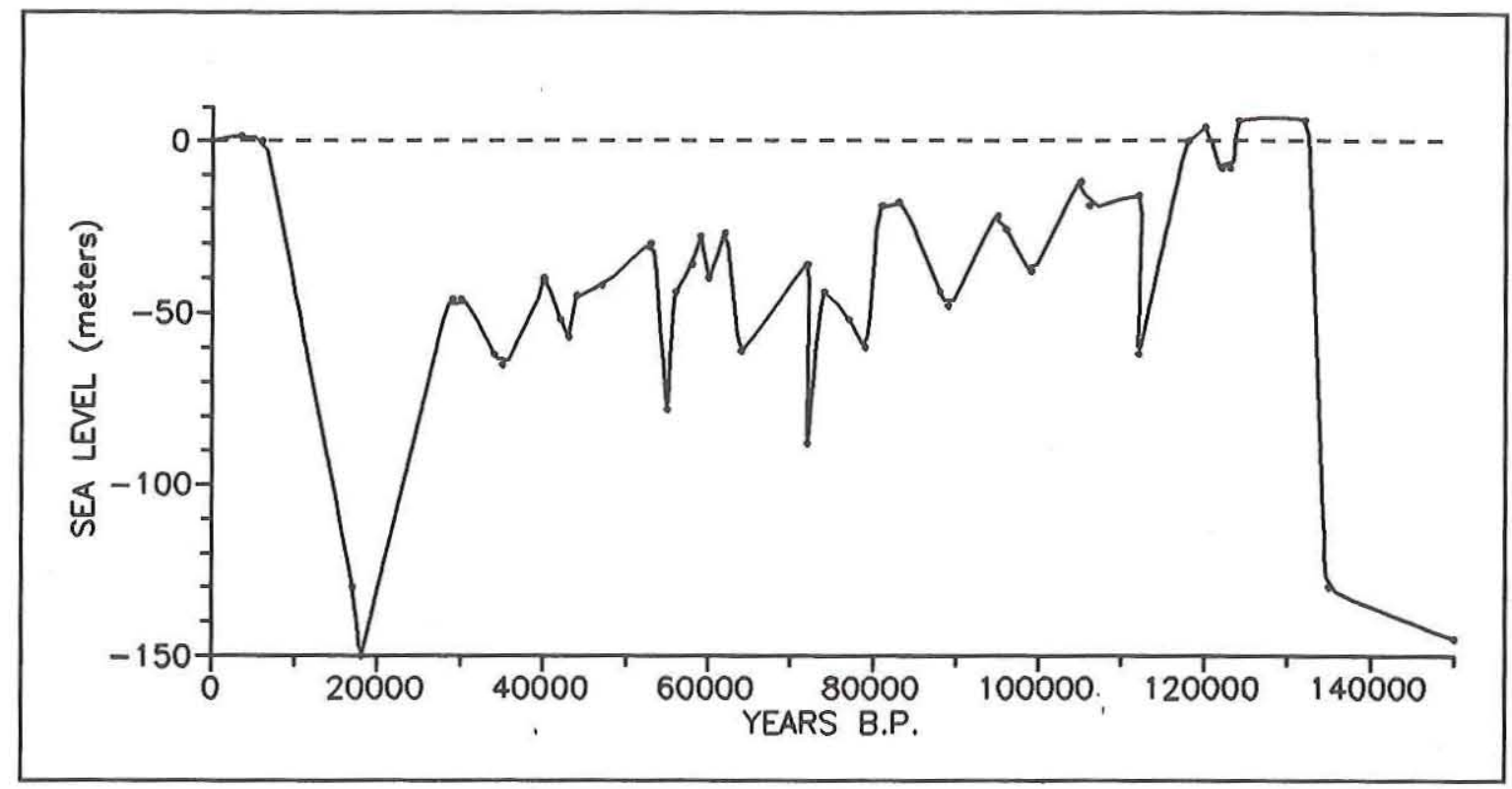

Figure 6. Sea level changes in the last 150,000 years (data from Chappell and Shackleton 1986 and Prewitt and Paine 1987).

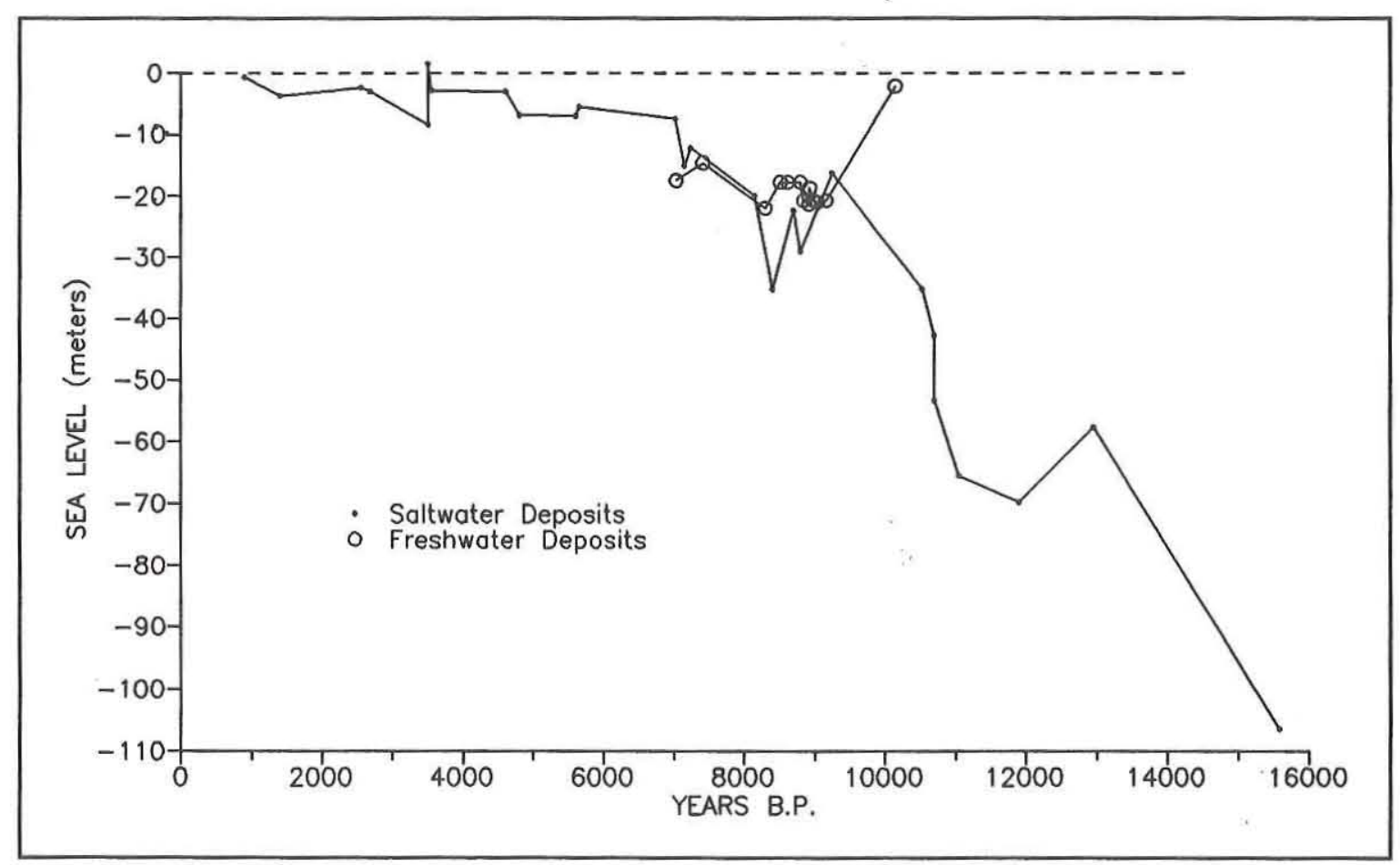

Figure 7. Gulf basin sea level changes as indicated by fresh- and saltwater-associated deposits in the last 16,000 years. Actual sea levels could be higher than saltwater-associated deposits or lower than freshwater deposits (data from Frazier 1974, Brown et al. 1980, Pearson et al. 1986, and Prewitt and Paine 1987). 
sea level is documented at approximately 3500 B.P. in the Coastal Bend region of Texas (Prewitt and Paine 1987), and there is no reason to believe that this was not experienced throughout the Texas Gulf Coast. At or slightly before this time, the barrier islands (Brazos, Padre, Mustang, and others) began to build up, forming Laguna Madre, a saline lagoon. Barrier island formation is dependent on a source of material (e.g., sands from the Rio Grande), sufficiently strong offshore currents, and a relatively stable sea level.

Directly south of the Beaumont.Formation, the present Rio Grande floodplain deposits and delta provide a direct analog for the Beaumont Formation. The McAllen-Brownsville geology map of the modern delta surface (Bureau of Economic Geology 1976) clearly shows meander belts bounded by overbank alluvial deposits which are mainly muds. The Rio Grande Valley becomes extremely flat in the western portion of the region. This low grade, extending east to the coast, does not provide the energy necessary to transport gravels and cobbles, and thus it is unlikely that knappable lithic materials occur in these recent fluvial deposits. These meanders in the floodplain and distributary channels in the delta still function as drainage channels known locally as resacas, and in some cases they form oxbow lakes. One large distributary channel of the Rio Grande is known as the Arroyo Colorado; at some point in time, it may have been the main channel of the Rio Grande. Interestingly, the Rio Grande, like the Brazos River, does not have a large inlet bay; instead, an extensive delta has developed. This suggests that infilling of the Pleistocene-eroded valleys is complete, which could be due to higher sediment loads in these river systems than in others that still have large inlet bays at the coast.

The last major sedimentary process in the Lower Rio Grande Valley is wind erosion and deposition. Much of northern Willacy and Hidalgo counties, most of Kenedy County, and most of the coast are covered by stable or active eolian deposits. The inland distributions of these sand bodies are usually along a southeast to northwest axis, mirroring the modern prevailing wind direction (Brown et al. 1980:27). The most likely source of the sands is the shore, but all of the previously mentioned Plio-Pleistocene or Holocene fluvial deposits are contributors as well. Sand dunes are still active in far northeast Willacy County and eastem Kenedy County. In fact the area between Kingsville and Raymondville is known as the South Texas Sand Sheet (Price 1958). Finegrained eolian deposits known as clay dunes occur along the east side of Laguna Madre and on the downwind side of some large inland lakes, e.g., La Sal Vieja. It is likely that clay dune formation along the coast is linked with sea level rise, and most extant coastal clay dunes probably postdate the last highstand at 3500 B.P. A preliminary inspection of coastal clay dune orientation, however, suggests that these dunes may date to more than one period or be the result of seasonal changes in prevailing winds. Obviously, more-detailed work is required to assess this hypothesis. Clay dunes associated with inland lakes should have much longer and more complete records of sedimentation as they are beyond the effects of marine transgressions and regressions. These inland lakes are generally believed to be blowouts resulting from wind scouring, and the analysis of Holz and Prewitt (1981) shows that a great number of blowouts of all sizes occur throughout the region, often in abandoned channel scars preserved on the surface of the Beaumont Formation (Fig. 8).

\section{Environmental Zones}

The research objectives of the initial archeological projects in the region were concerned with predicting site locations according to landforms. In order to develop these predictions, the environment was usually categorized into a large number of landform types or environmental zones. While this is worthwhile within the context of sample surveys, the project reported here has different objectives, and thus the environmental zones used in previous projects (Mallouf et al. 1977; Day 1981; Day et al. 1981; Hall et al. 1987) are not used here. One of the main objectives of the current project is to develop and test a set of models for prehistoric hunter-gatherer resource exploitation in the Lower Rio Grande Valley (see Chapter 3). The previous environmental zones chosen for site prediction overlooked environments with important resources that must have influenced prehistoric hunter-gatherer mobility, resource use, and territorial divisions. In order to develop realistic expectations of the models presented in Chapter 3, a new, less-complex set of environmental zones is presented below.

These zones are distinguished on the basis of geologic, climatic, botanic, faunal, hydrologic, and topographic characteristics. Zone boundaries 


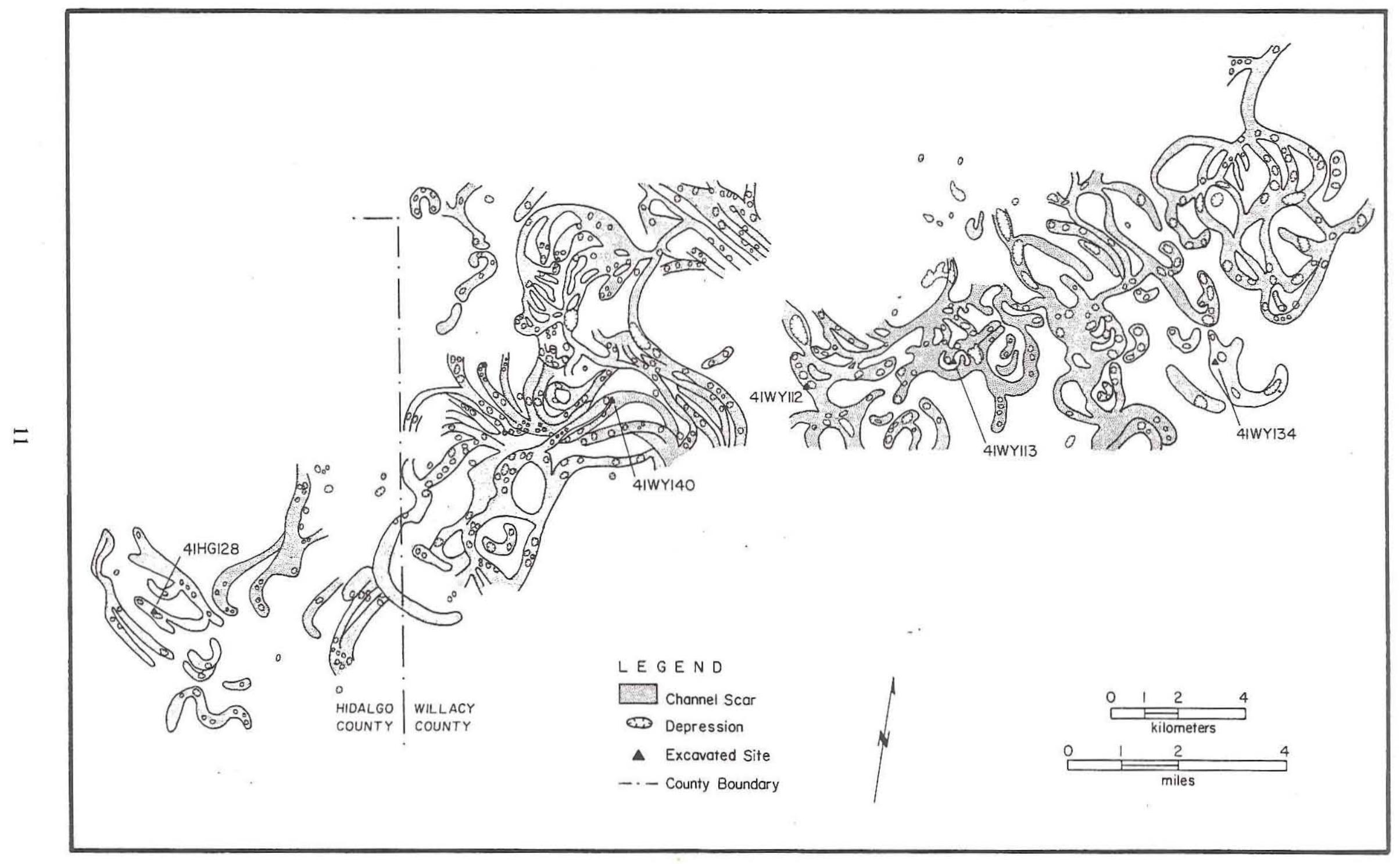

Figure 8. Abandoned Rio Grande channels and blowout depressions. 
represent transitional areas and, for the most part, are not well-defined on the ground. These zones identify the major resources available throughout the project area and thus help identify the exploitative potential of the Lower Rio Grande Valley to the hunter-gatherer groups who occupied the region prehistorically. The five zones discussed below are the sand sheet, the lowland plain, the upland plain, the coast, and the Rio Grande floodplain and delta (Fig. 9). To maintain continuity with previous projects, Table 1 presents a correlation between these five zones and the environmental zones used in previous projects.

\section{Sand Sheet}

This zone is a stabilized and active dune area that supports a savanna habitat. The general vegetation pattern is one of grasslands with dispersed live oak mottes. Mesquite and thorn brush thickets are documented here but are not common. Johnston (1955:2) calls this the eolian plain, while Clover (1937) labels it the Zacatal prairie grass. The sand sheet includes all of Kenedy and Brooks counties, northern Hidalgo and Willacy counties, and parts of Jim Hogg, Starr, Kleberg, Duval, and Jim Wells counties.

According to Brown et al. (1980:19), the dune fields probably developed during the Holocene when the climate became increasingly arid and the southeastern wind patterns developed; however, it is likely that the prevailing wind patterns were established long before the beginning of the Holocene period at ca. 10,000 B.P. As these dunes have not been dated chronometrically, Brown's hypothesis remains conjecture. Nevertheless, it is clear that eolian processes eroded and transported coastal plain sediments inland, thus creating large dune fields stretching from Baffin Bay to the Rio Grande Valley (Fig. 10). These active and stabilized dune deposits overlie the Goliad, Lissie, and Beaumont formations.

Few streams drain the surface of this zone because of the high permeability of the sands, the low rainfall budget, and the extremely flat topography of the area. A few streams do drain internal basins with saline lakes, but their catchments are small. McGraw (1984:9) and Hester (1980:34-35) suggest that groundwater was nearer the surface and more available prehistorically than today because of depletion of the underground water reservoir during historic times, especially during the twentieth century.
Surface water would have been available prehistorically at springs, in blowout playas, or near the surface in swales between sand dunes.

The most detailed study of the vegetation of the sand sheet was accomplished by Johnston (1955). Unfortunately, Johnston's study took place during the mid 1950s in the middle of the worst drought on record (see Fig. 3), and the then-current climatic conditions must be taken into account when using his study. He divided the vegetation into three major communities: oak mottes, prairies, and brush (Johnston 1955:47-112). Oak mottes occur most frequently on the higher sand hills and are replaced by prairie or brush on lower ground or near the coast. These different communities are considered to be serial progressions with brush being the climax community except on loose sand where oak mottes comprise the climax community (Johnston 1955:48). Johnston (1955:50) suggests that prairies are retained only by consistent burning and a lack of overgrazing. During the 1950s drought with its associated extreme overgrazing, it is possible that brush was indeed the climax community, or at least better adapted to those stressful conditions, but in wetter times and with natural grazing conditions, it is likely that prairies would have been climax communities in areas not favored by oak mottes. As the brush community is more common in other environmental zones, it is discussed in more detail below.

Plant composition in prairie communities varies, and Johnston (1955:95-106) has identified two types of prairies in the project area. One occurs on loose sands in the sand sheet zone. Where little disturbed by overgrazing or drought, a good plant cover exists and grasses might be up to $3 \mathrm{ft}$ high. Dominant perennial grass genera include Andropogon, Panicum, Paspalum, Elyonurus, Brachiaria, Cenchrus, and Chloris. As overgrazing increases, plant cover decreases and perennial grasses are replaced by forbs and species characteristic of other plant communities such as brush.

The oak mottes are dominated by live oak, Quercus virginiana or $Q$. oleoides quaterna, and most often occur on higher terrain and on loose sandy soil. Salt spray carried by strong offshore winds dramatically limits the eastward extension of oak mottes. Normally the mottes form small groves with a 15-ft canopy and little understory and provide the only shade in the sand sheet. In this shaded microenvironment, the grasses Vaseyochloa, Sporobolus, Trichoneura, Paspalum, Digitaria, and Cenchrus 


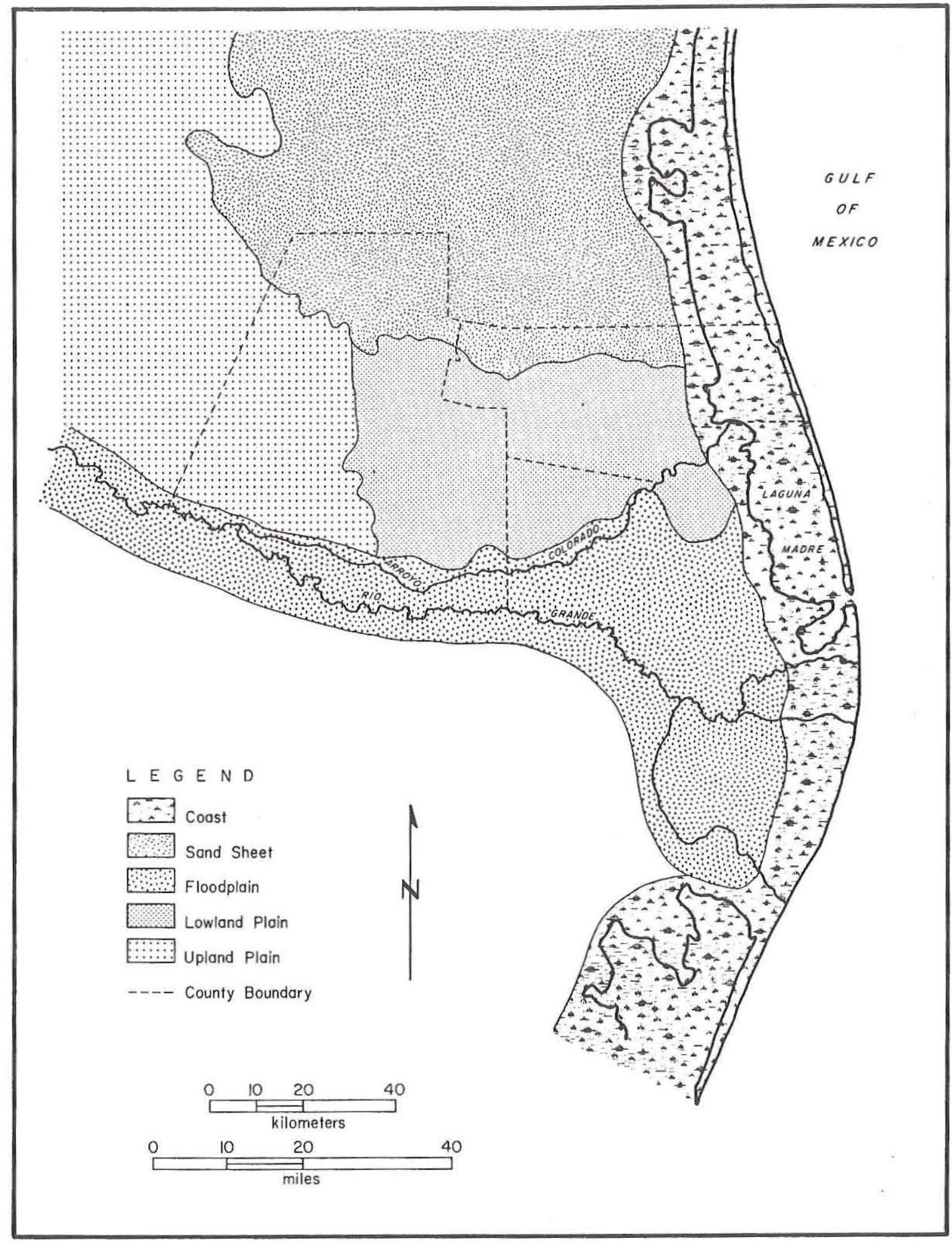

Figure 9. Map of the environmental zones in the Lower Rio Grande Valley. 
TABLE 1

CORRELATION OF ENVIRONMENTAL ZONES BETWEEN PRESENT AND PREVIOUS PROJECTS

\begin{tabular}{|l|l|l|}
\hline & $\begin{array}{l}\text { Zones from Mallouf } \\
\text { et al. 1977 }\end{array}$ & $\begin{array}{l}\text { Zones from Day et al. 1981 and } \\
\text { Hall et al. 1987 }\end{array}$ \\
\hline $\begin{array}{l}\text { Present Environmental Zones } \\
\text { Lowland Plain }\end{array}$ & III and V & III and V \\
Upland Plain & IV and II & IV and VIII \\
Coast & II and I & I, II, and VIII \\
Rio Grande Floodplain and Delta & VI and VII & VI and VII \\
& I (small portion) & IX \\
\hline
\end{tabular}

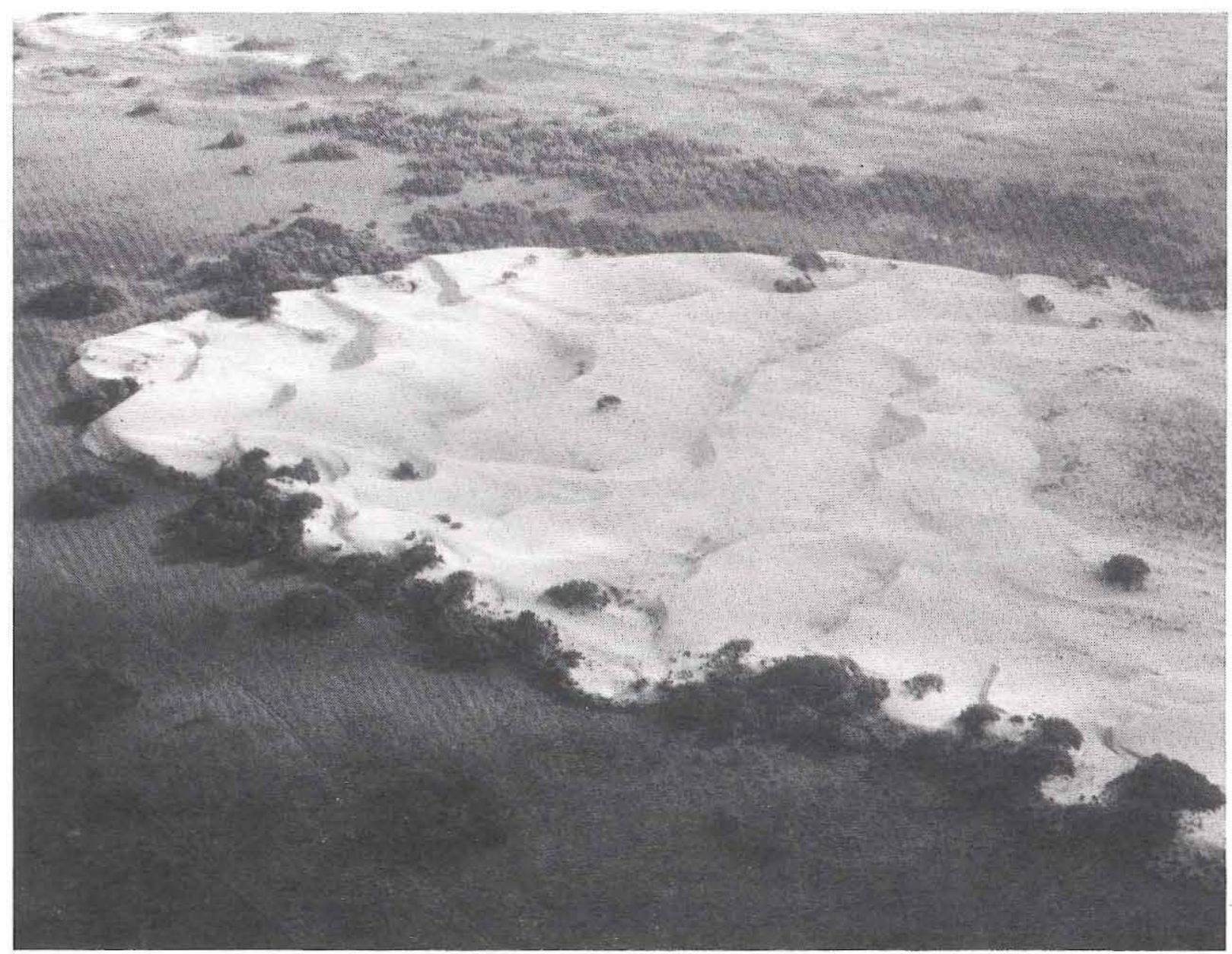

Figure 10. Photograph of active dune (foreground) and stabilized dune (background) in the southern sandsheet. 
occur. Among a variety of other plants commonly found in oak mottes, Mustang grape (Vitis candicans), yucca (Yucca treculeana), drummond wax-mallow (Malvaviscus drummondii), Mullein nightshade (Solanum verbascifolium), western soapberry (Sapindus drummondii), and woolybucket bumelia (Bumelia lanuginosa) are also present. Animals in the oak mottes are plentiful and include deer, turkey, javelina, turtles, snakes, and rodents.

\section{Lowland Plain}

This zone is characterized by a featureless landscape with no natural drainages. Scattered over its surface are shallow blowouts which form seasonal playas ringed by thin eolian deposits on an abandoned delta of the Rio Grande. Most of this area is intensively farmed today, and natural plant communities have been removed or recently covered by brush invaders. In the past, the upland portion of the zone had natural prairies, brush thickets, and a few oak mottes, while plants with greater water requirements surrounded the blowouts. This zone apparently had fewer resources and less water than most other zones in the project area. All archeological sites investigated during the present project are in this zone.

Johnston (1955:61-82) identifies two types of brush communities as "deep brush" and "short brush." It is mostly the deep brush community that characterizes the lowland plain zone. Clover (1937:50) refers to these brush plant communities as "mesquital-chaparral" and "mesquital-nopalera." The deep brush plant communities consist of xerophytic short trees and low shrubs which often grow in impenetrable thickets; many of the species found in brush plant communities are edible (Vines 1960). The most obvious plant species in brush thickets is mesquite (Prosopis juliflora), attaining heights of 10-30 ft, but significant other native plants include spiny hackberry (Celtis pallida), yucca (Yucca treculeana), several species of prickly pear (Opuntia spp.), Texas lantana (Lantana horrida), Mexican-marjoram (Lantana macropoda), saffronplum bumelia (Bumelia angustifolia), Humboldt coyotillo (Karwinskia humboldtiana), bluewood condalia (Condalia obovata), rubber-plant (Mozinna spathulata), and barbwire acanthocereus (Acanthocereus pentagonus). Small open glades scattered throughout brush communities are often dominated by grasses such as Buchloe, Chloris, and Heteropogon, legumes such as Rayado bundle-flower
(Desmanthus virgatus depressus) and thyrsus dalea (Dalea thyrsiflora), and composites such as dogweed (Dyssodia tenuiloba) and clappia (Clappia suaedaefolia) (Johnston 1955:73). Brush communities stop at the edges of blowouts where thickets of sugar hackberry (Celtis laevigata) and sweet acacia (Acacia farnesiana) or thick stands of Eragrostis spicata, a coarse bunch grass, often occur (Fig. 11).

The prairie community most commonly associated with the lowland plain is called the Sandy Loam Prairie (Johnston 1955:107-109). Johnston was unable to find any undisturbed stands of this community as most had been invaded by brush species to some degree. Among the plants commonly found in this community are perennial grasses (Cenchrus, Eragrostis, Chloris, Aristida, and Sporobolus), and forbs (Desmanthus virgatus depressus, Cassia fasciculata, Croton spp., and Eriogonum multiflorum).

\section{Upland Plain}

This zone is distinguished from the lowland plain mainly by a slight rise in elevation, more-rolling topography, and an increase in perennial and intermittent streams. This small escarpment consists of low calcareous gravelly hills of the Goliad Formation, and the characteristic plant community is low dense chaparral which Johnston (1955:67-68) has termed "short brush." Another major difference between the upland and lowland plain, at least to the prehistoric inhabitants of this region, is the presence of knappable lithic resources in the upland plain. The species composition of the short brush community is similar to the deep brush community with the addition of a number of cacti (e.g., Echinocereus spp., Ancistrocactus sp., and Neomammillaria spp.) and perennial herbs (Eriogonum sp., Heliotropium spp., Tetraclea sp., and various Verbena family members).

\section{Coast}

This zone is a linear strip of land parallel to the coastline. A number of diverse habitats are present, including the Gulf of Mexico, barrier islands, tidal flats and lagoons, clay dunes, wetlands, estuaries, sand dunes, and low-lying flats. The interplay between aquatic and terrestrial, and also between freshwater and saline environments causes this to be one of the most productive, complex, and fragile environmental zones in South Texas. In addition, 


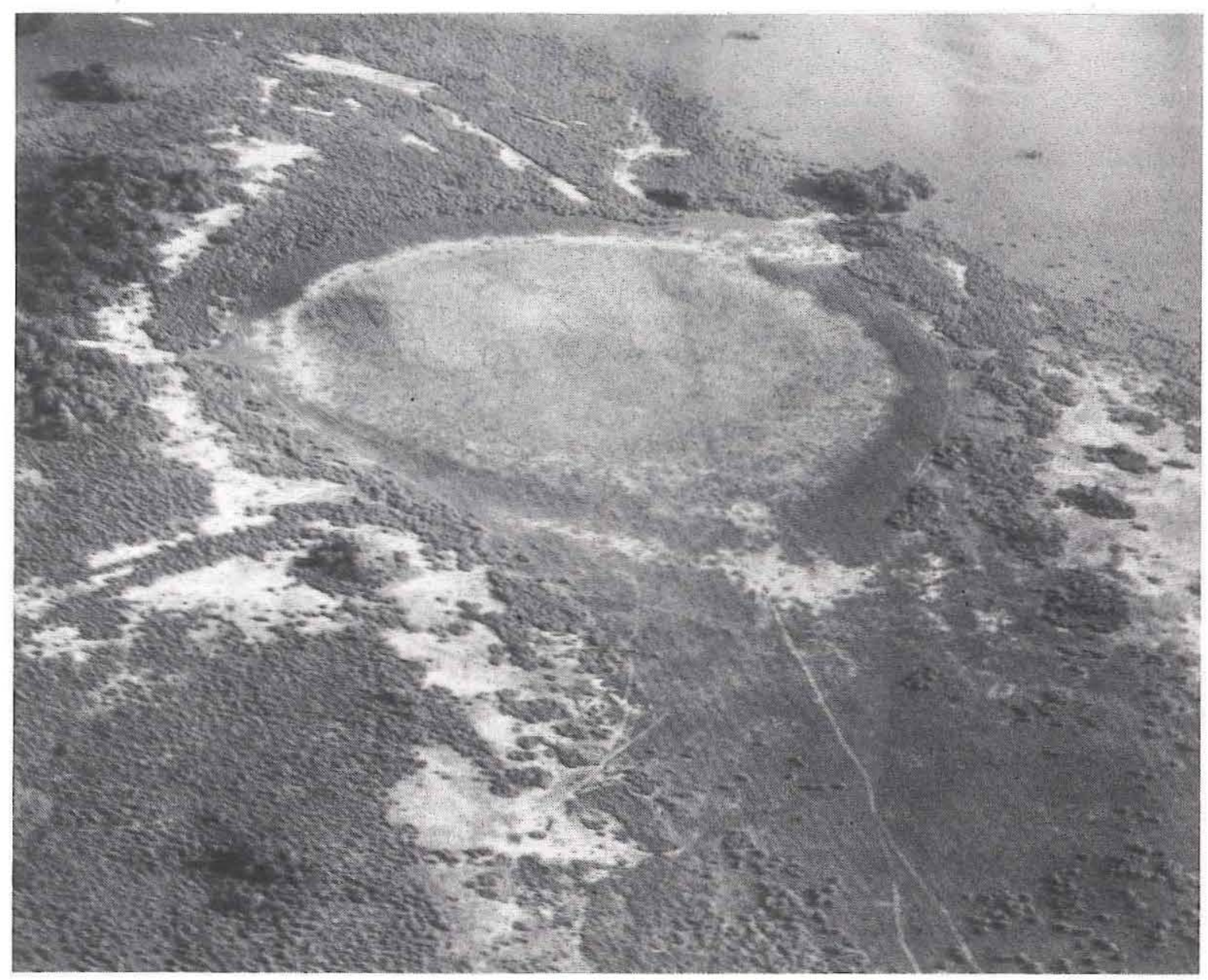

Figure 11. Aerial photograph of small blowout surrounded by natural vegetation.

the effects of storms and hurricanes make this one of the most unstable environments in the region.

The plants that inhabit this zone must be adapted to saline conditions. Offshore breezes deliver an almost constant source of salt to a wide band of land flanking the Gulf of Mexico and Laguna Madre. Oaks cannot live with this much exposure to salt, and thus the oak mottes disappear near the coast. Three distinctive plant communities occur in sequence and are controlled by their varying resistence to windbome salt, with increasing salt exposure dramatically reducing the diversity of the plant communities. The first community is dominated by bunch grass (Spartina spartinae) with rare occurrences of Houstonia nigricans and Hybanthus verticillatus platyphyllus. Closer to the saltwater and in moresaline soils than the first community is the BorrichiaBatis-Monathochloe community. The codominants of this herbaceous community are Borrichia frutescens, Monanthochloe littoralis, and Batis maritima. This community commonly occurs on low-lying clay soils along the coastline, and it surrounds clay dunes in the intertidal flats of Laguna Madre. Some clay dunes support a short brush community with mesquite, prickly pear, and the bunch grass, Sporobolus wrightii. Nearest the strand in the harshest of conditions is a community of succulent halophytes, the Batis-Salicornia-Suaeda community. The dominant plants include $B$. maritima, Salicornia perennis, Salicornia bigelovii, Suaeda conferta, and Suaeda linearis.

Plants are not the most important resources of the coastal zone; rather, shellfish, fish, and waterfowl provide the greatest economic opportunities. Prehistorically, the most important shellfish was the whelk, Busycon sp., but a number of other species are known 
to have been utilized (Steele 1987:220-221). Ethnohistoric documents (Ruecking 1953 and 1955; Salinas 1986; Campbell 1988) indicate the importance of fishing along the coast, but the utilized fish species are unknown. Migratory and nonmigratory waterfowl were certainly an important food source, and many species, especially ducks and geese, are present today. Waterfowl increase in availability seasonally, being more abundant in the winter than the summer.

\section{Rio Grande Floodplain and Delta}

This zone includes the Rio Grande floodplain and its modern delta. The Rio Grande is the major source of perennial water in the region and its importance cannot be overestimated. The topography of this zone is not marked as the stream gradient is very low. Scattered throughout the zone are a number of oxbow lakes which hold freshwater, and these provide additional environments that are rich in resources. Floodplain plant communities are found along some of the larger resacas, e.g., Arroyo Colorado, as well. The delta is a dynamic wetlands caused by small and large distributary channels that constantly change course.

The plant communities of the floodplain and delta are unique in the region. The floodplain is the best-wooded area, supporting the great lead-tree (Leucaena pulverulenta), Berlandier ash (Fraxinus berlandieriana), sugar hackberry (Celtis laevigata), anaqua (Ehretia anacua), ebony apes-earring (Pithecellobium flexicaule), western soapberry (Sapindus drummondii), and mesquite (Prosopis juliflora). These trees form a tall, 50- $\mathrm{ft}$ canopy in the few undisturbed portions of the floodplain; beneath this canopy are shrubs such as Barbadoscherry malpighia (Malpighia glabra), vines such as short-fruited serjania-vine (Serjania brachycarpa) and saw greenbrier (Smilax bona-nox), and herbs such as climbing plumbago (Plumbago scandens) and drummond wax-mallow (Malvaviscus drummondii). Away from the river, this floodplain community begins to change to a brush community characterized by mesquite and acacia.

In the delta area, a plant community dominated by palmetto palm trees, Sabal texana, has been documented (Clover 1937; Johnston 1955). This palm grove looks like a tropical plant community but is very limited in extent. Many of the trees found in the floodplain community also occur in this palmetto palm tree grove but in lesser frequencies. However, some plants such as Colubrina greggii occur in Texas only in this plant community, while others such as vine mimosa (Mimosa malacophylla) are more common here than in any other area of Texas.

\section{LAND MODIFICATIONS}

It is well documented that historic agricultural practices in the project area have drastically changed the local landscape (Mallouf et al. 1977; Day et al. 1981; Hall et al. 1987). Land leveling, brush clearing and burning, filling of depressions, and redistribution of topsoil have substantially altered the erosional and depositional dynamics of the area. As the entire project area has been subjected to historic farming and associated land-modification activities, it is doubtful that many intact undisturbed surfaces now exist (Fig. 12).

In addition to ground surface disturbances caused by agricultural activities, construction of the drainage ditches has altered the landscape in a more-localized manner; all archeological sites discussed in this report have been impacted by ditch construction. The ditches were dug with large draglines and the dirt placed in linear spoil piles $10-15 \mathrm{~m}$ away from the ditch edges. Access roads were built along both sides of the ditches. Construction of access roads often required filling depressions and leveling small low rises. These roads slope down away from the ditches, and are bounded on their outside edges by shallow ditches cut for water drainage. Road graders are used to maintain the roads, and dirt scraped off the roads is piled between the ditches and roads to form low berms. Through time, these berms build up with a sequence of buried road surfaces. As part of road maintenance, clay is often packed into gullies to prevent deep erosion along the sides of the ditches. Additionally, buried, concrete-lined culverts were constructed to allow drainage from intersected depressions into the ditches. Along the ditch banks at these culverts and at corners, stone or broken concrete riprap drapes are used to retard erosion.

Most of the landscape, plant and animal communities, and archeological sites in the Lower Rio Grande Valley have suffered some form of recent disturbance. The scale of impact is tremendous and the rate of disturbance is increasing. Large areas in Willacy County, previously unfarmed, are rapidly being cleared with bulldozers and put under the plow. 


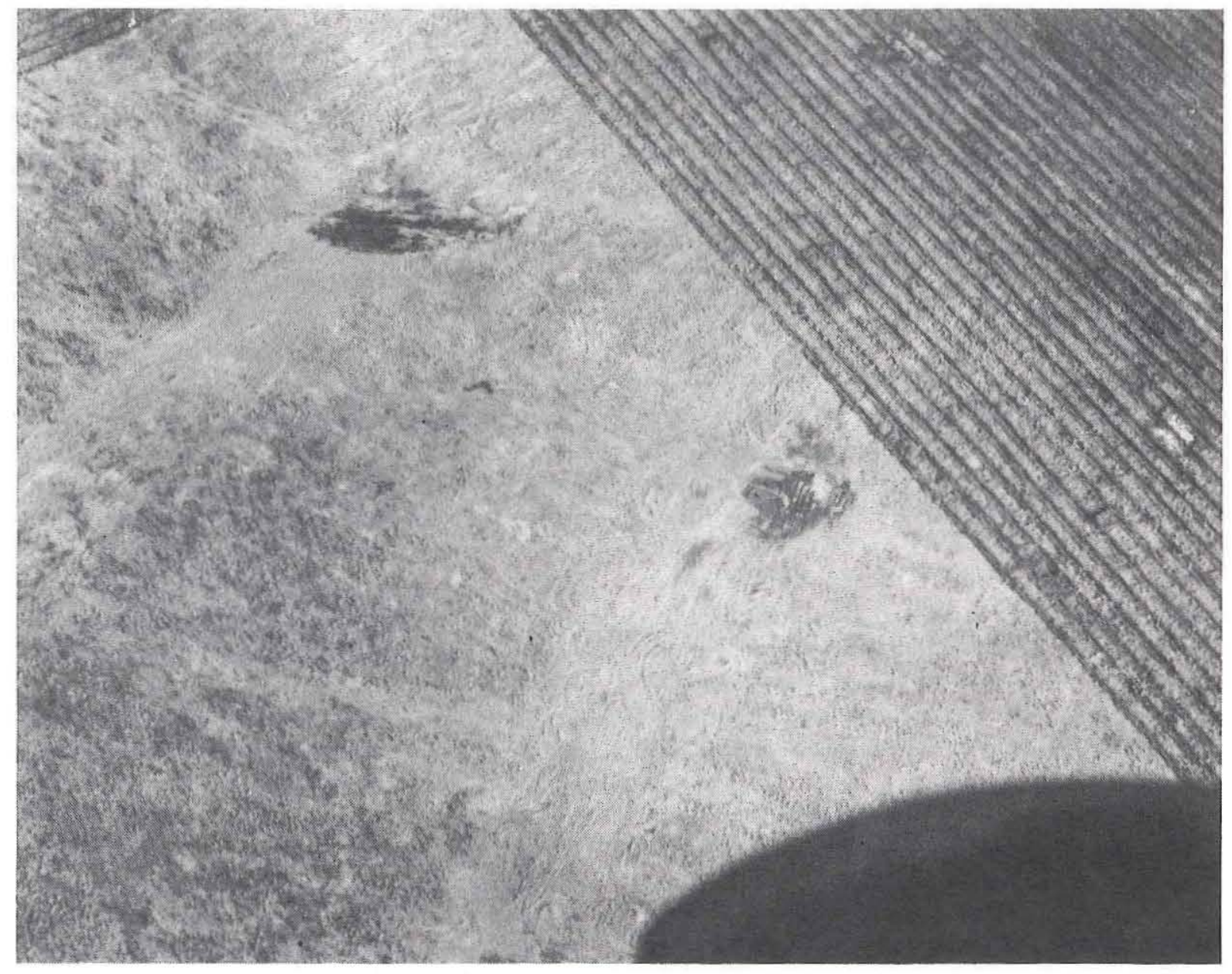

Figure 12. Aerial photograph of modern land-clearing activities; note plowing and bulldozed vegetation burned in piles.

Many archeological sites have undergone extensive disturbance and will continue to do so over the next few years. Previous botanical work has recorded the plant communities, and efforts are underway now to preserve and restore these communities; however, no such effort has been mounted for the preservation of the archeological resources in the Lower Rio Grande Valley. The current investigations represent a responsible effort by Hidalgo and Willacy counties to deal with the loss of archeological resources along the Hidalgo-Willacy Drainage Ditch. 


\section{ARCHEOLOGICAL BACKGROUND}

by Gail L. Bailey

This chapter consists of two sections. The first summarizes the previous investigations by providing a brief overview of the archeological research in the project area to date. The second section outlines the current theories of cultural chronology in the Rio Grande Delta area.

\section{PREVIOUS INVESTIGATIONS}

A brief summary of the major archeological work performed in the Rio Grande Delta and in Zapata and Starr counties is presented here. A more comprehensive overview of the literature on the archeology and ethnography of the region is provided in Table 2. The first significant archeological work accomplished in the Rio Grande Delta was by A. E. Anderson, a civil engineer in Brownsville, who made systematic collections from over 350 sites in Willacy and Cameron counties and northeastern Tamaulipas, Mexico between 1908 and 1940. His collections served as the basis of study for later archeologists attempting to synthesize the prehistoric cultures of South Texas (Sayles 1935; Mason 1935; Jackson 1940; Ekholm 1944; MacNeish 1947, 1958; Campbell 1960; and Prewitt 1974).

Sayles' (1935) synthesis of the archeology of far South Texas and adjacent northeast Mexico uses broad linguistic divisions. He identifies sites situated along the coast as the Brownsville Phase of the Tamaulipan Branch. These sites exhibit a specialized shell industry, occasionally contain Rockport or Huastecan-like pottery, and are geographically and culturally distinct from his inland Coahuiltecan
Branch. The Coahuiltecan Branch is characterized by large surface sites along small streams, stone rather than shell as manufacturing materials, and denser site distributions.

Mason (1935) analyzed the Anderson collection ceramics from the Rio Grande Delta and Huastecan ceramics from Mexico for his study of Mesoamerican influences north of the Rio Grande. He suggests that the ceramics from the delta region resemble Huastecan ceramics primarily in decoration:

Among the elements common to both ancient Huaxtec [sic] and Brownsville vessels, and to a less extent to modern Huaxtec [sic] vessels, are parallel straight lines and bands, scallops, triangles, concentric circles with central dot, and animal figures [Mason 1935:40].

He notes more similarities in vessel shape between the Brownsville ollas and the modern native pottery made in the Tampico region than with ancient Huastecan vessels (1935:38-40). Mason goes on to say that

as a result of our comparisons we may probably conclude with reasonable confidence that the Brownsville vessels were not made by Huaxtecs [sic] . . . but show Huaxtec [sic] influence to a moderate degree [1935:40].

Inexplicably, MacNeish (1947:7, 1958:186) states that Mason's report confirms that vessels from the 
TABLE 2

PUBLICATIONS AND TECHNICAL REPORTS ON THE RIO GRANDE DELTA

\begin{tabular}{|c|c|}
\hline Decade & Author/Date \\
\hline $\begin{array}{l}1930 \mathrm{~s} \\
(\mathrm{n}=3)\end{array}$ & Anderson 1932; Mason 1935; Sayles 1935 \\
\hline $\begin{array}{l}1940 \mathrm{~s} \\
(\mathrm{n}=7)\end{array}$ & $\begin{array}{l}\text { Jackson 1940; Evans 1941; Saldivar 1943; Ekholm 1944; McNeish 1947; Vigness 1948; } \\
\text { Campbell and Frizzell } 1949\end{array}$ \\
\hline $\begin{array}{l}1950 \mathrm{~s} \\
(\mathrm{n}=12)\end{array}$ & $\begin{array}{l}\text { Krieger and Hughes 1950; Hartle and Stephenson 1951; Cason 1952; Ruecking 1953; } \\
\text { Sears 1954; Suhm, Krieger, and Jelks 1954; Ruecking 1955; Vigness 1955; Krieger 1956; } \\
\text { Weir 1956; MacNeish 1958; Krieger n.d. }\end{array}$ \\
\hline $\begin{array}{l}1960 \mathrm{~s} \\
(\mathrm{n}=7)\end{array}$ & $\begin{array}{l}\text { Campbell 1960; Troike 1962; Campbell 1964; Newton 1968; Collins, Hester, and Weir } \\
\text { 1969; Hester 1969; Hester, Collins, Weir, and Ruecking } 1969\end{array}$ \\
\hline $\begin{array}{l}1970 \mathrm{~s} \\
(\mathrm{n}=24)\end{array}$ & $\begin{array}{l}\text { Hester and Rodgers 1971; Brown 1972; Hester 1972; Krieger 1972; Hall and } \\
\text { Grombacher 1974; Patterson 1974; Prewitt 1974; Scurlock, Lynn, and Ray 1974; } \\
\text { Campbell 1975; George 1975; Hester 1975a; Hester 1975b; Hester 1975c; Hester and } \\
\text { Shafer 1975; Nunley and Hester 1975; Hester 1976; Campbell 1977; U.S. Army Engineer } \\
\text { District, Galveston 1977; Mallouf, Baskin, and Killen 1977; Fox 1979; Goddard 1979; } \\
\text { Hester 1979; Hester and Kelly 1979; Mallouf and Zavaleta } 1979\end{array}$ \\
\hline $1980 \mathrm{~s}$ & $\begin{array}{l}\text { Kotter 1980; Day 1981; Day, Laurens-Day, and Prewitt 1981; Espey, Huston and Asso- } \\
\text { ciates 1981; Hester 1981; Etchieson and Boyd 1982; Campbell 1983; Mercado-Allinger } \\
\text { 1983; Paull and Zavaleta 1983; Willacy County Drainage District \#1 1983; Good 1985; } \\
\text { U. S. Army Engineer District, Galveston 1985; Shafer 1985; Salinas 1986; Hall, Collins, } \\
\text { and Prewitt 1987; Quigg, Boyd, and Prewitt } 1989\end{array}$ \\
\hline
\end{tabular}

Brownsville sites are Huastecan pots. This misinterpretation has unfortunately been incorporated into the modern literature.

MacNeish (1947, 1958) further subdivides Sayles' scheme on the basis of the Anderson collection and his own survey data from the Rio Grande Delta and Tamaulipas, Mexico. MacNeish distinguishes the Brownsville Complex, confined to the Texas side of the delta, from an earlier Barril Complex, located mostly south of the Rio Grande, and he provides extensive trait lists for each (MacNeish 1958). MacNeish also defines the Abasolo Complex (analogous to Sayles' Coahuiltecan Branch) and the Repelo Complex as predating the Brownsville Complex in the delta but predominantly occurring inland in northern Tamaulipas.
Suhm et al. (1954) identify two cultural units in the Falcon Reservior area located on the Rio Grande in Zapata and Starr counties. They use the Midwestern Taxonomic System (McKern 1939) and identify the Falcon Focus, an Archaic culture, and the Mier Focus, a late Archaic to Late Prehistoric culture. Both complexes were believed to represent long, stable adaptations with little cultural change. However, this concept was later changed because of further work that suggested a greater diversity of cultural adaptations relative to microenvironmental situations (Nunley 1971; Nunley and Hester 1975; Mallouf et al. 1977).

To the northwest of the project area, survey and limited excavation at sites located along the Arroyo Los Olmos have revealed projectile point types 
representative of the Paleoindian, Archaic, and Late Prehistoric periods (Newton 1968). Newton proposes a continuum of Lerma, Abasolo, Tortugas, Pandora, Refugio, Desmuke, Catan, Matamoros, and Starr projectile point types based on the morphological similarities of these types and the lack of a clear distinction in the tool types observed at the sites. $\mathrm{He}$ concludes that the archeology in this region represents a slowly evolving hunting and gathering adaptation with two cultural zones identified relative to two resource areas: campsites near the stream and foraging locales away from the stream. Additional survey work in this area primarily shows Archaic sites represented by two distinct adaptive strategies relative to topographic zones (Nunley and Hester 1975; Fox 1979). Sites situated on stream terraces (i.e., Gallery sites) reflect the utilization of terrestrial resources available in the floodplain, and sites on the uplands above the floodplain (i.e., Bower sites) reflect an adaptive strategy based on upland resources (Nunley and Hester 1975). It should be noted that these interpretations are based primarily on surface collections from terrace areas and bank exposures and generally lack firm chronological controls.

In a recent synthesis, Hester (1981) proposes two major adaptations in South Texas, savanna and maritime. The former is identified as an inland phenonmenon where cultures inhabited grasslands and riparian environments with low-density resource areas. These areas support vegetational and faunal communities that are more dispersed and limited in the diversity and quantity of resources as compared to high-density resource areas which contain multiple resources and are located in both the savanna and coastal zones (Hester 1981:120-124). Hester's maritime adaptation focuses on the utilization of marine resources, permitting successful hunting and gathering activities to be concentrated along the coast with limited use of adjacent prairies. The Hidalgo-Willacy eolian sand and loess plains, located roughly between these two zones and corresponding to the sand sheet utilized here, are characterized as widely dispersed low-density resource areas.

Although Anderson identified the general topographic settings in which archeological sites occur in the delta region (Texas Archeological Research Laboratory n.d.), it was not until Prewitt (1974) defined five distinct settings where sites are most frequently located that the relationship between site location and environment could be analyzed. Later this was more fully developed and a predictive model for archeological sites in the project area was established (Mallouf et al. 1977). This model allowed surveys to focus more practically and effectively on site discovery (Day 1981; Day et al. 1981; Etchieson and Boyd 1982; MercadoAllinger 1983; Hall et al. 1987; Quigg et al. 1989). These surveys resulted in the discovery of 175 prehistoric and/or historic sites along drainage ditch alignments in Hidalgo and Willacy counties.

Mallouf et al. (1977) identified eolian depressions or playas (occasionally spring related) as the dominant water sources in the project area attracting both wildlife and vegetation. Here too is where archeological sites are typically found, although some sites occur on adjacent elevated areas, perhaps intended to take adviantage of several playas.

Although there has been an increase in survey activity within the project area, only a handful of sites have heretofore received some form of excavation. As a result, cultural chronology, subsistence strategies, and settlement patterns for the area remain poorly known. Intact buried cultural deposits, absolute dates, and evidence of economic resources are sorely needed. Such information is required before the issues mentioned above can be addressed completely.

\section{CULTURAL CHRONOLOGY}

Although a substantial amount of survey work has been accomplished along the Hidalgo-Willacy Drainage Ditch, prior to this project only six prehistoric sites had undergone excavations ranging from subsurface probes to controlled hand excavations (41HG118, 41WY50, 41WY60, 41WY71, 41WY72, 41WY84, and 41WY113). Two sites, 41HG118 and 41WY50, yielded radiocarbon dates, but neither is associated with diagnostic materials. One radiocarbon date was obtained from human bones from 41 WY50, but this was from the inorganic (apatite) fraction and apatite dates are often unreliable (see Appendix D). The other radiocarbon date was obtained from soil humates from 41HG118, and such dates are also often unreliable. Attempts to interpret cultural chronology in the Rio Grande Delta therefore have relied heavily on comparisons with artifact types from surrounding areas such as the Trans-Pecos and Lower Pecos, Coastal Bend, Central Texas, and Northeastern Mexico, and previous investigations 
have emphasized that a cultural-chronological sequence has yet to be developed for the Rio Grande Delta (Mallouf et al. 1977:86-88; Day et al. 1981:14-15; Hall et al. 1987:17). The four periods defined by Suhm et al. (1954) for South Texas remain the current level of chronological resolution for the project area. These are Paleoindian, Archaic, Late Prehistoric, and Historic Contact and are discussed briefly below.

The Paleoindian period is poorly represented in the Rio Grande Delta and the project area by a few isolated projectile points (Mallouf et al. 1977). This period is commonly characterized by a dependence on the hunting of Pleistocene megafauna. More appropriately, this period may have seen use by small, mobile bands of nonspecialized hunters and gatherers occassionally utilizing megafauna perhaps only as the opportunity arose. The closest known occurrence of megafauna to the project area is at a site at the mouth of the Rio Grande where A. E. Anderson recovered a Clovis base (Suhm et al. 1954:121). Here W. A. Price observed mammoth bones eroding from a clay deposit near the site. Eleven localities at Falcon Reservoir had mammoth bones eroding from deposits that could have contained artifacts (Cason 1952:243, 251). The La Paloma Mammoth Site in northwestern Kenedy County is the nearest megafaunal site to the north of the project area; bison antiquus was also recovered at this site (Cason 1952). Isolated Paleoindian projectile points have been found immediately to the north of the Hidalgo-Willacy Drainage Ditch in the Norias eolian sand lobe; to the west at the La Perdida Site, Falcon Reservoir, and just north of Rio Grande City; and to the south near the mouth of the Rio Grande (Mallouf et al. 1977:167; Weir 1956:59, 65, 71, 72; Newton 1968:21; Suhm et al. 1954:136). No Paleoindian dart points have been recovered from archeological sites along the drainage ditch, however, and very little environmental and cultural data exist for the entire South Texas region for this period. Borrowing from the Southwest and Central Texas cultural areas, however, the Paleoindian period is presumed to have ended by 7,000 B.P. (Mallouf et al. 1977:67, Table 2).

The Archaic period is also poorly understood in the project area. Generally, in Texas this period signifies a shift to hunting smaller game and to plant gathering; sites in the coastal zone also demonstrate an emphasis on the exploitation of marine resources. Only one Archaic culture, the Aransas Focus, has been defined on the Texas Coast, and it is limited to Aransas and Corpus Christi bays far to the north. To the west, sites located along the Arroyo Los Olmos appear to have well-represented Archaic period deposits (Newton 1968; Nunley and Hester 1975), as do sites at Falcon Reservoir (Suhm et al. 1954), although both areas lack clear distinctions between the Archaic and Late Prehistoric periods. Earlier work in the Rio Grande Delta did not provide evidence to support a well-defined Archaic period in the region (Mallouf et al. 1977), but the presence of Archaic deposits on the delta "is indicated primarily by unstemmed triangular thin bifaces, gouges, and infrequent stemmed dart points" (Hall et al. 1987:18). Recent archeological investigations near the mouth of the Rio Grande have been limited to surveys and have not yielded prehistoric cultural materials identifiable as belonging to the Archaic period (Espey, Huston and Associates, Inc. 1981).

Within the project area, 16 prehistoric sites have yielded dart points representative of the Archaic period (41HG4, 41HG5, 41HG6, 41HG9, 41HG96, 41HG115, 41HG118, 41HG125, 41WY7, 41WY18, 41WY27, 41WY39, 41WY42, 41WY44, 41WY116, and 41WY117). Of these, only the Sardinas Resaca Site (41HG118) had been excavated prior to the current work and, based on a comparison of artifacts with similar forms from South Texas and northeastern Mexico, the artifact collection from this site is representative of late Archaic and/or Late Prehistoric periods (Hall et al. 1987:62). A radiocarbon date from bulk soil humates associated with undiagnostic prehistoric cultural materials at $41 \mathrm{HG} 118$ indicates that the earliest occupation was ca. 3500 B.P. (Hall et al. 1987:63). Based on this evidence and regional comparisons (Hester 1981), the Archaic period in the project area is tentatively placed at 7,000-5,000 to 800 B.P.

The Late Prehistoric is the best known of the three prehistoric periods for the Rio Grande Delta; it is defined by the presence of the bow and arrow and is marked by the production of small arrow points beginning around 800 B.P. (Hester 1981:122). Also generally characteristic of this period is the emergence of agriculture and pottery, but the evidence indicates that these practices were never developed in South Texas. Northward along the Texas coast, the Rockport Focus ceramic tradition is attributed to the Late Prehistoric and Historic periods, but it is spatially limited to the area between Baffin Bay and Matagorda Bay. 
The Brownsville and Barril complexes, identified as Late Prehistoric cultural adaptations present in this region, are characterized by a well-defined shell industry. MacNeish (1958:186-193) first described these two complexes in detail based on his survey work and the work by Anderson (1932), Mason (1935), and Sayles (1935). The Brownsville Complex was determined by MacNeish to be Late Prehistoric based on the presence of 10 specimens of Huastecan-like pottery indicative of the Panuco Period VI recovered from two sites in Cameron County (MacNeish 1958:186-189). The Barril Complex was believed to slightly predate the Brownsville Complex and is distinguished by the presence of conical bone and columella projectile points, while the Brownsville Complex is uniquely associated with conical pumice pipes (MacNeish 1958). The Brownsville Complex occurs throughout the Rio Grande Delta while the Barril Complex appears to be located predominately in northeastern Tamaulipas, Mexico. Sites assigned to the Brownsville Complex have been observed mostly in Cameron County near the coast and along the Arroyo Colorado.

No Late Prehistoric diagnostic materials have been recovered from the Hidalgo-Willacy Drainage
Ditch routes to date, with the possible exception of a side-notched projectile point from 41HG126 (Hall et al. 1987:Fig. 19g). Small triangular bifaces have not been convincingly associated with the Late Prehistoric period and may prove to be technologically related to resource locations and transportation rather than being temporal indicators. Previous surveys, however, have recovered diagnostic arrow points from six sites (41HG4, 41HG5, 41HG6, 41HG9, 41HG36, and 41HG38) in east-central Hidalgo County, four sites (41WY15, 41WY19, 41WY31, and 41WY32) surrounding the La Sal Vieja in western Willacy County, and an isolated find in central Willacy County (Mallouf et al. 1977:172-174, 258-265).

Historic Contact period Indian sites are noted by the presence of materials of European origin including such items as metal projectile points, other metal objects, trade beads, and wheel-made or glazed ceramics. The nearest known Historic Contact period sites are southeast and east of the project area where wheel-made or glazed sherds were recovered from four sites (41CF8 and three sites discovered by Anderson). The last record of aboriginal inhabitants in the area was in A.D. 1886 near Reynosa, Mexico (Salinas 1986:258). 


\section{MODELS OF LATE HOLOCENE HUMAN ADAPTATION IN THE LOWER RIO GRANDE VALLEY}

by Steve A. Tomka

To maximize the interpretive potential of the meager archeological record of the Lower Rio Grande Valley, a set of alternative models reflecting varying hunter-gatherer settlement mobility patterns is proposed. A series of archeological predictions and implications is provided which can be compared to the available data base from the region.

The investigation of human subsistence, settlement, and mobility strategies, as conditioned by resource opportunities and limitations, is a primary objective of archeological investigations in the Lower Rio Grande Valley. Using Binford's (1980) forager-collector continuum and viewing resource structure (Conaty 1987) as the primary factor conditioning subsistence and settlement strategies (Kelly 1980, 1983), one goal of archeological work along the Hidalgo-Willacy Drainage Ditch is the extraction of regional land-use patterns and the explication of factors that conditioned shifts in land use through time.

Although some changes in regional paleoenvironmental conditions are suggested by the geomorphic data (see Chapters 5 and 7), these changes probably were not of sufficient magnitude to significantly alter the resource structure in the Lower Rio Grande Valley region, but moredetailed data are needed before this can be assessed. Because of this presumed stability, it is accepted that the models presented here will describe the organizational range of resource procurement practices for much of the late
Holocene. This position implies that changes in the land-use pattern of a given region occur only under major environmental shifts or changes in other factors that alter the structure of the exploited resources, either in terms of the spatial or temporal distribution of the resources or human access to them (Hayden 1986; Conaty 1987). In the future when more paleoenvironmental data are available, it may be possible to tailor models to reflect environmental changes that would theoretically alter human responses, but until such data are in hand, the models, by default, must be based on the modern ecology.

In assessing the interpretive utility of the models, it is important to bear in mind that individual archeological sites discovered along the linear project area represent only a fraction of the settlement system and cannot be interpreted in isolation. The project area must be considered within the context of the region as a whole before the overall land-use strategies can be defined. With this in mind and for the purposes of model building, the project area is more broadly defined as the area bounded by Starr and Duval counties in the south and northwest, Nueces County in the north, the Rio Grande in the south, and the coast in the east.

\section{THEORETICAL BACKGROUND}

This section consists of six parts. The first provides an explanation of how forager and 
collector strategies differ; the second integrates some ideas based on optimal foraging theory; the third describes the resource structure of the project area; the fourth summarizes ethnohistoric data on resource use; the fifth presents three possible models of resource and territorial use of the region; and the final section presents the artifact predictions under each of the three models.

\section{The Forager-Collector Dichotomy}

Recent works by Binford (1980), Kelly (1980, 1983), and Hayden (1986, 1987) illustrate how resource acquisition among ethnographic groups can be categorized in broad terms as either forager- or collector-oriented. Foragers tend to move the consumers to the resources wherever they may be found in space or through time. Storage plays a minor role in foraging economies because few resources are available in large enough quantities to permit bulk acquisition and processing for lean-period consumption. Also, most forager groups live in areas where sufficient resources are available during these lean seasons to support the group. On the other hand, collectors move resources to the consumers through the employment of task groups to exploit resources occurring in bulk. The quantities obtained are sufficient to permit storage for delayed consumption. In regions inhabited by collectors today, the scarcity of lean-season resources is so marked that storage is necessary. Storage extends the availability of a resource into resource-scarce seasons.

The majority of the extensively studied ethnographic groups are foragers, while a few are collectors. Furthermore, some groups are foragers during a part of their annual cycle and collectors during the remainder. The forager-collector dichotomy characterizes resource acquisition patterns at the two extremes of a continuum and in environmentally extreme settings (e.g., tundra versus tropical rain forest). Realizing that most land-use patterns need to accommodate seasonal or longer-term shifts in the resource base and that resource acquisition patterns may vary through the annual cycle from forager- to collector-oriented, what is the utility of viewing land-use patterns in terms of this dichotomy? The answer lies partly in the factors that condition resource acquisition modes. Understanding the underlying causal factors generating different mobility patterns is crucial in explaining the driving forces of prehistoric settlement/subsistence patterns and developing more precise expectations and testable hypotheses for future archeological work. Furthermore, the forager-collector continuum is particularly useful for predicting the expected relationships between resource acquisition and mobility strategies, site function, assemblage composition, occupation length, group size, and regional settlement/subsistence patterns.

The following describes the relationship between environmental and climatological factors, resource structure, resource accessibility, and expected resource acquisition patterns. This discussion provides the theoretical basis of the models of resource and land-use patterns outlined for the project area below.

Binford (1980) argues that the structural properties of the environment and resources can be described by the annual mean and seasonal distribution of solar radiation. This is known as effective temperature or ET (Bailey 1960). The lower the ET, the more seasonal the environment and the shorter the growing season. The higher the ET, the less seasonal the environment and the longer the growing season. As climatic severity increases or as the length of the growing season decreases, the number of available resources usually decreases and the spatial and temporal incongruence between them tends to increase. Binford (1980) interprets this incongruence as the catalyst conditioning the manner in which resources are acquired.

Collectors use logistical strategies to resolve spatial or temporal conflicts in availability among critical resources (Binford 1980:15). Critical resources that are restricted in space and time are acquired by logistical task groups. The extreme lack of resources during the winter in temperate and colder environments is solved through increased seasonal sedentism and increased storage dependence (Goland 1983). Binford (1980) finds a relatively good concordance among 31 ethnographic cases between dependence on storage and decreasing ET. Only groups with an ET below $15^{\circ} \mathrm{C}$ practice significant levels of storage. Storage dependence seems to increase in environments with growing seasons of less than 200 days. In contrast, tropical rain forest groups maintain a high degree of mobility in response to evenly 
distributed resources. Foraging for food is done on an encounter basis, and the exhaustion of resources within the foraging radius is followed by relatively short-distance residential moves into the center of a new foraging area.

Binford's characterization of resource acquisition patterns in terms of ET values is useful in that it demonstrates the tendency for high ET environments to be exploited within a forager system and low ET environments to be exploited in a collector mode. It also suggests that in warm temperate zones characterized by median ET values, the resource acquisition patterns may be a complex mix of collecting and foraging strategies which may vary seasonally.

Hayden $(1986,1987)$ addresses the factors that generate logistically organized systems in temperate climates. He concurs that, in general, in temperate areas a foraging strategy is adaptive to evenly distributed, scarce, and unpredictable resources and generates a highly nomadic land-use pattern. However, in some temperate climates, once effective means were developed for the exploitation of small body sized, rapidly reproducing (i.e., r-selected) resources such as grass seeds, acorns, and rabbits, their utilization may have been conducted under logistical strategies. While there is a strong technological component to this argument, the aspect that is significant for the purposes of this discussion is the character of the resource base. Hayden (1986:86) suggests that the reliability, richness, and seasonal nature of the resources are the critical aspects conditioning the mode of resource use. Conaty (1987:60), based on analogies with predator-optimal foraging strategies (Horn 1968), sees availability and distribution (evenly distributed and stable versus highly clumped and transient) rather than density of the prey as the critical variables. Foraging strategies appear to correlate with the exploitation of evenly distributed and relatively stable resources. Collecting strategies appear to be more commonly employed in the exploitation of clumped and transient resources. Heffley (1981:133) suggests the following classifications of resources as important determinants of settlement patterns: (1) evenly spaced and stable; (2) mobile, clumped, and unpredictable; and (3) clumped and predictable. Evenly spaced and stable resources appear to be exploited by small groups under a dispersed, relatively mobile settle- ment pattern (i.e., foragers). Mobile, clumped, and unpredictable resources are often exploited in bulk by larger mobile groups, but the larger return for the energy invested generates storable surplus which permits some degree of seasonal sedentism (i.e., collectors). The highest degree of sedentism is found in the context of clumped and predictable resource exploitations (e.g., salmon runs by Northwest Coast groups). Seasonal variations in the mobility and patchiness of the resource base can stimulate a shift in mobility strategies by hunter-gatherers within a single year's cycle. Groups such as the Tanana (Heffley 1981:140142), that exploit mobile, clumped, and unpredictable resources for short periods in the spring, summer, and fall and evenly spaced stable resources throughout the remainder of the year, practice a seasonally varying mix of logistical (collector) and residential (forager) mobility.

One approach that characterizes resource acquisition modes in terms of resource structure, primary and secondary production, and biomass accessibility, is provided by Kelly $(1980,1983)$. Because it uses broad measures of resource availability rather than focusing on a limited set of arbitrarily chosen environmental attributes, it offers a theoretically robust explanation to account for global differences in resource acquisition. Different effective temperature regimes and rainfall amounts produce environments differing in primary production and primary biomass. It is the primary production and primary biomass that aid in defining the structure and accessibility of resources in a given environment. Primary production refers to the amount of energy in vegetation remaining from the process of photosynthesis after respiration. Primary biomass is the total amount of standing plant mass present in a region at a particular point in time. A third important element, secondary biomass, represents the amount of faunal mass present in a region at a given point in time. Environments with relatively high ETs have high primary and secondary biomass settings (e.g., tropical forests). As ET decreases, the primary and secondary biomass of the environment also decrease.

Primary biomass is shown by Kelly (1980) to be inversely related to the accessibility of plant and faunal resources, however. While tropical forests have extremely high primary biomass, the resources are largely inaccessible to human 
consumers. On the other hand, environments with low ETs, such as the tundra, have much lower but highly accessible secondary biomass. Holding ET constant, the body size of the fauna decreases and the individuals become more dispersed and less accessible as primary biomass increases (e.g, in tropical and subtropical settings). Holding primary biomass constant, as ET decreases the fauna decreases in density but individuals are often of larger body size, more gregarious, and more accessible (e.g., in the Great Plains and tundra settings). The implication is that high primary biomass environments with small, dispersed, secondary biomasses are exploited by residentially mobile foragers, while low biomass environments with large-bodied, gregarious fauna are exploited by logistically organized, semisedentary or fully sedentary collectors.

\section{Optimal Foraging Expectations}

One aspect of resource procurement that is not explained directly by these broad models is the actual mix of resources utilized by prehistoric groups given the regional resource structures outlined above. At present, the detailed botanical and faunal information needed to develop rigorous and quantified expectations regarding the resources utilized does not exist. Based on the extensive literature on hunter-gatherer foraging strategies (Pyke et al. 1977; Keene 1979; Winterhalder and Smith 1981; Jochim 1983), however, some broad expectations can be presented regarding the range and mix of resources utilized and, by implication, the seasons of use and overall mobility strategies. These expectations will, in turn, structure the archeological predictions outlined later in this chapter.

The optimal diet model predicts that in a patch where resources are encountered at random in proportion to their abundance, a predator will take a resource item only if the returns from obtaining and processing it are greater than those gained from searching for and processing another resource item. The model predicts that if the return from the item at hand is less than the alternate choice, then the item will be ignored and the predator will continue searching for higherranked resources (MacArthur and Pianka 1966; Charnov 1976). Time and energy are often used as measures of cost and benefit in optimal foraging models. In view of these currencies, a resource item is expected to be included or excluded from the diet based on: (1) its rank in energy gained per unit of handling time relative to other resources; and (2) the abundance of higher-ranked resources, or their encounter rate (O'Connell and Hawkes 1981:108). Handling time consists of the time used in the search, pursuit, and processing of a given resource. Search time refers to the time needed to locate a resource; pursuit time is the time needed to capture it; and processing time is the time needed to make the resource edible. Pursuit time is reduced in the case of stationary resources (e.g., acorn harvesting). In the case of mobile resources, search time is expected to decrease as resource density increases because of the associated increase in encounter probability. With increased resource mobility and/or decreased resource density, search time increases. The search time for mobile prey that move in predictable patterns is expected to be less than for prey that move in random patterns. Predictability tends to increase specialization in individual patch use by reducing visits to unfavorable patches (DysonHudson and Smith 1978:25-26; Smith 1981:4249; Winterhalder 1981:28-32). Predictability also allows a high degree of acquisition scheduling.

It is unclear, at present, whether for human foragers the costs of tool manufacture and maintenance should be considered in the overall costs of exploiting different resources (Shott 1989). Nevertheless, it is expected that in raw-materialpoor areas and under resource acquisition modes with high rates of tool failure (e.g., projectile point failure during hunting), tool replacement costs may significantly increase the acquisition costs for particular resources.

The model indicates that as the encounter rate for higher-ranked resources goes up, lowerranked resources are eliminated from the diet and vice versa, regardless of the absolute abundance of lower-ranked resources. This suggests that foragers might react quite differently to the same resource depending on the characteristics of other resources available in a given situation. That is, the structure of the resource, its composition, relative density, and spatial distribution relative to foraging populations condition the particular resource items included or excluded from the diet. 


\section{Regional Resource Structure}

Because resource structure conditions mobility, it is crucial to define the nature of the resources within the project area. ET is used as an estimate of resource structure in order to aid comparability with Binford's (1980) and Kelly's $(1980,1983)$ work. A calculation of the ET for Willacy County results in a figure of $16.8^{\circ} \mathrm{C}$, with the average annual precipitation being 27.5 inches. This ET value falls into Binford's semitropical environmental zone in which fully-nomadic settlement patterns dominate resource acquisition patterns. The mean length of the growing season, 327 days in Hidalgo County and 331 days in Willacy County (Natural Fibers Information Center 1987:237, 515), is similar to environments in which ethnographic groups are characterized by low dependence on storage (Binford 1980:16).

Analyses of global patterns of primary production indicate that, in general, semitropical and tropical environments have relatively high levels of primary production and primary biomass (Rosenzweig 1968:69; Whittaker and Likens 1975:306; Kelly 1983:284). Kelly (1983:284) indicates that under conditions of high primary production, primary and secondary biomass are also high. On the other hand, the accessibility of the primary production to humans and herbivores is relatively low.

The project area and the broader region are composed of five environmental zones (see Chapter 1). These five zones crosscut geologic and vegetational-community boundaries and represent relatively homogeneous resource areas. In general, primary production is considered to be high along the Rio Grande but less so away from the river. Because of climatological and geomorphic circumstances, however, the environmental zones are seen as being highly dynamic and consistently changing resource settings. For instance, the different stages of sand dune formation, stabilization, erosion, and migration generate a variety of microniches with associated vegetal and faunal variability. Similarly, hurricanes and storms keep the vegetation of the salt flats, marshes, and low islands in stages of progressive and retrogressive succession (Clover 1937:78). For example, Yucca treculeana forests once grew near Boca Chica and Port Isabel at the mouth of the Rio Grande but were wiped out by the 1933 hurricane (Clover
1937:80). Complex microniches occur in the extensive areas of Holocene meander segments and oxbow lakes. The deficient rainfall amounts in the region preclude the development of freshwater marshes in the cutoffs and channel segments except during wet cycles (Brown et al. 1980:54). However, they retain slightly more moisture than the surrounding areas and form microenvironments inhabited by a variety of moisture-loving species (Clover 1937:49-50).

The disruption of successional stages due to anthropogenic factors also contributes to a highly dynamic setting. Revegetation after overgrazing results in an increase not only in brush cover but also in species diversity (Johnston 1955:80). Mesquite (Prosopis sp.) is the first woody brush species to become established followed by other brush genera such as opuntia and yucca (Clover 1937:54,80; Johnston 1955:74). While the various cacti are thought to be primarily invaders, Clover (1937:84) indicates that more species are found in the western portion of the project area. Alternatively, this relationship could be due to either the correlation of the species with calcareous soil types or the general reduction in rainfall toward the west. Yucca constricta is rather abundant northeast of San Ygnacio in western Zapata County, occurring in large and dense patches in open grassy areas (Clover 1937:53), and this distribution could be due to human interferences and overgrazing. While the overgrazing discussed by Johnston (1955) was caused by cattle, some instances of prehistoric overgrazing (e.g., by local faunal population explosions) may have occurred and generated similar vegetational compositions. The movement of active dunes in the sand sheet may also generate successional stages mimicking those seen as a result of overgrazing.

The vegetational and faunal diversity of the environmental zones ensures that some resources will be available for human exploitation at any time in these settings. However, the distributional predictability of the resources is reduced in some patches (e.g., active sand sheets). A higher degree of resource predictability may be afforded by stabilized dunes; although early formation stages may be less predictable, they offer an increased variety of potentially useful resources (e.g., Atriplex, Amaranthus, and Chenopodium).

Two climax communities are noted in the project area, live oak mottes and riparian 
woodlands. Both of these communities offer a relatively high degree of spatial and compositional predictability. Live oak mottes (Querqus virginiana), which form on stabilized dunes, are distributed in Brooks, Hidalgo, Willacy, and Kennedy counties and the coastal strip of Kleberg and Nueces counties (Johnston 1955:89). According to Clover (1937:84), the most luxurious vegetation community, riparian woodlands, formerly occurred in the alluvial soils of the Rio Grande floodplain eastward from Penitas near the Hidalgo/Starr county line. Due to the increase in moisture toward the coast, vegetation tends to increase in size and in number of species. Also, plants with tropical affinities are more abundant in the area adjacent to Brownsville (Clover 1937:84). The wooded communities seldom grew more than half a mile from the river due to decreasingly available moisture. Similar woodlands may' have formerly occurred along some of the resacas in southern Cameron County (Johnston 1955:123). Another major plant resource was Agave lechuguilla, but it is restricted to patches in the far west in Zapata and Starr counties (Clover 1937:64).

The assumption is made here that the environmental changes that occurred during the late Holocene were not so great that the "resource structure" (sensu Conaty 1987) changed dramatically. More importantly, the changes that occurred were not great enough to force resource procurement patterns to move from a foraging system to a logistically organized pattern. Environmental changes almost certainly did occur, but these changes were not as significant as those thought to have occurred at the end of the Pleistocene or during the middle Holocene. For example, the stable isotope analysis in Chapter 6 suggests that botanic changes did occur but more details are required before these changes can be incorporated into model formulations. In addition, some indications exist that the coast may have seen some changes. For instance, Hester (1980) presents convincing evidence for an increase in the salinity level of Baffin Bay and Laguna Madre since ca. 4000 B.P. This hypersalinity changed the species composition and reduced the overall availability of local shellfish populations. However, seasonal decreases in the salinity of Laguna Madre caused by variations in rainfall (Brown et al. 1980) suggest that there may have been a more-pronounced seasonal shift in the availability of certain species rather than an overall decrease in mollusca. Similar patterns of availability probably occurred among fish species. Nevertheless, with the exception of early historic period land-clearing impacts, the vegetational communities described above and in Chapter 1 are viewed as having characterized the region throughout the late Holocene for the purpose of developing this model of hunter-gatherer exploitation. Until more-detailed data on paleoenvironmental changes come to light, the assumption of late Holocene paleoenvironmental stability, at least for purposes of model building and developing model expectations, is necessary.

In sum, the larger project area is viewed as a median primary biomass biome characterized by a secondary biomass composed of small to medium herbivores, relatively high species diversity, and dispersed faunal distribution patterns. Combining resource structure with the relatively high ET and relying upon the expectations derived from Binford (1980), Heffley (1981), and Kelly (1983), resource acquisition in the project area and the adjacent region should be characterized by a foraging system.

\section{Ethnohistoric Resource Exploitation Patterns}

The analysis of regional ethnohistoric accounts offers a view of the settlement and subsistence patterns used by native groups inhabiting the project area and its vicinity during the early historic period. The reader is referred to the extensive ethnohistoric literature reviews found in Ruecking (1953), Salinas (1986, 1990), and Campbell (1988) for detailed descriptions of Native American social organization, customs, movements, and trade patterns in South Texas in general, and the Lower Rio Grande Valley in particular. Rather than reciting generalities in these studies, a more selective and judicious use of these accounts is appropriate for the specific purposes of this analysis, namely the review of information relating to settlement patterns and subsistence practices. A reconstruction of these patterns and practices can provide, in turn, an initial assessment of how well the theoretical formulations fit the actual ethnographic observations.

The Coahuiltecan settlement pattern has been characterized as seminomadic with camps moving 
every two or three days (Ruecking 1953, 1955). Ruecking (1953:489) notes that the areas surrounding the camps were never completely exploited permitting the continued exploitation of resources even after the camps were moved to other locales. Settlements varied in size but most were small (Campbell 1988:51). During seasons that allowed some degree of group aggregation, maximum group size did not exceed 150-200 individuals, i.e., approximately 40 houses (Campbell $1988: 18,51)$. Although no minimum group sizes are given in the ethnohistoric sources, they probably consisted of only extended families (e.g., maximum of 8-10 individuals) (Campbell 1988:51). The movement of groups was cyclical and probably coincided with the ripening of various plant foods. Because of the generally low productivity of the area, the majority of the daylight hours were spent foraging (Campbell 1988:20; Salinas 1986:94). Apparently some resource processing and consumption activities occurred in the field while others took place in camp. During the winter and in low-density resource patches (e.g., agave collecting), foraging trips may have extended as far as five to eight miles from the camps (Campbell 1988:20). Winter food shortages occurred frequently (Campbell 1988:17).

All animals encountered in the environment were hunted, but the principal animal foods were deer, peccary, rats, mice, snakes, snails, and unspecified birds including waterfowl (Salinas 1986:213). Communal deer hunts were organized by some groups but only in association with ceremonial or other large group gatherings (Ruecking 1953:485; Campbell 1988:19). Various species of fish were the main source of food for Indians of the Rio Grande Delta. Fishing was done with bow and arrow and yucca fiber nets. In some parts of the region, fishing may have played a more important role during the winter months when plant resources were scarce. It is unclear whether this degree of seasonality also applied to groups in the Rio Grande Delta or only to groups located farther inland. Gathered foods included prickly pear, mesquite, agave, garlic, onion, palm, unspecified roots, fruits, and herbs (Salinas 1986:218). Pecans and walnuts were consumed but primarily by groups north of the project area in the lower Guadalupe River valley (Campbell 1988:20). Texas ebony, Pithecellobium flexicaule, also appears to have been utilized by some groups during early autumn (Campbell 1988:26, 29).

A seasonal dichotomy is evident in resource use. Prickly pear was the primary plant food in the summer (late May through late August) while various roots (e.g., agave) served as staples during the winter months (Campbell 1988:20). Plants with edible roots were thinly distributed relative to prickly pear (Campbell 1988:20). Groups north of the project area (e.g., in the lower Guadalupe River valley) substituted various nuts (pecans and walnuts) for roots in the fall. During the period leading up to and following the prickly pear season, groups relied on a broad range of sparsely occurring plant foods (Campbell 1988:29). Although Cabeza de Vaca's reports of large prickly pear patches refer to the area encompassed by Jim Wells, Duval, Kleberg, and Nueces counties (Campbell 1988:11), even larger prickly pear patches are reported in the early twentieth century by Davenport and Wells (1918-1919: 209-211) in Willacy, Hidalgo, and Cameron counties. If these patches existed in prehistoric times as well, it is likely that their utilization would have been largely similar to that noted among groups living in the lower Guadalupe River valley. Food storage was minimal. Prickly pear, mesquite, and agave were stored, but supplies lasted only short periods. Fish were dried (Salinas 1986:216) and stored by deltaic groups.

Most ethnohistoric sources suggest high aboriginal population densities along the Rio Grande floodplain and delta and north of Baffin Bay. It appears that the area between Baffin Bay and the Rio Grande was sparsely occupied during the mid eighteenth century. Some ethnohistoric groups are mentioned in northern Hidalgo and Willacy counties, and their presence seems to be correlated with salt exploitation at La Sal Vieja and El Sal del Rey. Ruecking (1955:36-38) associates the Lower Rio Grande Valley with the Carrizo cluster of Coahuiltecan hunter-gatherers. $\mathrm{He}$ names and shows the location of 51 groups distributed along the Rio Grande Valley and Delta extending south to the Rio San Fernando, west to the lower reaches of Rio Alamo, and north into modern Willacy County. He notes, however, that the range of the Carrizo groups may include the entire area between the mouth of the Nueces River and Rio San Fernando. It is unclear if this range is an annual resource procurement range or if it 
represents the broad distribution of bands that were lumped into the Carrizo cluster. Table 3 gives the name and approximate location of some of the bands most frequently described in ethnohistoric accounts as living in the vicinity of the project area (Salinas 1986:54-71; 89-93; 123132).

It is evident from the above summary that the ethnohistoric groups utilizing the region were highly mobile and had a subsistence pattern that included a broad range of resources with some degree of seasonal procurement. A large number of animal species were exploited with some focus on fish in the Rio Grande delta and deer in inland river valley settings. Group sizes were small, mobility was extremely high, and storage was limited. A judicious use of the optimal foraging model would require detailed calculations of energy yield and handling cost for each of the potential resources within the general project area and the subsequent ranking of these resource items based on these measures. Such data are not available at present. In general, however, it is evident that the patterns summarized above follow optimal foraging expectations. Even though handling costs appear to be relatively high for prickly pear and especially mesquite beans (Castetter and Underhill 1935; Castetter and Opler 1936; Bell and Castetter 1937), ethnohistorically they were the highest ranked plant resources during the summer. Because they occurred in dense patches, their exploitation resulted in higher yields per foraging trip. The intense utilization of many or all parts of a resource may extend its availability and offer sufficient gains to warrant the higher short-term handling costs. Prickly pear pads, tunas, and even the flour made of the seeds were consumed both fresh and in sun-dried form. Mesquite beans were also consumed both fresh or dried and ground into flour by some groups (Campbell 1988:37). Root crops were consumed during the winter, and although relatively expensive in terms of handling costs, they appear to have been the most highly ranked resources during an otherwise low plant yield season. The increased reliance upon fish during winter also may have been a response to the higher density and yield of these resources during a season when other high-yield resources were not available (e.g., prickly pear).

Unfortunately, the ethnohistoric sources provide no information about individual group territories and access to resources. It is probable that under low regional population densities, hunter-gatherer groups ranged over relatively large areas and had unrestricted access to resources. Such a situation may best apply to the Archaic and early Late Prehistoric period occupations of the area. With increased regional population densities, however, it is probable that some circumscription and reduced resource access may have occurred. The nonterritorial pattern may have shifted to small bands occupying adjacent but relatively well defined territories. Given the types, amounts, and structure of the resources, a highly mobile foraging system still should have characterized resource acquisition in each territory. The territorial pattern may have characterized land use during the later part of the Late Prehistoric period.

\section{HUMAN ADAPTATION DURING THE LATE HOLOCENE}

The theoretical foundation defined above argues that mobility is a result of resource scarcity and low yield. However, three relatively productive patches are present within the project area: the coastal estuaries in Cameron and Willacy counties, the lower Rio Grande floodplain and delta, and the stabilized sand sheet in extreme northern Willacy and Hidalgo counties and Kennedy County. It is likely that resource utilization patterns varied in the three patches in response to the overall density and dependability of resources. This may have permitted increased seasonal sedentism with increased territory definition in the Rio Grande floodplain and delta, or, alternatively, in highly productive portions of the coast and stabilized sand dunes. In addition, the development of defined territories occupied primarily by localized bands may have favored the development of regional exchange networks in both edible and nonedible resources as a riskreducing strategy (Wiessner 1977, 1982).

Of importance also are salt sources located at La Sal Vieja and El Sal del Rey, the exploitation of which may have had a significant effect upon regional mobility patterns. However, it is probable that the systematic exploitation and regional exchange or exportation of salt may have played a greater role during the Spanish colonial 


\begin{tabular}{|c|c|c|}
\hline \multicolumn{3}{|c|}{ SUMMARY OF ETHNOHISTORIC GROUPS, NAMES, AND LOCATIONS* } \\
\hline Group Name & $\begin{array}{l}\text { Date } \\
\text { Recorded }\end{array}$ & Location \\
\hline Anda el Camino & 1798 & $\begin{array}{l}\text { Northward from the Rio Grande to Arroyo Colorado, covered a large } \\
\text { part of Cameron County (54) }\end{array}$ \\
\hline Ayapaquemes & 1758 & North side of lower Rio Grande, western Cameron County (57) \\
\hline Cacolotes & 1757 & $\begin{array}{l}\text { In vicinity of Camargo and Revilla, also possibly near the inland saline } \\
\text { lakes north of the Rio Grande ( } 81-82)\end{array}$ \\
\hline Casa Chiquitas & $\begin{array}{l}1777 \\
1790\end{array}$ & $\begin{array}{l}\text { Northward from the Rio Grande in the vicinity of Mercedes, Texas; land } \\
\text { on both sides of the boundary between Cameron and Hidalgo counties } \\
\text { (58) }\end{array}$ \\
\hline Catanamepaque & 1757 & $\begin{array}{l}\text { Southeast of the inland saline lake El Sal del Rey in northeast Hidalgo } \\
\text { County (52) }\end{array}$ \\
\hline Comecrudos & $\begin{array}{l}1730 \\
1749\end{array}$ & Lower Rio Grande and Reynosa, Mexico area (65) \\
\hline Comesecapemes & 1757 & Near the present boundary between Cameron and Willacy counties (52) \\
\hline Como se Llama & $\begin{array}{l}1772 \\
1794\end{array}$ & $\begin{array}{l}\text { Ca. } 35 \text { miles north of Rio Grande; encamped at a locality between } \\
\text { Carricitos Ranch and El Sal del Rey where Cameron, Willacy, and } \\
\text { Hidalgo counties join (68-69) }\end{array}$ \\
\hline Cotonames & 1757 & $\begin{array}{l}\text { North of Rio Grande and linked with inland saline lakes (La Sal Vieja } \\
\text { and El Sal del Rey?) (71) }\end{array}$ \\
\hline $\begin{array}{l}\text { Gummescapem (or } \\
\text { Gumesacapem) }\end{array}$ & 1757 & South of a saline lake interpreted by Salinas as La Sal Vieja (52) \\
\hline $\begin{array}{l}\text { Maquites (or } \\
\text { Malaquitas) }\end{array}$ & 1766 & Associated with the Rio Grande Delta (132) \\
\hline Manos de Perro & 1766 & Between Corpus Christi and the Delta (132) \\
\hline Mayapemes & $\begin{array}{l}1757 \\
1790-98\end{array}$ & $\begin{array}{l}\text { North side of Rio Grande near the coast. In southwest Cameron County } \\
\text { and/or in Willacy and Kenedy counties (89) }\end{array}$ \\
\hline Mulatos & 1777 & Lower Rio Grande near Matamoros, Mexico but north of the river (93) \\
\hline Pasnacas (or Pasnacanes) & 1766 & Between Corpus Christi and the Delta (132) \\
\hline Patun & 1766 & Between Corpus Christi and the Delta (132) \\
\hline Pauraques & 1777 & East and west of the Cameron and Hidalgo County line (102) \\
\hline
\end{tabular}


Table 3, continued

\begin{tabular}{|l|l|l|}
\hline Group Name & $\begin{array}{l}\text { Date } \\
\text { Recorded }\end{array}$ & Location \\
\hline $\begin{array}{l}\text { Piguisas (or Piguicanes } \\
\text { or Piguiques) }\end{array}$ & 1766 & Between Corpus Christi and the Delta (132) \\
\hline $\begin{array}{l}\text { Pimaraqui (or } \\
\text { Pamaques) }\end{array}$ & 1766 & Between Corpus Christi and the Delta (132) \\
\hline Pintos & 1758 & $\begin{array}{l}\text { North side of Rio Grande in eastern Hidalgo County near the coast } \\
\text { between the Rio Grande and the Nueces River (108) }\end{array}$ \\
\hline $\begin{array}{l}\text { Tompacuas (or } \\
\text { Tompaqueses) }\end{array}$ & 1780 & $\begin{array}{l}\text { Near the coast between Baffin Bay and the mouth of the Rio Grande 60 } \\
\text { miles east of Reynosa (at Reynosa Diaz) and in Cameron, Willacy, and } \\
\text { possibly Kenedy counties (123) }\end{array}$ \\
\hline $\begin{array}{l}\text { Uscapemes (or } \\
\text { Usapemes) }\end{array}$ & 1798 & Cameron County north of Brownsville (52) \\
\hline
\end{tabular}

presence in the region. The occurrence of precolonial archeological sites on the margins of these lakes may indicate the utilization of a broad range of aquatic and terrestrial resources attracted to such bodies of water rather than the systematic exploitation of salt.

\section{Overview of the Models}

Keeping in mind the spatial distribution of the relatively more productive resource patches (coastal estuaries, floodplain/delta, and stabilized sand sheet) and the underlying assumption that within the territory of each band, resource acquisition patterns were organized on a foraging basis, three models are proposed for the project area (Fig. 13). These models grew out of initial formulations by Hester (1981), which were altered later by Prewitt and Associates, Inc. (1986). Model I (Fig. 13b) assumes a single territory occupied by a single group (A) with a low population density. The lack of territorial boundaries implies unobstructed access to all high- and lowyield resource patches and nonedible resources (e.g., lithic raw materials). Seasonal residential moves, while not random, would have been conditioned by patch location, resource productivity, and rank.

Model II (Fig. 13c) assumes the existence of linear band territories oriented perpendicular to the Rio Grande and paralleling the coast. This implies equal access of all bands to riverine environments (i.e., the Rio Grande floodplain). It emphasizes the importance of riverine and water resources in the distribution of band territories. The group occupying the delta and coastal stretch (Group C) would have had access to both of these high-yield environmental zones. The movement of this group during the annual foraging round would have paralleled the coast and would have focused on the exploitation of marine and estuarine resources with some access to the sand sheet and delta/floodplain resources to the north and south, respectively. No direct access to upland plain resources is presumed. The bands located on the interior lowland and upland plains (Groups B and A) would have had annual north-south-oriented foraging patterns extending from the Rio Grande floodplain across the interior plain to the sand sheet. Intergroup exchange between bands occupying the three broad environmental zones would have been minimal. However, access to products from adjacent environmental zones by bands occupying territories at the zone boundaries would have encouraged interregional exchange networks.

Model III (Fig. 13d) assumes band territories oriented perpendicular to the coast and paralleling the Rio Grande Valley. This model focuses on the importance of coastal resources and their equal distribution among territorial bands. The band located adjacent to the delta (Group A) would have had access to a disproportionate amount of deltaic and riverine resources while bands occupying territories located farther to the north (Groups B and $C$ ) would have inhabited water-scarce zones. The annual band foraging territories would have encompassed the shore and coastal estuaries 


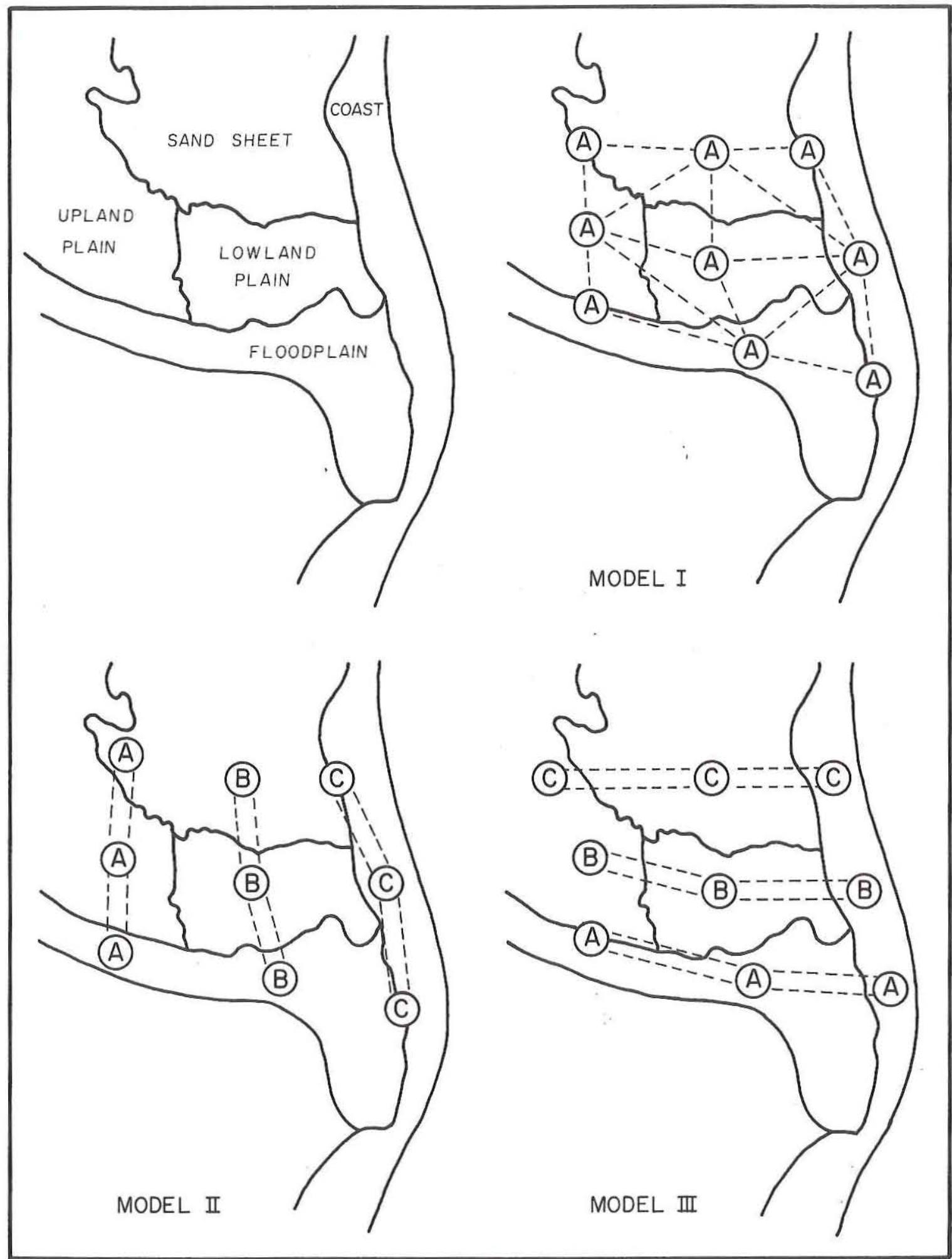

Figure 13. Regional environmental zones and hypothesized land-use models. (a) environmental zones; (b) Model I, single territory; (c) Model II, Rio Grande territorial groups; and (d) Model III, coastal territorial groups. 
and the inland environmental zones. Intergroup exchange networks may have developed and operated in a south to north direction, particularly between groups occupying territories along the Rio Grande floodplain and those lacking access to riverine resources. Exchange of coastal resources with groups having no access to the coast is expected to have occurred at the extreme western edge of the project area in the upland plain (e.g., Starr County).

In each model, the Rio Grande was used as a social boundary because the distribution of prehistoric artifacts known from north and south of the river has been used to suggest that the Rio Grande acted as such a boundary in the past (Day et al. 1981:47). This pattern appears to be supported by the fact that among modern huntergatherers, streams and channels often are used to form boundaries between neighboring huntergatherers (Yellen 1977:39). In addition, archeological analyses have demonstrated that stream channels and/or other landmarks often appear to correspond with prehistoric territorial boundaries among groups utilizing a hunter-gatherer form of subsistence (Schiffer 1975:105-106; Sampson 1988).

Instead of developing specific land-use expectations for each of the three models, a general description of foraging patterns is presented. These patterns describe broad resource acquisition patterns for Model I and within each band territory under either Model II or III. Furthermore, it is assumed that band territorial boundaries would have given rise to resource exchange networks and would have impacted intraterritory resource acquisition patterns to a lesser degree.

Only residential base camps and locations (Binford 1980) should occur under a foraging system. Base camps would have been moved often and over short distances (Kelly 1983). The number and distance of moves should have been conditioned by the productivity of the resource patch and the size of the foraging unit (Kelly 1983). On a regional level, some differences may be expected in residential base camp size. Highyield resource patches (e.g., prickly pear patches, stabilized sand sheet oak mottes, floodplain, delta, and coastal estuaries) may have permitted some degree of seasonal group aggregation resulting in longer occupations by larger groups. Once highly productive patches were exhausted and foraging groups moved out to exploit less productive resources (e.g., lowland active dune fields, blowouts, channel remnants, and upland-plain yucca and agave patches), residential groups are expected to have fissioned into smaller nuclear or extended family foraging units. In these less productive zones, it is expected that residential base camps would have been smaller in size and occupied for shorter periods because resources may have been more rapidly exhausted within the foraging radius of a camp (Kelly 1983). Group aggregation and fissioning may have had a seasonal character reflecting fluctuations in resource availability.

Given the relatively short-term occupation of prehistoric forager residential base camps and the limited need for bulk-resource processing, it is expected that features and facilities would have been few and functionally nonspecific, generating a poorly defined site structure (Binford 1980). Residential base camps located in or adjacent to highly productive resources may have contained processing features or facilities (such as fish drying racks). These features should have been located marginal to frequently used site areas. Artifact assemblages would have contained generalized tool kits reflecting the broad range, low quantities, and generalized resource-processing techniques employed by foraging groups (Hayden 1986). Variability in assemblage size and composition may reflect differences in the sizes of the occupying units and/or lengths of occupation, as opposed to functional differences between residential base camps (Yellen 1977). While the increased number of site types utilized by collectors increases the likelihood of lithic reduction activities occurring at sites other than base camps, under a foraging system a broad range of lithic manufacturing activities (e.g., manufacture, resharpening, rejuvenation, and discard) should be represented at residential base camps.

Faunal and botanical remains should reflect the broad range of resources exploited. Botanical remains may be relatively good indicators of season of occupation as base camps were positioned across the landscape to take advantage of different resource harvesting schedules (e.g., prickly pear and mesquite in summer, root crops and fish in winter). Small fauna such as mice, snakes, and insects, coupled with age-structure data on medium-sized mammals such as antelope and deer, may provide similar information. 
Locations as defined by Binford (1980) are different from residential base camps in that they represent specialized loci of resource procurement and processing. Locations generated by foragers should have been small and would be archeologically less visible due to low-bulk resource procurement and processing activities. Visibility may increase if a high degree of locational redundancy characterized foraging activities, for example at prickly pear patches, oak mottes in stabilized sand dunes, and water sources. Few features and facilities would have been constructed due to low-bulk resource extraction and short-term site use. Most processing activities are expected to have occurred at residential base camps with the exception of some related to prickly pear processing (Castetter and Underhill 1935:23; Kroeber 1935:50-51). Facilities and features (e.g., hearths) related to the processing of small quantities of food consumed on daily foraging trips should have low archeological visibility. Site structure would have been minimally developed due to the lack of maintenance activities on such short-term sites. Tool kits would have remained relatively generalized reflecting the overall make-up of subsistence activities. Artifact assemblages may have been composed primarily of expedient tools and/or tools discarded because of high transportation costs (e.g., hammerstones, anvils, and choppers). Tool maintenance and rejuvenation debris should not occur or should be low in frequency at locations, while debitage from expedient tool manufacture may be found in high frequencies. This relationship between rejuvenation and resharpening versus manufacture debitage may have been altered depending on raw material densities in the region. Faunal and botanical remains will be relatively scarce due to low-bulk resource procurement and processing. Locations within foraging systems should have been characterized by a low degree of resource specificity. That is, a relatively broad range of resources would have been exploited from foraging locations resulting in scarce but highly variable faunal and botanical samples.

\section{Analysis Attributes and Predictions of the Models}

Because lithic assemblages are integral elements of most subsistence-related activities, they may be used to investigate land-use patterns. Furthermore, the procurement of both lithic raw materials and subsistence resources is subject to the same kinds of constraints. Given that the parameters of the three models affect both subsistence activities and resource procurement patterns, it is assumed that an analysis of lithic asssemblages can serve as a test of the best fit between the models and the archeological data. Such a test is presented in Chapter 7, using twelve attributes: (1) frequency of early reduction debitage; (2) frequency of large debitage; (3) total debitage frequency; (4) core frequency; (5) frequency of resharpening flakes; (6) frequency of manufacture failures; (7) frequency of exhausted tools; (8) frequency of use-broken tools; (9) frequency of reused tools; (10) frequency of edge-modified debitage; (11) average number of working edges per uniface; and (12) average number of utilized edges per edge-modified flake.

Because these attributes are highly sensitive to differences in distance from raw material source and site use-intensity, they are well suited to test the three models. Five factors affect the spatial distribution and frequency of these attributes: (1) the distributions of raw materials in the project area; (2) the distances of sites from raw material sources; (3) the degree of decortication and the form of the raw materials transported outside of lithic source areas; (3) the environmental zone use-intensity; and (5) the presence and positioning of band territories with respect to raw material sources and environmental zones.

At present, lithic outcrops are known to occur only in the extreme western and southwestern (i.e., upland plain and Rio Grande gravels near La Joya) parts of the project area (Mallouf et al. 1977). For modeling purposes, it is assumed that this is an accurate picture of the distribution of usable lithic materials. Distance from these sources is assumed to have significantly affected lithic sample size and distribution. Some attributes are assumed to covary directly with distance from source while others are expected to be inversely correlated. The degree of decortication and the form in which raw materials were transported from the upland plain to material-poor zones should have affected the nature of the artifact samples in both areas. For this discussion, it is assumed that raw materials were decortified at the sources and transported in a decortified state 
(i.e., prepared cores, blanks, preforms, and finished tools) across the project area. The useintensity of a given resource patch, defined as the number of people per occupation episode, the number of revisits per year, and/or the duration of individual occupation episodes, should have affected assemblage size. Holding the distance from raw material sources constant, it is assumed that the more intensive the site use, the larger the lithic assemblage. Finally, the arrangement of band territories also should have limited access to lithic resources. Because under Model II only the upland plain group had access to lithic resources, it is necessary to consider the operation of an interregional raw material exchange network. The nature of the network, coupled with the exchange paths and the form of the materials exchanged, will have affected the lithic assemblages encountered at sites in the project area.

Predictions regarding the twelve lithic attributes for each of the three models are shown in Tables 4, 5, and 6. These predictions are grounded in cross-cultural ethnographic and ethnoarcheological data and by no means represent the entire range of variability that could have existed in prehistoric contexts. Furthermore, it is important to keep in mind that a comparison of the regional archeological data with the predictions outlined in these matrixes is a test of these assumed relationships rather than of the models themselves (Binford 1983:10-15).

The symbols used in the matrixes $(+,=,-)$ reflect the predicted frequencies of an attribute in relation to a homogeneous distribution throughout all cells. For example, a " + " in a cell for resharpening flakes indicates that the observed value of resharpening flakes in that particular cell should be greater than if resharpening flakes had an even distribution across the landscape. Thus, "+" refers to attributes occurring in greater than predicted frequencies, "-" reflects less than predicted frequencies, and " $="$ indicates attributes occurring in frequencies equal to the predicted values given a homogeneous distribution.

\section{Model I, Single Group and Territory}

A number of parameters related to lithic resource distributions, lithic procurement, and environmental zone use-intensity underlie the specific predictions of Model I. It is assumed that a single group occupied the entire project area and had unlimited access to all environmental zones (see Fig. 13). The most intensively used zone was the Rio Grande floodplain and delta, followed in decreasing order by the coast, sand sheet, lowland plain, and upland plain. Even within lowresource-yield environmental zones, moreintensive site occupations are expected to have occurred at the boundaries between low- and high-yield zones (e.g., lowland plain and coast; upland plain and sand sheet; and upland plain and floodplain). Lithic resources were available only in the upland plain zone, and as a result, the farther east a site was located, the greater the distance from raw material sources.

The model-specific predictions presented in Table 4 are summarized below. The frequencies of early reduction debitage, large debitage, total debitage, and manufacture failures are predicted to decrease with increasing distance from raw material sources within the Rio Grande floodplain and sand sheet. A similar west to east decrease is anticipated in the lowland plain, but lower frequencies of the four attributes are anticipated in the western portion of this zone due to lower useintensity. The coast should have consistently low frequencies of these attributes due to the great distance from lithic sources. Conversely, the upland plain should have consistently high frequencies due to the availability of raw materials. The frequency of cores is predicted to be lowest in the coast due to the distance from source areas. Because of the low use-intensity of the lowland plain, equally low frequencies are anticipated throughout this zone, even in the western portion which borders the upland plain. Core frequencies should decrease from moderate levels in the western and central portions of the Rio Grande floodplain and sand sheet to low counts in the eastern sections. Both the lower frequencies of cores in the western portions of the two zones and the west to east decrease are due to the effects of increasing distance from material sources. The frequencies of resharpening flakes and use-broken tools are assumed to be conditioned by the same factors and should show the same pattern. Resharpening flakes and use-broken tools are predicted to be equally frequent within all portions of the Rio Grande floodplain due to the high useintensity and greater length of occupation of the entire zone. Similarly high frequencies should 
TABLE 4

LITHIC ASSEMBLAGE PREDICTIONS, MODEL I

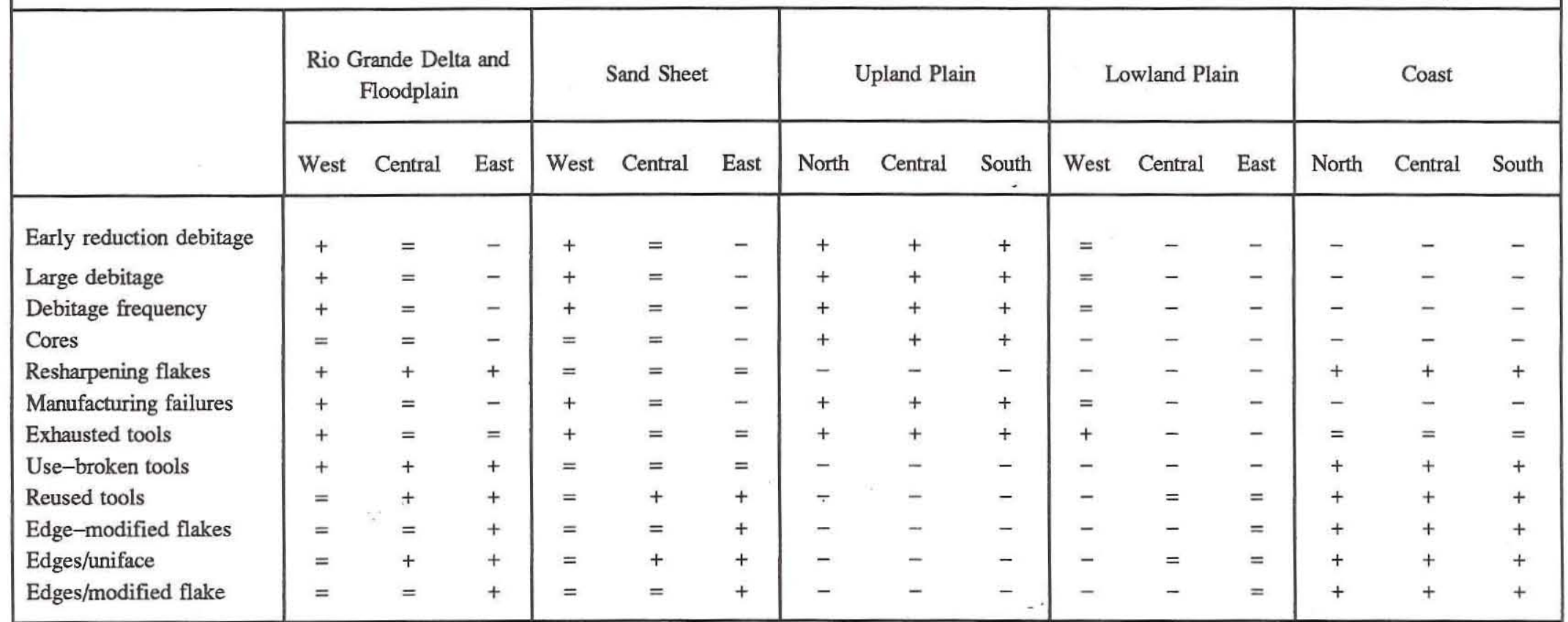

Note: $\quad$ Symbols indicate expectations relative to assumed homogeneous distribution; " $+"=$ greater than expected , "=" = average expected, "-" = less than expected. 


\section{TABLE 5}

LITHIC ASSEMBLAGE PREDICTIONS, MODEL II

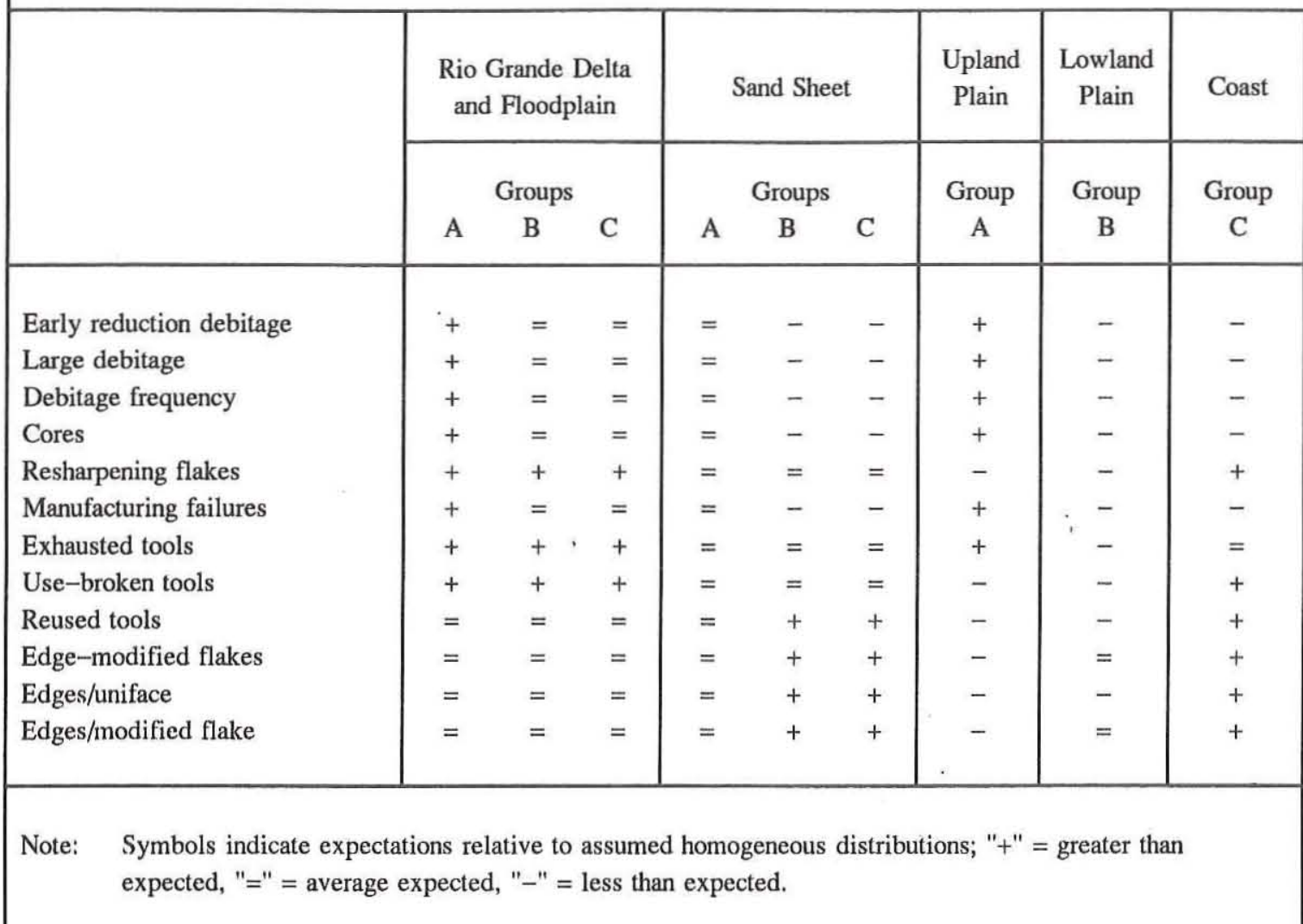

occur throughout the coast due to great distance from lithic source areas and high use-intensity. Intrazonally, even and moderate frequencies of both attributes are predicted in the sand sheet due to the relative closeness of the western portion to lithic sources and relatively low use-intensity. The lowest frequencies of resharpening flakes and use-broken tools should occur in the least intensively used lowland plain and in the upland plain where raw materials are readily available.

It is anticipated that high frequencies of exhausted tools will occur at or near raw material sources and moderate frequencies at high useintensity zones. High frequencies of exhausted tools are expected in the western portion of the lowland plain near raw material sources, but low frequencies should occur in the remainder of the zone due to low use-intensity and greater distance from lithic sources.

The frequency of reused tools and the mean number of working edges per uniface within a zone are assumed to be conditioned by useintensity and distance from raw material sources. The highest frequency of reused tools and the highest mean number of working edges per uniface are expected throughout the coast and in the central and eastern portions of the Rio Grande floodplain and sand sheet due to greater distance from lithic sources. The western portions of the latter two zones should have slightly lower frequencies due to reduced distance from raw material sources. The frequencies of the two attributes should be low in the western portion of the lowland plain due primarily to low use-intensity. The central and eastern portions of this zone are anticipated to have moderate frequencies due to greater distance from lithic sources. Consistently low frequencies are expected thoughout the upland plain due to the availability of raw materials.

The frequency of edge-modified flakes and the mean number of utilized edges per flake are assumed to be conditioned by the same factors. 
TABLE 6

LITHIC ASSEMBLAGE PREDICTIONS, MODEL III

\begin{tabular}{|c|c|c|c|c|c|c|c|c|c|}
\hline & \multirow{3}{*}{$\begin{array}{c}\begin{array}{c}\text { Rio Grande Delta } \\
\text { and Floodplain }\end{array} \\
\text { Group A }\end{array}$} & \multirow{3}{*}{$\begin{array}{l}\text { Sand Sheet } \\
\text { Group C }\end{array}$} & \multicolumn{3}{|c|}{ Upland Plain } & $\begin{array}{c}\text { Lowland } \\
\text { Plain }\end{array}$ & \multicolumn{3}{|c|}{ Coast } \\
\hline & & & \multicolumn{3}{|c|}{ Groups } & \multirow[b]{2}{*}{ Group B } & \multicolumn{3}{|c|}{ Groups } \\
\hline & & & A & B & $\mathrm{C}$ & & A & B & $\mathrm{C}$ \\
\hline Early reduction debitage & $=$ & $=$ & + & + & + & $=$ & - & - & - \\
\hline Large debitage & $=$ & $=$ & + & + & + & $=$ & - & - & - \\
\hline Debitage frequency & $=$ & $=$ & + & + & + & $=$ & - & - & - \\
\hline Cores & $=$ & $=$ & + & + & + & $=$ & - & - & - \\
\hline Resharpening flakes & + & + & - & - & - & $=$ & + & + & + \\
\hline Manufacturing failures & $=$ & $=$ & + & + & + & $=$ & - & - & - \\
\hline Exhausted tools & $=$ & $=$ & + & + & + & $=$ & $=$ & $=$ & $=$ \\
\hline Use-broken tools & + & + & - & - & - & $=$ & + & + & + \\
\hline Reused tools & + & + & - & - & - & $=$ & + & + & + \\
\hline Edge-modified flakes & + & + & - & - & - & $=$ & + & + & + \\
\hline Edges/uniface & + & + & - & - & - & $=$ & + & + & + \\
\hline Edges/modified flake & + & + & - & - & - & $=$ & + & + & + \\
\hline
\end{tabular}

Note: Symbols indicate expectations relative to assumed homogeneous distribution; " + " = greater than expected, "=" = average expected, "-" = less than expected.

The two attributes are anticipated to increase with increasing distance from lithic sources and increasing use-intensity. The highest figures are anticipated for the coast and the eastern segments of the Rio Grande floodplain and sand sheet. Although the western portions of the latter two zones are close to raw material sources, these areas are predicted to have moderate frequencies of edge-modified flakes and mean numbers of utilized edges per flake due to greater useintensity. The entire upland plain and the western and central portions of the lowland plain should have low frequencies due to raw material availability and low use-intensity. The eastern portion of the lowland plain should have slightly higher frequencies due to greater distance from material source.

\section{Model II, Rio Grande Territorial Groups}

A number of general assumptions that alter the parameters of the first model underlie the predictions defined for Model II. At the risk of oversimplification but for the purposes of modeling, it is assumed that three territorial groups occupied the project area (Groups A, B, and C). Group territories were arranged perpendicular to the Rio Grande and provided differential access to neighboring environmental zones (see Fig. 13c). It is assumed that the easternmost group (Group C) had no direct access to the lowland and upland plains and that the northern and southern portions of the group territory provided access to the sand sheet and delta, respectively. No lowland plain access is assumed for this group because of the accessibility to the more productive delta and sand sheet. The central group (Group B) had no direct access to the coast and upland plain, and its territory contained portions of the Rio Grande floodplain, the lowland plain, and the sand sheet. The westernmost group (Group A) had no access to the coast and lowland plain, but the northern and southern portions of its territory provided access to the sand sheet and Rio Grande floodplain, 
respectively. It is assumed that in the case of the westernmost and central groups (Groups A and B) the most intensively used zone was the Rio Grande floodplain, followed by the sand sheet and upland plain (Group A) and lowland plain (Group B). The easternmost group (Group C) occupied and used the delta and floodplain most intensively, followed by the coast and the sand sheet.

Because the Rio Grande delta and floodplain were the most productive environments in each group's territory, it is anticipated that these were occupied the longest and that intergroup exchange of lithic raw materials occurred there. While the westernmost group had direct access to raw material sources, Groups B and C received raw materials in the form of decortified cores, finished tools, and/or blanks and preforms. Greater degrees of reduction may have occurred as artifacts moved eastward from raw material sources. Because under this model the Rio Grande floodplain functioned as an artificial lithic source area, the twelve lithic attributes are anticipated to occur in similar patterns as discussed in Model I, except that distance-related relationships should be noted in a south-north fashion from the floodplain rather than from the actual lithic source areas in the upland plain.

The differences in the assumptions underlying Models I and II alter the predicted distributions of the twelve lithic attributes within and across environmental zones (see Table 5). The frequencies of early reduction debitage, large debitage, total debitage, cores, and manufacture failures are assumed to be higher in the western portion of the Rio Grande floodplain, the territory occupied by Group A. Because of the nature of the assumed raw material exchange network, the frequencies of the five attributes in the Group B and Group C portions of this zone should be equal but less than in the Group A territory. The frequencies of the five attributes should be moderate in the sand sheet Group A territory adjacent to the upland plain; however, the frequencies in the other two group territories in the sand sheet should be equally low because of the greater distance from material sources. Similarly low frequencies are predicted in the lowland plain occupied by Group B and the coast occupied by Group C. The predicted pattern in the central and eastern portions of the sand sheet is conditioned by the distance from the locus of raw material exchange, the Rio
Grande floodplain. The low frequency of the attributes in the lowland plain occupied by Group $\mathrm{B}$ is due primarily to low use-intensity. The distance of the coast, occupied by Group C, from material sources, coupled with the decortified and relatively finished nature of the artifacts brought to this zone, should generate low frequencies of early reduction debitage, large debitage, total debitage, cores, and manufacture failures. Conversely, the availability of raw materials in the upland plain Group A territory accounts for the high frequencies of these attributes.

Resharpening flake and use-broken tool frequencies are predicted to be high within the Group A and B territories and the Group C territory segments located in the Rio Grande floodplain and the coast. The pattern is assumed to be most strongly conditioned by the greater use-intensity of sites in these zones. Moderate frequencies are anticipated throughout the sand sheet due to low use-intensity. The frequencies of these are predicted to be lowest in the lowland plain Group B territory. The frequency of resharpening flakes and use-broken specimens in the upland plain Group A territory should be the same as in the lowland plain occupied by Group B. However, the pattern should be the result of a combination of reduced use-intensity and availability of raw materials. It is anticipated that exhausted tools will be frequent at the sources of raw materials, which in the case of Model II is in the upland plain Group A territory and in the Rio Grande floodplain occupied by all three groups. Exhausted tools should be found in moderate frequencies in the sand sheet and coast. The lowest frequencies should occur in the lowland plain Group B territory due to low use-intensity.

The frequency of reused tools and the mean number of working edges per uniface is predicted to be high in the Group B territory in the sand sheet and in the Group C territory of the coast. A similarly high frequency and mean should be noted in the portion of the Group C territory located in the sand sheet. The pattern is assumed to respond to the higher use-intensity of these zones and the lack of raw materials. The moderate frequency in the Group A territory in the sand sheet is due to its proximity to the raw-material-rich upland plain. The moderate frequencies anticipated along the Rio Grande are assumed to be the result of less raw material stress in this zone, high 
use-intensity, and the assumed intrazonal exchange of lithic materials. The lowland plain Group B territory should have lower frequencies of these attributes than the Rio Grande floodplain because of decreased use-intensity. Low frequencies of reused tools and low mean numbers of working edges per uniface should occur in the Group A territory in the upland plain due to the availability of raw materials. The Group B territory, the portion of the Group C territory located in the sand sheet, and the coastal portion of the Group C territory should have high frequencies of reused tools and mean numbers of edges per uniface because of the more intensive use of these segments.

The frequency of edge-modified flakes and the mean number of utilized edges per flake are predicted to pattern in a similar manner. High numbers of modified edges should occur in the Group B territory, the Group C territory segment located in the sand sheet, and in the coastal Group $\mathrm{C}$ territory. In both cases, the patterns are conditioned by use-intensity and distance from material sources. The Group A territory in the sand sheet is anticipated to have moderate frequencies of these two attributes because of lessened raw material stress near the upland plain. The lowland plain should also have a moderate frequency of edge-modified flakes and a moderate mean number of utilized edges per flake because it is assumed that the lowland plain contains resources that could be exploited with a tool kit composed primarily of expedient tools. Because raw material stress is reduced along the Rio Grande and use of this zone was intensive, the frequencies of edge-modified flakes and the mean numbers of utilized edges per tool in all group territories in the Rio Grande floodplain are anticipated to be moderate.

\section{Model III, Coastal Territorial Groups}

The assumptions underlying this model are probably oversimplifications but are necessary for modeling purposes. It is again assumed that three groups occupied the project area (Groups A, B, and C). Group territories were arranged perpendicular to the coast, which is assumed to have been the primary source of dietary resources for all three groups (see Fig. 13d). Because of the spatial arrangement of group territories with respect to the environmental zones, it is assumed that Group C had no access to the lowland plain or the Rio Grande floodplain and that its territory included portions of the coast, sand sheet, and upland plain. Group B had no access to the Rio Grande floodplain or the sand sheet, and its territory transected the coast, the lowland plain, and the upland plain. Group A had no access to the lowland plain or the sand sheet, and its territory included portions of the coast and Rio Grande delta and floodplain; its western segment also provided access to the upland plain. In the case of Group A, the most intensively used zone is assumed to have been the coast and delta region, followed by the inland portion of the Rio Grande floodplain and the upland plain. Group B also occupied and used primarily the coast, followed by the lowland plain; and upland plain. Group C, the northernmost group, most intensively used the coast followed by the sand sheet and upland plain. It is assumed that each group had direct access to lithic sources located in the upland plain. Raw materials were transported from the source areas in decortified form (i.e., prepared cores, blanks, preforms, and finished artifacts).

Given these underlying assumptions, the following lithic attribute distributions are predicted (see Table 6). The frequencies of early reduction debitage, large debitage, total debitage, cores, and manufacture failures are expected to pattern similarly. The upland plain group territories are predicted to have the highest frequencies of these attributes. The Rio Grande floodplain occupied by Group A, the lowland plain occupied by Group B, and the sand sheet occupied by Group $\mathrm{C}$ are anticipated to have moderate frequencies. The intrazonal and interzonal patterns in these five attributes are conditioned by distance from the lithic source areas. The frequencies of resharpening flakes and use-broken tools should pattern similarly. The Group A territory segment contained in the Rio Grande floodplain and the Group C segment located in the sand sheet should have high frequencies of these two attributes due to moreintensive use. The coastal portion of each group's territory also should have high frequencies due to both distance from material sources and greater use-intensity. The lowland plain Group B territory should have moderate frequencies of resharpening flakes and use-broken specimens because of distance from material sources and low 
use-intensity. All group territories in the upland plain are anticipated to have low frequencies of the two attributes due to the availability of raw materials and the low use-intensity.

Exhausted tools are assumed to occur frequently in the upland plain because of low replacement costs. Moderate frequencies are predicted in all other zones. Unlike the Model I expectations, the lowland plain occupied by Group $B$ will have moderate frequencies due to the slightly greater use-intensity assumed under this model. The frequencies of reused tools and edgemodified flakes and the mean numbers of working edges and utilized edges on unifaces and edgemodified flakes are assumed to respond to similar conditioning factors. The highest frequencies and means are anticipated along the coastal portion of each group's territory, the Rio Grande floodplain and delta occupied by Group A, and the sand sheet occupied by Group C. Moderate figures should occur throughout the lowland plain occupied by Group B because this is the secondranked resource zone in this group's territory. The lowest frequencies are anticipated for the upland plain because of the availability of raw materials.

These expected patterns are proposed here to serve as hypotheses describing the relationships between particular analytical categories and conditioning factors such as raw material availability and environmental zone use-intensity. It is hoped that the interzonal distributional patterns for the various analytical categories can be used to characterize the organization of technology of the groups that utilized the project area, and an attempt to achieve this goal is presented in Chapter 7. Regardless, the comparison of these assumed relationships with actual archeological patterns should contribute to the refinement of the assumptions and the advancement of our understanding of the operation of both land-use systems and resource procurement strategies under the particular constraints operating in the project area. 


\section{OBJECTIVES AND METHODS}

by Gail L. Bailey and C. Britt Bousman

Chapter 3 outlines the research framework within which the cultural resources of the Hidalgo-Willacy Drainage Ditch project were investigated. This chapter presents the objectives and methods of the National Register testing of five prehistoric sites--41HG128, 41WY112, 41WY113, 41WY134, and 41WY140. The objectives were based on defined gaps in the archeological record of the project area and were intended to provide the information necessary for assessing National Register eligibility. The field and laboratory methods were designed to provide the specific information required to address the research design (see Chapter 3), to more adequately and accurately assess the sparse archeological record of far South Texas, to assess the geological context of the archeological occurrences, and to insure that the results of the present project were comparable to the results of the previous projects on the Hidalgo-Willacy Drainage Ditch.

\section{ARCHEOLOGICAL OBJECTIVES}

The Phase I investigations identified 27 archeological sites that were judged to be potentially eligible for listing on the National Register of Historic Places; from these, 7 were recommended for National Register testing (Hall et al. 1987:77). Subsequently, however, it was agreed by the Hidalgo County Drainage District No. 1 , the Willacy County Drainage District No.
1, the State Historic Preservation Officer, the Galveston District Corps of Engineers, and Prewitt and Associates, Inc. that a select group of five sites subjected to Phase II excavations would meet the sampling requirements.

Development of the ethnohistorical, archeological, and paleoenvironmental records, along with an analysis and synthesis of these data, is the long-term objective of the Hidalgo-Willacy Drainage Ditch cultural resource investigations. Salinas (1986, 1990), along with Ruecking (1953, 1955), provides an adequate ethnohistoric record for the project area, and it is unlikely that additional ethnohistoric work on known documents would greatly enhance this data base. The paleoenvironmental and archeological records are still deficient, however, and their development is the major concern of this project. Full synthesis of these data must await construction of more complete and detailed paleoenvironmental and archeological records, but a general model has been proposed (Prewitt and Associates, Inc. 1986) and is elaborated upon in Chapter 3. Obviously, analysis and synthesis rarely occur in a single step, and the development of a research design, models, hypotheses, and tests of hypotheses should account for new data as it is recovered and should be fine-tuned as research proceeds. As part of this process, an additional objective of this project was to provide a data base that could be used for spatial and temporal intersite comparisons and, 
more specifically, for the first round of hypothesis testing of the models proposed in Chapter 3.

The five archeological sites reported here were selected for Phase II testing to provide (1) a sample of sites across the deltaic plain to assess spatial variability in the archeological record; (2) a sample of shallowly and deeply buried archeological sites to flesh out chronological patterns in the archeological record; and (3) a record of the depositional environments in which archeological remains occur. It was hoped that these sites would yield information on the. sequences of paleoenvironmental and cultural changes during the period of known human habitation. The characteristics on which the five sites were chosen for Phase II testing are presented below.

Site 41HG128 is a large site located adjacent to a relatively deep blowout depression. Several tool types (gouges, bifaces, and scrapers) were collected during the Phase I survey, and mussel shells and numerous burned clay lumps were noted. A possible historic component was also observed. The potential to yield environmental information and the high frequency of tool types were factors in recommending this site for further work.

Site $41 W Y 112$ is located adjacent to a blowout depression. During the Phase I investigations, lithic debitage, mammal bones, one conch shell fragment, and burned clay lumps were observed along the ditch banks at ca. $40 \mathrm{~cm}$ below the ground surface. The variety of material types present and the association with the blowout suggested that this site could yield both geologically and archeologically significant data.

Site 41 WY113 yielded a human burial during the Phase I investigations and two bifaces during a follow-up visit (see Appendix A). The initial excavation was limited to recovery of the burial, and more information was necessary to determine if this is also a habitation site. Good bone preservation, the potential for additional burials, and the presence of tools were also factors in recommending this site for further work.

Site $41 W Y 134$, located at the edge of a blowout depression, yielded numerous burned clay lumps, lithic debitage, and mammal bones during the Phase I work. The variety of materials and the potential for environmental data from the blowout deposits made this site a good candidate for further work.
Among the sites tested, 41 WY140 is uniquely situated adjacent to a small rise. Chipped stones and burned clay lumps were observed along the Drainage Ditch banks at depths of 1-1.5 $\mathrm{m}$ and 2-3 $\mathrm{m}$ below the surface. The topographic setting and the possibility of deeply buried cultural deposits suggested that this site could contribute to an understanding of the geology of the region and could provide data for intersite comparisons and hence interpretations of settlement patterns.

The specific goals of the work at each site were to determine the vertical and horizontal extent of the cultural deposits, to assess the integrity of the cultural deposits, to determine whether or not features are present, to assess the density of artifacts, to excavate an adequate sample of the site so that a reasonable estimate could be made of the amount of cultural materials present and, lastly, to identify the age of the cultural deposits through absolute or relative dating. These data could then be used for National Register assessments and recommendations for future investigations.

\section{GEOLOGICAL OBJECTIVES}

The Phase II geological investigations had four objectives. The first was to assess the geological context of the archeological materials at each site. As this area is heavily disturbed by historic agricultural activities (Mallouf et al. 1977) and ditch construction, the effects of these disturbances on the archeological record had to be identified. A second and related objective was to establish the chronological sequence of deposition at the sites. Little is known about the late Pleistocene and Holocene sedimentary chronology from the Rio Grande Delta region of Texas, and chronometric dates are sorely needed. A third objective, establishing the nature of the sedimentary and pedogenic processes active in site formation, required the identification of the depositional environments reflected by the stratigraphy and sediments. The last objective was to initiate paleoenvironmental studies in the project area. While pollen and phytolith samples were collected, it was decided that the geological deposits lacked sufficient stratigraphic resolution and context for these types of studies to provide useful and unbiased results. Consequently, stable isotopes were selected as the most productive type 
of paleoenvironmental data that could be obtained from the prehistoric geological deposits exposed during the present project.

\section{METHODS OF INVESTIGATIONS}

\section{Archeological Field Methods}

The five sites reported here--41HG128, 41WY112, 41WY113, 41WY134, and 41WY140--were located initially during Phase I investigations through examination of ditches after their excavation. They were relocated for Phase II testing using mileage designations on the State of Texas Site Data Forms. Prior to subsurface investigations, proton magnetometer surveys were conducted at 41WY112 and 41WY113 to evaluate the utility of magnetometry in the project area (see Appendix B). The tasks accomplished following the magnetometer surveys are described below.

The first task was to conduct a pedestrian survey of each site. This was accomplished with a six-person crew aligned perpendicular to the ditch bank and walking parallel to the drainage using pin flags to mark any observed cultural materials. A semi-permanent datum (a 30-cm long, 1/2-inch-diameter rebar stake) was then placed in the spoil pile above the road, with ca. 3 $\mathrm{cm}$ of the datum stake exposed above ground surface. At 41WY112, datum markers were placed at both the east and west ends of the site.

At most sites, the geological trench excavations preceded the excavation of archeological test units, and this provided a preview of the stratigraphy encountered during the hand excavations. This permitted the rapid identification and removal of disturbed historic deposits and overburden in archeological test units. At one site, 41HG128, test units were placed adjacent to geological trenches, the overburden was removed mechanically, and the hand excavations were begun at the bottom of the disturbed deposits. This procedure was not possible at all sites because the geological trenches often were placed in areas where they would provide a comprehensive view of the sediments, and these locales were not the most opportune spots for archeological test units.

A minimum of four $1 \times 1-m$ test units was excavated at each site. Test units were placed to sample the entire site area and investigate any features or artifact concentrations exposed along the ditch banks. Test units were numbered sequentially as they were excavated. At 41WY113, test units were also placed over anomalies identified in the magnetometer survey (see Appendix B). The test units were excavated in arbitrary $10-\mathrm{cm}$ levels to maintain vertical control in depositional zones greater than $20-\mathrm{cm}$ thick. When natural stratigraphy could be discerned, the excavation levels corresponded to stratigraphic zones. The excavation levels were numbered sequentially starting with Level 1 at the modern ground surface. This level usually consisted of the overburden zone which varied in thickness and was removed as one level. Vertical control was maintained by a line-level datum placed at the edge of each test unit. All excavated matrix was water screened through 1/4-inch-mesh hardware cloth. A sample from each level at all test units was fine screened and consisted of the northeast $50 \times 50-\mathrm{cm}$ quadrant of the level.

The water-screening system (see Appendix E) consisted of a 5-horsepower agricultural pump feeding two 3/4-inch-diameter discharge hoses (50 and $100 \mathrm{ft}$ ) with control nozzles set up at two screening stations (Fig. 14). A similar system using a trash pump was also employed periodically. When needed, a deflocculant (sodium hydrochloride) was used to soak the excavated matrix prior to screening. For fine screening, a 1/16-inch-mesh window screen, attached to the $1 / 4$-inch screen frame on one side to prevent strong winds from blowing it away, was laid into the screen and another 1/4-inch screen was placed on top. A sample quadrant of each level was screened through the 1/4-inch screen and then through the fine screen. Artifacts, burned clay lumps, snail shells, mussel and marine shells, calcium carbonate and manganese concretions, and modern materials were collected and tagged with the appropriate provenience.

The test units, backhoe trenches, line level datums, site datums, and general topography were mapped using a transit and metric stadia rod. Each site was also documented with 35-mm color and black-and-white photographs.

\section{Geological Methods}

A number of procedures were applied to accomplish the objectives of the geological 


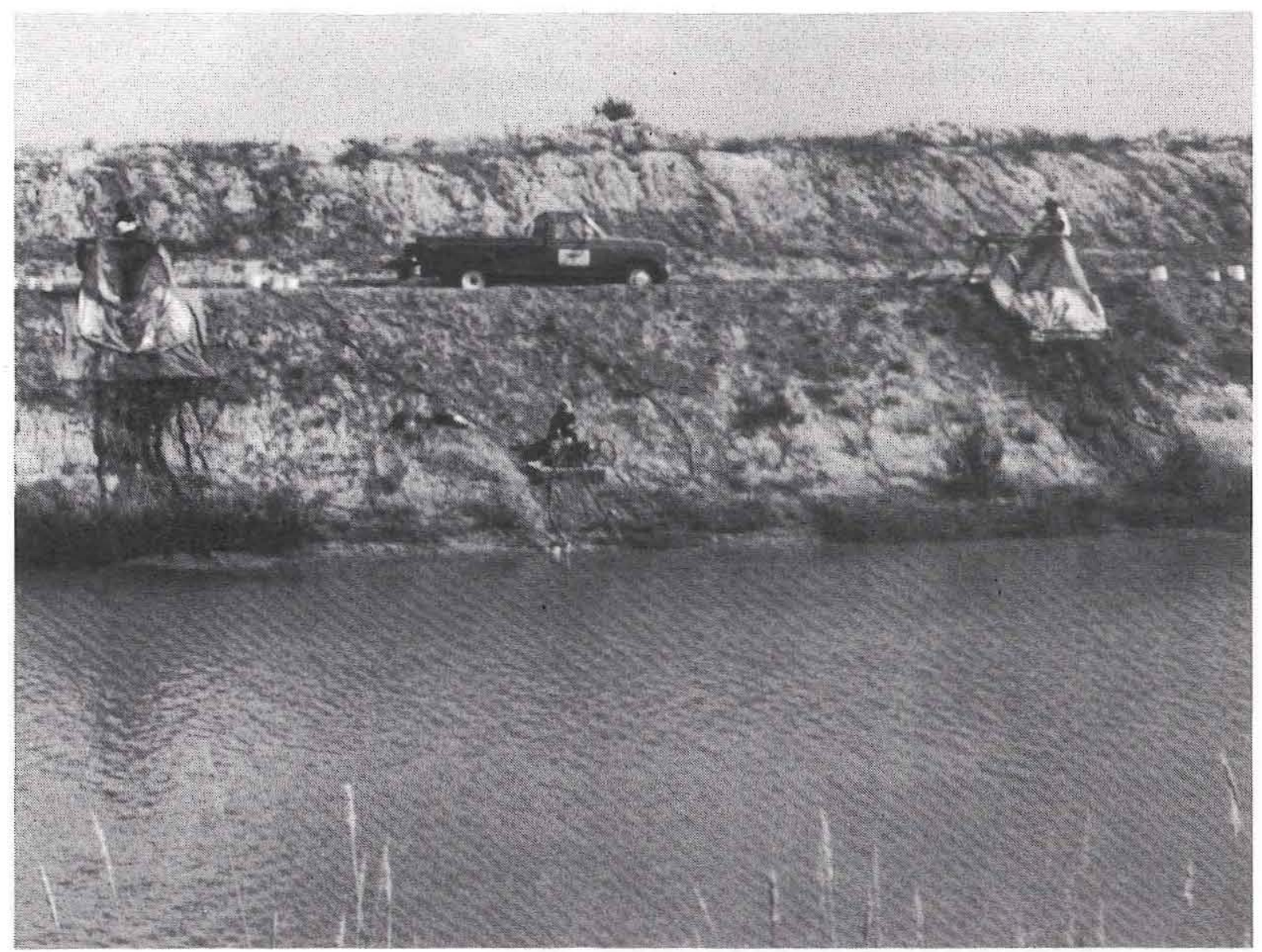

Figure 14. Photograph showing water-screening system at 41WY112, looking north.

investigations. First, a review of the background geological literature was undertaken. This indicated that no active fluvial deposition occurred at the sites during the period of human occupation, and that colluvial and eolian deposition and pedogenic alteration could be expected.

Two to five trenches were excavated mechanically across each site for the geological investigations. A trackhoe with a $150-\mathrm{cm}$-wide bucket and an operator were provided by the Willacy County Drainage District for the excavations in Willacy County, and the Hidalgo County Drainage District provided a backhoe with an 80 $\mathrm{cm}$-wide bucket and an operator for the excavations in that county. Geological trenches were placed so as to provide a comprehensive view of the deposits containing cultural materials.

Backhoe trenches and test unit wall profiles were described, photographed, and selectively sampled for textural analysis. Descriptions of the deposits used the geologically neutral concept of "zone". Zone transitions were identified by changes in color, particle size, sorting, cohesiveness, structure, and boundary attributes. Each recorded stratigraphic entity met the definition of a zone as "any regular or irregular ... layer ... of earth materials . . . characterized as distinct from surrounding parts by some particular property or content" (Gary et al. 1972:80). This versatile concept permits designation of any perceived layer in a profile as a zone whether it resulted from pedogenesis, sedimentation, cultural activity, or an unidentified process as long as it is readily distinguishable from adjacent zones. When sufficient information was available, a zone was assigned a specific label.

All sediment colors were read when the samples were moist using a Munsell Soil Color 
Chart. All sediment textures were estimated in the field by feel following the guidelines set forth by Soil Survey Staff $(1962,1975)$ and Olson (1981). Sedimentary structures and evidence of bioturbation, as discussed by Reineck and Singh (1975), were identified when possible. Surface topography was used to assess the environment of deposition. Additionally, subsurface evidence such as buried soils, erosional surfaces, and particle size changes were used to identify paleogeomorphic features.

After description and assessment, standard soil horizons as defined in Birkeland (1984:7-9) were applied. Standard master soil horizons $(\mathrm{O}$, A, E, B, C, and R) were augmented with a subordinate classification system denoted by a lowercase letter suffix to the master symbol marked by a capital letter. O horizons refer to the uppermost zone of a soil that retains identifiable organic material. A horizons have no identifiable organic material, but decomposed organic matter is present as well as mineral matter; these horizons are usually dark. Some horizons are characterized by a loss of material, usually clay or other materials, due to a downward movement of water, or eluviation. These are E horizons. B horizons have less organic matter but more mineral constituents than A horizons. They are characterized by the accumulation of minerals moved down from an E horizon, e.g. illuviation, and are usually not as dark as A horizons. In $\mathrm{C}$ horizons, the parent material is relatively less affected by pedogenesis than are the overlying soil horizons, but some indication of soil formation does exist. $\mathrm{R}$ horizons refer to bedrock, which for this area is unweathered Plio-Pleistocene fluvial deposits. The subordinate classifications used include $\mathrm{p}, \mathrm{b}, \mathrm{t}, \mathrm{k}$, and c. A lower-case $p$ denotes a horizon that has been disturbed by agricultural activities (i.e., a plowzone). A lower-case $b$ indicates a buried soil horizon and in this report is limited to the upper horizon in a single solum. A lower-case $t$ is restricted to B horizons and denotes clay accumulations due to illuviation or in situ genesis. The lower-case $\mathrm{k}$ designation indicates the presence of calcium carbonate in the form of nodules or filaments, while the lower-case $\mathrm{c}$ designation indicates the presence of iron or manganese concretions. When more than one subordinate designation is indicated, their relative positions reflect either the sequence of occurrence or the importance of the attributes. For example, an Apb horizon is an A horizon that was disturbed by plowing and later buried, while a Bkc horizon is a B horizon with more calcium carbonate nodules than manganese concretions. Roman numerals preceding the master horizon designation indicate a lithological discontinuity (Olson 1981). In all cases, this discontinuity marks a shift to a different sedimentary unit, and an unconformity separates the two units. For example, in this area a common profile sequence is an A horizon sitting on a IIC horizon. The A horizon is a Holocene soil that sits unconformably on a $\mathrm{C}$ horizon developed on the Pleistocene Beaumont Formation. Master soil horizons subdivided by subordinate classifications are numbered sequentially in descending order.

\section{Laboratory Processing Methods}

Laboratory processing and analysis of the cultural materials began immediately after completion of the fieldwork. Laboratory processing was the first task and consisted of washing all artifacts and drying all samples. Using India ink, the artifacts were labeled with a lot number indicating provenience. After being inventoried, the sediment and charcoal samples to be radiocarbon dated were packaged and submitted to Beta Analytic, Inc. and Geochron Laboratories, Inc., and the remainder were packaged for curation. The processing of photographs involved labeling all $35-\mathrm{mm}$ slides with the site number, a unique catalog number, and a description; 35-mm blackand-white negatives were labeled with the site number and a catalog number and placed in an envelope containing a typed description and a contact print. These procedures are in accordance with those required by the repository at which the materials generated by this project are curated, the Texas Archeological Research Laboratory at The University of Texas at Austin.

\section{EVALUATION OF THE METHODOLOGY}

Several methodologies applied during the Phase II investigations were notably effective. The geological investigations, conducted before and during the archeological excavations, identified intact or undisturbed deposits that might contain in situ cultural materials. Disturbed 
deposits were also recognized. Although this method is not new, it often occurs with minimal consultation between the geologist and archeologist during field investigations, or the geological work is done after or near the end of the archeological fieldwork. The geologic studies were aided by the rapid processing of two radiocarbon samples from $41 \mathrm{WY} 112$ before completion of fieldwork. This provided information that permitted the accurate assessment of historic disturbance while the geologist was still conducting fieldwork. Early identification of these disturbed deposits permitted their quick removal, and thus the majority of the field time was spent investigating intact deposits. Use of the backhoe to remove overburden and disturbed deposits also facilitated data recovery. Once such deposits were positively identified, they could be removed in bulk, and the hand excavations could proceed.

The previous work in the project area indicated that cultural materials are extremely sparse. This area is presumed to have been a resourcepoor environment (Hester 1981:120), and this presumption is supported by the archeological record which demonstrates that most sites in the project area reflect limited activities based on low artifact frequencies, limited tool assemblages, and the absence of features (only a few positively identified hearths exist). Considering the nature of archeological assemblages in the area, it was expected that lithic tool maintenance would be the most common activity at these sites, but its archeological visibility would be dependant on recovering microdebitage produced during this activity. Microdebitage could be recovered only by fine screening. This resulted in the identification of a component of the lithic assemblages that was previously undetected. Unfortunately, fine screening was not attempted previously at other prehistoric sites in the region.

Water screening of all excavated deposits was worthwhile also because it allowed the excavations to proceed at a rapid pace. Two water screening systems were evaluated, and the results are presented in Appendix E.

Of final note is the usefulness of information from local informants which aided in interpretation of the depositional environment at each site. The local farmers and county drainage district employees provided crucial information concerning recent land use in the project area. 


\section{SITE DESCRIPTIONS}

by Gail L. Bailey and C. Britt Bousman

This chapter describes the five prehistoric sites under investigation. Presented for 'each are descriptions of the site setting, the previous investigations, the work accomplished, the site extent and depth, the sediments and radiocarbon chronology, any cultural features observed, the materials recovered, and summary comments. The sites are presented in numerical order by county beginning with Hidalgo County and followed by Willacy County.

\section{HG128}

\section{Site Setting}

Site 41HG128 is located north of La Villa, Texas, along the South Main Channel approximately $1.95 \mathrm{~km}$ north-northwest of the intersection of FM 1925 and FM 491. It lies along the edges of a relatively deep depression and is exposed on the north bank of the drainage ditch (Fig. 15a). The site is at an elevation of $50 \mathrm{ft} \mathrm{msl}$ and is surrounded by cultivated fields. The central portion of the depression is not cultivated, probably because it is too marshy for crops and farm machinery. During drainage ditch excavation, fill was placed along the ditch edge to provide a dry access road (Fig. 15b).

\section{Previous Investigations}

Site 41HG128 was discovered by Elton R. Prewitt and recorded during the 1986 survey (Hall et al. 1987:99-100): The materials observed at this site consisted of two bifaces, one modified flake, five pieces of debitage, one aboriginal sherd (possibly of Haustecan influence, see Appendix A), seven bone fragments, several pieces of mussel shell (one possibly shaped), one piece of sandstone (possibly grooved), one piece of glass, and one possible historic ceramic sherd. These materials were eroding from the north bank of the drainage ditch. The site was estimated to extend ca. $40 \mathrm{~cm}$ below the modern surface and $350 \mathrm{~m}$ east-west along the drainage bank. Site 41HG128 was assessed as probably eligible for listing on the National Register of Historic Places based on the quantity and diversity of the cultural materials.

\section{Work Accomplished}

The current investigations consisted of a pedestrian survey of the site and excavation of five backhoe trenches and eleven 1x1-m test units (Fig. 16). The survey identified two areas on the north bank with somewhat dense scatters of artifacts. Test Units $1,2,7-9$, and 11 were placed along the bank to investigate these scatters; Test Units 3-6 and 10 sampled the remaining site area. Table 7 summarizes the test unit excavations. All except Test Units 3 and 4 were excavated into the Plio-Pleistocene bedrock formations. Test Units 7-11 were placed adjacent to small, mechanically excavated trenches. Overburden was first identified in the trench profiles and then mechanically removed from the test units. 


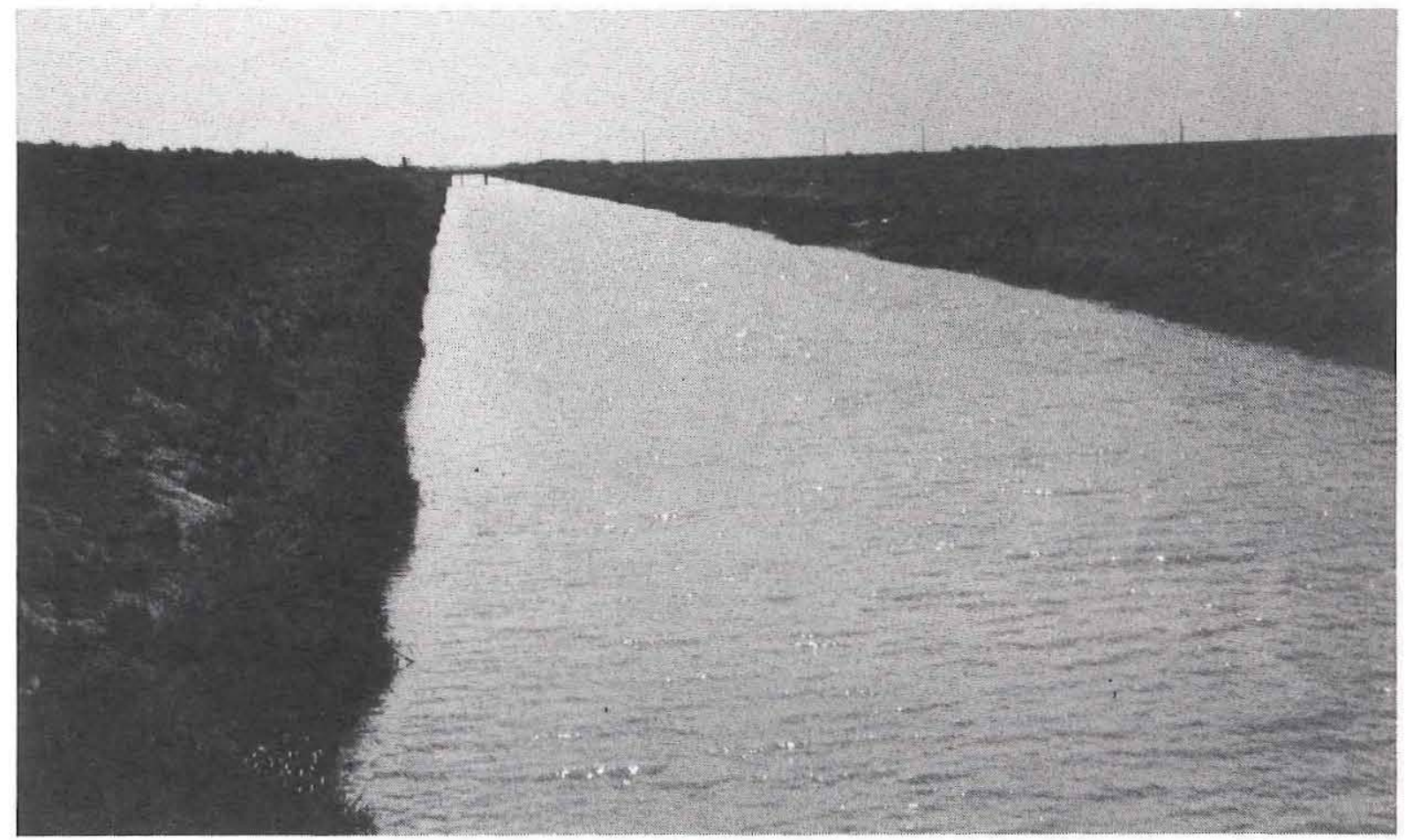

$a$

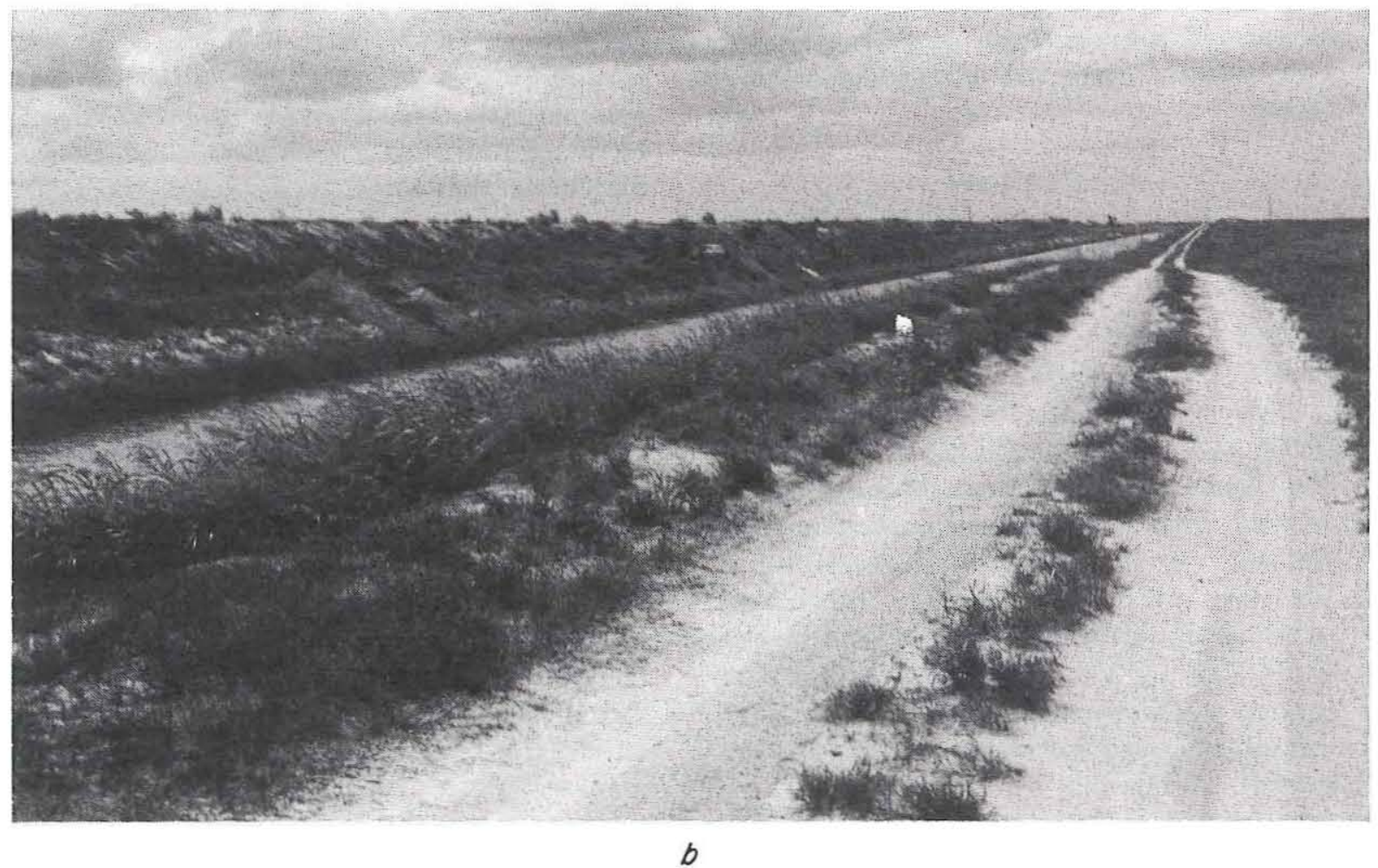

Figure 15. Photographs of 41HG128. (a) View from west before excavation; site is on left of drainage ditch. Note depression on south (right) side of ditch and culvert. (b) View from the southwest during excavation. Note the flat raised road on the north side compared to the depression on the south side of the ditch. 


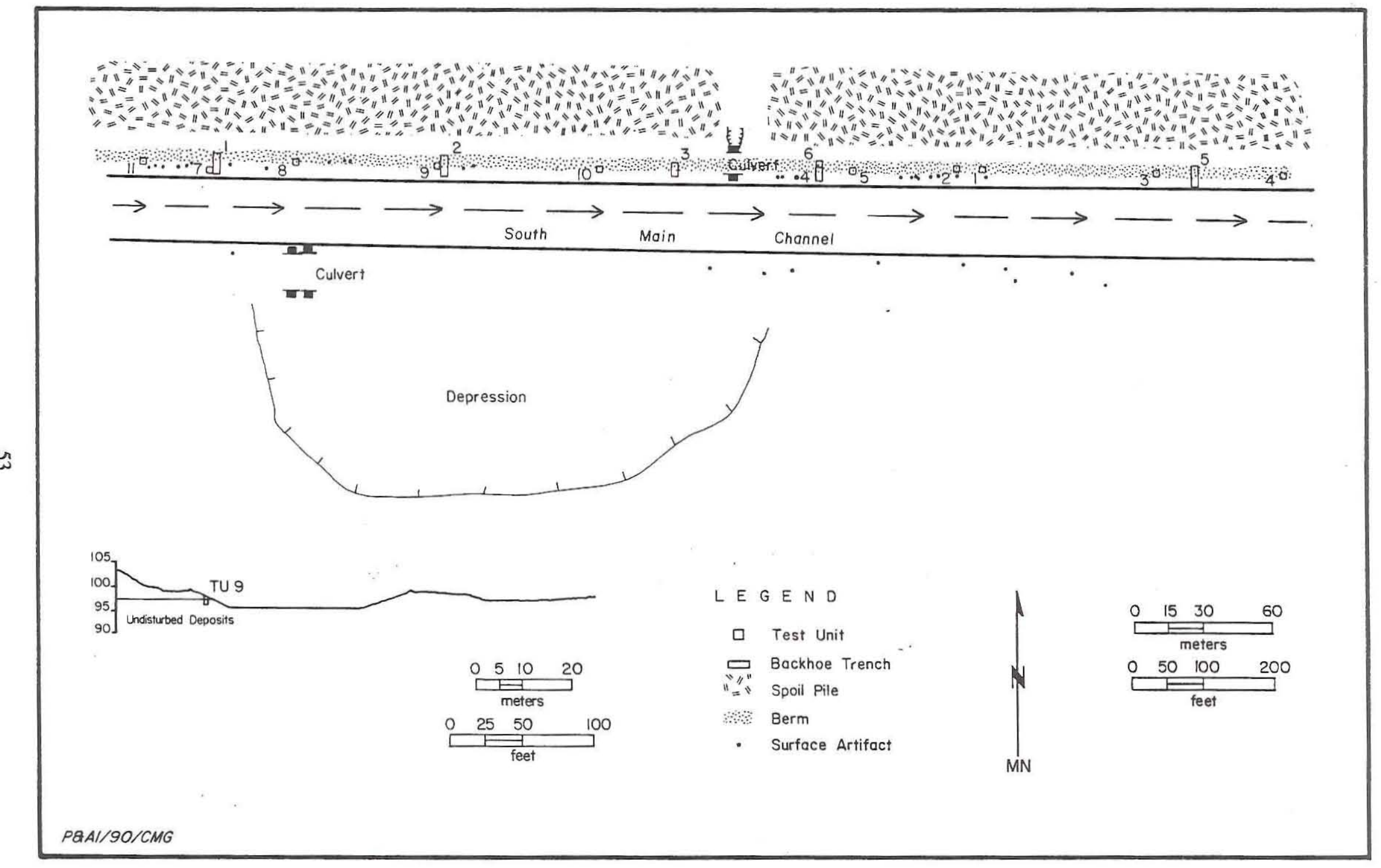

Figure 16. Site map, 41HG128. 


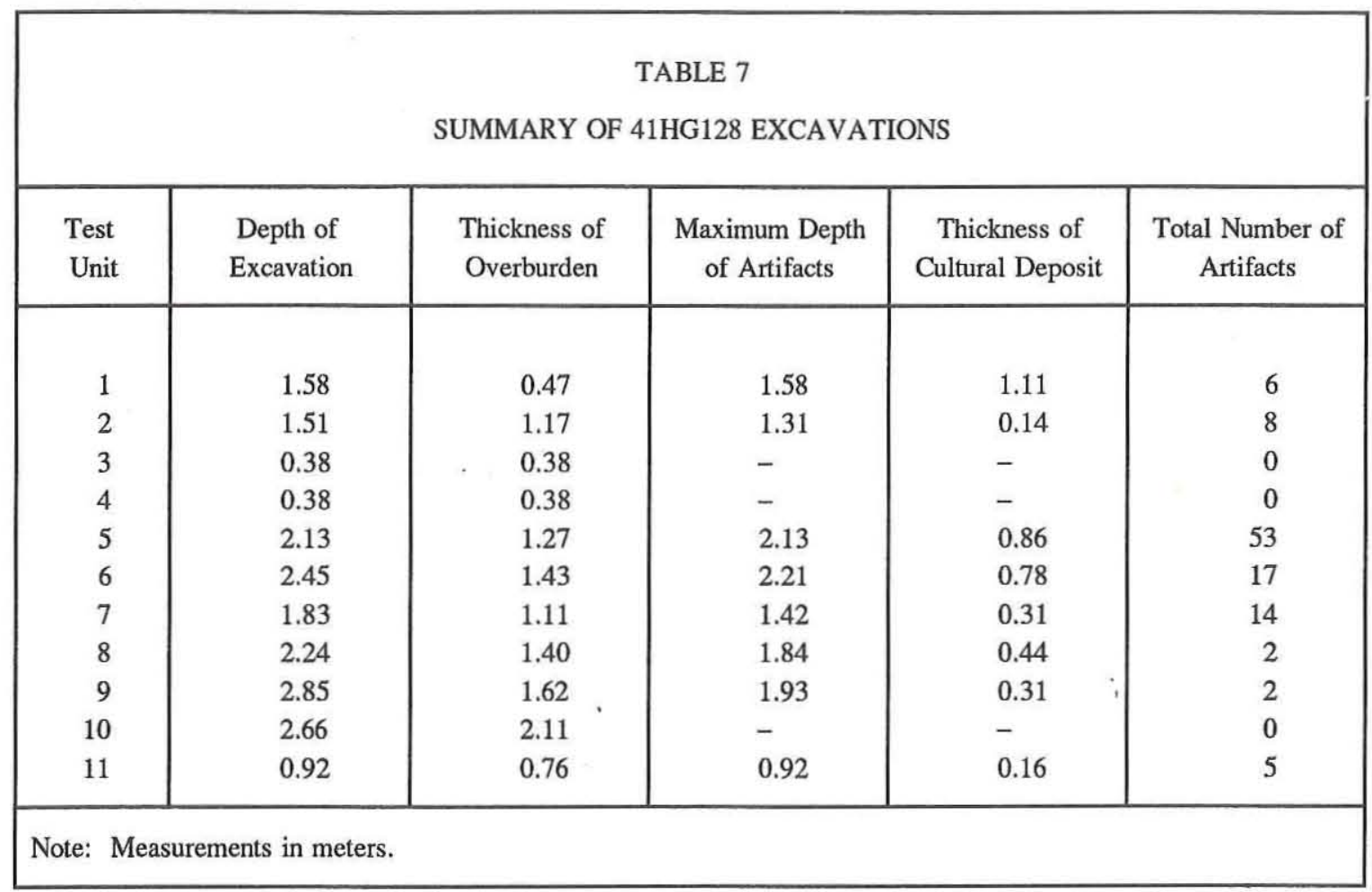

The placement of the five backhoe trenches for the geomorphic investigations was based on sampling the length of the site and the related deposits. The backhoe trenches ranged in depth from 255 to $300 \mathrm{~cm}$. Sediment and humate samples were collected from test units and backhoe trenches. The fieldwork at $41 \mathrm{HG} 128$ was completed in 52 person-days.

\section{Site Extent and Depth}

Prehistoric artifacts were recovered from 8 of 11 test units (see Table 7). Based on the distribution of surface and excavated materials, the site extends a minimum of ca. $10 \mathrm{~m}$ north-south and $390 \mathrm{~m}$ east-west. The vertical distribution of the artifacts is illustrated in Table 8. The cultural deposits range in thickness from 16 to $111 \mathrm{~cm}$. The densest concentration is located in Level 5 of Test Unit 5 but it is unclear whether these artifacts were recovered from in situ prehistoric-aged sediments (see Feature 3 below). In comparison with the other sites under investigation, the central portion of 41HG128 contains the highest density of artifacts (27 artifacts $\left./ \mathrm{m}^{3}\right)$ and prehistoric features.

\section{Sediments and Radiocarbon Chronology}

Site 41 HG128 is on the north slope of a winderoded depression. This depression is in an abandoned channel (Holz and Prewitt 1981) that appears to be near or on the boundary between the Lissie and Goliad formations (Bureau of Economic Geology, 1976) (see Figs. 5 and 8). The soils reflect the more recent eolian alteration of the area (Fig. 17). Over most of the area, Willacy fine sandy loam soils have formed on a large stabilized dune deposit that trends southeast to northwest and covers the bedrock formation discussed above. The age of this dune is unknown, but it probably was deposited in the late Pleistocene. Wind erosion created the large deflationary basin at 41HG128 and apparently removed the stabilized dune in and around the basin. Rio clay loam soils occur in the basin, while Racombes fine sandy loam soils occupy the surrounding slopes (Jacobs 1981).

The distribution of modern soils as mapped on the U.S.D.A. Soil Conservation Service Soil Survey Maps for Hidalgo and Willacy counties reflects the recent geological history of the region (Jacobs 1981; Turner 1982). In general, sandy clay loam soils have formed on uneroded Plio-Pleistocene 


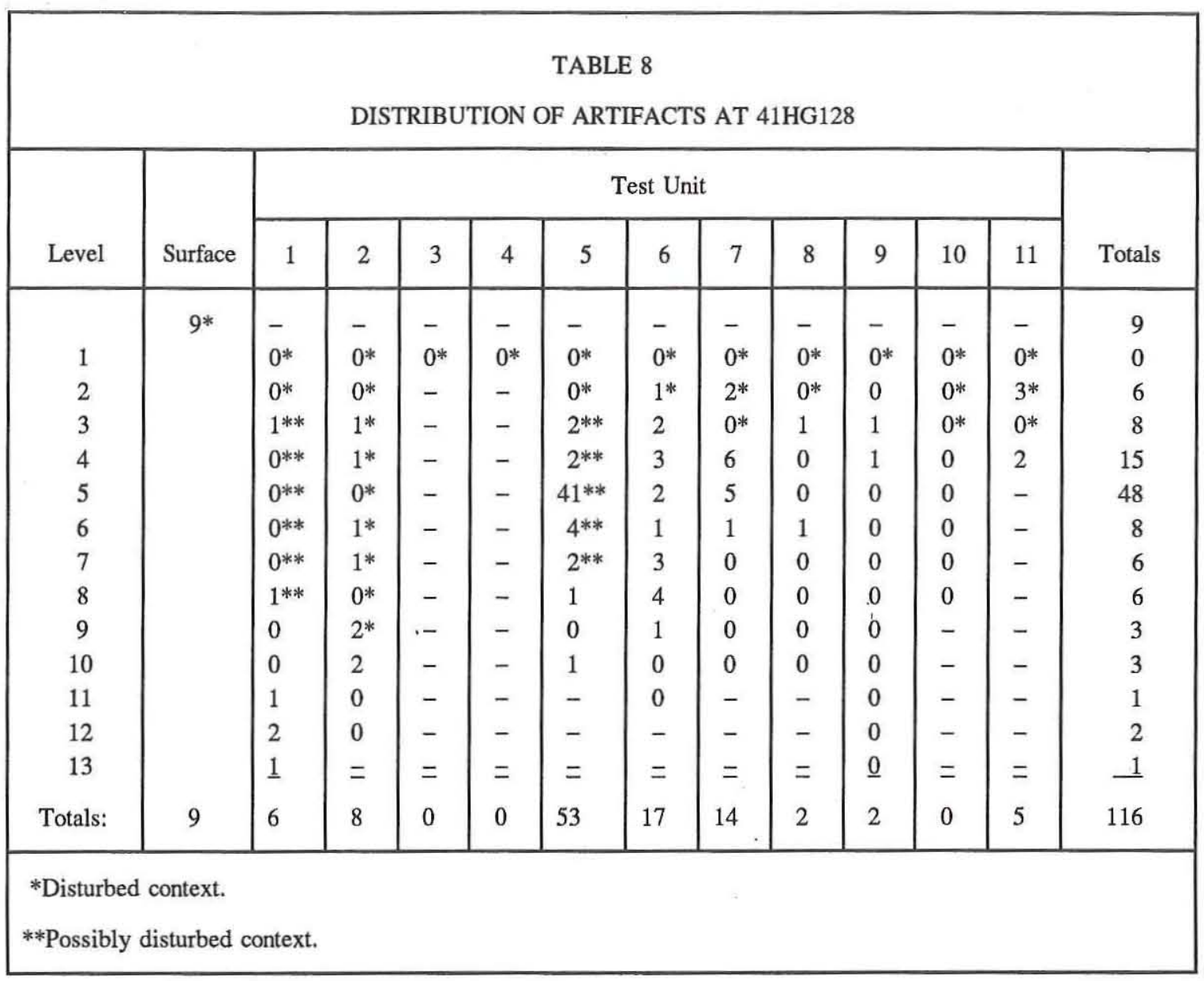

fluvial overbank deposits and abandoned channels. Most erosional depressions (blowouts) have been scoured out of these ancient, abandoned channels. Some channels have clay loam soils, but few blowouts occur in these settings as clay loam is not easily eroded by wind. Within most blowouts, the soils are very clayey because wind erosion has removed the sands and probably most of the coarser silts that were originally present or transported in through slopewash. Sandy loam eolian sediments occur on the north and northwest sides of many blowouts and apparently formed low dunes on the flat landscape. Within this century, these sandy loam dunes have been flattened and pushed into the blowouts for agricultural purposes. Nevertheless, a clear pattern of natural sediment sorting by wind erosion still is visible and observable on the soil maps for the two counties. In summary, intensive wind erosion removed sands and coarse silts and created depressions on the surface of the Plio-Pleistocene formations, usually in ancient stream channels, while the clays remained in the eroded areas. This process apparently occurred throughout the Pleistocene and Holocene epochs.

Backhoe Trench 1 has seven zones (Fig. 18). Zone $1(0-40 \mathrm{~cm})$ is very dark grayish brown and reddish yellow silt loam construction fill with an abrupt irregular lower boundary. Zone 2 (40-65 $\mathrm{cm}$ ) is dark gray friable loam with very weak coarse blocky structure and a clear smooth lower boundary. Zone $3(65-87 \mathrm{~cm})$ is dark gray firm loam with weak medium platy structure and an abrupt wavy lower boundary. This zone has been compacted by construction activities. Zone 4 (87$91 \mathrm{~cm}$ ) is dark gray firm loam with moderate fine platy structure and thin discontinuous irregular freshwater marl lenses that grade laterally into thin sand lenses. The lower boundary is very abrupt and wavy. All the deposits from Zone 4 and above appear to be a result of land clearance and ditch construction activities. Zone $5(91-140 \mathrm{~cm})$ is dark 


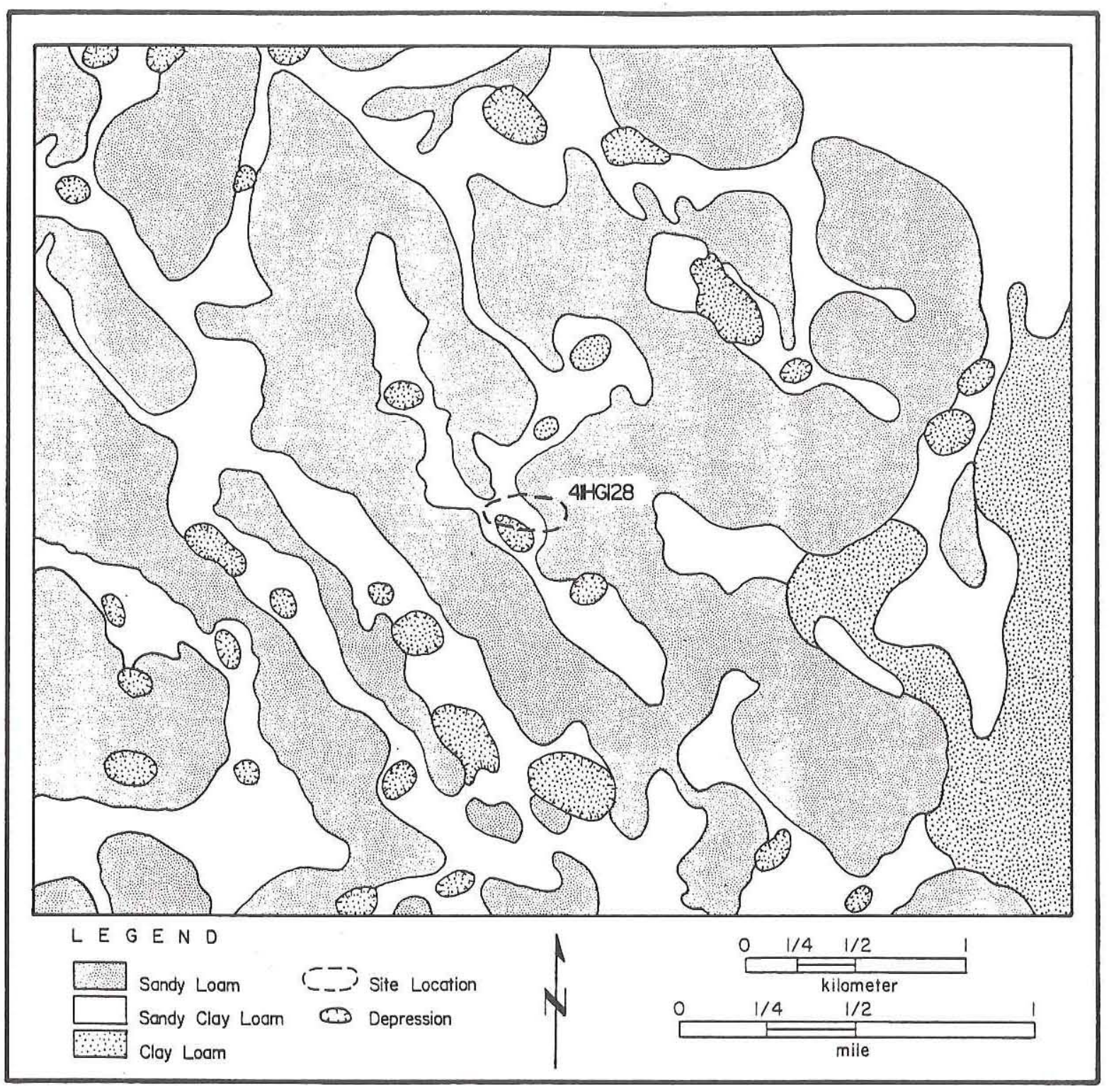

Figure 17. Distribution of soils and blowout depressions at 41HG128. Adapted from Jacobs 1981.

gray firm to friable loam to sandy loam with a gradual smooth lower boundary. This is an $\mathrm{Ab}$ horizon. Zone $6(140-170 \mathrm{~cm})$, a IICkc1 horizon, is grayish brown very friable loam to silt loam with pale brown mottles, few calcium carbonate nodules, and few manganese flecks and concretions. This horizon has developed on the Goliad Formation, and the upper boundary represents an unconformity. The lower boundary is smooth and gradual. Zone 7 $(170-250+\mathrm{cm})$ is a pale brown friable silt loam with distinct reddish brown mottles, many calcium carbonate nodules, and common manganese concretions. Zone 7 is a IICkc2 horizon.

Nine zones were identified at Backhoe Trench 2 (see Fig. 18). Zone $1(0-15 \mathrm{~cm})$ is very dark gray loose loam with a few soft small calcium carbonate nodules and a clear wavy lower boundary. Zone $2(15-50 \mathrm{~cm})$ consists of dark gray friable sandy loam with weak coarse blocky structure and a gradual smooth lower boundary. Zone $3(50-106 \mathrm{~cm})$ is very dark grayish brown, reddish yellow, and very pale brown sand to silt 


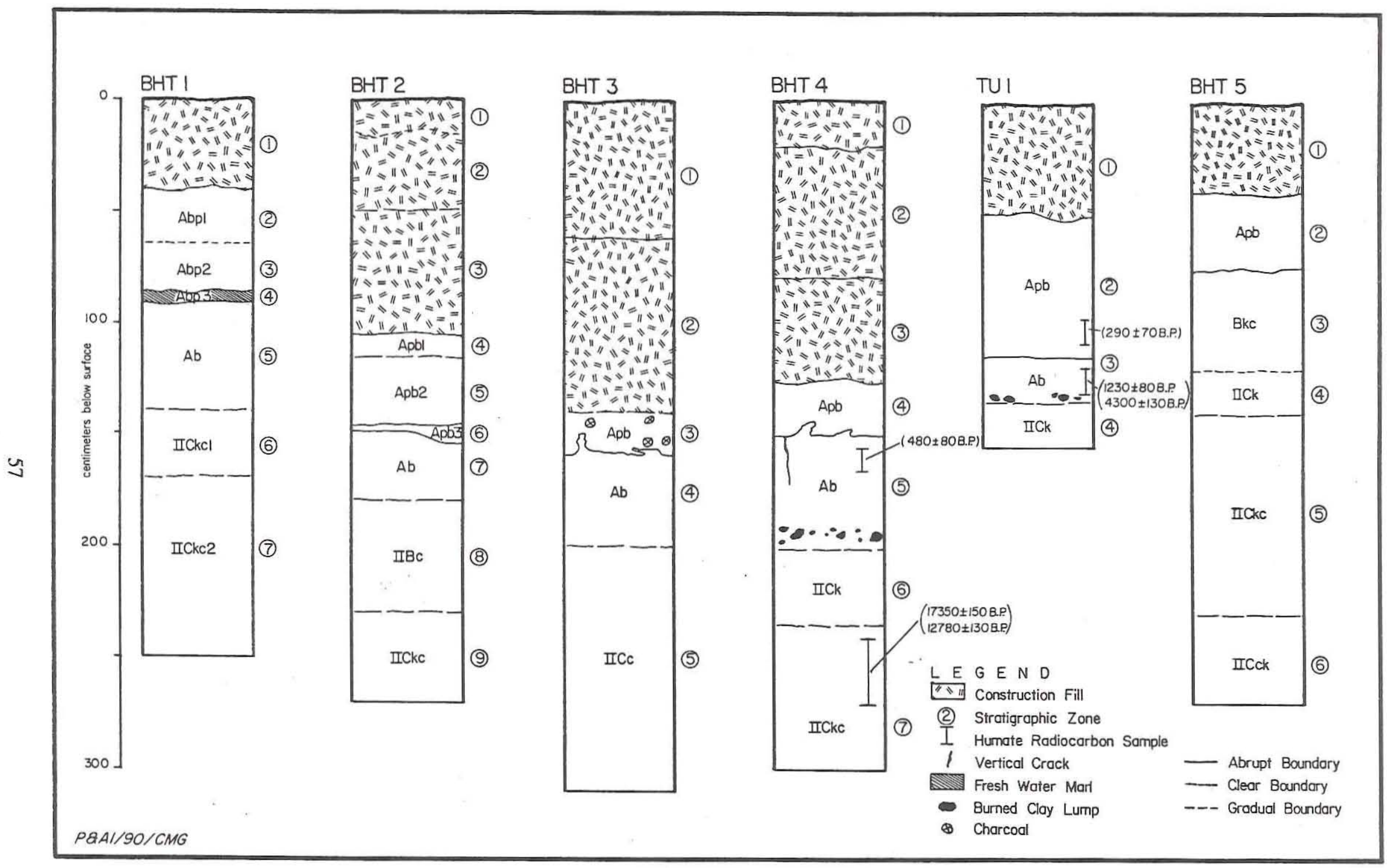

Figure 18. Selected geological profiles of backhoe trenches and test units at 41HG128. 
loam with coarse horizontal bedding and subrounded sediment clasts common throughout. The lower $6 \mathrm{~cm}$ are sandy with a very abrupt wavy lower boundary which is an obvious unconformity. Zone $4(106-122 \mathrm{~cm})$ is very dark gray firm loam, probably compacted by construction, with a gradual smooth lower boundary. Zone $5(122-147 \mathrm{~cm})$ is dark gray sandy loam with common scattered very dark gray to black clay lumps, rare charcoal flecks, one single whole snail shell, and an abrupt irregular lower boundary. Zone $6(147-149 \mathrm{~cm})$ is grayish brown to dark grayish brown sand lens that is continuous across the entire profile. Zone 6 has very dark grayish brown silt loam clasts, and in the eastern profile wall, a small depression is filled with well-laminated very thin alternating sand and clay lenses. The very abrupt lower boundary is smooth to wavy to irregular. All the deposits from Zone 6 and above are the result of historic agricultural disturbance and land clearing (Zones 4-6) and ditch construction activities (Zones 1-3). Zone 7 $(149-180 \mathrm{~cm})$, an Ab horizon, is very dark grayish brown loam with friable to firm consistency and weak medium blocky structure. A few charcoal flecks and chunks were observed, and it has a gradual smooth lower boundary. Zone 8 (180$230 \mathrm{~cm}$ ) is dark gray friable silt loam with moderate medium blocky structure and well-developed ped faces, rare manganese flecks, and a gradual smooth lower boundary. This is a IIBc horizon developed on the Goliad Formation. Zone 9 (230$270+\mathrm{cm}$ ) is gray silt loam with common strong brown very fine distinct mottles, common manganese concretions, and many calcium carbonate nodules which decrease down profile. Excavations did not extend through this IICkc horizon.

Backhoe Trench 3 has five zones identified (see Fig. 18). Zone $1(0-62 \mathrm{~cm})$ is very dark gray to dark grayish brown firm to very firm sandy loam to loam. This zone has been compacted by construction, and its lower boundary is very abrupt and smooth. Zone $2(62-140 \mathrm{~cm})$ is speckled pale brown to dark grayish brown sandy loam with subhorizontal dark grayish brown layers and a gradual smooth lower boundary. Zone 3 (140$159 \mathrm{~cm}$ ) consists of charcoal, white ash, and burned clay lumps with a very abrupt wavy to irregular lower boundary. Zone 3 represents the burning of a brush pile, which occurred either during historic land clearing in the early twentieth century or when the ditch was constructed. All the sediments above
Zone 3 represent filling of the depression during ditch construction. Zone $4(159-200 \mathrm{~cm})$ is very dark gray friable loam with weak coarse blocky structure rare snail shells, a thin sand lens in the upper $10 \mathrm{~cm}$, and a gradual smooth lower boundary. It is an Ab horizon. Zone $5(200-310+\mathrm{cm})$ is gray to very pale brown friable sandy loam with moderate medium blocky structure and common manganese concretions. The sediment is weathered Goliad Formation, and the soil horizon is classified as IICc. The backhoe trench was not excavated to the bottom of this zone.

Zone $1(0-20 \mathrm{~cm})$ in Backhoe Trench 4 is loose construction fill with a very abrupt smooth lower boundary (see Fig. 18). Zone $2(20-79 \mathrm{~cm})$ is very dark gray to dark grayish brown firm to very firm sandy loam to loam with a very abrupt smooth lower boundary. This zone has been compacted by ditch construction activities. Zone $3(79-126 \mathrm{~cm})$ is speckled pale brown to dark grayish brown loam with subhorizontal dark grayish brown layers and a very abrupt wavy lower boundary. Zones 1-3 represent artificial fill placed in the depression for construction of the ditch access road. Zone $4(126-150 \mathrm{~cm})$ is dark gray very firm to firm loam with coarse medium blocky structure. It appears to have been compacted during construction of the ditch. Also present are rare small burned clay lumps, a few charcoal fragments and snail shells, and calcium carbonate nodules. The lower boundary is very abrupt and wavy. This is an A horizon disturbed by plowing and later buried by fill (Apb). Zone 5 (150$200 \mathrm{~cm}$ ) is very dark gray silt loam with weak medium blocky structure, pale brown sand-filled cracks and insect burrows, many burned clay lumps between 190-195 cm, and a gradual smooth lower boundary. A bulk humate sample from the top of this zone $(155-165 \mathrm{~cm})$ was dated to $480 \pm 80$ B.P. suggesting a Late Prehistoric age for the top of this $\mathrm{Ab}$ horizon. It is likely that the soil continued to accumulate after 480 B.P. but that most of the younger sediments were disturbed by agricultural activities represented by Zone 4. Zone 6 (200$235 \mathrm{~cm}$ ) is dark gray to light gray to light brownish gray silt loam with weak medium blocky structure, a few calcium carbonate nodules and filaments, and a gradual smooth lower boundary. This is a IICk horizon. Zone $7(235-300+\mathrm{cm})$, a IICkc horizon, is dark gray to light brownish gray silt loam with weak medium blocky structure and many calcium 
carbonate nodules and manganese concretions. The backhoe trench was not excavated to the bottom of this zone. A sample of calcium carbonate nodules was submitted for radiocarbon dating. The outer and inner portions were removed by acid, and each was dated in an attempt to obtain a temporal range of pedogenic carbonate formation. Ages of $17,350 \pm 150$ B.P. (Beta-32204a) for the inner fraction and 12,780 \pm 130 B.P. (Beta-32204b) for the outer fraction were obtained. These ages suggest that a soil was in place and forming on the Goliad Formation for at least 4,500 years beginning during the Last Glacial Maximum.

Four sediment zones were identified in Test Unit 1 (see Fig. 18). Zone $1(0-50 \mathrm{~cm})$ is loose dark gray loam with a clear irregular lower boundary. This is berm construction fill. Zone 2 $(50-114 \mathrm{~cm})$ is very dark gray, very firm loam with coarse moderate blocky structure and a very abrupt smooth lower boundary. This zone has a few light brown sand-filled insect burrows, small clay lumps, and rare calcium carbonate filaments. A bulk soil humate sample from the bottom of this zone was dated by radiocarbon, yielding an age of $290 \pm 70$ B.P. (Beta-32202). Zone 3 (114$134 \mathrm{~cm}$ ) is very dark gray silt loam with weak moderate blocky structure and common large pebble-sized burned clay lumps and charcoal fragments occurring horizontally in the lower portion. This is a truncated Ab horizon, the lower boundary of which is gradual and smooth. Two radiocarbon dates were obtained from the layer of burned clay lumps and charcoal fragments (Level 10). A charcoal sample was dated to $4300 \pm$ 130 B.P. (Beta-32200), and a matching humate sample was dated to $1230 \pm 80$ B.P. (Beta-32201). These ages suggest that the soil developed on the Lissie Formation in this depression began to form by 4300 B.P. Zone $4(134-154 \mathrm{~cm})$ is dark gray to grayish brown silt loam with weak medium blocky structure and a few calcium carbonate nodules. This is a IICk horizon formed in Lissie Formation sediments.

Backhoe Trench 5 has six sediment zones (see Fig. 18). Zone $1(0-40 \mathrm{~cm})$ is composed of very dark grayish brown, reddish yellow, and very pale brown sand to silt loam construction fill with coarse horizontal bedding, subrounded sediment clasts common throughout, and a very abrupt wavy lower boundary. Zone $2(40-75 \mathrm{~cm})$ is dark gray sandy loam with common scattered very dark gray to black clay lumps, rare charcoal flecks, and an abrupt irregular lower boundary. This is an Apb horizon. Zone $3(75-120 \mathrm{~cm})$, a truncated Bkc horizon, is yellowish brown firm to extremely firm sandy loam to loam with strong medium blocky structure, a few small calcium carbonate nodules and filaments, light manganese coatings on some ped faces, and a clear smooth lower boundary. Zone $4(120-140 \mathrm{~cm})$ is light yellowish brown firm to extremely firm loam with strong medium to fine blocky structure, few calcium carbonate nodules and very many calcium carbonate filaments, and a gradual smooth lower boundary. This is a IICk horizon developed on the weathered Lissie Formation, and the upper boundary of this zone is an unconformity. Zone $5(140-230 \mathrm{~cm})$ is light gray friable silt loam with weak medium blocky structure, many large calcium carbonate nodules, and many manganese concretions. A well-laminated, 30-cm-thick, sand-filled paleochannel occurs at the bottom of this zone. Zone 5 has a gradual smooth lower boundary, and it is classified as a IICkc soil horizon. Zone $6(230-270+\mathrm{cm})$ is light gray friable silt loam with weak medium blocky structure, few large calcium carbonate nodules, and many manganese concretions. The paleochannel observed in the bottom of Zone 5 extends into Zone 6. This is a IICck horizon.

The upper sediments consisting of construction fill were removed from Test Unit 5. Four zones were identified in the remaining intact deposits (Fig. 19). Zone $1(98-133 \mathrm{~cm})$ is very dark grayish brown extremely firm sandy loam with medium moderate to coarse blocky structure and an abrupt to clear irregular lower boundary. This is a Apb1 horizon. Zone $2(133-150 / 182 \mathrm{~cm})$ is very dark gray firm sandy loam with moderate medium to coarse blocky structure and a clear to abrupt and very irregular lower boundary. Also observed were a few charcoal fragments and one small burned clay lump. Charcoal fragments from the upper portion of Zone 2 (Level 3) were radiocarbon dated; the resulting age is $120 \pm 80$ B.P. (Beta-32977), and the tree-ring calibrated intercepts are 254, 223, 132, 90, 29 and 0 B.P. Thus, this date cannot be used to determine if Zone 2 is historic or prehistoric in age, although the configuration of the lower boundary strongly suggests that it is a manmade stratigraphic feature. Zone 2 is classified as an Apb2 horizon as it is most likely of historic origin (see Features below). Zone 3 


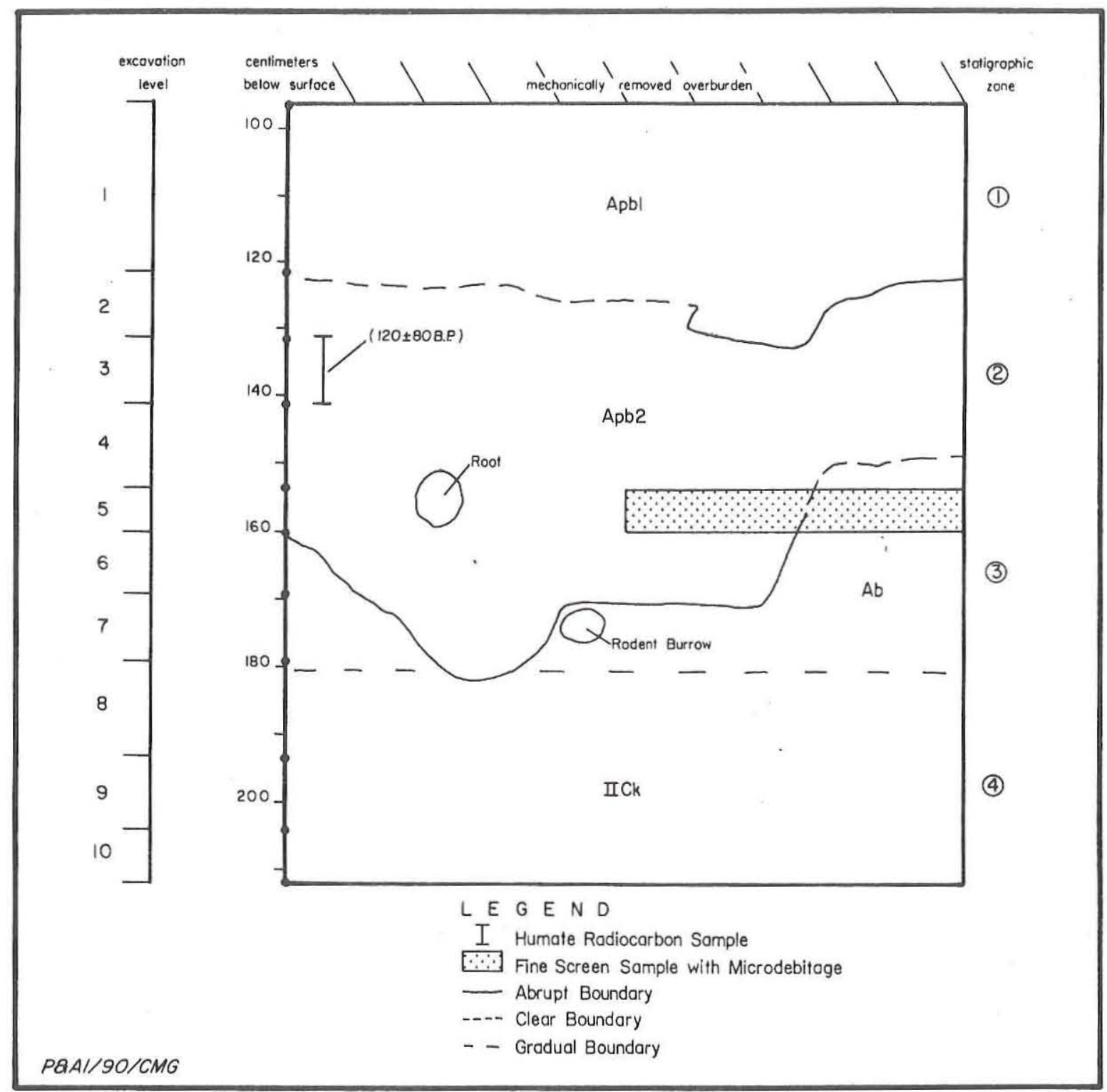

Figure 19. Geological profile of Test Unit 5, 41HG128.

$(150-180 \mathrm{~cm})$ is gray to grayish brown friable silt loam with weak coarse blocky structure. The lower boundary of this Ab horizon is gradual and smooth. Zone $4(180-213+\mathrm{cm})$ is light yellowish brown firm silt loam with rare calcium carbonate nodules. The test unit was not excavated to the bottom of this IICk horizon.

The upper sediments were removed mechanically from Test Unit 6, leaving four sedimentary zones identified in the remaining intact deposits (Fig. 20). Zone $1(118-139 \mathrm{~cm})$ is very dark grayish brown sandy loam with weak medium blocky structure and a very abrupt to abrupt slightly wavy lower boundary. This is an Apb horizon. Zone 2 (139-183 cm), an Ab horizon, is very dark gray firm sandy loam with moderate medium blocky structure, common large and small charcoal fragments, few burned clay lumps, and a clear to gradual wavy lower boundary. Large charcoal fragments from Zone 2 (Level 3) were dated by radiocarbon to $320 \pm 90$ B.P. (Beta-32978). Zone $3(183-225 \mathrm{~cm})$ is gray to grayish brown and light 


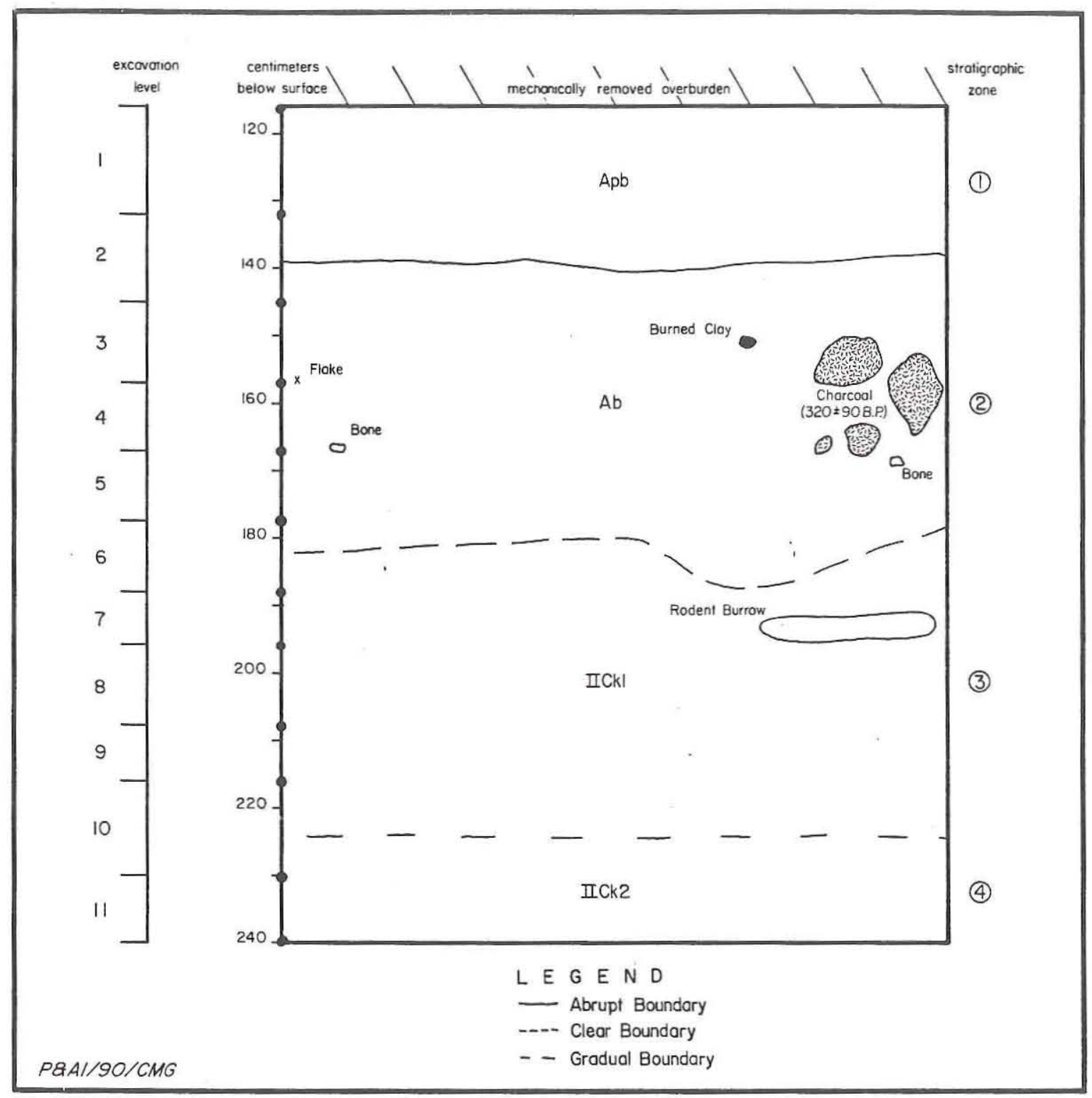

Figure 20. Geological profile of Test Unit 6, 41HG128.

yellowish brown firm to friable silt loam with few calcium carbonate filaments, rare calcium carbonate nodules, and a clear to gradual wavy lower boundary. Zone 3 is a IICk1 horizon. Zone 4 $(225-245+\mathrm{cm})$, a IICk2 horizon, is gray to grayish brown and light yellowish brown firm to friable silt loam with many calcium carbonate nodules. The lower boundary was not exposed in this test unit. The outer and inner portions of calcium carbonate nodules from Zone 4 were radiocarbon dated. The inner fraction yielded an age of $16,330 \pm 130$ B.P.
(Beta-32205a), and the outer provided an age of $15,010 \pm 170$ B.P. (Beta-32205b). As with the carbonate ages from Backhoe Trench 4, these also suggest the existence of a soil during the Last Glacial Maximum.

In summary, the deposits and radiocarbon ages at 41 HG128 demonstrate the existence of a soil during the Last Glacial Maximum (between ca. 17,500 and 12,000 B.P.) that developed on the Goliad and Lissie formations. This soil appears to have been truncated and the upper portion 
probably removed by wind erosion. A late Holocene soil began to accumulate by 4300 B.P., and it continued to develop and apparently accumulate sediments until historic times. During the historic period, vegetation was burned, the depression was filled for agricultural purposes, and the sediments were then altered by plowing. Lastly, construction of the ditch required more infilling of the depression for access road construction, and this activity also compacted a thin zone of deposits below the construction surface.

\section{Features}

Three cultural features were investigated during Phase II. Feature 1 is a modern bone dump exposed along the drainage bank; it is not discussed further because of its recent age. Feature 2 is a concentration of wood charcoal, bone fragmients, debitage, and burned clay lumps. Feature 3 consists of a pit-like feature, possibly associated with a dense zone of lithic debitage. At two other locations--Levels 9-11 in Test Unit 1 and Levels 5-7 in Test Unit 8--substantial amounts of burned clay lumps and sparse amounts of debitage suggest additional dispersed features.

Feature 2 was first observed as a layer of burned clay lumps exposed in the Backhoe Trench 4 wall during the geomorphic investigations. Test Unit 6 was placed at this location to further investigate the burned clay lumps. The excavations revealed a feature (see Fig. 20) located from 147 to $193 \mathrm{~cm}$ below the modern surface (Levels 3-6) and consisting of 3 large charcoal fragments and numerous smaller pieces, 38 burned clay lumps, $0.3 \mathrm{~g}$ of bone, 1 flake from the $1 / 4$-inch screen, and 8 flakes from the $1 / 16$-inch screen. The feature is in the lower portion of Zone 2 and may be lying on or near the surface of Zone 3. No pit or dense cluster of artifacts was noted. Associated charcoal yielded a radiocarbon age of $320 \pm$ 90 B.P. (Beta-32978) suggesting that the artifacts predate historic land modifications and are related to prehistoric cultural activities. The artifacts represent a typically sparse occupational zone.

Feature 3 was found in Test Unit 5 between 154 and $183 \mathrm{~cm}$ below the modern surface. An abrupt boundary between Zones 2 and 3 seems to outline a pit that was originally believed to be the result of historic disturbance (see Fig. 19). Zone 3 is an Ab horizon and clearly intact. When the fine-screen materials from the northeast quadrant of this test unit were processed, a large amount of microdebitage $(\mathrm{N}=41)$ was discovered from Level 5 (ca. 154-164 cm below surface). Unfortunately, the stratigraphic boundary was not recognized during excavation, and the level with the microdebitage crosscuts Zones 2 and 3; hence, the microdebitage could have come from either of these two zones. A charcoal sample from the upper portion of Zone 2 (Level 3, ca. 130-141 cm below surface) yielded a radiocarbon age of $120 \pm$ 80 B.P. (Beta-32977). Unfortunately this assay does not provide conclusive evidence as to the age of the lower portion of Zone 2 (see discussion in Sediments and Radiocarbon Chronology). The pitlike outline of Feature 3 may indeed be due to historic land modification, in which case, the prehistoric artifacts probably, originated from the undisturbed sediments in Zone 3. This feature seems to be typical of the types of disturbances resulting from historic land modifications, and the depth of the feature is within the expected range of modern disturbances.

\section{Materials Recovered}

A total of 116 artifacts was recovered from $41 \mathrm{HG} 128$, consisting of 2 projectile points, 3 biface fragments, 15 pieces of $1 / 4$-inch-screen debitage, 95 pieces of fine-screen debitage, and 1 core. Other materials observed include burned clay lumps, charcoal, snail shells, freshwater mussel shells, bones, calcium carbonate concentrations, gypsum, siliceous pebbles, and modern debris (see Appendix A).

\section{Discussion}

Site 41 HG128 yielded the highest frequency of artifacts in the Phase II investigations. The vertical distribution of artifacts demonstrates that there are intact prehistoric cultural materials present in the late Holocene soil, and the artifacts and associated materials from Features 2 and 3 indicate at least one period of occupation. The radiocarbon age (Beta-32978) of the Feature 2 materials places it near or in the Historic Contact period. The high frequency of debitage from the fine screen suggests that tool maintenance was an important activity at this site. No diagnostic artifacts were recovered in excavations, and the 
overall sparseness of artifacts suggests nonintensive use of the site.

\section{WY112}

\section{Site Setting}

Site 41WY112 is located on the north side of the South Main Channel, east of Lyford, Texas, approximately $2.8 \mathrm{~km}$ southwest of the intersection of FM 498 and FM 2099. It is on a bend of the drainage ditch (Fig. 21) at an elevation of $30-35 \mathrm{ft}$ $\mathrm{msl}$ and is surrounded by cultivated fields. An artesian well located across the ditch is no longer a water source since the water table has dropped in recent years. A small natural depression adjacent to the site was known to contain runoff and/or spring water in recent times (Jim Riggan and Douglas Oates, personal communication 1989). The depression has suffered numerous and substantial alterations during this century when high spots were leveled and low spots filled in to facilitate irrigation of the cultivated fields (Douglas Oates, personal communication 1989). Recently, during ditch construction, access roads were built to county road elevations, and one piece of heavy machinery was buried in thick muds near 41WY112 after extremely heavy rains (Jim Riggan, personal communication 1989).

\section{Previous Investigations}

This site was identified during the 1986 survey (Hall et al. 1987:108-109) and subsequently revisited in 1988. Cultural materials were exposed in the north bank of the drainage ditch and consisted of a number of burned clay lumps, several pieces of animal bone, two bifaces, six pieces of debitage, two pieces of mussel shell, and one possibly shaped conch shell fragment. As with most sites along the ditch, only an east-west extent could be estimated because of the presence of large spoil piles resulting from excavation of the ditch. The site extends ca. $250 \mathrm{~m}$ along the north side of the ditch at ca. $40-50 \mathrm{~cm}$ below modern ground surface. Hall et al. (1987:109) suggested that the site was possibly eligible for listing on the National Register of Historic Places based on "a great quantity and variety of cultural debris [which] is present at this site and it is relatively deep."

\section{Work Accomplished}

The Phase II investigations at $41 \mathrm{WY} 112$ consisted of a magnetometer survey, excavation of three backhoe trenches, and hand excavation of eleven 1x1-m test units (Fig. 22). The magnetometer survey covered a ca. $250 \times 9-\mathrm{m}$ area between the drainage bank and the spoil pile (see Appendix B). This survey identified several weak anomalies, but the correspondance of these anomalies with historic metal artifacts, construction disturbance, and biogenic features (e.g., red ant beds) demonstrates the inability of magnetometer surveys to provide useful data in highly disturbed contexts such as exist around the drainage ditch.

A surface survey of the drainage banks was undertaken to locate and record cultural materials exposed since the 1986 survey. Based on the locations of surface artifacts and the need to sample the entire site area, nine test units were placed along the ditch bank. Two additional units (Test Units 4 and 11) were placed on the north side of the access road to determine if undisturbed sediments with in situ cultural materials occurred in these areas. Table 9 summarizes the excavations. Test Units 1, 2, 4, and 6-11 were excavated into or just above the Beaumont Formation and ranged in depth from 34 to $165 \mathrm{~cm}$. The three backhoe trenches, ranging in depth from 205 to $275 \mathrm{~cm}$, were excavated for geomorphological investigations. At each backhoe trench, profiles were described and sampled. The Phase II investigations at 41WY112 were completed in 91 persondays.

\section{Site Extent and Depth}

Based on artifact distributions adjacent to the ditch, the site covers an area ca. $10 \mathrm{~m}$ wide parallel to the drainage ditch and extending ca. $160 \mathrm{~m}$ east-west. The vertical extent of cultural materials ranges from 10 to $72 \mathrm{~cm}$ based on the thickness of the undisturbed sediments. Eight of the 11 test units yielded a total of 32 prehistoric artifacts (see Table 9). Test Units 1 and 11, located in the western portion of the site, demonstrate low but consistent densities of artifacts distributed vertically in four consecutive levels (Table 10) and represent the highest artifact densities at this site. Test Units 1 and 11 also 


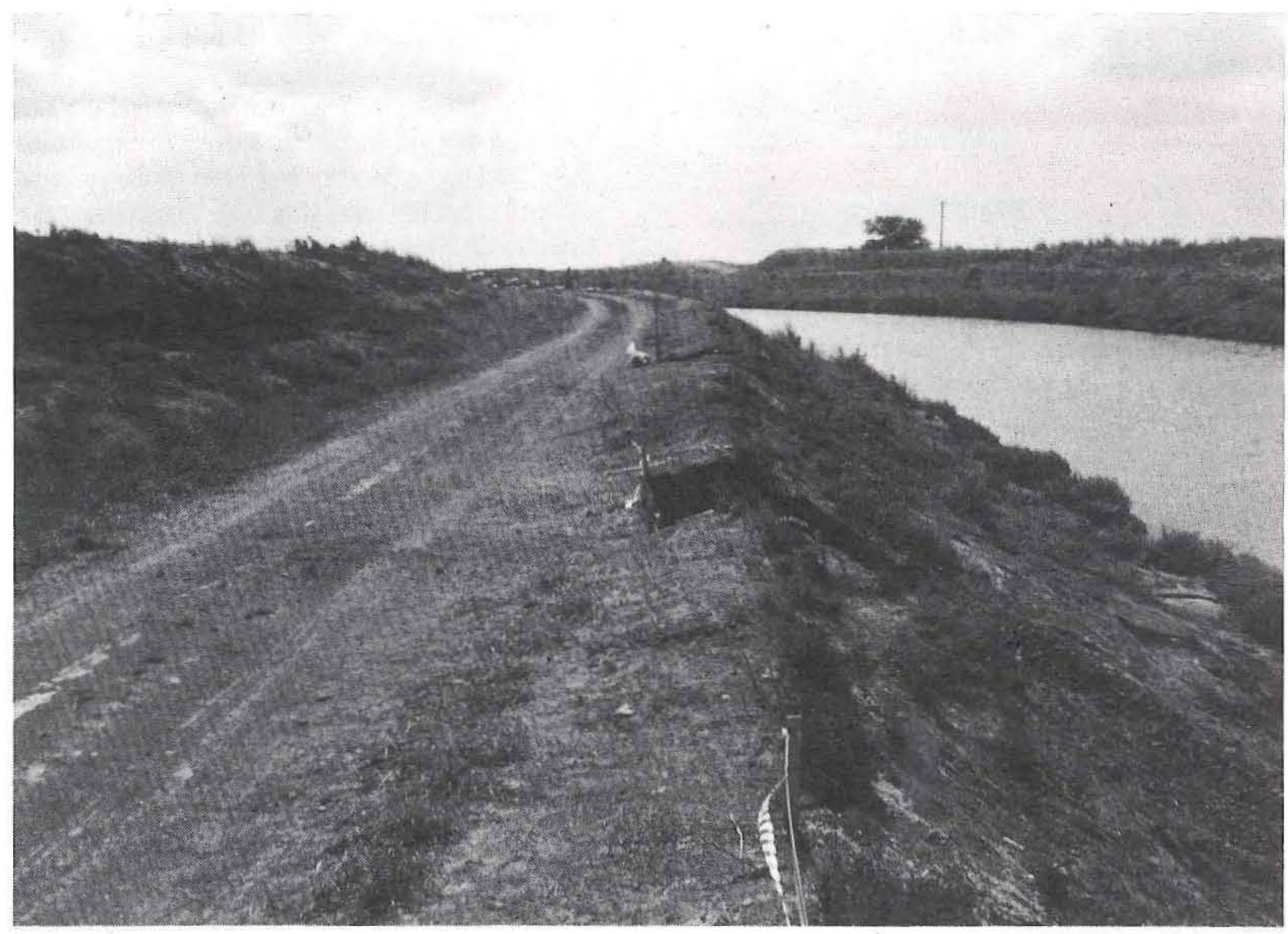

Figure 21. View of 41 WY112 from the west at Backhoe Trench 3; Test Units 5 and 6 in foreground.

appear to be located on the western edge of the depression.

The majority of the excavated artifacts ( 21 of 25) were recovered from undisturbed or possibly undisturbed deposits resulting in a density of 6 artifacts $/ \mathrm{m}^{3}$. The maximum depth to which artifacts were found is $146 \mathrm{~cm}$ with an overburden of $87 \mathrm{~cm}$. Although low, the artifact density at 41WY112 ranks second highest among the sites tested during this fieldwork.

\section{Sediments and Radiocarbon Chronology}

Site $41 \mathrm{WY} 112$ is on the Beaumont Formation (Bureau of Economic Geology 1976). According to Holz and Prewitt's (1981) plottings of abandoned stream channels on the exposed surface of the Beaumont Formation and modern wind deflated basins as shown on aerial photographs on USGS $7.5^{\prime}$ topographic maps, this site is on the southern and southwestern slopes of a small oblong defla- tionary basin positioned within an ancient abandoned channel still visible on the present surface of the Beaumont Formation (see Fig. 8). Before construction of the ditch drastically altered modern water drainage patterns, this depression probably held surface water on a seasonal basis and was a small playa. The soils within this wind-eroded depression are classified as Tiocano clays (Fig. 23). Racombes sandy clay loams occur around the depression and formed on uneroded Beaumont Formation sediments. On the north and northwest sides of the depression are Willimar fine sandy loams. These sandy loams are derived from the depression.

The geological sequence at this site is based on observations and radiocarbon dates from the 3 backhoe trenches and 11 test units. Profile descriptions for all backhoe trenches and selected test units are provided in Appendix C, and four profiles are discussed here to provide the sedimentary sequence for $41 \mathrm{WY} 112$. 


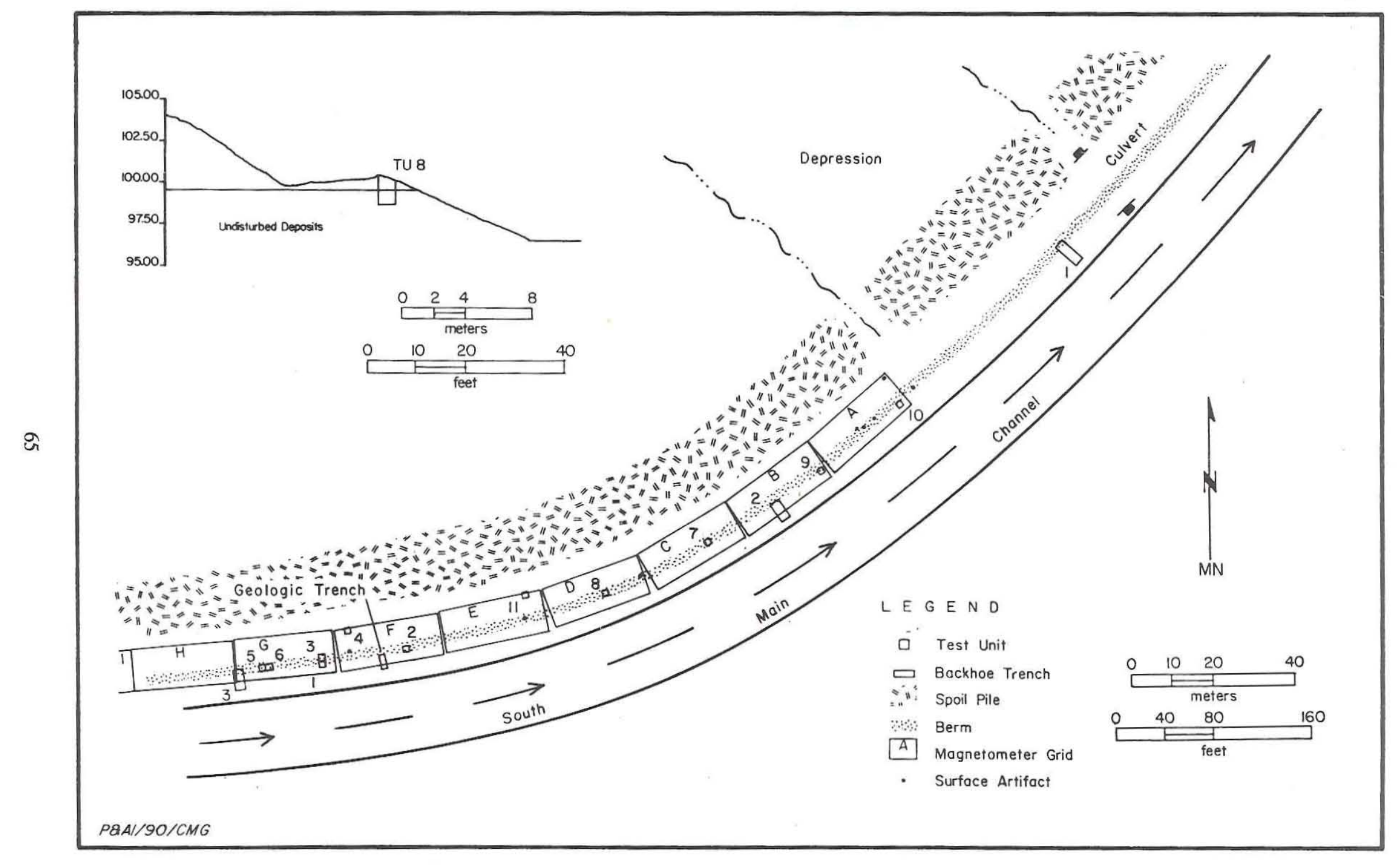

Figure 22. Site map, 41WY112. 


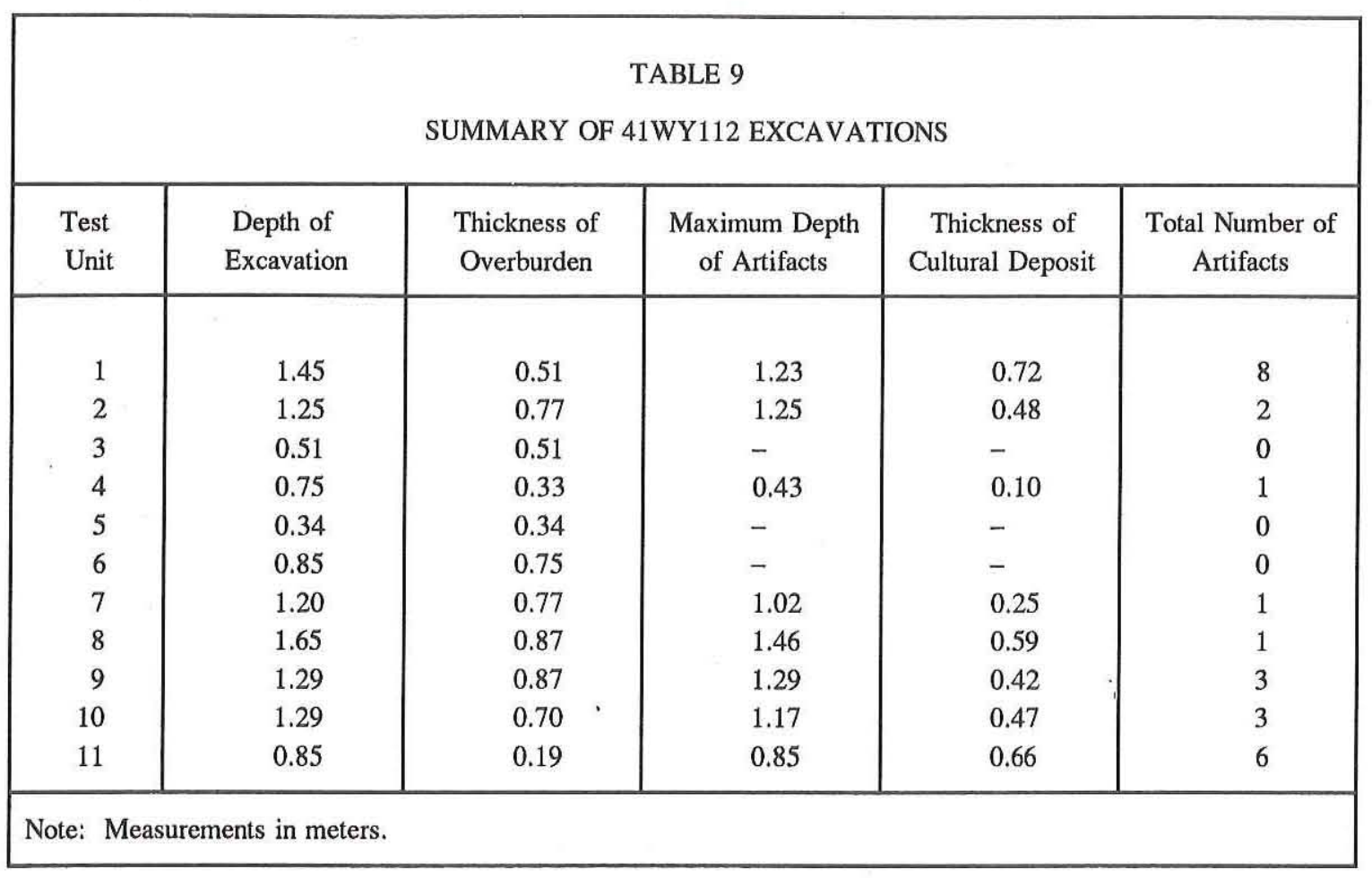

\begin{tabular}{|c|c|c|c|c|c|c|c|c|c|c|c|c|c|}
\hline \multicolumn{14}{|c|}{ TABLE 10} \\
\hline \multicolumn{14}{|c|}{ DISTRIBUTION OF ARTIFACTS AT 41 WY 112} \\
\hline \multirow[b]{2}{*}{ Level } & \multirow[b]{2}{*}{ Surface } & \multicolumn{11}{|c|}{ Test Unit } & \multirow[b]{2}{*}{ Totals } \\
\hline & & 1 & 2 & 3 & 4 & 5 & 6 & 7 & 8 & 9 & 10 & 11 & \\
\hline & $7^{*}$ & - & - & - & - & - & - & - & - & - & - & - & 7 \\
\hline 1 & & $0^{*}$ & $0^{*}$ & $0^{*}$ & $0^{*}$ & $0^{*}$ & $0^{*}$ & $0^{*}$ & $0 *$ & $0^{*}$ & $0^{*}$ & $0^{*}$ & 0 \\
\hline 2 & & $0^{*}$ & $0^{*}$ & $0^{*}$ & $0^{*}$ & $0^{*}$ & $0^{*}$ & $0^{*}$ & 0 * & $1^{*}$ & $0^{*}$ & $0 * *$ & 1 \\
\hline 3 & & $0^{*}$ & $0^{*}$ & $0^{*}$ & $0^{*}$ & - & $0^{*}$ & $0^{*}$ & $0^{*}$ & $1 *$ & $0^{* * *}$ & $0^{* *}$ & 1 \\
\hline 4 & & $2^{*}$ & $0^{*}$ & $0^{*}$ & $1^{*}$ & - & $0^{*}$ & $0 *$ & $0^{*}$ & $0 * *$ & $0^{* *}$ & $0 * *$ & 3 \\
\hline 5 & & $0^{* *}$ & $1^{* *}$ & - & 0 & - & $0 * *$ & $0^{* * *}$ & 0 & 0 & 1 & $1^{* *}$ & 3 \\
\hline 6 & & $2^{* *}$ & $0 * *$ & - & 0 & - & $0 * *$ & $0^{* *}$ & 0 & 0 & 1 & 1 & 4 \\
\hline 7 & & $0^{* *}$ & $0 * *$ & - & 0 & - & $0^{* *}$ & 0 & 0 & 1 & 1 & 3 & 5 \\
\hline 8 & & 1 & 0 & - & - & - & $0 * *$ & 1 & 0 & - & 0 & 1 & 3 \\
\hline 9 & & 0 & 1 & - & - & - & 0 & 0 & 1 & - & - & - & 2 \\
\hline 10 & & 1 & - & - & - & - & - & 0 & 0 & - & - & - & 1 \\
\hline 11 & & 2 & - & - & - & - & - & - & 0 & - & - & - & 2 \\
\hline 12 & & 0 & - & - & - & - & - & - & 0 & - & - & - & 0 \\
\hline 13 & & $\underline{0}$ & $=$ & $=$ & $=$ & $=$ & $=$ & $=$ & $=$ & $=$ & $=$ & $=$ & $\underline{0}$ \\
\hline Totals: & 7 & 8 & 2 & 0 & 1 & 0 & 0 & 1 & 1 & 3 & 3 & 6 & 32 \\
\hline \multicolumn{14}{|c|}{$\begin{array}{l}\text { *Disturbed context. } \\
\text { **Possibly disturbed context. }\end{array}$} \\
\hline
\end{tabular}




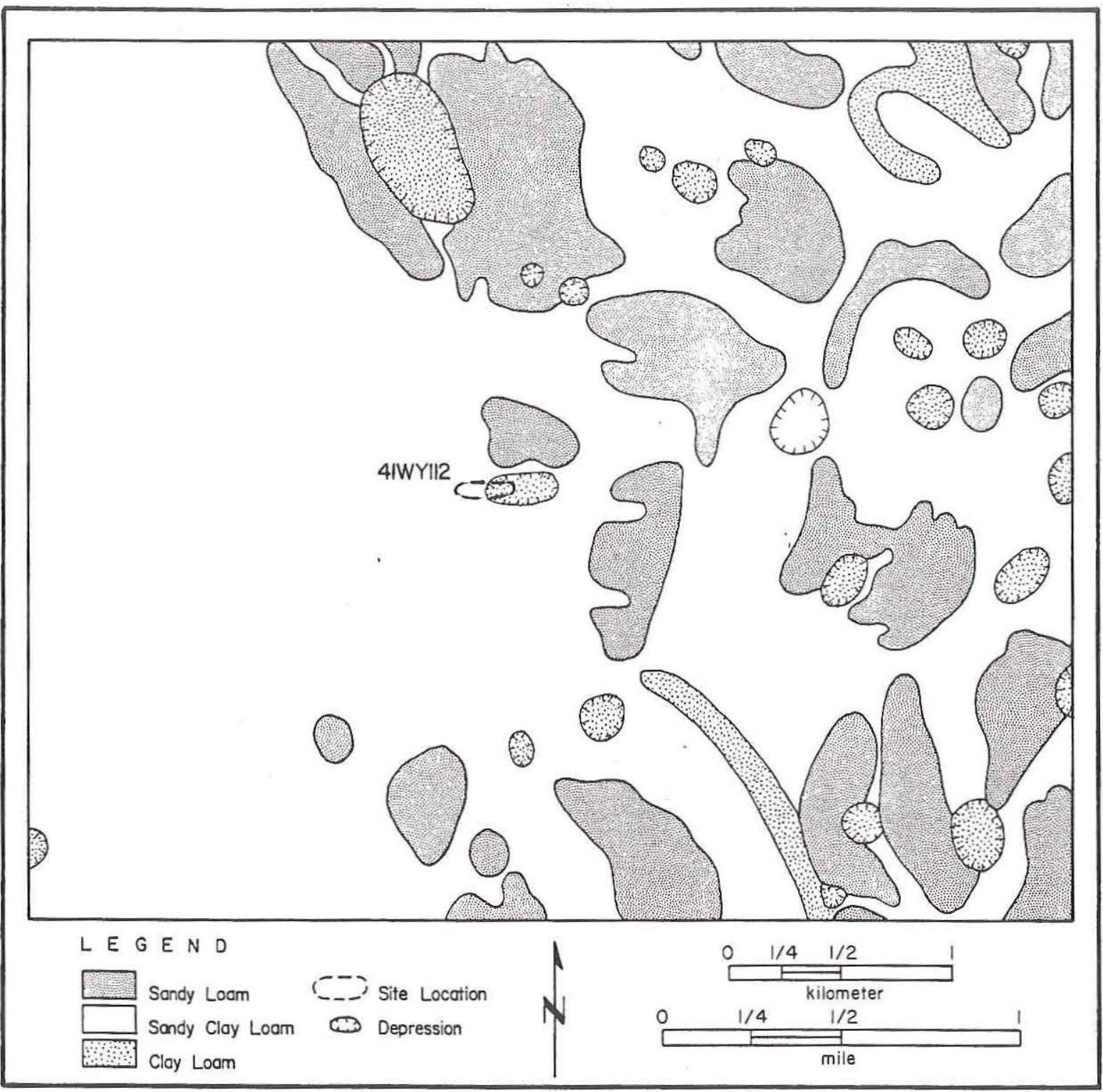

Figure 23. Distribution of soils and blowout depressions at 41WY112. Adapted from Turner 1982.

Backhoe Trench 1 was placed at the eastern edge of the site near the lowest portion (middle) of the deflationary basin. Thirteen sedimentary zones were observed (Fig. 24). Zone 1 consists of gray to pale brown silt loam to clay loam. This is construction fill shaped to form a small berm on the side of the ditch and edge of the access road. Zone 1 is $50 \mathrm{~cm}$ thick. Zone 2 is dark gray to very dark gray clay loam with fine moderate platy structure. This structure is caused by compaction of sediments which occurred during construction of the ditch. Zone 2 grades into Zone 3 at $55 \mathrm{~cm}$. The third zone consists of dark gray silt loam with medium to coarse blocky structure. Both zones have many snail shells. Zone 3 sits unconformably on Zone 4, a very dark gray silt loam with coarse weak blocky structure at $65-83 \mathrm{~cm}$. A heavily rusted piece of metal was observed at $82 \mathrm{~cm}$. The boundary between Zone 4 and Zone 5 is abrupt and wavy suggesting that an unconformity is represented between the two zones. Zone $5(83-106 \mathrm{~cm})$ is dark gray firm silt loam with blocks of very dark 

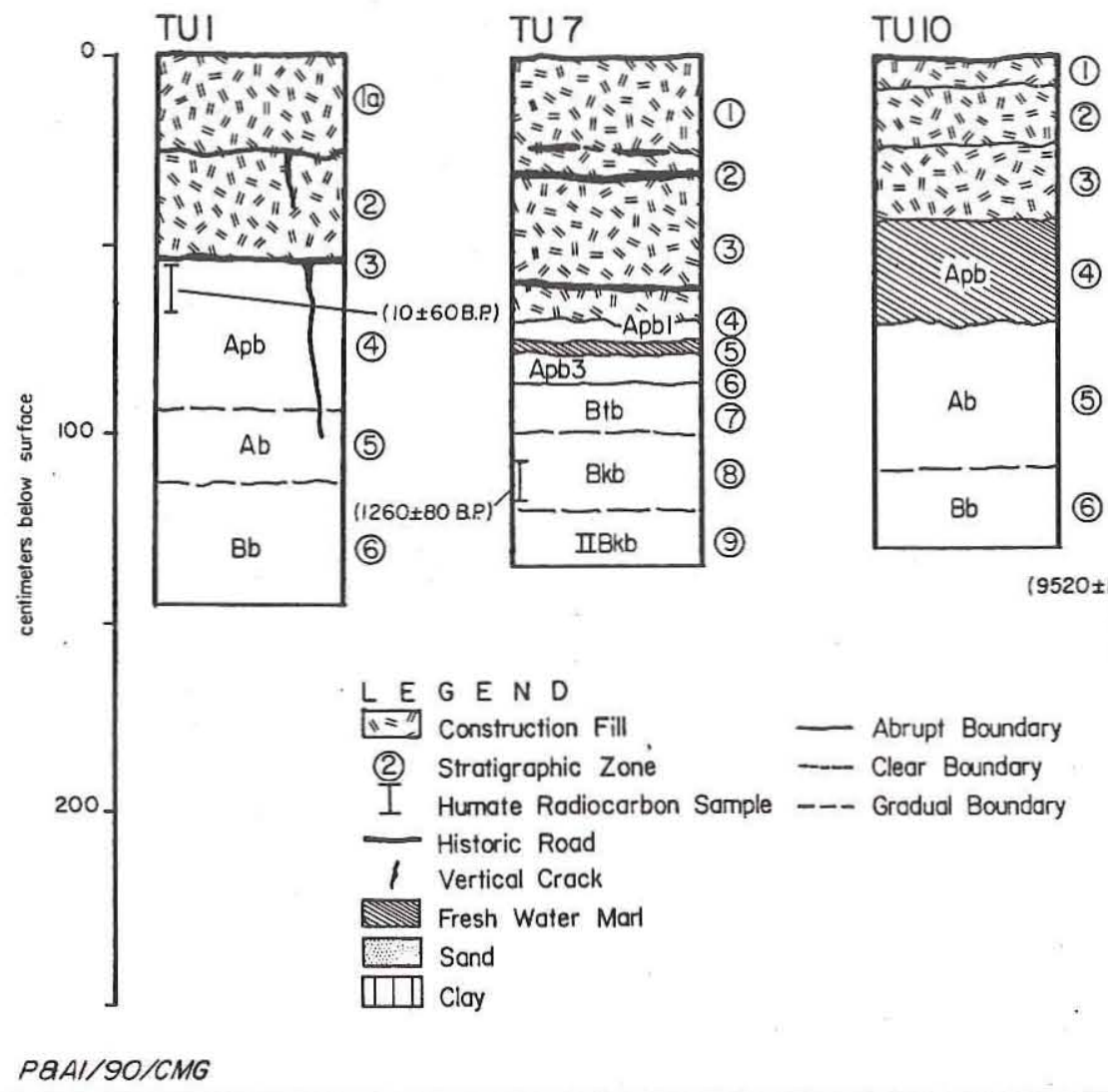

$\mathrm{BHT}$

- Abrupt Boundary

- Clear Boundary

--- Grodual Boundary

$520 \pm 120$ B.P )

(O B.P

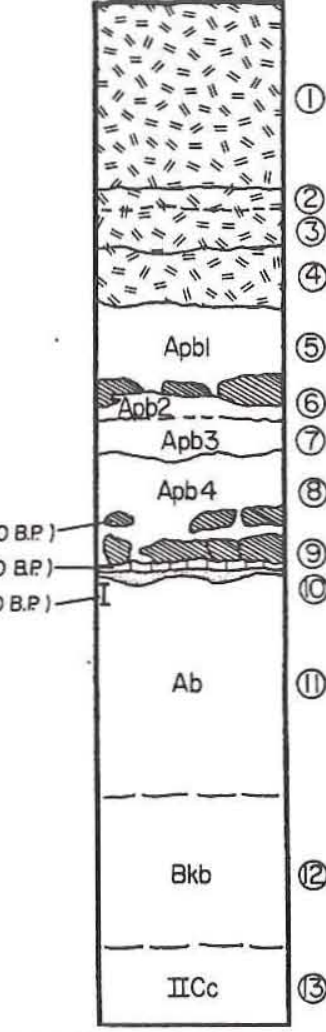

Figure 24. Selected geological profiles of backhoe trenches and test units at 41WY112.

gray silt loam (Zone 6 clasts) and freshwater marl deposits, i.e., light brownish gray calcium carbonate which strongly effervesces in a weak acid solution. Snail shells are common in the upper portion of the zone. The marls indicate water ponding and sit on an abrupt wavy boundary, between Zones 5 and 6 . Zone 6 consists of very dark gray extremely firm silt loam with coarse moderate blocky structure and many snail shell fragments between 106 and $110 \mathrm{~cm}$. The lower boundary is clear to abrupt and smooth. Zone $7(110-120 \mathrm{~cm})$ is dark gray to very dark gray friable loam with weak medium blocky structure and common calcium carbonate filaments. Its lower boundary is abrupt and wavy. Zone 8 $(120-148 \mathrm{~cm})$ is very dark gray to black extremely firm clayey sand with medium moderate blocky structure and very few snail shell fragments. Small calcium carbonate nodules occur in the upper portion of the zone, and brown to pink lenticular freshwater marls with an age of $9520 \pm 120$ B.P.
(Beta-32979) occur in the lower portion. Zone 9 $(148-149 \mathrm{~cm})$ is black extremely firm clay with fine moderate granular structure and a few fine calcium carbonate filaments; it is clearly water deposited. Bulk humates from this layer were dated to $104.3 \%$ of modern (Beta-31671). This value is typical of the years 1947 to 1952 when the C14 concentration in the atmosphere was being elevated by nuclear testing (M. Tamers, personal communication 1989). Zone 10 consists of gray fine laminated sands that form discontinuous lenses and have a very abrupt smooth to wavy lower boundary. Zone $11(151-210 \mathrm{~cm})$ is very dary gray friable loam with medium to coarse blocky structure and a gradual smooth lower boundary. This is a buried A soil horizon (Ab), and a bulk humate sample was dated by radiocarbon to $103.6 \%$ of modern (Beta-31672). The values from this radiocarbon sample are also characteristic of the years 1947-1952. Between $210-250 \mathrm{~cm}$, gray 
extremely firm sandy clay with a few calcium carbonate filaments and nodules comprises Zone 12 , a Bkb horizon. Below $250 \mathrm{~cm}$, pale brown silt loam with few manganese concretions and strong brown mottles forms a IICc horizon on the upper portion of the Beaumont Formation.

The sediments and radiocarbon dates indicate that the zones above Zone 11 are due to historic disturbance that disrupted the sediment equilibrium in this blowout. Some of the deposits between Zones 2 and 8 are certainly due to land-moving activities associated with vegetation clearing for agricultural use of this area. The great age (9520 B.P.) of the Zone 8 marl deposits is a reflection of the age of the ground water from which the carbonates formed and not the age of deposition. The radiocarbon date from the Zone 9 clays agrees with a twenticth-century date for the clearing of this land for agricultural purposes. Thus the sediments in Backhoe Trench 1 indicate that a soil formed on the Beaumont Formation and that this soil was covered by historic sediments. Some of this historic sedimentation was by natural agents, i.e., the Zone 9 clays, Zone 8 marls, and Zone 5 marls, while other deposits above Zone 11 may have been moved into the blowout by humans.

Test Unit 10 provides a geologic sequence toward the edge of the deflationary basin (see Fig. $25)$. As with Backhoe Trench 1, a series of upper deposits (Zones $1-3)$ at $0-43 \mathrm{~cm}$ was created by construction of the ditch itself. These three zones consist of strongly sloping grayish brown to dark gray loam. These sediments are slopewash and/or sediment mechanically packed on the sloping ditch wall. The lower boundary of Zone 3 marks the depth of ditch construction disturbance. Zone 4 $(43-70 \mathrm{~cm})$ consists of very dark gray firm to extremely firm loam with dispersed freshwater marl deposits on an abrupt irregular lower boundary. This is an Ap horizon and probably correlates to Zone 8 in Backhoe Trench 1 and reflects historic agricultural land-clearing activities and ponding in the early twentieth century. Zone 4 sits unconformably on Zone $5(70-108 \mathrm{~cm})$, which consists of very dark gray firm loam with a few calcium carbonate filaments. This buried A horizon (Ab) grades down to dark grayish brown firm to friable loam in Zone $6(108-128+\mathrm{cm})$, a Bb horizon.

Nine zones were identified in Test Unit 7, but the upper six appear to be the result of agricultural activities or ditch construction (see Fig. 24). Zones
1-3 $(0-70 \mathrm{~cm})$ consist of loose to firm silt loam to sandy loam. At least two layers of welllaminated sands and possibly a third thin sand lens within the upper three zones mark temporary road surfaces used during construction of the ditch. Very similar deposits were observed washing off the large spoil pile over the access road during the fieldwork at the site. The association of buried laminated sand layers with massive disturbance of deposits clearly reflects an abnormal increase in sediment supply. Zone $4(70-76 \mathrm{~cm})$ is very dark grayish brown loam with weak medium blocky structure that is separated from Zone 5 by a very abrupt wavy lower boundary. Zone $5(76-81 \mathrm{~cm})$, very dark gray extremely firm clay loam with dispersed brown marl deposits, also has a very abrupt wavy lower boundary. Zone 6 is very dark grayish brown firm loam with weak blocky structure and a clear to abrupt wavy lower boundary. Zones 4-6 appear to be due to twentieth-century agricultural land-clearing activities and roughly correlate with Zones 2-9 in Backhoe Trench 1. Zone 7 (89$100 \mathrm{~cm}$ ) is very dark gray firm to extremely firm clay loam with coarse strong blocky structure and a gradual smooth lower boundary. This is probably a truncated Btb horizon. Zone $8(100-120 \mathrm{~cm})$ is grayish brown firm loam with weak blocky structure, common calcium carbonate nodules, and a gradual smooth lower boundary. This is probably a Bkb horizon. A bulk humate sample from Zone 8 was dated to $1260 \pm 80$ B.P. (Beta-32197). Zone $9(120-135+\mathrm{cm})$ is dark gray friable loam with many calcium carbonate nodules. This IIBkb horizon is the pedogenically altered Beaumont Formation.

Test Unit 1 has six zones (see Fig. 24). Zone $1(0-26 \mathrm{~cm})$ consists of loose grayish brown silt loam with an abrupt smooth lower boundary. This is construction fill (Zone 1a) and slopewash (Zone $1 \mathrm{~b}$, not visible on profiled wall of Test Unit 1). Zone $2(26-54 \mathrm{~cm})$ is very dark gray firm loam with fine to medium weak blocky structure. It sits unconformably on Zone 3 and Zone 4 sediments; small cracks were observed in Zone 2 . Zone 3 , at $54 \mathrm{~cm}$, is a few millimeters thick and consists of light gray laminated sands. This is a construction road surface. Zone $4(54-89 \mathrm{~cm})$, very dark gray firm to extremely firm loam, is an Apb horizon that has been compacted by ditch construction activities. A bulk humate sample from the top of Zone 4 was dated to $10 \pm 60$ B.P. (Beta-32196). Zone 5 
(89-124 cm), dark grayish brown firm loam with medium moderate blocky structure, is a buried A horizon that is probably cumulative. Numerous cracks emanate from the upper surface of Zone 4 and extend down into Zone 5. Zone 6 (124$145+\mathrm{cm})$ is grayish brown firm clay loam with medium moderate blocky structure. This is a $\mathrm{Bb}$ horizon.

The general sedimentary sequence at 41 WY112 begins with the upper portion of the Beaumont Formation which has been altered by pedogenesis. A date on bulk humates from the lower portion of the soil formed on top of the Beaumont in Test Unit 7 (Beta-32197) suggests that this soil began to form by 1260 B.P. Other dates on bulk humates from the top of this soil in Backhoe Trench 1 (Beta-31672) and Test Unit 1 (Beta-32196) suggest that it continued to form and accumulate through modern times. All of the sediments above this soil either date to the twentieth century or were extensively modified by historic clearing, agricultural activities, or ditch construction. In the central portion of the basin, thick sedimentation has occurred, some of which reflects extensive ponding in the basin. All dates and temporally diagnostic data support a historic age for these pond deposits.

\section{Feature}

The single cultural feature identified at 41WY112 represents a modern road surface related to the drainage ditch construction and maintenance operations (Fig. 25). Two pieces of debitage were found lying $1 \mathrm{~cm}$ above this surface, and it was initially thought to be a possible prehistoric feature. Further investigation, however, identified this surface as a product of drainage ditch activities. It consists of a series of ca. 1-mm-thick fine sand and silt lenses, ca. 1-cm in total thickness. The surface is compacted and cracked, and it roughly follows the modern topography. These laminated sand lenses were eroded by slopewash from sediments disturbed during ditch construction. As described in Chapter 1, one common access road maintenance operation consists of a road grader cleaning out a small run-off ditch between the road and the spoil pile. This dirt is moved to the edge of the bank and is used to maintain the berm. This maintenance operation not only adds an additional sequence of deposits to the berm but also truncates and consolidates previously undisturbed deposits along the access road. Feature 1 is identified as the lowermost in the sequence of surfaces and is present in Test Units 1, 3, and 5-9. There are at least two additional surfaces related to ditch maintenance operations above Feature 1 with disturbed, compacted deposits appearing between the surfaces. These activities have resulted in a substantial amount of artificial deposition along the ditch.

\section{Materials Recovered}

A total of 32 artifacts consisting of 1 trianglular projectile point, 1 biface, 1 edge-modified flake, and 29 pieces of debitage was recovered during the Phase II investigations. The test unit excavations produced 15 flakes in the 1/4-inchmesh screens and 10 flakes in the 1/16-inch-mesh screens. An additional seven artifacts were collected from the surface. Other materials collected include burned clay lumps, charcoal, mussel shells, bones, snail shells, manganese concretions, calcium carbonate concretions, siliceous pebbles, and modern materials (see Appendix A).

\section{Discussion}

The cultural materials recovered from 41 WY112 are insufficient to allow meaningful interpretation of the components represented. The vertical distribution of artifacts demonstrates that there are intact cultural materials present within the thin, undisturbed Holocene deposits, but the sparse nature of the artifacts does not permit further temporal assessment. In addition, no diagnostic cultural materials were recovered; however, the age of the cumulative soil places the earliest possible occupations at this site in the Late Prehistoric period. The sparseness of the cultural materials suggests nonintensive use of the site.

\section{WY113}

\section{Site Setting}

Site 41WY113 is located east of Lyford, Texas, along the South Main Channel approximately $0.6 \mathrm{~km}$ east of the intersection of FM 2099 and the drainage ditch. It is at an elevation of 


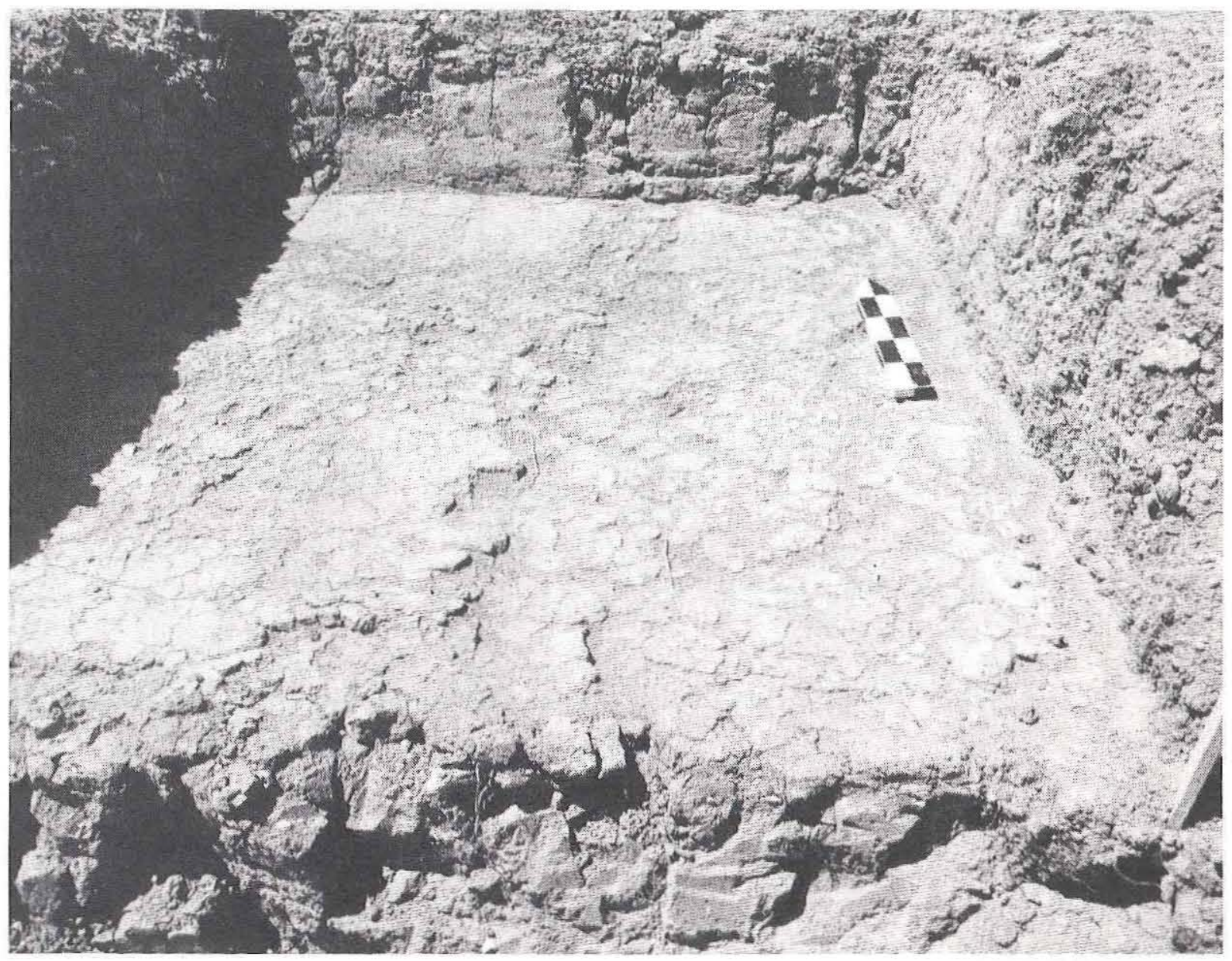

Figure 25. Photograph of Feature 1 road surface in Test Unit 5, 41WY112.

25-30 ft msl and is exposed on the north bank of the drainage ditch (Fig. 26). Adjacent to the site is a small, shallow depression in a cultivated field. The surrounding area is presently under cultivation, and land leveling and plowing undoubtedly disturbed the surface prior to ditch construction.

\section{Previous Investigations}

When this site was discovered during the 1986 survey (Hall et al. 1987:109), a partial skeleton of a young adolescent human, numerous mammal bones, several burned clay lumps, four mussel shell fragments, and one piece of glass were noted. All of the materials were exposed along the north bank of the drainage ditch. The site was estimated to extend $160 \mathrm{~m}$ east-west along the ditch bank, and the depth was recorded as ca. $40 \mathrm{~cm}$. Site
41 WY113 was assessed as possibly eligible for listing on the National Register of Historic Places based on the presence of the partially intact human burial and well-preserved animal bones.

\section{Work Accomplished}

The testing efforts at $41 \mathrm{WY} 113$ consisted of a magnetometer survey and the excavation of two backhoe trenches and four 1x1-m test units (Fig. 27). The magnetometer survey covered a 100x9-m area along the ditch access road between the bank and the spoil pile; three weak anomalies were identified. The clearest anomaly was investigated and was found to be a compacted surface resulting from the use of heavy equipment to maintain the access roads (see Appendix B). A surface survey was undertaken to locate cultural 


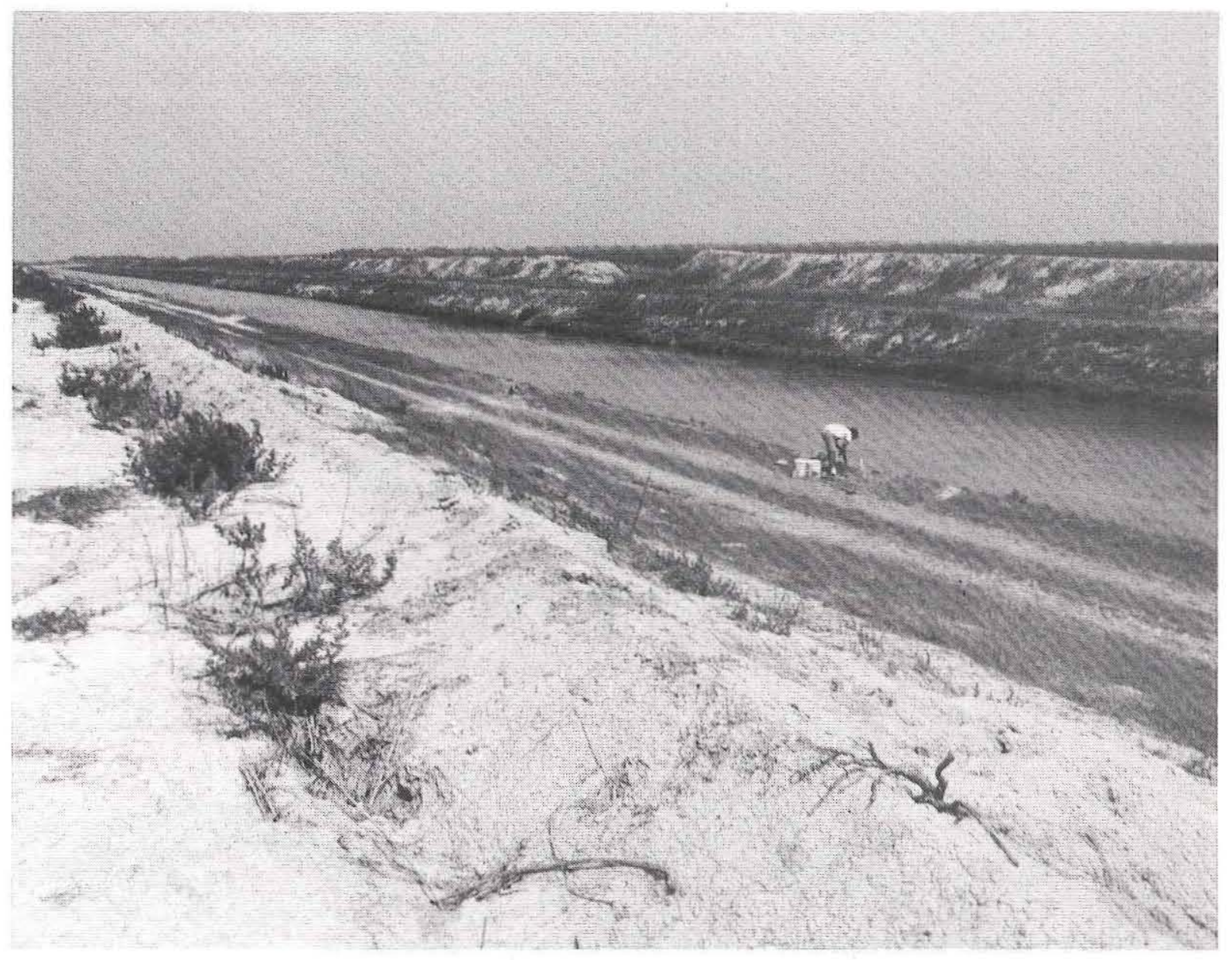

Figure 26. View of 41WY113 during excavation, taken from large spoil pile looking southeast. Crewpeople at Test Units 2 and 3.

materials, and an unsuccessful attempt was made to relocate the original position of the human burial removed in 1986 (Hall et al. 1987:193-196). Four test units ranging in depth from 55 to $104 \mathrm{~cm}$ were excavated to investigate the magnetometer anomaly and to expose two bone features (Table 11). Test Units 1-3 were excavated into the Beaumont Formation, and the fourth unit reached the top of the Beaumont Formation. Two backhoe trenches ranging in depth from 250 to $300 \mathrm{~cm}$ were excavated on either end of the site to investigate the geomorphology. Sediment and humate samples were collected for later processing. The fieldwork on $41 \mathrm{WY} 113$ was completed in 18 person-days.

\section{Site Extent and Depth}

Prehistoric artifacts were recovered from two of the four test units (see Table 11). Based on the surface artifacts and excavated materials, the known site area is a $10 \times 80-\mathrm{m}$ strip along the drainage ditch. The cultural materials are contained in a 50-cm-thick (maximum) zone of undisturbed deposits where one feature and four flakes were found. Two short-term occupations may be present at this site. As Table 12 demonstrates, a possible upper cultural zone may exist in Level 2 of Test Unit 2 where three flakes were recovered from undisturbed sediments. A possible 


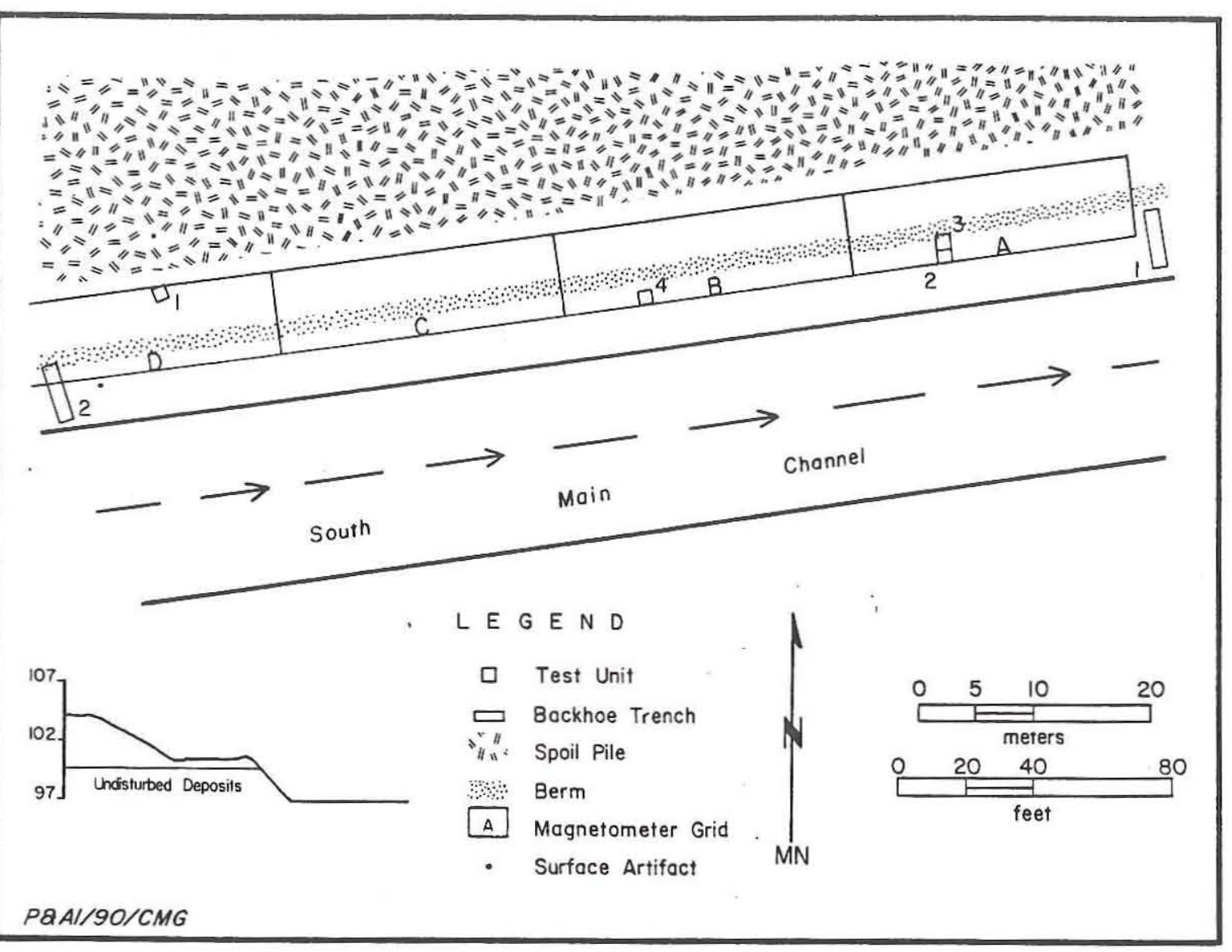

Figure 27. Site map, 41WY113.

TABLE 11

SUMMARY OF 41WY113 EXCAVATIONS

\begin{tabular}{|c|c|c|c|c|c|}
\hline $\begin{array}{c}\text { Test } \\
\text { Unit }\end{array}$ & $\begin{array}{c}\text { Depth of } \\
\text { Excavation }\end{array}$ & $\begin{array}{c}\text { Thickness of } \\
\text { Overburden }\end{array}$ & $\begin{array}{c}\text { Maximum Depth } \\
\text { of Artifacts }\end{array}$ & $\begin{array}{c}\text { Thickness of } \\
\text { Cultural Deposit }\end{array}$ & $\begin{array}{c}\text { Total Number of } \\
\text { Artifacts }\end{array}$ \\
\hline & & & & & \\
1 & 1.04 & 0.34 & 0.24 & 0.00 & 1 \\
2 & 0.96 & 0.16 & 0.66 & - & 5 \\
3 & 0.63 & 0.53 & - & - & 0 \\
4 & 0.55 & 0.35 & - & & 0 \\
\hline
\end{tabular}

Note: Measurements in meters. 


\begin{tabular}{|c|c|c|c|c|c|c|}
\hline \multicolumn{7}{|c|}{$\begin{array}{c}\text { TABLE } 12 \\
\text { DISTRIBUTION OF ARTIFACTS AT } 41 \text { WY113 }\end{array}$} \\
\hline \multirow[b]{2}{*}{ Level } & \multirow[b]{2}{*}{ Surface } & \multicolumn{4}{|c|}{ Test Unit } & \multirow[b]{2}{*}{ Totals } \\
\hline & & 1 & 2 & 3 & 4 & \\
\hline $\begin{array}{c}1 \\
2 \\
3 \\
4 \\
5 \\
6 \\
7 \\
8 \\
9 \\
10 \\
11\end{array}$ & $2^{*}$ & $\begin{array}{l}- \\
0^{*} \\
0^{*} \\
1^{*} \\
0^{*} \\
0 \\
0 \\
0 \\
0 \\
0 \\
0 \\
0\end{array}$ & $\begin{array}{l}- \\
0^{*} \\
3 \\
0 \\
0 \\
0 \\
2 \\
0 \\
0 \\
0 \\
- \\
=\end{array}$ & $\begin{array}{l}- \\
0^{*} \\
0^{*} \\
0^{*} \\
0^{*} \\
0 \\
- \\
- \\
- \\
- \\
- \\
=\end{array}$ & $\begin{array}{l}- \\
0^{*} \\
0^{*} \\
0^{*} \\
0 \\
0 \\
- \\
- \\
- \\
- \\
- \\
=\end{array}$ & $\begin{array}{l}2 \\
0 \\
3 \\
1 \\
0 \\
0 \\
2 \\
0 \\
0 \\
0 \\
0 \\
\underline{0}\end{array}$ \\
\hline Totals: & 2 & 1 & 5 & 0 & 0 & 8 \\
\hline
\end{tabular}

second, lower cultural zone was identified in Levels 5 and 6 of Test Unit 2. This consists of Feature 1 (deer bones and a bone tool) and one flake. The human burial recovered in 1986 appears to have been excavated from roughly the same stratigraphic position as the deer bones, but radiocarbon dates imply that the human burial is younger. Thus, it may be associated with the overlying artifacts or represent a third intermediate episode of use at $41 \mathrm{WY} 113$.

Artifacts were recovered to $66 \mathrm{~cm}$ below the surface, but at least $16 \mathrm{~cm}$ of this thickness is disturbed historic fill. Five of the eight artifacts recovered are from in situ deposits, resulting in a density of 1.25 artifacts $/ \mathrm{m}^{3}$. Even though two features were recovered from this site, the artifact density is extremely low.

\section{Sediments and Radiocarbon Chronology}

Site 41WY113 occurs on the Beaumont Formation (Bureau of Economic Geology 1976). Holz and Prewitt's (1981) analysis of abandoned Beaumont Formation channels and modern wind deflated basins demonstrates that this site occurs on the southeast side of a small circular deflationary basin positioned within an ancient abandoned channel on the present surface of the Beaumont Formation (see Fig. 8). This basin is not as deep as the one at $41 \mathrm{WY} 112$, but it probably held surface water on a seasonal basis before the ditch was constructed.

As at 41 WY112, the soils in this area reflect ancient and recent geological history (Fig. 28). Surrounding the deflationary basin are the Racombes and Hidalgo sandy clay loams that formed on alluvial overbank deposits of the Beaumont Formation. The soils in the blowout at 41 WY113 consist of Tiocano clays. Sandy eolian sediments occur on the west, south, and east sides of the blowout, but these are not all derived from the blowout at $41 \mathrm{WY} 113$ as numerous others occur nearby. Willimar and Lozano fine sandy loams have formed on these eolian sandy sediments, and within this century, these eolian deposits have been spread and flattened by agricultural practices. In short, near $41 \mathrm{WY} 113$ as in most areas, the Beaumont Formation is speckled with small deflationary basins in ancient abandoned river channels. All of these wind-eroded basins are ringed by eolian deposits. The uneroded Beaumont Formation consists of sandy clay loams from which wind has removed the coarser sandy sediments and left clay loams in the blowouts.

The geological sequence here is based on observations and radiocarbon dates from the two backhoe trenches and four test units. Detailed profile descriptions for all backhoe trenches and selected test units are provided in Appendix C, and four selected profiles are discussed here.

The upper $34 \mathrm{~cm}$ (Zone 1) of Backhoe Trench 1 consists of pale brown sand which is berm construction fill (Fig. 29). At $34-35 \mathrm{~cm}$, Zone 2 is a lens of pale brown silt loam that pinches out in the profile away (i.e., to the north) from the ditch bank. This is also related to ditch construction. Zone $3(35-70 \mathrm{~cm})$ is dark grayish brown loam with medium to coarse moderate platy to blocky structure. The structure in this zone has been altered by compaction during ditch construction and/or by plowing. This is an Apb horizon. Zone $4(70-100 \mathrm{~cm})$ is dark grayish brown firm silt loam with medium moderate blocky structure and common calcium carbonate nodules. This is a Bk horizon. Calcium carbonate nodules increase in Zone $5(100-215 \mathrm{~cm})$, which consists of friable 


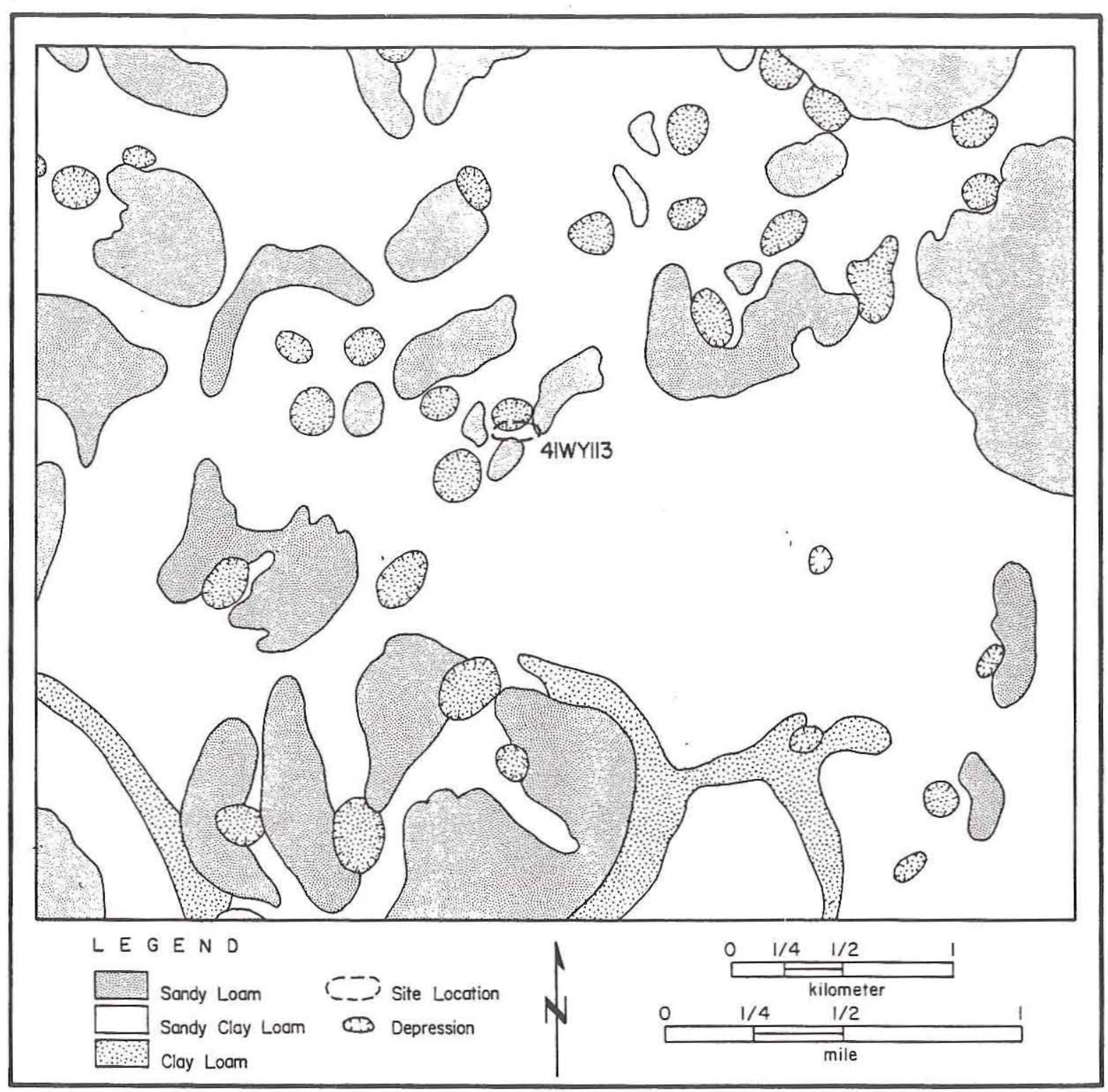

Figure 28. Distribution of soils and blowout depressions at 41WY113. Adapted from Turner 1982.

brown to strong brown silt loam with a diffuse lower boundary. Zone 5 is a IIBk horizon. Zone $6(215-300+\mathrm{cm})$ is brown friable silt loam to clay loam with weak granular structure and few calcium carbonate nodules and manganese concretions. This is a IICkc horizon.

Backhoe Trench 2 has five sediment zones (see Fig. 29). Zone $1(0-42 \mathrm{~cm})$ is pale brown sand with a very abrupt smooth lower boundary. This is construction fill. Zone $2(42-60 \mathrm{~cm})$ is extremely firm very dark gray silt loam with platy structure. The upper portion has been truncated, and the structure of the entire zone has been altered by compaction during ditch construction. Zone 2 is an Apb horizon. Zone $3(60-100 \mathrm{~cm})$, firm dark grayish brown silt loam with coarse moderate blocky structure, is an ABb horizon. Snail shells are common and calcium carbonate filaments are present. The lower boundary of Zone 3 is gradual and smooth. Zone $4(100-150 \mathrm{~cm})$, a IIBk horizon, is light brown friable silt loam with weak medium blocky structure and many calcium carbonate 


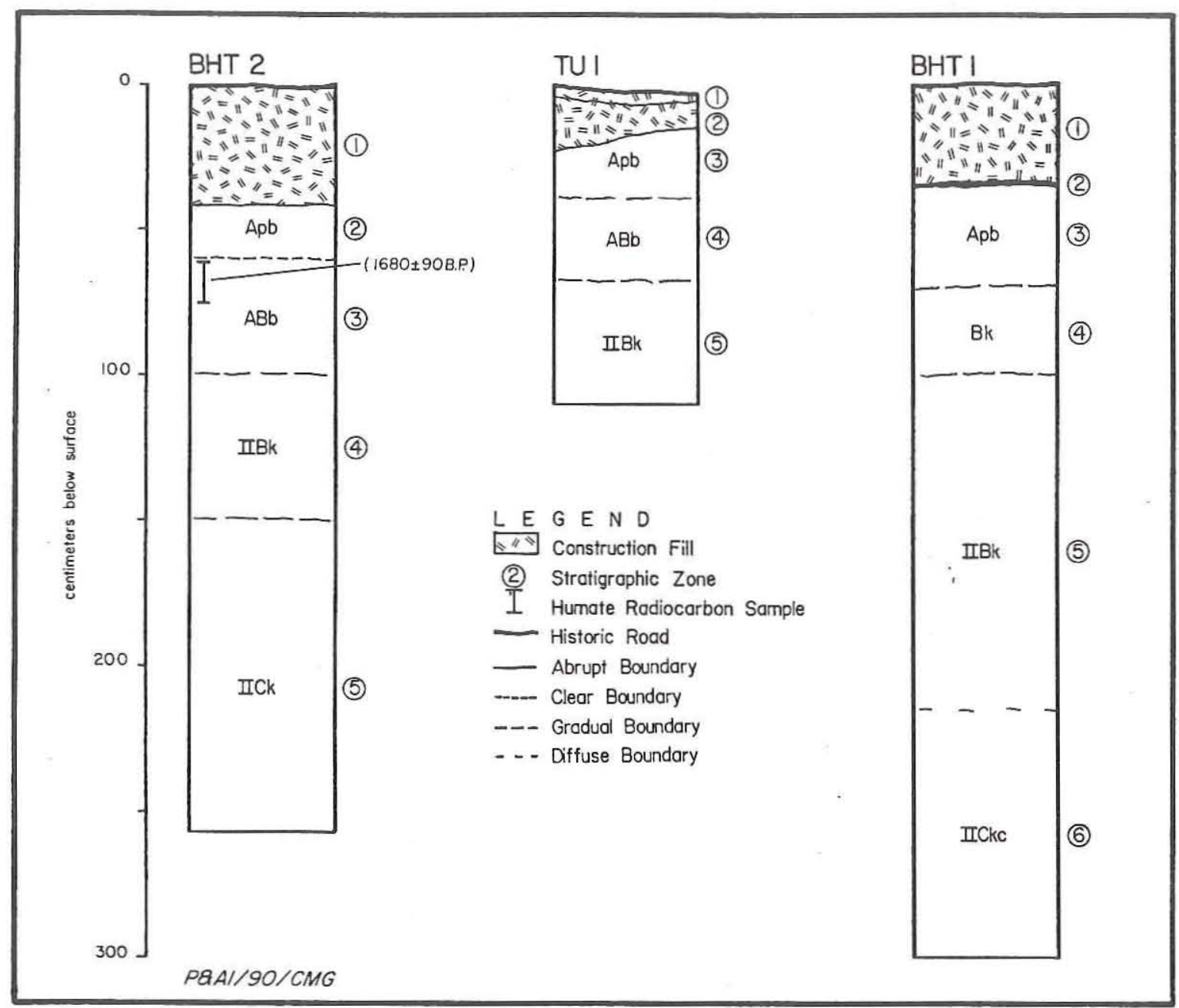

Figure 29. Selected geological profiles of backhoe trenches and test units at 41WY113.

nodules. Zone 4 grades into Zone 5 . Zone 5 extends below $250 \mathrm{~cm}$ and consists of brown silt loam with many fine distinct strong brown mottles, granular structure, and a few calcium carbonate nodules. This is a IICk horizon.

The upper $4 \mathrm{~cm}$ of Test Unit 1 consist of pale brown very thin horizontally laminated sands with an abrupt smooth lower boundary (see Fig. 29). This Zone 1 is very recent slopewash from the large spoil pile a few meters north of the test unit. Zone $2(4-21 \mathrm{~cm})$ is pale brown sandy loam with granular structure, common rootlets, and an abrupt wavy lower boundary. This zone also is slopewash, but it appears to have been compacted and to be old enough for grasses to have developed a thick root system. The lower boundary slopes away from the ditch and clearly marks a road surface used during construction of the ditch. This section of the ditch was dug before 1984 and the road surface probably dates to this event. Zone 3 $(21-38 \mathrm{~cm})$ is very dark gray extremely firm loam with medium strong blocky structure and a gradual smooth lower boundary. The upper surface of this $\mathrm{Apb}$ horizon has been truncated and compacted by construction activities. Zone $4(38-67 \mathrm{~cm})$ is very dark grayish brown firm loam with few calcium carbonate filaments and nodules that increase in frequency down-profile. This is an $\mathrm{ABb}$ horizon. Zone 4 grades into Zone 5 (67-110+), dark yellowish brown friable silt loam with common calcium carbonate nodules. Zone 5 is a IIBk horizon. 
Test Unit 2 has only threc stratigraphic zones (Fig. 30). Zone $1(0-23 \mathrm{~cm})$ is very dark grayish brown friable to loose loam with small, very dark gray and yellowish brown clay loam clasts. The lower boundary is abrupt and very wavy due to erosion. This zone is mostly thin $(0-3 \mathrm{~cm})$ as seen in the side wall profile (see Fig. 30 ) but extends down to $23 \mathrm{~cm}$ in an erosional rill in the back wall. This is construction fill. Zone $2(23-61 \mathrm{~cm})$, an $\mathrm{ABb}$ horizon, is dark brown extremely firm loam with medium moderate blocky structure and a few calcium carbonate nodules that increase in frequency down-profile. The lower boundary of Zone 2 is gradual and smooth. Zone $3(61-100+\mathrm{cm})$ is yellowish brown silty loam with common calcium carbonate nodules. This is a IIBk horizon.

A bulk humate sample and a deer radius from near the bottom of Zone 2 in Test Unit 2 were radiocarbon dated. The humate assay resulted in an age of $2740 \pm 100$ B.P. (Beta-32199). Two radiocarbon dates were obtained from the deer bones. The inorganic fraction was dated to $3040 \pm$ 235 B.P. (GX-15122-A). The gelatin fraction was dated by the AMS method, resulting in an age of $2560 \pm 100$ B.P. $(\mathrm{GX}-15122-\mathrm{G})$. The human burial excavated in 1986 from near the bottom of this zone yielded a radiocarbon age from the inorganic fraction of $1830 \pm 210$ B.P. (GX-15123A). The organic fraction of the burial was also dated by the AMS method yielding an age of $1088 \pm 90$ B.P. (GX-15123-G). Unfortunately, the exact location of this burial was not recorded, but photographs show the general stratigraphic position to be in the lower portion of Zone 2. The younger age of the burial suggests that it was placed in a pit dug down into this zone, but the pit was not discernible during excavation.

\section{Features}

Two cultural features were recorded during the Phase II investigations. Feature 1, a small amount of deer bone, is prehistoric, while Feature 2 is a modern bone dump; both were exposed along the drainage bank.

Feature 1 was observed eroding out of the base of the undisturbed sediments just above the contact with the Beaumont Formation at $50-60 \mathrm{~cm}$ below the modern surface (see Fig. 30). Test Units 2 and 3 were excavated to reveal a slightly disturbed feature measuring ca. $25 \times 15 \mathrm{~cm}$ and consisting of three long bones and several bone fragments which represent at least two mature deer. The long bones and fragments are identified as one complete left radius, two left radius proximal fragments, one right metacarpal, and numerous metacarpal fragments (see Appendix A). The bones appear to be lying on or near the contact with Zone 3. No pit outline or soil change was noted other than the contact with the Beaumont Formation. There is no direct evidence that this feature is cultural. The surrounding soil contains calcium carbonate filaments, and calcium carbonate has formed on portions of the bones obscuring cut marks if these are present. However, indirect evidence suggests that this feature is the result of prehistoric cultural activities. A modified bone found with the deer bone may represent a fragment of a compound fișhhook (see Appendix A). Additionally, one flake was recovered from the arbitrary level associated with Feature 1.

Although the location of the burial recovered from this site (Hall et al. 1987:193-197) remains uncertain, it does seem clear that Feature 1 was not associated with the burial. Figure 31 shows that the two features were found at similar depths, with the burial occurring at $29-38 \mathrm{~cm}$ below the original ground surface (Howard 1987:193) and Feature 1 at $50-60 \mathrm{~cm}$ below the modem surface or $34-$ $44 \mathrm{~cm}$ below the original ground surface. But the radiocarbon dating of bone samples from both indicates that the burial is significantly younger than the deer bones (Students $t$ test of samples GX-15122-G and GX-15123-A: $\mathrm{t}=3.14$, $\mathrm{p}<0.005)$. In addition, a humate sample taken from the same provenience as Feature 1 yielded a radiocarbon age of $2740 \pm 100$ years B.P., roughly coeval with the deer bones but clearly older than the burial. This suggests that the burial was placed in a pit, but the outline of the pit was obfuscated by later pedogenesis and possible bioturbation.

Feature 2 is a recent bone dump consisting of numerous animal bone fragments lying on the surface of the drainage bank. Test Unit 4 was excavated to investigate this feature and revealed fragmentary bones at ca. $20 \mathrm{~cm}$ downslope from the modern road. These bone fragments are a result of slopewash. Several recent bone dumps were noted along the drainage banks including a recent javalina carcass found during the magnetometer survey. According to local residents, dumping animal remains along the ditch banks is common. 


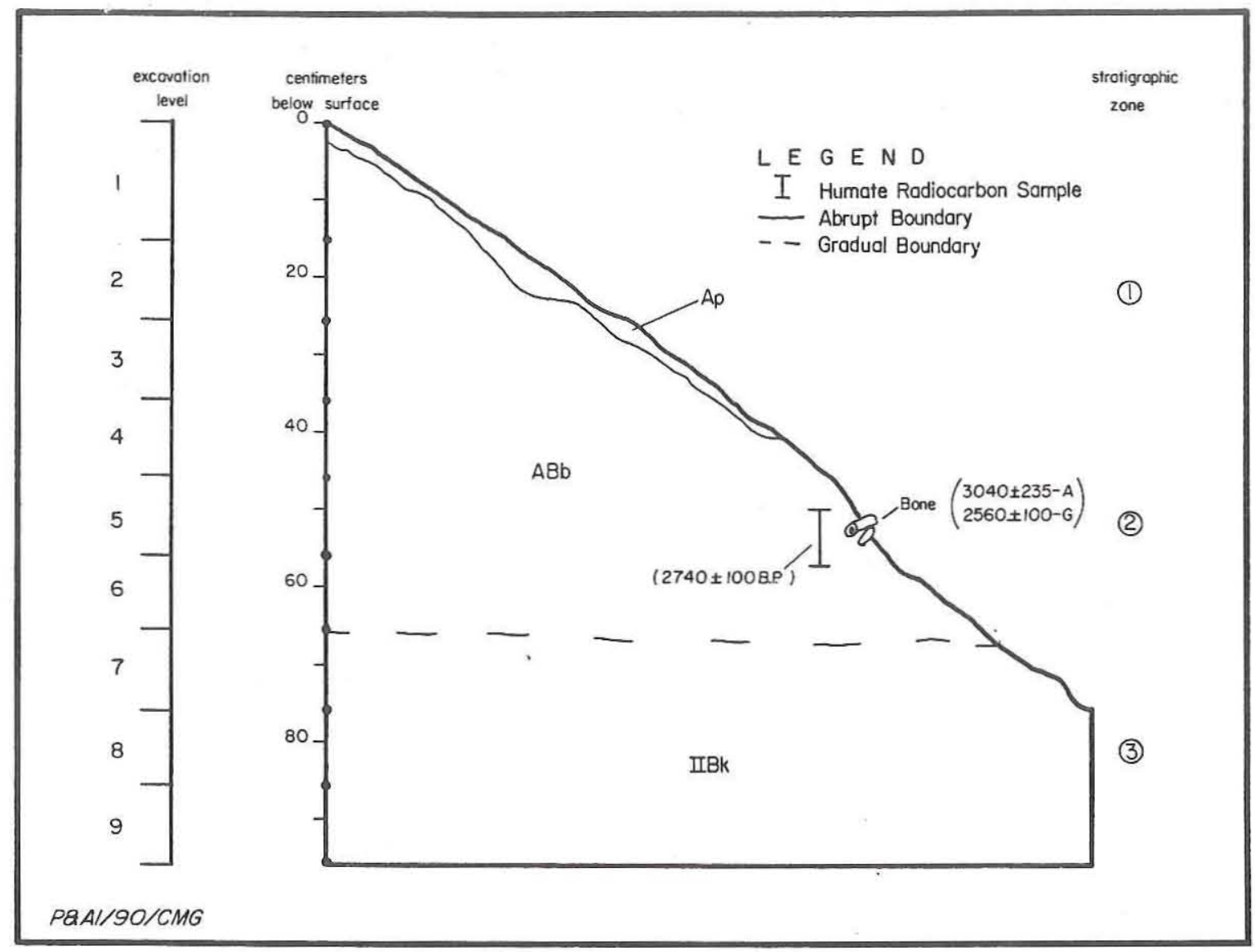

Figure 30. Geological profile of Feature 1, Test Unit 2, 41WY113.

\section{Materials Recovered}

Eight artifacts and one prehistoric bone feature were recovered from this site. One bone tool and five pieces of debitage were recovered from the excavations, and two bifaces were recovered in surface contexts from the spoil pile and bank slope. Other materials observed include burned clay lumps, charcoal, freshwater mussel shell fragments, snail shells and fragments, bones, gypsum, calcium carbonate and manganese concretions, siliceous pebbles, and modern debris (see Appendix A).

\section{Discussion}

Because of the sparse nature of the cultural materials and the lack of diagnostic artifacts at 41 WY113, it is difficult to identify cultural components. However, the radiocarbon dates from the burial and the deer bones, with their probable prehistoric cultural association and associated humate sample, suggest that there were at least two occupations of limited duration at this location. A possible third occupation may be reflected in the fine-screen debitage from Level 2 of Test Unit 2, although these artifacts could be associated with the burial or might be in a secondary context resulting from historic disturbances. The fact that so few cultural materials are present suggests very brief and limited use of this site.

\section{WY134}

\section{Site Setting}

Site 41WY134 is located east of Lyford, Texas, along the South Main Channel approximately $2.7 \mathrm{~km}$ southwest of the intersection of FM 1420 and FM 498. It is at an elevation of $20 \mathrm{ft}$ msl and is located along the north bank of the drainage ditch (Fig. 32). The site lies on the south side of a shallow depression and probably 


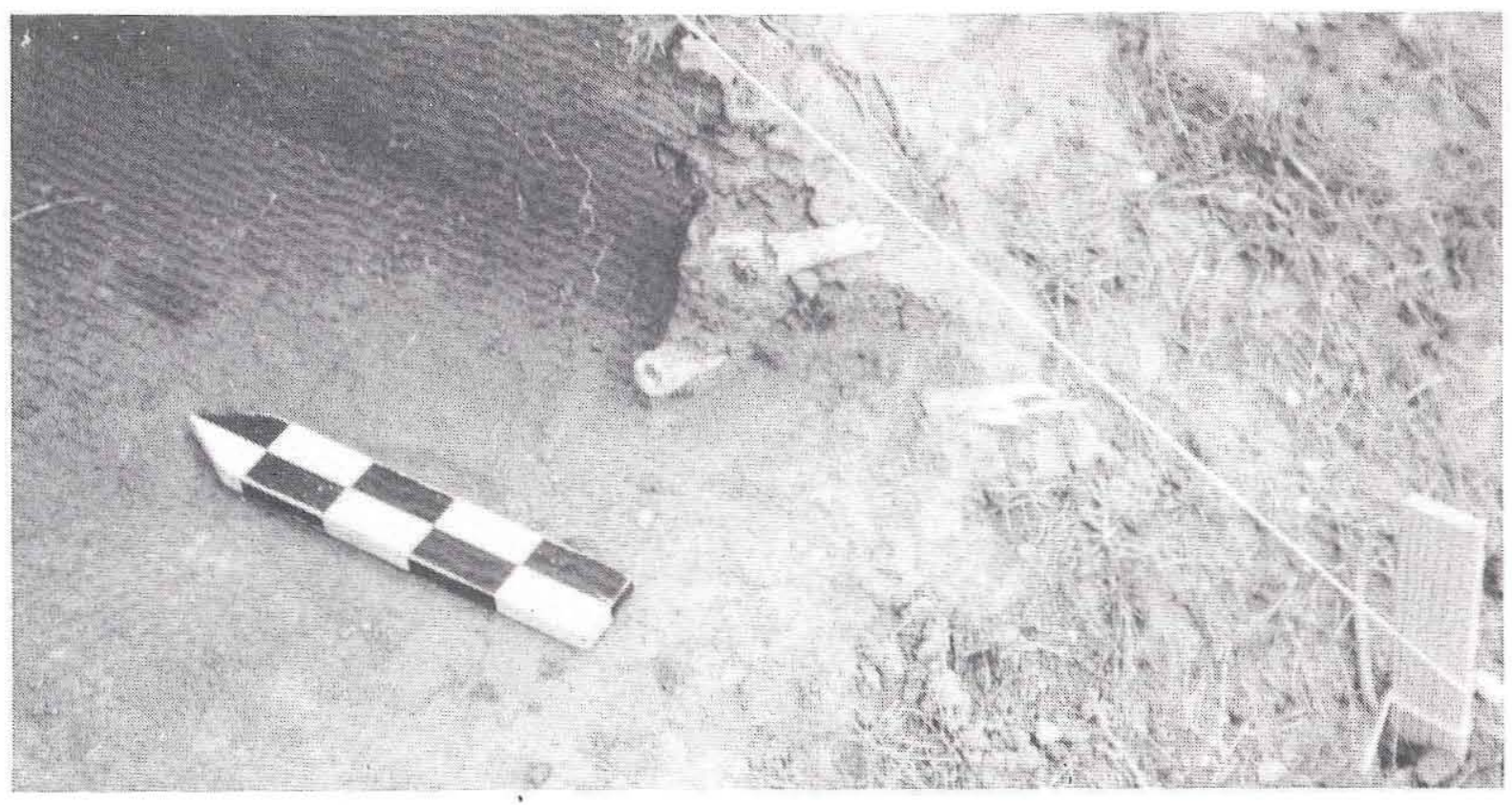

$a$

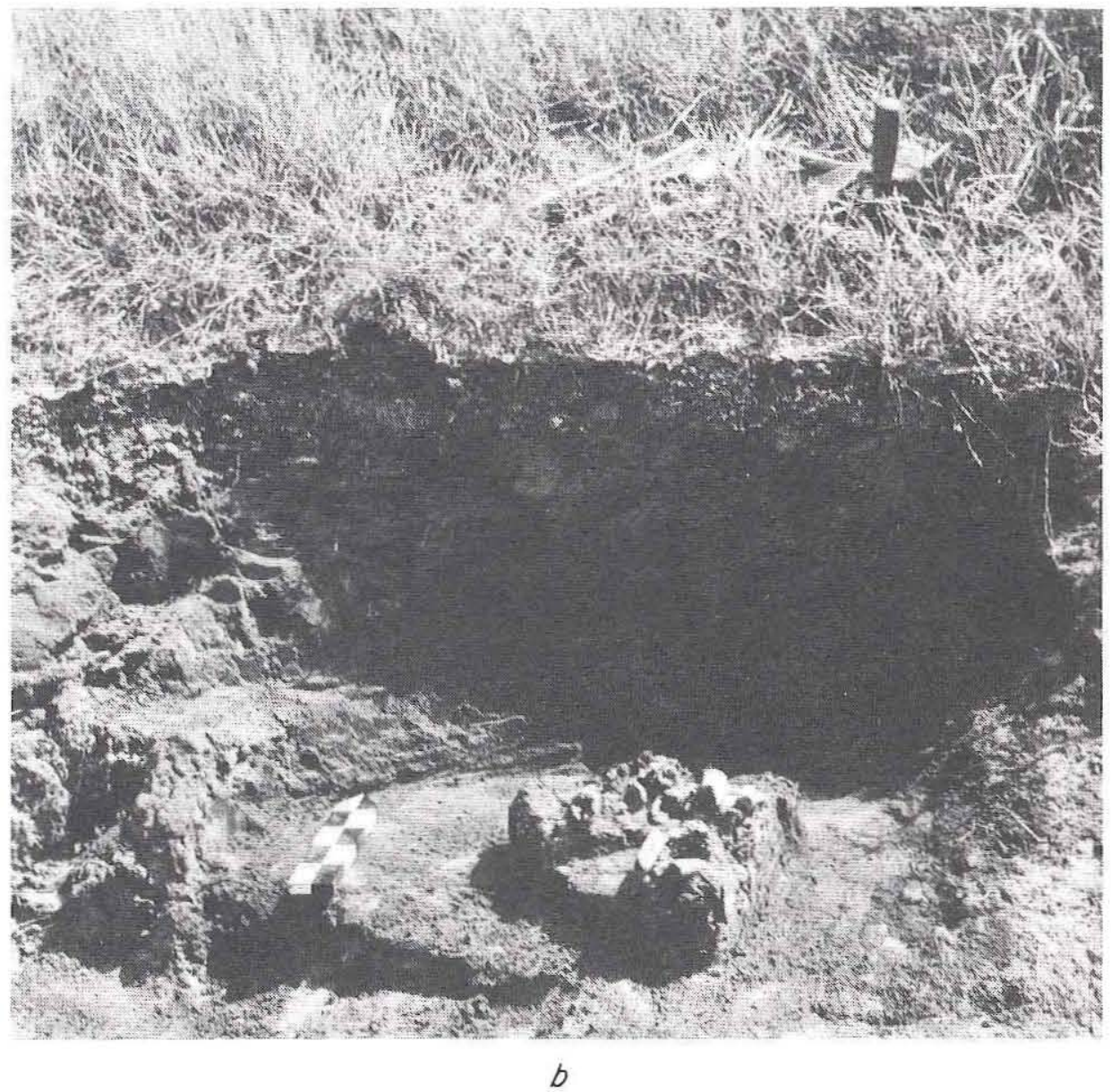

Figure 31. Photographs of features at 41WY113. (a) Feature 1, Test Unit 2, showing deer bones in east wall. Note bones near contact with weathered Beaumont Formation and overlying soil. (b) Human burial in drainage ditch bank, 1986. Note bones near contact with weathered Beaumont Formation and overlying soil. 


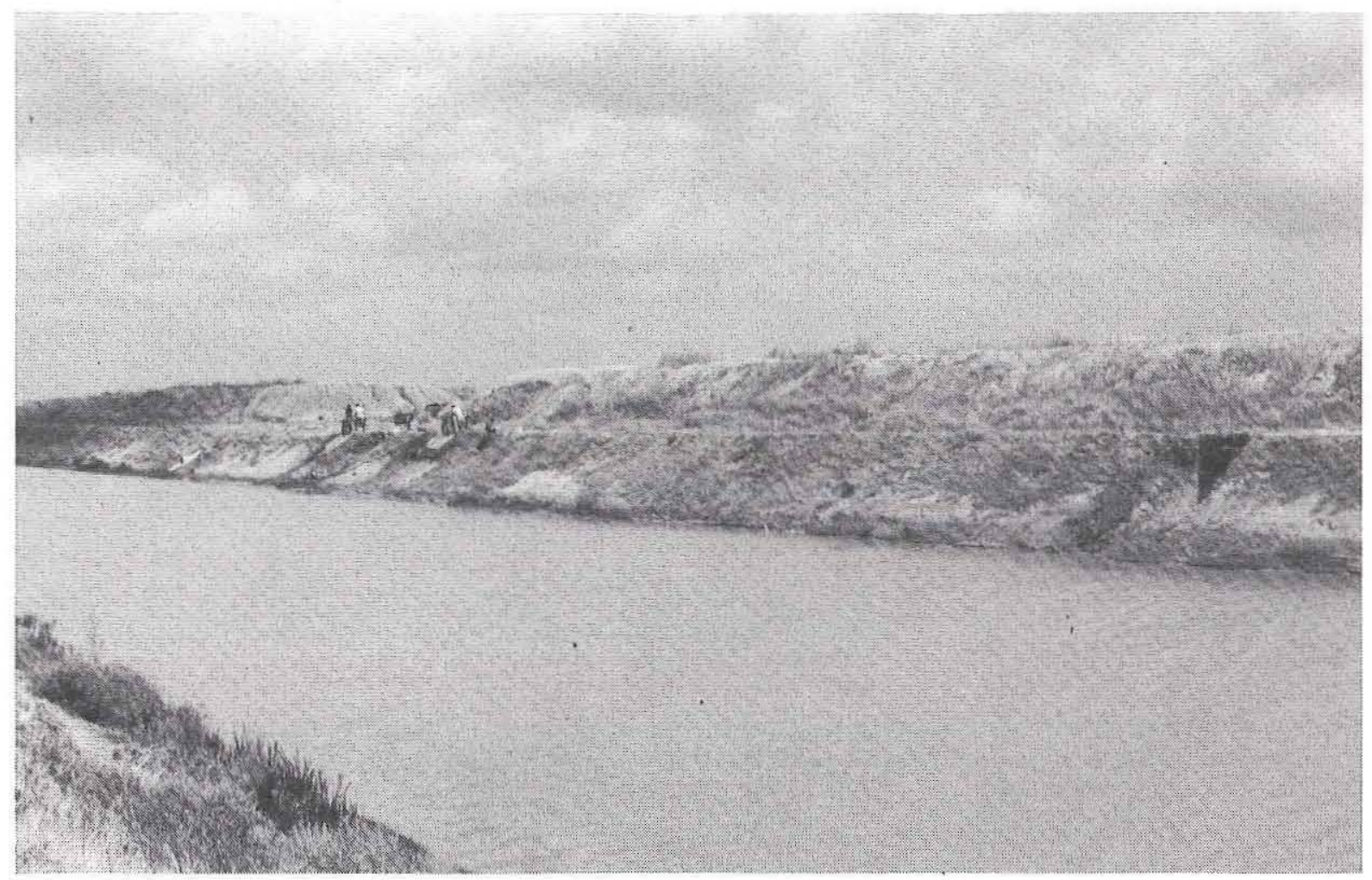

Figure 32. View from the southeast of 41WY134 during excavation; Backhoe Trench 1 on right.

continues northward into cultivated fields. Agricultural activities, land leveling, and ditch construction have undoubtedly disturbed the Holocene deposits.

\section{Previous Investigations}

This site was discovered by Elton R. Prewitt and Carolyn Good in 1985 and recorded during the 1986 survey (Hall et al. 1987:123). Materials observed include 5 pieces of debitage, 19 bone fragments, 7 burned clay lumps, 2 marine shell fragments, and 1 fish otolith exposed along the north bank of the drainage ditch. The site was estimated to extend $250 \mathrm{~m}$ north-south, an unknown distance east-west along the ditch, and an unknown depth below surface. It was assessed as being possibly eligible for listing on the National Register of Historic Places based on the density and variety of artifacts.

\section{Work Accomplished}

The Phase II testing efforts at site 41WY134 consisted of excavating two backhoe trenches and four 1x1-m test units (Fig. 33). A surface survey was conducted to locate cultural materials, but none were found. Two test units were placed adjacent to the backhoe trenches, and two additional test units were placed between them (Table 13). All test units were excavated into the upper portion of the Beaumont Formation. The two backhoe trenches excavated at either end of the site for the geomorphological investigations and to provide stratigraphic controls for the test units were $250 \mathrm{~cm}$ deep. The fieldwork at 41WY134 was completed in 24 person-days.

\section{Site Extent and Depth}

Because no cultural materials were found in the testing reported here, no additional information 


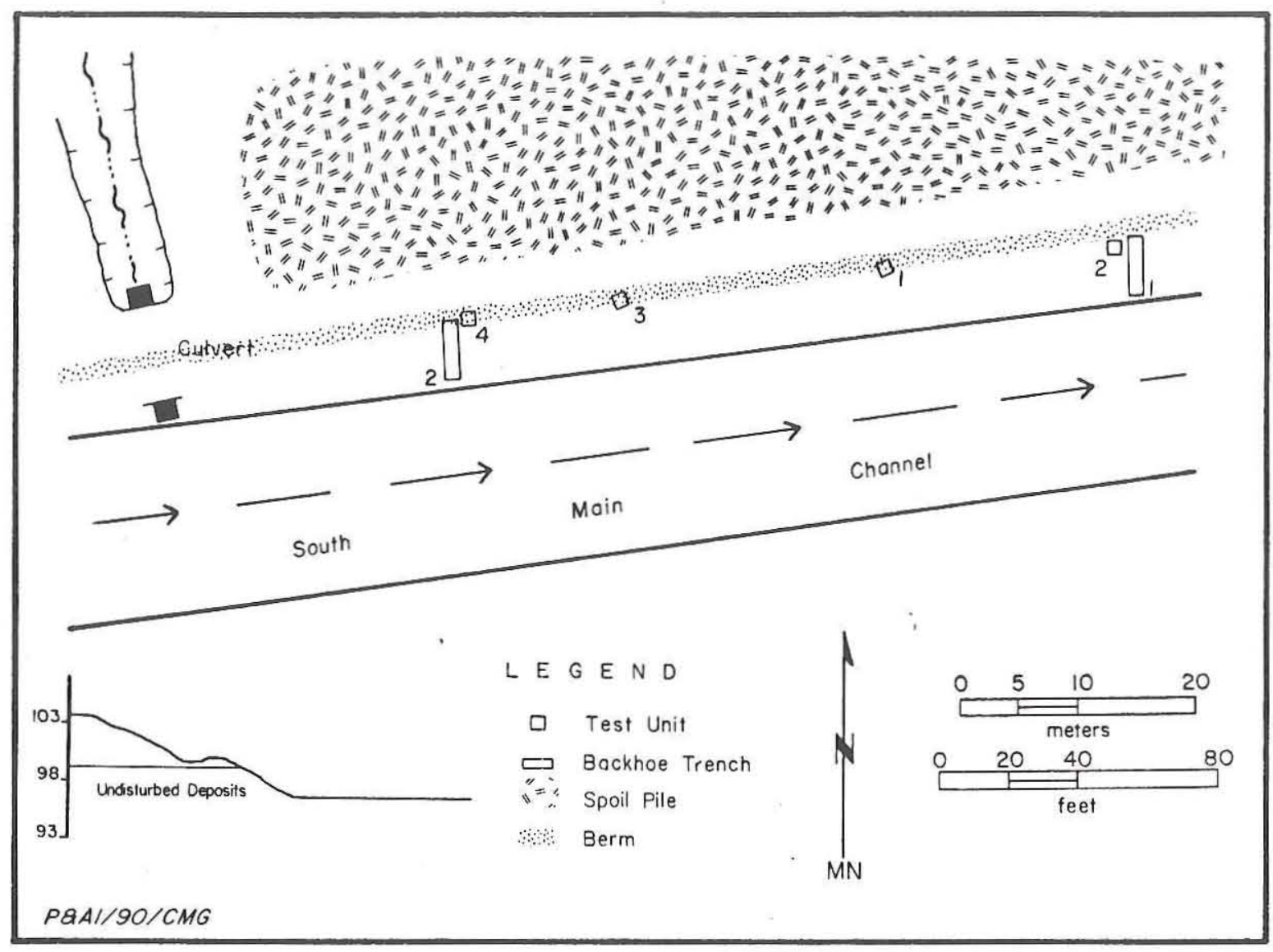

Figure 33. Site map, 41WY134.

\begin{tabular}{|c|c|c|c|c|c|}
\hline \multicolumn{7}{|c|}{ TABLE 13 } \\
\hline $\begin{array}{c}\text { SUMMARY OF 41WY134 EXCAVATIONS } \\
\text { Unit }\end{array}$ & $\begin{array}{c}\text { Depth of } \\
\text { Excavation }\end{array}$ & $\begin{array}{c}\text { Thickness of } \\
\text { Overburden }\end{array}$ & $\begin{array}{c}\text { Maximum Depth } \\
\text { of Artifacts }\end{array}$ & $\begin{array}{c}\text { Thickness of } \\
\text { Cultural Deposit }\end{array}$ & $\begin{array}{c}\text { Total Number of } \\
\text { Artifacts }\end{array}$ \\
\hline 1 & 0.98 & 0.75 & - & - & 0 \\
2 & 1.11 & 0.88 & - & - & 0 \\
3 & 0.81 & 0.69 & - & - & 0 \\
4 & 1.34 & 0.68 & - & & 0 \\
\hline
\end{tabular}


on the extent and depth of this site is available. Apparently most of the artifacts and numerous burned clay lumps observed in 1986 were along the edge of the depression in the plowed field north of the ditch. As the testing efforts were confined to the drainage right-of-way, the plowed fields to the north, i.e., the actual location of the site, were not investigated. It is clear, however, that 41WY134 does not extend southward to the ditch.

\section{Sediments}

Site 41WY134 occurs on the southern upper slopes of a moderate-size circular deflationary basin within an ancient abandoned channel on the present surface of the Beaumont Formation (see Fig. 8). This basin is not as deep as the ones at $41 \mathrm{WY} 112$ or $41 \mathrm{WY} 113$, and the modern soil distribution suggests that this area has been' less intensively eroded by wind. The soils in the basin near 41WY134 are sandy clay loams, and most of the relatively uneroded Beaumont Formation surface consists of sandy clay loams as well (Fig. 34). This is the easternmost site investigated and it is nearest to the active dunes along the coast and in the sand sheet. It is possible that an active dune blew through the depression and left a trail of sand or more sand may be present in this portion of the Beaumont Formation than occurs farther west at the other sites. The sediments in both backhoe trenches and one test unit are described below.

Backhoe Trench 1 has six zones (Fig. 35). Zone $1(0-42 \mathrm{~cm})$ is gray loose clay loam with a very abrupt irregular lower boundary. This is construction fill. Zone $2(42-75 \mathrm{~cm})$ is very dark gray firm silt loam with a few small calcium carbonate filaments. The lower boundary is very abrupt and irregular. This is a disturbed and compacted plow zone, and it is classified as an Apb horizon. Zone $3(75-112 \mathrm{~cm})$ is very dark grayish brown very firm silt loam with fine strong blocky structure and well-developed ped faces with clay films. A few calcite crystals were observed on ped faces. This is a truncated $\mathrm{ABb}$ horizon with a diffuse and smooth lower boundary. Zone 4 is grayish brown firm clay loam with medium moderate blocky structure and thin clay films on ped faces. Calcium carbonate nodules are common, and a few manganese concretions were observed. The lower boundary is smooth and diffuse. Zone 4 is classified as a Btkc horizon. Zone $5(170-235 \mathrm{~cm})$ is light brown friable clay loam with weak blocky structure and many calcium carbonate nodules. This is a IIBtk horizon formed on Beaumont Formation sediments. Zone 5 grades imperceptibly into Zone $6(235-250+\mathrm{cm})$, a light brown to brown friable silt loam with a few calcium carbonate nodules and manganese concretions. Zone 6 is a IICkc horizon.

Backhoe Trench 2 has six zones as well (see Fig. 35). Zone $1(0-56 \mathrm{~cm})$ is grayish brown loose silt loam with an abrupt irregular lower boundary. This is construction fill. Zone $2(56-72 \mathrm{~cm})$ is very dark gray firm silt loam with coarse moderate blocky structure and clasts of black silt loam from Zone 3. This zone is due to land leveling associated with vegetation clearing and farming and is classified as an Apb horizon. Zone $3(72-100 \mathrm{~cm})$ is black firm silt loam. It has fine to medium moderate blocky structure with thin clay films on ped faces, many fine calcium carbonate filaments, rare calcium carbonate nodules that increase downprofile, and a gradual smooth lower boundary. This is a truncated ABtkb horizon. Zone $4(100-$ $125 \mathrm{~cm}$ ) is a dark gray firm silt loam with medium moderate blocky structure, very thin clay films on ped faces, common calcium carbonate filaments, and few calcium carbonate nodules that gradually increase down-profile. The lower boundary is diffuse, and the zone is classified as a Btk horizon. Zone $5(125-165 \mathrm{~cm})$ is grayish brown friable clay loam with medium moderate blocky structure, common calcium carbonate nodules and filaments, rare manganese concretions, and a gradual smooth lower boundary. Zone 5 is a IIBtkc horizon formed on the weathered Beaumont Formation. Zone 6 $(165-250+\mathrm{cm})$ is light brown clay loam with less clay than Zone 5. It has weak medium blocky structure, a few calcite crystals, and a few calcium carbonate nodules, some of which are surrounded by light brownish gray clayey mottles. This is a IICkc horizon.

Test Unit 1 has three zones (see Fig. 35). Zone $1(0-48 \mathrm{~cm})$ is very dark gray loose loam with clasts of very dark gray sandy loam and yellowish brown clay loam. This is construction fill; three layers of well-laminated sands mark temporary surfaces in the fill. Zone $2(48-75 \mathrm{~cm})$ is very dark gray extremely firm loam with strong fine granular structure. Also present are rare calcium carbonate nodules and snail shells. The lower boundary is gradual and smooth. This zone is classified as an Apb horizon. Zone 3 (75$98+\mathrm{cm})$ is grayish brown firm loam with weak 


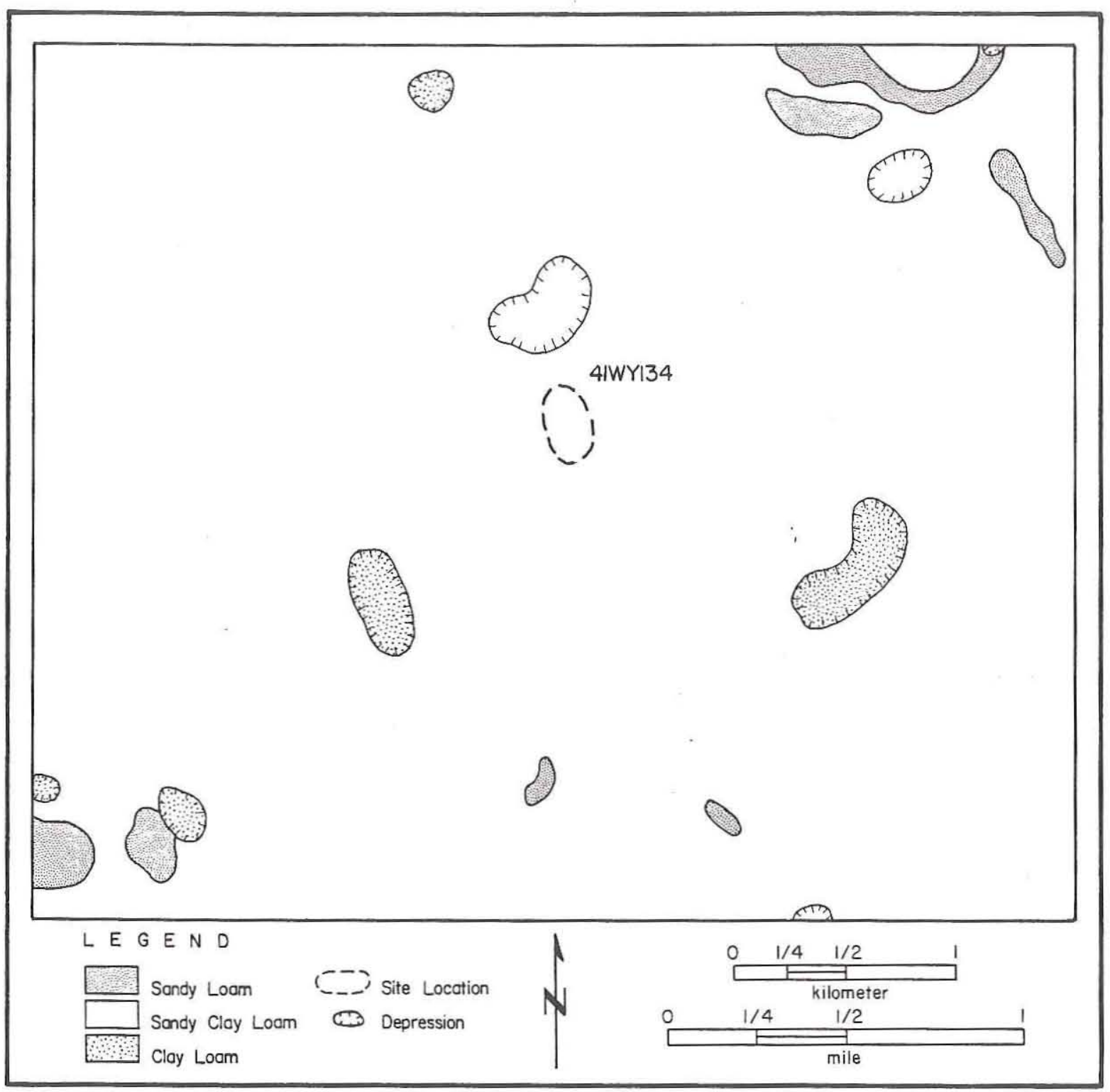

Figure 34. Distribution of soils and blowout depressions at 41WY134. Adapted from Turner 1982.

blocky structure, many snail shells in its upper portion, and a few calcium carbonate nodules. This is an $\mathrm{ABkb}$ horizon.

No radiocarbon dates were obtained from 41WY134, however, the site has consistent stratigraphy and correlations are clear. A soil has formed on the Beaumont Formation sediments, and it is likely that it is truncated. A more recent soil has formed over this older soil, and it appears to be cumulative. If wind-blown sediments were deposited in the depression as interpreted from the soil maps, then this could be the primary source of the materials in the cumulative soil. The upper portion of this recent soil has been altered by agricultural activities and then covered by landfill probably introduced to provide a dry access road adjacent to the ditch.

\section{Materials Recovered}

No artifacts were recovered as a result of the testing efforts. Other materials observed include 

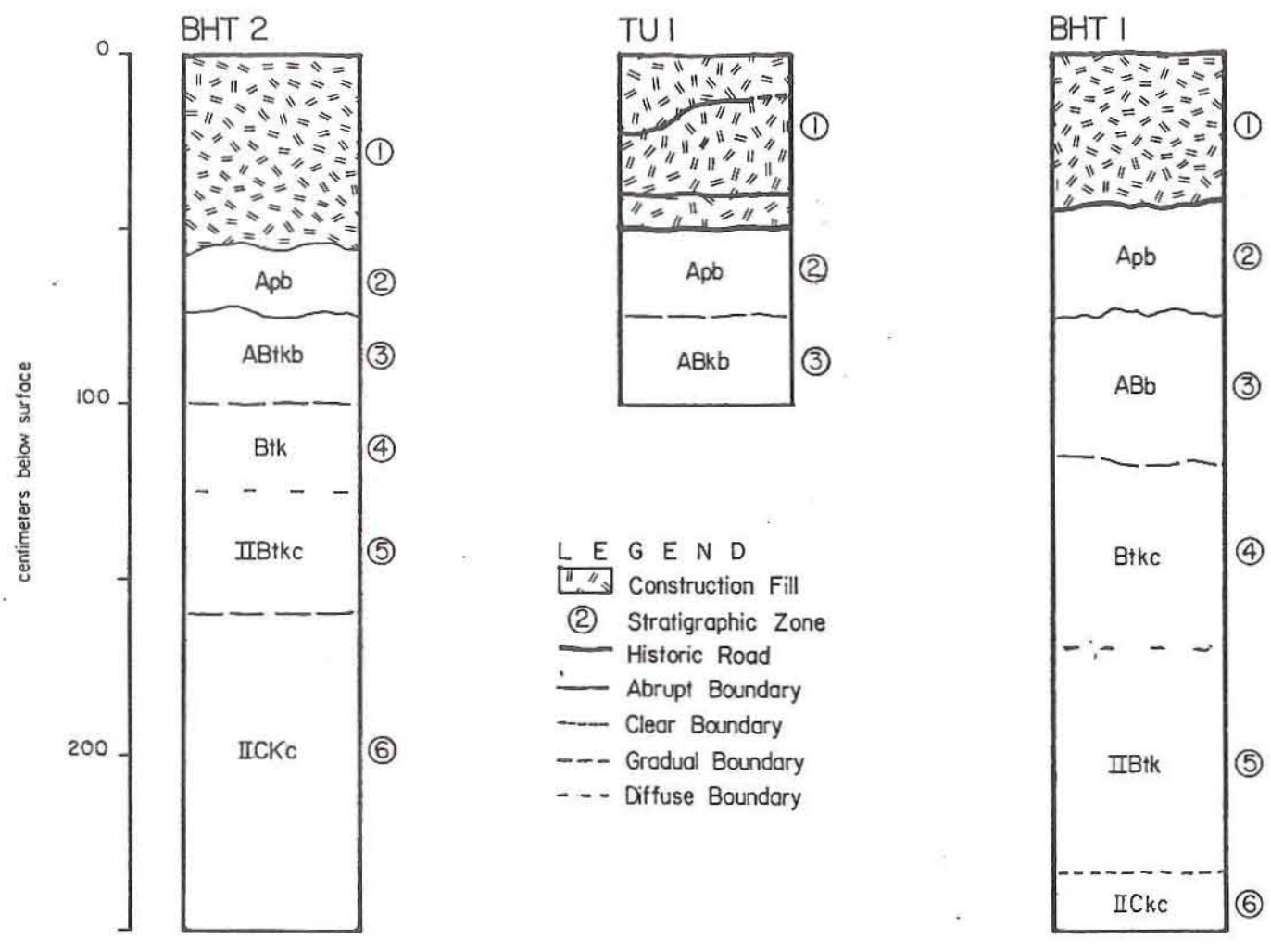

PQAI/9O/CMG

Figure 35. Selected geological profiles of backhoe trenches and test unit at 41WY134.

charcoal, one freshwater mussel shell fragment, snail shells, bones, calcium carbonate concretions, gypsum, silicious pebbles, and modern debris (see Appendix A). Because of the lack of cultural materials, the investigations were limited, and sediment and humate samples were not collected.

\section{Discussion}

The previous work at 41 WY134 recovered five lithic artifacts, but the testing efforts did not reveal any additional surface or buried cultural materials. The original plotting of the site and the general discussion of the materials collected during the survey suggest that $41 \mathrm{WY} 134$ is located primarily outside of the ditch right-of-way along the edge of the natural depression in a cultivated field. As areas outside of the drainage ditch right-of-way were not tested, the extent of the cultural deposits in and around the depression is unknown. Another possibility for the lack of cultural materials is that they were present in the upper portion of the Holocene deposits (i.e., Zone 2) along the ditch banks that were truncated and redeposited by farming and ditch construction activities. In either case, there are no cultural materials in primary contexts within the drainage ditch right-of-way at 41WY134.

\section{WY140}

\section{Site Setting}

Site 41WY140 is located southwest of Lyford, Texas, along the South Main Channel approximately $1.2 \mathrm{~km}$ southwest of the intersection of FM 491 and FM 448. It is at an elevation of 30$35 \mathrm{ft}$ msl along the west bank of the drainage ditch adjacent to a small rise surrounded by cultivated fields (Fig. 36). 


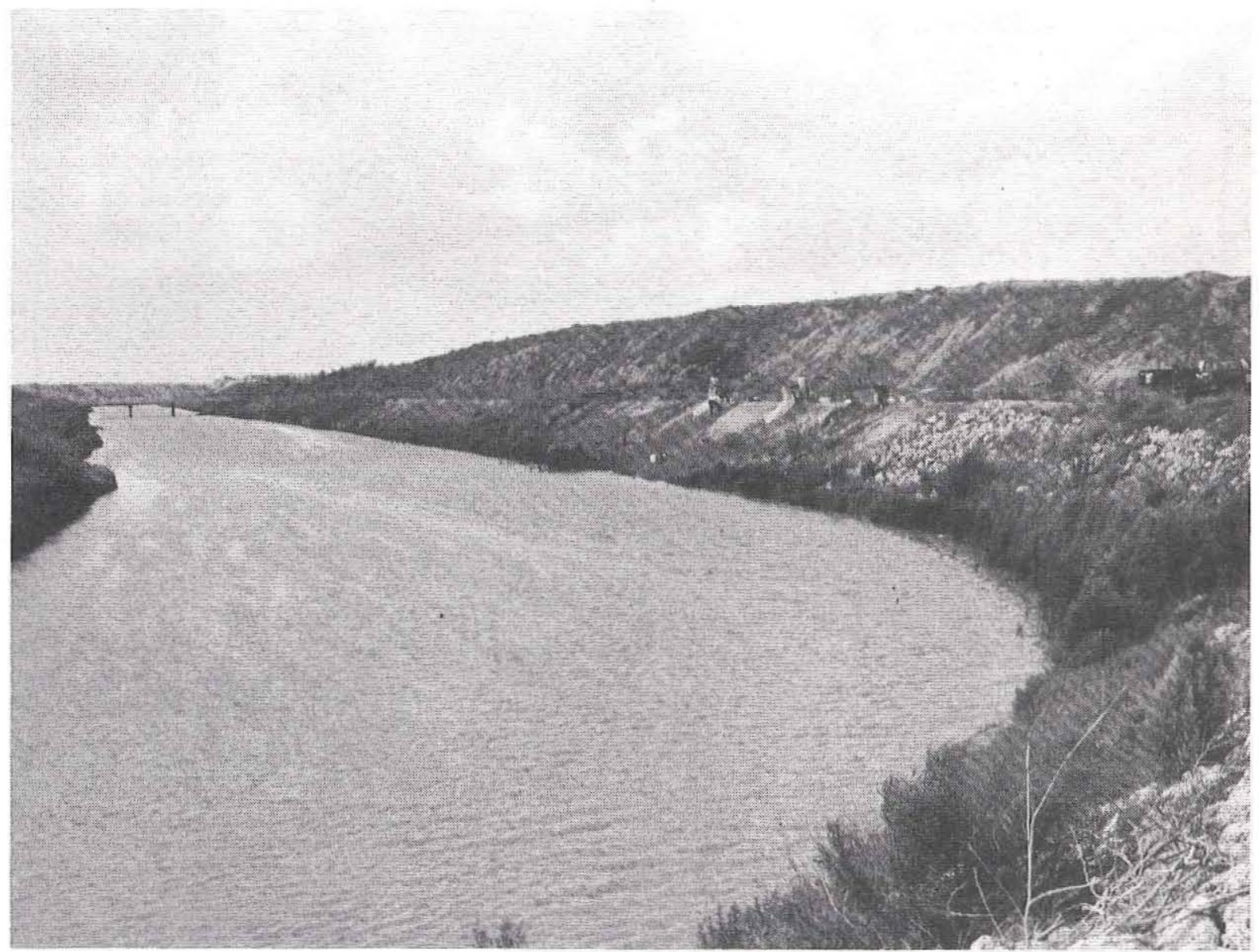

Figure 36. View to the northwest of $41 \mathrm{WY} 140$ during excavation. Note riprap on drainage ditch curve; Test Unit 1 on right.

\section{Previous Investigations}

The site was discovered by Elton R. Prewitt and Carolyn Good in 1985 and recorded during the 1986 survey (Hall et al. 1987:127). The materials observed included 3 pieces of debitage, 12 bone fragments, at least 2 burned clay lumps, and numerous mussel shell fragments. The site was reported to occur at $100-150 \mathrm{~cm}$ below modern surface with another possible cultural zone at 200 $300 \mathrm{~cm}$; the horizontal extent was estimated to be $150 \mathrm{~m}$ north-south along the ditch. Site $41 \mathrm{WY} 140$ was assessed as probably eligible for listing on the National Register of Historic Places based on the possible stratified nature of the cultural deposits and the unusual depth at which they occur.

\section{Work Accomplished}

The Phase II investigations at 41WY140 consisted of the excavation of two backhoe trenches and four 1x1-m test units (Fig. 37). Table 14 summarizes the work accomplished. All of the test units were excavated into the Beaumont Formation. The two backhoe trenches were excavated at both ends of the site to investigate the geology and to provide stratigraphic controls for the test unit excavations. The fieldwork at $41 \mathrm{WY} 140$ was completed in seven person-days.

\section{Site Extent and Depth}

Only two pieces of debitage were recovered below the historically disturbed deposits at 


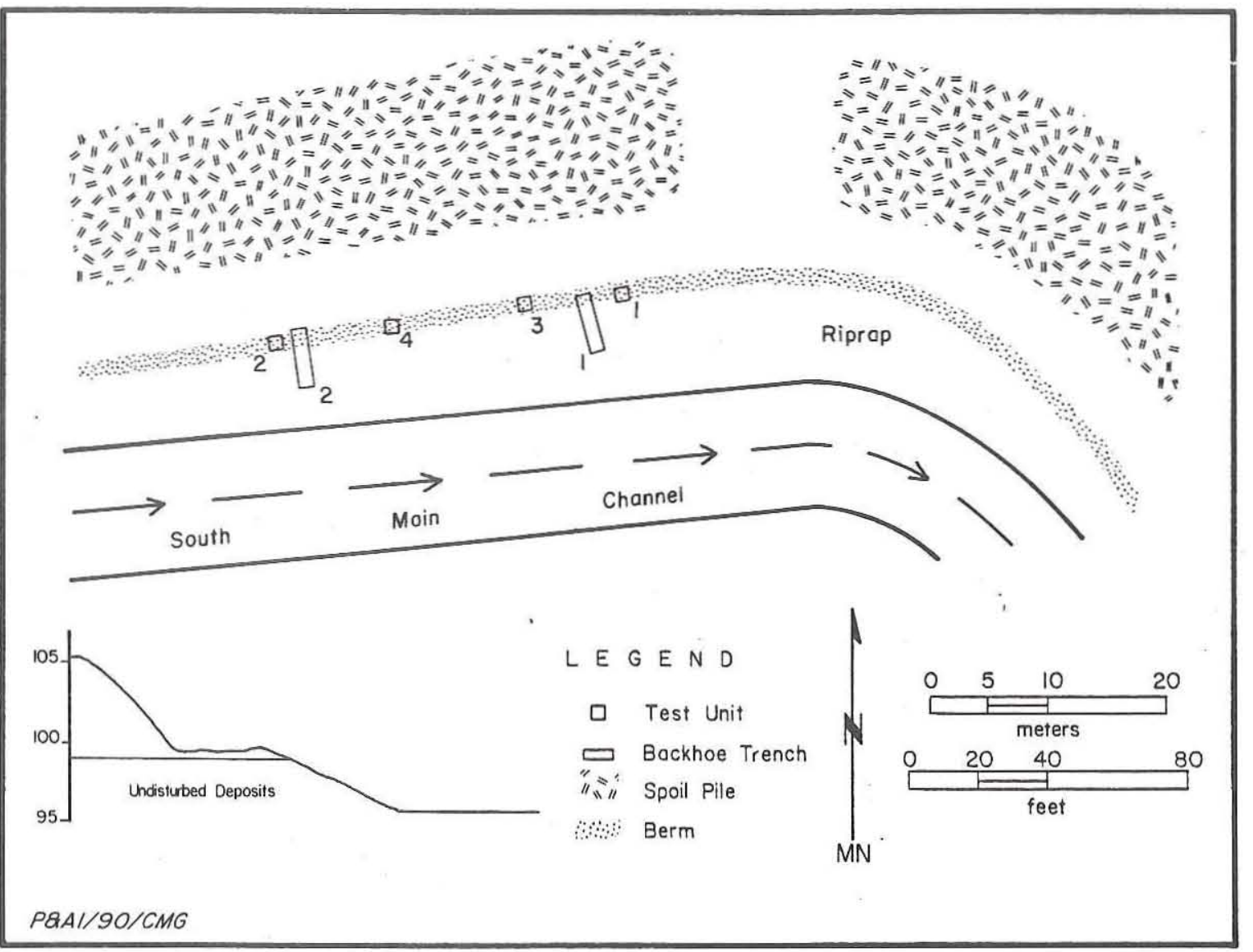

Figure 37. Site map, 41WY140.

\begin{tabular}{|c|c|c|c|c|c|}
\hline \multicolumn{7}{|c|}{ TABLE 14 } \\
SUMMARY OF 41WY140 EXCAVATIONS \\
\hline $\begin{array}{c}\text { Test } \\
\text { Unit }\end{array}$ & $\begin{array}{c}\text { Depth of } \\
\text { Excavation }\end{array}$ & $\begin{array}{c}\text { Thickness of } \\
\text { Overburden }\end{array}$ & $\begin{array}{c}\text { Maximum Depth } \\
\text { of Artifacts }\end{array}$ & $\begin{array}{c}\text { Thickness of } \\
\text { Cultural Deposit }\end{array}$ & $\begin{array}{c}\text { Total Number of } \\
\text { Artifacts }\end{array}$ \\
\hline 1 & 0.28 & 0.13 & - & - & 0 \\
2 & 0.34 & 0.26 & 0.34 & 0 & 1 \\
3 & 0.33 & 0.14 & 0.33 & - & 0 \\
4 & 0.35 & 0.23 & - & - & 1 \\
\hline
\end{tabular}


41WY140. Both were in the upper portion of the Beaumont Formation, which was encountered at 26 and $14 \mathrm{~cm}$ below the modern surface in Test Units 2 and 3, respectively. Based on the extremely low frequency of artifacts, the site dimensions cannot be determined.

\section{Sediments and Radiocarbon Chronology}

Site 41 WY140 is the only one tested during the current investigations that is on a low rise instead of in a depression on the Beaumont Formation (Bureau of Economic Geology 1976). Holz and Prewitt's (1981) analysis shows that the site is at the tip of a linear wedge of alluvial overbank deposits between two abandoned channels on the Beaumont surface (see Fig. 8, Fig. 38). The modem soil type is Racombes sandy clay loam which often develops on Beaumont Formation alluvial overbank deposits (Turner 1982). The sediments observed in the backhoe trenches are described below.

Backhoe Trench 1 has four zones (Fig. 39). Zone $1(0-5 \mathrm{~cm})$ is dark grayish brown silt loam. This construction fill shows a clear irregular lower boundary. Zone $2(5-80 \mathrm{~cm})$ is dark grayish brown extremely firm silt loam with platy structure in the upper $10 \mathrm{~cm}$ due to mechanical compaction. Below the compacted portion, it changes to medium strong blocky structure with well-developed ped faces and common calcium carbonate nodules that increase in frequency down-profile. Manganese concretions occur also. Zone 2 is a IIBkc1 horizon. Zone 3 $(80-150 \mathrm{~cm})$ is light brown extremely firm clay loam with medium moderate blocky structure, very many calcium carbonate nodules, and a gradual smooth lower boundary. Zone 3 is a IIBkc2 horizon. Zone $4(150+\mathrm{cm})$ was observed only in the large drainage ditch. It is similar to Zone 3 except that it has less clay and calcium carbonate nodules are not present. This is a IIC horizon.

Large, thick tortoise shell fragments were recovered in situ from undisturbed Zone 2 deposits $1 \mathrm{~m}$ south of Backhoe Trench 1 on the sloping surface of the ditch at 70-80 cm below the surface. The inorganic (apatite) fraction of the shell fragments yielded a radiocarbon age of $9360 \pm 415$ B.P. (GX-15125-A). This tortoise is probably the extinct giant species Gopherus hexagonatus as numerous other tortoise remains of this species have been recovered from the same stratigraphic position in this region (Westgate 1987:200-219).

Four stratigraphic zones were identified at Backhoe Trench 2 (see Fig. 39). Zone $1(0-5 \mathrm{~cm})$ is grayish brown firm silt loam with platy structure and an abrupt irregular lower boundary. This zone has been altered and compacted by construction activities. Zone $2(5-40 \mathrm{~cm})$ is dark grayish brown extremely firm silt loam with moderate coarse blocky structure and common calcium carbonate nodules. This zone is a truncated IIBk1 horizon. Zone $3(40-105 \mathrm{~cm})$ consists of brown silt loam with moderate coarse blocky structure and very many calcium carbonate nodules. This is a IIBK2 horizon. Zone $4(105-180+\mathrm{cm})$ is pale brown clay loam with medium moderate blocky structure and clay films on ped faces. Calcium carbonate nodules occur but decrease sharply down-profile. This zone is classified as a IICk horizon.

In summary, the sediments indicate that a truncated soil exists on Beaumont Formation sediments. This soil was definitely truncated by ditch construction and possibly by slope erosion of the natural rise as well. All of the deposits appear to be pedogenically altered Beaumont Formation, and this implies that the prehistoric cultural remains are not in primary archeological or geological contexts. The turtle remains from near the present top of the soil were dated to 9360 B.P., indicating that they are not contemporary with the Beaumont Formation.

\section{Materials Recovered}

Two pieces of debitage were recovered during the testing phase, one from the $1 / 4$-inch screen and one from 1/16-inch screen. No diagnostic artifacts were recovered. Other materials observed include charcoal, snail shells, bones, calcium carbonate concretions, gypsum, siliceous pebbles, and modern debris including siliceous flakes from bank stabilizing materials (see Appendix A).

\section{Discussion}

The geomorphologic investigations identified a truncated soil on the Beaumont Formation. The test unit excavations recovered two prehistoric artifacts from the upper portion of this soil. As this is a stable or possibly erosional surface rather 


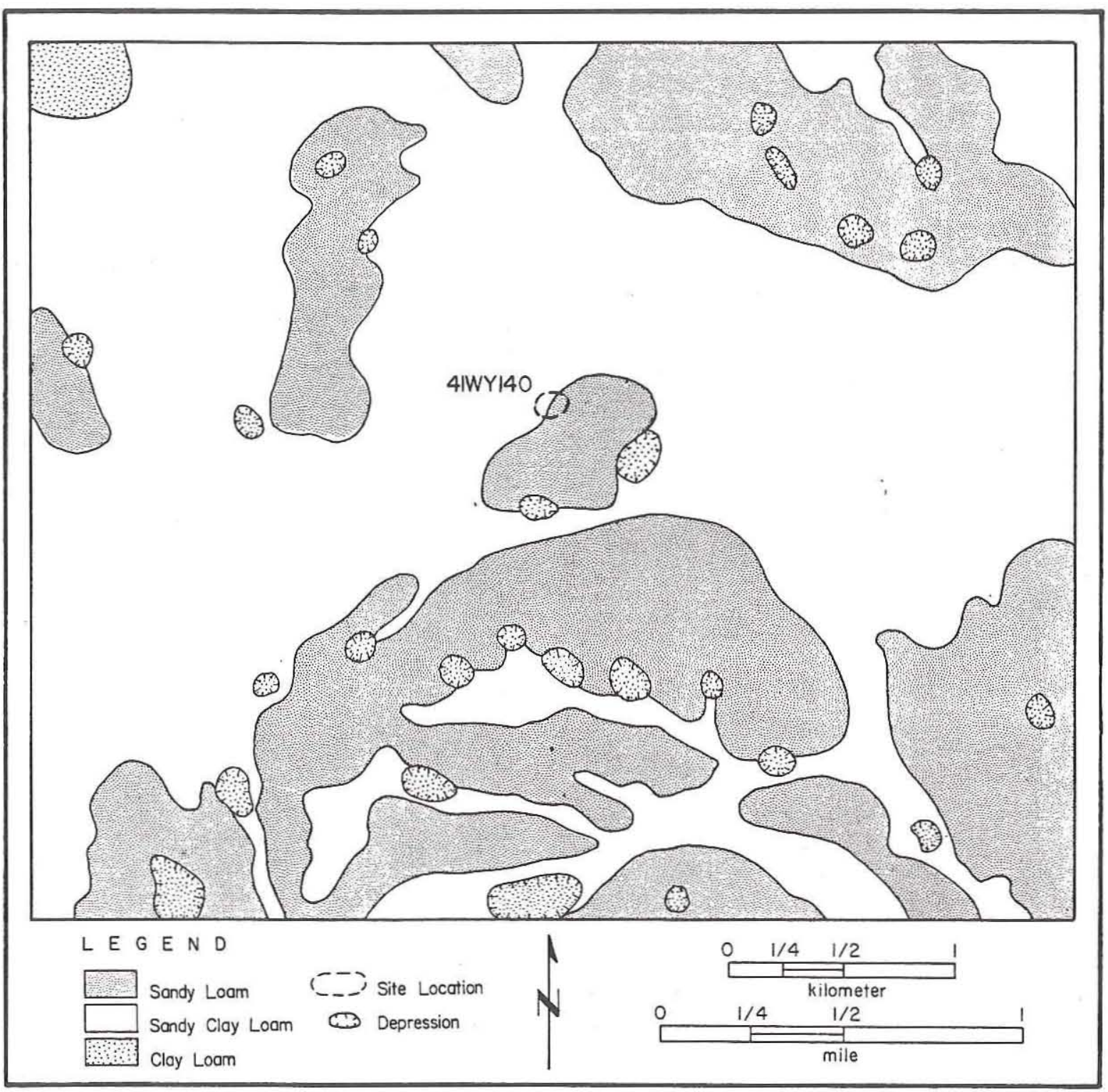

Figure 38. Distribution of soils and blowout depressions at 41WY140. Adapted from Turner 1982.

than a cumulative soil, the cultural materials are probably not in primary contexts but rather reflect vertical displacement. The initial assessment of cultural resources at this site suggested the possibility of deep occupations, but it is clear that these artifacts must have been vertically displaced as well. This displacement could be due to soil cracking, bioturbation, agricultural activities, or ditch construction. Thus, all of the cultural materials collected at $41 \mathrm{WY} 140$ are believed to be from secondary contexts. Even though the rise at 41 WY140 was utilized prehistorically, it appears that much or even most of the site has not survived intact. 


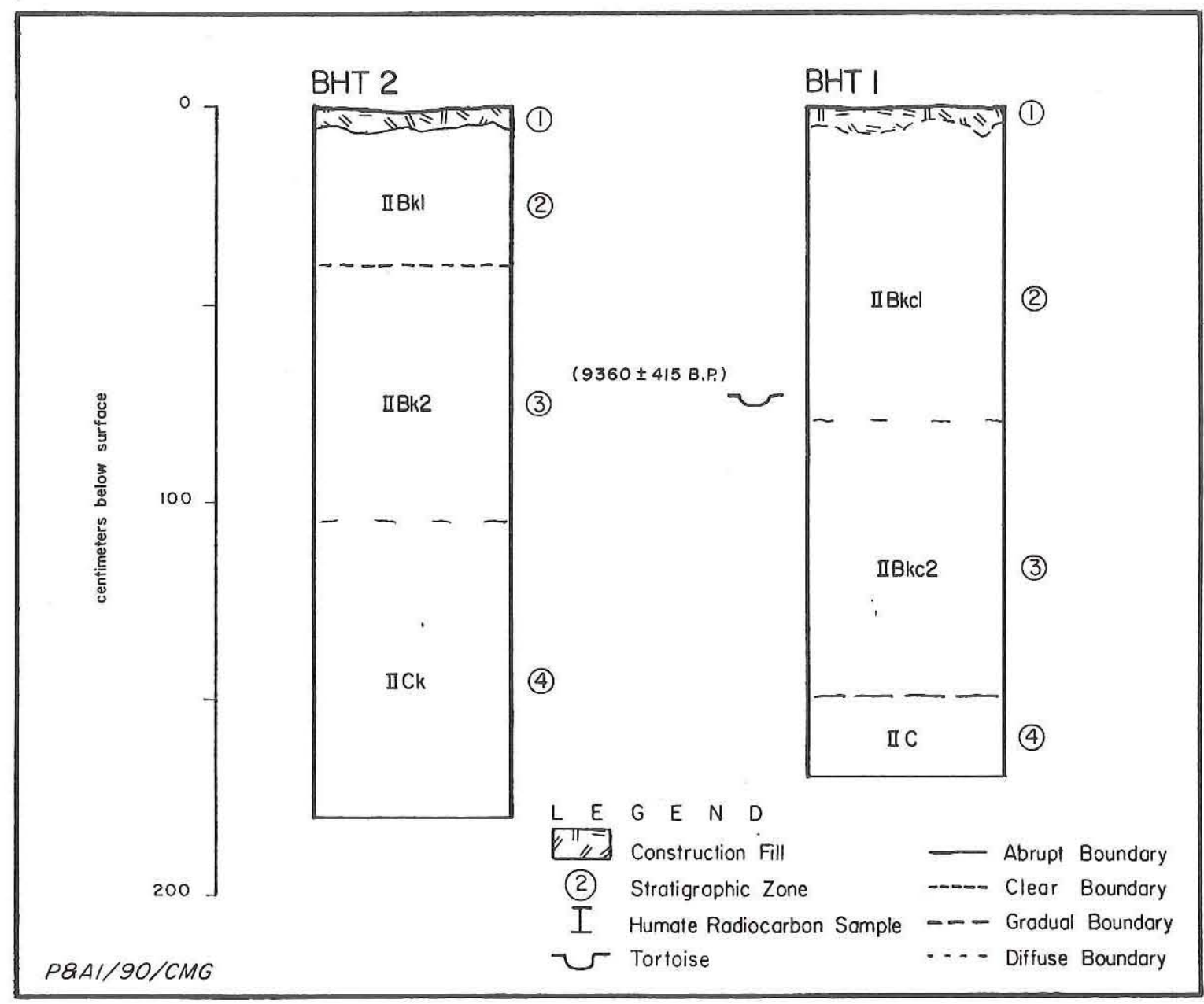

Figure 39. Selected geological profiles of backhoe trenches at 41WY140. 


\section{PALEOENVIRONMENTS AND HUMAN DIETS}

by C. Britt Bousman

In order to provide the contextual background necessary for understanding prehistoric human behavior in South Texas, both paleoenvironmental and human dietary information must be collected from as many sources as possible. In this chapter, stable isotopes have been used to provide evidence of both. More and more geologists, paleoclimatologists, and archeologists are using stable isotopes (especially carbon, nitrogen, and oxygen) for documenting past environments, climatic changes, and human dietary patterns. The sites discussed in this report generally have poorly preserved organic remains, and stable isotope analysis provides an avenue of environmental and dietary reconstruction that is unavailable from other sources. Stable carbon, nitrogen, or oxygen isotopes were measured on samples of bones, pedogenic calcium carbonate nodules, a freshwater limestone (marl), and bulk soil humates collected for radiocarbon dating during this project, and these provide evidence of changing climate, plant communities, and human diets in South Texas. The radiocarbon dates are introduced in the site descriptions sections of Chapter 5, while an analysis of the isotopic information is presented below. This provides a direct quantitative estimate of Pleistocene and early Holocene climate in South Texas and provides a view of late Holocene environmental change. Limited faunal remains provide additional data on early Holocene environments. Dietary reconstructions through isotopic analyses have far-reaching applications and implications for many aspects of human prehistory that are unavailable from other sources. Amassing environmental and dietary data ultimately will allow modeling efforts, such as presented in Chapter 3, to become more dynamic with time trajectories and thus more robust and explanatory.

\section{LATE PLEISTOCENE AND HOLOCENE PALEOENVIRONMENTAL CHANGE}

Virtually nothing is known about how human behavior was influenced and conditioned by climatic and environmental changes in the Lower Rio Grande Valley of Texas. One of the four major goals of the archeological investigations conducted for the Hidalgo-Willacy Drainage Ditch project is to fill this gap. The success of completing the other major goals of the project depends on obtaining paleoenvironmental and climatic data for the period of human habitation. Many types of paleoenvironmental data can be found in archeological sites, and careful documentation of the geology, often accompanied by analyses of pollen and faunal samples, is traditionally undertaken to assess environmental change during the period of occupation. However, it is unlikely that the highly weathered sediments observed in the sites discussed here have preserved pollen, and, as faunal remains are scarce, other sources of paleoenvironmental and climatic data were sought. It was determined that stable isotopes in soil humates and calcium carbonates 
would provide the most accurate and accessible sources of such data available from these sites. Below is an analysis of the stable isotope data that relates directly to climatic changes and paleoenvironments.

\section{Carbon Isotopes}

Most researchers argue that increases in ${ }^{13} \mathrm{C} /{ }^{12} \mathrm{C}$ ratios provide a measure of change in $\mathrm{C}_{4}$ and CAM plant versus $\mathrm{C}_{3}$ plant composition in the overall biota (Stuiver 1975; Flexor and Volkoff 1977; Vogel 1978; Krishnamurthy et al. 1982; Cerling 1984; Dzurec et al. 1985; Cerling and Hay 1986; Haas et al. 1986; Nakai and Koyama 1987; Schwartz et al. 1987; Volkoff and Cerri 1987; Natelhoffer and Fry 1988; Guillet et al. 1988; Cerling et al. 1989; Vitorello et al. 1989). All trees and many shrubs and grasses are $\mathrm{C}_{3}$ plants, some grasses and herbaceous plants such as Cheno-ams are $\mathrm{C}_{4}$, and most succulents, including cacti, are CAM plants. The photosynthetic pathway used and the chemical composition of the energy molecules produced distinguish $\mathrm{C}_{3}$ and $\mathrm{C}_{4}$ plants. Plants of the $\mathrm{C}_{3}$ group use the CalvinBenson photosynthetic pathway, which produces a three-carbon molecule, while $\mathrm{C}_{4}$ plants use the Hatch-Slack pathway, with a four-carbon molecule as the resulting product.

During the production of these three- or four-carbon molecules, the plant may use either of the two stable carbon isotopes, ${ }^{13} \mathrm{C}$ or ${ }^{12} \mathrm{C}$. These two isotopes of carbon do not change, i.e., decompose, into other elements as does ${ }^{14} \mathrm{C}$, and they are readily available in the atmosphere. Because of the slight weight differences in the two stable carbon isotopes, the chemical reactions and physical processes in the two photosynthetic pathways utilize ${ }^{13} \mathrm{C}$ and ${ }^{12} \mathrm{C}$ in slightly different ratios. Lighter isotopes have higher vibrational frequencies, form weaker bonds, and are more reactive in chemical processes than heavier isotopes. The $\mathrm{C}_{3}$ and $\mathrm{C}_{4}$ pathways have the same basic chemical steps but the $\mathrm{C}_{4}$ pathway has additional steps allowing it to more efficiently use all the available carbon. This has two effects. First, $\mathrm{C}_{4}$ plants are more resistant to water stress but less capable of withstanding cold temperatures, especially minimum temperatures during the growing season. Consequently, $\mathrm{C}_{3} / \mathrm{C}_{4}$ plant ratios reflect paleoclimatic parameters. Second, the heavier isotope,
${ }^{13} \mathrm{C}$, occurs in greater relative abundance in $\mathrm{C}_{4}$ plants than in $\mathrm{C}_{3}$ plants, and thus the isotopic difference between $\mathrm{C}_{3}$ and $\mathrm{C}_{4}$ plants can be measured accurately with mass spectrometers. A third group, CAM plants, has the ability to switch back and forth between the two photosynthetic pathways in response to climatic variables, but a study of the most common CAM plants in South Texas, prickly pear and agave, suggests that these plants normally use $\mathrm{a} \mathrm{C}_{4}$ pathway (Eickmeier and Bender 1976). In the discussion below, CAM plants are combined with $\mathrm{C}_{4}$ plants for isotopic analysis.

The measurement of carbon isotope ratios is calibrated from the ${ }^{13} \mathrm{C} /{ }^{12} \mathrm{C}$ ratio in a piece of marine belemnite limestone from the Pee Dee Formation in South Carolina. As this marine limestone, known as the PDB standard, has an enormous amount of ${ }^{13} \mathrm{C}$ in relation to ${ }^{12} \mathrm{C}$, measurements from most terrestrial sources such as living plants result in negative numbers. The difference between a ${ }^{13} \mathrm{C} /{ }^{12} \mathrm{C}$ ratio and the PDB standard is represented by $\delta^{13} \mathrm{C}$ and is expressed in parts per thousand or \%o. The preindustrial atmospheric $\delta^{13} \mathrm{C}$ value is estimated at $-6.0 \%$; $\mathrm{C}_{3}$ plants have much less ${ }^{13} \mathrm{C}$, and their average $\delta^{13} \mathrm{C}$ value is approximately $-27 \% ; \mathrm{C}_{4}$ and CAM plants have more ${ }^{13} \mathrm{C}$, and their average $\delta{ }^{13} \mathrm{C}$ value is near $-13 \%$, i.e., it is higher but heavier, reflecting more ${ }^{13} \mathrm{C}$. In materials that represent an accumulation of both types of plants, the $\delta^{13} \mathrm{C}$ value should range between $-27 \%$ and $-13 \%$, and, given no further chemical changes, the specific value should reflect the relative biomass contribution of $\mathrm{C}_{3}$ and $\mathrm{C}_{4}$ plants. Unfortunately, further chemical changes, known as fractionation effects, do occur in most materials such as soils, calcium carbonate nodules, and bones, and this complicates the picture. In fact, the assimilation of carbon isotopes into plant biomass through the process of photosynthesis is the first major fractionation step. Thus, $\mathrm{C}_{4}$ plants have fractionated the atmospheric source to a lesser extent than have $\mathrm{C}_{3}$ plants. As carbon isotopes pass from plants into animals, soils, and other materials, additional fractionation steps occur, and the degree of fractionation change varies by material. The following discussion of carbon isotopes and fractionation is organized by material; however, all stable isotopes undergo fractionation due to unequal mass weights, and it is this process that allows meaningful stable isotope analysis. 
At least five factors are known to influence isotopic composition of soil materials: (1) $\mathrm{C}_{3} / \mathrm{C}_{4}$ composition of the biotic source; (2) differential preservation of plant components such as lignin or cellulose; (3) variations in plant mass inputs; (4) decomposition of organic materials; and (5) illuviation. In alluvial systems, transportation of materials from nonlocal sources is a sixth possibility. The objective in most paleoenvironmental reconstructions is to determine the $\mathrm{C}_{3} / \mathrm{C}_{4}$ composition of the biotic source, but the other factors must be considered.

Differential preservation of plant components could hypothetically complicate the $\delta^{13} \mathrm{C}$ values in sediments. Lignin, which is acid-insoluble fiber, is more resistant to decomposition than are the water-soluble components (e.g., aminos, sugars, and starches), acid-soluble materials (e.g., holocellulose), and nonpolar extractable components (e.g., lipids and waxes) (Berg and Staaf 1980; McClaugherty et al. 1985; Benner et al. 1987). Each of these materials has a different $\delta^{13} \mathrm{C}$ value with lignin being the most depleted in ${ }^{13} \mathrm{C}$ and cellulose the most enriched. Among oak litter and fine roots, the $\delta^{13} \mathrm{C}$ values vary by $5.1 \%$ and $3.6 \%$, respectively (Natelhoffer and Fry 1988:1635). Differential preservation, however, appears to be a significant factor for only short periods after the introduction of plant materials (Berg et al. 1984; Tucker et al. 1986). Thus for most sediment samples that are 100 or more years old, isolated by burial from introduced nondecomposed plant materials and not uniquely well preserved, it is unlikely that differential preservation of various plant components would pose a problem.

Microbial decomposition of organic materials enriches the ${ }^{13} \mathrm{C}$ content of sediments from the isotopic values of the original plants (Dzurec et al. 1985; Natelhoffer and Fry 1988). Generally, $\delta^{13} \mathrm{C}$ values increase in single soil solums as total carbon decreases (Natelhoffer and Fry 1988), and the implication is that a reduction of carbon reflects more decomposition of organics. However, a better measurement of organic decomposition is the ratio between total carbon and total nitrogen (Birkeland 1984:15), and future studies should incorporate carbon isotope changes and $\mathrm{C}: \mathrm{N}$ ratios for more accurate determinations of the relationship between decomposition and carbon isotope fractionation. Organic inputs act to decrease $\delta{ }^{13} \mathrm{C}$ values toward the $\delta^{13} \mathrm{C}$ of the organic material, while decomposition tends to increase these values. Since decomposition has the final fractionation effect, this must be considered in paleoenvironmental reconstructions.

Illuviation has a compounding effect on $\delta^{13} \mathrm{C}$ isotopes in sediments. Several studies have demonstrated shifts in the $\mathrm{C}_{3} / \mathrm{C}_{4}$ composition of biotic sources using a column of stable isotope measurements, and it is clear that down-profile leaching of organic materials, including stable isotopes, occurs (Dzurec et al. 1985; Volkoff and Cerri 1987; Vitorello et al. 1989). In radiocarbon dating of sediments, the concept of mean residence time (MRT) is used to express the mixed source and time span represented by ${ }^{14} \mathrm{C}$ in a sample. This concept is applicable to ${ }^{13} \mathrm{C}$ values obtained from sediments as well. The implication is that sediment $\delta^{13} \mathrm{C}$ values represent a time span potentially composed of multiple events, and the resulting measurement is an average of these events.

The $\delta{ }^{13} \mathrm{C}$ value of soil carbonate clearly reflects illuviated carbon and is related to the isotopic composition of the soil atmosphere, which, in turn, is controlled by the biomass ratio of $\mathrm{C}_{3} / \mathrm{C}_{4}$ plants growing on the surface and soil respiration rates (Cerling 1984:233). As noted above, the $\delta^{13} \mathrm{C}$ value of atmospheric carbon is $-6.0 \%$. As the ${ }^{12} \mathrm{C}$ and ${ }^{13} \mathrm{C}$ isotopes in carbon dioxide have different atomic weights, they also have different diffusion rates through the soil atmosphere. This results in a fractionation shift in soil carbon dioxide from the soil organic matter. The carbon isotopic ratio of the soil atmosphere systematically becomes heavier (i.e., less negative) toward the surface because of soil respiration; however, isotopic gradients in most soils stabilize below $30 \mathrm{~cm}$. Freezing of soil to the depth of carbonate precipitation can influence the fractionation of carbon isotopes, but even during the Last Glacial Maximum, it is doubtful that soil freezing at such depths would have significantly affected stable carbon isotope ratios in South Texas. The following analysis assumes that an equilibrium exists between the atmospheric and soil organic carbon and that little or no inherited carbon is present in the analyzed samples, i.e., the carbon source is from plants. Previous research on pedogenic carbonates in nonlimestone environments suggests that this is a valid assumption (Cerling and Hay 1986). Cerling (1984:Table 1) 
presents data from a series of locales where $\delta^{13} \mathrm{C}$ values in soil carbonates and matching percents of $\mathrm{C}_{3}$ plant biomass have been measured. A linear regression of data from soils that do not experience freezing at the depth of carbonate formation shows a strong correlation $\left(r^{2}=0.973\right)$ between soil carbonate $\delta^{13} \mathrm{C}$ values and percent of $\mathrm{C}_{3}$ plant biomass (Fig. 40). This produces an end $\delta^{13} \mathrm{C}$ value of $+1.3 \%$ for a pure $\mathrm{C}_{4} / \mathrm{CAM}$ plant community and a value of $-11.6 \%$ for a pure $\mathrm{C}_{3}$ plant community. The linear regression formula for pedogenic carbonates is:

$$
C_{3} \text { Biomass Percent }=\delta^{13} \mathrm{C}(-7.783)+10.106 .
$$

values can be adjusted for fractionation effect and the relative contribution of $\mathrm{C}_{3}$ versus $\mathrm{C}_{4} / \mathrm{CAM}$ plants calculated through the formula:

$$
\begin{gathered}
\text { Estimated Percent of } C_{3} \text { Plant Biomass }= \\
\left.\left[\left(\delta^{13} \mathrm{C}-3.5\right)+13\right)\right] /(-0.14) .
\end{gathered}
$$

These formulas assume that the mean $\delta^{13} \mathrm{C}$ value for $\mathrm{C}_{3}$ plants is $-27.0 \%$ and the mean $\delta^{13} \mathrm{C}$ value for $\mathrm{C}_{4} / \mathrm{CAM}$ plants is $-13.0 \%$. Also, the soil humate model assumes that carbon isotopes in soil humates are fractionated by $+3.5 \%$. It should be noted that there is some disagreement on the mean $\delta{ }^{13} \mathrm{C}$ values, or the degree of

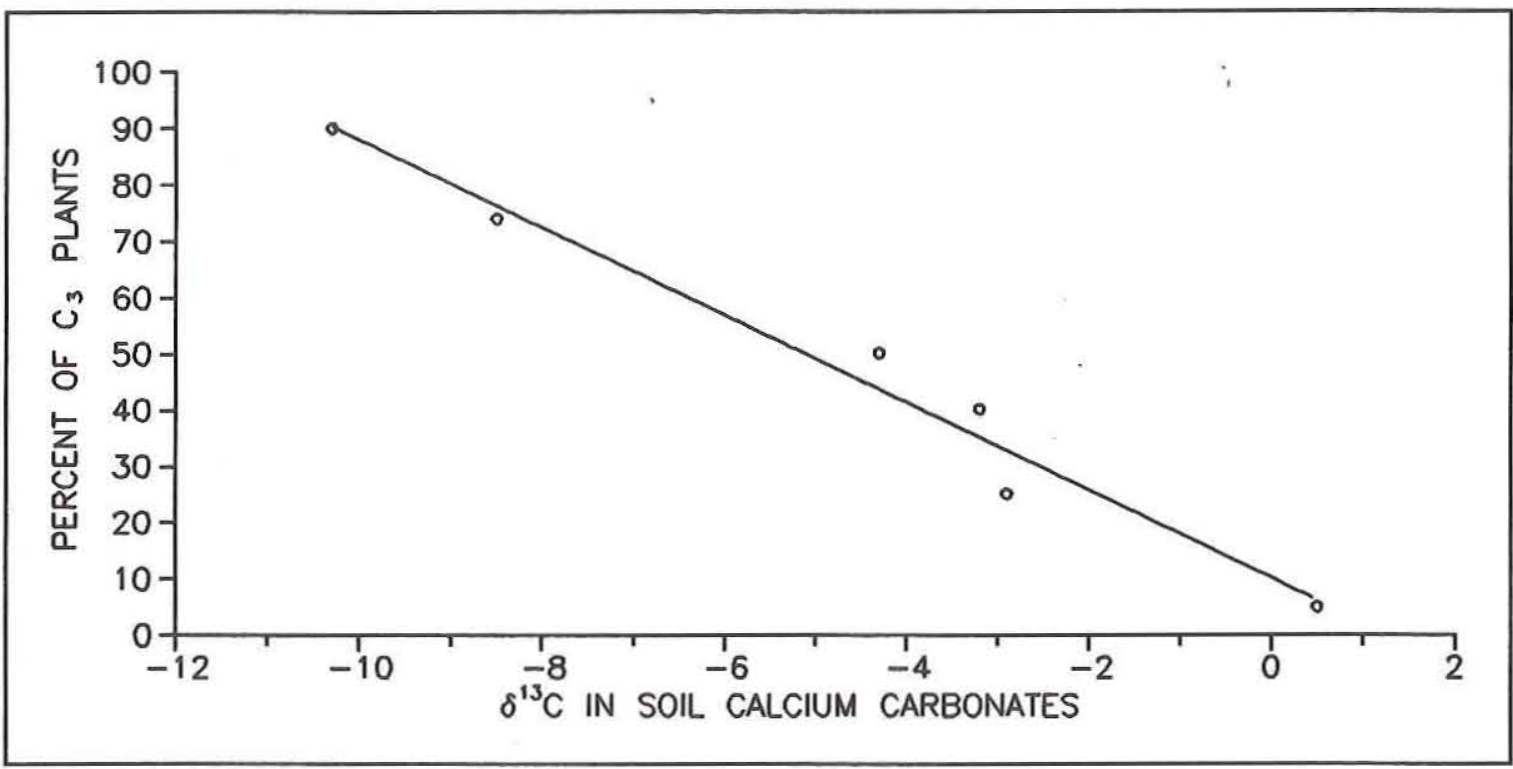

Figure 40. Linear regression of $\delta^{13} \mathrm{C}$ in nonfreezing soil carbonates and percent of $\mathrm{C}_{3}$ biomass, $\mathrm{r}^{2}=0.973$ (data adapted from Cerling 1984:Table 1).

Additionally, the carbon isotopes from sediment humates can be used for assessing the same botanic changes between $\mathrm{C}_{3}$ and $\mathrm{C}_{4} / \mathrm{CAM}$ plants (Stuiver 1975; Flexor and Volkoff 1977; Krishnamurthy et al. 1982; Dzurec et al. 1985; Haas et al. 1986; Nakai and Koyama 1987; Schwartz et al. 1986; Volkoff and Cerri 1987; Guillet et al. 1988; Natelhoffer and Fry 1988; Cerling et al. 1989; Vitorello et al. 1989). Dzurec et al. (1985) and Natelhoffer and Fry (1988) suggest that a +3 to $+4 \%$ shift in carbon isotopes occurs because of microbial decomposition of organic materials in the soils. Soil humate $\delta^{13} \mathrm{C}$ fractionation used, in the above formula, and slightly different mean values would change the estimates marginally.

The graph below (Fig. 41) shows the estimated $\mathrm{C}_{3}$ plant biomass percentages for the Lower Rio Grande Valley obtained from the isotopic analysis of calcium carbonates and the soil humates. These estimates imply that the late Pleistocene environment was dominated by $\mathrm{C}_{4}$ and/or CAM plants. A major gap exists in the record between the early and late Holocene. Then, at ca. 2800 B.P. when the record starts again, the carbon isotopes suggest that the biotic 


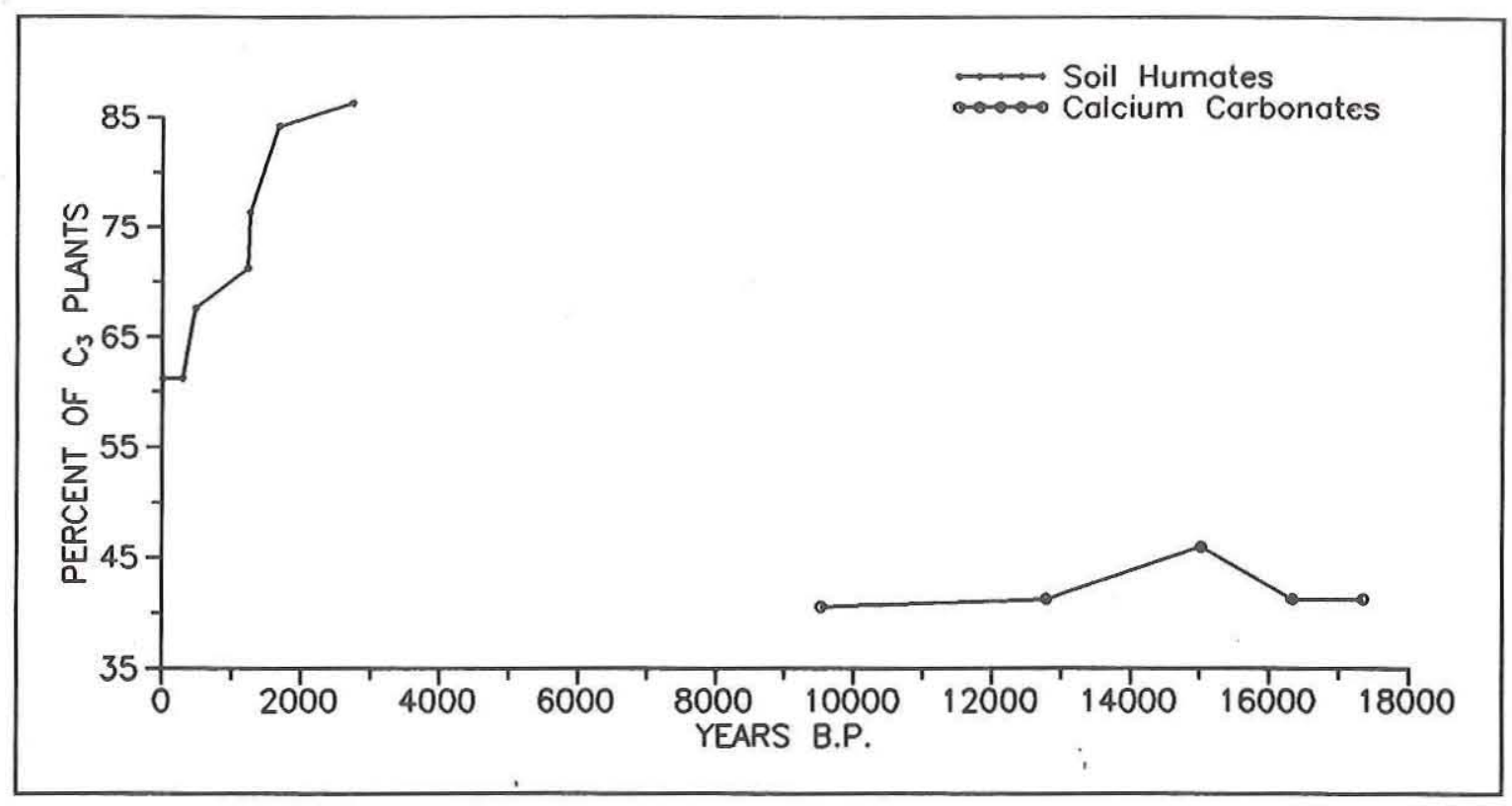

Figure 41. Estimates of $\mathrm{C}_{3}$ plant percentages for humate and pedogenic carbonate samples.

environment was overwhelmingly dominated by $\mathrm{C}_{3}$ plants. Through the remaining 2,800 years, the isotopic record suggests a rapid and consistent shift toward more $\mathrm{C}_{4}$ and/or CAM plants, but never to the levels that existed during the late Pleistocene and early Holocene. One possible scenario is that the lower $\mathrm{C}_{3}$ percentages represent increases in prickly pear, agave, and $\mathrm{C}_{4}$ grasses due to increasingly drier conditions, and that the higher $\mathrm{C}_{3}$ percentages represent the influx of more arboreal species, such as oak, due to increasingly benign, wetter conditions. It is not mere coincidence that a mesic interval defined by pollen analysis in the Lower Pecos region is dated to ca. 2500 B.P. (Bryant and Holloway 1985) and that coeval drops in dated soil humate $\delta^{13} \mathrm{C}$ values occur from a wide range of sites in Texas, from the Southern Plains to East and Central Texas (Boyd and Tomka 1990; Collins and Bousman 1990). Clearly a mesic interval occurred throughout much of Texas at approximately 2500 B.P., and it is registered in the carbon isotope ratios from South Texas.

\section{Oxygen Isotopes}

Changes in the ${ }^{18} \mathrm{O} /{ }^{16} \mathrm{O}$ ratios in the calcium carbonate accumulations reflect temperature of local meteoric (i.e., rain) water (Cerling et al.
1977; Cerling 1984; Cerling and Hay 1986). Cerling (1984) argues that oxygen isotopic composition of meteoric water and mean annual temperature are correlated strongly at continental locations that receive less than $1000 \mathrm{~mm}(39.4$ inches) of rain annually. Stable oxygen isotopes, sporadically occurring from ca. 17,350 to 9500 B.P., are available from pedogenic carbonates from 41HG128 and freshwater marls from $41 \mathrm{WY} 112$, and it is assumed that they were in isotopic equilibrium with their coeval meteoric rainwater. It should be added that the sites in Willacy and Hidalgo counties would have been much farther from the coast and much less influenced by marine weather patterns in the late Pleistocene and early Holocene than today. Additionally, as the ground surface is flat and natural drainage systems are lacking, it is likely that groundwater has accumulated with local meteoric water as its primary source.

Oxygen isotopes measured from carbonates are normally compared to ${ }^{18} \mathrm{O} /{ }^{16} \mathrm{O}$ ratios in the PDB standard; however, stable oxygen isotope ratios in meteoric water are traditionally compared to Standard Mean Ocean Water (SMOW). Oxygen isotope ratios based on the PDB standard are not equal to those calculated from SMOW, and they can be corrected with a simple linear regression formula (Blatt et al. 1980:213), but this 
correction is not necessary for the following analysis.

Stable oxygen isotope ratios in carbonates can be used to estimate their associated $\delta^{18} \mathrm{O}$ value in meteoric water using a linear regression (Fig. 42). This linear relationship suggests that oxygen isotope ratios in pedogenic carbonates and meteoric water are in equilibrium. It is well documented that $\delta^{18} \mathrm{O}$ values in meteoric water are controlled by temperature (Dansgaard 1964; Gat 1980; Yurtsever and Gat 1981; Heaton, et al. 1986), and the relationship also can be estimated with a linear regression (Fig. 43). Evaporation, the mechanism controlling the oxygen isotopic composition of meteoric water (Faure 1986), selectively removes the lighter ${ }^{16} 0$ isotope first, and then as evaporation continues, ${ }^{18} 0$ isotopes are vaporized. Thus, during periods of warmer temperatures and increased evaporative activity, greater amounts of heavier oxygen isotopes are removed from water sources, directly increasing the $\delta^{18} \mathrm{O}$ values of meteoric water. As meteoric water is the primary source of oxygen isotopes in pedogenic calcium carbonates, these data can be used to estimate temperatures during accumulation of meteoric waters. The two linear regressions can be combined in the following formula to provide an estimation of the mean annual temperature:

$$
\begin{aligned}
& \text { Mean Annual Temperature }\left({ }^{\circ} F\right)= \\
& \left.\quad\left\{\left(\delta^{18} \mathrm{O}\right)(0.955)-1.361\right](3.975)\right\}+84.319 .
\end{aligned}
$$

The freshwater marl carbonate sample from 41WY112 has been grouped with pedogenic calcium carbonate nodules for the purposes of climatic estimation. It is possible that the different chemical exchanges that occur in carbonates from these two different depositional environments could cause a systematic difference in fractionation of stable isotopes. More potential oxygen reservoir sources exist for marl than for pedogenic carbonates. As no natural drainages transport significant amounts of water into the area where the marl samples were collected, it is suggested that the primary source of oxygen isotopes in these marls is from local meteoric water that accumulated and remained in the region. It is very likely that this water moved an unknown distance subsurface through the Beaumont aquifer, but it is important to realize that at 9500 B.P., when this rain fell, sea levels were much lower and water tables would have been lower as well. The rapid rise of sea level would have slowed the movement of water in the aquifer and allowed this old water to remain in the system until the historic period when it was precipitated as marl at 41WY112. Until additional data from South Texas are available, it is assumed that the pedogenic carbonates

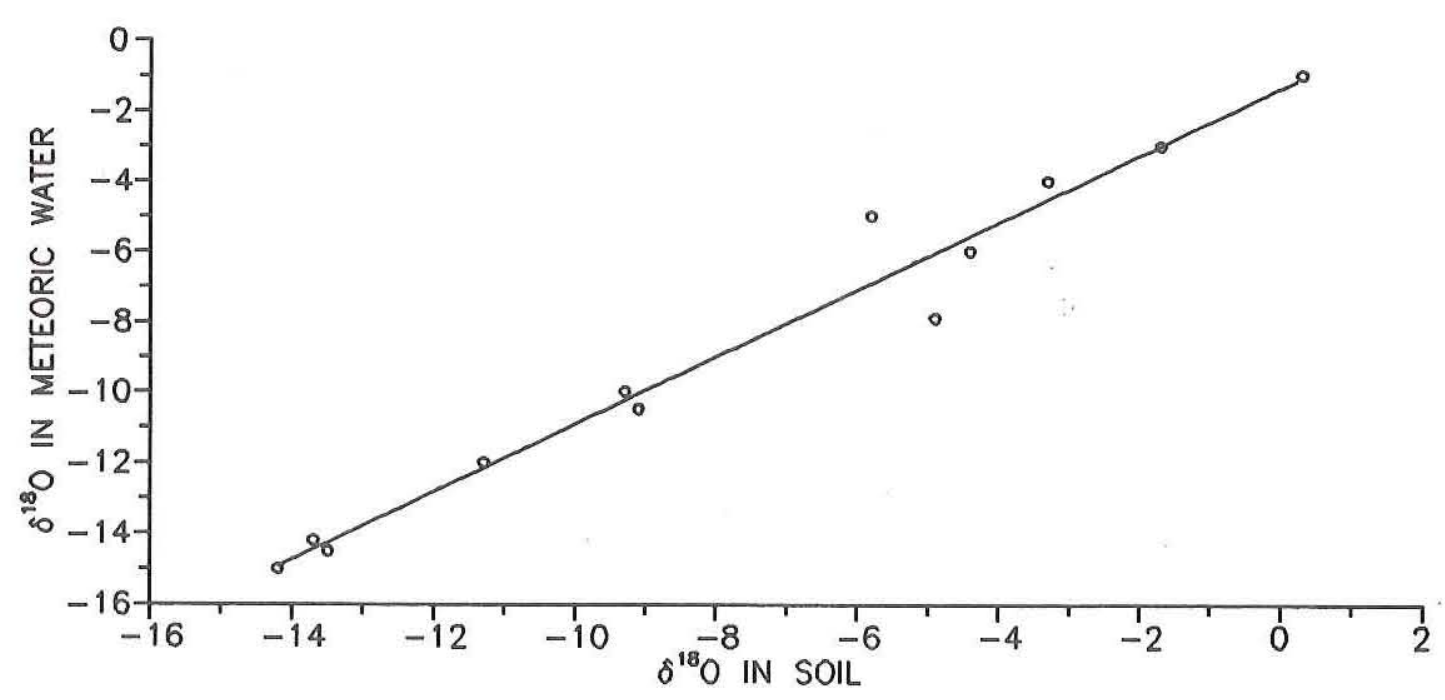

Figure 42. Linear regression between ${ }^{18} \mathrm{O} /{ }^{16} \mathrm{O}$ ratios in soil carbonates and associated meteoric water (data from Cerling 1984:Table 1). 


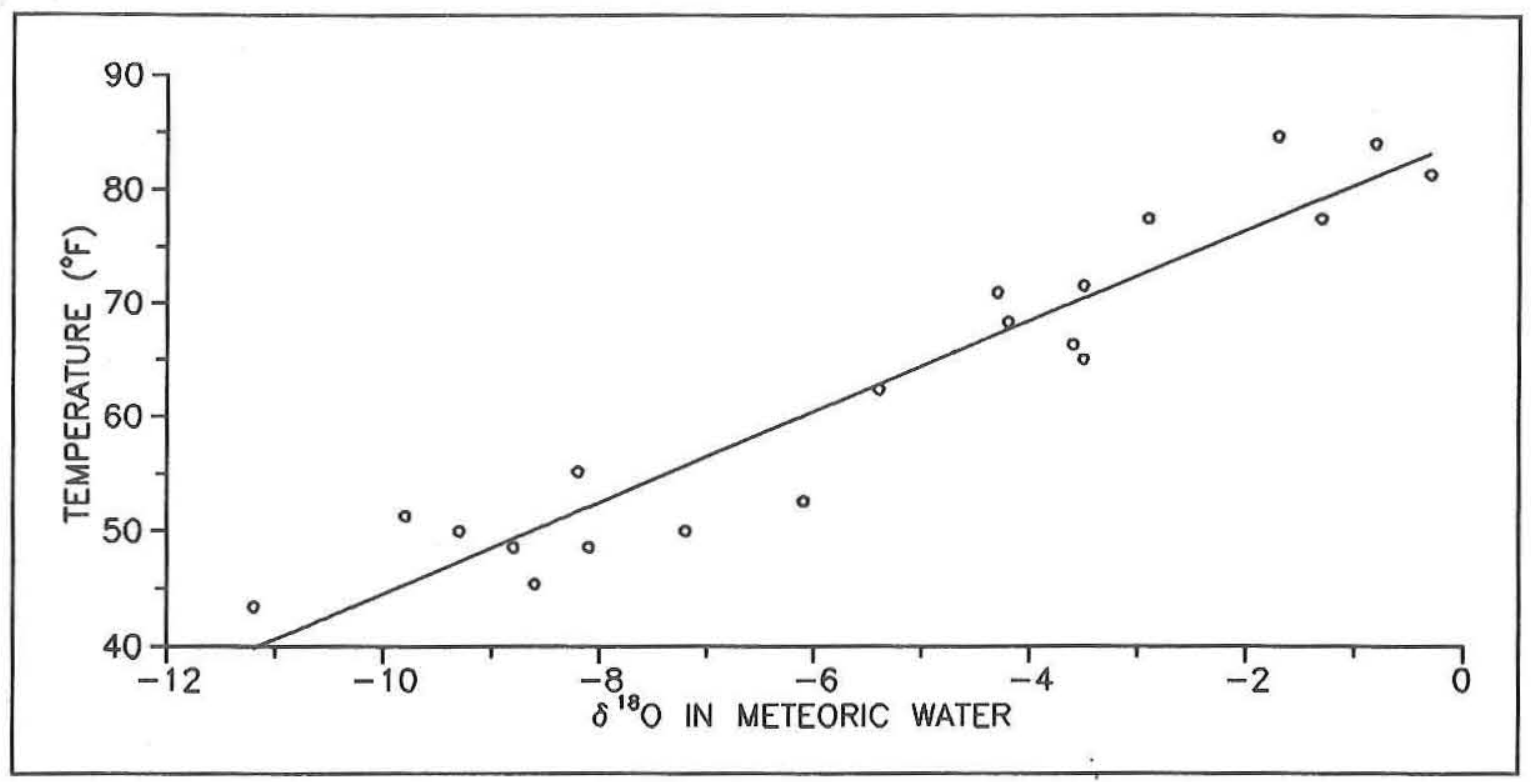

Figure 43. Linear regression between ${ }^{18} \mathrm{O} /{ }^{16} \mathrm{O}$ ratios in local meteoric water and mean annual temperature (data after Cerling 1984:Figure 4).

and freshwater marl are in isotopic equilibrium with coeval meteoric water and that no consistent fractionation difference exists.

The estimates of temperature derived from oxygen isotopes suggest that temperature increased significantly in the late Pleistocene and early Holocene (Fig. 44). The mean annual temperature estimate for 17,350 B.P. is $63^{\circ} \mathrm{F}\left(17.2^{\circ} \mathrm{C}\right)$. This is the modern approximate mean annual temperature for the Southern Plains in Texas today, although it is unlikely that the late Pleistocene seasonal temperature variations in South Texas were the same as those in the Southern Plains today. The modern mean annual temperature in the Lower Rio Grande Valley is $73^{\circ} \mathrm{F}\left(22.8^{\circ} \mathrm{C}\right)$, and this represents an increase of $10^{\circ} \mathrm{F}\left(5.6^{\circ} \mathrm{C}\right)$ from the Last Glacial Maximum to modern day. It has been suggested that the $\delta^{18} \mathrm{O}$ composition of oceans was $1.4 \%$ higher during the Last Glacial Maximum because of the disproportionately large amounts of ${ }^{16} \mathrm{O}$ isotopes trapped in glaciers (Shackleton 1977; Kahn et al. 1981). If this assumption is figured into the temperature calculations, then the estimated temperature for the oldest pedogenic carbonate would be $57.6^{\circ} \mathrm{F}$ $\left(14.2^{\circ} \mathrm{C}\right)$, which would result in a $15.4^{\circ} \mathrm{F}$ $\left(8.6^{\circ} \mathrm{C}\right)$ difference between modern temperature and that at 17,350 B.P. Irrespective of which assumptions are correct, the most rapid tempera- ture rise occurred between 17,350 and 15,010 B.P., and this is clearly a period of increasing temperatures worldwide throughout the late Pleistocene. However, this temperature rise occurred earlier here than is generally documented for the late Pleistocene in the northern hemisphere (CLIMAP 1981), but a major component of the northern hemisphere records reflects rising sea levels as a measure of climatic change (Overpeck et al. 1989:554). Evidence from the unglaciated southern hemisphere suggests that the rise in temperature occurred shortly after 18,000 B.P. (Vogel 1985), and recent entomological evidence from Iowa suggests that warming may have occurred earlier in North America as well (Schwert and Ashworth 1988). The very real possibility exists that there was a lag between surface temperatures and sea level response, as well as earlier warming in lower latitudes. The drop in estimated temperatures at 12,780 B.P. is not unexpected as terminal Pleistocene climates fluctuated a great deal as shown by glacial sequences from the United States and Mexico (Richmond and Fullerton 1986; White 1986). Apparently, the driving mechanism for this terminal Pleistocene climatic fluctuation was cold freshwater from rapidly melting glaciers surging into the Gulf of Mexico via the Mississippi River between 15,000 and 11,000 B.P. (peaking at 


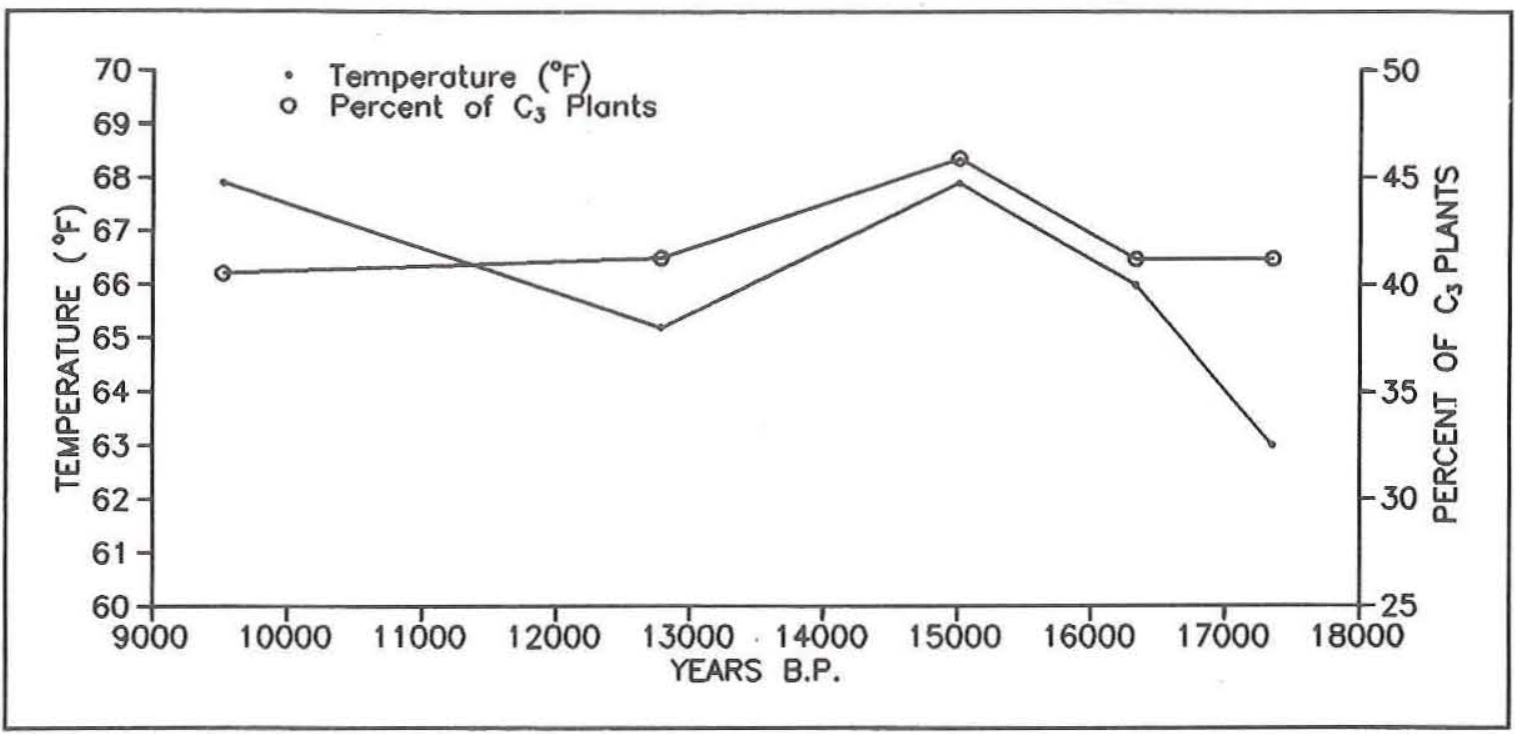

Figure 44. Estimates of $\mathrm{C}_{3}$ plants and temperature using oxygen and carbon stable isotopes from carbonates.

13,000 to 12,000 B.P.), and then rapidly shifting to the North Atlantic via the St. Lawrence River. This caused a dramatic drop in Gulf surface temperatures during peak meltwater discharge which appears to have stimulated high pressure near the surface and resulted in stronger western Atlantic trade winds and drier conditions regionally (Overpeck et al. 1989:555). These drier and cooler conditions between 13,000 and 12,000 B.P. are seen in pollen spectra from Boriack Bog (Bryant 1977; Collins and Bousman 1990).

As Figure 44 shows, slight changes in $\mathrm{C}_{3}$ plant biomass seem to be in part related to temperature changes; however, the apparent early Holocene increase in temperature was not accompanied by an increase in $\mathrm{C}_{3}$ plants. This might be due to an early Holocene dry phase, i.e., the Altithermal, well documented in other portions of the continental United States. Clearly, a large amount of climatic and botanic variation could occur between the few dated sample points presented here. More dates and stable isotopes on pedogenic carbonates, including ones dating to the Holocene, could flesh out a paleoclimatic and paleobotanic record that is lacking for the Lower Rio Grande Valley. It is most unfortunate that a coeval pollen record does not exist for South Texas, but the pollen record from Boriack Bog, the only pollen sequence from Texas that spans the late Pleistocene and early Holocene, shows a significant increase in grasses beginning in the early Holocene (Bryant 1977). A similar pattern may have occurred. in South Texas, and if so, it could account for an increase in $\mathrm{C}_{4}$ grasses at the beginning of the Holocene as the temperatures in the late Pleistocene may have been too low for $\mathrm{C}_{4}$ grasses. An increase of $\mathrm{C}_{4}$ grasses in South Texas would account for the higher $\delta^{13} \mathrm{C}$ values and the lower $\mathrm{C}_{3}$ plant estimate for the early Holocene sample. As phytolith evidence does exist for the widespread occurrence of $\mathrm{C}_{4}$ grasses in the early Holocene in South Texas (Robinson 1979, 1982), this seems to be a reasonable model. If $\mathrm{C}_{4}$ grass biomass was limited in the Pleistocene because of lower temperatures, this would have provided a ceiling on $\delta^{13} \mathrm{C}$ values and a lower limit on $\mathrm{C}_{4}$ plant estimations, as apparently occurs in the late Pleistocene samples. This would suggest that the $\mathrm{C}_{4}$ component in the late Pleistocene is constituted of CAM plants, such as prickly pear or agave, and not of $\mathrm{C}_{4}$ grasses. Further pollen, phytolith, and isotope data could more fully document the nature of Pleistocene and Holocene environmental changes in South Texas.

\section{Faunal Remains}

At 41WY140, large and thick tortoise shell fragments were recovered in situ from undisturbed Zone 2 deposits on the sloping surface of the ditch 
$1 \mathrm{~m}$ south of Backhoe Trench 1 at $70-80 \mathrm{~cm}$ below surface. The age of the inorganic (apatite) fraction of the tortoise shell is calculated to be $9360 \pm 415$ B.P. $(\mathrm{GX}-15125-\mathrm{A})$. This tortoise is probably the extinct giant species Gopherus hexagonatus, as numerous other tortoise remains of this species have been recovered from the same stratigraphic position in this region (Westgate 1987:200-219). These $G$. hexagonatus remains were tentatively assigned to an early Wisconsin age by Westgate (1987:207) because the samples were all found in the upper Beaumont Formation; however, no tortoisc samples, other than that from $41 \mathrm{WY} 140$, were chronometrically dated. It is generally believed that the Beaumont Formation was deposited during a period of high sea levels in the late Pleistocene, and its estimated age span ranges from 132,000 to 120,000 B.P. (see Chapter 1). In vicw of the difference between the tortoise radiocarbon age and the estimated age span of the Beaumont Formation, it is significant that Gopherus is a burrowing tortoise and that Westgate (1987:204) found a few individuals in a position that suggested the use of burrows. Thus, the presumed stratigraphic association of the Beaumont Formation and the tortoises may be not be correct. Nevertheless, the 4IWY140 tortoise radiocarbon age should not be accepted without question, as apatite and not collagen was used, and apatite is notorious for producing unreliable radiocarbon ages (Taylor 1987:53-61). Unfortunately, gelatin (collagen) was not present in the tortoise shell. It can be argued that if the tortoise remains are the same age as the Beaumont Formation, it is unlikely that the apatite date would be so recent. More radiocarbon dates on tortoises, especially on the collagen fraction, are necessary before a terminal Pleistocene date can be accepted without reservation, but at present, this is the only chronometric age estimate for Gopherus remains in South Texas. If the age is correct, then it appears that the tortoise was present in South Texas when conditions became warmer in the early Holocene (see Fig. 44). More work is required to determine if the tortoise remains extend back into the Pleistocene and are associated with colder climatic conditions.

\section{STABLE ISOTOPES AND HUMAN DIET}

Since Vogel and van der Merwe (1977:238242) presented the first dietary analysis in archeology using stable carbon isotopes in prehistoric human bone, an explosion of applications has occurred (van der Merwe 1982; DeNiro 1987; Price 1989). A great deal more is now known about stable carbon isotopes, diets, and fractionation effects in bone, and stable isotopes from other elements, such as nitrogen, now are known to yield additional types of information. Carbon and nitrogen stable isotope ratios were measured on all individuals recovered from previous projects on the Hidalgo-Willacy Drainage Ditch. The dietary implications of the stable isotope analysis are presented below; however, first it is necessary to discuss the radiocarbon dating of these samples.

\section{Radiocarbon Dates on Human Bone}

The remains of three individual humans were recovered during previous projects along the Hidalgo-Willacy Drainage Ditch by Prewitt and Associates, Inc. (Day et al. 1981; Hall et al. 1987), and all have been radiocarbon dated. One of these, the burial from 41WY50 (Prewitt 1981), was redated in the current project because the previous date was obtained from apatite, the inorganic fraction of bone, and the date was not corrected for carbon isotope fractionation effect. Much research on bone dating has shown that apatite dates are often unreliable, especially if secondary carbonates are not carefully removed from the inorganic fraction (Hassan et al. 1977; Taylor 1987:53-61). Whenever possible, the organic fractions (bone gelatin or collagen) should be dated, but recent research has shown that even collagen can be altered by diagenesis (Stafford et al. 1987; Stafford et al. 1988). Thus all bone dates, not just apatite, must be considered with caution. All new dates discussed in this section were corrected for carbon isotope fractionation effect and use the 5,570-year half-life.

The previous apatite age of the $41 \mathrm{WY} 50$ burial was $540 \pm 110$ B.P. (Tx-4256), while the new gelatin age is $1415 \pm 140$ B.P. (GX-15124$\mathrm{G})$. The new date is almost three times older than the original radiocarbon assay, and this clearly represents a significant difference. The present gelatin date on the 41 WY 50 burial is considered more reliable than the previous date, because it was run on the gelatin fraction and corrected for fractionation effect. Little collagen was obtained from the 41WY113 burial, and an accelerator date was required, producing an age of $1088 \pm 90$ B.P. 
$(\mathrm{GX}-15123-\mathrm{G})$. The apatite fraction from this burial was also radiocarbon dated resulting in an age of $1830 \pm 215$ B.P. (GX-15123-A). At this point in time, the AMS date on the gelatin fraction from the 41WY113 burial is probably more reliable, and this is accepted as the correct age of the burial. The two gelatin dates from 41WY50 and $41 \mathrm{WY} 113$ are fairly close in time, but a Student's $t$-test $(t=1.964)$ indicates that the probability of contemporaneity is less than $5 \%$. Only the inorganic apatite fraction could be dated from the 41WY67 burial, resulting in an age of $4495 \pm 350$ B.P. (GX-15254-A). Gelatin was recovered from the $41 \mathrm{WY} 67$ bone sample, but the large differences between the stable carbon isotopes from the gelatin and apatite fractions (see Appendix D) and a visual inspection of the gelatin suggested that the gelatin had experienced diagenetic change (Harold Krueger, personal cominunication 1989). These radiocarbon dates on human bone can be used to argue that occupation throughout the late Holocene is likely, but they provide no evidence of human occupation during the middle or early Holocene or during the terminal Pleistocene in the Lower Rio Grande Valley.

\section{Carbon Isotopes}

Bone is constructed of organic and inorganic materials. The inorganic components constitute approximately $70 \%$ of the dry weight, the organic components make up $20 \%$, and bound water accounts for most of the remaining $10 \%$. The pathways for carbon inclusion in the inorganic fraction, i.e., apatite, and the organic fraction, i.e., collagen, are apparently different (Krueger and Sullivan 1984; Sillen et al. 1989).

Krueger and Sullivan (1984) argue that in herbivores, the source of carbon in collagen and apatite is carbohydrates from plant foods, although collagen and apatite phases fractionate stable carbon isotopes to different degrees. For herbivores, collagen is on the average $5 \%$ higher and apatite is $12 \%$ higher than the diet. More important for human dietary studies is the fractionation that occurs between herbivore diet and the portions eaten by humans. Lipids (fat) in herbivores are $1 \%$ less than diet, while herbivore protein (meat) is $5 \%$ higher than diet. In carnivores, ingested meat protein is the greatest contributor to collagen, while ingested lipids contribute most of the carbon to apatite. Carnivore collagen does not fractionate from the protein $+5 \%$ level, but carnivore apatite fractionates $+9 \%$ from the lipid level of $-1 \%$, or $+8 \%$ from carnivore prey diet.

The situation is more complex for omnivores such as humans. Krueger and Sullivan (1984) argue that humans incorporate carbon into collagen, a protein, directly from meat protein, but most of the carbon in apatite is acquired initially from plant carbohydrates, secondly from meat lipids, and then only a small amount from meat protein. Circumstantial evidence suggests that significant amounts of carbon isotopes in human collagen are obtained from both meat and plants (Vogel and van der Merwe 1977; Klepinger and Mintel 1986; Bousman et al. 1989), but the relative contribution of each is currently unknown (Sillen et al. 1989). It is also unknown how the relative contribution of carbon isotopes from each source changes as one or the other food source is altered within the diet. Nevertheless, through one path or the other, it is clear that carbon isotopes in human collagen are fractionated $+5.0 \%$ above either the plant foods ingested directly by humans or the plant foods ingested by herbivore prey animals eaten by humans. If the primary source of carbon isotopes is through prey animals, then biotic changes should be registered in the human carbon isotope ratios. This proposition assumes that prey-animal diets reflect biotic changes. While this has not been demonstrated for South Texas, data are available from Africa to suggest this is correct (Sealy 1986, 1989; Bousman et al. 1989). Thus, if $\delta^{13} \mathrm{C}$ values from human remains mirror changes in the botanical environment, one can take the extreme viewpoint that the major carbon pathway is from plant to herbivore to human, and that changes in human $\delta{ }^{13} \mathrm{C}$ values are due simply to environmental changes that are transferred trophically to humans with no change of diet. However, if the human and environmental patterns differ, then one must assume that this reflects a true dietary difference that cannot be explained as simply a botanical change that is indirectly registered in human isotopes. Clearly a measure of environmental $\delta^{13} \mathrm{C}$ change is needed, and carbon isotopes from radiocarbon-dated, bulk soil humates are the best and most easily acquired source.

Stable carbon isotope ratios from dated sediment samples and human collagen are plotted in Figure 45. Collagen $\delta{ }^{13} \mathrm{C}$ values obtained from 


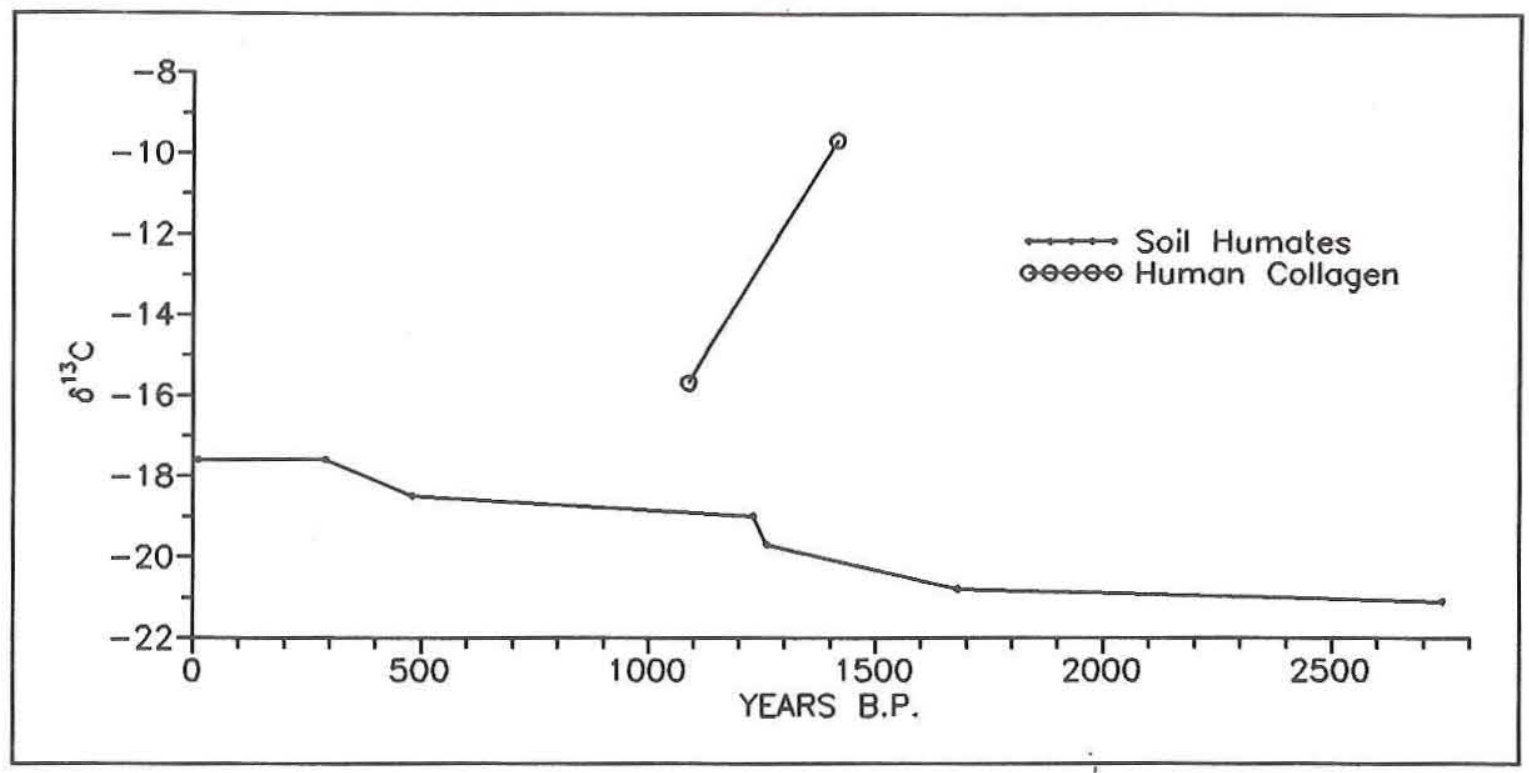

Figure 45. Soil humate and human stable carbon isotope ratios.

the 41 WY 67 remains are not included because the collagen was poorly preserved. In addition, apatite $\delta{ }^{13} \mathrm{C}$ values are not used because their chemical taphonomy is poorly understood. The $\delta{ }^{13} \mathrm{C}$ values from soil humates show a trajectory from low to high through time; however, the trajectory for human carbon isotope ratios is opposite to this environmental trend. This suggests that environmental change does not account for the difference between the two human carbon isotope ratios. The older human sample is from a coastal clay dune at $41 \mathrm{WY} 50$, and the younger sample is from the inland site 41WY113. A $6.0 \%$ difference exists between the two human $\delta{ }^{13} \mathrm{C}$ values (sec Appendix D), and the underlying environmental trend, if registered in the human isotope ratios, may have helped make this difference less than it might have been with no environmental change. A $6.0 \%$ difference would reflect a $40-45 \%$ difference in $\mathrm{C}_{3}$ versus $\mathrm{C}_{4} / \mathrm{CAM}$ plant use, and the coastal human clearly ingested more $\mathrm{C}_{4} / \mathrm{CAM}$ plants or animals that ate $\mathrm{C}_{4} / \mathrm{CAM}$ plants than the individual at 41WY113. Given only two human collagen measurements, it is unreasonable to suggest a temporal pattern in diets; rather, a coastal and inland difference in prehistoric diets is a more reasonable possibility.

If one assumes that the carbon isotope ratios in these two individuals represent the mix of $\mathrm{C}_{3}$ and $\mathrm{C}_{4} / \mathrm{CAM}$ plants directly ingested, then the individual from 41WY113 ate approximately 55\% $\mathrm{C}_{3}$ plants, but the individual from 41WY50 ate only $12 \%, \mathrm{C}_{3}$ plants. This is a dramatic difference that requires some explanation. First, the mixed $\mathrm{C}_{3}$ and $\mathrm{C}_{4} / \mathrm{CAM}$ plant dict of the $41 \mathrm{WY} 113$ individual seems intuitively reasonable given a presumed consumption of prickly pear (a CAM plant), oak ( $\mathrm{a} \mathrm{C}_{3}$ plant), and deer (herbivores that eat mostly $\mathrm{C}_{3}$ plants). However, the high $\mathrm{C}_{4} / \mathrm{CAM}$ plant utilization by the 41 WY50 individual is anomalous. The coast is not an area known for a great dominance of $\mathrm{C}_{4} / \mathrm{CAM}$ plants such as agave or prickly pear (see Chapter 1), and normally, marine environments mimic $\mathrm{C}_{3}$ plant $\delta^{13} \mathrm{C}$ values (i.e., -27 to $-20 \%$ ). A very limited number of stable carbon isotopes, however, are available from Redfish Bay along the Texas coast near Corpus Christi (Parker 1964), and these indicate that marine plants and animals from this portion of the Texas coast have $\delta^{13} \mathrm{C}$ values that fall within the range of $\mathrm{C}_{4}$ and CAM plants. The mean value of five plants and animals is $-15.0 \%$. Assuming that these plants and animals were all eaten and contributed equally to human collagen, then fractionation of these values by $+5.0 \%$ could produce human collagen values of $-10.0 \%$. The $\delta{ }^{13} \mathrm{C}$ collagen value of the $41 \mathrm{WY} 50$ individual is $-9.7 \%$. Thus, it is very likely that the lower coastal marine environments also have similar $\delta{ }^{13} \mathrm{C}$ values which mimic a $\mathrm{C}_{4} / \mathrm{CAM}$ plant signal 
and that these high $\delta^{13} \mathrm{C}$ values are reflected in the stable carbon isotope ratios in the individual from $41 \mathrm{WY} 50$.

\section{Nitrogen Isotopes}

In terrestrial ecosystems, ${ }^{15} \mathrm{~N} /{ }^{14} \mathrm{~N}$ ratios can be used to separate plants into two groups: legumes and all other plants (Virginia and Delwiche 1982). These ratios are compared to ${ }^{15} \mathrm{~N} /{ }^{14} \mathrm{~N}$ ratios in air which are used as the standard unit like the PDB standard in carbon isotopes. Legumes have slightly less ${ }^{15} \mathrm{~N}$ and their corresponding $\delta^{15} \mathrm{~N}$ values are consistently lower. The difference is not due to isotopic fractionation by plants, like the fractionation of carbon isotopes by photosynthesis, but rather it is due to the ability of legumes to extract, i.e., fix, nitrogen from two sources: $\mathrm{N}_{2}$ from the atmosphere and nitrate and ammonium ions from the soil. Nonlegume plants can only fix nitrogen from soil nitrate and ammonium. Atmospheric $\delta{ }^{15} \mathrm{~N}$ values average $0 \%$, as it is the standard for measurement, while nitrate and ammonium have variable but higher $\delta^{15} \mathrm{~N}$ values (Letolle 1980). As atmospheric $\mathrm{N}_{2}$ has lower $\delta^{15} \mathrm{~N}$ values than soil nitrogen, this difference is transferred to plants with very little alteration. On average, legumes have $\delta^{15} \mathrm{~N}$ values near $1 \%$, and $\delta{ }^{15} \mathrm{~N}$ values of nonlegume plants are close to $9 \%$ (DeNiro 1987).

In marine ecosystems, ${ }^{15} \mathrm{~N} /{ }^{14} \mathrm{~N}$ ratios of plants are controlled by the isotopic ratios available from inorganic sources, which include atmospheric $\mathrm{N}_{2}$ and soil nitrates and ammonium dissolved in ocean waters. Only blue-green algae are capable if fixing dissolved $\mathrm{N}_{2}$ from the oceans, and their corresponding $\delta^{15} \mathrm{~N}$ values are approximately $0 \%$. Other marine plants, such as phytoplankton, use only dissolved nitrates and ammonium and no atmospheric $\mathrm{N}_{2}$. Correspondingly, these plants are more enriched in ${ }^{15} \mathrm{~N}$ and have higher $\delta^{15} \mathrm{~N}$ values. Unfortunately, $\delta^{15} \mathrm{~N}$ values in oceans are highly variable geographically, and the base level, starting point for $\delta^{15} \mathrm{~N}$ values in the Gulf of Mexico and Laguna Madre is unknown. It is currently impossible to estimate the expected environmental $\delta^{15} \mathrm{~N}$ values of this marine ecosystem.

Two additional factors complicate stable nitrogen isotope dietary studies. The first is the enrichment of ${ }^{15} \mathrm{~N}$ as nitrogen isotopes pass from primary producers (plants) to consumers (animals), increasing $\delta^{15} \mathrm{~N}$ values by approximately $3 \%$ for each trophic level; this occurs in both marine and terrestrial food webs (DeNiro 1987). As marine ecosystems have more trophic levels, they generally have higher $\delta^{15} \mathrm{~N}$ values than terrestrial systems. For example, the mean $\delta^{15} \mathrm{~N}$ value for marine plants is $7 \%$ (DeNiro 1987). If the nitrogen isotopes traveled through two trophic levels, i.e., zooplankton and fish, before human ingestion and $100 \%$ of the human diet was from marine sources, then the isotopes would have passed through three trophic levels, and the predicted $\delta{ }^{15} \mathrm{~N}$ value for human collagen would be $9 \%$ higher, or $16.0 \%$. In terrestrial systems, however, if $70 \%$ of a person's diet consisted of nonlegume plants with a $\delta^{15} \mathrm{~N}$ value of $9 \%$ and $30 \%$ was derived from animals that ate nonlegume plants, then the predicted $\delta^{15} \mathrm{~N}$ value of that individual's bone collagen would be approximately $13 \%$. If, in the same ecosystem, a person ingested $20 \%$ legumes, $50 \%$ nonlegume plants, and $30 \%$ animals that ate nonlegume plants, then the predicted $\delta^{15} \mathrm{~N}$ value would be $11.3 \%$.

The second complication consists of environmental effects on $\delta^{15} \mathrm{~N}$ values in natural ecological systems (Heaton 1987). Two known environmental effects are aridity and salinity. Heaton et al. (1986) and Sealy et al. (1987) have shown that stable nitrogen isotope ratios in human and mammal bone collagen are negatively correlated with mean annual rainfall, while Heaton (1987) has demonstrated that $\delta^{15} \mathrm{~N}$ values in plants are also negatively correlated with mean annual rainfall. Even though the higher $\delta^{15} \mathrm{~N}$ values in plants would be passed on to animals, the rate of nitrogen fractionation correlated to aridity is greater in animals than in plants; regression slopes between rainfall and plant $\delta^{15} \mathrm{~N}$ values range from ca. -0.3 to -0.4 , while regression slopes between rainfall and animal bone collagen $\delta^{15} \mathrm{~N}$ values range from ca. -1.1 to -1.3 . Higher $\delta^{15} \mathrm{~N}$ values in animals appear to be a metabolic response to water stress, but this response has not been demonstrated for plants. In fact, Shearer et al. (1978) have shown that $\delta^{15} \mathrm{~N}$ values in total soil nitrogen are most strongly correlated with aridity, and this suggests that the nitrogen isotopic ratios of soils are transferred to plants and probably that no nitrogen fractionation by plants occurs. The mechanisms that control soil $\delta^{15} \mathrm{~N}$ values are unknown. Research has shown also that plant $\delta{ }^{15} \mathrm{~N}$ values are elevated near coasts (Virginia and 
Delwiche 1982; Heaton 1987). As $\delta^{15} \mathrm{~N}$ values of ocean water are generally higher than terrestrial sources, it seems likely that sca-spray could introduce nitrates with high $\delta^{15} \mathrm{~N}$ values and that this would influence the $\delta^{15} \mathrm{~N}$ values of plants growing near the coast. Heaton (1987) has demonstrated that plants growing at inland saline environments similar to La Sal Vieja also have high $\delta{ }^{15} \mathrm{~N}$ values. It is known that salt can influence a number of metabolic, physical, and chemical processes and reactions, and one or a combination of these apparently accounts for the elevated $\delta{ }^{15} \mathrm{~N}$ values in saline environments.

The $\delta{ }^{15} \mathrm{~N}$ values measured in human collagen from the three burials recovered along the Hidalgo-Willacy Drainage Ditch are $9.6 \%$ (41WY50), $6.2 \%$ (41WY67), and $7.6 \%$ (41WY113) (see Appendix D). As stated above, the collagen from the $41 \mathrm{WY} 67$ burial is poorly preserved and the carbon isotope ratios are suspect, but it is unknown if the stable nitrogen isotope ratios were affected. Assuming the $\delta{ }^{15} \mathrm{~N}$ value from this burial was not altered by diagenesis, it appears that the coastal burial from $41 \mathrm{WY} 50$ has the highest $\delta^{15} \mathrm{~N}$ value, as would be expected in an individual who intensively utilized plants and animals from marine and near-marine environments. It is interesting that the 41WY113 burial has a higher $\delta^{15} \mathrm{~N}$ value than the 41WY67 individual, and it is possible that this individual may have exploited environments that were more saline, but not necessarily coastal, such as La Sal Vieja.

\section{SUMMARY}

Stable isotopic analysis in Texas archeology is just beginning, and the results reported here are limited. Nevertheless, the potentials are farreaching, and stable isotopes can provide challenging new data on environmental change and human diets. The more traditional form of isotopic analysis, radiocarbon dating, suggests that a Pleistocene tortoise, Gopherus sp., common to South Texas may have lived as recently as 9,400 years ago. Radiocarbon dating of human bone provides the oldest chronometric evidence of human occupation in the Lower Rio Grande Valley at ca. 4500 B.P. Humans may have occupied, and probably did occupy, the region before this time, but unquestionable evidence is lacking.

Carbon and nitrogen isotopes in human bone collagen suggest that human diets near the coast may have been different from those farther inland. Only three individuals were assessed, and additional assays could and probably would significantly change the picture. This initial attempt was made to assess the potential of the technique, and in those terms, it is clear that the technique has merit and can provide information on human diets that is unavailable from any other source.

Analyses of stable oxygen and carbon isotopes from carbonates and carbon isotopes from soil humates provide the first direct paleoenvironmental information from this region. Again, this was an attempt to assess the potential of the technique, and it is clear that these isotopic analyses can provide extremely useful paleoenvironmental data for the region. The results suggest that plant communities were dramatically different in the late Pleistocene and early Holocene and that plant communities in the late Holocene were not stable, but in a state of flux. These data also provide the first paleotemperature estimates for the Last Glacial Maximum in Texas. Further stable oxygen isotope analyses on spelothems from caves as abound in Central Texas might provide a more-detailed paleoclimatic record than is possible from pedogenic carbonates. While far from conclusive, the paleoenvironmental and dietary studies presented in this chapter constitute a step in providing some of the kinds of contextual data that are needed for interpreting the archeological information that has been collected from South Texas and in identifying the kinds of data that need to be recovered in future investigations. 


\section{TESTING THE HUNTER-GATHERER MOBILITY AND TERRITORIAL MODELS FOR THE LOWER RIO GRANDE VALLEY}

by Steve A. Tomka and C. Britt Bousman

The three models developed in Chapter 3 provide alternative explanations for resource exploitation patterns in the Lower Rio Grande region by incorporating optimal foraging theory and assuming that territorial divisions limited access to resources. These factors would have conditioned the intensity of artifact use, curation, and distribution. In this chapter, an attempt is made to assess which model best matches the actual data from the region and, in the process, provide a more comprehensive picture of prehistoric human adaptations in the Lower Rio Grande Valley.

\section{THE REGIONAL DATA BASE}

A test of the three models necessitates a broad regional perspective. Such is not afforded by the small artifact samples from the five archeological sites investigated during this project along the Hidalgo-Willacy Drainage Ditch. A review of published artifact analyses from previous projects revealed that many attributes had been recorded that were useful for testing the three models. Some important attributes, however, were not recorded, and a reanalysis of selected artifact attributes from previously recorded sites was undertaken to provide an appropriate and comparable regional data base.

Neither the present archeological project nor previous investigations (Mallouf et al. 1977; Day et al. 1981; Hall et al. 1987) provide a represen- tative sample of sites in all five environmental zones described in Chapter 1. Most sites along the drainage ditch occur in the lowland plain, the sand sheet, and the upland plain; no previously analyzed site collections are available from the Rio Grande floodplain or delta, and only limited data are available from the coastal zone. Even though artifacts were collected from many sites in Cameron County, especially by Anderson in the early twentieth century, and these collections could provide information that might significantly alter regional interpretations, it was not feasible to consider analysis of these artifacts during this project. For this reason, additional sites in the floodplain, delta, and coastal zones in Cameron County are not formally included in this assessment of the hunter-gatherer models.

Another problem with the available site collections is that they are small. Small sample sizes prohibit meaningful quantified analysis on a site-by-site basis, and one solution to this problem is to lump sites into groups or spatial clusters. Seven site clusters were defined within Hidalgo and Willacy counties (Fig. 46). Table 15 lists the sites included in each cluster. The first cluster consists of 16 sites surrounding Laguna La Sal Vieja in the central portion of the sand sheet. Site cluster 2 has nine sites located in the eastern portion of the sand sheet. No site clusters were defined for the western portion of the sand sheet. Cluster 3 consists of nine sites in the westernmost portion of the project area in the center of the 


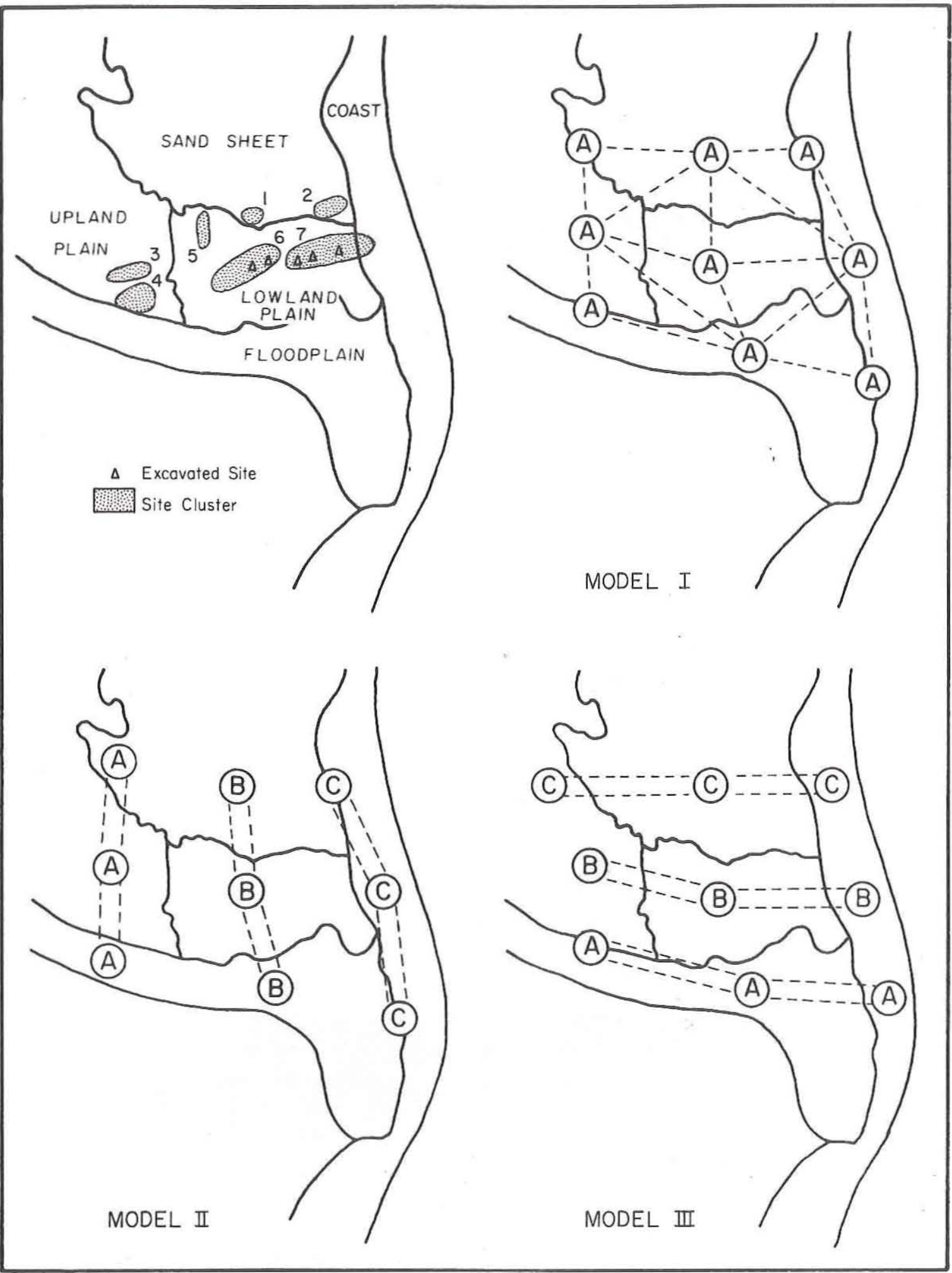

Figure 46. Site clusters and hunter-gatherer mobility/territorial models. 


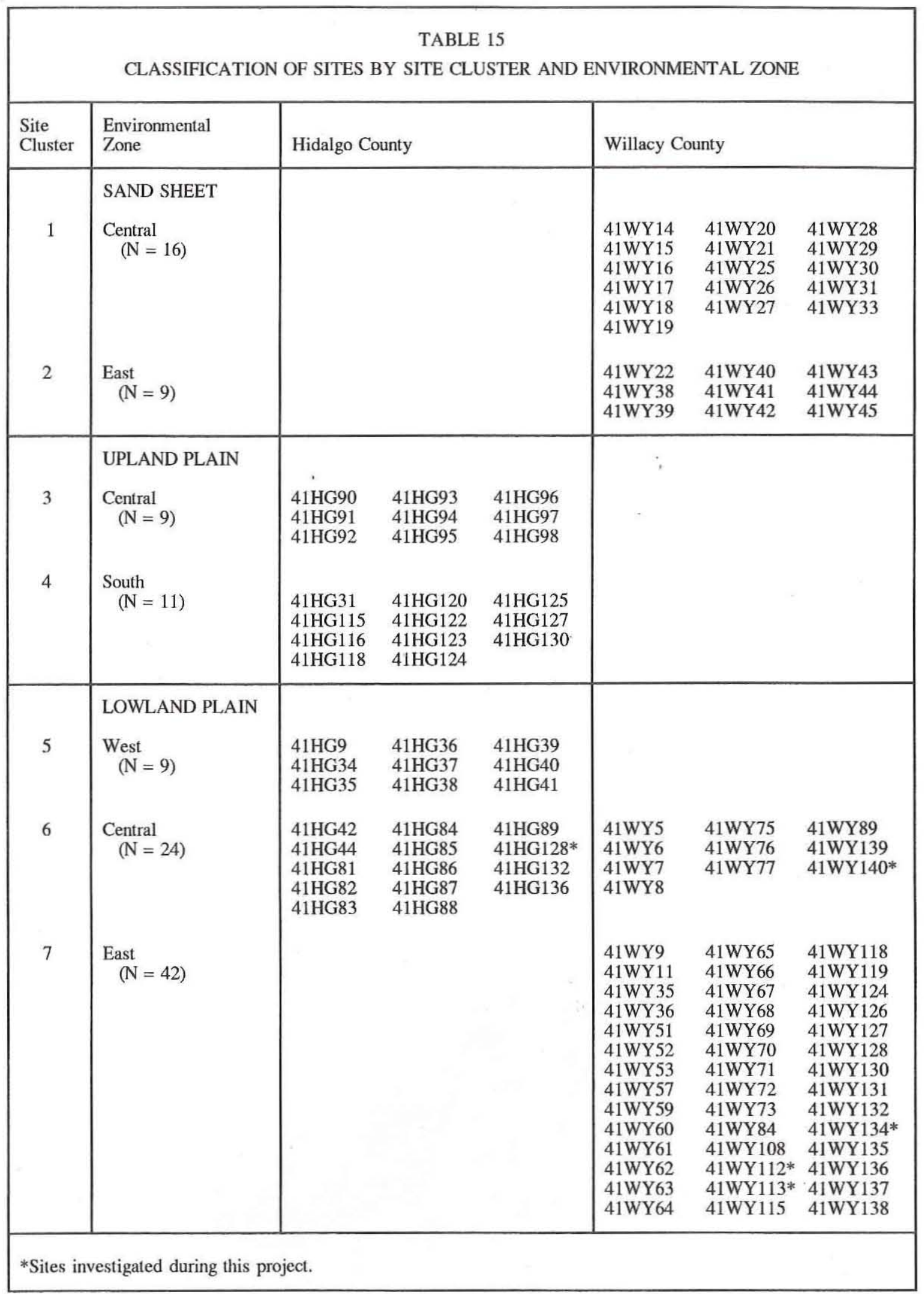


upland plain. Cluster 4 has 11 sites located near the junction of Arroyo Colorado and the Rio Grande in the southern portion of the upland plain. This is the only cluster located near the Rio Grande floodplain. Cluster 5, with nine sites, is located in the western portion of the lowland plain. Cluster 6 has 24 sites and is located in the central lowland plain. Forty-two sites comprise the seventh cluster, and these are located primarily in the eastern portion of the lowland plain. Some of the sites in this zone are located in the coastal environmental zone but have been grouped in the eastern lowland plain because of very small artifact sample sizes. The sites investigated during this project occur in two clusters. Sites 41HG128 and 41WY140 are in Cluster 6, while 41WY112, 41WY113, and 41WY134 are in Cluster 7.

\section{ANALYTICAL METHODS}

In Chapter 3, predictions were developed for the distributions of individual artifact classes for each of the three hypothetical models of human adaptation. These predictions were presented as deviations from even or homogeneous distributions of artifacts across the landscape. In this chapter, the real data are presented and compared to the predictions. The raw data are not directly compared to the models; rather, they are transformed statistically so that the real deviations can be compared to the predicted deviations. The discussion that follows presents the criteria used to define the individual artifact classes and the statistical techniques used to calculate the deviations.

\section{Attribute Definitions}

Based on the data presented in published reports and on limited reanalysis of selected artifact attributes, artifacts are categorized into the analytical groupings defined in Chapter 3 . The unmodified lithic debitage is classified by reduction stage, size category, and removal intent. In addition, relative frequencies are tabulated by site cluster. To maintain statistically significant samples by cluster, both complete and fragmentary flakes are considered in each analysis.

Primary (i.e., corticate) and secondary (i.e., partially decorticate) complete flakes, proximal fragments, and chips (medial and distal fragments) are considered as early reduction debitage, while late reduction debitage consists of tertiary (i.e., decorticate) debitage. Maximum dimension size categories are defined for debitage in $10-\mathrm{mm}$ increments. Due to the small size of raw materials, the largest size category consists of flakes larger than $30 \mathrm{~mm}$. Also, the smallest size class is not used in the analysis because of different collection procedures, i.e., fine screening in the present project. Finally, complete flakes and proximal fragments are classified as resharpening flakes or other flakes based on removal intent. Resharpening flakes consist of both uniface and biface resharpening flakes. The first type consists of flakes with single facets, numerous microstep fractures immediately dorsal to the platform surface, and rounding of the edge formed by the dorsal facet and striking platform proper. In general, these flakes are trapezoidal, are slightly longitudinally curved at their distal ends, and have dorsal ridges running perpendicular to the long axes immediately dorsal to the curves. Biface resharpening flakes consist of tertiary flakes with thin, narrow, multifaceted striking platforms that exhibit rounding, facet-scar smoothing, and polish on the platform surfaces and dorsal facets adjacent the platforms. These flakes, removed by a soft percussor, have slight longitudinal curves along their entire lengths, and expand toward their distal ends. Most of the resharpening flakes in the collections derive from uniface resharpening.

In addition to the usual tool categories of projectile points, unifaces, and bifaces, four analytical categories are used to cross classify formal tools. These are manufacture failures, exhausted tools, use-broken tools, and reused tools. Manufacture rejects and specimens broken in manufacture are regarded as manufacture failures. Manufacture rejects are those complete but unfinished specimens (e.g., Stage 2 and 3 bifaces; Callahan 1979:18) exhibiting manufacture problems that prohibited the successful conclusion of the manufacture sequence. Manufacture breaks were identified by comparison with experimentally produced breaks (Johnson 1979, 1981; Tomka 1986). Those tools on which the length of the functional element (i.e., blade or working edge) is less than one-third of the total length of the tool are considered exhausted specimens. The categorization of nonhafted tools is based on a 
comparison of the overall artifact size to the average size of artifacts of the same type in the site collection and the analyst's opinion on whether or not the tool could perform its intended task. Uniface resharpening breaks were also determined based on comparison with experimentally replicated resharpening breaks. Their morphology resembles that generated as a result of use. As in the case of manufacture and uniface resharpening breaks, use-broken tools were identified by comparison to experimentally produced breaks (Rondeau 1981; Odell and Cowan 1986). Due to this similarity in break morphologies, and because unifaces broken during resharpening represent finished tools dulled through use and broken during rejuvenation, they were combined with use-broken specimens. Those tools that were broken in manufacture or use and subsequently used to perform new tasks are considered reused (e.g., scrapers made on broken projectile points). Complete tools that show wear traces indicative of the performance of two distinct tasks (e.g., the proximal end of a thin biface showing use as a gouge while the lateral edges exhibit cutting use wear) are considered reused also. Few complete reused specimens are present in the collections. Due to functional similarity and for the sake of simplicity, distally beveled bifaces (e.g., bifacial gouges) are grouped with unifaces. Flakes with edge modifications resulting from use are classified as edge-modified flakes. Specimens with edge modification derived from intentional retouch are classified as unifaces.

The raw data for each analytical category by site cluster and environmental zone is presented in Table 16. The frequencies of certain artifact categories by site were taken directly from the respective reports when the data were shown in sufficient detail. Limited additional analyses were performed on other artifact categories, during which some artifact classifications were changed from those originally reported. Disagreements between artifact frequencies used here and those shown in the reports and differences in counts of the same artifact category in Table 16 stem from such analytical reassignments and the use of a combination of previously reported and reanalyzed data.

Different data recovery techniques have been used on various projects conducted in the region. For example, the majority of the lithic debitage recovered from 41HG128, 41WY112, 41WY113, and $41 \mathrm{WY} 140$ is from the fine screen. A comparison of the smallest debitage size frequencies from these sites with those of previous projects indicates that the use of fine screening greatly increases the recovery rate of debitage smaller than $10 \mathrm{~mm}$. The use of fine screening is considered crucial to the nonskewed recovery of lithic artifacts in the project area. For example, the collection of microdebitage allows for a more accurate assessment of tool maintenance activities. However, due to the inconsistent debitage recovery techniques used by different projects, debitage less than or equal to $10 \mathrm{~mm}$ in maximum size recovered during the present archeological work is excluded from the formal analysis. Larger size cate-gories were consistently collected by previous archeological projects, and it is the larger flakes that are formally analyzed in this report.

\section{Statistical Analysis Techniques}

This analysis relies heavily on the use of standardized deviates (see Table 16) (Mosteller and Parunak 1985:197). Standardized deviates provide an analogue of standard deviations but accomodate categorical (i.e., count) data instead of measured data. Their calculation is straightforward and simple, and standardized deviates provide a technique for dissecting and analyzing count data arranged in tables.

The first step in calculating standardized deviates is the calculation of the expected values such as those used in a Chi-Square Goodness-ofFit Test or a Chi-Square Test-of-Independence (Ott 1977:266-273, 294-298). Parenthetically, it should be added that a Chi-Square Goodness-ofFit Test looks at the distribution of only one element (e.g., artifact class), by itself, while a Chi-Square Test-of-Independence investigates the distributions of two or more elements together. If no independent information is available to suggest otherwise, the calculations of expected values usually assumes an even distribution of artifact frequencies through space and time. For example, if a single artifact class is located at 5 sites and a total of 25 artifacts are discovered, then the expected value of that artifact at each site is 5 (25 divided by 5). This is the method used with a Chi-Square Goodness-of-Fit Test, and it assumes that the distribution of an individual artifact type 
TABLE 16

ANALYTICAL CATEGORIES BY SITE CLUSTER AND ENVIRONMENTAL ZONE*

\begin{tabular}{|c|c|c|c|c|c|c|c|c|c|c|c|c|c|c|c|}
\hline & \multicolumn{4}{|c|}{ Sand Sheet } & \multicolumn{4}{|c|}{ Upland Plain } & \multicolumn{6}{|c|}{ Lowland Plain } & \multirow[b]{3}{*}{ Totals } \\
\hline & \multicolumn{2}{|c|}{ Cluster 1} & \multicolumn{2}{|c|}{ Cluster 2} & \multicolumn{2}{|c|}{ Cluster 3} & \multicolumn{2}{|c|}{ Cluster 4} & \multicolumn{2}{|c|}{ Cluster 5} & \multicolumn{2}{|c|}{ Cluster 6} & \multicolumn{2}{|c|}{ Cluster 7} & \\
\hline & $\mathrm{O}$ & $\mathrm{S}$ & $\mathrm{O}$ & $\mathrm{S}$ & $\mathrm{O}$ & S & $\mathrm{O}$ & $\mathrm{S}$ & $\mathrm{O}$ & $S$ & $\mathrm{O}$ & $\mathrm{S}$ & $\mathrm{O}$ & S & \\
\hline $\begin{array}{l}\text { DEBITAGE REDUCTION STAGE } \\
\text { Early reduction } \\
\text { Late reduction } \\
\text { Totals: }\end{array}$ & $\begin{array}{r}93 \\
\frac{215}{308}\end{array}$ & $\begin{array}{r}-2.37 \\
1.88\end{array}$ & $\begin{array}{r}568 \\
957 \\
1525\end{array}$ & $\begin{array}{r}-0.85 \\
0.67\end{array}$ & $\begin{array}{l}301 \\
\frac{367}{668}\end{array}$ & $\begin{array}{r}2.69 \\
-2.13\end{array}$ & $\begin{array}{l}354 \\
410 \\
764\end{array}$ & $\begin{array}{r}3.44 \\
-2.73\end{array}$ & $\begin{array}{r}9 \\
\frac{11}{20}\end{array}$ & $\begin{array}{r}0.46 \\
-0.37\end{array}$ & $\begin{array}{r}50 \\
\frac{168}{218}\end{array}$ & $\begin{array}{r}-3.72 \\
2.95\end{array}$ & $\begin{array}{r}24 \\
\frac{98}{122}\end{array}$ & $\begin{array}{r}-3.36 \\
2.67\end{array}$ & $\begin{array}{l}1399 \\
\frac{2226}{3625}\end{array}$ \\
\hline $\begin{array}{l}\text { DEBITAGE SIZE } \\
\leq 10 \mathrm{~mm} \\
11-20 \mathrm{~mm} \\
21-30 \mathrm{~mm} \\
>30 \mathrm{~mm} \\
\text { Totals: } \\
\text { Totals minus } \leq 10 \mathrm{~mm} \text { class: }\end{array}$ & $\begin{array}{r}7 \\
186 \\
118 \\
14 \\
325 \\
318\end{array}$ & $\begin{array}{r}- \\
0.99 \\
0.81 \\
-3.60\end{array}$ & $\begin{array}{r}3 \\
675 \\
664 \\
221 \\
1563 \\
1560\end{array}$ & $\begin{array}{r}- \\
-5.96 \\
5.47 \\
3.57\end{array}$ & $\begin{array}{r}9 \\
430 \\
212 \\
67 \\
718 \\
709\end{array}$ & $\begin{array}{r}- \\
2.25 \\
-2.06 \\
-1.36\end{array}$ & $\begin{array}{r}13 \\
775 \\
319 \\
121 \\
1228 \\
1215\end{array}$ & $\begin{array}{r}- \\
4.43 \\
-4.86 \\
-1.24\end{array}$ & $\begin{array}{r}0 \\
21 \\
5 \\
\frac{0}{26} \\
26\end{array}$ & $\begin{array}{r}- \\
1.82 \\
-1.32 \\
-1.70\end{array}$ & $\begin{array}{r}98 \\
59 \\
31 \\
\frac{5}{193} \\
95\end{array}$ & $\begin{array}{r}- \\
1.02 \\
-0.30 \\
-1.72\end{array}$ & $\begin{array}{r}18 \\
45 \\
38 \\
21 \\
122 \\
104\end{array}$ & $\begin{array}{r}- \\
-1.54 \\
0.36 \\
2.76\end{array}$ & $\begin{array}{r}148 \\
2191 \\
1387 \\
449 \\
4175 \\
4027\end{array}$ \\
\hline $\begin{array}{l}\text { DEBITAGE FREQUENCY } \\
\text { Total debitage } \\
\text { Tools and cores } \\
\text { Totals: }\end{array}$ & $\begin{array}{r}334 \\
\frac{49}{383}\end{array}$ & $\begin{array}{r}-0.51 \\
1.51\end{array}$ & $\begin{array}{r}1598 \\
\frac{92}{1690}\end{array}$ & $\begin{array}{r}2.12 \\
-6.24\end{array}$ & $\begin{array}{r}751 \\
88 \\
839\end{array}$ & $\begin{array}{r}-0.05 \\
0.16\end{array}$ & $\begin{array}{r}1269 \\
131 \\
1400\end{array}$ & $\begin{array}{r}0.38 \\
-1.12\end{array}$ & $\begin{array}{l}34 \\
\frac{20}{54}\end{array}$ & $\begin{array}{r}-2.07 \\
6.11\end{array}$ & $\begin{array}{r}98 \\
\frac{73}{171}\end{array}$ & $\begin{array}{r}-4.47 \\
13.18\end{array}$ & $\begin{array}{r}115 \\
30 \\
145\end{array}$ & $\begin{array}{r}-1.32 \\
3.89\end{array}$ & $\begin{array}{r}4199 \\
\frac{483}{4682}\end{array}$ \\
\hline CORE FREQUENCY & 4 & -3.34 & 29 & 2.50 & 35 & 3.90 & 32 & 3.20 & 0 & -4.28 & 24 & 1.33 & 4 & -3.34 & 128 \\
\hline $\begin{array}{l}\text { FREQUENCY OF RESHARPENING } \\
\text { FLAKES } \\
\text { Resharpening flakes } \\
\text { Other flakes } \\
\quad \text { Totals: }\end{array}$ & $\begin{array}{l}125 \\
200 \\
325\end{array}$ & $\begin{array}{r}6.62 \\
-3.46\end{array}$ & $\begin{array}{r}544 \\
1019 \\
1563\end{array}$ & $\begin{array}{r}11.40 \\
-5.96\end{array}$ & $\begin{array}{r}72 \\
646 \\
718\end{array}$ & $\begin{array}{r}-6.61 \\
3.45\end{array}$ & $\begin{array}{r}69 \\
1159 \\
1228\end{array}$ & $\begin{array}{r}-11.98 \\
6.26\end{array}$ & $\begin{array}{r}8 \\
\frac{18}{26}\end{array}$ & $\begin{array}{r}1.03 \\
-0.54\end{array}$ & $\begin{array}{l}23 \\
\frac{73}{96}\end{array}$ & $\begin{array}{r}0.53 \\
-0.28\end{array}$ & $\begin{array}{r}30 \\
\frac{75}{105}\end{array}$ & $\begin{array}{r}1.58 \\
-0.82\end{array}$ & $\begin{array}{r}871 \\
3190 \\
4061\end{array}$ \\
\hline
\end{tabular}

*Debitage reduction stage data tabulated directly from published reports and present project results only. All other artifact categories include data from published reports, reanalyzed collections and present project results. The $\leq 10-\mathrm{mm}$ debitage size class was omitted from all standardized deviate calculations and formal analysis.

$\mathrm{O}=$ Observed values; $\mathrm{S}=$ Standardized deviates. 
Table 16, continued

\begin{tabular}{|c|c|c|c|c|c|c|c|c|c|c|c|c|c|c|c|}
\hline & \multicolumn{4}{|c|}{ Sand Sheet } & \multicolumn{4}{|c|}{ Upland Plain } & \multicolumn{6}{|c|}{ Lowland Plain } & \multirow[b]{3}{*}{ Totals } \\
\hline & \multicolumn{2}{|c|}{ Cluster 1} & \multicolumn{2}{|c|}{ Cluster 2} & \multicolumn{2}{|c|}{ Cluster 3} & \multicolumn{2}{|c|}{ Cluster 4} & \multicolumn{2}{|c|}{ Cluster 5} & \multicolumn{2}{|c|}{ Cluster 6} & \multicolumn{2}{|c|}{ Cluster 7} & \\
\hline & $\mathrm{O}$ & $\mathrm{S}$ & $\mathrm{O}$ & $\mathrm{S}$ & $\mathrm{O}$ & $S$ & $\mathrm{O}$ & $\mathrm{S}$ & 0 & $\mathrm{~S}$ & $\mathrm{O}$ & $\mathrm{S}$ & $\mathrm{O}$ & $S$ & \\
\hline $\begin{array}{l}\text { REASONS FOR TOOL DISCARD } \\
\text { Manufacture failures } \\
\text { Exhausted } \\
\text { Use-broken } \\
\text { No reason } \\
\text { Totals: }\end{array}$ & $\begin{array}{r}5 \\
11 \\
20 \\
\frac{9}{45}\end{array}$ & $\begin{array}{r}-1.61 \\
1.40 \\
1.15 \\
-0.91\end{array}$ & $\begin{array}{r}8 \\
17 \\
23 \\
\frac{15}{63}\end{array}$ & $\begin{array}{r}-1.64 \\
2.16 \\
0.29 \\
-0.49\end{array}$ & $\begin{array}{r}24 \\
7 \\
10 \\
\frac{12}{53}\end{array}$ & $\begin{array}{r}3.49 \\
-0.52 \\
-1.92 \\
-0.62\end{array}$ & $\begin{array}{r}29 \\
5 \\
38 \\
\frac{27}{99}\end{array}$ & $\begin{array}{r}1.42 \\
-2.73 \\
0.68 \\
0.04 \\
\end{array}$ & $\begin{array}{r}3 \\
6 \\
6 \\
5 \\
20\end{array}$ & $\begin{array}{r}-0.71 \\
1.56 \\
-0.33 \\
-0.18\end{array}$ & $\begin{array}{r}8 \\
8 \\
16 \\
\frac{17}{49}\end{array}$ & $\begin{array}{r}-0.92 \\
0.05 \\
-0.20 \\
1.03\end{array}$ & $\begin{array}{r}3 \\
3 \\
9 \\
\frac{11}{26}\end{array}$ & $\begin{array}{r}-1.18 \\
-0.57 \\
0.02 \\
1.50\end{array}$ & $\begin{array}{r}80 \\
57 \\
122 \\
96 \\
355\end{array}$ \\
\hline $\begin{array}{l}\text { REASON FOR UNIFACE DISCARD } \\
\text { Manufacture failures } \\
\text { Exhausted } \\
\text { Use-broken } \\
\text { None } \\
\quad \text { Totals: }\end{array}$ & $\begin{array}{r}0 \\
6 \\
2 \\
\frac{7}{15}\end{array}$ & $\begin{array}{r}-0.31 \\
1.52 \\
-1.58 \\
0.49\end{array}$ & $\begin{array}{r}1 \\
13 \\
17 \\
\frac{13}{44}\end{array}$ & $\begin{array}{r}1.32 \\
1.12 \\
-0.02 \\
-0.99\end{array}$ & $\begin{array}{r}0 \\
4 \\
7 \\
10 \\
21\end{array}$ & $\begin{array}{r}-0.37 \\
-0.26 \\
-0.40 \\
0.65\end{array}$ & $\begin{array}{r}0 \\
1 \\
18 \\
\frac{13}{32}\end{array}$ & $\begin{array}{r}-0.46 \\
-2.26 \\
1.58 \\
0.16\end{array}$ & $\begin{array}{r}0 \\
5 \\
3 \\
2 \\
10\end{array}$ & $\begin{array}{r}-0.26 \\
1.92 \\
-0.45 \\
-0.96\end{array}$ & $\begin{array}{r}0 \\
2 \\
7 \\
10 \\
19\end{array}$ & $\begin{array}{r}-0.35 \\
-1.05 \\
-0.14 \\
0.97\end{array}$ & $\begin{array}{r}0 \\
2 \\
5 \\
4 \\
11\end{array}$ & $\begin{array}{r}-0.27 \\
-0.25 \\
0.35 \\
-0.13\end{array}$ & $\begin{array}{r}1 \\
33 \\
59 \\
59 \\
152\end{array}$ \\
\hline $\begin{array}{l}\text { REASON FOR BIFACE DISCARD } \\
\text { Manufacture failures } \\
\text { Exhausted } \\
\text { Use-broken } \\
\text { None } \\
\text { Totals: }\end{array}$ & $\begin{array}{l}5 \\
1 \\
2 \\
\underline{0} \\
8\end{array}$ & $\begin{array}{r}0.16 \\
0.43 \\
0.53 \\
-1.15\end{array}$ & $\begin{array}{l}5 \\
1 \\
1 \\
1 \\
8\end{array}$ & $\begin{array}{r}0.16 \\
0.43 \\
-0.32 \\
-0.27\end{array}$ & $\begin{array}{r}23 \\
1 \\
3 \\
1 \\
28\end{array}$ & $\begin{array}{r}1.66 \\
-0.85 \\
-0.83 \\
-1.68\end{array}$ & $\begin{array}{r}27 \\
4 \\
9 \\
\frac{11}{51}\end{array}$ & $\begin{array}{r}-0.49 \\
-0.09 \\
0.07 \\
0.91\end{array}$ & $\begin{array}{l}2 \\
0 \\
0 \\
\frac{0}{2}\end{array}$ & $\begin{array}{r}0.77 \\
-0.40 \\
-0.59 \\
-0.57\end{array}$ & $\begin{array}{r}6 \\
2 \\
4 \\
3 \\
15\end{array}$ & $\begin{array}{r}-0.92 \\
0.69 \\
0.88 \\
0.34\end{array}$ & $\begin{array}{r}3 \\
1 \\
2 \\
4 \\
10\end{array}$ & $\begin{array}{r}-1.17 \\
0.20 \\
0.21 \\
1.84\end{array}$ & $\begin{array}{r}71 \\
10 \\
21 \\
20 \\
122\end{array}$ \\
\hline $\begin{array}{l}\text { REASON FOR PROJECTILE POINT } \\
\text { DISCARD } \\
\text { Manufacture failures } \\
\text { Exhausted } \\
\text { Use-broken } \\
\text { None } \\
\quad \text { Totals: }\end{array}$ & $\begin{array}{r}0 \\
4 \\
16 \\
2 \\
22\end{array}$ & $\begin{array}{r}-1.47 \\
0.10 \\
1.36 \\
-1.22\end{array}$ & $\begin{array}{l}2 \\
3 \\
5 \\
1 \\
11\end{array}$ & $\begin{array}{r}0.88 \\
0.80 \\
-0.29 \\
-0.86\end{array}$ & $\begin{array}{l}1 \\
2 \\
0 \\
1 \\
4\end{array}$ & $\begin{array}{r}0.96 \\
1.57 \\
-1.44 \\
0.18\end{array}$ & $\begin{array}{r}2 \\
0 \\
11 \\
\frac{3}{16}\end{array}$ & $\begin{array}{r}0.33 \\
-1.66 \\
0.94 \\
-0.20\end{array}$ & $\begin{array}{l}1 \\
1 \\
3 \\
\frac{3}{8}\end{array}$ & $\begin{array}{r}0.24 \\
-0.33 \\
-0.56 \\
1.02\end{array}$ & $\begin{array}{r}2 \\
4 \\
5 \\
\frac{4}{15}\end{array}$ & $\begin{array}{r}0.43 \\
0.87 \\
-1.00 \\
0.27\end{array}$ & $\begin{array}{l}0 \\
0 \\
2 \\
\frac{3}{5}\end{array}$ & $\begin{array}{r}-0.70 \\
-0.93 \\
-0.37 \\
1.90\end{array}$ & $\begin{array}{r}8 \\
14 \\
42 \\
\frac{17}{81}\end{array}$ \\
\hline
\end{tabular}

Table 16 continued on next page 
Table 16, continued

\begin{tabular}{|c|c|c|c|c|c|c|c|c|c|c|c|c|c|c|c|}
\hline & \multicolumn{4}{|c|}{ Sand Sheet } & \multicolumn{4}{|c|}{ Upland Plain } & \multicolumn{6}{|c|}{ Lowland Plain } & \multirow[b]{3}{*}{ Totals } \\
\hline & \multicolumn{2}{|c|}{ Cluster 1} & \multicolumn{2}{|c|}{ Cluster 2} & \multicolumn{2}{|c|}{ Cluster 3} & \multicolumn{2}{|c|}{ Cluster 4} & \multicolumn{2}{|c|}{ Cluster 5} & \multicolumn{2}{|c|}{ Cluster 6} & \multicolumn{2}{|c|}{ Cluster 7} & \\
\hline & $\mathrm{O}$ & $\mathrm{S}$ & $\mathrm{O}$ & $\mathrm{S}$ & $\mathrm{O}$ & $\mathrm{S}$ & $\mathrm{O}$ & $S$ & $\mathrm{O}$ & $\mathrm{S}$ & $\mathrm{O}$ & $S$ & $\mathrm{O}$ & $\mathrm{S}$ & \\
\hline $\begin{array}{l}\text { TOOL REUSE } \\
\text { Resharpened tools } \\
\text { Reused tools } \\
\text { None } \\
\quad \text { Totals: }\end{array}$ & $\begin{array}{r}18 \\
9 \\
5 \\
32\end{array}$ & $\begin{array}{r}-0.08 \\
1.74 \\
-1.22\end{array}$ & $\begin{array}{r}40 \\
15 \\
\underline{6} \\
61\end{array}$ & $\begin{array}{r}0.85 \\
1.71 \\
-2.56\end{array}$ & $\begin{array}{r}25 \\
3 \\
26 \\
54\end{array}$ & $\begin{array}{r}-1.07 \\
-1.90 \\
3.02\end{array}$ & $\begin{array}{l}45 \\
12 \\
40 \\
97\end{array}$ & $\begin{array}{r}-1.42 \\
-0.86 \\
2.74\end{array}$ & $\begin{array}{r}9 \\
5 \\
0 \\
14\end{array}$ & $\begin{array}{r}0.34 \\
1.87 \\
-1.94\end{array}$ & $\begin{array}{r}35 \\
5 \\
6 \\
46\end{array}$ & $\begin{array}{r}1.68 \\
-0.85 \\
-1.81\end{array}$ & $\begin{array}{r}16 \\
3 \\
5 \\
24\end{array}$ & $\begin{array}{r}0.61 \\
-0.41 \\
-0.57\end{array}$ & $\begin{array}{r}188 \\
52 \\
88 \\
328\end{array}$ \\
\hline $\begin{array}{l}\text { FREQUENCY OF EDGE- } \\
\text { MODIFIED FLAKES } \\
\text { Unmodified debitage } \\
\text { Edge-modified flakes } \\
\text { Totals: }\end{array}$ & $\begin{array}{r}325 \\
\frac{9}{334}\end{array}$ & $\begin{array}{r}0.11 \\
-0.60\end{array}$ & $\begin{array}{r}1563 \\
\quad 35 \\
1598\end{array}$ & $\begin{array}{r}0.45 \\
-2.42\end{array}$ & $\begin{array}{r}718 \\
33 \\
751\end{array}$ & $\begin{array}{r}-0.31 \\
1.67\end{array}$ & $\begin{array}{r}1228 \\
\quad 41 \\
1269\end{array}$ & $\begin{array}{r}0.02 \\
-0.11\end{array}$ & $\begin{array}{r}26 \\
\frac{8}{34}\end{array}$ & $\begin{array}{r}-1.20 \\
6.51\end{array}$ & $\begin{array}{r}96 \\
\frac{2}{98}\end{array}$ & $\begin{array}{r}0.13 \\
-0.68\end{array}$ & $\begin{array}{r}105 \\
10 \\
115\end{array}$ & $\begin{array}{r}-0.59 \\
3.20\end{array}$ & $\begin{array}{r}4061 \\
138 \\
4199\end{array}$ \\
\hline $\begin{array}{l}\text { NUMBER OF WORKING } \\
\text { EDGES/UNIFACE } \\
\text { Number of working edges } \\
\text { Number of unifaces } \\
\text { Mean number of working } \\
\text { edges/uniface }\end{array}$ & $\begin{array}{l}30 \\
15 \\
\\
2.0\end{array}$ & & $\begin{array}{l}96 \\
43 \\
\\
2.2\end{array}$ & & $\begin{array}{l}31 \\
22 \\
\\
1.4\end{array}$ & $=$ & $\begin{array}{l}42 \\
31 \\
\\
1.4\end{array}$ & & $\begin{array}{l}21 \\
11 \\
\\
1.9\end{array}$ & & $\begin{array}{l}31 \\
19 \\
\\
1.6\end{array}$ & & $\begin{array}{l}24 \\
11 \\
\\
2.2\end{array}$ & & $\begin{array}{r}275 \\
152 \\
\\
1.8 \pm \\
0.35^{* *}\end{array}$ \\
\hline $\begin{array}{l}\text { NUMBER OF UTILIZED } \\
\text { EDGES/EDGE-MODIFIED FLAKE } \\
\text { Number of utilized edges } \\
\text { Number of edge-modified flakes } \\
\text { Mean number of utilized } \\
\text { edges/edge-modified flake }\end{array}$ & $\begin{array}{c}14 \\
9 \\
1.6\end{array}$ & & $\begin{array}{l}48 \\
35 \\
\\
1.4\end{array}$ & & $\begin{array}{l}52 \\
33 \\
1.6\end{array}$ & & $\begin{array}{l}58 \\
41 \\
\\
1.4\end{array}$ & - & $\begin{array}{r}13 \\
8 \\
\\
1.6\end{array}$ & & $\begin{array}{c}3 \\
2 \\
1.5\end{array}$ & & $\begin{array}{l}16 \\
10 \\
\\
1.6\end{array}$ & & $\begin{array}{r}204 \\
138 \\
\\
1.5 \pm \\
0.10 * *\end{array}$ \\
\hline
\end{tabular}


is the important pattern irrespective of the distributions of any other artifact classes. An example of this method of calculation in the data presented in Table 16 is cores. At 7 site clusters, 128 cores were documented, and an even distribution of cores among the 7 clusters would result in approximately 18.3 cores per cluster.

Most contingency table analyses do not investigate the distribution of a single element, i.e., a single artifact class such as cores, but rather look at how one artifact type varies in relation to another artifact type or types. This is known as a Chi-Square Test-of-Independence. The expected values are calculated differently than for the ChiSquare Goodness-of-Fit Test, and these can best be explained by referring back to Table 16 . Debitage has been classified as either early reduction or late reduction. The total count of early reduction debitage from all site clusters equals 1,399 , and it comprises $38.6 \%$ of the total amount of debitage. If early reduction debitage was evenly distributed across each site cluster, then $38.6 \%$ of the debitage at each site would be early reduction and the actual raw number would be dependent on the sample size of the individual site clusters. For example, Cluster 1 (sand sheet) has a total of 308 pieces of debitage, and $38.6 \%$ of 308 equals 118.9. Thus 118.9 is the expected value of early reduction debitage in Cluster 1 . This process is used to calculate expected values for debitage reduction stage, debitage size, frequency of resharpening flakes, reasons of discard, tool reuse, and frequency of edge-modified flake classes.

With the expected and observed values, standardized deviates are obtained for each artifact class in each site cluster by applying the following formula:

$$
\text { Standardized Deviate }=\frac{(O-E)}{\sqrt{E}}
$$

where $\mathrm{O}=$ observed value and $\mathrm{E}=$ expected value. For the purposes of the following analysis, standardized deviates less than or equal to -1 represent observed values occurring in less than expected frequencies, standardized deviates that are equal to or greater than +1 represent observed values occurring in greater than expected frequencies, and standardized deviates that are between
+1 and -1 reflect observed values that are approximately equal to the expected values.

The calculation of standardized deviates for any particular analytical category (e.g., tool type or debitage type) takes into account the relative frequencies of all other categories intentionally included in the specific matrix. As a result, it generates an underlying relationship between categories within the matrix. This procedure in turn requires that the categories in a matrix be behaviorally related to each other. Because of these underlying factors, not all analytical categories were included in one matrix to derive the standardized deviates to be compared with the predictions derived from the three models. Rather, seven matrixes were used to calculate the standardized deviates, and these contained the following analytical categories: (1) the frequencies of early and late reduction specimens; (2) debitage size categories greater than $10 \mathrm{~mm}$; (3) the combined unmodified and edge-modified debitage frequencies compared to the combined frequencies of tools and cores; (4) the frequencies of resharpening and other flakes; (5) manufacture failure, exhausted, and use-broken tool frequencies, and tools without technological discard reasons; (6) the frequencies of resharpened and reused tools and tools showing neither of the traits; and (7) edgemodified and unmodified flake frequencies.

For two analytical categories, mean number of working edges per scraper and mean number of working edges per edge-modified flake, actual standard deviations and not standardized deviates were calculated. If the observed value is within a single standard deviation range around the mean, it is considered to be equal to the expected value. If it is below or above the one standard deviation range, then the observed value is classified as less than or greater than the expected value, respectively. It should be noted that significance tests, such as Chi-Square, have not been included for the twelve analytical categories.

Factor analysis is used to investigate the relationships between the different artifact categories. Factor analysis is a multivariate statistical technique based on the assumption that the statistical covariation among the observed artifact categories, seen as equal and dependent variables, is due to underlying, unmeasured, and unobserved independent variables otherwise known as factors (Kim and Mueller 1978:12). Thus, the various 
artifact categories are considered as dependent variables that are controlled by one or more unidentified independent variable. Factor analysis searches for and identifies patterns of covariation among the measured variables, consisting of artifact categories in this report, and each distinct pattern is related to a single factor. The correspondence between factors and actual prehistoric behaviors must be identified by the researcher, however, and this can be very easy or very difficult depending on the interpretability of the artifact categories and the nature of their covariation. One problem with the assumptions of factor analysis is that it assumes that relationships and covariations are linear. The relationships are characterized by factor loadings for each variable on each factor. The factor loadings may be positive or negative, and it is the extreme positive or negative loadings that allow for the characterization of an individual factor. On individual factors, most variables will have factor loadings near zero, and thus they do not contribute to the characterization of the factor. If a factor is characterized by high positive and high negative factor loadings on certain variables, then it is characterized as a bipolar factor. On a bipolar factor, the variables that have similar factor loadings, either positive or negative, have positive correlations with each other, and they as a group have negative correlations with variables that are inversely loaded. However, factors need not be bipolar. Factors can have only high positive loadings meaning that variables only have positive correlations for that individual factor. This is a nonbipolar factor.

In this analysis, a principal components factor extraction method was used with an oblique solution and a varimax factor rotation. A principal components factor extraction method selects factors along the axes of maximum variance in $\mathrm{N}$ dimensional space, an oblique solution allows the factors to be correlated unlike an orthogonal solution which forces the factors to be uncorrelated, and a varimax rotation tends to increase the large loadings and decrease the small factor loadings for individual variables (Afifi and Azen 1979:320-336). Other important information on factor analysis includes variable complexity and an individual factor's proportion of the variance. Variable complexity indicates the factor density of a variable. The objective of most factor analyses is to identify factors with simple structures, meaning that individual variables are accounted for by no more than one factor. Variable complexity is a measure of structural simplicity, and the ideal simple structure produces variable complexity values of 1.0 (BrainPower, Inc. 1986:123-124). Proportion of the common variance is a measure of the contribution of an individual factor to the total explained variance by the factor analysis.

\section{DISCUSSION OF RESULTS}

Two levels of analysis and comparison are undertaken in this study. The first is by site cluster, and the second is by environmental zone. These provide different scales of comparison that allow a more complete understanding of the regional archeological patterns than if only one level of analysis was achieved. Also, the test of the models can take place only on the site cluster level, but important artifact utilization patterns are seen more clearly at the environmental level. Lastly, it is only at the environmental zone level that new sites can be assessed as to their potential for providing useful and unique data for the regional data base.

\section{Site Cluster Comparisons}

The simplified standardized deviate categories for each of the 12 analyzed attributes of the collections are shown on maps for each site cluster in Figure 47. The standardized deviates are illustrated as one of three states: greater than, less than, or approximately equal to the expected values. These maps, along with the numerical data presented in Table 16, form the springboard for the following analysis, which focuses on the spatial distributions for the twelve attributes and a comparison between these standardized deviates with the predictions for each of the three models presented and discussed at length in Chapter 3. The detailed comparisons of the observed standardized deviates with the individual model predictions are listed in Tables 17, 18, and 19. From these comparisons, a scoring system was developed that allows an unbiased assessment of the three models; the scoring process is discussed in more detail below. It is through this admittedly laborious and sometimes tedious process that an accurate assessment of the three hunter-gatherer 


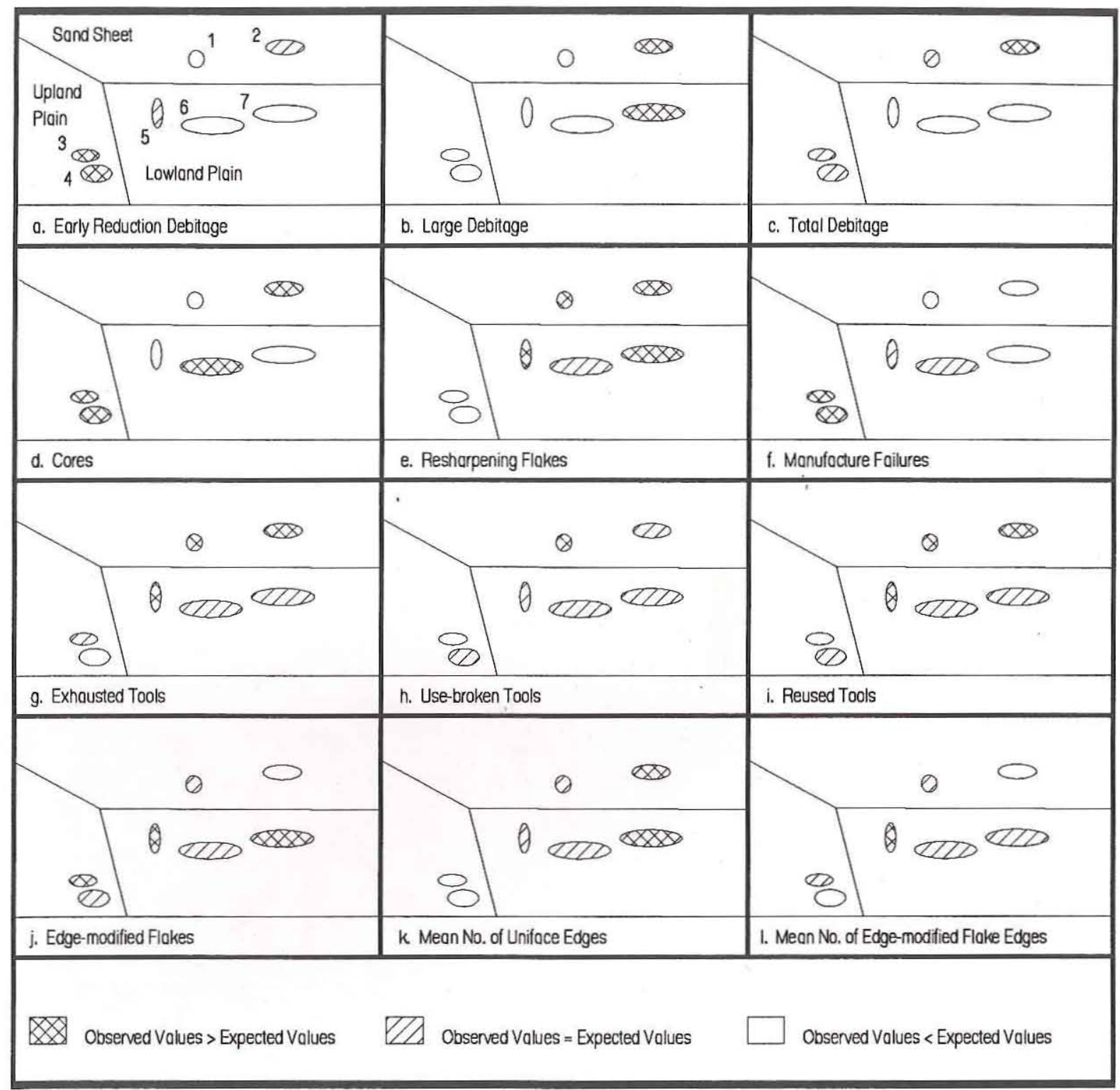

Figure 47. Observed values versus expected values by site cluster for analyzed attributes of the collections.

mobility and territoriality models is achieved, and the end result provides an exciting and stimulating assessment of the prehistory of the Lower Rio Grande Valley.

\section{Frequency of Early Reduction Debitage}

The observed distribution of early reduction debitage (see Fig. 47a) in the sand sheet is oppo- site the predicted pattern in Model I and differs from those of Models II and III (see Tables 17, 18, and 19). The observed distribution of the early reduction debitage in the upland plain is identical to the patterns predicted by all three models. The observed pattern in the lowland plain is identical to that predicted under Model I and, with the exception of its western portion, is similar to that predicted by Model II. The observed 


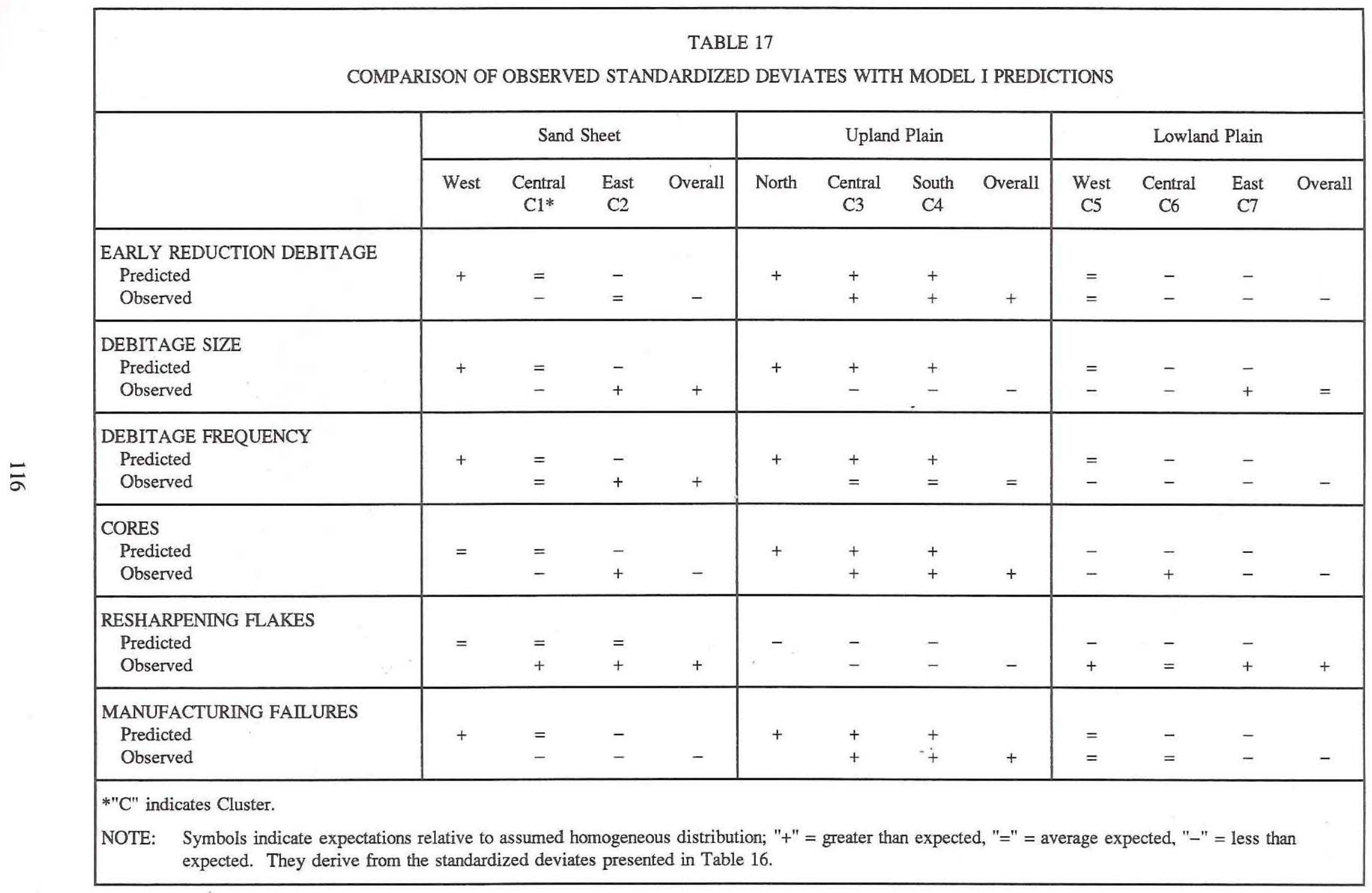


Table 17, continued

\begin{tabular}{|c|c|c|c|c|c|c|c|c|c|c|c|c|}
\hline & \multicolumn{4}{|c|}{ Sand Sheet } & \multicolumn{4}{|c|}{ Upland Plain } & \multicolumn{4}{|c|}{ Lowland Plain } \\
\hline & West & $\begin{array}{c}\text { Central } \\
\text { C1* }\end{array}$ & $\begin{array}{c}\text { East } \\
\mathrm{C} 2\end{array}$ & Overall & North & $\begin{array}{c}\text { Central } \\
\text { C3 }\end{array}$ & $\begin{array}{c}\text { South } \\
\text { C4 }\end{array}$ & Overall & $\begin{array}{c}\text { West } \\
\text { C5 }\end{array}$ & $\begin{array}{c}\text { Central } \\
\text { C6 }\end{array}$ & $\begin{array}{c}\text { East } \\
\text { C7 }\end{array}$ & Overall \\
\hline $\begin{array}{l}\text { EXHAUSTED TOOLS } \\
\text { Predicted } \\
\text { Observed }\end{array}$ & + & $\begin{array}{l}= \\
+\end{array}$ & $\begin{array}{l}= \\
+\end{array}$ & + & + & $\begin{array}{l}+ \\
=\end{array}$ & $\begin{array}{l}+ \\
-\end{array}$ & - & $\begin{array}{l}+ \\
+\end{array}$ & $\begin{array}{l}- \\
=\end{array}$ & $\begin{array}{l}- \\
=\end{array}$ & $=$ \\
\hline $\begin{array}{l}\text { USE-BROKEN TOOLS } \\
\text { Predicted } \\
\text { Observed }\end{array}$ & $=$ & $\begin{array}{l}= \\
+\end{array}$ & $\begin{array}{l}= \\
=\end{array}$ & $=$ & - & - & - & $=$ & $\begin{array}{l}- \\
=\end{array}$ & $\begin{array}{l}- \\
=\end{array}$ & $\begin{array}{l}- \\
=\end{array}$ & $=$ \\
\hline $\begin{array}{l}\text { REUSED TOOLS } \\
\text { Predicted } \\
\text { Observed }\end{array}$ & $=$ & $\begin{array}{l}+ \\
+\end{array}$ & $\begin{array}{l}+ \\
+\end{array}$ & + & - & - & $\begin{array}{l}- \\
=\end{array}$ & - & + & $\begin{array}{l}= \\
=\end{array}$ & $\begin{array}{l}= \\
=\end{array}$ & $=$ \\
\hline $\begin{array}{l}\text { EDGE-MODIFIED FLAKES } \\
\text { Predicted } \\
\text { Observed }\end{array}$ & $=$ & $\begin{array}{l}= \\
=\end{array}$ & $\begin{array}{l}+ \\
-\end{array}$ & - & - & $\begin{array}{l}- \\
+\end{array}$ & $\begin{array}{l}- \\
=\end{array}$ & $=$ & $\begin{array}{l}- \\
+\end{array}$ & $\begin{array}{l}- \\
=\end{array}$ & $\begin{array}{l}= \\
+\end{array}$ & + \\
\hline $\begin{array}{l}\text { EDGES/UNIFACE } \\
\text { Predicted } \\
\text { Observed }\end{array}$ & $=$ & $\begin{array}{l}+ \\
=\end{array}$ & $\begin{array}{l}+ \\
+\end{array}$ & + & - & - & - & - & - & $\begin{array}{l}= \\
=\end{array}$ & $\begin{array}{l}= \\
+\end{array}$ & $=$ \\
\hline $\begin{array}{l}\text { EDGES/EDGE-MODIFIED FLAKE } \\
\text { Predicted } \\
\text { Observed }\end{array}$ & $=$ & $\begin{array}{l}= \\
=\end{array}$ & $\begin{array}{l}+ \\
-\end{array}$ & - & - & $\begin{array}{l}- \\
=\end{array}$ & $=$ & $=$ & $\begin{array}{l}- \\
+\end{array}$ & $\begin{array}{l}- \\
=\end{array}$ & $\begin{array}{l}= \\
=\end{array}$ & $=$ \\
\hline
\end{tabular}


TABLE 18

COMPARISON OF OBSERVED STANDARDIZED DEVIATES WITH MODEL II PREDICTIONS

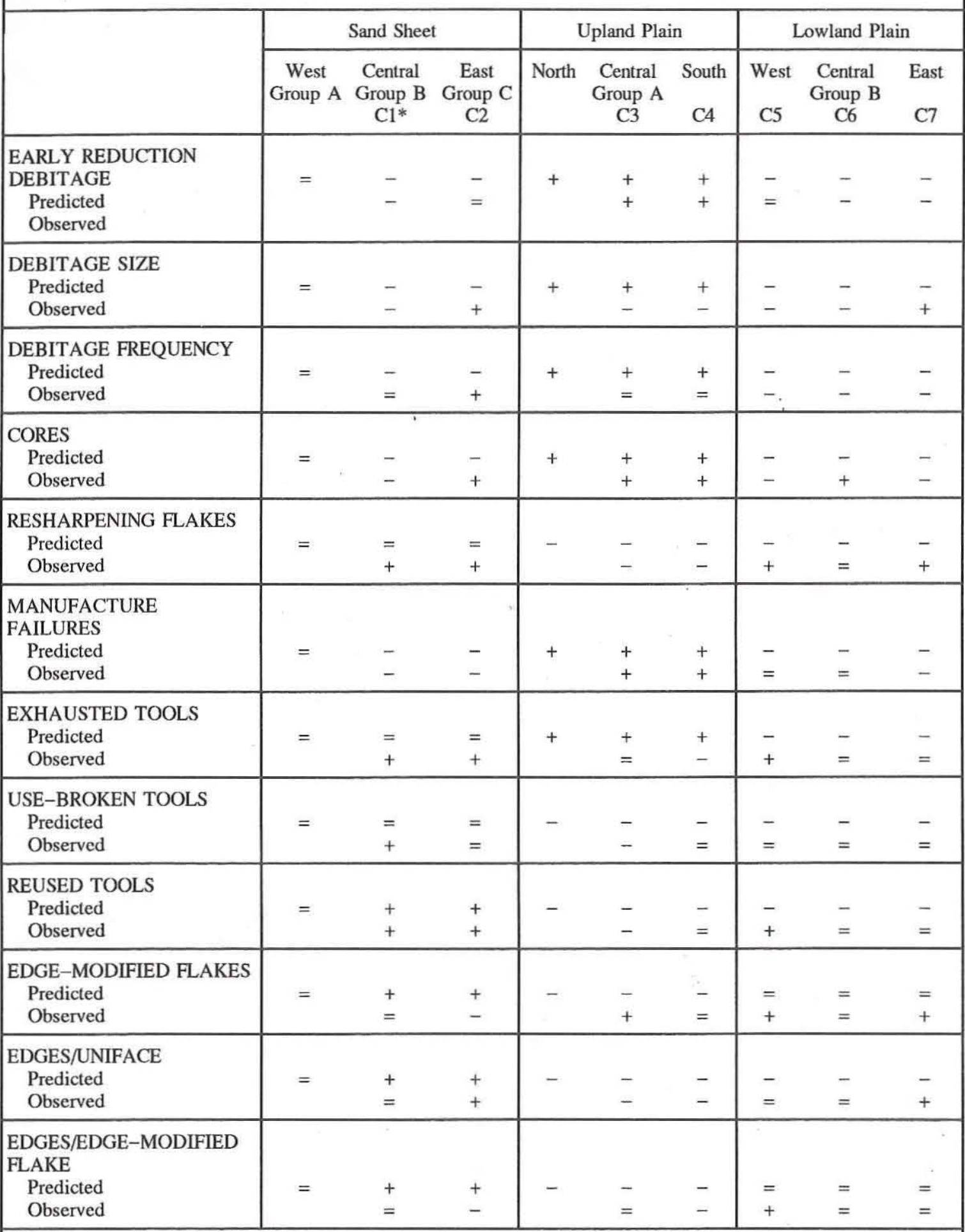

*"C" indicates Cluster.

NOTE: Symbols indicate expectations relative to assumed homogeneous distribution; "+" = greater than expected, "=" = average expected, "-" = less than expected. They derive from the standardized deviates presented in Table 16. 


\begin{tabular}{|c|c|c|c|c|c|c|c|c|c|}
\hline \multicolumn{10}{|c|}{$\begin{array}{c}\text { TABLE } 19 \\
\text { COMPARISON OF OBSERVED STANDARDIZED DEVIATES WITH MODEL III PREDICTIONS }\end{array}$} \\
\hline & \multicolumn{3}{|c|}{ Sand Sheet } & \multicolumn{3}{|c|}{ Upland Plain } & \multicolumn{3}{|c|}{ Lowland Plain } \\
\hline & West & $\begin{array}{l}\text { Central } \\
\text { Group C } \\
\mathrm{Cl}^{*}\end{array}$ & $\begin{array}{l}\text { East } \\
\mathrm{C} 2\end{array}$ & $\begin{array}{l}\text { North } \\
\text { Group C }\end{array}$ & $\begin{array}{l}\text { Central } \\
\text { Group B } \\
\text { C3 }\end{array}$ & $\begin{array}{l}\text { South } \\
\text { Group A } \\
\text { C4 }\end{array}$ & $\begin{array}{l}\text { West } \\
\text { C5 }\end{array}$ & $\begin{array}{l}\text { Central } \\
\text { Group B } \\
\text { C6 }\end{array}$ & $\begin{array}{l}\text { East } \\
\text { C7 }\end{array}$ \\
\hline $\begin{array}{l}\text { EARLY REDUCTION } \\
\text { DEBITAGE } \\
\text { Predicted } \\
\text { Observed }\end{array}$ & $=$ & $\begin{array}{l}= \\
-\end{array}$ & $\begin{array}{l}= \\
=\end{array}$ & + & $\begin{array}{l}+ \\
+\end{array}$ & $\begin{array}{l}+ \\
+\end{array}$ & $\begin{array}{l}= \\
=\end{array}$ & $\begin{array}{l}= \\
-\end{array}$ & $=$ \\
\hline $\begin{array}{l}\text { DEBITAGE SIZE } \\
\text { Predicted } \\
\text { Observed }\end{array}$ & $=$ & $\begin{array}{l}= \\
-\end{array}$ & $\begin{array}{l}= \\
+\end{array}$ & + & $\begin{array}{l}+ \\
-\end{array}$ & $\begin{array}{l}+ \\
-\end{array}$ & $\begin{array}{l}= \\
-\end{array}$ & = & $\begin{array}{l}= \\
+\end{array}$ \\
\hline $\begin{array}{l}\text { DEBITAGE FREQUENCY } \\
\text { Predicted } \\
\text { Observed }\end{array}$ & $=$ & $\begin{array}{l}= \\
=\end{array}$ & $\begin{array}{l}= \\
+\end{array}$ & + & $\begin{array}{l}+ \\
=\end{array}$ & $\begin{array}{l}+ \\
\stackrel{+}{=}\end{array}$ & $\begin{array}{l}= \\
-\end{array}$ & $\begin{array}{l}= \\
-\end{array}$ & $\begin{array}{l}= \\
-\end{array}$ \\
\hline $\begin{array}{l}\text { CORES } \\
\text { Predicted } \\
\text { Observed }\end{array}$ & $=$ & $\begin{array}{l}= \\
-\end{array}$ & $\begin{array}{l}= \\
+\end{array}$ & + & $\begin{array}{l}+ \\
+\end{array}$ & $\begin{array}{l}+ \\
+\end{array}$ & $\begin{array}{l}= \\
-\end{array}$ & $\begin{array}{l}= \\
+\end{array}$ & $\begin{array}{l}= \\
-\end{array}$ \\
\hline $\begin{array}{l}\text { RESHARPENING FLAKES } \\
\text { Predicted } \\
\text { Observed }\end{array}$ & + & $\begin{array}{l}+ \\
+\end{array}$ & $\begin{array}{l}+ \\
+\end{array}$ & - & $\begin{array}{l}- \\
-\end{array}$ & $\begin{array}{l}- \\
-\end{array}$ & $\begin{array}{l}= \\
+\end{array}$ & $\begin{array}{l}= \\
=\end{array}$ & $\begin{array}{l}= \\
+\end{array}$ \\
\hline $\begin{array}{l}\text { MANUFACTURE } \\
\text { FAILURES } \\
\text { Predicted } \\
\text { Observed }\end{array}$ & $=$ & $\begin{array}{l}= \\
-\end{array}$ & $\begin{array}{l}= \\
-\end{array}$ & + & $\begin{array}{l}+ \\
+\end{array}$ & $\begin{array}{l}+ \\
+\end{array}$ & $\begin{array}{l}= \\
=\end{array}$ & $\begin{array}{l}= \\
=\end{array}$ & $\begin{array}{l}= \\
-\end{array}$ \\
\hline $\begin{array}{l}\text { EXHAUSTED TOOLS } \\
\text { Predicted } \\
\text { Observed }\end{array}$ & $=$ & $\begin{array}{l}= \\
+\end{array}$ & $\begin{array}{l}= \\
+\end{array}$ & + & $\begin{array}{l}+ \\
=\end{array}$ & $\begin{array}{l}+ \\
-\end{array}$ & $\begin{array}{l}= \\
+\end{array}$ & $\begin{array}{l}= \\
=\end{array}$ & $\begin{array}{l}= \\
=\end{array}$ \\
\hline $\begin{array}{l}\text { USE-BROKEN TOOLS } \\
\text { Predicted } \\
\text { Observed }\end{array}$ & + & $\begin{array}{l}+ \\
+\end{array}$ & $\begin{array}{l}+ \\
=\end{array}$ & - & $\begin{array}{l}- \\
-\end{array}$ & $\begin{array}{l}\bar{y} \\
\overline{1}\end{array}$ & $\begin{array}{l}= \\
=\end{array}$ & $\begin{array}{l}= \\
=\end{array}$ & $\begin{array}{l}= \\
=\end{array}$ \\
\hline $\begin{array}{l}\text { REUSED TOOLS } \\
\text { Predicted } \\
\text { Observed }\end{array}$ & + & $\begin{array}{l}+ \\
+\end{array}$ & $\begin{array}{l}+ \\
+\end{array}$ & - & - & $\begin{array}{l}- \\
=\end{array}$ & $\begin{array}{l}= \\
+\end{array}$ & $\begin{array}{l}= \\
=\end{array}$ & $\begin{array}{l}= \\
=\end{array}$ \\
\hline $\begin{array}{l}\text { EDGE-MODIFIED FLAKES } \\
\text { Predicted } \\
\text { Observed }\end{array}$ & + & $\begin{array}{l}+ \\
=\end{array}$ & + & - & $\overline{+}$ & $\begin{array}{l}\bar{y} \\
=\end{array}$ & $\begin{array}{l}= \\
+\end{array}$ & $\begin{array}{l}= \\
=\end{array}$ & $\begin{array}{l}= \\
+\end{array}$ \\
\hline $\begin{array}{l}\text { EDGES/UNIFACE } \\
\text { Predicted } \\
\text { Observed }\end{array}$ & + & $\begin{array}{l}+ \\
=\end{array}$ & $\begin{array}{l}+ \\
+\end{array}$ & - & - & $\begin{array}{l}- \\
-\end{array}$ & $\begin{array}{l}= \\
=\end{array}$ & $\begin{array}{l}= \\
=\end{array}$ & $\begin{array}{l}= \\
+\end{array}$ \\
\hline $\begin{array}{l}\text { EDGES/EDGE-MODIFIED } \\
\text { FLAKE } \\
\text { Predicted } \\
\text { Observed }\end{array}$ & + & $\begin{array}{l}+ \\
=\end{array}$ & $\begin{array}{l}+ \\
-\end{array}$ & - & $\begin{array}{l}- \\
=\end{array}$ & - & $\begin{array}{l}= \\
+\end{array}$ & $\begin{array}{l}= \\
=\end{array}$ & $\begin{array}{l}= \\
=\end{array}$ \\
\hline \multicolumn{10}{|c|}{$\begin{array}{l}\text { *"C" indicates Cluster. } \\
\text { NOTE: Symbols indicate expectations relative to assumed homogeneous distribution; " }+"=\text { greater than expected, } \\
\text { "=" = average expected, "-" = less than expected. They derive from the standardized deviates presented } \\
\text { in Table } 16 .\end{array}$} \\
\hline
\end{tabular}


distribution differs from the Model III predictions in the lowland plain.

Because both observed lowland and upland plain patterns are identical to those predicted under Model I, it appears that this particular model might best explain the distribution of early reduction debitage. The underrepresentation of early reduction flakes in the central portion of the sand sheet is not surprising either, as it is relatively far from known upland plain raw material sources. In light of this, it is surprising that early reduction flakes occur in greater than expected frequencies in the eastern sand sheet cluster. The observed west to east patterning of standardized deviates does not reflect the expected fall-off curve with increasing distance from source. Clearly, the observed pattern in the eastern portion of the sand sheet is aberrant to all model predictions. Based on the frequency of early reduction flakes, it appears that the debitage collections recovered from the eastern sand sheet sites represent the entire reduction sequence. This pattern could be due to at least two possibilities. First is the transport of tested cores from upland plain sources to the eastern sand sheet. The equal to expected early reduction debitage frequencies in the western lowland plain (Cluster 5) might indicate the eastward transportation of corticate flake blanks from the upland plain sources. However, the western sand sheet and central and eastern lowland plain clusters have a dearth of early reduction debitage, and this does not fit a transportation model. The second possibility is that raw materials were acquired from relatively nearby but presently unknown sources. As there is no evidence supporting the long distance transportation of raw materials in most of the site clusters located in the sand sheet and lowland plain, the second factor may more likely account for the observed patterns.

\section{Debitage Size Frequencies}

The observed distribution of the largest flake size (see Fig. 47b) in the sand sheet differs from the predicted patterns in all three models (see Tables 17, 18, and 19). Large flakes occur in less than expected frequencies in the central and southern upland plain rather than being overrepresented, as is predicted by the models. The observed lowland plain patterns are most similar to the Model II predictions.

The overrepresentation of large debitage in the easternmost portion of the sand sheet is again aberrant and supports the initial impression of the exploitation of nearby raw material sources. In relation to all model predictions, the underrepresentation of large debitage in the upland plain site clusters is extremely surprising. In light of the overrepresentation of early reduction debitage in these clusters, this pattern may indicate the exportation of large tertiary flake blanks from these raw material source areas to raw material poor areas. Alternatively, the relative lack of large debitage may be consistent with the use of many sites in these clusters strictly for raw material procurement. Given that tool manufacture would be a primary activity at such sites and most tools would be made from large flake blanks, the pattern may simply be an indication of the extreme utilization or selection of large debitage for tool blanks. The overrepresentation of the largest debitage size group in the eastern cluster of the lowland plain is also aberrant. Given its proximity to the easternmost cluster in the sand sheet, the pattern may be indicative either of the importation of large flakes from that cluster or direct access to the same raw material sources as those used by people utilizing the eastern sand sheet sites. The underrepresentation of early reduction debitage at the eastern lowland plain sites, however, suggests that importation rather than direct access to raw materials is the most plausible explanation. On the other hand, the underrepresentation of large debitage in the western lowland plain cluster is consistent with the tentative interpretation of the early reduction debitage pattern seen in the same cluster. The absence of large debitage may be explained by the reduction of large flake blanks possibly imported from upland plain sources. Flake blank reduction would result in the further reduction of debitage size and the underrepresentation of the largest size class.

\section{Debitage Frequency}

The observed pattern of debitage frequencies (see Fig. 47c) in the sand sheet, again, is opposite or different from the patterns predicted under all three models (see Tables 17, 18, and 19). The observed debitage frequencies for the upland plain 
are less than those predicted by any of the three models. However, the pattern of even distribution between the central and southern portions of the upland plain follows the predictions of all three models. Finally, the observed lowland plain pattern is identical to the Model II prediction, but differs from that of Model III. In general, the observed pattern is similar to the Model I predictions, although the observed west to east debitage drop-off rate is much more rapid than predicted.

The overabundance of debitage at the eastern sand sheet sites is consistent with the possibility of a nearby raw material source. The lack of debitage overabundance at the two upland plain clusters is somewhat surprising considering that these are near the only known raw material source. It may, however, be explained by the exportation of large flake blanks, as opposed to the selective on-site utilization and discard of large debitage as tool blanks. The latter pattern should result in an increase in debitage frequencies over the observed quantities at the upland plain clusters. The consistent underrepresentation of debitage and associated overrepresentation of tools and cores at all lowland plain clusters suggest that some complete tool manufacture sequences occurred at the procurement sites while subsequent resharpening and/or rejuvenation took place at sites outside of the source areas. The early reduction debitage and large debitage patternings in the western lowland plain cluster, however, suggest that the continuous staged reduction of unfinished tools or tool blanks may have also occurred as groups moved away from the upland plain raw material sources.

\section{Core Frequency}

The high frequency of cores (see Fig. 47d) in the eastern sand sheet cluster is opposite the predictions derived from both Models I and II (see Tables 17 and 18). Instead of a west to east decrease as in Model I or an even distribution as in Model II, the observed core frequencies increase toward the east. The pattern differs from the Model III predictions as well (see Table 19). The observed upland plain pattern is identical to the predictions proposed for all three models. The lowland plain pattern differs from those of all three models although, with the exception of the central cluster in the lowland plain, it is similar to those of both Models I and II.

The overrepresentation of cores in the easternmost sand sheet cluster is identical to the pattern seen in the upland plain clusters. In light of the patterns already noted in the other artifact categories, this supports the conclusion that the lithic debitage from this cluster is the result of the reduction of locally available raw materials. The overrepresentation of cores in the central cluster in the lowland plain is also aberrant. It is impossible at present to explain why cores are overrepresented while all the previously discussed lithic attributes observed in the cluster are underrepresented. A reanalysis of these cores to establish their state of reduction (e.g., degree of exhaustion or testing) may clarify whether these specimens represent tested cores that were being transported to other zones without significant reduction at sites in the cluster or cores that arrived relatively well reduced and were subsequently exhausted and discarded there. Also, as a difference in the raw materials exists between the upland plain cores and the eastern sand sheet cores, it would be instructive to identify the source of the central lowland plain cores as an indication of transportation direction.

\section{Resharpening Flake Frequency}

The observed distribution of resharpening flakes (see Fig. 47e) in the sand sheet clusters is identical to the Model III predictions (see Table 19). In addition, it is similar to the Models I and II (see Tables 17 and 18) sand sheet predictions with the exception that the observed frequency of resharpening flakes is consistently higher than predicted by both models. The observed upland plain pattern is identical to the predictions derived from all three models. The observed pattern in the lowland plain differs significantly from those proposed for all three models.

The overrepresentation of resharpening flakes in the sand sheet clusters supports the expectation derived from optimal foraging theory regarding the use-intensity of oak mottes found in this zone (see Chapter 3). Within the same framework, the overrepresentation of resharpening flakes in the westernmost and easternmost clusters in the lowland plain may indicate more intensive use of these two areas than predicted under the optimal foraging scenario. In the case of the easternmost 
cluster, however, the pattern may be generated by the inclusion of a number of sites within and near the coastal zone, an area assumed to have been more intensively used than the lowland plain. The aberrance of the westernmost cluster cannot be explained in a similar manner. The underrepresentation of resharpening flakes in both upland plain clusters indicates that these sites were used primarily for lithic procurement with only a minor amount of tool resharpening and rejuvenation. In light of the debitage size and debitage and core frequencies, the overrepresentation of resharpening flakes in the eastern sand sheet cluster suggests that these sites represent habitation and lithic and nonlithic resource procurement areas. The possibility of a nearby lithic source, the resource richness of the sand sheet oak mottes, and the proximity of the coast may have acted in concert to provide a unique resource nexus for hunter-gatherers in the region.

\section{Manufacture Failures}

The observed distribution of tool manufacture failures (see Fig. 47f) in the sand sheet clusters is identical to the predictions derived from Model II (see Table 18). In general, the sand sheet pattern is similar to the Model I predictions (see Table 17) although the frequency of manufacture failures decreases at a more rapid rate than proposed by this model. The sand sheet clusters contain fewer manufacture failures than predicted by Model III (see Table 19). The observed upland plain pattern agrees with the predictions derived from all three models, while the observed lowland plain pattern differs from the predictions of all three models. It differs most from the Model II predictions while having some similarity to those of Models I and III.

The underrepresentation of manufacture failures in the eastern sand sheet cluster is somewhat surprising given the previous conclusion that a significant proportion of the debitage collections represent early stage core reduction and/or biface manufacture. This pattern may indicate that, in contrast to the lithic procurement patterns in the upland plain zone, core reduction took place at sites in the eastern sand sheet clustcr and further reduction of blanks and preforms occurred at sites located in other clusters or at sites outside of the seven clusters analyzed here. In the western and central lowland plain clusters, manufacture failures occur in frequencies equal to those expected if this artifact type was evenly distributed across the landscape. This pattern is consistent with the distribution of the early reduction debitage and the debitage size classes in the western lowland plain cluster and supports the staged manufacture of unfinished tools as groups moved away from the upland plain raw material sources.

\section{Exhausted Tool Frequencies}

The observed distribution of exhausted tools in the sand sheet clusters (see Fig. 47g) is greater than predicted by Models I, II, or III (see Tables 17, 18, and 19). The upland plain clusters differ from all model predictions as well; in all cases, the observed frequencies are: less than expected. The observed lowland plain distributions differ from those of Models I and II and are most similar to the Model III predictions.

The overrepresentation of exhausted tools in the sand sheet and their equal to expected (central portion) and lower than expected (southern portion) frequencies in the upland plain suggest that tool discard behavior was opposite that assumed to underlie all three models. That is, instead of exhausted tools having been discarded at lithic source areas, they may have been discarded wherever they became too small to be functional. This is reasonable if large debitage was curated and transported to provide tool blanks when needed. In terms of regional land use, this observed pattern follows the lithic assemblage organizations expected under highly mobile foraging systems. The assumption that exhausted tool discard should occur at raw material sources, within the context of gearing up preparatory to group moves (Binford 1979:268), may best characterize logistically organized systems. It appears that the more intensively a resource area is occupied, the higher the expected frequencies of exhausted tools will be regardless of raw material proximity. The underrepresentation of exhausted tools in the southern cluster in the upland plain, combined with the underrepresentation of resharpening flakes at these same sites, suggests that the land-use pattern was not particularly oriented to the broad based exploitation of ecotones. Instead, sites in this cluster seem to represent primarily the exploitation of lithic raw materials. An analysis 
of exhausted tool frequencies by tool type in the upland plain clusters indicates that in the southern portion, both unifaces and projectile points are underrepresented while bifaces occur in equal to expected frequencies (see Table 16). In the central portion, projectile points are overrepresented while the other two tool types occur in equal to expected frequencies. This pattern suggests that projectile point discard may have been governed by factors different from those governing the discard of other tool types. In addition, it suggests that hunting, in association with raw material procurement, may have been a significant activity within the central portion of the upland plain.

The observed values of exhausted tools equal the expected values in the lowland plain, but the overrepresentation of unifaces in the western lowland plain sites is consistent with the overrepresentation of resharpening flakes in that cluster (see Table 16). The pattern appears to suggest a greater intensity of use for these sites than for sites in other clusters in the lowland plain even though the overall artifact frequency is lower. The specific reasons for the greater use-intensities may be determined by a more careful survey of resource types found in the area. In the lowland plain, exhausted projectile points and bifaces occur in frequencies equal to expected, while exhausted unifaces are overrepresented in the western lowland plain cluster. This distribution suggests that the western lowland plain was utilized for hide processing; however, since no microwear analyses have been conducted on the unifaces, they could also represent plant processing (e.g., prickly pear, agave, and sotol).

\section{Use-broken Tool Frequencies}

An even distribution of use-broken tools in the sand sheet clusters is predicted by Models I and II, while even but overrepresented frequencies are predicted by Model III. The observed sand sheet distribution differs equally from the predictions of Models I, II, and III (see Tables 17, 18, and 19). The observed upland plain pattern differs from all three models and shows a slight southerly increase as opposed to the consistent pattern predicted by all three models. The observed lowland plain pattern is identical to the Model III predictions, but the observed trend is similar to those suggested under all models.

In the central sand sheet cluster, projectile points are highly overrepresented, unifaces are underrepresented, and bifaces occur in equal to expected frequencies (see Table 16). On the other hand, the eastern sand sheet cluster shows the three tool types occurring in frequencies equal to those expected. Within this context, the higher than expected frequencies of use-broken projectile points may indicate a relatively specialized use (e.g., hunting) of the central portion of the sand sheet.

The underrepresentation of use-broken projectile points in the central upland plain cluster is consistent with the earlier observation that these upland plain sites appear to have been used primarily for raw material procurement. The southern upland plain sites have a frequency of use-broken tools that is equal to the expected value. The distribution of use-broken tool types in this cluster indicates that unifaces are overrepresented while bifaces and projectile points occur in equal to expected frequencies. The implications of this are contrary to those of the observed resharpening flake and exhausted tool distributions and support the conclusion that occupations in ecotonal resource zones also contained a limited resource procurement and/or processing component in addition to raw material procurement.

\section{Reused Tool Frequencies}

The observed distribution of reused tools in the sand sheet is identical to that predicted under all three models (see Tables 17, 18, and 19). The observed upland plain pattern differs equally from all three model predictions in that the southernmost cluster has a slightly higher frequency of reused tools than proposed by the models. The observed lowland plain pattern differs from the predictions derived from all three models, although it is most similar to those of Model III.

The observed frequency of reused tools in the central sand sheet cluster is consistent with the assumption outlined in Chapter 3 that reused tool frequency increases as the distance from raw material sources and site use-intensity increase. The overrepresentation of reused tools in the easternmost cluster, however, does not fit the assumption if earlier conclusions regarding the 
proximity of raw materials to this cluster are correct. It is possible that use-intensity conditioned the rate of tool reuse. In other words, site use-intensity may have had an equal or greater effect on tool reuse frequency than did distance from raw material sources. This conclusion may be consistent with the foraging land-use system suggested for the project area. Reused tools may represent the use of readily available items (e.g., broken tools) as opposed to backup tools to replace use-broken specimens. The availability of backup tool kits may be more characteristic of collector systems. The overrepresentation of reused tools at the westernmost sites in the lowland plain is consistent with the observed frequencies of resharpening flakes and exhausted tools. Overall, the pattern of lithic artifact frequencies in sites in this cluster suggests greater occupational intensity than at sites in clusters located farther east.

\section{Edge-modified Flakes}

The observed distribution of edge-modified flakes relative to unmodified debitage in the sand sheet clusters (see Table 16 and Fig. 47) does not fit any of the three models (see Tables 17, 18, and 19). The observed upland plain pattern also differs from the predictions derived from the three models, as the frequency is more than expected for any portion of the upland plain. The observed lowland plain pattern differs from the predictions of all models as well. The slight increase in the relative frequency of edge-modified flakes between the central and eastern portions of the lowland plain suggests a trend similarity to Model I, although the western portion is greatly dissimilar.

Based on Model I, the frequency of edgemodified flakes relative to unmodified debitage is predicted to increase with increasing distance from raw material sources in intensively used zones. The observed sand sheet pattern is the opposite of this expectation, suggesting that the actual relationship between edge-modified flake frequencies and raw material distance is the inverse of the one proposed. However, the likelihood of a raw material source near the easternmost sand sheet cluster may explain the underrepresentation of edge-modified flakes in a fashion consistent with the assumptions underlying the Model I predictions. The high frequency of edge-modified flakes in the upland plain clusters supports the inverse relationship explanation. The observed lowland plain pattern follows, with one exception, the relationship outlined under Model I although the edge-modified flake frequencies are higher than predicted under the model. The overrepresentation of edge-modified flakes in the westernmost cluster of the lowland plain does not follow the predictions.

\section{Mean Number of Working Edges per Uniface}

In the sand sheet, the observed mean number of working edges per uniface differs from all three model predictions (see Tables 17, 18, and 19). In the upland plain, the observed is identical to all three model predictions. The pattern noted in the lowland plain is most similar to the predictions under Model III.

Within the sand sheet, the observed pattern differs from that predicted in the models only in the central portion of the zone. Here a slightly lower than predicted mean number of working edges is observed. This pattern is difficult to explain, especially in light of the overrepresentation of exhausted, use-broken, and reused tools in this portion of the sand sheet. The increased number of working edges farther east in the zone suggests that this attribute was conditioned by distance from raw material sources. The greater than expected mean number of working edges per uniface in the eastern portion of the zone, even in light of a possible nearby raw material source, suggests that use-intensity may also have affected the attribute. The lower than expected mean numbers of working edges in the central and southern portions of the upland plain support this conclusion. That is, given ready raw material availability, tool use-intensity was reduced. The overall equal to expected mean number of working edges per uniface in the lowland plain is consistent with the observation that the attribute was at least partially conditioned by environmental zone useintensity. The trend in the lowland plain clusters indicates that distance from raw material sources also played an important role in determining the intensity of tool use.

\section{Mean Number of Utilized Edges per Edge-modified Flake}

The observed mean numbers of utilized edges per edge-modified flake in the sand sheet and 
upland plain differ from the three model predictions (see Tables 17, 18, and 19). The observed lowland plain pattern shows a spatial trend through the clusters opposite of that predicted in Model I and differing slightly from the predictions of Models II and III.

The decline between the central and eastern clusters in the sand sheet may be a function of the availability of raw material sources adjacent to the easternmost site cluster. The similarity to the pattern noted in the frequency of edge-modified flakes supports this conclusion. A decline in the mean number of utilized edges is expected in the upland plain compared to the sand sheet; however, a slight increase is documented. An overall pattern identical to that of the upland plain is seen in the lowland plain clusters, although the cluster patterns are notably different.

\section{Conclusions of Site Cluster Comparisons}

A simple procedure is used to assess the relative merits of the models. For each attribute distribution, a single point is awarded for an exact match between the model predictions and the observed values in a specific environmental zone (see Tables 17, 18, and 19). For example, the Model III debitage frequency in the lowland plain equals one point for an exact match. Also, a single point is given for a similar trend match, e.g., a change from higher to lower across an environmental zone. This is done because at this level of model development, it must be realized that the predicted values might vary slightly from the statistical standardized deviates, and it is the trend change rather than the absolute predicted value that is important. An example of a similar trend match is the Model III manufacture failures in the lowland plain. As twelve attribute distributions are used in the present analysis and site clusters occur in three environmental zones, a perfect score would be 36 for each model. However, if an exact match or a trend match does not occur between the observed values and the model predictions, then no score is given. This occurs a number of times, e.g., debitage size in the lowland plain in all three models. Table 20 illustrates the scores for each model by environmental zone, the total score, and the percent score. Model I has the highest score $(41.7 \%)$, Model II the next highest (36.1\%), and Model III the lowest (33.3\%). Interestingly, all three models have the same high

\begin{tabular}{|c|c|c|c|c|c|}
\hline \multicolumn{7}{|c|}{ TABLE 20} \\
MODEL SCORES BY ENVIRONMENTAL ZONE \\
Model & $\begin{array}{c}\text { Sand } \\
\text { Sheet }\end{array}$ & $\begin{array}{c}\text { Upland } \\
\text { Plain }\end{array}$ & $\begin{array}{c}\text { Lowland } \\
\text { Plain }\end{array}$ & Total & Percent \\
\hline I & 4 & 6 & 5 & 15 & 41.7 \\
\hline II & 5 & 6 & 2 & 13 & 36.1 \\
\hline III & 4 & 6 & 2 & 12 & 33.3 \\
\hline
\end{tabular}

score in the upland plain. This suggests that the individual models are able to predict the effects of known raw material sources with a reasonable and equal degree of accuracy. Model II ranks slightly higher than the other two models in the sand sheet, however, it is clear from the results of the analysis that an undocumented raw material source in the sand sheet is a possibility. Once the location of this source becomes known, models should be constructed that take this into account, and it is probable that their scores would improve markedly in the sand sheet. In the lowland plain, Model I ranks the highest, and with new model formulation that takes into account a sand sheet raw material source, the model scores would improve. Additionally, a temporal shift in exploitation patterns between a coastal-oriented and a Rio Grande floodplain-oriented system should be considered as a possibility, but without better temporal controls on the material remains, it is impossible to distinguish between a temporally collapsed pattern that simply looks like Model I and a system that actually functions like Model I. Thus, the higher score for Model I must be viewed cautiously. As stated above, the highest score is 15 points $(41.7 \%)$ in Model I. This suggests that more than half of the observed variability was not accounted for by any of the three models. Clearly, this implies that the models are not very robust or the specific model expectations need fine-tuning and adjustment. The integration of a sand sheet raw material source, if it can be documented, is one such important adjustment.

In an attempt to summarize the patterns discussed in the analysis above and to consider the possibility that unrecognized patterns may be inherent in the data base, a factor analysis was run on the standardized deviates in Table 16. Again, 
the dual purpose is summary and exploratory. The site clusters are used as individual cases and the analytical attributes as variables; thus, the results have spatial implications. The factor analysis uses the manufacture failure, exhausted tool, and use-broken tool standardized deviates derived for individual tool categories (i.e., unifaces, bifaces, and projectile points) rather than those for these categories combined. The factor extraction method employed is principal components. An oblique rotation with a varimax solution was selected because it does not assume that individual factors are independent of each other as does an orthogonal rotation procedure.

Five factors are identified, and the factor loadings for the artifact attributes are listed in Table 21. Factor loadings equal to or greater than 0.500 are considered significant. In general, the patterns are in strong agreement with the previous discussions, but additional insights are gained by a careful examination of the individual factors.

Factor I has a bipolar pattern with high negative loadings on four attributes--early reduction debitage, cores, use-broken unifaces, and projectile point manufacture failures--and high positive loadings on resharpening flakes, uniface manufacture failures, exhausted unifaces, reused tools, and mean number of utilized edges per uniface. This is a complex factor that appears to generally characterize tool production and tool maintenance, but it is likely that raw material availability, tool curation, and tool use-intensity all play a role in the characterization of this factor.

Factor II has a bipolar pattern with high positive loadings on three attributes--early reduction debitage, debitage frequency, and biface manufacture failures--and high negative loadings on exhausted and use-broken bifaces. This factor can be interpreted as reflecting biface manufacture, use, and discard. It seems logical that biface production, as reflected by biface manufacture failures, occurs with early reduction debitage and that intensively used bifaces, as indicated by exhausted and use-broken bifaces, do not occur with the manufacturing of bifaces. This implies transportation of bifaces away from the locales of manufacture.

Factor III, a bipolar factor, has high positive loadings on debitage frequency and core frequency and high negative loadings on edge-modified flakes and mean number of utilized edges per edge-modified flake. This factor seems to reflect use-intensity of edge-modified flakes as conditioned by raw material availability. It can be argued that it measures at least one dimension of tool curation where intensively utilized flakes were not discarded in areas of readily available raw materials. Or perhaps rather than suggesting the transportation of edge-modified flakes away from source areas, the factor is indicative of the moreintensive use of debitage as expedient tools in environmental zones with low raw material availability.

Factor IV, again a bipolar factor, has high negative loadings on projectile point manufacture failures and exhausted projectile points and a high positive loading on use-broken projectile points. This factor seems to indicate that exhausted projectile points were discarded at the loci of manufacture, as reflected by their association with manufacture failures. This factor could be used to suggest that discard patterns among projectile points differ depending on the reason for discard. Exhausted projectile points, i.e., projectile points that remained functional throughout their use-lives, may have been discarded in expectation of breakage or failure at the loci of projectile point manufacture, while use-broken projectile points were discarded wherever they broke.

Factor $\mathrm{V}$ is the only nonbipolar pattern and has high positive loadings on large debitage and use-broken unifaces. This factor seems to indicate the possibility that large debitage was transported away from the material sources to the locales of uniface use, at least as indicated by the occurrence of use-broken unifaces.

Taken as a whole, the results of the factor analysis provide some useful insights into the assumptions made by the various models. It is clear that many variables are controlled by more than one factor (see variable complexity in Table 21). For example, debitage frequency has high loadings on both Factors II and III suggesting that the occurrence of debitage is not controlled by a single process. In this case, the production and use of bifacial tools and edge-modified flakes are different activities that are independently correlated among the site clusters as shown by the intercorrelations in Table 22. It is significant also that the only two factors that have even moderately high, albeit negative, correlations are Factors 


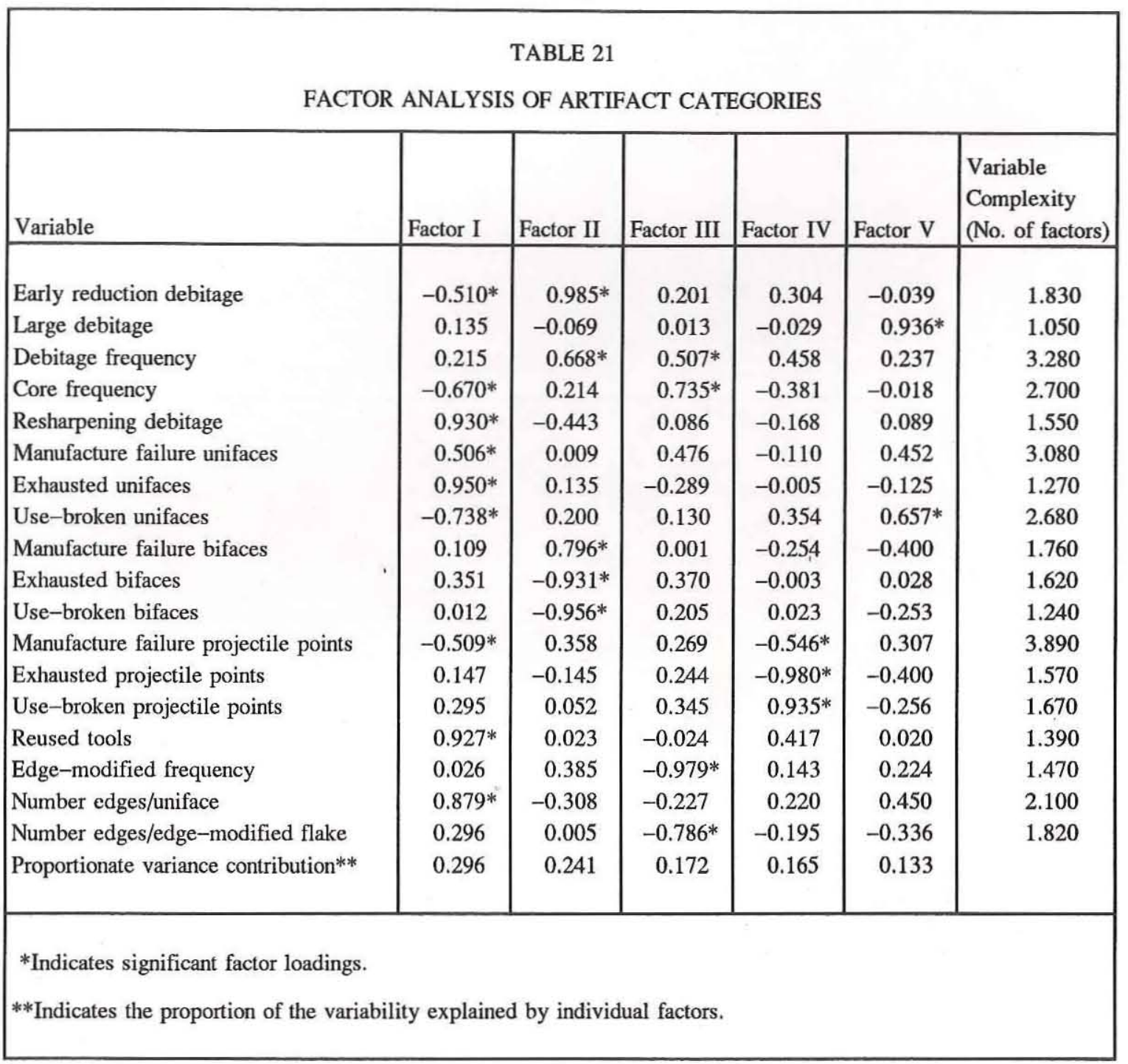

TABLE 22

PRIMARY INTERCORRELATIONS OF FACTORS

\begin{tabular}{|l|r|r|r|r|c|}
\hline & Factor I & Factor II & Factor III & Factor IV & Factor V \\
\hline Factor I & 1.000 & & & & \\
Factor II & -0.196 & 1.000 & & & \\
Factor III & 0.136 & 0.076 & 1.000 & & \\
Factor IV & -0.230 & -0.402 & -0.071 & 1.000 & \\
Factor V & 0.118 & 0.047 & 0.277 & -0.191 & 1.000 \\
\hline
\end{tabular}


II and IV (sce Table 22). This means that the two factors do not co-occur in space. Factor II reflects patterning of bifaces, and Factor IV primarily indicates patterning among projectile points. These results suggest that future model building and testing can be fine-tuned with these relationships incorporated into the logic of the models resulting in an increase in assemblage predictability and thus explanation.

\section{Environmental Zone Comparisons}

The previous discussion focused primarily on a comparison of observed lithic attributes to the expected patterns as proposed by the three models. The goal was to establish the definition of the land-use patterns employed by the prehistoric inhabitants of the region as exhibited by the twelve lithic attributes. This section summarizes the observed patterns in lithic attributes by environmental zone (see Table 17; Fig 48) and relates them to lithic procurement strategies and the organization of technology.

One of the assumptions underlying the models outlined in Chapter 3 is that core frequencies should be related to raw material availability as conditioned by quantity or distance from sources. Furthermore, from a technological point of view, raw material availability should affect the relative frequencies of early reduction debitage, the largest flake size class relative to smaller size classes, and overall debitage. Also, it was assumed that, in a less direct way, raw material availability affects the relative frequencies of resharpening flakes and manufacture-broken, exhausted, usebroken, and reused tools, as well as the mean number of working edges per scraper. With the exception of manufacture-broken specimens, these attributes also should be affected by resource zone use-intensity.

The observed overall upland plain pattern indicates an overrepresentation of cores; they are, however, underrepresented in the other two zones. The observed frequencies of early reduction debitage parallel core frequencies, but the frequencies of large debitage appear to behave in an inverse pattern to core frequencies, with the sand sheet having the greatest frequency of large flakes. As noted earlier, however, the possible occurrence of a lithic raw material source in the eastern portion of the sand sheet and/or the transportation of flake blanks from raw material sources in other areas may explain these inverse patterns. The observed total debitage frequencies may be due to the convergent effect of two factors, raw material availability and environmental zone use-intensity. The exportation of large flake blanks may have reduced debitage frequencies even at source areas. In addition, the production of only early reduction stage specimens at procurement locations may have further contributed to low debitage frequencies. Both of these factors, combined with low use-intensity, may characterize and explain the observed upland plain pattern. The probable presence of a lithic source near the eastern portion of the sand sheet, coupled with greater useintensity, may have generated an overrepresentation of debitage in this zone in contrast to the upland plain. Similarly, the underrepresentation of debitage in the lowland plain is probably due both to its lack of raw materials and low use-intensity.

The frequencies of manufacture failures parallel those of cores and early reduction debitage. Contrary to the raw material blank exportation hypothesis, the lack of a distancerelated trend in manufacture-broken specimen frequencies suggests that most manufacture occurred at the sources. The relative frequencies of exhausted and reused tools parallel each other and are opposite the trend noted in core frequencies. It appears that, in addition to raw material availability, these two attributes were also conditioned by resource use-intensity. In the sand sheet where cores are underrepresented but use-intensity is presumed to be high, exhausted and reused tool frequencies are also high. Where core frequencies are high but use-intensity is low, i.e., the upland plain, the relative frequencies of reused and exhausted tools are also low. Where core frequencies are low but use-intensity is presumed moderate, i.e., the lowland plain, the two attributes also occur in moderate frequencies. Usebroken tools are evenly distributed across the landscape. There are some indirect and complex ways in which tool breakage may be related to distance from raw material sources and resource zone use-intensity. However, the distribution of use-broken specimens suggests that neither of the two variables conditioned their breakage or their spatial distribution. Rather, it is probable that tool breakage and subsequent discard was conditioned by a complex relationship between tool 


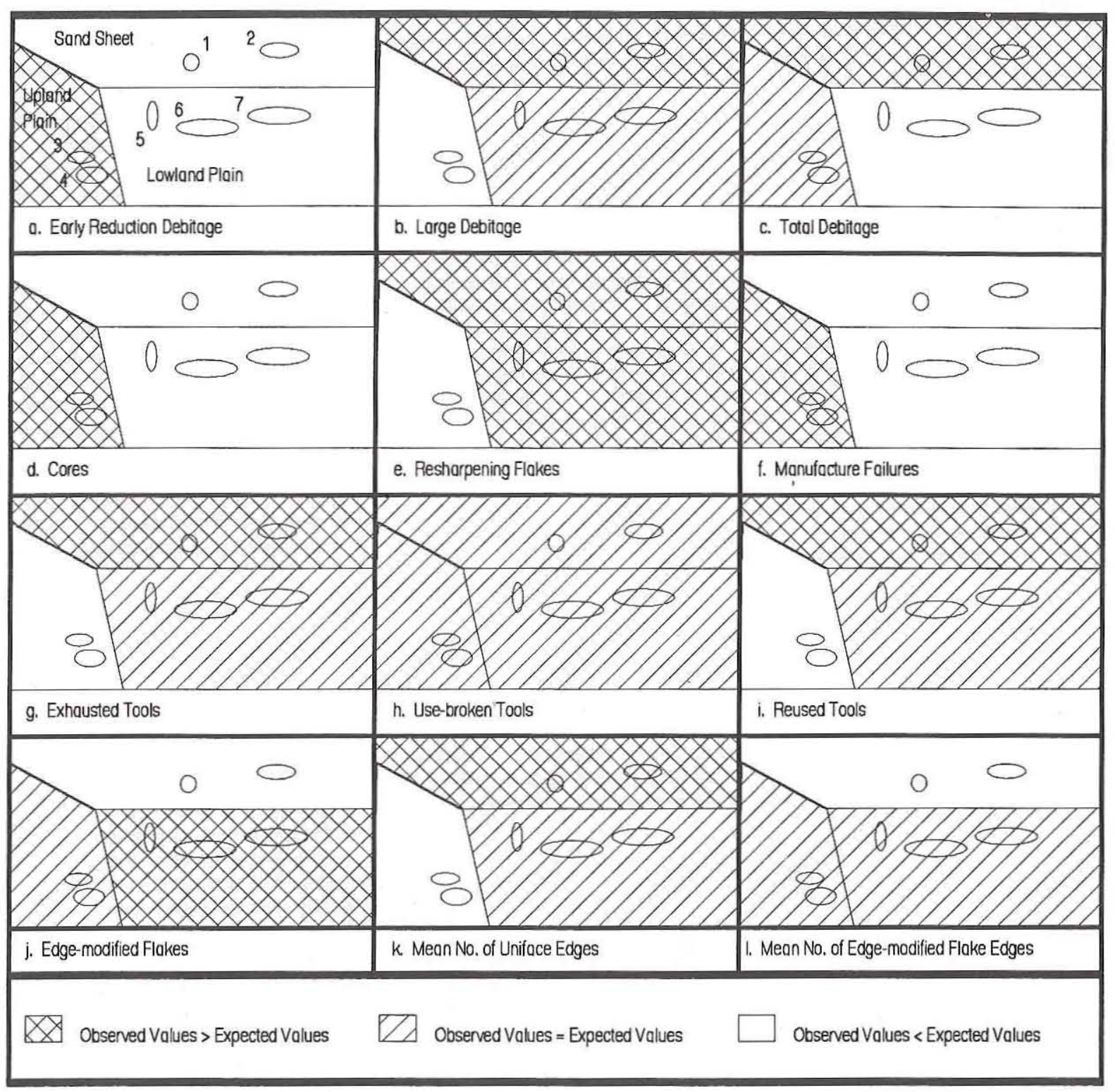

Figure 48. Observed distribution of artifact frequencies by environmental zone.

type, the nature of the task, relationships between morphologically weak points, break probability and subsequent potential for reworking and/or reuse, and raw material type, to mention only a few.

The frequencies of resharpening flakes are inversely related to the frequencies of manufacture failures, cores, and early reduction debitage. The pattern supports the underlying assumption that tool use-intensity was inversely related to raw material availability. However, because of the consistent overrepresentation of resharpening flakes in both the sand sheet and the lowland plain, it appears that their frequencies responded in a stepped manner rather than in a gradual, distance-related manner to raw material availability. That is, much of the debitage at sites located in areas where raw materials were not available, 
regardless of distance from sources, consists of resharpening flakes. The pattern strongly supports the suggested limited role of staged reduction manufacture sequences in the regional land-use pattern.

The parallels between the mean number of working edges per uniface and the exhausted and reused tool frequencies are not surprising. They indicate, consistent with earlier conclusions, that tool use-intensity responded to zone use-intensity and raw material availability. The pattern of edge-modified flake frequencies, especially in contrast to total debitage frequencies, presents a consistent regional picture. The sand sheet, with a greater than expected overall total debitage frequency, has a low overall edge-modified flake frequency relative to unmodified debitage. The upland plain, with overall debitage frequencies equal to the expected, has observed edgemodified flake frequencies also equal to the expected. In contrast, the lowland plain, with low overall debitage frequencies, has greater than expected frequencies of edge-modified flakes compared to unmodified flakes. The observed overall regional pattern supports the inverse relationship between edge-modified flake and unmodified debitage frequencies outlined in Model I. The comparison of the observed patterns between the three environmental zones indicates that the mean number of working edges per edgemodified flake was conditioned neither by raw material constraints nor occupation intensity. This conclusion is consistent with the general perspective of edge-modified flakes representing expedient tools. The patterns suggest that the use and discard of expedient tools were not constrained by the same factors as were the use and discard of formal, shaped tools.

\section{SUMMARY AND CONCLUSIONS}

The major purpose of this chapter is to test the three hunter-gatherer mobility and territorial models proposed in Chapter 3. This analysis provides a framework for understanding the archeological record from a broad regional perspective. More specifically, these models were developed to predict lithic assemblage patterns recovered from archeological investigations along the Hidalgo-Willacy Drainage Ditch. The prediction of assemblage patterns is crucial to gaining an understanding of the primary factors that conditioned the spatial distribution of artifacts left by prehistoric groups occupying the Lower Rio Grande Valley during the late Holocene. If the predictions are accurate, then it is assumed that the controlling factors are sufficiently understood so that an explanation of the artifact discard and settlement system is more or less at hand. Although sample sizes from individual sites are extremely small, it is suggested that the regional data base offers interpretable patterns of resource use and that these sites provide data that can be used as an initial test of the models.

Two levels of analysis were undertaken. Sites were first grouped into seven clusters because of small artifact samples from individual sites, and the patterns for each cluster were compared to the model expectations on a cluster by cluster basis. On a larger scale, the same attribute distributions were analyzed by environmental zone.

Possibly because of small sample sizes, the clearest artifact distributional patterns are at the environmental level. The frequencies of early reduction debitage, cores, and manufacture failures are spatially correlated and concentrated in the upland plain. Resharpening flakes are inversely correlated to these three categories with concentrations occurring in the sand sheet and lowland plain. These patterns appear to have been conditioned primarily by the availability of raw material. Large debitage, exhausted tools, reused tools, and high mean numbers of utilized uniface edges occur in a distinctive pattern with the greatest concentrations in the sand sheet and the least in the upland plain. It is possible that this pattern reflects the exportation of lithic raw materials into areas of low raw material availability. Second, it is possible that the frequencies of exhausted and reused tools were influenced by environmental zone use-intensity. Edge-modified flakes, with concentrations in the lowland plain, are inversely associated with debitage frequency, with a concentration in the sand sheet. The frequencies of these artifact categories also appear to have been conditioned by raw material availability and environmental zone use-intensity. Only use-broken tools occur evenly throughout all three environmental zones, and this may reflect a series of relationships that are not related to raw material availability or environmental zone use-intensity. 
While more difficult to interpret, analysis on the level of site clusters provides a level of understanding that is complementary to that obtained from the analysis by environmental zone. The site cluster approach suggests that Model I, a nonterritorial exploitation pattern, may explain more of the variability observed in the regional data base than the other two models, but no model accounts for a majority of the variability observed in the collections. Early reduction debitage, large debitage, debitage frequency, and core frequency all point to the possible existence of an eastern sand sheet lithic raw material source, or, alternatively, the transportation of lithic materials to the area in an unreduced form. While some manufacture sequences began and were finished at or near the lithic procurement areas, some tool manufacture appears to have occurred in staged sequences across the landscape. Exchange of tool blanks across hunter-gatherer territorial boundaries is a possibility, but if a spatial exploitation pattern similar to Model I was in place for most of the late Holocene, much of the west to east movement of raw materials would not have required exchange between bands. Formal tools were not discarded with the same constraints as expedient tools, and, in fact, some types of formal tools were discarded differently from other types of formal tools. In general, exhausted tool distributions suggest that these artifacts were not discarded at raw material sources, but rather exhausted tools were discarded when and where they wore out. Exhausted projectile points are an exception to this rule, however, and appear to have been discarded at the loci of manufacture. These results suggest that the replacement strategy for formal tools varies and that some tools were replaced near a material source in "expectation of failure," while others were "replaced upon exhaustion" (Kuhn 1989).

Although the three models, by their nature, are simplified explanations, and the conclusions from the archeological analyses are preliminary, the regional perspective offers four important considerations for future research. First, the aberrance of the eastern sand sheet is well documented in the lithic analysis, and it highlights the potential for an unknown lithic raw material source in this area. As stated above, the certainty rather than the presumption of a lithic source in the eastern sand sheet would greatly alter the expectations of any theoretical model that attempted to explain hunter-gatherer mobility and exploitation patterns.

Second, the formal test of the models included only chipped stone artifact samples and other data can be brought to bear on this issue. Figure 49a illustrates the distribution of all archeological sites recorded at the Texas Archeological Research Laboratory from Hidalgo, Willacy, and Cameron counties as of December 1989. The overall distribution of these sites is strongly controlled by research intensity, and it would be a mistake to read occupational intensity directly from recorded site density. Rather, it is more prudent to compare the occurrence of materials and the occurrence of known sites.

In this portion of Texas, marine shells are widely used as alternative materials for tool manufacture, and it is expected that huntergatherer exploitation patterns that focused on the coast, or alternatively the Rio Grande floodplain, would have produced distinctively different distributional patterns of marine shell artifacts. Figure $49 \mathrm{~b}$ shows that the drop-off rate of marine shells away from the coast is not dramatic, and this could support Model I or Model III. On the other hand, the rather limited distribution of obsidian is coastal, although only seven sites are known to have obsidian artifacts and thus this distribution may be due only to small sample size (Fig. 49c). Most ceramics in the region are Haustecan or Haustecan-like and are not considered to be of local manufacture. The distribution of ceramics shows greater concentrations along the coast and Rio Grande floodplain, but again, this may be due to sample size (Fig. 49d). The stable isotope analysis of human bones (see Chapter 6) suggests that distinct coastal and inland dietary groups may have existed. The stable isotope patterns, as well as the obsidian and ceramic distributions, tentatively support an exploitation pattern similar to Model II. Obviously, future investigations should formally incorporate these and other lines of evidence to more clearly elucidate the patterning of hunter-gatherer exploitation in the region.

Third, much of the difficulty of evaluating the fit between model expectations and observed archeological patterns is due to the absence of archeological data from two environmental zones. The Rio Grande floodplain and delta are not represented, and insufficient samples are available 


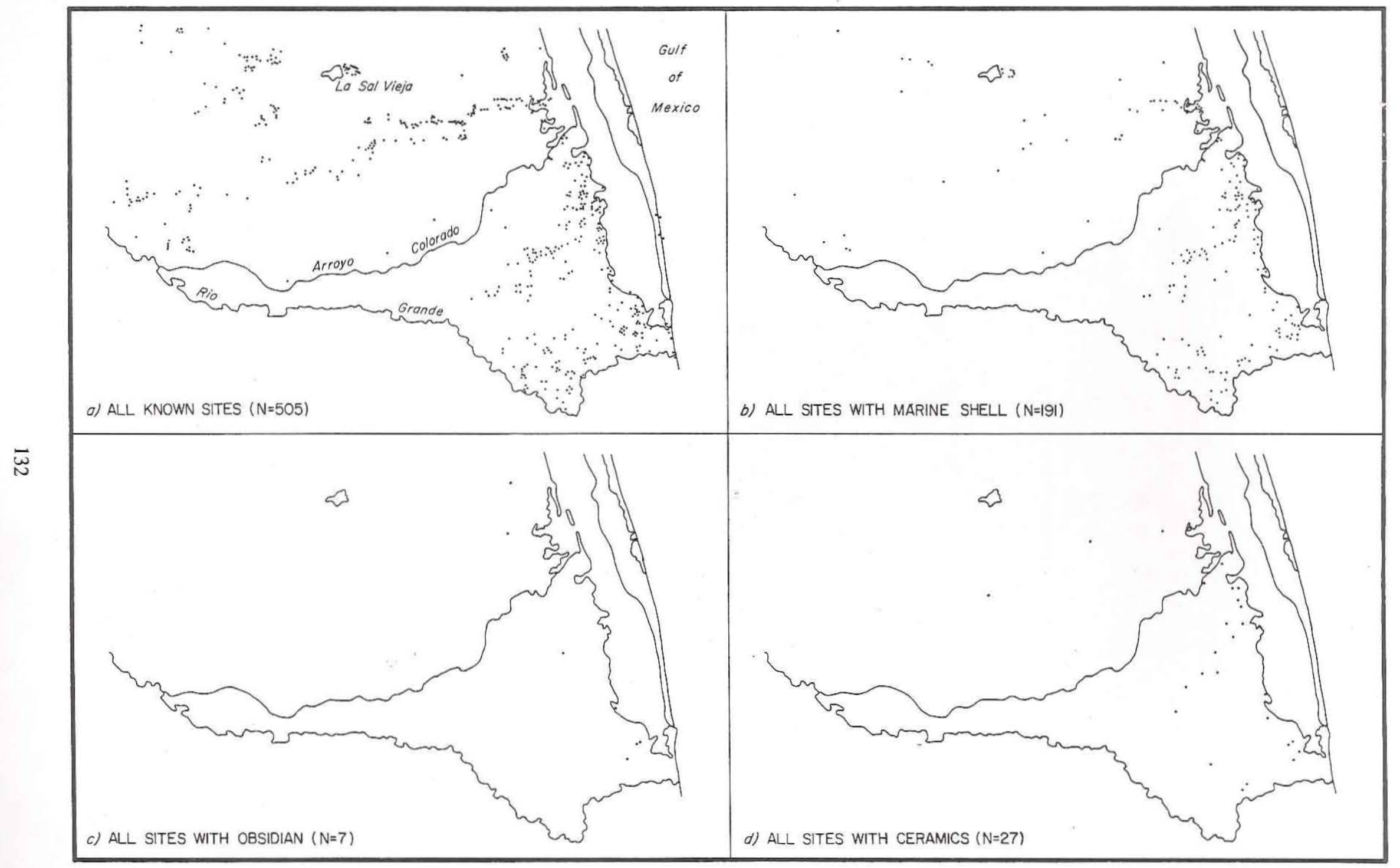

Figure 49. Distribution of all known sites and sites with marine shells, obsidian, and ceramics. 
from the coast. It is in these areas that ethnographic documents and the models predict that the most intensive prehistoric utilization occurred, and thus the models have been tested by investigating the fringes of the region and not the core areas. Given this limitation, the testing of the models and assessment of the organization of technology for the Lower Rio Grande Valley was surprisingly successful. However, future archeological research should concentrate on clarifying the role of these two environmental zones in prehistoric land-use patterns.

Finally, it is clear that the environmental variables that conditioned hunter-gatherer responses are not fully known, especially in terms of a temporal trajectory. Continued collection of paleoenvironmental data should help to resolve this problem; however, a coordinated approach between the collection and analysis of paleoenvironmental data and archeological research is important. Otherwise, paleoenvironmental data will accumulate that will not provide information useful for archeological analysis. In addition, it is unclear if appropriate temporal controls on the archeological data base can easily be obtained, but efforts must be made to acquire this data base as well.

The previous discussion has identified a number of inaccuracies demonstrating that the models, and thus the interpretations, require alteration and fine-tuning. This is a normal and expected result. The current work constitutes an attempt to identify where and how this fine-tuning should proceed, thus providing directions for future investigations in the region. 



\section{CONCLUSIONS AND SITE ASSESSMENTS}

by C. Britt Bousman and Steve A. Tomka

This final chapter presents a summary of the results of this project and some conclusions and speculations on the archeology and paleoenvironments in South Texas. These investigations have focused on what many might consider unworthy archeological sites, but it must be remembered that most of the archeological record for the Lower Rio Grande Valley consists of exactly these types of sites. It is argued herein that these sites can provide informative and significant data that clearly influence interpretations of the prehistory of South Texas. In addition, the integration of archeological and paleoenvironmental studies, including geoarcheology, provides the information necessary to develop reasonable research strategies that maximize the retrieval of archeological and paleoenvironmental data. The sections that follow present the results of the geological studies, the archeological interpretations, and an assessment of the individual archeological sites.

\section{GEOLOGICAL RESULTS}

The results of the geological investigations can be summarized as three major points. First, all in situ archeological remains are in a single cumulative soil that sits unconformably on the Pliocene and Pleistocene Beaumont, Lissie, or Goliad formations. The base of this soil has been dated to 4300 B.P. at $41 \mathrm{HG} 128$, to 1260 B.P. at 41WY112, and to 2560-3040 B.P. at 41WY113. A series of more recent dates are scattered throughout this soil in proper stratigraphic order, which demonstrates a continual development and build-up of these soil profiles into the historic period. Most of the archeological sites are located in or on the edge of small wind-deflated basins known as blowouts. It appears that these blowouts were scoured some time before the late Holocene, although not necessarily synchronously, and the modern soils began to form after the scouring events.

Second, the Beaumont, Lissie, and Goliad formations are presumably much older than the first human occupation in North America and thus cannot contain in situ archeological remains. In the upper, highly weathered portion of these formations, calcium carbonate nodules are common at all sites. These calcium carbonate nodules are of pedogenic origin, and dated inner and outer fractions of two samples from 41HG128 demonstrate the probable existence of a late Pleistocene soil. The radiocarbon ages range from 17,350 and 16,330 B.P. on the inner fractions to 12,780 and 15,010 B.P. on the outer fractions. These dates show that the nodules did, in fact, build up chronologically. The degree of weathering in the upper portion of the Goliad, Lissie, and Beaumont formations, the documentation of an unconformity between the modem soil and the underlying Pliocene and Pleistocene formations, and the radiocarbon ages all imply the existence of a truncated late Pleistocene soil.

Third, the analyses of oxygen and carbon stable isotopes suggest that climatic warming occurred very early, i.e., by 15,000 B.P., and that 
the late Pleistocene and early Holocene plant communities were dominated by $\mathrm{C}_{4}$ and CAM species. If the 9360 B.P. date for the tortoise remains from $41 \mathrm{WY} 140$ is correct and if the tortoise remains documented by Westgate (1987) are roughly coeval with this individual, then it appears that conditions were not dramatically harsh at that time. It is possible that the late Pleistocene soil was still in place. Glacial sequences from the United States and Mexico demonstrate that terminal Pleistocene environments fluctuated greatly (Richmond and Fullerton 1986; White 1986), however, and the pollen profiles from Boriack and Gause bogs in east-central Texas support this interpretation (Bryant 1977; Bryant and Holloway 1985). Thus, it is possible that the Willacy County tortoise remains date to one or more warm interval in the terminal Pleistocene period. Unfortunately, no paleoenvironmental data are available for most of the early Holocene, so the climatic conditions that accompanied the erosion of the late Pleistocene soil are undocumented. In general, the paleoenvironmental data recovered from the Hidalgo-Willacy Drainage Ditch support a general model of fluctuating climatic conditions throughout the late Pleistocene and Holocene (Black 1989:12-14), although it is clear that more data are needed to provide the level of detail necessary for meaningful paleoenvironmental interpretations for South Texas.

\section{GEOLOGICAL MODEL}

The three major results discussed above require explanation and allow the formation of a model. As most of the tested sites occur on the edges of and in deflationary basins, the obvious scenario is that increased wind activity aided by drier conditions during the early to middle Holocene removed sediments. The dates from the extant surface soil and from the calcium carbonate nodules discussed above, indicate that a late Pleistocene soil was removed sometime between 12,780 and 4300 B.P. The tortoise might indicate that erosion began after 9400 B.P. It was not until after approximately 5000 B.P. that the latest episode of sediment storage occurred and cumulative soils began to form in these basins; additionally, direct evidence of the first human occupation in the region postdates 5000 B.P., i.e., the
41 WY60 burial dated to 4495 B.P.

This model of erosion associated with a dry episode is supported by geomorphic evidence from 41 HG118 where a gully eroded into a Beaumont Formation knoll began to fill by 4500 B.P. (Hall et al. 1987; Collins et al. 1989). This suggests that early to middle Holocene erosion may have been fairly widespread. Other supportive evidence comes from sediment analysis at Arenosa Shelter (Patton and Dibble 1982:111) and a variety of pollen spectra (Bryant and Holloway 1985:56) from the Lower Pecos River region where an early Holocene dry period occurs by 9000 B.P. (Fig. 50). To the north of the Lower Rio Grande Valley at Choke Canyon Reservoir in Live Oak County and at Coleto Creek in Goliad County, phytolith analyses suggest that $\mathrm{C}_{4}$ grasses probably were widespread during the early to middle Holocene and that a significant dry phase occurred during this time (Robinson 1979, 1982). All of these studies demonstrate the existence of an early to middle Holocene dry interval, and it is likely that similar climatic conditions existed in South Texas during this time as well. However, if erosion removed the late Pleistocene soil and other surficial sediments in far South Texas, where were these sediments deposited?

A few geological studies from nearby areas provide data that may answer this question. At Choke Canyon Reservoir (Bunker 1982:498-517), Applewhite Reservoir (Rolfe Mandel, personal communication 1989), and the middle Pedernales River (Blum 1989:13-15), thick, fine-grained, silty, terrace deposits date from the terminal Pleistocene to the middle Holocene (see Fig. 50). The Applewhite terrace sediments comprise a significant proportion of the middle Medina River valley fill and are tentatively identified as eolian silt deposits similar to loess (Rolfe Mandel, personal communication 1989). In addition, an unstudied $10-12-\mathrm{m}$ silty terrace, very similar to the terraces in Applewhite Reservoir, has been observed by the primary author on the Guadalupe River as it flows off the Edwards Plateau. Lastly, between these sites and the HidalgoWillacy Drainage Ditch is the extensive South Texas sand sheet. The geological history of the sand sheet is unknown, nevertheless it is possible that significant portions date to the terminal Pleistocene and early Holocene, as stabilized dunes within it are aligned along the modern 


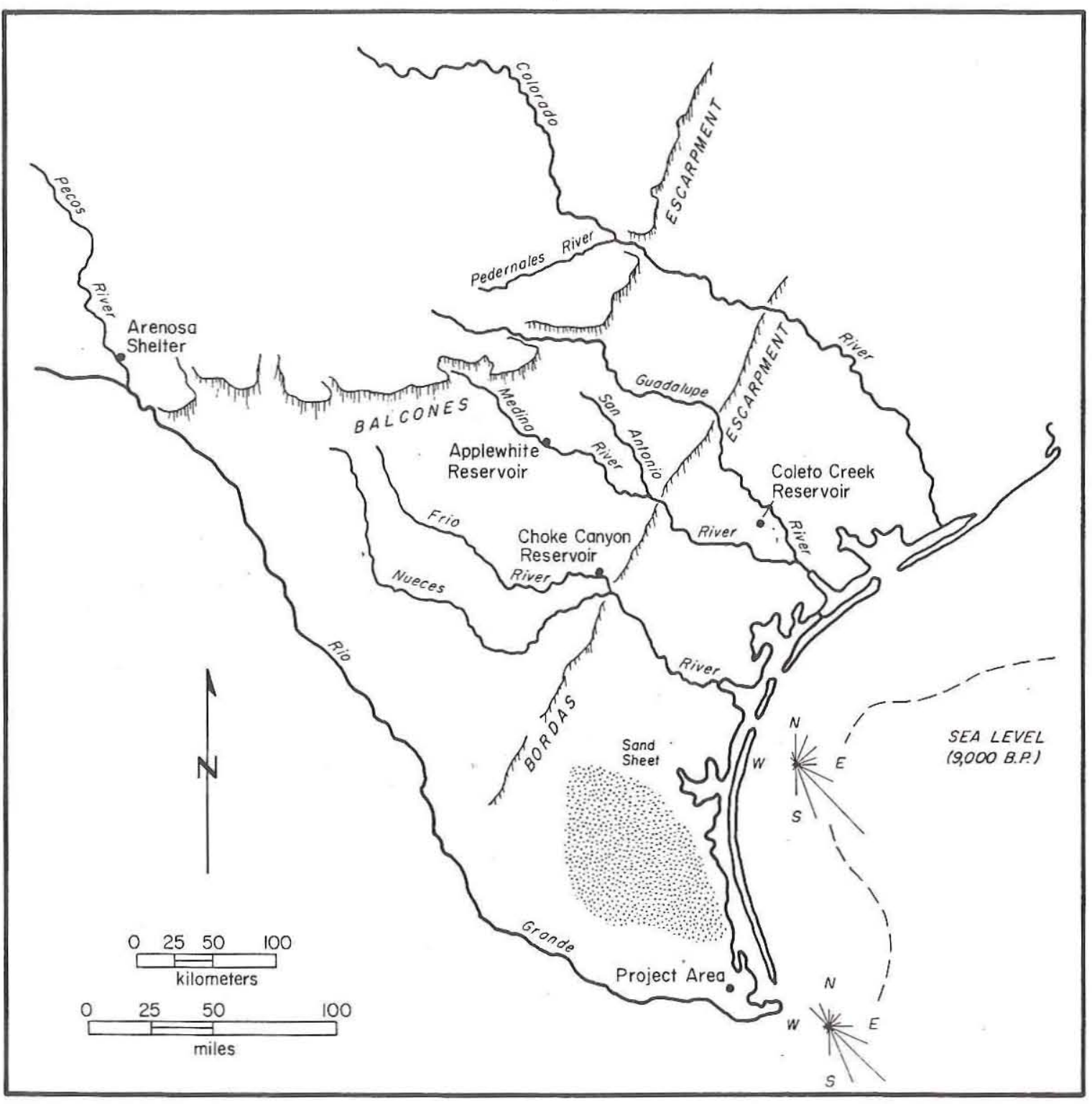

Figure 50. South Texas physiographic features and some of the major archeological projects.

predominant wind directions (as shown by wind roses in Fig. 50) suggesting recent deposition.

It is possible that terminal Pleistocene and early Holocene wind erosion removed a significant amount of sediment from the coastal region of Texas. Sea levels were ca. $20 \mathrm{~m}$ lower at that time, and unconsolidated fluvial deposits along the coastal plain would have been available for wind erosion (see Fig. 50). If large amounts of sediment were transported by wind, then the coarser sand particles would have been transported the shortest distances and the finer grained sediments would have been carried much farther. The modern surface wind patterns in this region are dominated by winds from the south to southeast, and Central Texas is in a direct line from these prevailing winds (see Fig. 50). Also, the Balcones Escarpment is the only major obstruction to winds from the coast, although the smaller Bordas Escarpment, which is the approximate location of Choke Canyon Reservoir, is a minor obstructional feature. Thus, as wind blows up and over the 
escarpments, it loses energy and speed, and this loss of energy would be enough to reduce the amount of sediment transported. It is of more than passing interest that in a worldwide series of computer climatic simulations calculated at 3,000year intervals between 18,000 and 0 B.P., based on Milankovitch orbital parameters (eccentricity, axial tilt, and precession), the strongest southern wind flows in South Texas were simulated for 9000 and 6000 B.P., while levels at 12,000 and 3000 B.P. were near modern wind speeds (COHMAP 1988: 1048). If the computer simulations are correct, then these early Holocene winds could have eroded the late Pleistocene soil in South Texas.

A modern study of eolian deposition on the Edwards Plateau shows that the Pedernales River basin, Applewhite Reservoir, and the middle Guadalupe River valley are in or downstream from the portion of the Edwards Plateau that receives the greatest amounts of modern eolian accumulations (Rabenhorst et al. 1984; Rabenhorst and Wilding 1986). Unfortunately, the sources of the modern Edwards Plateau eolian sediments were not identified in this study, but a significant sediment source area could be the Texas coast, as suggested above from modern and simulated wind patterns. While modern eolian deposition rates are low ( $1 \mathrm{~cm}$ per 1000 years), the study was conducted during a fairly wet year (1981) which would have reduced the eolian transportation rate. If fact, Rabenhorst and Wilding (1986:685) state that variations in eolian sedimentation would be expected with climatic changes. It is suggested that changing climate toward more mesic conditions after 5000 B.P. and rising sea levels throughout the early Holocene culminating with the $+1.5-\mathrm{m}$ proposed sea level highstand dated to ca. 4500 B.P. (Prewitt and Paine 1987), would have limited the amount of eolian erosion near the coast and reduced deposition inland.

In sum, the geological data recovered on this project and other archeological projects in the region can be used to construct a geological model for the late Pleistocene and Holocene. It is suggested that an early Holocene dry period was of sufficient magnitude to allow wind erosion that removed the late Pleistocene surface soil and pond deposits from blowouts and other areas that now dot the low-lying areas near the present coastline. Additional sediment sources could have been the portion of the coastal plain that is now submerged but was exposed by lower sea levels during the late Pleistocene and early Holocene, or any of the fairly unconsolidated Eocene or more recent fluvial/deltaic formations that ring the coastal region. In South Texas, wind flow may have been strong enough to transport significant quantities of sediment northwestward. The heavier sands dropped out to form a portion of the South Texas sand sheet, while the lighter silts continued to be carried to the Balcones Escarpment where they were dumped on the flanks and top of the Edwards Plateau due to a drop in wind speed. It is possible that the wind-borne sediment loads were large enough to partially choke the drainage systems along the edges of the Balcones Escarpment, and this might account for the homogeneous textures found in some terraces which were apparently stream deposited. If this model is generally correct, it may help to explain why so little information has been recovered on late Pleistocene and early Holocene occupations in the Lower Rio Grande Valley. It can also be suggested that early Holocene sites with good archeological integrity are likely to occur in eolian deposits, such as the clay dunes near the large inland playas (e.g., La Sal Vieja). At present this model should be considered as an untested hypothesis that can and should be assessed by future research, and it is proposed, in part, as a polemic designed to encourage the collection of additional paleoenvironmental data and stimulate more dialogue on paleoenvironmental change in South Texas.

\section{ARCHEOLOGICAL RESULTS}

Five prehistoric sites were tested during Phase II investigations along the Hidalgo-Willacy Drainage Ditch. A summary of the results of individual site investigations is presented. These are followed by the results of the radiocarbon dating of human remains and then by the results of the artifact analysis.

At 41 HG128, eleven $1 \times 1-m$ test units were excavated, and a total of 107 artifacts were recovered from the excavations. Another nine artifacts were collected from the surface. Most of the excavated artifacts are very small flakes and were recovered in the upper levels with associated radiocarbon ages ranging from 120 to 480 B.P. A small number of artifacts were recovered from 
deposits that could be as old as 4300 B.P. Two possible cultural features were identified. One possible prehistoric feature consisted of burned clay lumps and associated large charcoal fragments. The charcoal yielded a radiocarbon age of 320 B.P. Nine lithic flakes were recovered in association with this feature. It is possible that the charcoal and burned clay lumps are the result of a natural fire and the artifacts are fortuitously associated. The second feature was a pit clearly outlined in profile, but the associated radiocarbon age is young (i.e., 120 B.P.) and it could be historic in age. Prehistoric artifact associations with this feature were unclear. In summary, this site was utilized during the late Holocene and probably for short periods at sporadic intervals.

At $41 \mathrm{WY} 112$, a magnetometer survey was completed and eleven 1x1-m test units were excavated. A total of 25 artifacts were recovered from the excavations, and 7 artifacts were collected from the surface. The majority of excavated artifacts at $41 \mathrm{WY} 112$ occur in the upper levels below the zones of historic disturbance and appear to be younger than 1260 B.P. It is not possible to provide more accurate chronological control for these artifacts. This site appears to have been sporadically occupied during the latter half of the late Holocene.

A magnetometer survey was completed at 41WY113, and four $1 \times 1-m$ test unit were excavated. Only six artifacts were recovered from the excavations and two were collected from the surface. Two features have been documented at this site. In 1986, a human burial was excavated, and during the present project, a cluster of deer bones and one bone artifact were documented. Collagen from the human burial was dated to 1088 B.P., and collagen from the deer bones yielded a radiocarbon age of 2560 B.P. As some of the artifacts are near the top of the undisturbed deposits, this site reflects very light utilization over a long period of time during the late Holocene.

At 41WY134, four 1x1-m test units were excavated but as no artifacts were recovered, no radiocarbon samples were submitted from this site. It appears that the focus of prehistoric occupation was north of the ditch right-of-way.

At 41WY140, four 1x1-m test units were excavated, but only two lithic artifacts were recovered. Also recovered were fragments of a tortoise from the top of the Beaumont Formation; these are discussed above in the geological results. It is unlikely that in situ archeological remains occur at this site.

Three previously recovered human skeletal remains were dated by radiocarbon and analyzed for stable isotopes. The radiocarbon ages of the human burials suggest that occupation of the area extends back over 4,400 years, and the occurrence of burials in the Lower Rio Grande Valley is older than previously suggested (Prewitt 1981). It is also clear that much care must be given to the direct dating of human remains. Dating the organic fraction of bone produces more reliable dates than dating the inorganic fraction, and isotopic fractionation corrections for radiocarbon dates should be calculated for every radiocarbon date. An additional benefit of correcting radiocarbon dates for fractionation effect is isotopic dietary information. The very limited stable isotope analysis of human remains obtained during this project suggests that distinct coastal and inland dietary patterns may exist. Nevertheless, many more isotopic measurements are necessary before such patterns can be accepted without justifiable skepticism.

A formal analysis of prehistoric artifact collections from sites recorded along the drainage ditch was designed in order to test a series of hypothetical hunter-gatherer mobility and resource exploitation models. The individual artifact assemblages from the five sites investigated during this project were too small for meaningful analysis, and in order to test the models, a broader regional approach was considered necessary. The published artifact data from previous archeological investigations was used to provide the data base required to test the models. A limited amount of reanalysis was undertaken to obtain data that could be used to test the models. Still, artifact numbers from individual sites were too low for meaningful statistical analysis, and the sites were grouped into seven clusters that could be compared to the models.

The models were constructed along three general land-use patterns. The first assumes that hunter-gatherer territories extended over the entire region and access to resources was not limited by territorial boundaries. The second model assumes that hunter-gatherer territories focused on the Rio Grande and extended north into the upland plain, the lowland plain, and the coast. East-west 
access, however, was limited. The third model assumes that hunter-gatherer territories were centered on the coast, and that north-south access was limited by neighboring hunter-gatherer territories.

Twelve lithic artifact categories are used as the primary data base with which to test the explanatory value of the three models, with specific model predictions being derived for each of the twelve analytical categories. Underlying these predictions are a series of assumptions regarding the relationships between lithic categories and distance from raw material sources and environmental zone use-intensity. While somewhat distinct predictions are outlined for each of the models, the differences between the models derive from the manner in which the territorial boundaries affect access to raw material sources, determine the mix of high- and low-yield environmental zones within each group's territory, and condition the form and location of lithic raw material exchange networks. The relationships underlying the predictions are:

(1) frequencies of early reduction debitage, large debitage, total debitage, manufacture failures, and cores are negatively correlated with distance from raw material source and environmental zone use-intensity;

(2) frequencies of resharpening flakes and use-broken tools are positively correlated with environmental zone use-intensity;

(3) discard of exhausted tools occurred at raw material sources while the frequency of exhausted tools is positively correlated with environmental zone use-intensity;

(4) frequencies of reused tools and the mean number of working edges per uniface are positively correlated with environmental zone useintensity and distance from raw material source; and

(5) frequencies of edge-modified flakes and the mean number of utilized edges per flake are positively correlated with distance from raw material and use-intensity; however, the response to distance from material source is assumed to be somewhat more gradual in the case of the edgemodified flakes than in the case of formal tools.

These assumed relationships between lithic assemblages, raw material availability, and environmental zone use-intensity are based on a number of more general assumptions regarding raw material distributions in the project area and environmental zone use-intensities. Specifically, raw material sources are not known to exist east of the upland plain zone and east of La Joya in the Rio Grande floodplain. Based on an assessment of environmental zone productivity potential, the following zone use-intensity rankings are assumed, in decreasing order: coastal zone, Rio Grande floodplain, sand sheet, lowland plain, and upland plain. Although the zones generally are assumed to be internally homogeneous in resource potential, it is assumed that, within low resourceyield zones, use-intensity may have been higher at the boundaries with higher resource-yield zones.

The test of the models was equivocal. However, Model I, a no-limited-access exploitation pattern, was slightly favored over Model II, a Rio Grande floodplain exploitation pattern and Model III, a coastal exploitation pattern. Given the nature of the data base, this unclear patterning is not surprising. The more important consequence of the analysis stems from how the results reflect on the underlying assumptions of lithic artifact manufacture, use, and discard used in the model constructions. This analysis allows for the refinement of a number of the simplified assumptions which underlie the models and permits more precise modeling and understanding of the organization of lithic technology, resource acquisition practices, and general land-use patterns employed by inhabitants of the region. The following alterations are suggested to the initial assumptions.

(1) The distributions of early reduction debitage, large debitage, total debitage, and cores suggest that the general assumption regarding the lack of raw material sources east of the upland plain zone and east of La Joya may be incorrect. These attributes suggest that raw material sources do occur in the extreme eastern portion of the sand sheet. Alternatively, this evidence could indicate the long-distance transport of nonprepared cores into the eastern sand sheet from sources in the upland plain zone or perhaps from northwest of this site cluster.

(2) The frequencies of early reduction debitage and manufacture failures appear to support the initially assumed inverse relationship between the frequencies of such artifacts and distance from source. Because of the aberrant patterning noted in the eastern sand sheet, it is impossible to establish whether use-intensity 
contributed to the relationship in the manner assumed.

(3) The patterning derived from the large debitage and total debitage distributions may indicate a more complex relationship between these categories and distance from raw material sources and environmental zone use-intensity. It appears that, in contexts of low regional raw material availability, the exportation of large flake blanks may have reduced the overall frequency of the large debitage class at raw material procurement sites (e.g., the upland plain). In addition, the exportation of large flake blanks, coupled with the possibility that only some manufacture sequences were completed at the procurement sites, may have resulted in a lowering of overall debitage frequencies contrary to the pattern assumed.

(4) While the overrepresentation of core frequencies at the eastern sand sheet cluster is aberrant, the overrepresentation of cores in the central lowland plain cluster, a position halfway between the two possible raw material sources, does suggest that perhaps raw materials in the form of cores were transported to this raw material scarce setting.

(5) The overrepresentation of resharpening flakes at the sand sheet site clusters indicates a pattern consistent with the assumption that the frequency of resharpening flakes is directly related to zone use-intensity. However, the overrepresentation of this category in two of the three lowland plain site clusters suggests that the frequency of such artifacts was also conditioned by a relationship between distance from raw material source and the nature of the artifacts exported from raw material rich zones. That is, it appears that, in areas of low raw material availability, the proportion of debitage derived from tool resharpening was greater than that derived from the other stages of artifact reduction. However, the overrepresentation of resharpening flakes at the western and eastern lowland plain site clusters, both of which are relatively near higher-yield resource zones, may also support the assumption of increased use-intensity of low-yield zones located in ecotonal settings.

(6) The exhausted tool distribution also shows a pattern more complex than initially assumed, but it appears that the discard of exhausted tools tended not to occur at the raw material source. Rather, exhausted bifaces and unifaces appear to have been discarded at the locations where they become too small to function. On the other hand, the distribution of exhausted projectile points shows a pattern following that assumed by the models. That is, exhausted projectile points were discarded at the source areas in anticipation of future failure as opposed to being utilized until actual failure, which could have occurred in zones with low raw material availability thus reducing the possibility of immediate replacement.

(7) The overall frequency of use-broken tools also contradicts the assumed patternings. Rather than having a distributional pattern showing a direct relationship to environmental zone useintensity, use-broken specimens appear to be almost evenly distributed between low and high use-intensity zones. This suggests that the breakage of tools during use was not determined by environmental zone use-intensity. However, the analysis of use-broken specimen frequencies by tool type suggests that, rather than searching for patterns in overall use-broken tool frequencies, a more productive approach is the focus on use breakage rates by tool type. This shift in the scale or focus of the analysis seems to be well justified as not all tool types are likely to have been used with the same intensity in all zones.

(8) In general, the frequency of reused tools and the mean number of working edges per uniface support the assumed relationship between distance and environmental zone use-intensity. However, the overrepresentation of both categories in the eastern sand sheet cluster, an area that may have nearby raw material sources, suggests that the effect of environmental zone use-intensity may be a stronger conditioning factor than distance from raw material source.

(9) The distributional patterns in edgemodified flake frequency and the mean number of utilized edges per flake show contradictory results across the different environmental zones. Neither appears to follow the proposed relationships, and the overall results suggest that the underlying assumption that these two categories respond to similar conditioning factors in ways similar to formal tools may be incorrect.

These alterations in the original assumptions affect the hypothesized relationships between lithic analytical categories, raw material source areas, and environmental zone use-intensity in some 
important ways, and, as a consequence, the specific predictions derived for each of the models proposed for the project area need reformulation. It is hoped that such refinement of the models can serve as the focus of future investigations in the region.

\section{SITE ASSESSMENTS AND RECOMMENDATIONS}

A number of criteria are used to assess the eligibility of cultural resources for listing on the National Register of Historic Places. Specifically, eligible resources are those that

possess integrity of location, design, setting, materials, workmanship, feeling, and association, and

A. that are associated with events that have made a significant contribution to the broad patterns of our history; or

B. that are associated with the lives of persons significant in our past; or

C. that embody the distinctive characteristics of a type, period, or method of construction, or represent the works of a master, or possess high artistic values, or represent a significant and distinguishable entity whose components may lack individual distinction; or

D. that have yielded or may be likely to yield information important in prehistory or history. [U.S. Department of the Interior, National Park Service, National Register Division 1982:1].

Clearly, the criteria of integrity and ability to yield important information (Criterion D) are most relevant to the archeological sites tested in this project.

The theoretical models of hunter-gatherer exploitation patterns, mobility, and territorial divisions described in Chapter 3 provide a starting point for identifying how individual sites in the Lower Rio Grande Valley can contribute important information concerning the prehistory of the region. Hence, these models offer a basis for assessing the National Register eligibility of the five sites reported in this volume, as well as for site assessments in future projects. Stated simply, any site that has the capacity to yield substantive data allowing testing or refinement of these models should be considered to contain important information and thus be eligible for listing on the National Register of Historic Places.

Before assessing the five sites tested during this project, five general points about the regional archeology merit mention. First, there is a notable dearth of published archeological information from two of the environmental zones defined for the area: the Rio Grande floodplain and delta and the coast. As full evaluation of the models presented here requires a regional perspective, obtaining information from sites in these settings is an important objective for future work in the area. This issue is especially relevant to the HidalgoWillacy Drainage Ditch because sites in one of these zones, i.e., the coast, may be affected by the project, and these sites could contribute significant information to the regional prehistory.

The second point relates to the problems of chronology and context. Obviously, little chronological control has been obtained to date on most of the artifact samples from the Lower Rio Grande Valley. It is for this reason that the models proposed in Chapter 3 are temporally static, and without better chronological data these models will never contribute much to understanding diachronic changes in exploitation patterns. This problem is a function of the low density of archeological remains and corresponding scarcity of temporally diagnostic artifacts, the paucity of datable materials, and the lack of well-stratified sites. While artifact recovery rates increase with fine screening, most sites in the area have sparse archeological remains. These sparse sites are an integral aspect of the archeological record, but at this point sites with richer records have the potential to contribute more-useful information than sparse sites, and these richer sites should be considered quite important. Another facet of this problem is the difficulty of identifying artifacts that reliably reflect temporal patterning in the region. It appears that projectile point size can be influenced by distance to raw material or intensity of use. Without good chronological controls on the archeological record, regional analysis of archeological data will be stymied. 
Third, the radiocarbon dating program of this project can be used to suggest a number of procedures that would result in better chronologies in the future. All radiocarbon ages should be corrected for the fractionation effect of stable carbon isotopes, even for charcoal samples. This can significantly change radiocarbon ages, and it is only corrected radiocarbon ages that can be used in the high resolution tree-ring calibration curves. Fractionation correction is especially important if soils or bones are used. Additionally, if bones are used for radiocarbon dating, the organic or gelatin fraction should be dated whenever possible. The inorganic or apatite fraction often produces unreliable radiocarbon ages. Additionally, the stable isotope values can provide paleoenvironmental and paleodietary information.

Fourth, in the future a bioarcheological analysis of cemeteries and burials, especially if supplemented by stable-isotope analysis and direct radiocarbon dates, can provide data within a chronological framework that is directly pertinent to hunter-gatherer economic adaptations, mobility, and social organization in the Lower Rio Grande Valley. Such archeological data can add "flesh to the bones" of ethnohistory, and provide independent evidence of the adequacy of the historic record. A regional approach to this problem will provide the most useful spatial and temporal patterning.

Fifth, because of their geomorphic contexts, most sites in the area contain limited or dubious paleoenvironmental data. When obtained from good contexts, such data are especially important in efforts to relate the behavior of past cultural groups to resource exploitation and mobility patterns. Should sites containing such data be identified, they should be accorded special attention. Possible settings for sites with this kind of data include clay dunes on the coast and inland eolian deposits in the South Texas sand sheet or around inland lakes or playas, such as La Sal Vieja. Lacking well-stratified sites containing pollen, phytoliths, and fauna, however, alternate dependable data sources need to be sought. The paleoenvironmental studies undertaken during this project, involving analyses of dated stable isotopes, are an attempt to find such sources and have provided some tantalizilng clues about environmental changes in the region.

As a group, the five sites tested during this
project--41HG128, 41WY112, 41WY113, 41WY134, and 41WY140--suffer from a number of shortcomings that have been identified at other sites tested previously along the Hidalgo-Willacy Drainage Ditch. All have very sparse cultural remains, with the largest artifact sample consisting of microdebitage recovered from the fine screen at 41HG128. Only small quantities of faunal and macrobotanical remains were recovered at 41HG128. With such small samples, it is doubtful that any of the sites is capable of yielding sufficient artifactual, ecofactual, or feature data to permit meaningful analysis. Substantive interpretation is also precluded by the inability to define reasonably discrete, datable components or periods of use, as all five sites lack well-stratified contexts. Further, the integrity of the cultural remains at all five sites is compromised to some extent by historic land-use practices. In short, while these five sites have proven useful in assessing the utility of the hunter-gatherer settlement models proposed here, they do not have the potential to significantly contribute to further testing or refinement of these models. Thus, 41HG128, 41WY112, 41WY113, 41WY134, and 41WY140 are judged to be ineligible for listing on the National Register of Historic Places.

Two final recommendations are offered here. First, at some point it will be crucial to search for the presumed raw material source in the South Texas sand sheet. Its existence is strongly implicated by the data, but until this source is documented, the analysis of prehistoric archeological assemblages will be hampered. This particular objective may be particularly difficult because of land access problems. Nevertheless, the discovery and characterization of this raw material source, if it does in fact exist, would greatly facilitate the understanding of prehistoric adaptations in the Lower Rio Grande Valley.

Second, there are two coastal clay dune sites, $41 \mathrm{WY} 50$ and $41 \mathrm{WY} 60$, that were tested during an earlier phase of this project and that have the potential to contribute important information (Day et al. 1981). These sites appear to have good stratigraphic and archeological context, as well as reasonable organic preservation. Sites with such superior organic and contextual preservation warrant stratigraphic excavation, and the materials recovered should be analyzed with many of the techniques suggested in the 1988 work plan as 
well as the new techniques exployed in the investigations reported here. As discussed in the 1988 work plan, such sites may require large areal excavations because it is doubtful that high artifact densities will be found at any sites in the region, except possibly along the Rio Grande or near raw material sources. But the increased stratigraphic control at these sites should allow good spatial integration of numerous, low-density occupations, and these are the types of sites needed to make significant contributions to understanding the archeological record of the region. 


\section{REFERENCES CITED}

Afifi, A. A., and S. P. Azen

1979 Statistical Analysis: A Computer Oriented Approach. Academic Press, New York.

Anderson, A. E.

1932 Artifacts of the Rio Grande Delta Region. Bulletin of the Texas Archeological and Paleontological Society 4:29-31.

Aten, Lawrence E.

1983 Indians of the Upper Texas Coast. Academic Press, New York.

Bailey, Harry P.

1960 A Method of Determining the Warmth and Temperateness of Climate. Geografiska Annaler 43(1):1-16.

Bell, Willis, H., and Edward F. Castetter

1937 The Utilization of Mesquite and Screwbean by the Aborigines in the American Southwest. The University of New Mexico Bulletin, Ethnobiological Studies in the American Southwest. Whole Number 314; Biological Series Vol. 5 No. 2.

Benner, R., M. L. Fogel, E. K. Sprague, and R. E. Hodson

1987 Depletion of 13C in Lignin and Its Implications for Stable Carbon Isotope Studies. Nature 329:708-710.

Berg, B., and H. Staaf

1980 Decomposition Rate and Chemical Changes of Scots Pine Needle Litter, II: The Influence of Chemical Composition. In Structure and Function of Northem Coniferous Forests: An Ecosystem Study, edited by T. Persson, pp. 373-390. Ecological Bulletin 32:373-390.

Berg, Bjorn, Gunnar Eckhohm, and Charles McClaugherty

1984 Lignin and Holocellulose Relations During Long-term Decomposition of Some Forest Litters: Long-term Decomposition in a Scots Pine Forest, IV. Canadian Journal of Botany 62:25402550.

Binford, Lewis R.

1980 Willow Smoke and Dogs' Tails: Hunter-Gatherer Settlement Systems and Archaeological Site Formation. American Antiquity 45(1):4-20.

Birdseye, Richard U., and Saul Aronow

1988 Late Quaternary Geology of Southwestern Louisiana and Southeastern Texas. South- Central Friends of the Pleistocene, Sixth Field Conference.

Birkeland, Peter W.

1984 Soils and Geomorphology. Oxford University Press, New York.

Black, Stephen L.

1989 Environmental Setting. In From the Gulf to the Rio Grande: Human Adaptation in Central, South, and Lower Pecos Texas, by Thomas R. Hester, Stephen L. Black, D. Gentry Steele, Ben W. Olive, Anne A. Fox, Karl J. Reinhard, and Leland C. Bement. Research Series No. 33. Arkansas Archeological Survey, Fayetteville. 
Blatt, Harvey, Gerard Middleton, and Raymond Murray

1980 Origin of Sedimentary Rocks. Prentice-Hall, Inc., Englewood Cliffs.

Blum, Michael D.

1989 Quatemary Stratigraphy of the Pedernales River. In Geomorphology, Quaternary Stratigraphy, and Paleoecology of Central Texas, by Michael D. Blum, James F. Petersen, and Richard S. Toomey, III. Seventh Annual Meeting of the Friends of the Pleistocene, South Central Cell, Fredericksburg, Texas.

Bomer, George W.

1983 Texas Weather. The University of Texas Press, Austin.

Bousman, C. B., L. Scott, N. J. Schackleton, and J. C. Vogel

1989 Pollen, Stable Isotopes and Paleoenvironmental Reconstructions in Africa. Paper presented at the 54th Annual Meeting of the Society for American Archaeology, Atlanta.

Boyd, Douglas K., and Steve A. Tomka

1990 Summary and Conclusions. In Phase II Investigations at Prehistoric and Rock Art Sites, Justiceburg Reservoir, Garza and Kent Counties, Texas, Vol. I, by Douglas K. Boyd, James T. Abbott, William A. Bryan, Colin M. Garvey, Steve A. Tomka, and Ross C. Fields. Reports of Investigations No. 71. Prewitt and Associates, Inc., Austin.

BrainPower, Inc.

1986 Statview 512+. BrainPower, Inc., Calabasas, Ca.

Brown, Douglas R.

1972 An Assessment of the Archeological Resources to be Affected by Construction of Retamal International Diversion Dam, United States Dike and Modified Hackney Floodway and Closure of Mission Floodway, Hidalgo County, Texas. Project Report 15. Texas Archeological Survey, The University of Texas at Austin.

Brown, L. F., Jr., J. L. Brewton, T. J. Evans, J. H. McGowen, W. A. White, C. G. Groat, and W. L. Fisher

1980 Environmental Geologic Atlas of the Texas Coastal Zone -- Brownsville-Harlingen Area. Bureau of Economic Geology, The University of Texas at Austin.

Bryant, Vaughn M., Jr.

1977 A 16,000 Year Pollen Record of Vegetational Change in Central Texas. Palynology 1:143156.

Bryant, Vaughn M., Jr., and Richard G. Holloway

1985 A Late Quaternary Paleoenvironmental Record of Texas: An Overview of the Pollen Evidence. In Pollen Records of Late Quaternary North American Sediments, edited by Vaughn M. Bryant, Jr., and Richard G. Holloway, pp. 39-70. American Association of Stratigraphic Palynologists Foundation, Dallas.

Bunker, Russel C.

1982 The Geomorphic Framework of Human Occupation in the Frio River Valley, Choke Canyon Dam Reservoir Area, Live Oak and McMullen Counties, Texas. Appendix II in Archaeological Investigations at Choke Canyon Reservoir, South Texas: The Phase I Findings, by Grant D. Hall, Stephen L. Black, and Carol Graves, pp. 498-517. Choke Canyon Series, Volume 5. Center for Archacological Research, The University of Texas at San Antonio. 
Bureau of Economic Geology

1976 Geologic Atlas of Texas, McAllen-Brownsville Sheet. Bureau of Economic Geology, The University of Texas at Austin.

Callahan, Errett

1979 The Basics of Biface Knapping in the Eastern Fluted Point Tradition, A Manual for Flintknappers and Lithic Analysts. Archaeology of Eastern North America 7:1-180.

Campbell, Thomas Nolan

1960 Archeology of the Central and South Sections of the Texas Coast. Bulletin of the Texas Archeology Society 29(for 1958):145-176.

1964 Appraisal of the Archeological Resources of Padre Island, Texas. Report submitted to the National Park Service by The University of Texas at Austin.

1975 The Payaya Indians of Southern Texas. Special Publication 1. Southern Texas Archaeological Association, San Antonio.

1977 Ethnic Identities of Extinct Coahuiltecan Populations: Case of the Juacana Indians. The Pearce-Sellard Series 26. Texas Memorial Museum, The University of Texas at Austin.

1983 Coahuiltecans and Their Neighbors. In Southwest, edited by Alfonso Ortiz, pp. 343-360. Handbook of North American Indians, vol. 10, William C. Sturtevant, general editor. Smithsonian Institution, Washington, D.C.

1988 The Indians of Southern Texas and Northeastern Mexico: Selected Writings of Thomas Nolan Campbell. Texas Archeological Research Laboratories, The University of Texas at Austin.

Campbell, Thomas N., and Jack Q. Frizzell

1949 Notes on the Ayala Site, Lower Rio Grande Valley, Texas. Bulletin of the Texas Archeological and Paleontological Society 20:63-72.

Cason, Joe F.

1952 Report on Archeological Salvage in Falcon Reservoir, Season of 1952. Bulletin of the Texas Archeological and Paleontological Society, 23:218-259.

Castetter, Edward F., and Ruth M. Underhill

1935 The Ethnobiology of the Papago Indians. The University of New Mexico Bulletin, Ethnobiological Studies in the American Southwest. Whole Number 275; Biological Series, Vol. 4, No. 3.

Castetter, Edward F., and M. E. Opler

1936 III. The Ethnobiology of the Chiricahua and Mexcalero Apache. A. The Use of Plants for Foods, Beverages, and Narcotics. The University of New Mexico Bulletin, Ethnobiological Studies in the American Southwest. Whole Number 297; Biological Series, Vol. 4, No. 5.

Cerling, Thure E.

1984 The Stable Isotopic Composition of Modern Soil Carbonate and Its Relationship to Climate. Earth and Planetary Science Letters 71:229-240. 
Cerling, Thure E., and Richard L. Hay

1986 An Isotopic Study of Paleosol Carbonates from Olduvai Gorge. Quaternary Research 25:6378.

Cerling, T. E., R. L. Hay, and J. R. O'Neil

1977 Isotopic Evidence for Dramatic Climatic Changes in East Africa During the Pleistocene. Nature 267:137-138.

Cerling, T. E., J. Quade, Y. Wang, and J. R. Bowman

1989 Carbon Isotopes in Soils and Palaeosols as Ecology and Palaeoecology Indicators. Nature 341:138-139.

Chappell, J., and N. J. Shackleton

1986 Oxygen Isotopes and Sea Level. Nature 324:137-140.

Charnov, Eric L.

1976 Optimal Foraging, the Marginal Value Theorem. Theoretical Population Biology 9:129-136.

CLIMAP Project Members

1981 Seasonal Reconstructions of the Earth's Surface at the Last Glacial Maximum. Map Chart Series MC-36. Geological Society of America.

Clover, Elzada U.

1937 Vegetational Survey of the Lower Rio Grande Valley, Texas. Madrono 4:41-72.

COHMAP Project Members

1988 Climatic Changes of the Last 18,000 Years: Observations and Model Simulations. Science 241:1043-1052.

Collins, M. B., T. R. Hester, and F. A. Weir

1969 The Floyd Morris Site (41CF2), a Prehistoric Cemetery Site in Cameron County, Texas. Part I in Two Prehistoric Cemetery Sites in the Lower Rio Grande Valley of Texas, by Thomas Roy Hester, Michael B. Collins, Frank A. Weir, and Frederick Ruecking, Jr. Bulletin of the Texas Archeological Society 40:119-146.

Collins, Michael B., and C. Britt Bousman

1990 Cultural Implication of Late Quaternary Environmental Change in Northeast Texas. Unpublished manuscript on file at the Texas Historical Commission, Austin.

Collins, Michael B., Grant D. Hall, and C. Britt Bousman

1989 Archaeological Applications of Geochronological Techniques in Southern Texas. La Tierra 16:14-27.

Conaty, Gerald T.

1987 Comments on Hayden's Resource Models of Inter-Assemblage Variability. Lithic Technology 16(2-3):59-61.

Dansgaard, W.

1964 Stable Isotopes in Precipitation. Tellus 16:436-468. 
Davenport, Harbert, and Joseph K. Wells

1918- The First Europeans in Texas, 1528-1536. Southwestern Historical Quarterly 22(2):111-112;

1919 22(3):205-259.

Day, D. William

1981 An Assessment of Archeological Sites 41 WY71 and 41WY72, Willacy County, Texas. Reports of Investigations No. 17. Prewitt and Associates, Inc., Austin.

Day, D. William, Jane Laurens-Day, and Elton R. Prewitt

1981 Cultural Resources Surveys and Assessments in Portions of Hidalgo and Willacy Counties, Texas. Reports of Investigations No. 15. Prewitt and Associates, Inc., Austin.

DeNiro, Michael J.

1987 Stable Isotopy and Archaeology. American Scientist 75:182-191.

Dyson-Hudson, Rada, and Eric Alden Smith

1978 Human Territoriality: An Ecological Reassessment. American Anthropologist 80(1):21-41.

Dzurec, R. S., T. W. Boutton, M. M. Caldwell, and B. N. Smith

1985 Carbon Isotope Ratios of Soil Organic Matter and Their Use in Assessing Community Composition Changes in Curlew Valley, Utah. Oecologia 66:17-24.

Eickmeier, William G., and Margaret M. Bender

1976 Carbon Isotope Ratios of Crassulacean Acid Metabolism Species in Relation to Climate and Phytosociology. Oecologia 25:341-347.

Ekholm, G. F.

1944 Excavations at Tampico and Panuco, in the Huasteca, Mexico. Anthropological Papers of the American Museum of Natural History, Vol. 38, Part 5.

Espey, Huston and Associates, Inc.

1981 Proposed Deepwater Channel and Multipurpose Terminal Construction and Operation Near Brownsville, Texas. Cultural Resources Technical Report. Espey, Huston and Associates, Inc., Austin.

Etchieson, G. Meeks, and Douglas K. Boyd

1982 Cultural Resources Survey for Proposed Rehabilitation and a New Drain for Hidalgo County Irrigation District No. 16. Department of the Interior, Bureau of Reclamation, Southwest Region, Amarillo.

Evans, Glen L.

1941 Artifact Occurrence in the Second Terrace of the Rio Grande in Starr County, Texas. Bulletin of the Geological Society of America 52(12, Part 2):1998-1999.

Faure, Gunter

1986 Principles of Isotope Geology. John Wiley and Sons, New York.

Flexor, J. M., and B. Volkoff

1977 Distribution de l'Isotope Stable ${ }^{13} \mathrm{C}$ dans la Matiere Organique d'un sol Ferrallitique de l'Etat de Bahia (Bresil). C.R. Acad. Seances Sci. Paris Serie D. 284:1655-1657. 
Fox, Daniel E.

1979 An Intensive Survey of Sixteen Prehistoric Archaeological Sites in Starr County, Texas. Archaeological Survey Report No. 72. Center for Archaeological Research, The University of Texas at San Antonio.

Frazier, David E.

1974 Depositional Episodes: Their Relationship to the Quaternary Stratigraphic Framework in the Northwestern Portion of the Gulf Basin. Geological Circular 74-1. Bureau of Economic Geology, The University of Texas at Austin.

Gary, Margaret, Robert McAfee, Jr., and Carol L. Wolf (editors)

1972 Glossary of Geology. American Geological Institute, Washington, D.C.

Gat, J. R.

1980 The Isotopes of Hydrogen and Oxygen in Precipitation. In Handbook of Environmental Isotope Geochemistry. 1. The Terrestrial Environment, edited by A. P. Fritz and J. Ch. Fontes, pp. 21-47. Elsevier, Amsterdam.

George, Eugene

1975 Historical Architecture of Texas: The Falcon Reservoir. Texas Historical Commission and Texas Historical Foundation, Austin.

Goddard, Ives

1979 The Languages of South Texas and the Lower Rio Grande. In The Languages of Native America: Historical and Comparative Assessment, edited by Lyle Campbell and Marianne Mithun, pp. 335-389. The University of Texas Press, Austin.

Goland, Carol Ann

1983 The Ecological Context of Hunter-Gatherer Storage Strategies. Unpublished Master's Thesis, Department of Anthropology, University of North Carolina, Chapel Hill.

Good, Carolyn

1985 Letter Report: Project Area in Willacy County, Texas. Corps of Engineers, Galveston District, Permit 17513. On file at the Texas Historical Commission, Austin.

Guillet, B., P. Faivre, A. Mariotti, and J. Khobzi

1988 The ${ }^{14} \mathrm{C}$ Dates and ${ }^{13} \mathrm{C} /{ }^{12} \mathrm{C}$ Ratios of Soil Organic Matter as a Means of Studying the Past Vegetation in Intertropical Regions: Examples from Columbia (South America). Palaeogeography, Palaeoclimatology, Palaeoecology 65:51-58.

Haas, Herbert, Vance Holliday, and Robert Stuckenrath

1986 Dating of Holocene Stratigraphy with Soluble and Insoluble Organic Fractions at the Lubbock Lake Archaeological Site, Texas: An Ideal Case Study. Radiocarbon 28:2A:473-485.

Hall, Grant D., Michael B. Collins, and Elton R. Prewitt

1987 Cultural Resources Investigations Along Drainage Improvements, Hidalgo and Willacy Counties, Texas: 1986 Investigations. Reports of Investigations No. 59. Prewitt and Associates, Inc., Austin, Texas. 
Hall, Grant D., and Kerry A. Grombacher

1974 An Assessment of the Archeological and Historical Resources to be Affected by the Brazos Island Harbor Waterway Project, Texas. Research Report No. 30. Texas Archeological Survey, The University of Texas at Austin.

Hartle, P. D., and R. L. Stephenson

1951 Archaeological Investigations at the Falcon Reservoir, Starr County, Texas. Mimeographed report on file at the Texas Archeological Research Laboratory.

Hassan, Afifa A., John D. Termine, and C. Vance Haynes, Jr.

1977 Mineralogical Studies on Bone Apatite and Their Implication for Radiocarbon Dating. Radiocarbon 19:364-374.

Hayden, Brian

1986 Resource Models of Inter-Assemblage Variability. Lithic Technology 15(3):82-89.

1987 Reply to Conaty. Lithic Technology 16(2-3):62.

Heaton, T. H. E.

1987 The ${ }^{15} \mathrm{~N} /{ }^{14} \mathrm{~N}$ Ratios of Plants in South Africa and Namibia: Relationship to Climate and Coastal/Saline Environments. Oecologia 74:236-246.

Heaton, T. H. E., A. S. Talma, and J. C. Vogel

1986 Dissolved Gas Paleotemperatures and ${ }^{18} 0$ Variations Derived from Groundwater Near Uitenhage, South Africa. Quaternary Research 25:79-88.

Heffley, S.

1981 The Relationship Between Northern Athapaskan Settlement Patterns and Resource Distribution: an Application of Horn's Model. In Hunter-Gatherer Foraging Strategies: Ethnographic and Archaeological Analyses, edited by Bruce Winterhalder and E. A. Smith, pp. 126-147. University of Chicago Press, Chicago.

Hester, Thomas Roy

1969 The Floyd Morris and Ayala Sites: A Discussion of Burial Practices in the Rio Grande Valley and the Lower Texas Coast. Part III in Two Prehistoric Cemetery Sites in the Lower Rio Grande Valley of Texas, by Thomas Roy Hester, Michael B. Collins, Frank A. Weir, and Frederick Ruecking, Jr. Bulletin of the Texas Archeological Society 40:157-166.

1972 The Evidence for Prehistoric Trade on the Rio Grande Plain. In Archaeological Papers Presented to J. W. House, assembled by T. R. Hester, Department of Anthropology, University of California at Berkeley.

1975a A Chronological Overview of Prehistoric Southern and South-Central Texas. Paper presented at (1975) Conference on the Prehistory of Northeastern Mexico and Texas, Monterrey, Mexico.

1975b Chipped Stone Industries on the Rio Grande Plain, Texas: Some Preliminary Observations. The Texas Journal of Science 26(1-2).

1975c Late Prehistoric Cultural Patterns Along the Lower Rio Grande of Texas. Bulletin of the Texas Archeological Society 46:107-126. 
1976 Hunters and Gatherers of the Rio Grande Plain and the Lower Coast of Texas. Issued by the Center for Archaeological Research, The University of Texas at San Antonio.

1980 Changing Salinity in Baffin Bay, Texas and Its Possible Effects on Prehistoric Occupation. In Papers on the Archaeology of the Texas Coast, edited by L. Highley and T. R. Hester, pp. 105-108. Special Report No. 11. Center for Archaeological Research, The University of Texas at San Antonio.

1981 Tradition and Diversity Among the Prehistoric Hunters and Gatherers of Southern Texas. Plains Anthropologist 26(92):119-128.

Hester, T. R., (editor)

1979 A Preliminary Archaeological and Historical Assessment of the Proposed Tenneco Pipeline: Hidalgo to Victoria Counties, Texas. Archaeological Survey Report 51. Center for Archaeological Research, The University of Texas at San Antonio.

Hester, T. R., M. B. Collins, F. A. Weir, and F. Ruecking, Jr.

1969 Two Prehistoric Cemetery Sites in the Lower Rio Grande Valley of Texas. Bulletin of the Texas Archeological Society 40:119-166.

Hester, Thomas R., Thomas C. Kelly

1979 Phase II Archaeological Investigations Along the Proposed Route of the Del Norte Pipeline. Archaeological Survey Report No. 74. Center for Archaeological Research, The University of Texas at San Antonio.

Hester, T. R., and R. W. Rodgers

1971 Additional Data on the Burial Practices of the Brownsville Complex. The Texas Journal of Science 22(4):367-372.

Hester, T. R., and H. J. Shafer

1975 A Preliminary Study of Blade Technology on the Lower Texas Coast. Plains Anthropologist 26(1-2):213-222.

Holz, Robert K., and Elton R. Prewitt

1981 Airphoto Analysis. In Cultural Resources Surveys and Assessments in Portions of Hidalgo and Willacy Counties, Texas, by D. W. Day, J. Laurens-Day, and E. R. Prewitt, pp. 163-184. Reports of Investigations No. 15. Prewitt and Associates, Inc., Austin.

Hom, Henry S.

1968 The Adaptive Significance of Colonial Nesting in the Brewers Blackbird (Euphagers cyanocephalus). Ecology 49:682-694.

Howard, Margaret Ann

1987 Analysis of Feature 1 Burial at 41WY113. Appendix 3 in Cultural Resources Investigations Along Drainage Improvements, Hidalgo and Willacy Counties, Texas: 1986 Investigations, by Grant D. Hall, Michael B. Collins, and Elton R. Prewitt, pp. 191-197. Reports of Investigations No. 59. Prewitt and Associates, Inc., Austin.

Jackson, A. T.

1940 Tubular Pipes and Other Tubes in Texas. Bulletin of the Texas Archeological and Paleontological Society 12:99-137. 
Jacobs, Jerry L.

1981 Soil Survey of Hidalgo County, Texas. U. S. Department of Agriculture, Soil Conservation Service.

Jochim, Michael

1983 Optimization Models in Context. In Archaeological Hammers and Theories, edited by James A. Moore and Archur S. Keene, pp. 157-172. Academic Press, New York.

Johnson, Jay K.

1979 Archaic Biface Manufacture: Production Failures, A Chronicle of the Misbegotten. Lithic Technology VIII(2):25-35.

1981 Further Additional Biface Production Failures. Lithic Technology 10(2-3):26-28.

Johnston, Marshall Conring

1955 Vegetation of the Eolian Plain and Associated Coastal Features of Southern Texas. Ph.D. dissertation, The University of Texas at Austin.

Kahn, Michael I., Tadamichi Oba, and Teh-Lung Ku

1981 Paleotemperatures and the Glacially Induced Changes in the Oxygen-isotope Composition of Seawater During the Late Pleistocene and Holocene Time in Tanner Basin, California. Geology 9:485-490.

Keene, Arthur S.

1979 Economic Optimization Models and the Study of Hunter-Gatherer Subsistence Settlement Systems. In Transformations: Mathematical Approaches to Culture Change, edited by Colin Renfrew and Kenneth L. Cooke, pp. 369-404. Academic Press, New York.

Kelly, Robert L.

1980 Hunter-Gatherer Settlement Systems. Unpublished Master's Thesis, Department of Anthropology, University of New Mexico, Albuquerque.

1983 Hunter-Gatherer Mobility Strategies. Journal of Anthropological Research 39(3):277-306.

Kim, Jae-On, and Charles W. Mueller

1978 Introduction to Factor Analysis, What It Is and How To Do It. Sage Publications, Inc., Beverly Hills, Ca.

Klepinger, L. L., and R. W. Mintel

1986 Metabolic Considerations in Reconstructing Past Diet from Stable Carbon Isotope Ratios of Bone Collagen. In Proceedings of the 24th International Archaeometry Symposium, edited by J. S. Olin and M. J. Blackman, pp. 43-48. Smithsonian Institution Press, Washington, D. C.

Kotter, Steven M.

1980 Archeological Assessments at Site 41ZP73, Falcon State Recreation Area, Zapata County, Texas. Reports of Investigations No. 9. Prewitt and Associates, Inc., Austin.

Kreiger, Alex D.

1956 Food Habits of the Texas Coastal Indians in the Early 16th Century. Bulletin of the Texas Archeological Society 27:47-58. 
1972 The Travels of Alvar Nuñez Cabeza de Vaca in Texas and Mexico, 1534-1536. In An Ethnohistorical Survey of Texas Indians, by Lydia Lowndes Maury Skeels, pp. 57-73. Report No. 22. Office of the State Archeologist, Texas Historical Survey Committee, Austin.

n.d. Archeology, Ethnography, and Early Spanish History of the Falcon Reservoir Area. On file, Texas Archeological Research Laboratory, The University of Texas at Austin.

Krieger, Alex D., and Jack T. Hughes

1950 Archeological Salvage in the Falcon Reservoir Area: Progress Report 1. Mimeograph manuscript on file at Texas Archeological Research Laboratory, The University of Texas at Austin.

Krishnamurthy, R. V., Michael J. DeNiro, and R. K. Pant

1982 Isotope Evidence for Pleistocene Climatic Changes in Kashmir, India. Nature 298:640-641.

Kroeber, A. L.

1935 Walapai Ethnography. American Anthropological Association Memoirs No. 42.

Krueger, Harold W., and Charles H. Sullivan

1984 Models for Carbon Isotope Fractionation Between Diet and Bone. In Stable Isotopes in Nutrition, edited by Judith R. Turnlund and Phyllis E. Johnson, pp. 205-220. ACS Symposium Series No. 258.

Kuhn, Steven L.

1989 Hunter-gatherer Foraging Organization and Strategies of Artifact Replacement and Discard. Unpublished manuscript on file at Prewitt and Associates, Inc., Austin.

Letolle, $R$.

1980 Nitrogen-15 in the Natural Environment. In Handbook of Environmental Isotope Geochemistry. 1. The Terrestrial Environment, edited by A. P. Fritz and J. Ch. Fontes, pp. 21-47. Elsevier, Amsterdam.

MacArthur, Robert H., and Eric R. Pianka

1966 On Optimal Use of a Patchy Environment. American Naturalist 100:603-609.

MacNeish, Richard S.

1947 A Preliminary Report on Coastal Tamaulipas. American Anthropologist 13(1):1-15.

1958 Preliminary Archeological Investigations in Sierra de Tamaulipas, Mexico. Transactions of the American Philosophical Society 48:6.

Mallouf, Robert J., Barbara J. Baskin, and Kay L. Killen

1977 A Predictive Assessment of Cultural Resources in Hidalgo and Willacy Counties, Texas. Survey Report 23. Office of the State Archeologist, Texas Historical Commission, Austin.

Mallouf, Robert J., and Anthony N. Zavaleta

1979 The Unland Site, A Prehistoric Group Burial From Laguna Atascosa National Wildlife Refuge, Cameron County, Texas. Special Report 25. Office of the State Archeologist, Texas Historical Commission, Austin. 
Mason, J. Alden

1935 The Place of Texas in Pre-Columbian Relationships Between the United States and Mexico. Bulletin of the Texas Archeological and Paleontological Society, Vol. 7.

McClaughtery, C. A., John Pastor, J. D. Aber, and J. M. Melillo

1985 Forest Litter Decomposition in Relation to Soil Nitrogen Dynamics and Litter Quality. Ecology 66:266-275.

McGraw, A. Joachim

1984 Archaeology in the South Texas Sand Sheet: A Study of Chevron Properties in Brooks County. Archaeological Survey Report No. 129. Center for Archaeological Research, The University of Texas at San Antonio.

McKern, William C.

1939 The Midwestern Taxonomic Method as an Aid to Archeological Culture Study. American Antiquity 4:301-313.

Mercado-Allinger, Patricia A.

1983 Survey, Testing, and Assessment of Cultural Resources in Portions of Willacy County Drainage District No. l, Willacy County, Texas. Reports of Investigations No. 20. Prewitt and Associates, Inc., Austin.

Mosteller, Frederick, and Anita Parunck

1985 Identifying Extreme Cells in a Sizable Contingency Table: Probabilistic Exploratory Approaches. In Explooring Data Tables, Trends, and Shapes, edited by David C. Hoaglin, Frederick Mosteller, and John W. Tukey, pp. 189-224. John Wiley \& Sons, New York.

Nakai, N., and M. Koyama

1987 Reconstruction of Paleoenvironments From the View-points of the Inorganic Constituents, C/N Ratio and Carbon Isotope Ratio in the $1400 \mathrm{~m}$ Core from Lake Biwa. In History of Lake Biwa, edited by S. Horie. Contribution No. 553. Institute of Paleolimnology and Paleoenvironment on Lake Biwa, Kyoto University, Japan.

Natelhoffer, K. J., and B. Fry

1988 Controls on Natural Nitrogen-15 and Carbon-13 Abundances in Forest Soil Organic Matter. Soil Science Society of America Journal 52:1663-1640.

Natural Fibers Information Center

1987 The Climates of Texas Counties. Natural Fibers Information Center, Bureau of Business Research, The University of Texas at Austin.

Newton, M. B., Jr.

1968 The Distribution and Character of Sites, Arroyo Los Olmos, Starr County, Texas. Bulletin of the Texas Archeological Society 38:18-24.

Norwine, Jim, and Ralph Bingham

1986 Frequency and Severity of Droughts in South Texas: 1900-1983. In Livestock and Wildlife Management During Drought, edited by R. D. Brown, pp. 1-17. Caesar Kleberg Wildlife Research Institute, Kingsville. 
Nunley, J. Parker

1971 Sociocultural Units of the Southwestern Texas Archaic: An Analytical Approach. Ph.D. dissertation, Southern Methodist University. University Microfilms, Ann Arbor.

Nunley, Parker, and Thomas R. Hester

1975 An Assessment of Archaeological Resources in Portions of Starr County, Texas. Archaeological Survey Report 7. Center for Archaeological Research, The University of Texas at San Antonio.

O'Connell, James F., and Kristen Hawkes

1981 Alyawara Plant Use and Optimal Foraging Theory. In Hunter-Gatherer Foraging Strategies Ethnographic and Archeological Analyses, edited by Bruce Winterhalder and Eric Alden Smith, pp. 99-125. Academic Press, New York.

Odell, George H., and Frank Cowan

1986 Experiments with Spears and Arrows on Animal Targets. Journal of Field Archaeology 13(2):195-212.

Olson, Gerald W.

1981 Soils and Environment: A Guide to Soil Surveys and Their Applications. Chapman and Hall, New York.

Ott, Lyman

1977 An Introduction to Statistical Methods and Data Analysis. Duxbury Press, Boston.

Overpeck, Jonathan T., Larry C. Peterson, Nilva Kipp, John Imbrie, and David Rind

1989 Climate Change in the Circum-North Atlantic Region During the Last Deglaciation. Nature 338:553-557.

Parker, P. L.

1964 The Biogeochemistry of the Stable Isotopes of Carbon in a Marine Bay. Geochima et Cosmochimia Acta 28:1155-1164.

Patterson, L. W.

1974 Prismatic Blade Distribution in Texas. La Tierra 1(1):9-14.

Patton, Peter C., and David S. Dibble

1982 Archeologic and Geomorphic Evidence for the Paleohydrological Record of the Pecos River in West Texas. American Journal of Science 282:97-121.

Paull, Gene J., and Anthony N. Zavaleta

1983 Archeology and Ethnology of the Boscaje de Palmas. Borderlands Journal 6(2):111-149.

Pearson, C. E., D. B. Kelley, R. A. Weinstein, and S. M. Gagliano

1986 Archaeological Investigations on the Outer Continental Shelf: A Study Within the Sabine River Valley, Offshore Louisiana and Texas. Coastal Environments, Inc., Baton Rouge.

Prewitt and Associates, Inc.

1986 Continued Cultural Resources Surveys and Assessments along Drainage Improvements in Portions of Hidalgo and Willacy Counties, Texas. A technical proposal submitted to Hidalgo County Drainage District No. 1 and Willacy County Drainage District No. 1, Edinburgh, Texas. 
1988 Phase II National Register Testing of Cultural Resources along Drainage Improvements in Hidalgo and Willacy Counties, Texas. Work plan submitted to Hidalgo County Drainage District No. 1 and Willacy County Drainage District No. 1, Edinburgh, Texas.

Prewitt, Elton R.

1974 Preliminary Archeological Investigations in the Rio Grande Delta Area of Texas. Bulletin of the Texas Archeological Society 45:55-65.

1981 Radiocarbon Dating. Appendix VIII in Cultural Resources Surveys and Assessments in Portions of Hidalgo and Willacy Counties, Texas, by D. William Day, Jane Laurens-Day, and Elton R. Prewitt, pp. 411-415. Reports of Investigations No. 15. Prewitt and Associates, Inc., Austin.

Prewitt, Elton R., and Jeffery G. Paine

1987 The Swan Lake Site (41AS16) on Copano Bay, Aransas County, Texas: Settlement, Subsistence, and Sea Level. Bulletin of the Texas Archeological Society 58:147-174.

Price, T. Douglas

1989 The Chemistry of Prehistoric Human Bone. Cambridge University Press, Cambridge.

Price, W. Armstrong

1933 Reynosa Problem of South Texas, and Origin of Caliche. Bulletin of American Association of Petroleum Geologists 17:488-522.

1958 Sedimentary and Quaternary Geomorphology of South Texas. Transactions of the Gulf Coast Association of Geological Societies 8:41-75.

Pyke, G. H., H. R. Pulliam, and E. L. Charnov

1977 Optimal Foraging: A Selected Review of Theory and Tests. Quarterly Review of Biology 52:137-154.

Quigg, J. Michael, Douglas K. Boyd, and Elton R. Prewitt

1989 An Archeological Survey of Proposed Drainage Ditch Realignments in the Southwest and Mercedes Laterals, Hidalgo County, Texas. Technical Reports No. 2. Prewitt and Associates, Inc., Austin.

Rabenhorst, M. C., and L. P. Wilding

1986 Pedogenesis on the Edwards Plateau, Texas: 1. Nature and Continuity of Parent Material. Soil Science Society of America Journal 50:678-686.

Rabenhorst, M. C., L. P. Wilding, and C. L. Girdner

1984 Airborne Dusts in the Edwards Plateau Region of Texas. Soil Science Society of America Journal 48:621-627.

Reineck, H. -E., and I. B. Singh

1975 Depositional Sedimentary Environments with Reference to Terrigenous Clastics. SpringerVerlag, Berlin. 
Richmond, Gerald M., and David S. Fullerton

1986 Summation of Quaternary Glaciations in the United States of America. In Quaternary Glaciations in the Northern Hemisphere, edited by V. Sibrava, D. Q. Bowen, and R. M. Richmond, pp. 183-196. Pergamon Press, Oxford.

Robinson, Ralph L.

1979 Biosilica and Climatic Change at 41GD21 and 41GD21A. Appendix IV in Archaeological Investigations of Two Prehistoric Sites on the Coleto Creek Drainage, Goliad County, Texas, by Dan E. Fox, pp. 102-113. Archaeological Survey Report 69. Center for Archaeological Research, The University of Texas at San Antonio.

1982 Biosilica Analysis of Three Prehistoric Archaeological Sites in the Choke Canyon Reservoir, Live Oak County, Texas: Preliminary Summary of Climatic Implications. Appendix VIII in Archaeological Investigations at Choke Canyon Reservoir, South Texas: The Phase I Findings, by Grant D. Hall, Stephen L. Black, and Carol Graves, pp. 597-599. Choke Canyon Series Volume 5. Center for Archaeological Research, The University of Texas at San Antonio.

Rondeau, Michael F.

1981 An Additional Failure Type During Biface Manufacture. Lithic Technology 10(1):11.

Rosenzweig, Michael L.

1968 Net Primary Productivity of Terrestrial Communities: Prediction from Climatological Data. The American Naturalist 102(923):67-74.

Ruecking, Frederick, Jr.

1953 The Economic System of the Coahuiltecan Indians of Southern Texas and Northeastern Mexico. The Texas Journal of Science 5(4):480-497.

1955 The Coahuiltecan Indians of Southern Texas and Northeastern Mexico. Unpublished Master's thesis, Department of Anthropology, The University of Texas at Austin.

Saldivar, Gabriel

1943 Los Indios de Tamaulipas. Publicación tomo núm 70. Instituto Panamericano de Geographía e Historia, Mexico, D.F.

Salinas, Martin

1986 Historic Indian Populations of the Rio Grande Delta and Vicinity: An Approach to Definition of Basic Ethnic Units. Unpublished Master's thesis, Department of Anthropology, The University of Texas at Austin.

1990 Indians of the Rio Grande Delta, Their Role in the History of Southern Texas and Northeastern Mexico. The University of Texas Press, Austin.

Sampson, C. Garth

1988 Stylistic Boundaries among Mobile Hunter-foragers. Smithsonian Institution Press, Washington, D.C.

Sayles, E. B.

1935 An Archeological Survey of Texas. Medallion Papers 17. Gila Pueblo, Globe, Arizona. 
Schiffer, Michael B.

1975 Some Further Comments on the Dalton Settlement Pattern Hypothesis. In The Cache River Archeological Project, and Experiment in Contract Archeology, edited by Michael B. Schiffer and John H. House, pp. 103-112. Research Series No. 8. Arkansas Archeological Survey, Fayetteville.

Schwartz, D., A. Mariotti, R. Lanfranchi, and B. Guillet

$1986{ }^{13} \mathrm{C} /{ }^{12} \mathrm{C}$ Ratios of Soil Organic Matter as Indicators of Vegetation Changes in the Congo. Geoderma 39:97-103.

Schwert, Donald P. and Allan C. Ashworth

1988 Late Quaternary History of the Northern Beetle Fauna of North America: A Synthesis of Fossil and Distributional Evidence. Memoirs of the Entomological Society of Canada 144:93107.

Scurlock, Dan, Warren M. Lynn, and R. Thomas Ray

1974 Archeological Assessment: Padre Island National Seashore, Texas. Special Reports 11. Office of the State Archeologist, Texas Historical Commission, Austin.

Sealy, Judith Clare

1986 Stable Carbon Isotopes and Prehistoric Diets in the Southwestern Cape Province, South Africa. Cambridge Monographs in African Archaeology 15, BAR International Series 293. British Archaeological Reports, Oxford.

1989 Reconstruction of Later Stone Age Diets in the Southwestern Cape, South Africa: Evaluation and Application of Five Isotopic and Trace Element Techniques. Unpublished Ph.D. Dissertation, The University of Cape Town.

Sealy, Judith C., Nikolaas J. van der Merwe, Julia A. Lee Thorp, and John L. Lanham

1987 Nitrogen Isotopic Ecology in Southem Africa: Implications for Environmental and Dietary Tracing. Geochimica et Cosmochimia Acta 51:2707-2717.

Sears, William H.

1954 The Sociopolitical Organization of Pre-Columbian Culture on the Gulf Coastal Plain. American Anthropologist 56(3):339-346.

Shackleton, N. J.

1977 The Oxygen Isotope Stratigraphic Record of the Late Pleistocene. Philosophical Transactions of the Royal Society, London B280:169-182.

Shafer, H. J.

1985 Prehistory of the Rio Grande Delta, Texas. Central Texas Archeologist 10:97-109.

Shearer, Georgia, Daniel H. Kohl, and Sen-Hsiung Chien

1978 The Nitrogen-15 Abundance in a Wide Variety of Soils. Soil Science Society of America Journal 42:899-902.

Shott, Michael J.

1989 On Tool-Class Use Lives and the Formation of Archaeological Assemblages. American Antiquity 54(1):9-30. 
Sillen, Andrew, Judith C. Sealy, and Nikolaas J. van der Merwe

1989 Chemistry and Paleodietary Research: No More Easy Answers. American Antiquity 54:504512.

Smith, Eric Alden

1981 The Application of Optimal Foraging Theory to the Analysis of Hunter-Gatherer Group Site. In Hunter-Gatherer Foraging Strategies Ethnographic and Archeological Analyses, edited by Bruce Winterhalder and Eric Alden Smith, pp. 36-65. Academic Press, New York.

Soil Survey Staff

1962 Soil Survey Manual. U.S. Department of Agriculture Handbook 18, first issued August 1951. Agricultural Research Administration, United States Department of Agriculture. U.S. Government Printing Office, Washington, D.C.

1975 Soil Taxonomy: A Basic System of Soil Classification for Making and Interpreting Soil Surveys. Agriculture Handbook 436. U.S. Department of Agriculture, Soil Conservation Service, Washington, D.C.

Stafford, Thomas W., Jr., A. J. T. Jull, Klaus Brendel, Raymond C. Duhamel, and Douglas Donahue

1987 Study of Bone Radiocarbon Dating Accuracy at the University of Arizona NSF Accelerator Facility for Radioisotope Analysis. Radiocarbon 29:24-44.

Stafford, Thomas W., Jr., Klaus Brendel, and Raymond C. Duhamel

1988 Radiocarbon, ${ }^{13} \mathrm{C}$ and ${ }^{15} \mathrm{~N}$ Analysis of Fossil Bone: Removal of Humates with XAD-2 Resin. Geochimica et Cosmochimica Acta 52:2257-2267.

Steele, D. Gentry

1987 Utilization of Marine Mollusks by Inhabitants of the Texas Coast. Bulletin of the Texas Archeological Society 58:215-248.

Stuiver, Minze

1975 Climate Versus Changes in ${ }^{13} \mathrm{C}$ Content of the Organic Component of Lake Sediments During the Late Quaternary. Quaternary Research 5:251-262.

Suhm, Dee Ann, Alex D. Krieger, and Edward B. Jelks

1954 An Introductory Handbook of Texas Archeology. Bulletin of the Texas Archeological Society 25 (entire volume).

Suhm, Raymond, and Thomas R. Hester

1980 The La Paloma Mammoth Site, Kenedy County, Texas. In Papers on the Archaeology of the Texas Coast, edited by Lynn Highley and Thomas R. Hester. Special Report No. 11. Center for Archaeological Research, The University of Texas at San Antonio.

Taylor, R. E.

1987 Radiocarbon Dating: An Archaeological Perspective. Academic Press, Orlando.

Texas Archeological Research Laboratory

n.d. Collections and unpublished notes of A. E. Anderson, 1908 to 1940. On file at Texas Archeological Research Laboratory, The University of Texas at Austin. 
Tomka, Steve A.

1986 Biface Manufacture Failures. Manuscript on file at the Texas Archeological Research Laboratory, The University of Texas at Austin.

Troike, Rudolph C.

1962 Notes on Coahuiltecan Ethnography. Bulletin of the Texas Archeological Society 32(for 1961):57-63.

Tucker, J., J. M. Melillo, J. Aber, A. Linkins, K. Nadelhoffer, and A. Turner

1986 Changes in Carbon Quality in Decaying Plant Materials in Forests. In Agronomy Abstracts, ASA, Madison, Wisconsin, p. 268.

Turner, August J.

1982 Soil Survey of Willacy County, Texas. U.S. Department of Agriculture, Soil Conservation Service.

U.S. Army Engineer District, Galveston

1977 Preliminary Descriptions of Lower Rio Grande Basin Sample Sites, Willacy and Hidalgo Counties, Texas, 1-10' March 1977. Department of the Army.

1985 Letter Report: Concerning Project Area in Willacy County, Texas. Corps of Engineers, Galveston District, Permit 13363(03). On file at Texas Historical Commission, Austin.

U.S. Department of the Interior, National Park Service, National Register Division

1982 How to Apply the National Register Criteria for Evaluation. National Park Service, Department of the Interior, Washington, D.C.

van der Merwe, Nikolaas J.

1981 Carbon Isotopes, Photosynthesis and Archaeology. Unpublished manuscript.

1982 Carbon Isotopes, Photosynthesis, and Archaeology. American Scientist 70:596-606.

Vigness, David Martell

1948 The Lower Rio Grande Valley, 1836-1846. Unpublished Master's thesis, The University of Texas at Austin.

Vines, Robert A.

1960 Trees, Shrubs, and Woody Vines of the Southwest, A Guide for the States of Arkansas, Louisiana, New Mexico, Oklahoma, and Texas. The University of Texas Press, Austin.

Virginia, Ross A., and C. C. Delwiche

1982 Natural ${ }^{15} \mathrm{~N}$ Abundance of Presumed $\mathrm{N}_{2}-$ fixing and Non- $\mathrm{N}_{2}-$ fixing Plants From Selected Ecosystems. Oecologia 54:317-325.

Vitorello, V. A., C. C. Cerri, F. Andreux, C. Feller, and R. L. Victoria

1989 Organic Matter and Natural Carbon-13 Distribution in Forested and Cultivated Oxisols. Soil Science Society of America Journal 53:773-778.

Vogel, J. C.

1978 Isotopic Assessment of the Dietary Habits of Ungulates. South African Journal of Science 74:298-301. 
1985 Southern Africa at 18000 yrs BP. South Africa Journal of Science 81:250-251.

Vogel, J. C., and Nikolaas J. van der Merwe

1977 Isotopic Evidence for Early Maize Cultivation in New York State. American Antiquity 42(2):238-242.

Volkoff, B., and C. C. Cerri

1987 Carbon Isotopic Fractionation in Subtropical Brazilian Grassland Soils: Comparison with Tropical Forest Soils. Plant and Soil 102:27-31.

Weir, Frank A.

1956 Surface Artifacts from La Perdida, Starr County, Texas. Bulletin of the Texas Archeological Society 27:59-78.

Westgate, James E.

1987 A Preliminary Report on a Large Concentration of the Remains of the Giant Gopher Tortoise, Gopherus hexagonatus, in the Late Pleistocene Beaumont Formation of Willacy County, Texas. Appendix 4 in Cultural Resources Investigations Along Drainage Improvements, Hidalgo and Willacy Counties, Texas: 1986 Investigations, by Grant D. Hall, Michael B. Collins, and Elton R. Prewitt, pp. 199-219. Reports of Investigations No. 59. Prewitt and Associates, Inc., Austin.

White, Sidney E.

1986 Quaternary Glacial Stratigraphy and Chronology of Mexico. In Quaternary Glaciations in the Northern Hemisphere, edited by V. Sibrava, D. Q. Bowen, and R. M. Richmond, pp. 201-205. Pergamon Press, Oxford.

Whittaker, Robert H., and Gene E. Likens

1975 The Biosphere and Man. In Primary Productivity of the Biosphere, edited by H. Lieth and R. H. Whittaker, pp. 305-328. Springer-Verlag, New York.

Wiessner, Polly

1977 Hxaro: A Regional System of Reciprocity for Reducing Risk Among the !Kung San. Ph.D. dissertation, University of Michigan. University Microfilms, Ann Arbor.

1982 Risk, Reciprocity, and Social Influences on !Kung San Economics. In Politics and History in Band Societies, edited by Eleanor Leacock and Richard Lee, pp. 61-84. Cambridge University Press.

Willacy County Drainage District \#1

1983 Site Survey and Possible Test Excavations of the Area Under Consideration: Approximately 14 Miles of Right-of-Way Near Lyford, Willacy County, Texas. On file, Texas Antiquities Committee, Austin.

Winterhalder, Bruce

1981 Optimal Foraging Strategies and Hunter-Gatherer Research in Anthropology: Theory and Models. In Hunter-Gatherer Foraging Strategies Ethnographic and Archeological Analyses, edited by Bruce Winterhalder and Eric Alden Smith, pp. 13-35. Academic Press, New York.

Winterhalder, Bruce, and Eric Alden Smith (editors)

1981 Hunter-Gatherer Foraging Strategies Ethnographic and Archeological Analyses. Prehistoric Archeology and Ecology Series. University of Chicago Press, Chicago. 
Yellen, John E.

1977 Archaeological Approaches to the Present Models for Reconstructing the Past. Academic Press, New York.

Yurtsever, Y., and J. R. Gat

1981 Atmospheric Waters. In Stable Isotope Hydrology, edited by J. R. Gat and R. Gonfiantini, pp. 103-142. Technical Report Series 210. International Atomic Energy Agency, Vienna. 

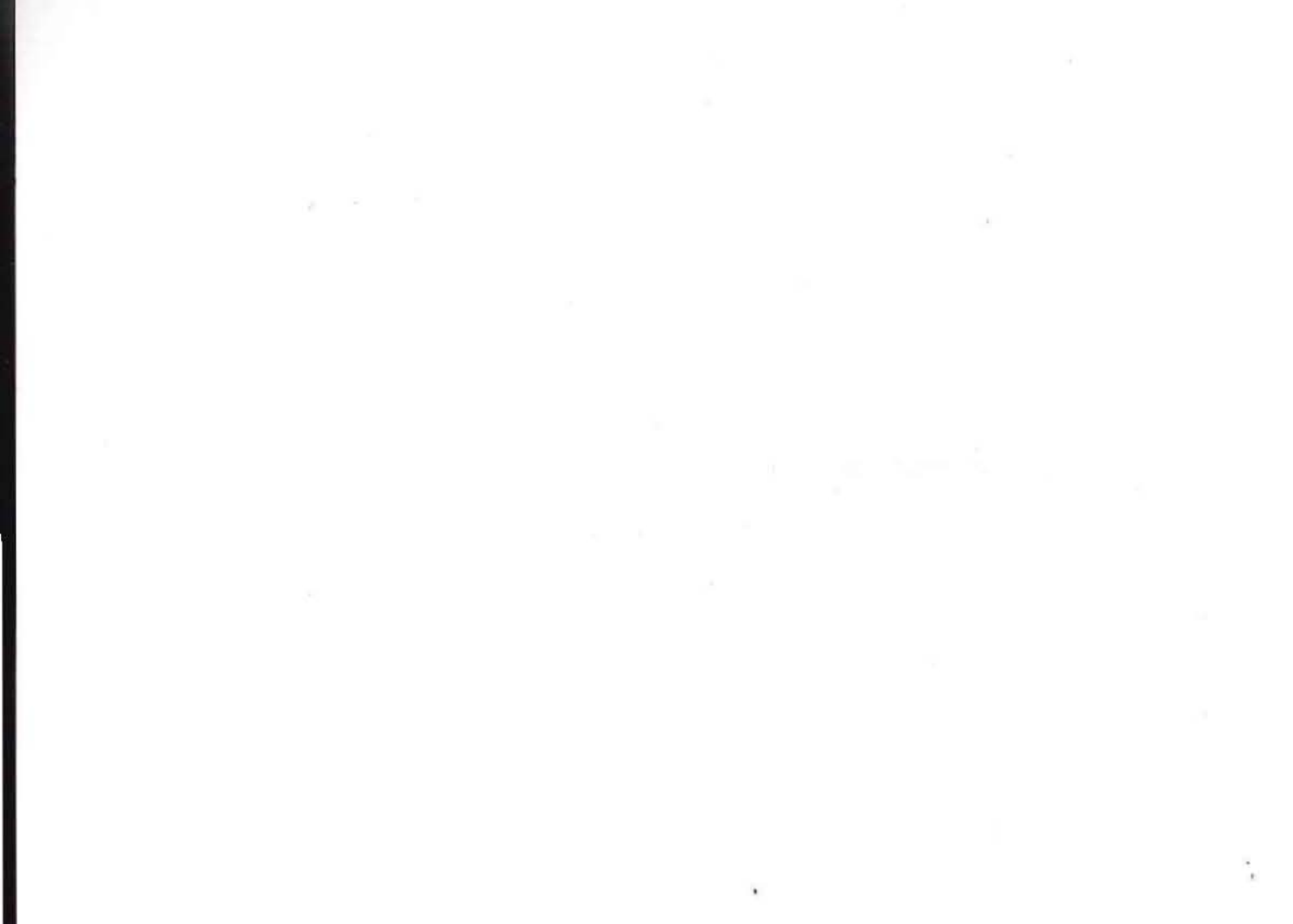

,

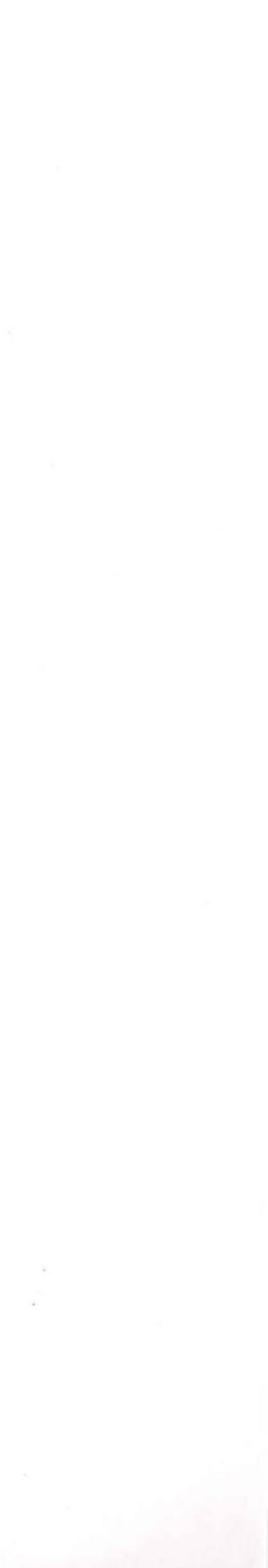


APPÉNDIX A: Materials Recovered

Gail L. Bailey,

Steve A. Tomka,

and

C. Britt Bousman 


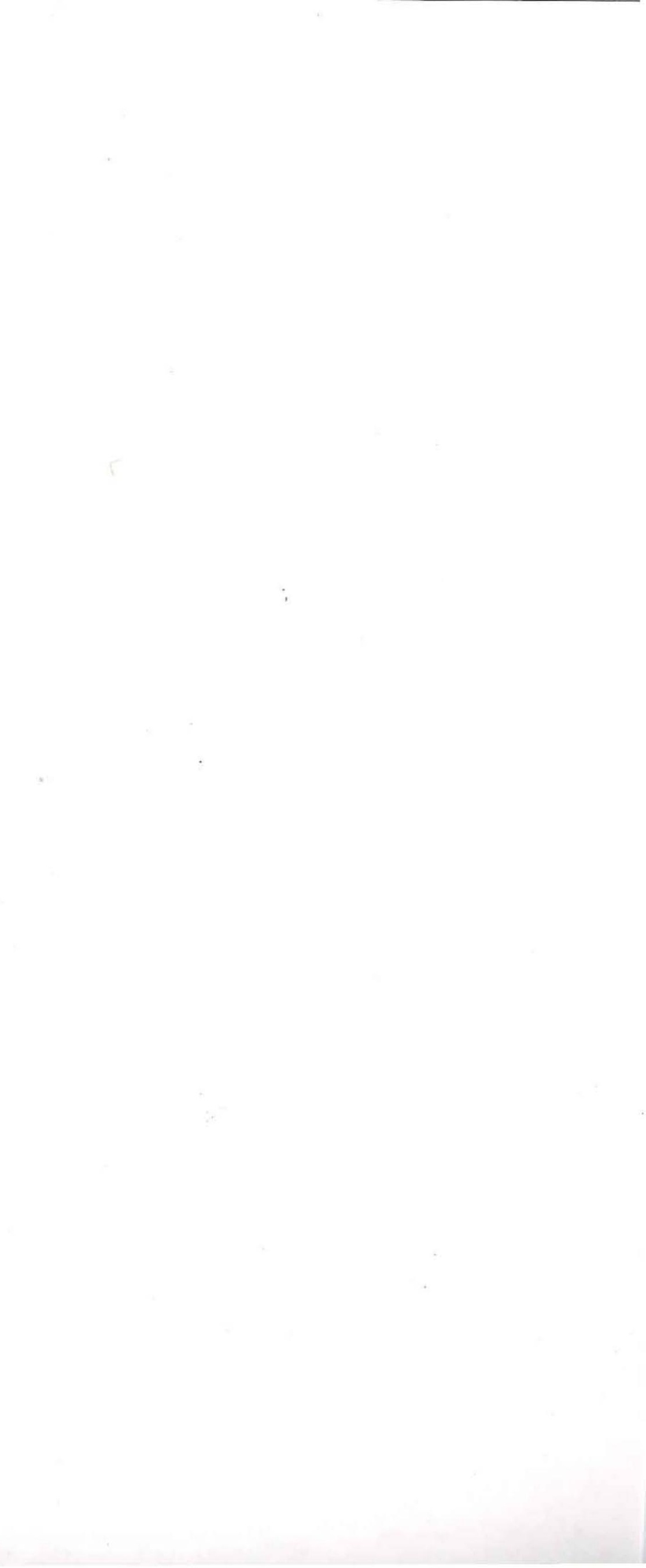
. 


\section{INTRODUCTION}

This appendix describes the materials recovered during Phase II investigations at 41HG128, 41WY112, 41WY113, 41WY134, and 41WY140. The cultural materials are discussed first, of which lithic artifacts represent the major type recovered from these sites followed by modified bone. Also included is a discussion of a ceramic sherd recovered in 1986 from 41HG128. The nonartifactual materials are described next and consist of burned clay lumps, charcoal, mollusks (i.e., marine shell, freshwater mussel shells, and land snails), bones, and miscellaneous materials. The miscellaneous materials may result from depositional, postdepositional, and/or pedogenic processes rather than prehistoric human activities at these sites.

\section{LITHIC ARTIFACTS}

A total of 157 chipped stone artifacts was recovered from four sites--41HG128, 41WY112, $41 \mathrm{WY} 113$, and 41WY140. None were recovered at 41WY134. Unmodified debitage makes up the largest category ( $93 \%)$, followed by hafted bifaces $(3 \%)$, nonhafted bifaces $(2 \%)$, biface fragments $(1 \%)$, one edge-modified flake $(0.5 \%)$, and a single tested cobble $(0.5 \%)$. Each specimen is described individually except the unmodified debitage which is characterized by flake type, cortex category, platform type, material type, and size.

\section{Hafted Bifaces}

Four hafted bifaces were recovered and all are considered to be projectile points. Two of these share the beveled-edge trait considered diagnostic of Olmos bifaces (Hester 1969:29-30, Shafer and Hester 1971). According to Shafer and Hester (1971), these bifacial artifacts were hafted with the beveled edge as the distal end, and functioned as gouges or scrapers based on microwear found on this edge. The bifaces discussed here, however, lack use wear along any portion of their beveled edges, and lack hafting wear along the lateral edges and/or dorsal or ventral surface of their pointed ends; thus all four specimens are considered to be projectile points.

The first specimen (Fig. 51a), recovered from the surface at $41 \mathrm{HG} 128$, is similar to Group 3
Olmos bifaces described by Shafer and Hester (1971:4-5). It is a mottled cream and tan chert complete triangular biface measuring $27 \mathrm{~mm}$ in length, $21 \mathrm{~mm}$ in base width, and $7 \mathrm{~mm}$ in thickness. The base is beveled by three longitudinally directed thinning flakes which terminate in hinge fractures, and some reworking of the two corners of the base is evident. The two lateral edges are beveled on the face opposite the basal bevel. Viewed along its longitudinal axis, the point is asymmetrically leaning away from the margin with the steepest bevel. The beveled edges and longitudinal asymmetry suggest that the specimen has undergone several rejuvenation and resharpening episodes. The edge beveling appears to represent the last sequence of flake removals, while the longitudinal asymmetry represents an expedient reworking technique, the goal of which is to generate a new tip by reworking only one edge rather than realigning both lateral edges of a proximal biface fragment. The specimen appears to represent the reworking of a biface proximal fragment.

The second specimen (see Fig. 51b), from Level 4 of Test Unit 9 at 41HG128, also resembles an Olmos biface (Hester 1969, Shafer and Hester 1971). It is a mottled cream and tan chert complete triangular biface measuring $18 \mathrm{~mm}$ in length, $13 \mathrm{~mm}$ in base width, and $3 \mathrm{~mm}$ in thickness. It retains a portion of its original ventral flake surface. The blade exhibits alternately beveled edges with one edge having a considerably steeper bevel than the other. The base is beveled on the face opposite the steepest beveled edge and the corner of the base adjacent to the steep beveled edge has also been reworked. The point is longitudinally asymmetrical, leaning away from the edge with the steep bevel. The edge bevel and longitudinal asymmetry again suggest the reworking of a biface proximal fragment with the same technique as noted for the first specimen. This point has probably undergone several stages of resharpening and appears to be exhausted.

The third specimen, from the surface at $41 \mathrm{WY} 112$, is an untyped triangular projectile point (see Fig. 51c). It is complete and measures $26 \mathrm{~mm}$ in length, $19 \mathrm{~mm}$ in base width, and $7 \mathrm{~mm}$ in thickness. It is made from reddish brown chert with small red inclusions and a high luster indicating heat treatment. The point has steep 

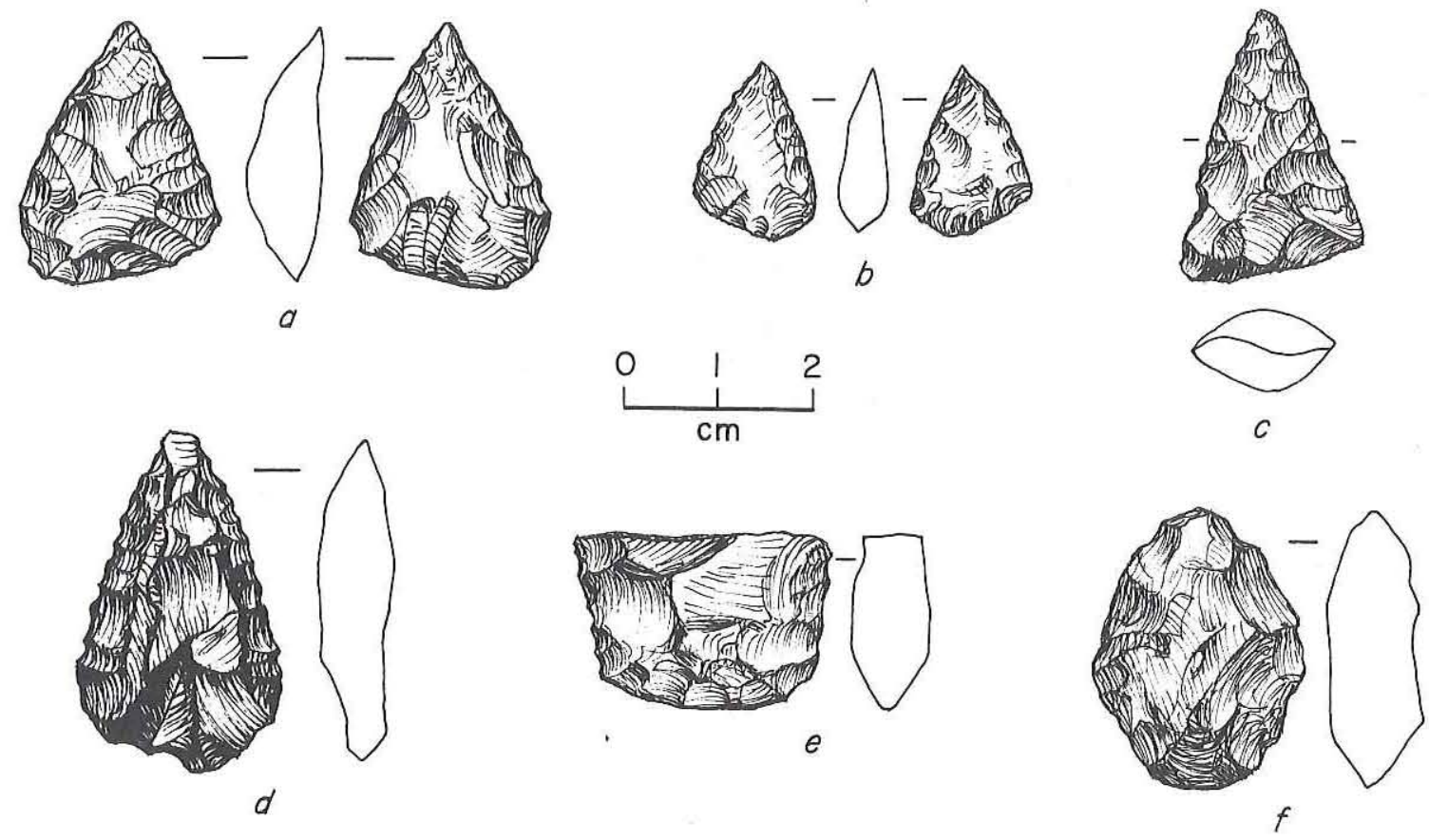

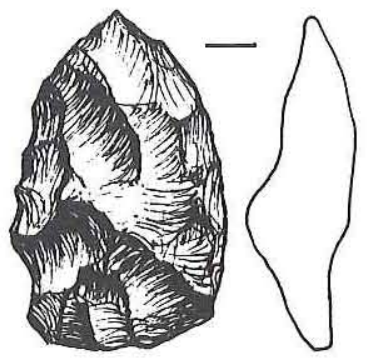

$g$
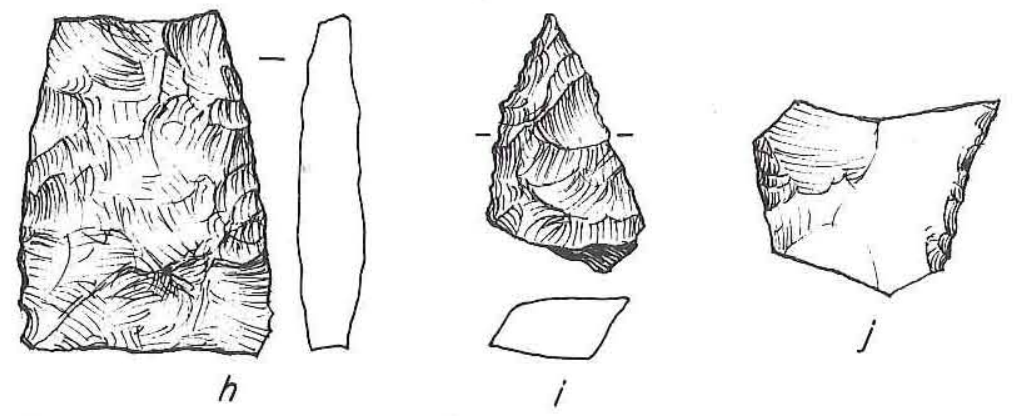

Figure 51. Lithic tools. (a-b) projectile points, 41HG128; (c-d) projectile points, 41WY112 and 41WY113; (e-g) nonhafted bifaces, 41HG128, 41WY112, and 41WY113; (h-i) biface fragments, 41HG128; (j) edge-modified flake, 41WY112.

lateral edges that are alternately beveled and a straight, bifacially thinned base. As in the case of the other two points, this specimen is longitudinally asymmetrical. The asymmetry results primarily from the steep bevel on one of the lateral edges. This bevel, together with the removal of flakes from the opposite edge of the same face, represent the last sequence of flake removals. The point represents the reworking of a proximal fragment in a fashion similar to that of the specimens described above.

The fourth specimen, from the surface at $41 \mathrm{WY} 113$, is a complete projectile point (Fig. 51d). It measures $36 \mathrm{~mm}$ in length, $21 \mathrm{~mm}$ in base width, and $7 \mathrm{~mm}$ in thickness and is made from grayish brown and black chert with small white inclusions. It has a uniformly distributed luster diagnostic of heat treatment. The lateral edges show small rejuvenation flake scars perpendicular to the long axis of the blade while large flake scars occur on the interior of both sides and nearer the base. Several hinge fractures are present along one edge and represent attempts at removing a small knot. The base is rounded but scarred by an internal fracture. Because the projectile point shows evidence of resharpening, it was probably discarded during rejuvenation and/or resharpening. The internal fracture in the material and the unsuccessful attempt to remove a small knot probably led to its discard. 


\section{Nonhafted Bifaces}

This category consists of three specimens that are identified as nonhafted bifaces because they lack evidence of having been hafted or were discarded prior to reaching a finished stage when hafting could have occurred. None of the specimens show evidence of use, although one may have been functional while the other two appear to be manufacturing failures or rejects.

The first specimen, from Level 4 of Test Unit 7 at $41 \mathrm{HG} 128$, is a proximal fragment measuring $18 \mathrm{~mm}$ in length, $27 \mathrm{~mm}$ in width, and $8 \mathrm{~mm}$ in thickness (see Fig. 51e). It is made from yellowish brown quartzite and has slightly expanded lateral edges and a convex base. Both sides exhibit hinge scars indicating difficulty in reducing this material. The break morphology suggests that the specimen was broken during manufacture.

The second specimen, from the surface at 41 WY 112 , is a complete biface measuring $28 \mathrm{~mm}$ in length, $21 \mathrm{~mm}$ in width, and $9 \mathrm{~mm}$ in thickness and is oval in shape (see Fig. 51f). It is made from poor quality yellow and black chert with quartz crystal inclusions. Although the poor quality of material appears to have caused several hinged flake removals, the specimen may have been functional.

The third specimen, from the surface at $41 \mathrm{WY} 113$, is a complete biface measuring $34 \mathrm{~mm}$ in length, $21 \mathrm{~mm}$ in width, and $9 \mathrm{~mm}$ in thickness (see Fig. 51g). It is made from light and medium gray chert with white inclusions. The distal end of the biface shows evidence of heat treatment in the form of crazing, luster, and reddening of the white inclusions. The biface exhibits several hinged flake removal scars resu'ting from unsuccessful attempts to remove a large knot. The knot, combined with the parent-flake ventral surface remnant evident on one face, suggest that the biface is a manufacture reject.

\section{Miscellaneous Biface Fragments}

One medial and one distal biface fragment were recovered from the surface at 41HG128. The medial fragment measures $34 \mathrm{~mm}$ in length, $25 \mathrm{~mm}$ in width, and $7 \mathrm{~mm}$ in thickness (see Fig. 51h) and is made from translucent white chalcedony with tan and gray inclusions and bands.
The lateral edges are slightly convex and flake scars run perpendicular to the long axis of the blade. Pressure flake scars measuring 3-5 mm, in combination with bifacial polish along the edges, indicate resharpening following a cutting use. The two fracture morphologies derive from use in a prying task or as a projectile point.

The distal fragment measures $26 \mathrm{~mm}$ in length, $15 \mathrm{~mm}$ in width, and $6 \mathrm{~mm}$ in thickness and exhibits steep alternately beveled edges (see Fig. 51i). It is made from a cream chert with red inclusions and gray mottles. Based on break morphology, the specimen is classified as a usebroken tool. The alternate beveling suggests that the tool functioned as a knife (Sollberger 1971), possibly in addition to serving as a projectile point.

\section{Edge-modified Flake}

This catagory consists of one specimen recovered from the surface at $41 \mathrm{WY} 112$ (see Fig. 51j). It is a decorticate chip measuring $22 \mathrm{~mm}$ in length, $21 \mathrm{~mm}$ in width, and $3 \mathrm{~mm}$ in thickness. It is a pinkish tan chert with small red and white inclusions. The dorsal face of the specimen exhibits use-related microflake scaring on two edges, both of which appear to have been used in scraping tasks. The fragmentary modified edges are 18 and $11 \mathrm{~mm}$ in length.

\section{Tested Cobble}

One possibly tested cobble was recovered from the surface at $41 \mathrm{HG} 128$. It is made of reddish brown chert with white inclusions and retains three rather clustered flake scars on one end. The specimen measures $56 \mathrm{~mm}$ in length, $42 \mathrm{~mm}$ in width, and $39 \mathrm{~mm}$ in thickness. Because of the lack of clearly definable platform surfaces and negative bulbs of percussion and because the specimen was recovered near the access road, it is possible that the flake scars are the result of heavy machinery damage rather than prehistoric modification.

\section{Unmodified Debitage}

A total of 146 pieces of unmodified lithic debitage was recovered during the Phase II investigations. Table 23 shows the debitage recovered 
TABLE 23

FREQUENCY OF DEBITAGE BY SITE AND ATTRIBUTE

\begin{tabular}{|c|c|c|c|c|c|c|c|c|}
\hline \multirow[b]{2}{*}{ Attribute } & \multicolumn{2}{|c|}{$41 \mathrm{HG} 128$} & \multicolumn{2}{|c|}{$41 W Y 112$} & \multicolumn{2}{|c|}{$41 W Y 113$} & \multicolumn{2}{|c|}{$41 \mathrm{WY} 140$} \\
\hline & $\#$ & $\%$ & $\#$ & $\%$ & $\#$ & $\%$ & $\#$ & $\%$ \\
\hline \multicolumn{9}{|l|}{ Flake Type: } \\
\hline Flake & 51 & 46 & 12 & 41 & 2 & 40 & 1 & 50 \\
\hline Chip & 59 & 54 & 17 & 59 & $\underline{3}$ & 60 & 1 & 50 \\
\hline Totals: & 110 & 100 & 29 & 100 & 5 & 100 & 2 & 100 \\
\hline \multicolumn{9}{|l|}{ Cortex Category: } \\
\hline \multicolumn{9}{|l|}{ Flakes } \\
\hline Primary & - & - & - & - & - & - & - & - \\
\hline Secondary & 1 & 1 & 1 & 3 & - & - & - & - \\
\hline Tertiary & 50 & 46 & 11 & 38 & 2 & 40 & 1 & 50 \\
\hline \multicolumn{9}{|l|}{ Chips } \\
\hline Primary & - & - & - & - & - & - & - & - \\
\hline Secondary & 3 & 3 & 4 & 14 & - & - & - & - \\
\hline Tertiary & $\underline{56}$ & 50 & $\underline{13}$ & 45 & $\underline{3}$ & 60 & 1 & 50 \\
\hline Totals: & 110 & 100 & 29 & 100 & 5 & 100 & 2 & 100 \\
\hline \multicolumn{9}{|l|}{ Platform Type: } \\
\hline Cortex & 1 & 2 & 2 & 16 & - & - & - & - \\
\hline Single facet & 29 & 57 & 5 & 42 & - & - & - & - \\
\hline Multiple facet & $\underline{21}$ & 41 & $\underline{5}$ & 42 & $\underline{2}$ & $\underline{100}$ & $\underline{1}$ & $\underline{100}$ \\
\hline Totals: & 51 & 100 & 12 & 100 & 2 & 100 & 1 & 100 \\
\hline \multicolumn{9}{|l|}{ Material Type: } \\
\hline Chert & 84 & 76 & 26 & 90 & 2 & 40 & 2 & 100 \\
\hline Quartzite & 7 & 6 & 1 & 3 & 1 & 20 & - & - \\
\hline Chalcedony & 18 & 16 & 2 & 7 & 2 & 40 & - & - \\
\hline Silicified wood & 1 & 1 & $=$ & $=$ & $=$ & $=$ & $=$ & $=$ \\
\hline Totals: & 100 & 100 & 29 & 100 & 5 & 100 & 2 & 100 \\
\hline \multicolumn{9}{|l|}{ Size: } \\
\hline $0-10 \mathrm{~mm}$ & 96 & 87 & 12 & 41 & 5 & 100 & 1 & 50 \\
\hline $11-20 \mathrm{~mm}$ & 6 & 5 & 13 & 45 & - & - & - & - \\
\hline $21-30 \mathrm{~mm}$ & 5 & 5 & 1 & 3 & - & - & - & - \\
\hline $31-40 \mathrm{~mm}$ & 3 & 3 & 2 & 7 & - & - & 1 & 50 \\
\hline $41+\mathrm{mm}$ & - & - & 1 & 3 & $=$ & $=$ & $=$ & - \\
\hline Totals: & 110 & 100 & 29 & 100 & 5 & 100 & 2 & 100 \\
\hline
\end{tabular}

from each site in terms of four attributes, the first of which divides the specimens into the categories of flakes and chips. Flakes are defined as specimens that have a striking platform and that may or may not be complete. Chips are defined as specimens that lack a striking platform. Cortex category, raw material, and size attributes were recorded for both flakes and chips. The cortex category consists of specimens with cortex on the entire dorsal surface (i.e., primary), specimens with cortex on some but not all of the dorsal surface (i.e., secondary), and specimens with no cortex (i.e., tertiary). Platform type consists of cortex, single-facet, and multiple-facet categories. The raw material type consists of chert, quartzite, chalcedony, and silicified wood. Size is defined by maximum dimension and is divided into five groups, 1-10 mm, 11-20 mm, 21-30 mm, 31-40 $\mathrm{mm}$, and $41+\mathrm{mm}$. The methodology used for this analysis is derived in part from more-detailed 
analyses of unmodified debitage (Tomka et al. 1988; Tomka et al. 1989; Tomka and Fields 1990). It was also designed to maintain comparability with previous analyses from the region (Mallouf et al. 1977; Day et al. 1981; Hall et al. 1987).

The breakdown of the collections by flake type reveals that the ratios of flakes to chips are roughly the same. Initially this parity may be surprising as chips greatly outnumber complete flakes in most collections. Two factors account for this pattern. The definition of a flake used in this analysis combines both complete specimens and proximal fragments. Such a definition automatically deflates the number of chips. On the other hand, a majority of the flakes in the collection appear to be late reduction rejuvenation and/or resharpening flakes removed by pressure flaking. The use of the pressure-flaking technique tends to increase the frequency of complete flakes (Tomka and Fields 1990) contributing to some of the parity noted above.

The most striking observation regarding cortex category is the absence of primary flakes and chips. Most of the debitage consists of tertiary flakes and chips. Although sample sizes are small, evidence of early reduction stages is absent in the collections recovered from the sites. Instead, the collections represent the late stages of tool manufacture as well as tool rejuvenation and resharpening.

The analysis of platform type indicates that the percentages of single- and multi- faceted flakes are evenly distributed at $41 \mathrm{HG} 128$ and 41WY112. It is likely that these flakes derive from the rejuvenation and/or resharpening of unifacial and bifacial artifacts (see Chapter 7). The frequencies suggest a similarity in the intensity of resharpening and, by implication, of use of unifaces and bifaces at the two sites.

Platform attributes, in combination with overall flake morphology, reflect the predominance of tool resharpening. Using the criteria discussed in Chapter 7, $93(64 \%)$ of 146 debitage specimens were classified as uniface and/or biface resharpening flakes. Of the 93 specimens, 66 $(71 \%)$ have striking platforms which exhibit usepolish, rounding, and microstep fracturing immediately dorsal to the platform facet. The remaining portion consists of chips $(n=27,29 \%)$ that retain sufficient morphological characteristics (i.e., longitudinal curvature, perpendicular dorsal ridge, use-polish, and/or use-generated microstep fracture scars near the former striking platform) to classify them as derived from tool resharpening.

The most abundant material type observed is chert, followed in decreasing frequency by chalcedony, quartzite, and silicified wood. These materials are typical of those found along the Rio Grande and, to a lesser extent, the uplands (Mallouf et al. 1977; Day et al. 1981; Hall et al. 1987).

Although sample sizes are small, analysis by size category shows a higher percentage of small size debitage at 41HG128 and 41WY112, which suggests that the primary activity at these sites was late-stage reduction, rejuvenation, and resharpening of tools. The debitage from $41 \mathrm{WY} 112$ reveals that $86 \%$ of the specimens are evenly distributed between two size groups (1-10 $\mathrm{mm}$ and $11-20 \mathrm{~mm}$ ) while $87 \%$ of debitage from 41 HG128 falls into the $0-10 \mathrm{~mm}$ size $(43 \%$ of those were recovered from the fine-screen matrix from Level 5 of Test Unit 5). The debitage collections from $41 \mathrm{WY} 113$ and $41 \mathrm{WY} 140$ are too small to make any reliable comparisons.

Of the 146 debitage specimens, $112(77 \%)$ were recovered from the fine screens; had the fine-screening technique not been used, only $23 \%$ $(n=34)$ of the specimens would have been recovered (Table 24). In areas of lithic raw material scarcity, most of the debitage generated at archeological sites will be of small size. The distance from raw material sources, coupled with intensive use and potential reuse of lithic artifacts contribute to reduce the overall artifact sizes. It is paramount that future archeological work in the project area employ intensive data recovery techniques such as fine screening. The recovery of the smallest size class debitage potentially can contribute to an understanding of the degree of raw material stress in the project area, as well as a more complete understanding of lithic procurement practices and the organization of technology (Binford 1979).

In summary, the extremely sparse lithics recovered from 41WY113 and 41WY140 do not allow for meaningful interpretations. Those from 41HG128 and 41WY112, however, exhibit a high percentage of tertiary chips, flakes with single and multiple facets, and small size debitage. This suggests that lithic reduction activities at these sites focused on late-stage preforms and/or the rejuvenation and resharpening of finished and worn tools. The sparseness of the artifacts may suggest that these sites were only briefly occupied by 


\begin{tabular}{|c|c|c|c|c|c|c|c|c|}
\hline \multirow[b]{3}{*}{ Provenience } & \multicolumn{5}{|c|}{$\begin{array}{c}\text { TABLE } 24 \\
\text { MATERIALS RECOVERED* }\end{array}$} & & & \multirow[b]{3}{*}{$\begin{array}{l}\text { Modern } \\
\text { Debris }\end{array}$} \\
\hline & \multicolumn{2}{|c|}{ Debitage } & \multirow[b]{2}{*}{$\begin{array}{l}\text { Burned } \\
\text { Clay }\end{array}$} & \multirow[b]{2}{*}{ Charcoal } & \multirow[b]{2}{*}{ Shells } & \multicolumn{2}{|c|}{ Bones } & \\
\hline & $\begin{array}{l}1 / 4^{\prime \prime} \\
\text { Screen }\end{array}$ & $\begin{array}{l}1 / 16^{\prime \prime} \\
\text { Screen }\end{array}$ & & & & $\begin{array}{l}1 / 4^{\prime \prime} \\
\text { Screen }\end{array}$ & $\begin{array}{l}1 / 16^{\prime \prime} \\
\text { Screen }\end{array}$ & \\
\hline \multicolumn{9}{|l|}{ 41HG128: } \\
\hline Surface & 5 & - & - & - & - & - & - & - \\
\hline \multicolumn{9}{|l|}{ Test Unit 1} \\
\hline Level $1^{* *}$ & - & - & - & 0.4 & - & - & - & $X$ \\
\hline Level $2 * *$ & - & - & - & 0.1 & - & - & - & - \\
\hline Level $3^{* * *}$ & - & 1 & - & 0.3 & - & - & - & $\mathrm{X}$ \\
\hline Level $4 * * *$ & - & - & - & 0.4 & - & - & - & - \\
\hline Level $5^{* * *}$ & - & - & - & 0.2 & - & - & - & - \\
\hline Level 6*** & - & - & - & - & - & - & $; \mathrm{X}$ & $\mathrm{X}$ \\
\hline Level $7 * * *$ & - & - & - & 0.4 & - & - & - & $\mathrm{X}$ \\
\hline Level $8 * * *$ & - & 1 & - & 0.3 & - & - & $\mathrm{X}$ & - \\
\hline Level 9 & - & - & 1 & - & - & 0.3 & $\mathrm{X}$ & - \\
\hline Level 10 & - & - & 24 & 1.4 & - & - & - & - \\
\hline Level 11 & - & 1 & 35 & - & - & - & - & - \\
\hline Level 12 & - & 2 & - & - & - & - & - & - \\
\hline Level 13 & - & 1 & - & - & - & - & $\mathrm{X}$ & - \\
\hline \multicolumn{9}{|l|}{ Test Unit 2} \\
\hline Level $1 * *$ & - & - & - & - & - & - & - & - \\
\hline Level $2^{* *}$ & - & - & - & 0.5 & - & - & $\mathrm{X}$ & - \\
\hline Level $3 * *$ & - & 1 & - & 0.1 & - & 0.1 & - & - \\
\hline Level $4 * *$ & - & 1 & - & 0.6 & - & - & - & - \\
\hline Level $5^{* *}$ & - & - & - & - & - & - & $\mathrm{X}$ & - \\
\hline Level 6** & - & 1 & - & 0.4 & - & - & - & - \\
\hline Level $7 * *$ & - & 1 & - & 0.5 & - & - & $\mathrm{X}$ & - \\
\hline Level $8^{* *}$ & - & - & - & 0.1 & - & - & $\mathrm{X}$ & $\mathrm{X}$ \\
\hline Level 9** & - & 2 & - & 0.9 & - & - & - & - \\
\hline Level 10 & - & 2 & - & 0.2 & - & - & $\mathrm{X}$ & - \\
\hline Level 11 & - & - & 4 & 0.3 & - & - & - & - \\
\hline Level 12 & - & - & - & - & - & - & - & - \\
\hline \multicolumn{9}{|l|}{ Test Unit 3} \\
\hline Level $1 * *$ & - & - & - & - & - & - & - & - \\
\hline \multicolumn{9}{|l|}{ Test Unit 4} \\
\hline Level 1** & - & - & - & - & - & - & - & - \\
\hline \multicolumn{9}{|l|}{ Test Unit 5} \\
\hline Level $1 * *$ & - & - & - & 2.3 & 1 & - & - & $X$ \\
\hline Level 2** & - & - & - & 2.4 & - & - & $\mathrm{X}$ & - \\
\hline \multicolumn{9}{|c|}{$\begin{array}{l}\text { *Frequency given in numbers except charcoal and } 1 / 4 \text {-inch screen bones which are given in grams and } 1 / 16- \\
\text { inch screen bones and modern debris which are shown as present or absent. }\end{array}$} \\
\hline
\end{tabular}


Appendix A: Materials Recovered

Table 24, continued

\begin{tabular}{|c|c|c|c|c|c|c|c|c|}
\hline \multirow[b]{2}{*}{ Provenience } & \multicolumn{2}{|c|}{ Debitage } & \multirow[b]{2}{*}{$\begin{array}{l}\text { Bumed } \\
\text { Clay }\end{array}$} & \multirow[b]{2}{*}{ Charcoal } & \multirow[b]{2}{*}{ Shells } & \multicolumn{2}{|c|}{ Bones } & \multirow[b]{2}{*}{$\begin{array}{l}\text { Modem } \\
\text { Debris }\end{array}$} \\
\hline & $\begin{array}{l}1 / 4^{\prime \prime} \\
\text { Screen }\end{array}$ & $\begin{array}{l}1 / 16^{\prime \prime} \\
\text { Screen }\end{array}$ & & & & $\begin{array}{l}1 / 4^{\prime \prime} \\
\text { Screen }\end{array}$ & $\begin{array}{l}1 / 16^{\prime \prime} \\
\text { Screen }\end{array}$ & \\
\hline Level $3 * * *$ & - & 2 & - & 9.4 & - & - & $\mathrm{X}$ & - \\
\hline Level $4 * * *$ & - & 2 & - & 0.1 & - & - & $\mathrm{X}$ & $X$ \\
\hline Level $5 * * *$ & - & 41 & 1 & - & - & - & $\mathrm{X}$ & - \\
\hline Level $6 * * *$ & - & 4 & - & - & - & - & - & - \\
\hline Level $7 * * *$ & - & 2 & - & - & - & - & - & - \\
\hline Level 8 & 1 & - & - & - & - & - & $\mathrm{X}$ & - \\
\hline Level 9 & - & - & - & - & - & - & - & - \\
\hline Level 10 & - & 1 & - & - & - & - & - & - \\
\hline \multicolumn{9}{|l|}{ Test Unit 6} \\
\hline Level $1 * *$ & - & - & - & 0.4 & - & - & - & - \\
\hline Level $2 * *$ & 1 & - & 1 & 1.8 & - & - & $\mathrm{X}$ & - \\
\hline Level 3 & 1 & .1 & 3 & 274.2 & - & '- & $\mathrm{X}$ & - \\
\hline Level 4 & - & 3 & 2 & 56.7 & - & 0.3 & $\mathrm{X}$ & - \\
\hline Level 5 & - & 2 & 23 & 0.9 & - & - & $\mathrm{X}$ & - \\
\hline Level 6 & - & 1 & 10 & - & - & - & $\mathrm{X}$ & - \\
\hline Level 7 & 1 & 2 & - & 0.1 & - & - & $\mathrm{X}$ & - \\
\hline Level 8 & 1 & 3 & - & 1.0 & - & - & - & - \\
\hline Level 9 & 1 & - & - & - & - & - & $\mathrm{X}$ & - \\
\hline Level 10 & - & - & - & - & - & - & - & - \\
\hline Level 11 & - & - & - & - & - & - & $\mathrm{X}$ & - \\
\hline \multicolumn{9}{|l|}{ Test Unit 7} \\
\hline Level $1 * *$ & - & - & - & 0.5 & - & - & - & - \\
\hline Level $2^{* *}$ & - & 2 & - & 2.0 & - & - & $\mathrm{X}$ & $\mathrm{X}$ \\
\hline Level 3** & - & - & - & 0.4 & - & - & $\mathrm{X}$ & - \\
\hline Level 4 & - & 5 & - & 0.2 & - & - & $\mathrm{X}$ & - \\
\hline Level 5 & - & 5 & 1 & - & - & - & - & - \\
\hline Level 6 & 1 & - & - & - & - & - & - & - \\
\hline Level 7 & - & - & - & 0.1 & - & - & - & - \\
\hline Level 8 & - & - & - & - & - & - & - & - \\
\hline Level 9 & - & - & - & - & - & - & - & - \\
\hline Level 10 & - & - & - & - & - & - & - & - \\
\hline \multicolumn{9}{|l|}{ Test Unit 8} \\
\hline Level $1 * *$ & - & - & - & 0.3 & - & - & - & - \\
\hline Level $2 * *$ & - & - & - & 1.7 & - & - & $\mathrm{X}$ & - \\
\hline Level 3 & - & 1 & - & 4.0 & - & 0.9 & $\mathrm{X}$ & - \\
\hline Level 4 & - & - & - & 0.1 & - & 0.1 & $\mathrm{X}$ & - \\
\hline Level 5 & - & - & 3 & 0.8 & - & - & $\mathrm{X}$ & - \\
\hline Level 6 & - & 1 & 3 & 0.1 & - & 1.5 & $\mathrm{X}$ & - \\
\hline Level 7 & - & - & 5 & 0.8 & - & 4.0 & $\mathrm{X}$ & - \\
\hline Level 8 & - & - & - & 0.1 & - & 2.5 & - & - \\
\hline Level 9 & - & - & - & 0.1 & - & - & $\mathrm{X}$ & - \\
\hline Level 10 & - & - & - & 0.1 & - & - & $\mathrm{X}$ & - \\
\hline \multicolumn{9}{|l|}{ Test Unit 9} \\
\hline Level $1 * *$ & - & - & - & 0.3 & - & - & $\mathrm{X}$ & - \\
\hline Level 2 & - & - & - & 4.4 & - & - & $\mathrm{X}$ & - \\
\hline Level 3 & - & 1 & - & 3.1 & - & - & $\mathrm{X}$ & - \\
\hline
\end{tabular}

Table 24 continued on next page 
Table 24, continued

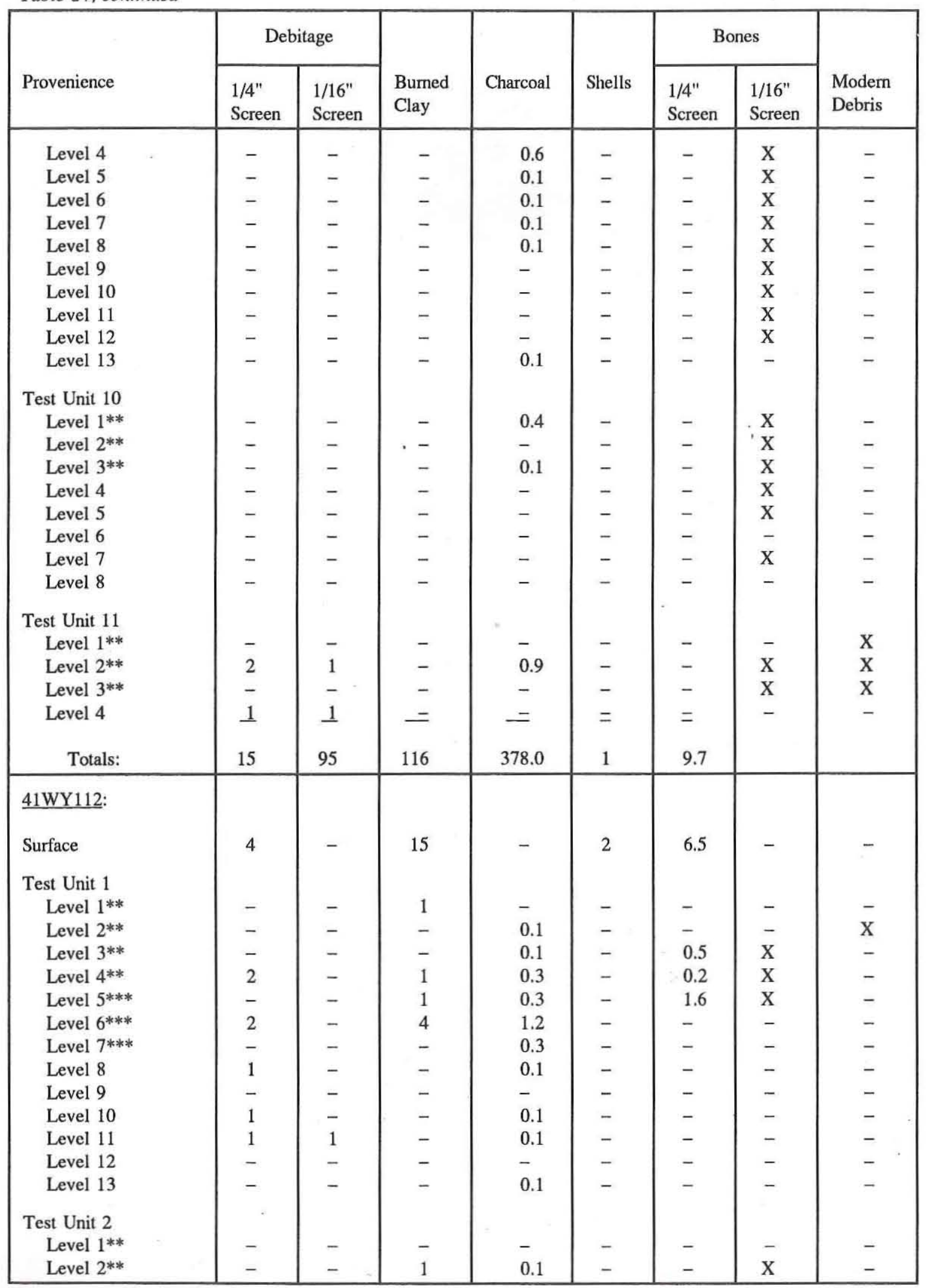

Table 24 continued on next page 
Table 24, continued

\begin{tabular}{|c|c|c|c|c|c|c|c|c|}
\hline \multirow[b]{2}{*}{ Provenience } & \multicolumn{2}{|c|}{ Debitage } & \multirow[b]{2}{*}{$\begin{array}{l}\text { Burned } \\
\text { Clay }\end{array}$} & \multirow[b]{2}{*}{ Charcoal } & \multirow[b]{2}{*}{ Shells } & \multicolumn{2}{|c|}{ Bones } & \multirow[b]{2}{*}{$\begin{array}{l}\text { Modern } \\
\text { Debris }\end{array}$} \\
\hline & $\begin{array}{l}1 / 4^{\prime \prime} \\
\text { Screen }\end{array}$ & $\begin{array}{l}1 / 16^{\prime \prime} \\
\text { Screen }\end{array}$ & & & & $\begin{array}{l}1 / 4^{\prime \prime} \\
\text { Screen }\end{array}$ & $\begin{array}{l}1 / 16^{\prime \prime} \\
\text { Screen }\end{array}$ & \\
\hline Level 3** & - & - & - & - & - & - & - & - \\
\hline Level 4** & - & - & - & 0.1 & - & - & $\mathrm{X}$ & - \\
\hline Level $5^{* * * *}$ & 1 & - & - & 0.2 & - & 0.3 & $\mathrm{X}$ & $\mathrm{X}$ \\
\hline Level $6^{* * * *}$ & - & - & - & 0.1 & - & - & - & - \\
\hline Level $7 * * * *$ & - & - & - & 0.1 & - & - & $\mathrm{X}$ & $\mathrm{X}$ \\
\hline Level 8 & - & - & - & 0.1 & - & - & $\mathrm{X}$ & - \\
\hline Level 9 & - & 1 & - & 0.1 & - & 0.5 & - & - \\
\hline \multicolumn{9}{|l|}{ Test Unit 3} \\
\hline Level $1 * *$ & - & - & - & - & - & - & - & - \\
\hline Level $2 * *$ & - & - & - & 0.1 & - & - & $\mathrm{X}$ & - \\
\hline Level $3 * *$ & - & - & - & 0.1 & - & - & $\mathrm{X}$ & - \\
\hline Level $4^{* *}$ & - & - & - & 0.2 & - & - & $\mathrm{X}$ & - \\
\hline \multicolumn{9}{|l|}{ Test Unit 4} \\
\hline Level $1^{* *}$ & - & - & - & - & - & - & - & - \\
\hline Level 2** & - & - & - & 0.1 & - & - & $\mathrm{X}$ & - \\
\hline Level 3** & - & - & - & 0.2 & - & - & $\mathrm{X}$ & - \\
\hline Level $4 * * *$ & - & 1 & - & 0.1 & - & - & $\mathrm{X}$ & - \\
\hline Level 5 & - & - & - & 0.1 & - & - & $\mathrm{X}$ & - \\
\hline Level 6 & - & - & - & 0.1 & - & - & - & - \\
\hline Level 7 & - & - & - & 0.1 & - & - & - & - \\
\hline \multicolumn{9}{|l|}{ Test Unit 5} \\
\hline Level $1 * *$ & - & - & - & - & - & - & - & $\mathrm{X}$ \\
\hline Level $2 * *$ & - & - & - & 0.1 & - & - & - & - \\
\hline \multicolumn{9}{|l|}{ Test Unit 6} \\
\hline Level $1 * *$ & - & - & - & - & - & - & - & - \\
\hline Level 2** & - & - & - & - & - & - & $\mathbf{X}$ & - \\
\hline Level 3** & - & - & - & - & - & - & - & - \\
\hline Level $4 * *$ & - & - & - & 0.3 & - & - & $\mathrm{X}$ & $\mathrm{X}$ \\
\hline Level $5^{* * *}$ & - & - & - & 0.1 & - & - & $\mathrm{X}$ & $\mathrm{X}$ \\
\hline Level $6^{* * * *}$ & - & - & - & 0.2 & - & 0.6 & $\mathrm{X}$ & $\mathrm{X}$ \\
\hline Level $7 * * *$ & - & - & - & 0.1 & - & 0.8 & $\mathrm{X}$ & $\mathrm{X}$ \\
\hline Level $8 * * *$ & - & - & - & - & - & 1.4 & $\mathrm{X}$ & - \\
\hline Level 9 & - & - & - & - & - & - & $\mathrm{X}$ & - \\
\hline \multicolumn{9}{|l|}{ Test Unit 7} \\
\hline Level $1 * *$ & - & - & - & - & - & - & - & - \\
\hline Level $2 * *$ & - & - & - & - & - & - & - & - \\
\hline Level $3 * *$ & - & - & - & - & - & - & $\mathrm{X}$ & - \\
\hline Level 4** & - & - & - & - & - & - & - & - \\
\hline Level $5 * * *$ & - & - & - & 0.1 & - & - & $\mathrm{X}$ & $\mathrm{X}$ \\
\hline Level 6*** & - & - & - & 0.2 & - & 0.6 & $\mathrm{X}$ & $\mathrm{X}$ \\
\hline Level 7 & - & - & - & 2.6 & - & - & $\mathrm{X}$ & - \\
\hline Level 8 & 1 & - & - & 0.1 & - & - & $\mathrm{X}$ & - \\
\hline Level 9 & - & - & - & - & - & 0.1 & - & - \\
\hline Level 10 & - & - & - & - & - & - & - & - \\
\hline
\end{tabular}


Table 24, continued

\begin{tabular}{|c|c|c|c|c|c|c|c|c|}
\hline \multirow[b]{2}{*}{ Provenience } & \multicolumn{2}{|c|}{ Debitage } & \multirow[b]{2}{*}{$\begin{array}{l}\text { Burned } \\
\text { Clay }\end{array}$} & \multirow[b]{2}{*}{ Charcoal } & \multirow[b]{2}{*}{ Shells } & \multicolumn{2}{|c|}{ Bones } & \multirow[b]{2}{*}{$\begin{array}{l}\text { Modem } \\
\text { Debris }\end{array}$} \\
\hline & $\begin{array}{l}1 / 4^{\prime \prime} \\
\text { Screen }\end{array}$ & $\begin{array}{l}1 / 16^{\prime \prime} \\
\text { Screen }\end{array}$ & & & & $\begin{array}{l}1 / 4^{\prime \prime} \\
\text { Screen }\end{array}$ & $\begin{array}{l}1 / 16 " \\
\text { Screen }\end{array}$ & \\
\hline \multicolumn{9}{|l|}{ Test Unit 8} \\
\hline Level $1^{* * *}$ & - & - & - & - & - & - & - & - \\
\hline Level 2** & - & - & - & 5.1 & - & 0.5 & $\mathrm{X}$ & $\mathrm{X}$ \\
\hline Level $3 * *$ & - & - & - & 0.1 & - & 0.1 & $\mathrm{X}$ & $\mathrm{X}$ \\
\hline Level 4** & - & - & - & - & - & 2.1 & $\mathrm{X}$ & - \\
\hline Level 5 & - & - & - & 0.3 & - & 0.2 & $\mathrm{X}$ & - \\
\hline Level 6 & - & - & - & 0.1 & - & - & - & - \\
\hline Level 7 & - & - & 12 & - & - & 1.3 & $\mathrm{X}$ & - \\
\hline Level 8 & - & - & 7 & 0.1 & - & 0.3 & $\mathrm{X}$ & - \\
\hline Level 9 & 1 & - & 1 & - & - & - & $\mathrm{X}$ & - \\
\hline Level 10 & - & - & 2 & 0.2 & - & - & $\mathrm{X}$ & - \\
\hline Level 11 & - & - & - & - & - & - & $\mathrm{X}$ & - \\
\hline Level 12 & - & - & - & - & - & - & $; \mathrm{X}$ & - \\
\hline \multicolumn{9}{|l|}{ Test Unit 9} \\
\hline Level $1 * *$ & - & - & - & - & - & - & - & - \\
\hline Level $2 * *$ & - & 1 & 4 & 0.1 & - & 1.4 & $\mathrm{X}$ & $\mathrm{X}$ \\
\hline Level $3 * *$ & - & 1 & - & 0.9 & - & - & $\mathrm{X}$ & $\mathrm{X}$ \\
\hline Level 4 **** & - & - & - & - & - & 1.2 & - & $\mathrm{X}$ \\
\hline Level 5 & - & - & - & 0.2 & - & - & $\mathrm{X}$ & - \\
\hline Level 6 & - & - & - & 0.1 & - & - & - & - \\
\hline Level 7 & - & 1 & - & 0.1 & - & - & $\mathrm{X}$ & - \\
\hline \multicolumn{9}{|l|}{ Test Unit 10} \\
\hline Level $1 * *$ & - & - & - & - & - & - & - & - \\
\hline Level 2** & - & - & - & 0.1 & - & - & $\mathrm{X}$ & $\mathrm{X}$ \\
\hline Level $3 * * *$ & - & - & - & 0.1 & - & - & $\mathrm{X}$ & $\mathrm{X}$ \\
\hline Level $4 * * *$ & - & - & - & 0.2 & - & 1.0 & $\mathrm{X}$ & $\mathrm{X}$ \\
\hline Level 5 & - & 1 & - & 0.1 & - & 0.2 & $\mathrm{X}$ & - \\
\hline Level 6 & - & 1 & - & - & - & 0.6 & - & - \\
\hline Level 7 & - & 1 & - & 0.1 & - & - & - & - \\
\hline Level 8 & - & - & 1 & - & - & 0.1 & - & - \\
\hline \multicolumn{9}{|l|}{ Test Unit 11} \\
\hline Level 1** & - & - & - & - & - & - & - & - \\
\hline Level 2*** & - & - & - & - & - & - & - & - \\
\hline Level $3 * * *$ & - & - & - & 0.1 & - & 0.3 & - & - \\
\hline Level $4 * * *$ & - & - & - & 0.3 & - & 1.0 & $\mathrm{X}$ & - \\
\hline Level $5^{* * * *}$ & 1 & - & 1 & 0.1 & - & 0.4 & - & - \\
\hline Level 6 & 1 & - & 1 & - & - & - & $\mathrm{X}$ & - \\
\hline Level 7 & 3 & - & - & - & - & - & $\mathrm{X}$ & - \\
\hline Level 8 & - & 1 & - & 0.1 & - & - & $\mathrm{X}$ & - \\
\hline Geological Trench & $=$ & $=$ & $=$ & $=$ & $=$ & 1.4 & - & - \\
\hline Totals: & 19 & 10 & 52 & 16.9 & 2 & 25.2 & & \\
\hline \multicolumn{9}{|l|}{ 41WY113: } \\
\hline Surface & - & - & 10 & - & - & 151.5 & - & - \\
\hline
\end{tabular}


Table 24, continued

\begin{tabular}{|c|c|c|c|c|c|c|c|c|}
\hline \multirow[b]{2}{*}{ Provenience } & \multicolumn{2}{|c|}{ Debitage } & \multirow[b]{2}{*}{$\begin{array}{l}\text { Burned } \\
\text { Clay }\end{array}$} & \multirow[b]{2}{*}{ Charcoal } & \multirow[b]{2}{*}{ Shells } & \multicolumn{2}{|c|}{ Bones } & \multirow[b]{2}{*}{$\begin{array}{l}\text { Modern } \\
\text { Debris }\end{array}$} \\
\hline & $\begin{array}{l}1 / 4^{\prime \prime} \\
\text { Screen }\end{array}$ & $\begin{array}{l}1 / 16^{\prime \prime} \\
\text { Screen }\end{array}$ & & & & $\begin{array}{l}1 / 4^{\prime \prime} \\
\text { Screen }\end{array}$ & $\begin{array}{l}1 / 16^{\prime \prime} \\
\text { Screen }\end{array}$ & \\
\hline \multicolumn{9}{|l|}{ Test Unit 1} \\
\hline Level $1 * *$ & - & - & - & 0.1 & 1 & - & $\mathbf{X}$ & - \\
\hline Level $2^{* *}$ & - & - & - & 0.1 & - & - & $\mathrm{X}$ & - \\
\hline Level $3 * *$ & - & 1 & - & 0.5 & 1 & 0.4 & $\mathrm{X}$ & $\mathrm{X}$ \\
\hline Level $4 * *$ & - & - & - & 3.5 & - & - & $\mathrm{X}$ & $\mathrm{X}$ \\
\hline Level 5 & - & - & - & 1.3 & - & - & - & - \\
\hline Level 6 & - & - & - & 0.1 & - & - & - & - \\
\hline Level 7 & - & - & - & - & 1 & - & - & - \\
\hline Level 8 & - & - & - & - & - & - & $\mathrm{X}$ & - \\
\hline Level 9 & - & - & - & - & - & - & $\mathrm{X}$ & - \\
\hline Level 10 & - & - & - & - & - & - & $\mathrm{X}$ & - \\
\hline Level 11 & - & - & - & - & - & ; - & $\mathrm{X}$ & - \\
\hline \multicolumn{9}{|l|}{ Test Unit 2} \\
\hline Level $1^{* *}$ & - & - & - & 0.1 & - & - & - & - \\
\hline Level 2 & - & 3 & - & - & - & - & - & - \\
\hline Level 3 & - & - & - & - & - & - & - & - \\
\hline Level 4 & - & - & - & - & - & - & - & - \\
\hline Level 5 & - & - & - & 0.1 & - & - & $\mathrm{X}$ & - \\
\hline Level 6 & - & 1 & - & 0.1 & - & - & $\mathrm{X}$ & - \\
\hline Level 7 & - & - & - & - & - & - & - & - \\
\hline Level 8 & - & - & - & - & - & - & - & - \\
\hline Level 9 & - & - & - & - & - & - & - & - \\
\hline \multicolumn{9}{|l|}{ Test Unit 3} \\
\hline Level $1^{* *}$ & - & - & - & - & - & - & - & - \\
\hline Level $2^{* * *}$ & - & - & - & 0.1 & - & - & $\mathrm{X}$ & - \\
\hline Level $3 * *$ & - & - & - & 0.2 & - & - & $\mathrm{X}$ & - \\
\hline Level $4 * *$ & - & - & - & 0.4 & - & - & - & - \\
\hline Level 5 & - & - & - & 0.4 & - & - & $\mathrm{X}$ & - \\
\hline \multicolumn{9}{|l|}{ Test Unit 4} \\
\hline Level $1^{* *}$ & - & - & - & - & - & 11.3 & $\mathrm{X}$ & $\mathrm{X}$ \\
\hline Level 2** & - & - & - & - & - & 1.3 & $\mathrm{X}$ & - \\
\hline Level $3^{* *}$ & - & - & - & - & - & 0.3 & - & - \\
\hline Level 4 & - & - & - & - & - & 0.2 & - & - \\
\hline Level 5 & $=$ & $=$ & $=$ & $=$ & $=$ & 3.7 & - & - \\
\hline Totals: & 0 & 5 & 10 & 7.0 & 3 & 168.7 & & \\
\hline \multicolumn{9}{|l|}{ 41WY134: } \\
\hline Surface & - & - & - & - & 1 & - & - & - \\
\hline \multicolumn{9}{|l|}{ Test Unit 1} \\
\hline Level $1 * *$ & - & - & - & - & - & - & - & - \\
\hline Level $2^{* * *}$ & - & - & - & 0.3 & - & - & $\mathrm{X}$ & - \\
\hline Level $3 * *$ & - & - & - & - & - & 0.2 & $\mathrm{X}$ & $\mathrm{X}$ \\
\hline Level $4 * *$ & - & - & - & 0.9 & - & - & $\mathrm{X}$ & $\mathrm{X}$ \\
\hline Level 5 & - & - & - & 0.1 & - & - & - & - \\
\hline Level 6 & - & - & - & - & - & - & - & - \\
\hline
\end{tabular}


Table 24, continued

\begin{tabular}{|c|c|c|c|c|c|c|c|c|}
\hline \multirow[b]{2}{*}{ Provenience } & \multicolumn{2}{|c|}{ Debitage } & \multirow[b]{2}{*}{$\begin{array}{l}\text { Burned } \\
\text { Clay }\end{array}$} & \multirow[b]{2}{*}{ Charcoal } & \multirow[b]{2}{*}{ Shells } & \multicolumn{2}{|c|}{ Bones } & \multirow[b]{2}{*}{$\begin{array}{l}\text { Modern } \\
\text { Debris }\end{array}$} \\
\hline & $\begin{array}{l}1 / 4^{\prime \prime} \\
\text { Screen }\end{array}$ & $\begin{array}{l}1 / 16^{\prime \prime} \\
\text { Screen }\end{array}$ & & & & $\begin{array}{l}1 / 4^{\prime \prime} \\
\text { Screen }\end{array}$ & $\begin{array}{l}1 / 16^{\prime \prime} \\
\text { Screen }\end{array}$ & \\
\hline \multicolumn{9}{|l|}{ Test Unit 2} \\
\hline Level $1 * *$ & - & - & - & - & - & - & - & - \\
\hline Level $2 * *$ & - & - & - & 0.4 & - & - & $\mathrm{X}$ & - \\
\hline Level 3** & - & - & - & 0.7 & - & 0.2 & $\mathrm{X}$ & - \\
\hline Level 4** & - & - & - & 1.0 & - & 0.4 & $X$ & - \\
\hline Level $5 * *$ & - & - & - & - & - & - & $\mathrm{X}$ & - \\
\hline Level 6** & - & - & - & 0.1 & - & - & $\mathrm{X}$ & $\mathrm{X}$ \\
\hline Level 7 & - & - & - & - & - & - & - & - \\
\hline Level 8 & - & - & - & - & - & 2.0 & - & $\mathrm{X}$ \\
\hline \multicolumn{9}{|l|}{ Test Unit 3} \\
\hline Level 1** & - & - & - & - & - & - & - & - \\
\hline Level $2 * *$ & - & - & - & 1.8 & - & - & $\mathrm{X}$ & $\mathrm{X}$ \\
\hline Level $3 * *$ & - & - & . - & 1.8 & - & - & $\mathrm{X}$ & $\mathrm{X}$ \\
\hline Level $4 * *$ & - & - & - & 1.1 & - & 0.3 & $\mathrm{X}$ & $X$ \\
\hline Level 5 & - & - & - & 0.4 & - & - & $\mathrm{X}$ & - \\
\hline \multicolumn{9}{|l|}{ Test Unit 4} \\
\hline Level $1 * *$ & - & - & - & - & - & - & - & - \\
\hline Level 2** & - & - & - & 5.4 & - & 1.6 & $X$ & $\mathrm{X}$ \\
\hline Level 3** & - & - & - & 8.3 & - & - & $\mathrm{X}$ & $\mathrm{X}$ \\
\hline Level 4 & - & - & - & 7.3 & - & - & $\mathrm{X}$ & - \\
\hline Level 5 & - & - & - & 0.7 & - & - & $\mathrm{X}$ & - \\
\hline Level 6 & - & - & - & 0.1 & - & - & $X$ & - \\
\hline Level 7 & - & - & - & 0.5 & - & - & $\mathrm{X}$ & - \\
\hline Level 8 & - & - & - & 0.1 & - & - & $\mathrm{X}$ & - \\
\hline Level 9 & - & - & - & 0.1 & - & - & $\mathrm{X}$ & - \\
\hline Level 10 & $=$ & $=$ & $=$ & $\underline{0.1}$ & $=$ & $=$ & $\mathrm{X}$ & - \\
\hline Totals: & 0 & 0 & 0 & 31.2 & 1 & 4.7 & & \\
\hline \multicolumn{9}{|l|}{ 41WY140: } \\
\hline Surface & - & - & - & - & - & - & - & $\mathrm{X}$ \\
\hline \multicolumn{9}{|l|}{ Test Unit 1} \\
\hline Level $1^{* *}$ & - & - & - & - & - & - & - & - \\
\hline Level 2 & - & - & - & 0.2 & - & - & $\mathrm{X}$ & - \\
\hline \multicolumn{9}{|l|}{ Test Unit 2} \\
\hline Level $1 * *$ & - & - & - & - & - & - & - & - \\
\hline Level 2 & - & 1 & - & 0.1 & - & - & $\mathrm{X}$ & - \\
\hline \multicolumn{9}{|l|}{ Test Unit 3} \\
\hline Level $1 * *$ & - & - & - & - & - & - & - & - \\
\hline Level 2 & - & 1 & - & 0.1 & - & - & $\mathrm{X}$ & - \\
\hline \multicolumn{9}{|l|}{ Test Unit 4} \\
\hline Level $1^{* *}$ & - & - & - & - & - & - & - & - \\
\hline Level 2 & $=$ & $=$ & $=$ & $=$ & $=$ & $=$ & $\mathrm{X}$ & - \\
\hline Totals: & 0 & 2 & 0 & 0.4 & 0 & 0 & & \\
\hline
\end{tabular}


highly mobile groups, although the low frequencies of debitage may also be due to overall low numbers of lithic tools in highly curated tool assemblages.

\section{MODIFIED BONE}

A single modified bone was recovered from Feature 1 at $41 \mathrm{WY} 113$. This specimen consists of a small fragment which has been bifacially ground on both ends (Fig. 52) and may be part of a compound fishhook similar to those recovered from other coastal sites (Story 1968:Fig. 48 E, F, and $\mathrm{K})$.
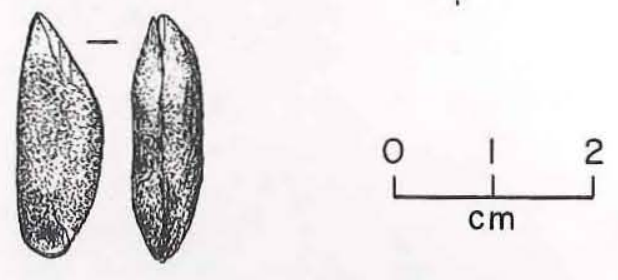

Figure 52. Modified bone from 41WY113.

\section{CERAMIC SHERD FROM 41HG128}

During the Phase I investigations, a single prehistoric ceramic sherd was recovered from 41HG128 (Hall et al. 1987). This specimen was described as "one plain aboriginal sherd" (Hall et al. 1987:99) but was not described in detail. Before 1986, only three sites with prehistoric pottery were known--41WY9 (Mallouf et al. 1977:189), 41WY60 (Day et al. 1981:335), 41WY72 (Day 1981:47). The sherd from 41WY9 is described as a fine sandy paste sherd with a brown slip on both surfaces, and the sherds from $41 \mathrm{WY} 60$ and $41 \mathrm{WY} 72$ are described as sandy paste wares.

The sherd recovered from $41 \mathrm{HG} 128$ is a small, thin fragment measuring $23 \times 18 \mathrm{~mm}$ in size and $4.5 \mathrm{~mm}$ in thickness. Vessel forms found in the Lower Rio Grande Valley (Mason 1935) can produce small sherds with varying interior/exterior curvatures (i.e., body, shoulder, or neck fragments); this specimen is slightly curved and the convex surface is fire-blackened suggesting an exterior surface. The interior surface is a creamy buff color which results from oxidation during the firing process and underlies a well-polished or burnished slip of yellowish red (5YR 5/8). The paste is well-compacted fine clay with naturally occurring quartz sand inclusions. The sherd is well made and does not resemble prehistoric ceramics from the Texas coast such as Rockport wares, yet it is similar to sherds collected in the Rio Grande Delta area by A. E. Anderson. The specimen from $41 \mathrm{HG} 128$ is very similar to an olla described as Huastecan-like from La Loma Atravasada in northeastern Tamaulipas, Mexico with regard to thickness, surface treatment, paste, and color (Texas Archeological Research Laboratory n.d.).

A. E. Anderson describes five types in his collection of Rio Grande Delta ceramics; one of these is described as buff colored, thin, undecorated, and fire-blackened (Anderson 1932:30). Mason (1935) made a study of the ceramics from Anderson's collection, comparing these specimens with Huastecan ceramics and Huastecan-influenced ceramics from San Fernando, Mexico. He concludes that the ceramics from Brownsville sites (e.g., Anderson's collection) are possibly of Huastecan influence, "As a result of our comparisons we may probably conclude with reasonable confidence that the Brownsville vessels were not made by Huaxtecs [sic] . . . but show Huaxtec influence to a moderate degree" (Mason 1935:40). The ceramics from the Brownsville area and Huastecan area are not as similar in shape as they are in other attributes such as color, hardness, wall thickness, materials used in decoration (asphaltum and red ocher), and decorative motif. Parallel straight lines and bands, scallops, triangles, concentric circles with central dot, and animal figures are found on ancient Huaxtec and Brownsville vessels (Mason 1935:37-40).

The sherd from $41 \mathrm{HG} 128$ is neither decorated nor large enough to determine the shape of the vessel, and the surface context in which it was found does not provide conclusive evidence that it was associated with prehistoric activities. The fact that a possible historic earthenware sherd also was observed but not collected at the site during the 1986 survey adds to the uncertainty as to whether or not the specimen predates the contact 
period. Undeniably the characteristics of the sherd are similar to Huastecan ceramics, but without a thorough analysis of Huastecan and Brownsville ceramics, little more can be stated with assurance.

\section{BURNED CLAY LUMPS}

Burned clay lumps are difficult to identify as a direct or indirect result of human activity even when the specimens are in good context. Those identified as potentially associated with prehistoric human activities are shown on Table 24. When clay lumps are not associated with artifacts but are within the site area, they should be viewed only as possible prehistoric cultural materials (Mallouf et al. 1977:100; Day et al. 1981:347).

Burned clay lumps occur quite commonly in the project area as a result of recent land clearing and brush burning practices as well as from natural processes such as grass fires over clayey surfaces or diagenesis (see below). The burned clay lumps can be quite hard or very friable depending on the degree of burning. A lowtemperature firing resulting from a surface fire can create small burned clay lumps that may not exhibit the common characteristics of burning (i.e., discoloration and cracking). Through time natural processes also tend to fragment burned clay lumps. Ethnographic evidence from South Texas (Campbell 1988:36-37) indicates that pit ovens were used to process plant foods. This could create burned clay lumps but at present no pit ovens have been identified.

The magnetometer studies at 41WY112 and $41 \mathrm{WY} 113$ showed that burned clay lumps did not produce measurable signals during the controlled experiments (see Appendix B). Frederick and Abbott point out that there are at least three possible causes of clay lumps of this kind: (1) the specimens may have been fired at low temperatures which are insufficient to produce thermoremanent magnetic signals; (2) the magnetic mineral content of the clay may be insufficient for measurement; or (3) the specimens may be unfired products of diagensis. In this case, diagensis is a process resulting in the cementation of individual particles that are bonded together by calcium carbonate. Most of the clay lumps react to a $10 \%$ solution of hydrochloric acid showing that calcium carbonate is present.

Because of the uncertainty in identifying clay lumps as burned and because of the difficulty in determining if the burned clay lumps on the surface are the result of natural processes, historic land clearing, or prehistoric cultural activities, certain criteria are used to identify clay lumps with the greatest potential for being associated with prehistoric cultural activities. Proveniences of undisturbed context that predate historic land modification in the region were identified, presuming that clay lumps in these contexts are not historic. Specimens collected from surface contexts are considered to be possibly related to prehistoric activites since these specimens are not in direct association with artifacts. For purposes of this analysis, clay lump specimens are identified as burned if they exhibit hairline cracks, angular or sharp edges typically observed on firecracked rocks, discoloration (i.e., reddened or blackened surfaces resulting from oxidation during firing), and a maximum diameter equal to or greater than $20 \mathrm{~mm}$ (based on the observation that calcium carbonate and manganese nodules present in the same deposits are usually smaller than or equal to $20 \mathrm{~mm}$ in maximum diameter). Specimens smaller than $20 \mathrm{~mm}$ are usually very friable and are a likely product of diagensis.

Burned clay lumps, as defined above, were recovered from three of five sites--41HG128, 41WY112, and 41WY113. Site 41HG128 revealed six possible associations of burned clay and prehistoric cultural activity based on the presence of artifacts and undisturbed contexts. Levels $9-11$ of Test Unit 1 revealed 60 burned clay specimens, and fine-screen debitage was recovered from Levels 8 and 11-13. The distribution of artifacts and the number of burned clay lumps from this location strongly suggest that these burned clay specimens are the result of a prehistoric cultural activities. Level 11 of Test Unit 2 revealed four burned clay lumps in undisturbed context but not directly associated with artifacts; however, four pieces of fine-screen debitage were recovered from Levels 9 and 10 . Level 5 of Test Unit 5 yielded one piece of burned clay which is possibly associated with the fine-screen debitage from this level (see Chapter 5). Levels 2-6 of Test Unit 6 revealed 39 burned clay lumps associated with 7 pieces of fine-screen debitage and 2 pieces of $1 / 4$-inch-screen debitage (see Chapter 5). In addition, fine-screen and 1/4inch-screen debitage was also recovered from 
Levels 7-9. As the profile of Test Unit 6 shows (see Chapter 5), Level 2 is partially disturbed and the burned clay specimens and artifacts could have come from either disturbed or undisturbed sediments. Level 5 of Test Unit 7 revealed one burned clay specimen associated with five pieces of fine-screen debitage. Fine-screen debitage and one biface also were recovered from Level 4 and one piece of 1/4-inch-screen debitage was recovered from Level 6. Levels 5-7 of Test Unit 8 yielded 11 burned clay lumps associated with 1 piece of fine-screen debitage.

Site 41WY112 contains at least four proveniences where burned clay lumps occur in undisturbed contexts and might represent direct or indirect results of prehistoric cultural activities. Five burned clay specimens recovered from Levels 5 and 6 of Test Unit 1 are associated with two pieces of debitage. Levels $7-10$ of Test Unit 8 revealed a substantial number of burned clay lumps $(\mathrm{N}=22)$ associated with one piece of debitage in Level 9. One burned clay lump recovered from Level 8 of Test Unit 10 is well below recently disturbed deposits but is not associated with artifacts. Levels 5 and 6 of Test Unit 11 revealed two burned clay lumps associated with two pieces of debitage. At $41 \mathrm{WY} 113$, all the burned clay specimens were recovered from historically disturbed deposits, hence no determination of origin can be made.

No burned clay specimens occurred in contexts indicative of in situ hearths; however, some might represent displaced hearth stones, boiling stones, or the result of indirect firing of the clayey deposits from surface or pit fires. Although the burned clay specimens and associated artifact frequencies are low, they tend to support the general scenario of limited human activity and high mobility (see Chapter 3).

\section{CHARCOAL}

Table 24 presents the distribution of the charcoal collected during the testing phase showing the combined weights from 1/4-inch-screen and fine-screen recovery. This charcoal was handpicked from water-screened matrix. With the exception of those associated with historic features, the majority of charcoal specimens weigh less than $1 \mathrm{~g}$ and consist of small fragments of unidentified wood.

\section{MOLLUSCA}

Seven freshwater mussel shell fragments and one conch shell fragment were recovered from the Phase II excavations (see Table 24). Most of these specimens were recovered from surface contexts. Surface finds of freshwater mussel shells are not a reliable indicator of prehistoric human activity as mussels inhabit the drainage bottoms today. The occurrence of mussel shell fragments on the surface along the drainage may result from dredging the bottoms where mussels live or from modern collections by animals or humans.

Three mussel shell fragments were recovered from Levels 1, 3, and 7 of Test Unit 1 excavations at $41 \mathrm{WY} 113$. The specimen from Level 3 is in association with one piece of finescreen debitage and is possibly related to prehistoric human activities. All specimens are small, heavily weathered fragments which exhibit no evidence of human modification.

The surface collections consist of four specimens. A single conch shell fragment was recovered from the surface at $41 \mathrm{WY} 112$ at the top of the drainage bank. This specimen is a small, heavily weathered columella fragment which is culturally unmodified. One mussel shell from the surface of Test Unit 5 at 41 HG128 is considered modern as it retains portions of the outer periostracum. The remaining two specimens recovered from surface contexts at 41WY112 and 41WY134 are small weathered fragments which do not exhibit signs of human modification. There is no direct evidence that any of these surfacecollected specimens are the result of prehistoric human activities, although the conch shell must have been transported from the coast and it is possible that this was done by hunter-gatherers prehistorically.

The presence of land snails in archeological sites is usually attributed to natural rather than cultural processes; there have been no concentrations observed in the project area that could be the result of prehistoric human activity. Land snails occur in dense numbers in many locations along the drainage ditch (Hall et al. 1987:53). As no archeological or ethnohistorical data demonstrates that snails were a source of food for prehistoric people in the project area, perhaps a more viable use of gastropod studies is for environmental 
reconstruction. Adequate and reliable stratigraphic contexts, however, were lacking at the five investigated sites; therefore, this type of paleoenvironmental analysis was not pursued. In the future, gastropods excavated from sites with better stratigraphic contexts should be considered for paleoenvironmental analysis.

Site $41 \mathrm{HG} 128$ yielded $176 \mathrm{~g}$ of snail shells, $41 \mathrm{WY} 112$ yielded $2655 \mathrm{~g}, 41 \mathrm{WY} 113$ yielded 419 $\mathrm{g}, 41 \mathrm{WY} 134$ yielded $882 \mathrm{~g}$, and $41 \mathrm{WY} 140$ yielded $2 \mathrm{~g}$. The Rabdotus sp. is by far the most abundant gastropod species observed in the collections. This species is tolerant of a wide variety of environmental conditions and does not provide specific habitat data for the sites in the project area. Rabdotus prefers a habitat of earlyto mid-successional brush in slightly higher elevations than the investigated sites and avoids direct water. They are a brush and tree snail often found clinging to branches, but they lay eggs in soil. Concentrations of whole shells and fragments can result from rain washing, from wood rats eating the snail and discarding the shell, or from road runners collecting and smashing the shells to get to the snail meat.

\section{BONES}

Little faunal material was recovered at any of the five excavated sites and most were unidentifiable fragments of bone (see Table 24). The greatest amount $(168.7 \mathrm{~g})$ was recovered from $41 \mathrm{WY} 113$, and this was due to the recovery of Feature 1. Feature 1 consisted of one complete left deer radius, one left deer proximal radius shaft, and one right deer metacarpal, as well as the one bone artifact discussed above. A deer radius from 41WY113 was submitted for radiocarbon dating (see Appendix D).

At $41 \mathrm{WY} 112$, a total of $25.2 \mathrm{~g}$ of bone was recovered from the excavations, and five specimens were identifiable. Recovered were one large mammal tooth fragment (deer size) from Level 7 of Test Unit 6, one distal deer phalange from Level 8 of Test Unit 6, one possible deer distal unfused metapodial from Level 8 of Test Unit 8, one possible rabbit vertebra from Level 3 of Test Unit 11, and one fragmentary pelvis with acetabulum, probably rabbit, from the hand dug Geological Trench $1.22 \mathrm{~m}$ below surface.

Only $9.7 \mathrm{~g}$ and $4.7 \mathrm{~g}$ of bone were recovered from 41HG128 and 41WY134, respectively. At $41 \mathrm{HG} 128$, a single rabbit-sized unfused distal femoral condyle was recovered from Level 4 of Test Unit 8. No bone was recovered from excavations at $41 \mathrm{WY} 140$; however, fragments of a tortoise shell were collected from sediments adjacent to Backhoe Trench 1 and this was submitted for radiocarbon dating (see Appendix D).

\section{MISCELLANEOUS MATERIALS}

Calcium carbonate and manganese oxide concretions were noted during the Phase II investigations. These mineral concretions are believed to be formed by individual particles of the minerals being bonded together by materials (in this case calcite) precipitated from ground water. These concretions result from pedogenic processes in the sediments.

A small amount of gypsum was recovered from the excavations and is known to occur in the deposits throughout the project area. Gypsum is a mineral formed by the evaporation of saline water, usually sea water, in a warm, dry environment. The gypsum specimens from these excavations are usually small, averaging less than $10 \mathrm{~mm}$ in maximum diameter and under $1 \mathrm{~g}$ in weight.

Siliceous pebbles were noted in the test unit excavations and are probably attributable to lateral fluvial processes contributing to the original formation of the delta. The presence of these specimens are the result of geomorphic rather than cultural processes at the sites.

Modern debris was collected from the test unit excavations to denote the presence of possibly disturbed deposits and/or bioturbation processes which could have displaced these materials. Table 24 shows the presence or absence of these materials which include metal fragments, plastic, glass, cigarette filters, a 22 -caliber bullet, plastic gun shell casings, modern ceramic fragments, and petroleum residue. 


\section{REFERENCES CITED}

Anderson, A. E.

1932 Artifacts of the Rio Grande Delta Region. Bulletin of the Texas Archeological and Paleontological Society 4:29-31.

Binford, Lewis R.

1979 Organization and Formation Processes: Looking at Curated Technologies. Journal of Anthropological Research 35:255-273.

Campbell, T. N.

1988 The Indians of Southern Texas and Northeastern Mexico: Selected Writings of Thomas Nolan Campbell. The University of Texas at Austin.

Day, D. William

1981 An Assessment of Archeological Sites 41 WY71 and 41WY72, Willacy County, Texas. Reports of Investigations No. 17. Prewitt and Associates, Inc., Austin.

Day, D. William, Jane Laurens-Day, and Elton R. Prewitt

1981 Cultural Resources Surveys and Assessments in Portions of Hidalgo and Willacy Counties, Texas. Reports of Investigations No. 15. Prewitt and Associates, Inc., Austin.

Hall, Grant D., Michael B. Collins, and Elton R. Prewitt

1987 Cultural Resources Investigations Along Drainage Improvements, Hidalgo and Willacy Counties, Texas: 1986 Investigations. Reports of Investigations No. 59. Prewitt and Associates, Inc., Austin.

Hester, Thomas Roy

1969 Archeological Investigations in Kleberg and Kenedy Counties, Texas in August, 1967. Report No. 15, Archeological Program. State Building Commission, Austin.

Mallouf, Robert J., Barbara J. Baskin, and Kay L. Killen

1977 A Predictive Assessment of Cultural Resources in Hidalgo and Willacy Counties, Texas. Survey Report 23. Office of the State Archeologist, Texas Historical Commission, Austin.

Mason, J. Alden

1935 The Place of Texas in Pre-Columbian Relationships Between the United States and Mexico. Bulletin of the Texas Archeological and Paleontological Society, Vol. 7.

Shafer, Harry J., and Thomas Roy Hester

1971 A Study of the Function and Technology of Certain Bifacial Tools from Southern Texas. Archeological Report Number 20, Texas Historical Survey Committee.

Sollberger, J. B.

1971 A Technological Study of Beveled Knives. Plains Anthropologist 16(53):209-218.

Story, Dee Ann

1968 Archeological Investigations at Two Central Texas Gulf Coast Sites. Archeological Program Report No. 13. State Building Commission, Austin. 
Texas Archeological Research Laboratory

n.d. Unpublished notes of A. E. Anderson. On file at Texas Archeological Research Laboratory, The University of Texas at Austin.

Tomka, Steve A., Ross C. Fields, J. Michael Quigg, and David L. Miller

1988 Descriptions of the Materials Recovered. Appendix B in National Register Assessments of Six Prehistoric Sties at the Jewett Mine, Leon County, Texas, by Ross C. Fields, C. Britt Bousmann, and Sylvia Kooren, pp. 113-158. Reports of Investigations No. 67. Prewitt and Associates, Inc., Austin.

Tomka, Steve A., L. Wayne Klement, Ross C. Fields, Gail L. Bailey, and J. Michael Quigg

1989 Descriptions of Materials Recovered from Prehistoric Sites. Appendix B in National Register Assessment of Eight Prehistoric and Four Historic Sites at the Jewett Mine, Freestone and Leon Counties, Texas, by Ross C. Fields, L. Wayne Klement, C. Britt Bousman, David H. Jurney, and Melissa M. Green, pp. 277-350. Reports of Investigations No. 73 (Review Draft). Prewitt and Associates, Inc., Austin.

Tomka, Steve A., and Ross C. Fields

1990 Chipped Stone Artifacts, 41LN29A and 41LN106. Chapter 9 in Excavations at the Charles Cox, Lambs Creek Knoll, and Buffalo Branch Sites, Jewett Mine Project, Leon and Freestone Counties, Texas, edited by Ross C. Fields, pp. 141-288. Reports of Investigations No. 70. Prewitt and Associates, Inc., Austin. 
APPENDIX B: Magnetic Investigations at Sites $41 \mathrm{WY} 112$ and $41 \mathrm{WY113}$

Charles D. Frederick

and

James T. Abbott 


\section{INTRODUCTION}

This report presents the results of two magnetic surveys undertaken during the testing phase of archeological investigations at two sites in Willacy County, Texas. These sites were selected for a pilot study designed to evaluate the utility of magnetometry in locating subsurface burned features within the confines of the site boundaries. The results of the two site surveys, together with information gathered on the magnetic susceptibility of some thermally altered objects procured from one of the sites, provide information useful for future magnetic prospection in this area.

\section{THEORETICAL BACKGROUND}

The following section provides a brief introduction to the physics of magnetometry and its application to archeology. For more thorough reviews, see Breiner (1973), Aitken (1974), and Weymouth and Huggins (1985). The earth is enveloped by a magnetic field similar in configuration to one surrounding a simple bar magnet. This field is composed of lines of magnetic force or flux that issue from the earth's magnetic poles. The intensity of the magnetic field at any location is a function of the density of the lines of flux and varies from approximately 25,000 gammas (a symbol of magnetic intensity that hereafter is represented by the symbol $\gamma$ ) in the tropical latitudes to over $70,000 \gamma$ at the magnetic poles.

Proton magnetometers are portable instruments that provide a measure of the total magnetic field intensity at a given location independent of field orientation. The sensor consists of a wire coil surrounding a bottle of fluid rich in hydrogen ions, such as water, kerosene, or decane. The nuclei of the hydrogen ions behave as small, spinning magnetic dipoles and precess about an axis parallel to the magnetic field of the earth at a rate directly proportional to its intensity. Under normal conditions, the precession of individual protons in the fluid is out of phase, and no current is produced in the coil. However, when a strong current is passed through the coil, a magnetic field is generated which temporarily polarizes the protons. After the current is eliminated, the protons resume precession in phase and generate a minute voltage signal in the coil. This signal is directly proportional to the total magnetic field intensity and is largely inde- pendent of the sensor coil orientation. After a few seconds, the protons once again become out of phase and the signal fades (Breiner 1973; Steponaitis and Brain 1976).

The proton magnetometer measures the overall field strength of the magnetic field at a given point in time and space. The total field strength is a composite of the earth's field strength and local permutations caused by induced and remanent magnetization of nearby objects. Induced, or viscous, magnetization refers to the interaction of a material with the ambient magnetic field where the presence of the field acts to magnetize the object that in turn, influences the configuration of the field. Remanent magnetism refers to the permanent magnetic alignment of material independent of the magnetic field. Of these two types of magnetization, remanent is the more important archeologically (Breiner 1973; Aitken 1974; Weymouth and Huggins 1985).

The most significant form of remanent magnetism for archeological purposes results from heating and is termed thermoremanent magnetism. Under normal conditions, the electron orbits of magnetic minerals contained within a substance are locked into randomly oriented alignments. However, when materials containing magnetic minerals are heated above the curie point $\left(\mathrm{ca} .600^{\circ} \mathrm{C}\right.$ ), the electrons of the magnetic particles are thermally agitated and begin to rotate freely. As the material cools, the electron orbits tend to align with the earth's magnetic field and, with further cooling, are locked in place. Heating to temperatures below the curie point usually results in partial thermoremanent magnetization, resulting in a less pronounced but often still detectable overall magnetization of the material.

Thermoremanent magnetism allows the determination of the azimuth and inclination of the magnetic pole at the time that the material cooled and the orbits were frozen and thus provides the basis of paleomagnetic and archeomagnetic dating (Bradley 1985:86-98; Eighmy 1980). In addition, this uniform alignment also tends to give the material strong magnetic properties that can produce dramatic signatures in archeological applications (Breiner and Coe 1972; Weymouth 1979; Weymouth and Huggins 1985).

Archeological magnetic surveys are designed to detect spatial anomalies due to localized phenomena (e.g., burned archeological features). 
However, because all readings cannot be taken simultaneously, the survey data also contains a temporal component that must be eliminated. The earth's magnetic field varies both on a fairly predictable daily basis (i.e., diurnal variations of up to several hundred $\gamma$ a day) and on a random short-term basis (i.e., micropulsations of 10-100 $\gamma$ at unpredictable intervals). In practice, one of two methods is typically used to control for the effects of these variations: either control readings are taken periodically at a given reference point (e.g., Gibson 1986; Hamilton 1986), or a second magnetometer is typically employed as a stationary recording base station (e.g., Weymouth 1979, 1987; Espey, Huston and Associates, Inc. 1988). During processing, these base data are used to correct for the effect of diurnal drift on the field data.

Magnetic anomalies take the form of an individual or group of monopole or dipole sources. Monopoles are formed where the lines of flux converge upon a single given point. As Breiner (1973) points out, many monopole sources are not truly monopolar, but rather are dipolar sources of sufficient size that only one end of the local field is detected. Dipoles, similar in configuration to the earth's field as a whole, are the more common archeological signatures. Typical dipole signatures consist of paired positive and negative anomalies that represent the warping of the field around the source. Unless the object is shallowly buried, the position of the anomaly is usually offset from the position of the source in a direction related to the orientation and inclination of the ambient field of the source.

Both monopolar and dipolar signatures vary considerably depending upon the size, magnetic intensity, depth, and orientation of the feature producing them and the latitude and orientation of transect lines. The strength of an anomaly as measured by a magnetometer varies as the inverse cube of its distance from the sensor. Thus, small features located near the ground surface typically produce a sharply defined peak with little areal extent, while large, deeply buried features result in a more extensive, gradual signature.

As a general rule, archeological anomalies are more intense than the surrounding matrix (Breiner 1973). With the exception of ferrous objects, burned and fired cultural materials with thermoremanent magnetic properties produce the strongest signatures. Other differences arise from strong variations in the magnetic susceptibility of site sediments. For example, humus-rich sediment is typically more magnetic than surrounding soil, permitting the identification of humus concentrations, filled pits, and other inconsistencies in the composition of the substrate. Walls and other structural elements may be constructed of highly magnetic materials, such as igneous rocks, and result in a positive anomaly, or they may displace a highly magnetic soil and result in a negative anomaly. Continued displacement of surface soil by the movement of inhabitants can result in lower magnetism than surrounding soil affected by incremental viscous magnetization. If the subsurface composition of a site is complex, then the results of magnetic survey can be a confusing juxtaposition of superimposed anomalies that is impossible to interpret. At the other extreme, the contrast in magnetic susceptibility may be insufficient to indicate any anomalies at all, even in the presence of burned features.

\section{SURVEY PROCEDURES}

Prior to the magnetic survey, the entire survey area was swept with a metal detector in order to remove any ferrous objects that might mask anomalies associated with prehistoric features. Measurement of the magnetic field over the site was accomplished using two Geometrics G856X portable proton precession magnetometers. These instruments have a theoretical sensitivity of $0.1 \gamma$ (although the practical sensitivity suggested by repeatability of readings is probably on the order of 0.5 to $1.0 \gamma$ ). One of the magnetometers (the base station) was situated in an untrafficked area on the northern side of the spoil mound and placed in automatic mode in order to record fluctuations in the earth's magnetic field (diurnal drift) during the survey at 10 -second intervals. The other magnetometer was operated by a two-person team; one person placed the sensor while the other operated the instrument pack. For this project, field readings were taken on a 1-m grid at a sensor height of $75 \mathrm{~cm}$.

The survey grids were established by means of a transit and two fiberglass measuring tapes with the corners marked by wooden stakes. Individual grid points were located by stretching two fiberglass measuring tapes along the long axis of the survey grid and then placing another tape between 
paired points every third survey line. At the end of each survey, the data collected were dumped onto a Macintosh personal computer and subsequently corrected for diurnal drift and any errors incurred in the field. A total of $3,111 \mathrm{~m}^{2}$ was surveyed during the feasibility study in April, 1989.

The results of the magnetic survey were plotted as gray-scale intensity maps in which the range of values is divided into ten different classes and each point is assigned to a class. Anomalies of interest were identified from these plots and redrawn as line contour maps for closer examination. In consideration of previous theoretical and empirical studies that have examined burned feature magnetic anomalies (Breiner 1973; Gibson 1986; Sternberg 1987), and a review of results obtained from previous investigations at Stacy Reservoir in Coleman, Concho, and Runnels counties, Texas (Abbott and Frederick 1989a) and Justiceburg Reservoir in Garza and Kent counties, Texas (Abbott and Frederick 1989b), only anomalies exhibiting apparent dipolar signatures were selected for detailed inspection. In all, 12 anomalies were selected from the magnetic maps for further examination and contouring. Of these, four appeared to be dipoles with the remaining eight apparently being complex anomalies. Depth estimations for dipolar anomalies were calculated using the slope technique outlined by Breiner (1973:31). These anomalies are discussed further in the site descriptions sections.

In order to better evaluate the potential signal strength expected at the two sites, two different tests of burned clay lumps were performed in the field. In the first of these, the magnetic susceptibility of one large (about $75 \mathrm{~g}$ ) clay lump was evaluated by holding the object away from the sensor and taking a reading and then immediately taking another reading with the object adjacent to the sensor. This procedure was repeated three times and each time no increase in the magnetic field was observed during the second reading. The other test of the magnetic signal produced by these objects involved gathering approximately 10 large clay lumps and placing them in a pile and then running a small $\mathrm{X}$-shaped survey over the group. As in the previous test, no change in the magnetic field was observed in the vicinity of the objects.

Although both of these tests should provide a crude indication of the magnetic susceptibility of the clay lumps, neither produced a measurable signal. Three possible explanations for this are presented here: the objects are unfired and are the products of diagenesis, the objects were fired at a temperature well below the Curie point of the material and therefore retain no thermoremanent magnetic signal, or insufficient amounts of magnetic mineral species are present to result in a measurable thermoremanent magnetic signal.

\section{SITE 41 WY112}

The portion of this site chosen for the magnetometer survey was located along a curve in the road situated on the northern side of the ditch. A transit and two fiberglass measuring tapes were used to establish a set of six $25 \times 8-m$ rectangular grids that shared comer points on the inside of the curve, and one $100 \times 8-\mathrm{m}$ grid on a straight portion of the road immediately west of the curve. For purposes of analysis, the $100-\mathrm{m}$ grid was subdivided into four segments. The grids were designated A-J (see Fig. 22 for location and orientation of prospection grids). Each of the small grids was rotated in such a manner as to maximize the portion of the grid that covered the flat section of the road, and effectively minimize the portion of the grid situated over the sloping margin of the ditch on or below the small berm. In most cases, the last two and occasionally three readings were made with the sensor placed on the sloping margin of the ditch below the berm.

Subsequent to the establishment of the survey grids, the entire set of prospection blocks was swept with a metal detector. All of the grid blocks yielded metallic debris, but the first two (A and B) contained the most metal. Items recovered consisted primarily of shotgun shell cartridges, pop/beer-can pull tabs, and other, usually unrecognizable, ferrous objects.

The magnetic survey of this site resulted in the collection of 2,304 data points recorded on two successive days. Although all of the grid blocks were surveyed as a group, each 25-m block was plotted separately in order to facilitate analysis of the resulting magnetic map.

Numerous magnetic anomalies were observed in the plots of the magnetic field strength of this site (Figs. 53 and 54). All of the resulting magnetic maps shared the distinct trend of exhibiting a magnetic gradient that was strongest immediately adjacent to the portion of the survey nearest to the 


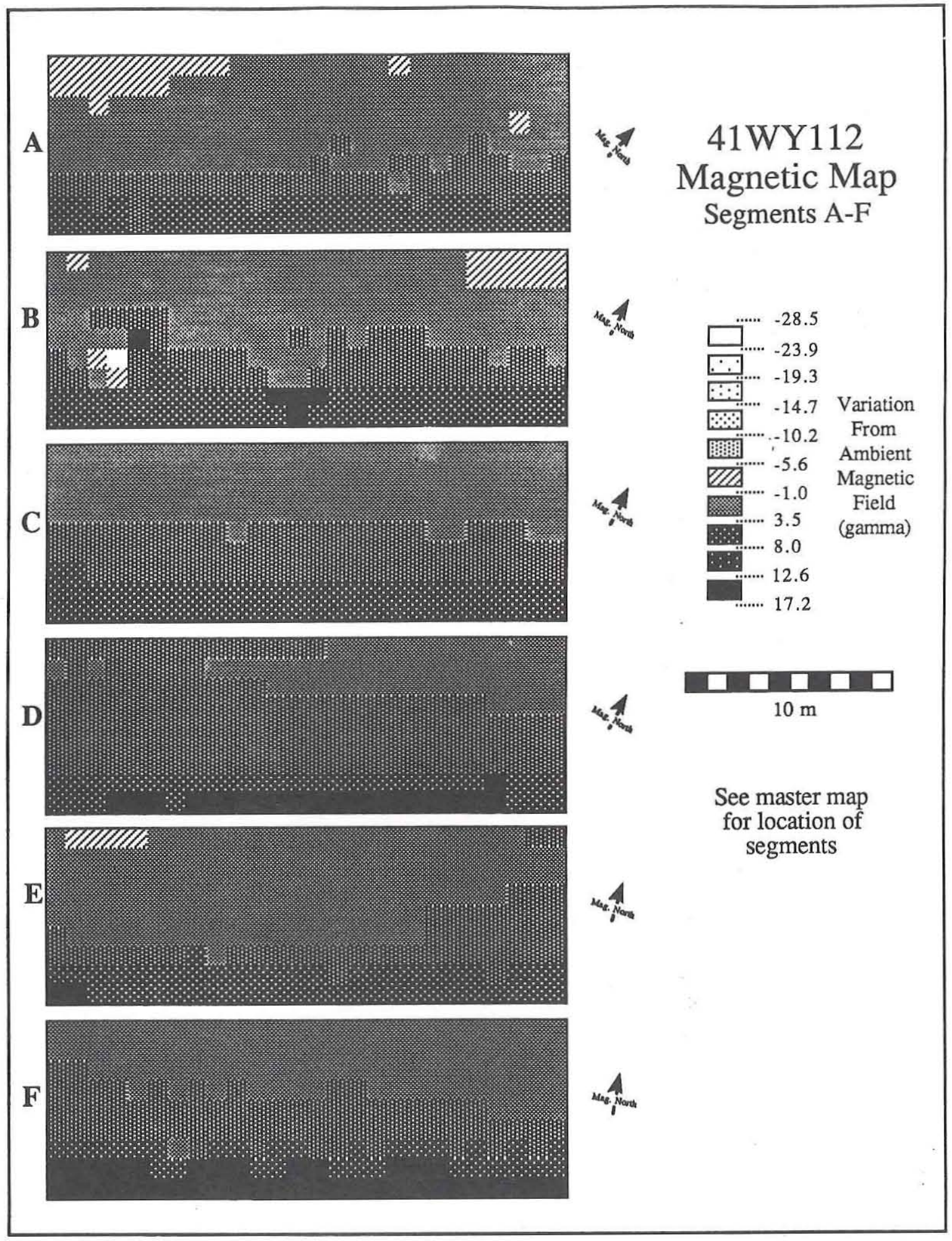

Figure 53. Magnetic map, Segments A-F, 41WY112. 


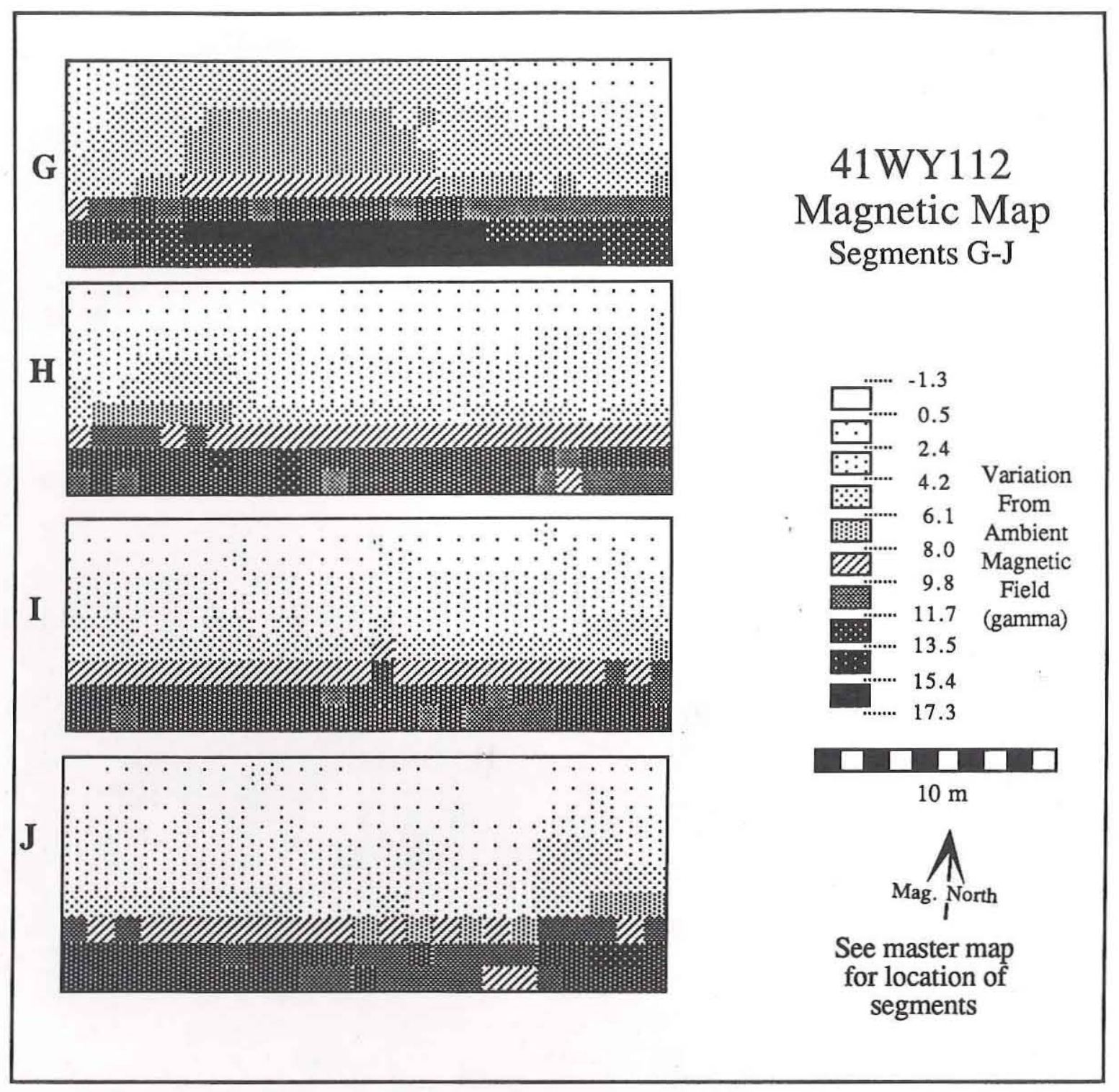

Figure 54. Magnetic map, Segments G-J, 41WY112.

sloping ditch margin. Evaluation of the site geology and the location of the sensor in this vicinity indicated that the gradient exhibited on the magnetic maps was probably a function of two factors: a thickening of the A horizon toward the ditch margin below the berm due to scraping and grading of the road surface, and the proximity of the sensor to the A horizon on the readings made along the sloping margin of the ditch. The magnetic intensity of the A horizon was apparently a function of the amount of organic matter present.
In addition to this gradient, seven discrete anomalies of variable size and magnitude were observed and considered worthy of field verification. These anomalies, numbered 1-7, exhibited a range of morphology, among which were four dipoles. Illustrations of these anomalies may be found in Figures 55 and 56. Anomaly 1 was situated along survey lines 2-6 at the northeastern end of grid block A (see Fig. 55a). It consisted of a complex anomaly which appeared to be a small, very weak rotated dipole with an amplitude of 


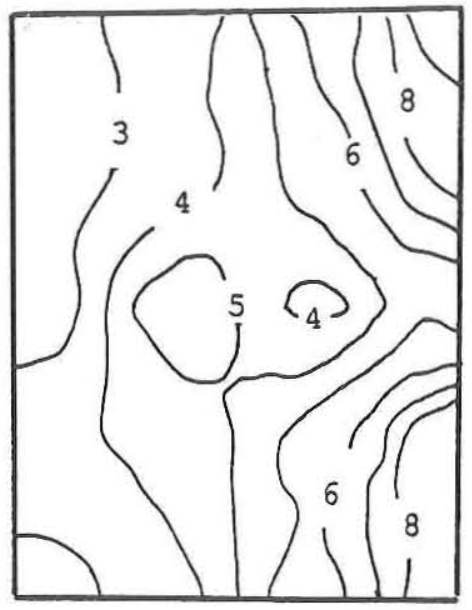

a) Anomaly $1,1-\gamma$ contour interval

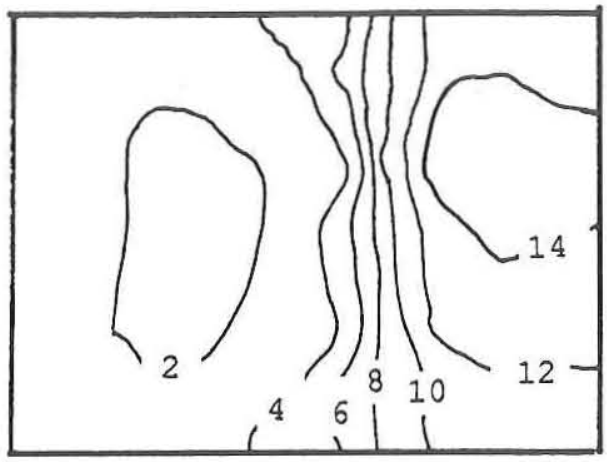

b) Anomaly 2, 2- $\gamma$ contour interval
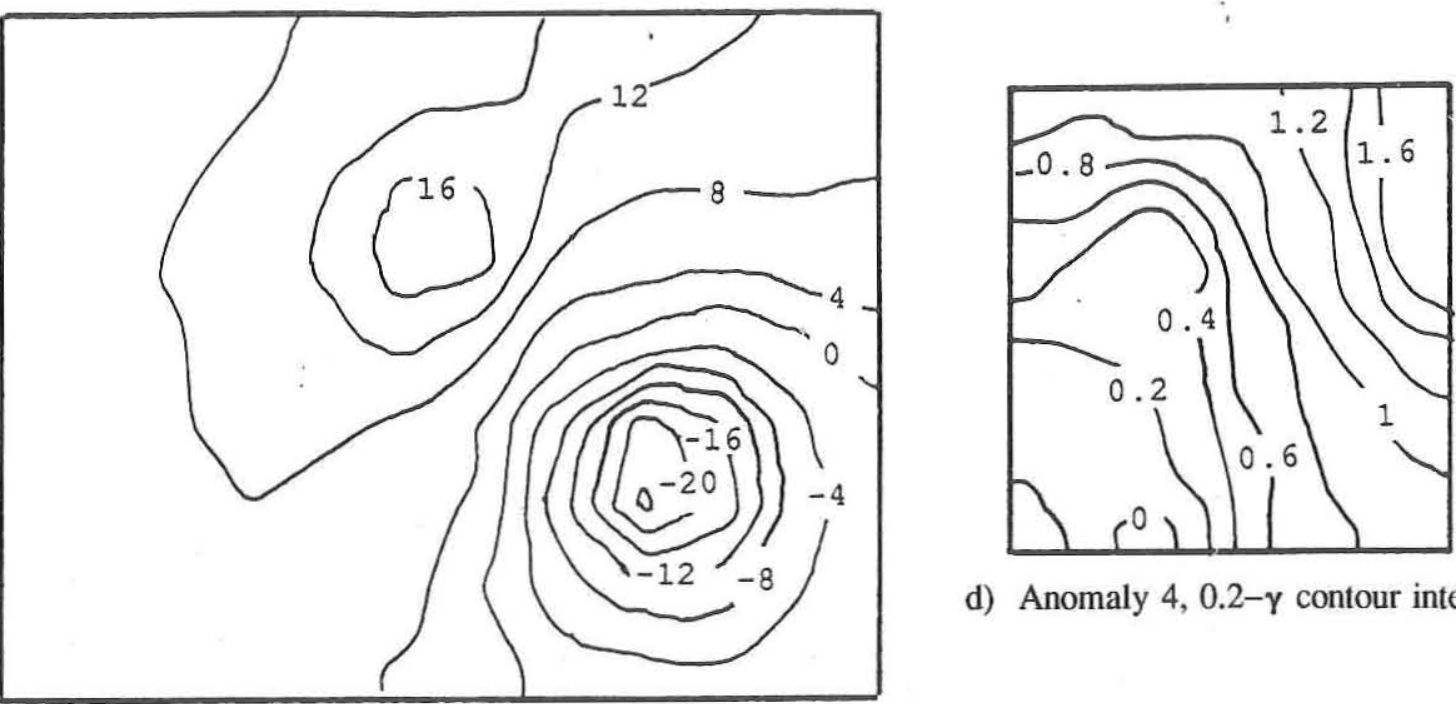

d) Anomaly 4, 0.2- $\gamma$ contour interval

c) Anomaly 3, 4- $\gamma$ contour interval

Figure 55. Contour plots of Anomalies 1-4, 41WY112.

$2.1 \gamma$. The orientation and amplitude of this anomaly are consistent with either a small piece of ceramic or very small piece of ferrous metal. Anomaly 2 was located near the center of the second grid along survey lines 13-16. This anomaly was a rotated dipole possessing an amplitude of $15.9 \gamma$ (see Fig. 55b). The orientation and intensity of this feature indicate that the source is most likely a metal object buried between 0.4 and $1.34 \mathrm{~m}$ below the surface. Anomaly 3 was a $45.7 \gamma$ rotated dipole situated on survey lines
20-24 near the southwestern end of grid block B (see Fig. 55c). As with Anomaly 2, the intensity and orientation of this feature suggest that it is a piece of metal that may be located at a depth between 0.6 and $1.85 \mathrm{~m}$. Anomaly 4 was situated along survey lines $10-12$ in the northeastern half of grid block E. This magnetic feature appeared to be a complex anomaly characterized by a $1.8 \gamma$ gradient present in one 2-m interval in an otherwise magnetically quiet portion of the map (see Fig. 55d). The source of this feature is unknown. A 


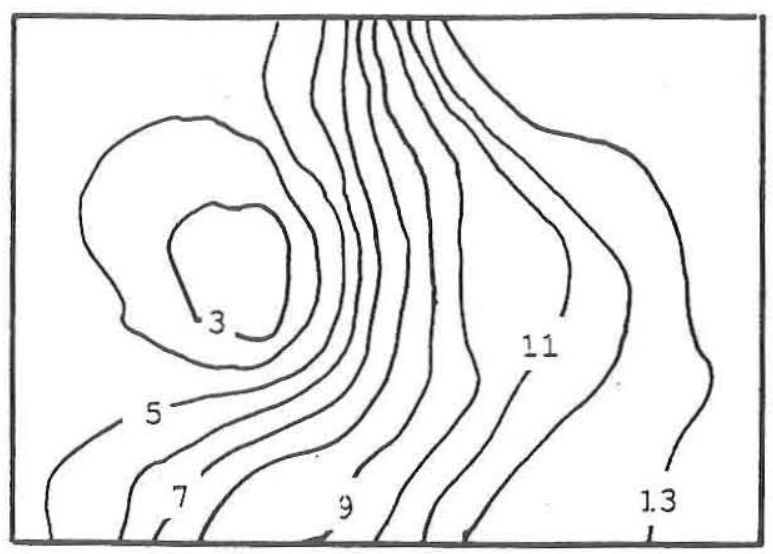

a) Anomaly 5, 1- $\gamma$ contour interval

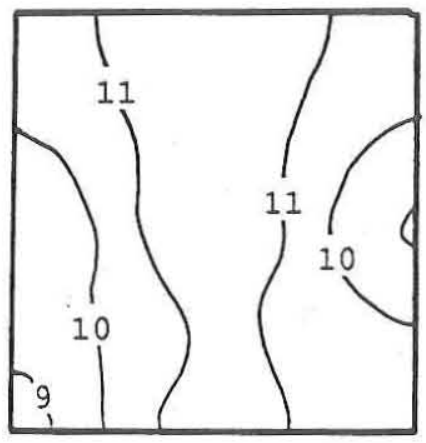

b) Anomaly 6, 1- $\gamma$ contour interval

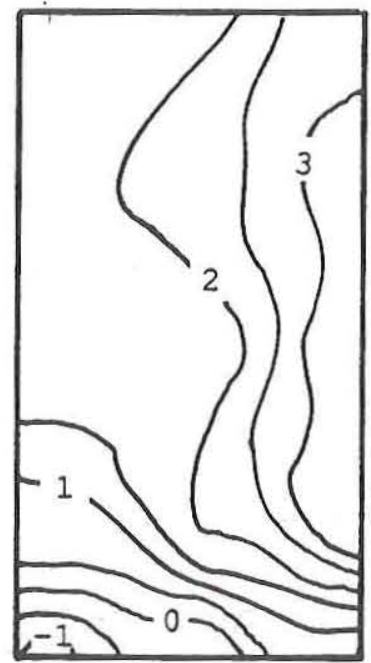

c) Anomaly $7,0.5-\gamma$ contour interval

Figure 56. Contour plots of Anomalies 5-7, 41WY112.

fifth anomaly was a magnetic low spot situated adjacent to the magnetic high present along the southern margin of grid block $\mathrm{G}$ along survey lines 19-21 (see Fig. 56a). It is possible that this anomaly is a dipole but that the positive portion of the anomaly is obscured by the high intensity zone caused by the organic soil horizon present in this area. If this is the case, the intensity of the feature is roughly $14.4 \gamma$. If, however, this is simply a monopolar low, the intensity of the anomaly is about $2.7 \gamma$ below the surrounding field. The origin of this anomaly is unknown. Anomaly 6 was located at the southeastern edge of grid block $\mathrm{G}$ (see Fig. 56b). It was present on survey lines 2426 and was of interest because it appeared to be a magnetic low spot within the uniformly high region adjacent to the ditch margin. As such, it could represent a rotated dipole with an intensity of about $2.7 \gamma$ which would be consistent with a very small piece of metal or ceramic. The contour plot of this anomaly failed to provide better resolution, in part due to the location of the anomaly along the edge of the survey block. The last anomaly examined at this site (Anomaly 7) 
was located on survey lines 5-9 of grid block J. Also a complex feature, this anomaly appeared to be a small gradient present in a magnetically quiet portion of the grid (see Fig. 56c). Table 1 provides a summary of the type, intensity, probable source, and known source when identified of each magnetic anomaly at $41 \mathrm{WY} 112$. horizon of the modern soil. By evaluating the plots of magnetic intensity produced from this survey, five anomalies were selected for closer examination. Anomaly 1 was an elongate $32.8 \gamma$ dipole oriented roughly east-west (Fig. 58a). This anomaly was situated along the northern margin of grid blocks A (survey lines 19-26) and B (survey

TABLE 25

TARGET ANOMALIES AT 41WY112

\begin{tabular}{|c|l|c|l|l|}
\hline Anomaly Number & Type & Intensity in $\gamma$ & Probable Source & Known Source \\
\hline 1 & Dipole & 2.1 & Metal or ceramic & Metal \\
2 & Dipole & 15.9 & Metal & Unknown \\
3 & Dipole & 45.7 & Metal & Metal \\
4 & Complex & 1.8 & Unknown & Unknown \\
5 & Monopole & 2.7 or 14.4 & Metal & Unknown \\
6 & Complex & 2.7 & Unknown & Unknown \\
7 & Complex & 5.1 & Unknown & Unknown \\
\hline
\end{tabular}

\section{SITE 41 WY113}

The survey grid established at this site measured $100 \times 7 \mathrm{~m}$ and was situated along a straight portion of the road on the north side of the ditch (see Fig. 27 for location and orientation of prospection grids). A total of 807 data points was collected on the afternoon of April 26, 1989. As with the survey at $41 \mathrm{WY} 112$, the last two and occasionally three readings of each survey line were made with the sensor placed on the sloping margin of the ditch at or below the berm. Likewise, the entire grid was surveyed with a metal detector prior to the magnetometer survey in order to remove any ferrous objects that could obscure more subtle magnetic features. Numerous metal objects were obtained during this process, but not as many items were present on this site as at 41WY112. Prior to processing the magnetic survey data, the file was split into four $25-\mathrm{m}$ segments (A-D) in order to facilitate examination of the magnetic map.

As at site $41 \mathrm{WY} 112$, the magnetic plots of this site displayed a magnetic gradient from north to south, with the most intense portion of the field present along the sloping margin of the ditch (Fig. 57). This feature was also interpreted as a function of road construction and sensor proximity to the $\mathrm{A}$ lines 1-3). The intensity and orientation of this feature are consistent with a piece of metal but the shape of the contoured anomaly indicates that not all of the feature was within the survey grid making a depth estimate impractical. The other features identified at this site were all present in grid block $\mathrm{D}$, and were all complex anomalies (see Fig. 58b and 58c). No discrete dipolar features were observed among any of these anomalies, although the complex field variations present in both of these regions initially give such an impression. The source of these anomalies is unknown. Table 26 provides a summary of the anomalies examined at this site.

\section{CONCLUSIONS}

Although both of the survey grids discussed here were cleared of metallic debris with a metal detector prior to the magnetic survey, some ferrous objects appear to have eluded detection. All of the dipolar anomalies observed on the magnetic maps appear to be consistent with signals generated by metallic objects with the exception of Anomaly 1 at site $41 W Y 112$ which may be produced by either a ceramic or metal object. Of the other anomalies examined at these sites, all appeared to be complex anomalies characterized by a magnetic gradient in 


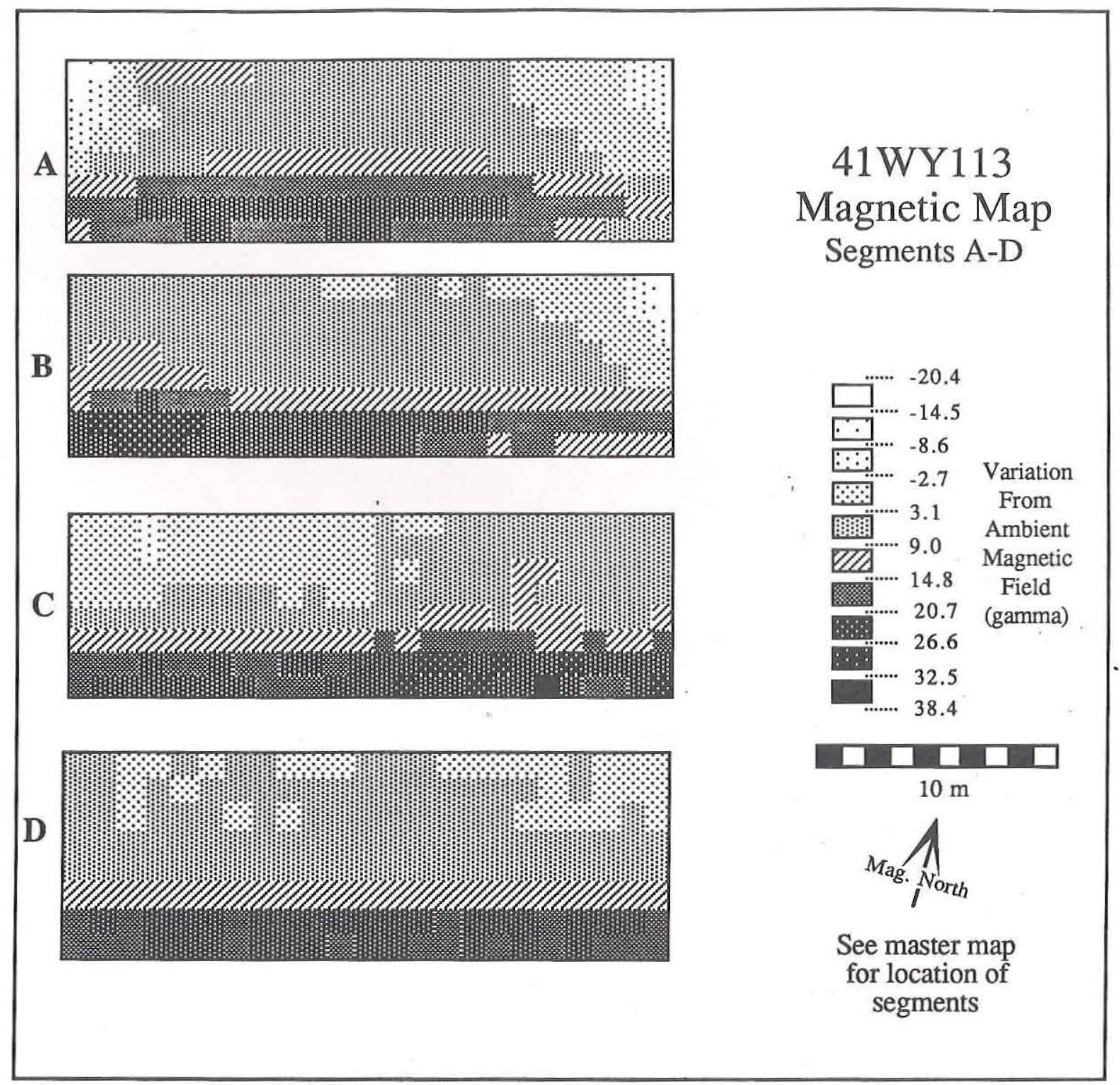

Figure 57. Magnetic map, Segments A-D, 41WY113.

an otherwise quiet area. No source for these anomalies is known. A cursory examination of the magnetic susceptibility of the only known thermally modified objects present at both sites, the burned clay lumps, indicated that these objects possess little or no thermoremanent magnetic signal, suggesting that if they have been fired, the temperature of the fire was less than roughly $600^{\circ} \mathrm{C}$, they possess little in the way of magnetic mineral species such as magnetite or maghemite, or that they are products of diagenesis. 

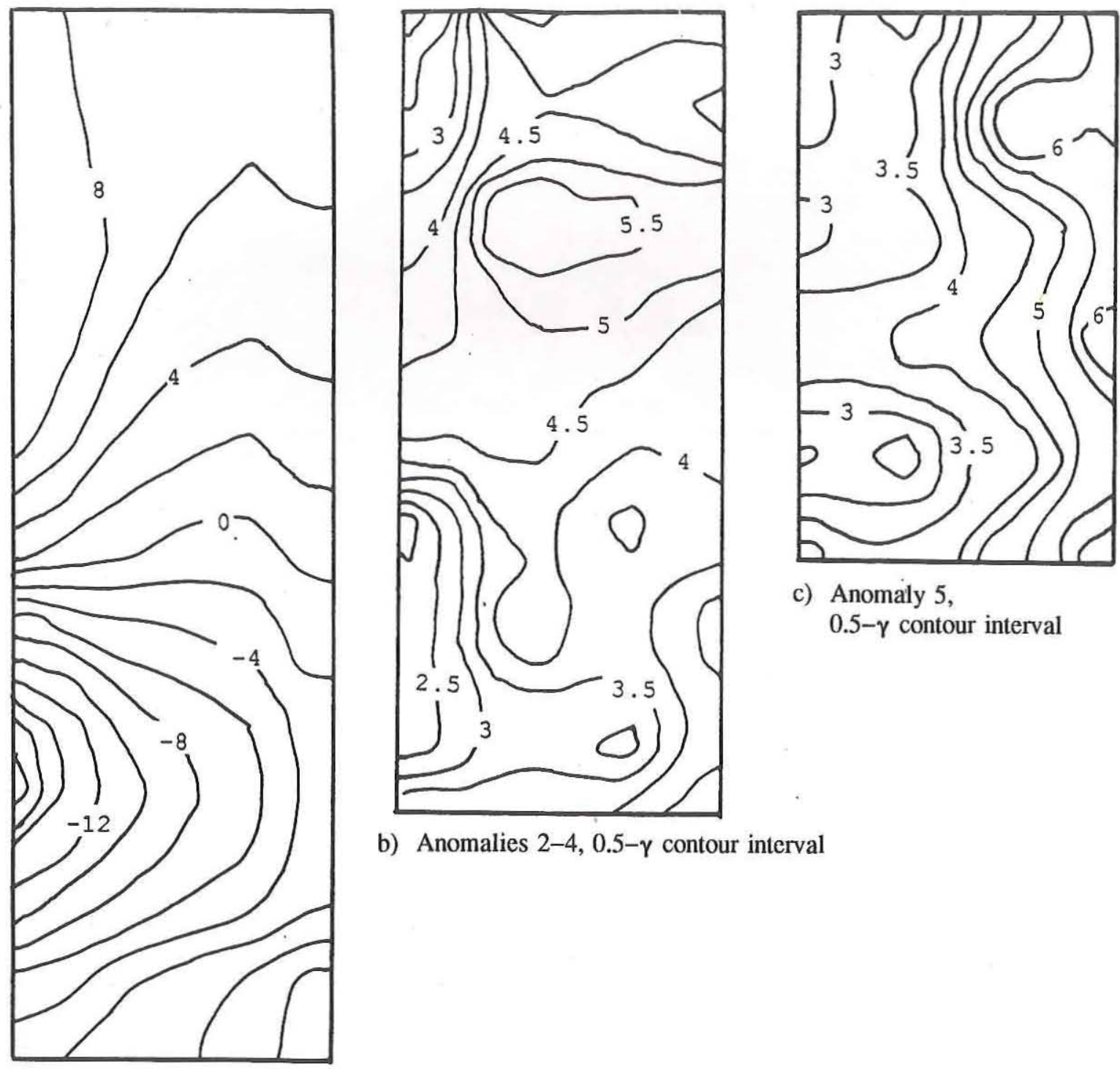

c) Anomaly 5 ,

$0.5-\gamma$ contour interval

b) Anomalies $2-4,0.5-\gamma$ contour interval

a) Anomaly $1,2-\gamma$ contour interval

Figure 58. Contour plots of Anomalies 1-5, 41WY113.

\begin{tabular}{|c|l|c|l|l|}
\hline \multicolumn{5}{|c|}{ TABLE 26 } \\
\hline TARGET ANOMALIES AT 41WY113 \\
\hline Anomaly Number & Type & Intensity in $\gamma$ & Probable Source & Known Source \\
\hline 1 & Dipole & 32.8 & Metal & Unknown \\
$2,3,4$ & Complex & 4.9 & Unknown & Unknown \\
5 & Complex & 3.9 & Unknown & Tire tool \\
\hline
\end{tabular}




\section{REFERENCES CITED}

Abbott, James T., and Charles D. Frederick

1989a Prospection and Burned Feature Investigation with Portable Proton Magnetometers at Stacy Reservoir: Final Report. Draft submitted to Mariah Associates, Inc., Albuquerque.

1989b Magnetometer Surveys at 41GR323 and 41KT53. Appendix B in Phase II Investigations at Prehistoric and Rock Art Sites, Justiceburg Reservoir, Garza and Kent Counties, Texas, by Douglas K. Boyd, James T. Abbott, William A. Bryan, Colin M. Garvey, J. Michael Quigg, and Ross C. Fields, pp. 345-362. Reports of Investigations No. 71. Prewitt and Associates, Inc., Austin.

Aitken, M. J.

1974 Physics and Archaeology. Clarendon Press, Oxford.

Bradley, R. S.

1985 Quaternary Paleoclimatology: Methods of Paleoclimatic Reconstruction. Allen and Unwin, Boston.

Breiner, S.

1973 Applications Manual for Portable Magnetometers. E.G. \& G. Geometrics, Sunnyvale, California.

Breiner, S., and M. D. Coe

1972 Magnetic Exploration of the Olmec Civilization. American Scientist 60:566-575.

Eighmy, J. L.

1980 Archeomagnetism: A Handbook for the Archaeologist. U.S. Department of the Interior, Washington, D.C.

Espey, Huston and Associates, Inc.

1988 Cultural Resources Magnetometer Survey and Testing: Great Highway/Ocean Beach Seawall Project, San Francisco, California. Report Prepared for San Francisco Clean Water Program. Austin.

Gibson, T. H.

1986 Magnetic Prospection on Prehistoric Sites in Western Canada. Geophysics 51:553-560.

Hamilton, S.

1986 Magnetic Testing at Hb Rf-31. In The End of Season Report of the 1986 Excavations at Rocky Mountain F4 (HbRf-31). Ms. on file, Department of Archaeology, Simon Fraser University, Burnaby, British Columbia.

Steponaitis, V. P., and J. P. Brain

1976 A Portable Differential Proton Magnetometer. Journal of Field Archaeology 3:455-463.

Sternberg, R. S.

1987 Archaeomagnetism and Magnetic Anomalies in the American Southwest. Geophysics 52:368-371.

Weymouth, J. W.

1979 A Magnetic Survey of Tumacacori National Monument. Report PX-6115-8-0096 submitted to the Midwest Archaeological Center, National Park Service. 
Prehistoric Archeology and Paleoenvironments in Hidalgo and Willacy Counties

1987 Magnetic Surveys in Fort Davidson State Park, Pilot Knob, Missouri: Final Report. Report submitted to Ittner and Bowersox, Inc., St. Louis, Mo.

Weymouth, J. W., and R. Huggins

1985 Geophysical Surveying of Archaeological Sites. In Archaeological Geology, edited by G. Rapp, Jr., and J. A. Gifford. Yale University Press, New Haven. 


\title{
APPENDIX C: Geological Profile Descriptions
}

\author{
C. Britt Bousman
}

and

Gail L. Bailey 
$\underline{\text { Zone }} \quad \underline{\text { Surface }(\mathrm{cm})} \quad \underline{\text { Description of Zone }}$

\section{BACKHOE TRENCH 1}

1

2

40-65

3

$65-87$

4

87-91

5

6

$140-170$

7

170-250+

BACKHOE TRENCH 2

1

0-15

2

$15-50$

3

50-106

4

$106-122$
Very dark grayish brown and reddish yellow (10YR 3/2 and 7.5YR 6/6) silt loam, construction fill, abrupt irregular lower boundary.

Dark gray (10YR 4/1) friable loam with very weak coarse blocky structure, few insect burrows and charcoal flecks, clear smooth lower boundary.

Dark gray (10YR 4/1) firm loam with weak medium platy structure (probably compacted), common charcoal fragments, few subrounded clay clasts, abrupt wavy lower boundary.

Dark gray (10YR 4/1) firm loam with moderate fine platy structure, thin (1-10 mm) discontinuous irregular freshwater marl lenses that grade laterally into thin sand lenses, few small $\mathrm{CaCO}_{3}$ nodules, thin single lens marks very abrupt wavy lower boundary.

Dark gray (10YR 4/1) firm to friable loam to sandy loam, few roots and rootlets, few charcoal flecks and small lenses of organic partings, gradual smooth lower boundary.

Grayish brown (10YR 5/2) very friable loam to silt loam with pale brown (10YR 6/3) mottles that increase down profile, dark grayish brown (10YR 4/3) sandy loam filled rodent burrows, few $\mathrm{CaCO}_{3}$ nodules, few manganese flecks and small concretions, very few snail shell fragments, gradual smooth lower boundary.

Pale brown (10YR 6/3) friable silt loam with few distinct fine reddish brown mottles, many soft $\mathrm{CaCO}_{3}$ nodules some with hard kernels, common manganese concretions, lower boundary not visible.

Very dark gray (10YR 3/1) loose loam, common roots and rootlets, few soft small $\mathrm{CaCO}_{3}$ nodules, clear wavy lower boundary.

Dark gray (10YR 4/1) friable sandy loam with weak coarse blocky structure, gradual smooth lower boundary.

Very dark grayish brown, reddish yellow, and very pale brown (10YR $3 / 2,7.5 \mathrm{YR} 6 / 6$, and 10YR 8/3) sand to silt loam with coarse horizontal bedding, subrounded sediment clasts common throughout, lower $6 \mathrm{~cm}$ is sandy, very abrupt wavy lower boundary is obvious unconformity.

Very dark gray (10YR 3/1) firm loam, probably compacted by construction, few rootlets, gradual smooth lower boundary. 
Depth Below

Zone $\quad$ Surface $(\mathrm{cm})$

5

$122-147$

6

$147-149$

7

$149-180$

8

$180-230$

9

230-270+

\section{Description of Zone}

Dark gray (10YR 4/1) sandy loam with common scattered very dark gray to black (10YR 3/1 to N2) clay lumps, rare charcoal flecks, one single whole snail shell, abrupt irregular lower boundary.

Grayish brown to dark grayish brown (10YR $5 / 2$ to $4 / 2$ ) sand lens that is continuous across entire profile, very dark grayish brown (10YR 3/1) silt loam clasts, in eastern profile wall a small depression is filled by Zone 6 sands with multiple well-bedded very thin alternating sand and clay lenses, very abrupt smooth to wavy to irregular lower boundary.

Very dark grayish brown (10YR 3/1) friable to firm loam with weak medium blocky structure, rare rootlets, few charcoal flecks and chunks, gradual smooth lower boundary.

Dark gray (N4) friable silt loam with moderate medium blocky structure and well-developed ped faces, rare manganese flecks, gradual smooth lower boundary.

Gray (10YR 5/1) silt loam with common strong brown (7.5YR $5 / 8$ ) very fine distinct mottles, common manganese concretions and many $\mathrm{CaCO}_{3}$ nodules that decrease down profile, lower boundary not visible.

\section{BACKHOE TRENCH 3}

1

$0-62$

2

$62-140$

3

4

$159-200$

5

$200-310+$
Very dark gray to dark grayish brown (10YR $3 / 1$ to $4 / 2$ ) firm to very firm sandy loam to loam, compacted by construction, very abrupt smooth lower boundary.

Speckled pale brown to dark grayish brown (10YR 6/2 to $4 / 2$ ) sandy loam with subhorizontal dark grayish brown (10YR 4/2) layers, gradual smooth lower boundary.

Charcoal, white ash, and burnt clay lumps, very abrupt wavy to irregular lower boundary.

Very dark gray (10YR 3/1) friable loam with weak coarse blocky structure, few rootlets, rare snail shells, thin sand lens in upper $10 \mathrm{~cm}$ of zone, gradual smooth lower boundary.

Gray to very pale brown (10YR $5 / 1$ to $7 / 3$ ) friable sandy loam with moderate medium blocky structure, common manganese concretions, lower boundary not visible.

\section{BACKHOE TRENCH 4}


Depth Below

Zone $\quad$ Surface $(\mathrm{cm})$

2

20-79

$79-126$

3

$79-126$

4

$126-150$

5

$150-200$

6

200-235

7

235-300+

\section{BACKHOE TRENCH 5}

1

0-40

2

40-75

3

$75-120$

4

\section{Description of Zone}

Very dark gray to dark grayish brown (10YR 3/1 to 4/2) firm to very firm sandy loam to loam, compacted by construction, very abrupt smooth lower boundary.

Speckled pale brown to dark grayish brown (10YR $6 / 2$ to $4 / 2$ ) loam with subhorizontal dark grayish brown (10YR 4/2) layers, very abrupt wavy lower boundary.

Dark gray (10YR 4/1) very firm to firm loam with coarse medium blocky structure, rare small burned clay lumps and $\mathrm{CaCO}_{3}$ nodules, few charcoal lumps and snail shells, few light brownish gray (10YR 6/2) sand filled insect burrows, very dark gray (10YR 3/1) loam filled rodent burrows, few rootlets on ped faces, very abrupt wavy lower boundary.

Very dark gray (10YR 3/1) silt loam with weak medium blocky structure, pale brown (10YR 6/4) sand-filled cracks and insect burrows, many burned clay lumps between $190-195 \mathrm{~cm}$, gradual smooth lower boundary.

Dark gray to light gray to light brownish gray (10YR 4/1 to $6 / 1$ to $6 / 2$ ) silt loam with weak medium blocky structure, few $\mathrm{CaCO}_{3}$ nodules and filaments, few hollow insect burrows, rare roots and rootlets, gradual smooth lower boundary.

Dark gray to light gray to light brownish gray (10YR $4 / 1$ to $6 / 1$ to $6 / 2$ ) silt loam with weak medium blocky structure, many $\mathrm{CaCO}_{3}$ nodules and manganese concretions, lower boundary not visible.

Very dark grayish brown, reddish yellow, and very pale brown (10YR 3/2, 7.5YR 6/6, and 10YR 8/3) sand to silt loam with coarse horizontal bedding, subrounded sediment clasts common throughout, very abrupt wavy lower boundary.

Dark gray (10YR 4/1) sandy loam with common scattered very dark gray to black (10YR 3/1 to N2) clay lumps, rare charcoal flecks, abrupt irregular lower boundary.

Yellowish brown (10YR 5/4) firm to extremely firm sand loam to loam with strong medium blocky structure, few roots, few small $\mathrm{CaCO}_{3}$ nodules and filaments, light manganese coatings on some ped faces, clear smooth lower boundary.

Light yellowish brown (10YR 6/4) firm to extremely firm loam with strong medium to fine blocky structure, few $\mathrm{CaCO}_{3}$ nodules but very many $\mathrm{CaCO}_{3}$ filaments, gradual smooth lower boundary. 


\section{Zone}

5

Depth Below

Surface $(\mathrm{cm})$

140-230

6

230-270+

\section{TEST UNIT 1}

1

0-50

2

50-114

3

114-134

4

134-154

1

$98-133$

2

133-182

3

182-213+

\section{Description of Zone}

Light gray (2.5Y 7/2) friable silt loam with weak medium blocky structure, many large $(2-3 \mathrm{~cm}) \mathrm{CaCO}_{3}$ nodules, many manganese concretions, well-laminated 30-cm-thick sand filled paleochannel in sidewall at bottom of zone, gradual smooth lower boundary.

Light gray (2.5Y 7/2) friable silt loam with weak medium blocky structure, few large $(2-3 \mathrm{~cm}) \mathrm{CaCO}_{3}$ nodules, many manganese concretions, well laminated $30-\mathrm{cm}$-thick sand filled paleochannel in sidewall at top of zone, lower boundary not visible.

Loose dark gray loam, berm construction fill, clear irregular lower boundary.

Very dark gray (10YR 3/1) very firm loam with coarse moderate blocky structure, few light brown sand-filled insect burrows, few rootlets and small clay lumps, rare $\mathrm{CaCO}_{3}$ filaments, very abrupt smooth lower boundary.

Very dark gray (10YR 3/1) silt loam, weak moderate blocky structure, few rootlets, large pebble-sized burned clay lumps and charcoal fragments occur horizontally in the lower portion of zone, gradual smooth lower boundary.

Dark gray to grayish brown (10YR 4/1 to 5/2) silt loam, weak medium blocky structure, few $\mathrm{CaCO}_{3}$ nodules, rare snail shells in the upper portion of zone.

\section{Removed mechanically.}

Very dark grayish brown (10YR 3/2) extremely firm sandy loam with medium moderate to coarse blocky structure, few rootlets and small burned clay lumps, abrupt to clear irregular lower boundary.

Very dark gray firm sandy loam with moderate medium to coarse blocky structure, few charcoal fragments, one small burned clay lump, clear to abrupt very irregular lower boundary.

Gray to grayish brown grading down profile to a light yellowish brown (10YR $5 / 1$ to $5 / 2$ and 6/4) silt loam, weak coarse blocky structure, consistency grades from a friable to firm, rare $\mathrm{CaCO}_{3}$ nodules.

TEST UNIT 6

Removed mechanically. 
Depth Below

Zone

Surface (cm)

1

$121-142$

2

$142-187$

3

$187-228$

4

$228-245+$

\section{BACKHOE TRENCH 1}

1

$0-50$

2

$50-55$

3

$55-65$

4

$65-83$

5

83-106

6

$106-110$

7

$110-120$

\section{Description of Zone}

Very dark grayish brown (10YR 3/2) sandy loam with weak medium blocky structure, few rootlets, very abrupt to abrupt slightly wavy lower boundary.

Very dark gray (10YR 3/1) firm sandy loam with moderate medium blocky structure, common large and small charcoal fragments, few burned clay lumps, clear to gradual wavy lower boundary.

Gray to grayish brown and light yellowish brown (10YR 5/1 to 5/2 and 6/4) firm to friable silt loam, few $\mathrm{CaCO}_{3}$ filaments, rare $\mathrm{CaCO}_{3}$ nodules, clear to gradual wavy lower boundary.

Gray to grayish brown and light yellowish brown (10YR 5/1 to 5/2 and 6/4) firm to friable silt loam, many $\mathrm{CaCO}_{3}$ nodules, lower boundary not visible.

\section{WY112}

Gray to pale brown (10YR 5/1 to 6/3) silt loam to clay loam, canal berm fill, abrupt wavy lower boundary.

Dark gray to very dark gray (N4 to N3) clay loam with fine moderate platy structure, compacted by construction, common snail shells, few roots and rootlets, few charcoal flecks, clear irregular lower boundary.

Dark gray (10YR 4/1) silt loam with medium to coarse moderate blocky structure, many snail shells (some whole), few charcoal flecks and $\mathrm{CaCO}_{3}$ filaments, few rootlets, abrupt wavy lower boundary.

Very dark gray (10YR 3/1) silt loam with coarse weak blocky structure, few snail shells (most fragments), metal fragment at $82 \mathrm{~cm}$, few roots and charcoal flecks, abrupt wavy lower boundary.

Dark gray (10YR 4/1) firm silt loam, with blocks of Zone 6 clasts and freshwater marls (light brownish gray 10YR 6/2 clayey sand cemented by $\mathrm{CaCO}_{3}$ and few snail shell fragments) at bottom of zone, common snail shells, abrupt wavy lower boundary.

Very dark gray (10YR 3/4) extremely firm silt loam with coarse moderate blocky structure, many snail shell fragments, few charcoal flecks, few rootlets, few strong brown clayey sand clasts, upper portion interfingers with Zone 5, clear to abrupt smooth lower boundary.

Dark gray to very dark gray (10YR 4/1 to $3 / 1$ ) friable loam with weak medium blocky structure, common very fine $\mathrm{CaCO}_{3}$ filaments, few snail shell fragments, abrupt wavy lower boundary. 
Depth Below

Zone $\quad$ Surface $(\mathrm{cm})$

$8 \quad 120-148$

$9 \quad 148-149$

10

149-151

11

$151-210$

12

$210-250$

13

$250+$

BACKHOE TRENCH 2

1

0-50

2

50-77

3

77-98

4

\section{Description of Zone}

Very dark gray to black (10YR $3 / 1$ to $2 / 1$ ) extremely firm clayey sand with medium moderate blocky structure, few rootlets, very few snail shell fragments, small $\mathrm{CaCO}_{3}$ nodules, between 131-148 cm are brown to pink (7.5YR 5/4 to $7 / 4$ ) lenticular $\mathrm{CaCO}_{3}$ sandy clay bodies that are freshwater marls, abrupt irregular lower boundary.

Black (N2) extremely firm clay with fine moderate granular structure, few rootlets, few fine $\mathrm{CaCO}_{3}$ nodules, abrupt wavy lower boundary.

Gray (10YR 5/1) fine laminated sand, discontinuous thin lenses some disturbed by small burrows, others have very fine bedding, very abrupt smooth to wavy lower boundary.

Very dark gray (10YR 3/1) friable loam with medium to coarse blocky structure, few rootlets and charcoal flecks, very few snail shell fragments, 'few sand filled burrows that are possibly crayfish produced, few sand filled root molds and/or insect burrows, gradual smooth lower boundary.

Gray (10YR 5/1) extremely firm sandy clay, no structure, very few roots, few $\mathrm{CaCO}_{3}$ nodules and flecks, few manganese flecks, gradual smooth lower boundary.

Pale brown (10YR 6/3) silt loam, few manganese concretions that increase down profile, strong brown (7.5YR 5/6) faint to distinct mottles surrounding some manganese concretions, gray (10YR 5/1) discontinuous silt lenses, lower boundary not observed.

Grayish brown (10YR 5/2) loam, berm construction fill, abrupt smooth lower boundary.

Dark gray (10YR 4/1) friable silt loam with fine medium blocky structure, common roots, few snail shells, small marl inclusions, clear wavy lower boundary.

Very dark gray (10YR 3/1) silt loam but more clayey than Zone 2, coarse moderate to strong blocky structure, few marl clasts in top of zone with with thin sand layers draped over clast, few thin $\mathrm{CaCO}_{3}$ filaments, common roots and rootlets, discontinuous zone of marl blocks at bottom of zone, blocks tilted up toward profile wall, very abrupt irregular lower boundary.

Dark gray (10YR 4/1) discontinuous very thin (ca. 1.0-0.5 mm) well bedded planar alternating fine sand and silt layers, very abrupt wavy lower boundary. 
Depth Below

Zone $\quad \underline{\text { Surface }(\mathrm{cm})}$

5

99-135

6

135-195

7

$195+$

\section{BACKHOE TRENCH 3}

1

0-35

2

$35-85$

3

$85-145$

4

145-240+

\section{TEST UNIT 1}

1

0-26

2

$26-54$

3

\section{Description of Zone}

Very dark gray (10YR 3/1) firm to friable silt loam with coarse moderate blocky structure, common $\mathrm{CaCO}_{3}$ filaments that increase down profile, few rootlets and snail shells, snail shells increase down profile, gradual smooth lower boundary.

Gray to dark gray (10YR 5/1 to 4/1) clay loam with medium moderate blocky structure, many snail shells, common $\mathrm{CaCO}_{3}$ filaments, few manganese flecks, diffuse smooth lower boundary.

Light brownish gray (10YR 6/2) silt loam with thin clay films on ped faces, common $\mathrm{CaCO}_{3}$ nodules increasing down profile, sand filled insect burrows, few manganese concretions.

Grayish brown (10YR 5/2) silt loam, berm construction fill, abrupt irregular lower boundary.

Dark gray (10YR 4/1) silt loam with coarse moderate blocky structure, few snail shells and insect burrows, common roots and rootlets, gradual smooth lower boundary.

Grayish brown (10YR 5/2) grading down to light brownish gray (10YR $6 / 2$ ) clay loam with medium moderate blocky structure, ped faces better developed down profile, common snail shells, few rootlets and $\mathrm{CaCO}_{3}$ nodules, diffuse smooth lower boundary.

Pale brown (10YR 6/3) firm to friable clay loam with moderate blocky structure, well developed ped faces with clay films, common $\mathrm{CaCO}_{3}$ nodules, few manganese concretions that increase down profile, lower boundary not observable.

Loose grayish brown (10YR 5/2) silt loam, berm construction fill, abrupt smooth lower boundary.

Comments: This material has been transported by slopewash and forms a lens of material capping Zone 2 sediments, the slopewash is designated as Zone $1 \mathrm{~b}$.

Very dark gray (10YR 3/1) firm loam, fine to medium weak blocky structure, small light brownish gray (10YR 6/2) mottles, small cracks extend down from upper boundary, common rootlets, common snail shells and insect burrows, very abrupt wavy lower boundary.

Light gray (10YR 7/2) finely laminated sand and silt layers, up to eight layers, very friable, rootlets occur along layer surfaces and penetrate cracks, very abrupt wavy lower boundary. 


\begin{abstract}
Depth Below
Zone $\quad$ Surface $(\mathrm{cm})$

$4 \quad 54.2-89$

$5 \quad 89-124$

$6 \quad 124-145+$

Description of Zone

Very dark gray (10YR 3/1) firm to extremely firm loam, medium to fine moderate blocky structure, wide cracks emanate from the surface of Zone 4 and extend down into Zone 5, common snail shells, gradual smooth lower boundary.

Dark grayish brown (10YR 4/2) firm loam, fine to medium moderate blocky structure, few snail shells, common $\mathrm{CaCO}_{3}$ filaments, gradual smooth lower boundary.

Grayish brown (10YR 5/2) firm clay loam, fine to medium moderate blocky structure, few $\mathrm{CaCO}_{3}$ nodules and filaments.
\end{abstract}

TEST UNIT 7

1

0-37

2

$37-40$

3

40-70

4

70-76

5

76-81

6

81-89

7

89-100

8

$100-120$

9

Loose grayish brown (10YR 5/2) silt loam, recent trash, berm con struction fill, mottles due to construction activities, road surfaces visible, abrupt smooth lower boundary.

Grayish brown (10YR 5/2) firm sandy loam with platy structure, structure result of compaction caused by ditch construction, zone represents a modern road surface, abrupt smooth lower boundary.

Dark grayish brown (10YR 4/2) extremely firm loam, coarse strong blocky structure, firmness result of compaction caused by ditch construction, very dark grayish brown (10YR 3/2) mottles, common $\mathrm{CaCO}_{3}$ nodules, few snail shells, road surface visible in zone, very abrupt very irregular lower boundary probably represents bottom of plow zone.

Very dark grayish brown (10YR 3/2) loam, weak medium blocky structure, few snail shells, very abrupt wavy lower boundary.

Very dark gray (10YR 3/1) extremely firm clay loam, medium strong blocky structure, brown (10YR 5/3) marl deposit, few $\mathrm{CaCO}_{3}$ nodules, abrupt to very abrupt wavy lower boundary.

Very dark grayish brown (10YR 3/2) firm loam, weak blocky structure, few snail shell fragments, clear to abrupt wavy lower boundary.

Very dark gray (10YR 3/1) firm to extremely firm clay loam, coarse strong blocky structure, few snail shell fragments, gradual smooth lower boundary.

Grayish brown (10YR 5/2) firm loam, weak blocky structure, very few snail shell fragments, common $\mathrm{CaCO}_{3}$ nodules, gradual smooth lower boundary.

Dark gray (10YR 4/1) friable loam, many $\mathrm{CaCO}_{3}$ nodules. 
Depth Below

$\underline{\text { Zone }}$

Surface (cm)

TEST UNIT 10

1

0-7

2

$7-23$

3

$23-43$

4

43-70

5

70-108

6

108-128+
Description of Zone
Grayish brown (10YR 5/2) friable to loose loam, slopewash, common rootlets, insects, and snail shells, abrupt sloping lower boundary.

Grayish brown (10YR 5/2) loam, slopewash, weak fine platy structure, common roots and rootlets, common snail shell fragments and insects, abrupt sloping lower boundary.

Very dark gray (10YR 3/1) firm to friable loam, common roots and rootlets, few snail shell fragments and $\mathrm{CaCO}_{3}$ nodules, abrupt to clear irregular sloping lower boundary.

Very dark gray (10YR 3/1) firm to extremely firm loam and marl deposits, few rootlets, abrupt irregular lower boundary.

Very dark gray (10YR 3/1) firm loam, few rootlets, few $\mathrm{CaCO}_{3}$ filaments, gradual smooth lower boundary.

Dark grayish brown (10YR 4/2) firm grading to friable loam, common snail shells and $\mathrm{CaCO}_{3}$ nodules.

\section{WY113}

\section{BACKHOE TRENCH 1}

1

$0-34$

2

$34-35$

3

$35-70$

4

$70-100$

5

$100-215$

6

215-300+
Pale brown (10YR 6/3) sand, many roots, few $\mathrm{CaCO}_{3}$ nodules, canal berm fill, abrupt smooth lower boundary.

Pale brown (7.5YR 6/4) silt loam, lens pinches out toward canal wall, berm base, abrupt smooth lower boundary.

Dark grayish brown (10YR 3/2) loam, medium coarse moderate platy to blocky structure, common roots that decrease in frequency down profile, very firm at upper boundary grading down profile to firm below compaction zone, gradual smooth lower boundary.

Dark grayish brown (10YR 4/2) firm silt loam, medium moderate blocky structure, common $\mathrm{CaCO}_{3}$ nodules, gradual smooth lower boundary.

Brown to strong brown (7.5YR 5/4 to 5/6) silt loam, medium moderate blocky structure, grading from firm to friable down profile, many $\mathrm{CaCO}_{3}$ nodules, diffuse smooth lower boundary.

Brown (7.5YR 5/4) friable silt loam to clay loam, weak granular structure, few to rare $\mathrm{CaCO}_{3}$ nodules and manganese concretions. 


\section{Depth Below \\ Zone $\quad \underline{\text { Surface }(\mathrm{cm})}$ \\ Description of Zone}

\section{BACKHOE TRENCH 2}

$\begin{array}{lc}1 & 0-42 \\ 2 & 42-60 \\ 3 & 60-100 \\ 4 & 100-150 \\ 5 & 150-250+\end{array}$

Pale brown (10YR 6/4) sand, canal berm fill, very abrupt lower boundary.

Very dark gray (10YR 3/1) silt loam with platy structure, extremely firm probably compacted by canal construction machinery, upper boundary probably truncated, clear smooth lower boundary.

Dark grayish brown (10YR 4/2) firm silt loam with coarse moderate blocky structure, common snails, fine $\mathrm{CaCO}_{3}$ filaments, gradual smooth lower boundary.

Light brown (10YR 6/4) friable silt loam with weak medium blocky structure, many $\mathrm{CaCO}_{3}$ nodules, gradual smooth lower boundary.

Brown (7.5YR 5/4) silt loam with many fine distinct strong brown (7.5YR 5/6) mottles and granular structure, few $\mathrm{CaCO}_{3}$ nodules.

\section{TEST UNIT 1}

1

2

3

4

$38-67$

5

$67-110+$
Pale brown thin horizontal laminated sand layers, recent slopewash from large spoil berm, abrupt smooth lower boundary.

Pale brown sandy loam with granular structure, common rootlets, slopewash from large spoil berm, abrupt wavy lower boundary.

Very dark gray (10YR 3/1) extremely firm loam, medium strong blocky structure, few rootlets and insect burrows, gradual smooth lower boundary.

Very dark grayish brown (10YR 3/2) firm loam, rare $\mathrm{CaCO}_{3}$ filaments and nodules that increase in frequency down profile, few rootlets and insect burrows, rare charcoal fragments, gradual smooth lower boundary.

Dark yellowish brown (10YR 4/4) silt loam, firm grading to friable down profile, common $\mathrm{CaCO}_{3}$ nodules, rare rootlets.

\section{TEST UNIT 2}

1

$0-23$

2

23-61
Very dark grayish brown (10YR 3/2) friable to loose loam, few very dark gray (10YR 3/1) and yellowish brown (10YR 5/4) clay loam clasts, few snail shells, common rootlets, very abrupt wavy lower boundary.

Dark brown (10YR 4/3) extremely firm loam with medium moderate blocky structure, few $\mathrm{CaCO}_{3}$ nodules that increase in frequency down profile, few rootlets and snail shells, common insect burrows, gradual smooth lower boundary. 
$\underline{\text { Zone } \quad \begin{array}{l}\text { Depth Below } \\ \text { Surface }(\mathrm{cm})\end{array}}$

$361-100+$

\section{Description of Zone}

Yellowish brown (10YR 5/4) silty loam, common $\mathrm{CaCO}_{3}$ nodules, very few rootlets and snail shells.

\section{WY134}

\section{BACKHOE TRENCH 1}

$1 \quad 0-42$

2

42-75

3

$75-112$

4

$112-170$

5

170-235

$235-250+$

\section{BACKHOE TRENCH 2}

1

$$
0-56
$$

2

$56-72$

$72-100$
Gray (5Y 5/1) loose clay loam, berm construction fill, many roots, very abrupt irregular lower boundary.

Very dark gray (10YR 3/1) firm silt loam, few roots and rootlets, few sand filled small burrows, few very small $\mathrm{CaCO}_{3}$ filaments, very abrupt to abrupt irregular lower boundary.

'Very dark grayish brown (10YR 3/2) very firm silt loam with fine strong blocky structure and well developed ped faces with clay films, calcite crystals on ped faces, common roots, few small burrows, diffuse smooth lower boundary.

Grayish brown (10YR 5/2) firm clay loam with medium moderate blocky structure and thin clay films on ped faces, common $\mathrm{CaCO}_{3}$ nodules, very few roots and rootlets, few manganese concretions that increase down profile, diffuse smooth lower boundary.

Light brown (7.5YR 6/4) friable clay loam with weak blocky structure, many large $\mathrm{CaCO}_{3}$ nodules, few manganese concretions, diffuse smooth lower boundary.

Light brown to brown (7.5YR 6/4 to 5/4) friable silt loam, few $\mathrm{CaCO}_{3}$ nodules and manganese concretions, lower boundary not observed.

Grayish brown (10YR 5/2) loose silt loam, berm construction fill, many rootlets, abrupt irregular lower boundary.

Very dark gray (10YR 3/1) firm silt loam with coarse moderate blocky structure, common rootlets, few snail shells and charcoal flecks, rare calcite crystals and $\mathrm{CaCO}_{3}$ filaments, very rare clasts of Zone 3 blocks, very abrupt wavy lower boundary represents obvious unconformity.

Black (10YR 2/1) firm silt loam with more clay than Zone 2, fine to medium moderate blocky structure with thin clay films on ped faces, many thin $\mathrm{CaCO}_{3}$ filaments, few snail shell fragments, few rootlets in upper portion of zone, few $\mathrm{CaCO}_{3}$ nodules that increase down profile, gradual smooth lower boundary. 


$\begin{array}{ll}\text { Zone } & \begin{array}{l}\text { Depth Below } \\ \text { Surface (cm) }\end{array} \\ 4 & 100-125 \\ 5 & 125-165 \\ 6 & 165-250+\end{array}$

TEST UNIT 1

1

$0-48$

2

48-75

3

$75-98+$

\section{Description of Zone}

Dark gray (10YR 4/1) firm silt loam with medium moderate blocky structure, ped faces with very thin clay films, common $\mathrm{CaCO}_{3}$ filaments and few $\mathrm{CaCO}_{3}$ nodules that increase down profile, diffuse smooth lower boundary.

Grayish brown (10YR 5/2) friable clay loam with medium moderate blocky structure, common $\mathrm{CaCO}_{3}$ nodules and filaments, rare manganese concretions, gradual smooth lower boundary.

Light brown (7.5YR 6/4) clay loam although less clay than Zone 5, weak medium blocky structure, ped faces with clay films, few $\mathrm{CaCO}_{3}$ nodules some of which are surrounded by light brownish gray (2.5YR 6/2) clayey mottles, few calcite crystals, and dark rootlet casts, single whole snail shell at $187 \mathrm{~cm}$, lower boundary not observable.

Very dark gray (10YR 4/2) loose loam with chunks of very dark gray (10YR 3/1) sandy loam and yellowish brown (10YR 5/4) clay loam, few $\mathrm{CaCO}_{3}$ nodules and snail shells, large vertical cracks begin in this zone and extend to the bottom of the unit, three surfaces marked by laminated alternating sand and silt layers were probably created by ditch construction, abrupt wavy lower boundary.

Very dark gray (10YR 3/1) extremely firm loam with strong fine granular structure, few rootlets and $\mathrm{CaCO}_{3}$ nodules, rare snail shells, probably a plow zone that has been compacted by ditch construction activities, gradual smooth lower boundary.

Grayish brown (10YR 5/2) firm loam with weak blocky structure, many snail shells in upper portion of zone, few $\mathrm{CaCO}_{3}$ nodules.

\section{WY140}

\section{BACKHOE TRENCH 1}

$1 \quad 0-5$

2

$5-80$
Dark grayish brown (10YR 4/2) silt loam, construction fill, clear irregular lower boundary.

Dark grayish brown (10YR 4/2) extremely firm silt loam with platy structure in upper $10 \mathrm{~cm}$ due to compaction on road, changing to medium strong blocky structure with well developed ped faces without clay films below $10 \mathrm{~cm}$, common $\mathrm{CaCO}_{3}$ nodules that increase in frequency down profile, few manganese concretions, diffuse smooth lower boundary. 
Depth Below

Zone

Surface $(\mathrm{cm})$

3

$80-150$

4

$150+$

\section{BACKHOE TRENCH 2}

1

$0-5$

2

$5-40$

3

40-105

4

105-180+

2

27-34

3

$34+$

\section{Description of Zone}

Light brown (7.5YR 6/4) extremely firm clay loam with medium to coarse moderate blocky structure, very many $\mathrm{CaCO}_{3}$ nodules that decrease in frequency down profile, gradual smooth lower boundary.

Observed only on ditch bank below Backhoe Trench 1, generally same as Zone 3 but many fewer $\mathrm{CaCO}_{3}$ nodules.

Grayish brown (10YR 5/2) firm silt loam with platy structure, compacted construction fill, abrupt irregular lower boundary.

Dark grayish brown (10YR 4/2) extremely firm silt loam with moderate coarse blocky structure, common $\mathrm{CaCO}_{3}$ nodules increasing in frequency down profile, clear smooth lower boundary.

Brown (10YR 5/3) silt loam with moderate coarse blocky structure, very many $\mathrm{CaCO}_{3}$ nodules that decrease down profile, common manganese concretions, diffuse smooth lower boundary.

Pale brown (10YR 6/3) clay loam with medium moderate blocky structure and clay films on ped faces, few $\mathrm{CaCO}_{3}$ nodules, lower boundary not observable.

Grayish brown (10YR 5/2) loose silt loam, common $\mathrm{CaCO}_{3}$ nodules, compacted berm construction fill with old road surface composed of alternating sand and silt laminations at $11 \mathrm{~cm}$ below surface, abrupt wavy lower boundary.

Very dark grayish brown (10YR 3/2) firm loam with clasts of yellowish brown (10YR 5/4) clay loam, few $\mathrm{CaCO}_{3}$ nodules and rootlets, construction fill, abrupt wavy lower boundary.

Yellowish brown (10YR 5/4) to pale brown (10YR 6/4) extremely firm clay loam, strong coarse blocky structure, many $\mathrm{CaCO}_{3}$ nodules. 
APPENDIX D: Radiocarbon Dating

C. Britt Bousman 


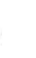

.
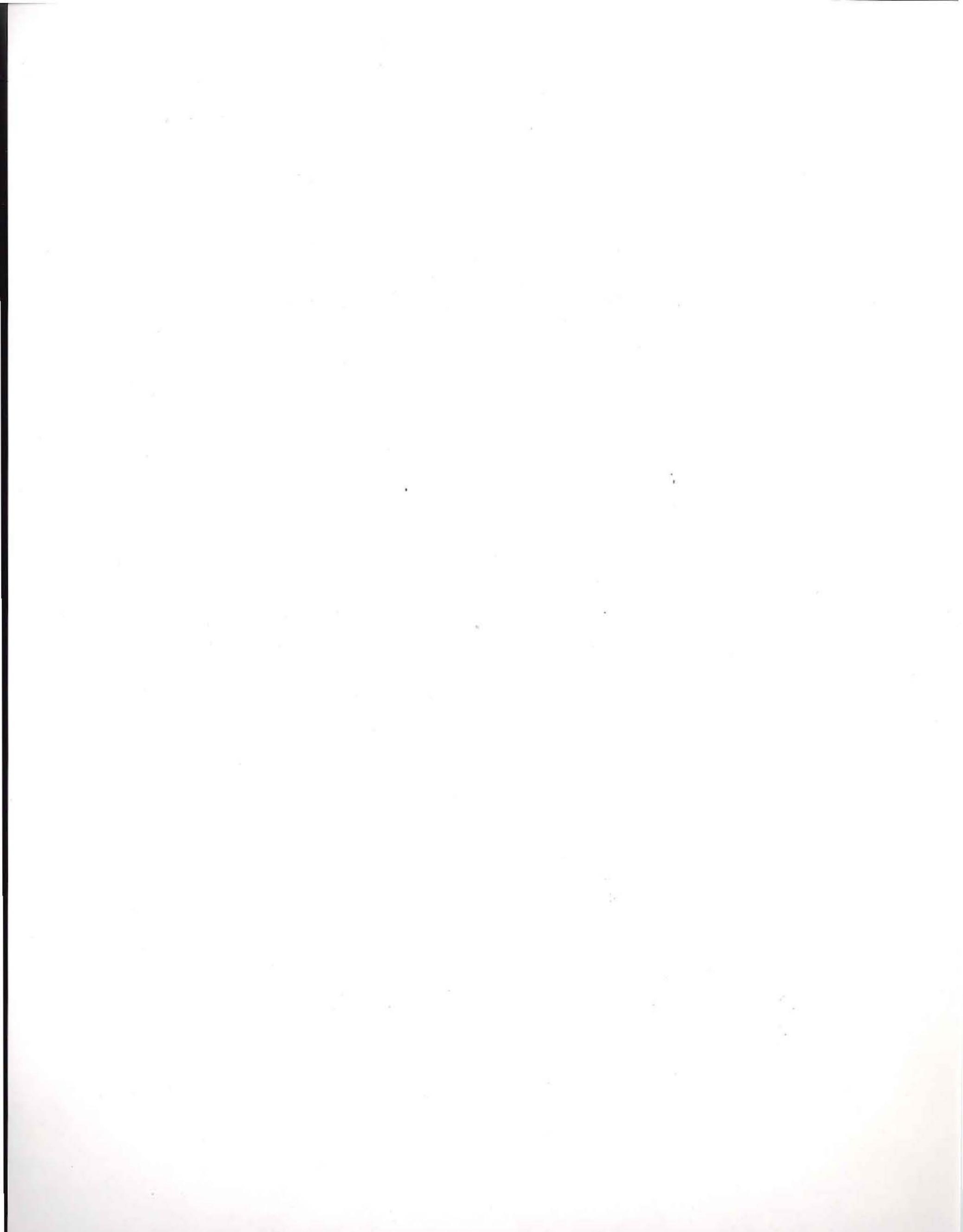
Twenty-four radiocarbon dates were obtained from a variety of materials in the Hidalgo-Willacy Drainage Ditch project area. The dated materials consist of charcoal, calcium carbonate nodules, freshwater marl, gelatin and apatite fractions of human and animal bones, and bulk soil humates, i.e., sediments, from buried soils and pond deposits. Table 27 lists the uncorrected (Libby half-life), the $\delta^{13} \mathrm{C}$ corrected, and when possible, tree-ring calibrated ages, as well as associated carbon, nitrogen, and oxygen stable isotope ratios. The stable isotope measurements on bones are from the collagen (gelatin) fractions unless otherwise indicated. Ages younger than 8100 B.P. were calibrated using the 20-year atmospheric record which requires $\delta^{13} \mathrm{C}$ corrected dates (Stuiver and Reimer 1986). The ages within the parentheses represent the intercepts on the calibration curve, and the two ages outside of the parentheses represent the one standard deviation range on either side of the intercept(s). Ages between 8100 and 13,300 B.P. can be roughly calibrated by the formula:

\section{Calibrated age $=1.05($ corrected age $)+470$.}

Radiocarbon ages older than 13,300 B.P. cannot be calibrated. Ages younger than 200 B.P. fall within the nonlinear portion of the calibration curve and have too many intercepts for useful calibration. Gelatin samples from the human burial and deer radius at 41WY113 were so small that these could be dated only by the AMS (accelerator mass spectrometer) technique, and samples were prepared by Geochron Laboratories and sent to the Institute of Nuclear Research at D.S.I.R. in New Zealand for this analysis. However, the conventional radiocarbon lab (Geochron) dated the apatite fractions of these samples, and has generously made these dates and stable isotopes available.

The graph below (Fig. 59) shows that ages corrected for fractionation effect can change significantly from the uncorrected ages, especially when younger than 5000 B.P. Only three dates were obtained from charcoal. On two of these, the uncorrected and corrected ages are the same; for the third, the age is reduced by the fractionation correction. In materials such as bulk soil humates, bones, and calcium carbonate, however, the fractionation correction consistently alters the ages, sometimes by significant amounts. Considering the amount of $\mathrm{C}_{4}$ vegetation in this region, dates on bulk soil humates and bones should always be corrected for fractionation effect. This graph demonstrates why corrected radiocarbon dates must be used in the new calibration curves.

Much recent research on bone dating has shown that apatite dates are often unreliable, especially if secondary carbonates are not carefully removed from the inorganic fraction (Hassan et al. 1977; Taylor 1987:53-61). Whenever possible, the organic fractions (i.e., bone gelatin or collagen) should be dated, but recent research has also shown that even these fractions can be altered by diagenesis (Stafford et al. 1987; Stafford et al. 1988). Thus all bone dates must be considered with caution.

Two radiocarbon dates have been obtained from bone from the human burial at 41WY50. Previously, an apatite sample produced an age of $540 \pm 110$ B.P. (Tx-4256) (Prewitt 1981); however, this date was not corrected for carbon isotope fractionation effect (Sam Valastro, personal communication 1989). The burial was well preserved and, in an effort to obtain a more accurate age for the burial, a small sample of gelatin was extracted for radiocarbon dating and stable isotope analysis. The resulting conventional gelatin age of $1415 \pm 140$ B.P. $(G X-15124-G)$ is considered more reliable than the previous date, because it was run on gelatin and corrected for fractionation effect. At 41WY113, gelatin and apatite fractions from two separate bone samples were dated as well. The gelatin dates are younger by 742 years in one case $(\mathrm{GX}-15123-\mathrm{G}$ versus $\mathrm{GX}-15123-\mathrm{A})$ and 480 years in the other (GX$15122-\mathrm{G}$ versus $\mathrm{GX}-15122-\mathrm{A})$. In all three cases where matching gelatin (i.e., collagen) and apatite radiocarbon dates are available, the difference between the matched pairs represents a significant change in estimated age (Student's $\mathrm{t}=1.88, \mathrm{p}$ $<0.07$ [41WY113, deer], Student's $t=4.91, \mathrm{p}$ $<0.01$ [41WY50, human burial], Student's $t=3.25$, $\mathrm{p}<0.01$ [41WY113, human burial]). In two additional radiocarbon bone samples, i.e., the $41 \mathrm{WY} 67$ human remains (GX-15254-A) and the 41WY140 turtle shell (GX-15125-A), only apatite dates were possible because of poor preservation of the gelatin fraction. While both apatite dates are very interesting and challenging to regional prehistoric interpretations and models, they must be regarded with added caution. 
TABLE 27

RADIOCARBON AGES

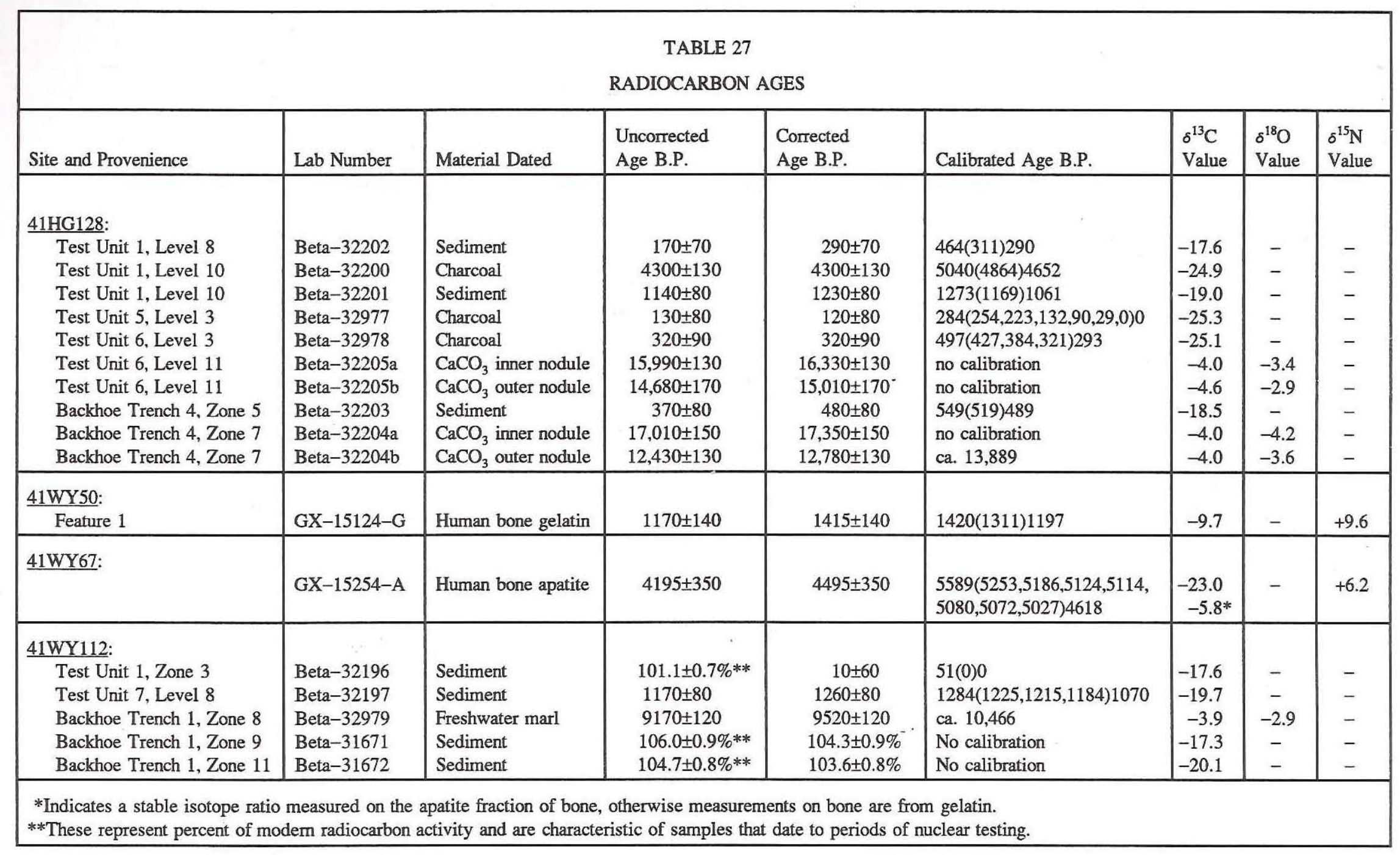


Table 27, continued

\begin{tabular}{|c|c|c|c|c|c|c|c|c|}
\hline Site and Provenience & Lab Number & Material Dated & $\begin{array}{l}\text { Uncorrected } \\
\text { Age B.P. }\end{array}$ & $\begin{array}{l}\text { Corrected } \\
\text { Age B.P. }\end{array}$ & Calibrated Age B.P. & $\begin{array}{l}\delta^{13} \mathrm{C} \\
\text { Value }\end{array}$ & $\begin{array}{l}\delta^{18} \mathrm{O} \\
\text { Value }\end{array}$ & $\begin{array}{l}\delta^{15} \mathrm{~N} \\
\text { Value }\end{array}$ \\
\hline \multicolumn{9}{|l|}{ 41WY113: } \\
\hline & GX-15123-G & Human bone gelatin & $940 \pm 90$ & $1088 \pm 90$ & $1069(980) 931$ & - & - & - \\
\hline & GX-15123-A & Human bone apatite & $1530 \pm 210$ & $1830 \pm 210$ & $1999(1804,1786,1760) 1530$ & $-6.1 *$ & - & - \\
\hline Test Unit 2 & $\mathrm{GX}-15122-\mathrm{G}$ & Deer radius gelatin & $2410 \pm 100$ & $2560 \pm 100$ & $2768(2742) 2489$ & - & - & - \\
\hline Test Unit 2 & $\mathrm{GX}-15122-\mathrm{A}$ & Deer radius apatite & $2745 \pm 235$ & $3040 \pm 235$ & $3479(3263) 2887$ & $-6.3 *$ & - & - \\
\hline Backhoe Trench 2, Zone 3 & Beta-32198 & Sediment & $1610 \pm 90$ & $1680 \pm 90$. & $1706(1569) 1515$ & -20.8 & - & - \\
\hline Test Unit 2, Level $5 / 6$ & Beta-32199 & Sediment & $2670 \pm 100$ & $2740 \pm 100$ & $2949(2850) 2759$ & -21.1 & - & - \\
\hline \multicolumn{9}{|l|}{ 41WY140: } \\
\hline Backhoe Trench 1, Zone 2 & $\mathrm{GX}-15125-\mathrm{A}$ & Turtle shell apatite & $9040 \pm 415$ & $9360 \pm 415$ & ca. 10,298 & $-4.9 *$ & - & - \\
\hline
\end{tabular}




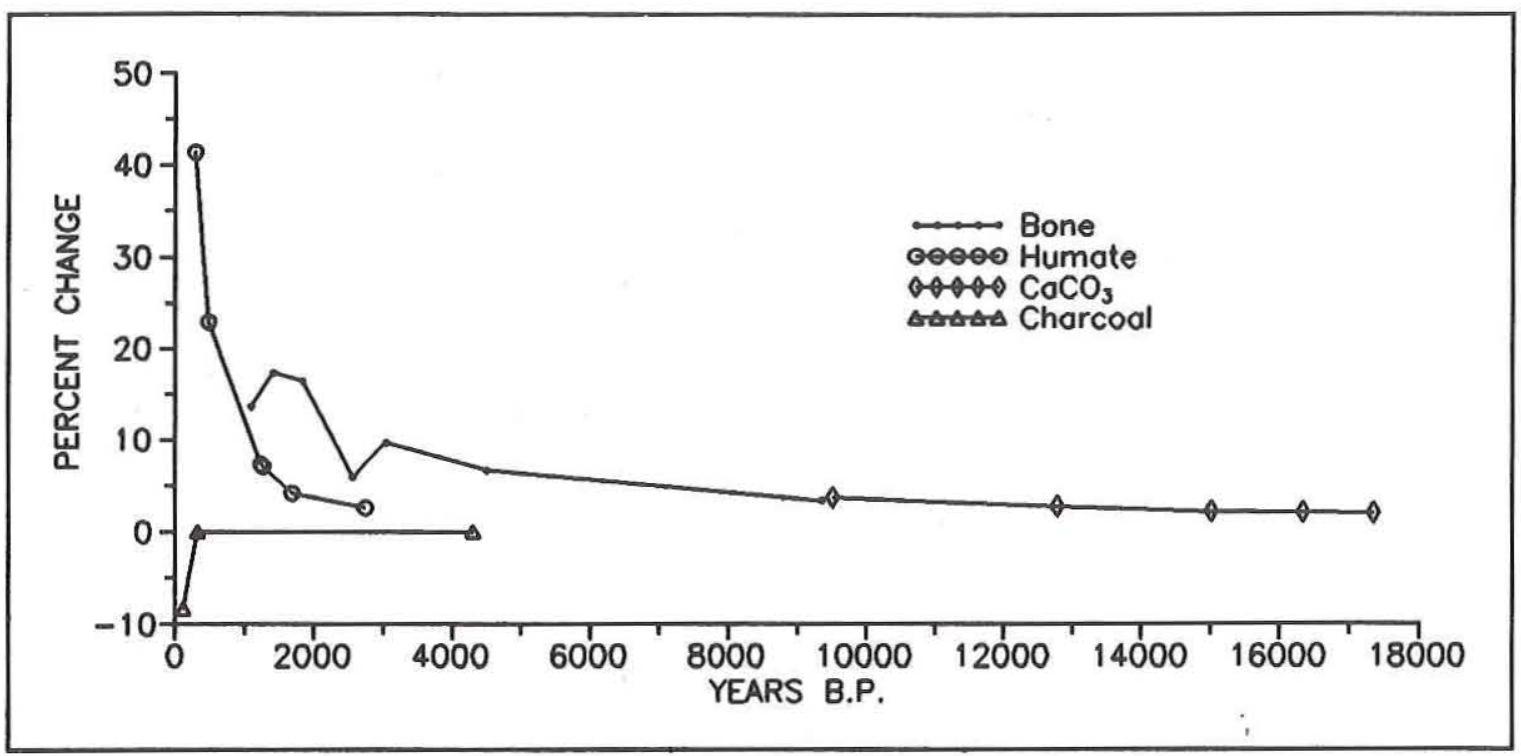

Figure 9. Percent change between uncorrected and corrected radiocarbon dates. 


\section{REFERENCES CITED}

Hassan, Afifa A., John D. Termine, and C. Vance Haynes, Jr.

1977 Mineralogical Studies on Bone Apatite and Their Implication for Radiocarbon Dating. Radiocarbon 19:364-374.

Prewitt, Elton R.

1981 Radiocarbon Dating. Appendix VIII in Cultural Resources Surveys and Assessments in Portions of Hidalgo and Willacy Counties, Texas, by D. William Day, Jane Laurens-Day, and Elton R. Prewitt, pp. 411-415. Reports of Investigations No. 15. Prewitt and Associates, Inc., Austin.

Stafford, Thomas W., Jr., A. J. T. Jull, Klaus Brendel, Raymond C. Duhamel, and Douglas Donahue 1987 Study of Bone Radiocarbon Dating Accuracy at the University of Arizona NSF Accelerator Facility for Radioisotope Analysis. Radiocarbon 29:24-44.

Stafford, Thomas W., Jr., Klaus Brendel, and Raymond C. Duhamel

1988 Radiocarbon, 13C and 15N Analysis of Fossil Bone: Removal of Humates with XAD-2 Resin. Geochimica et Cosmochimica Acta 52:2257-2267.

Stuiver, Minze, and Paula J. Reimer

1986 A Computer Program for Radiocarbon Age Calibration. Radiocarbon 28:2B:1022-1030.

Taylor, R. E.

1987 Radiocarbon Dating: An Archaeological Perspective. Academic Press, Orlando. 
APPENDIX E: Application and Comparison of Two Water Pump Systems

\author{
Colin M. Garvey
}




\section{INTRODUCTION}

During the current project, two different water pump systems were employed in water screening. The following is a brief discussion of their functions as well as advantages and disadvantages to practical archeological field application. This is not intended to be a comparison of makes and models but simply a comparison of tested pump alternatives.

\section{THE AGRICULTURAL PUMP OR POSITIVE DISPLACEMENT ROLLER SPRAY PUMP}

This apparatus is a proven system in its normal agricultural stop-and-go spraying of corrosive liquid fertilizers, pesticides, and herbicides. This task requires a noncorrosive pump with an ability to run multiple high pressure discharge lines while protecting the system against power surges. These qualities make it useful for archeological water- screening applications, particularly its ability to feed several stations at once without a great loss of pressure. This is accomplished by means of a manually preset pressure relief valve located in the pump outlet which reduces the chance of engine over-load (Fig. 60).

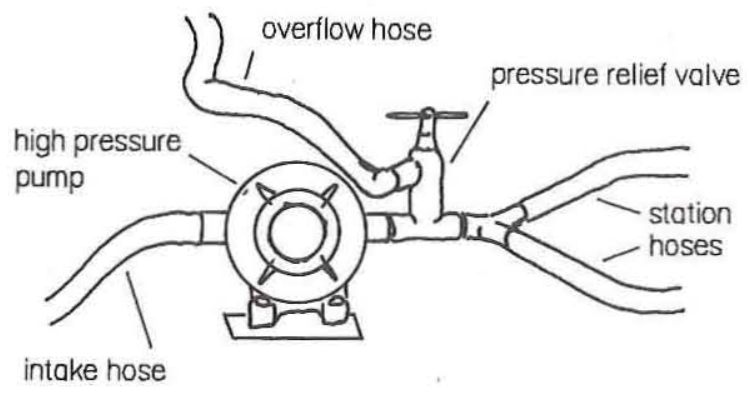

Figure 60. Drawing of agricultural pump.

Another convenience of the agricultural pump is that it requires only 3/4-inch-diameter high pressure hoses, eliminating the need for the larger-diameter (2-inch or 3-inch) vinyl hoses utilized by trash and transfer pumps. Also, the high pressure hoses are far less prone to punctures and carry a greater pound per square inch (psi) load without blowing fittings.

To power the agricultural pump in the field, a 5-horsepower Briggs and Stratton horizontal gasoline engine was used. This provided a maximum available pressure of 300 psi with a single discharge line. Although no more than two discharge lines were used, it is possible to operate the system with more. Each additional discharge line will reduce the psi to each screening station. For example, each discharge line in a two-line setup could carry as much as $150 \mathrm{psi}$, in four lines $75 \mathrm{psi}$ and so on. By comparison, a typical outdoor household spicket averages 40-60 psi. While these figures represent ideal performance levels but do not account for poor equipment conditions, it is evident that a system such as this is extremely useful in providing the various pressure needs encountered in archeological water screening.

\section{THE TRASH PUMP}

The trash pump is commonly used for archeological purposes simply because it is generally more available. Its design emphasizes movement of large volumes at the expense of pressure. An advantage of these pumps is the speed with which they can drain flooded excavations by utilizing a large-diameter hose. Additionally, many of the newer models are equipped with engines that include an automatic shut-off protecting against damages resulting from low or no oil in the crankcase.

The disadvantages of the trash pump are many in comparison to the agricultural pump. Since the trash pump is a volume mover, serious problems from pressure feedback can result due to alterations such as stepping down the main discharge hose size to increase the pressure or increasing the number of discharge lines off the main discharge line (Fig. 61). It is important to maintain a constant flow of water through the discharge line or lines since the trash pump is not equipped with a relief valve. The ideal would be to allow the main discharge line to run freely but this would require handling a two-inch-diameter hose at the screening station which could be a very cumbersome task. The trash pump is also subject to additional strain when attempting to force water 

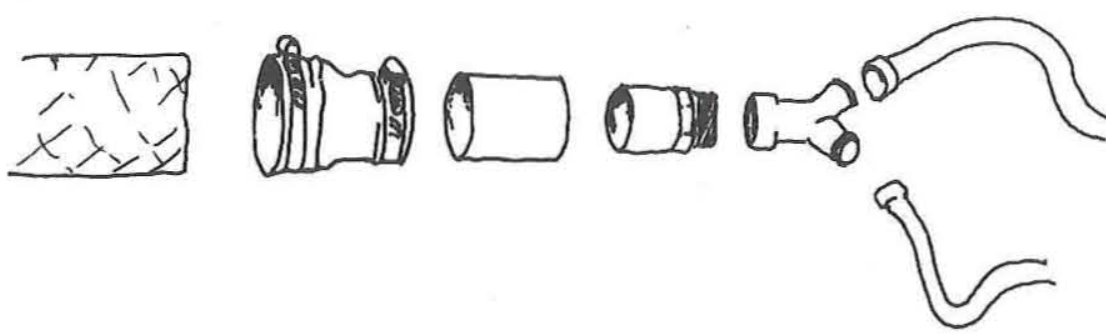

Figure 61. Drawing of trash pump showing main feeder hose and step-down mechanism for smaller hoses.

up steep inclines where screening stations must be placed in some field situations.

\section{SUMMARY}

The basic difference between the two pumps discussed here is their accomodation of pressure and volume. For most screening operations, a controllable pressure system using an adjustable nozzle is preferable to a constant high-volume low-pressure unalterable flow. An agricultural pump system is not only more efficient, it is considerably less expensive to customize or rent. It can allow for far greater flexibility with less labor. 
APPENDIX F: Archeological Reconnaissance of a Realigned Segment of the Mission-Lateral, Hidalgo County, Texas

J. Michael Quigg 



\section{INTRODUCTION}

Archeological reconnaissance of a realigned channel segment of the Mission-McAllen Lateral west of Edinburg, Texas, was conducted for Hidalgo County Drainage District No. 1 during the month of April, 1989 by Prewitt and Associates, Inc., Austin. This work is a continuation of a survey program intended to mitigate damages to cultural resources resulting from implementation of drainage improvements (Mallouf et al. 1977; Day et al. 1981; Hall et al. 1987).

The Mission-McAllen Lateral ditch realignment lies nearly $9.6 \mathrm{~km}$ (6 miles) west of the Edinburg courthouse and $3.5 \mathrm{~km}$ ( 2.25 miles) south of Highway 107. It extends from the north-south Edinburg Canal westward nearly $800 \mathrm{~m}(0.5$ miles) crossing Bentsen Road, then turns $90^{\circ}$ north for another $450 \mathrm{~m}$ ( 0.25 miles) to connect with a previously surveyed segment (Fig. 62). The Mission-McAllen Lateral lies in the lowland plain (see Chapter 1). The realigned segment crosses an area near an eolian depression, most of which has been cultivated in the past. Presently, the portion lying east of Bentsen Road is overgrown with various acacia trees with virtually ne ground cover. The remaining portion is overgrazed pasture with sparse grasses and few acacia trees.

\section{METHODS, RESULTS, AND RECOMMENDATIONS}

The realigned segment was traversed in a zigzag fashion between the marked right-of-way boundaries from Bentsen Road to each end and back again. The ground surface, including small water ditches and rodent holes, was inspected for signs of cultural materials.

No prehistoric or historic sites were discovered during this surface reconnaissance. Materials observed include sparse land snails (Rabdotus sp.), recent garbage, and recent bovid elements in various stages of decay. No gravels were observed except immediately adjacent to Bentsen Road.

This realigned segment reveals no surface evidence of archeological resources. However, in kecping with previous programs of investigations in the Hidalgo-Willacy Drainage Ditch project, it is recommended that this high-potential area adjacent to the depression be reinspected following the excavation of the ditch. Examination of the ditch banks following construction should permit a clearer understanding of geology in this area and an opportunity to recognize buried sites.

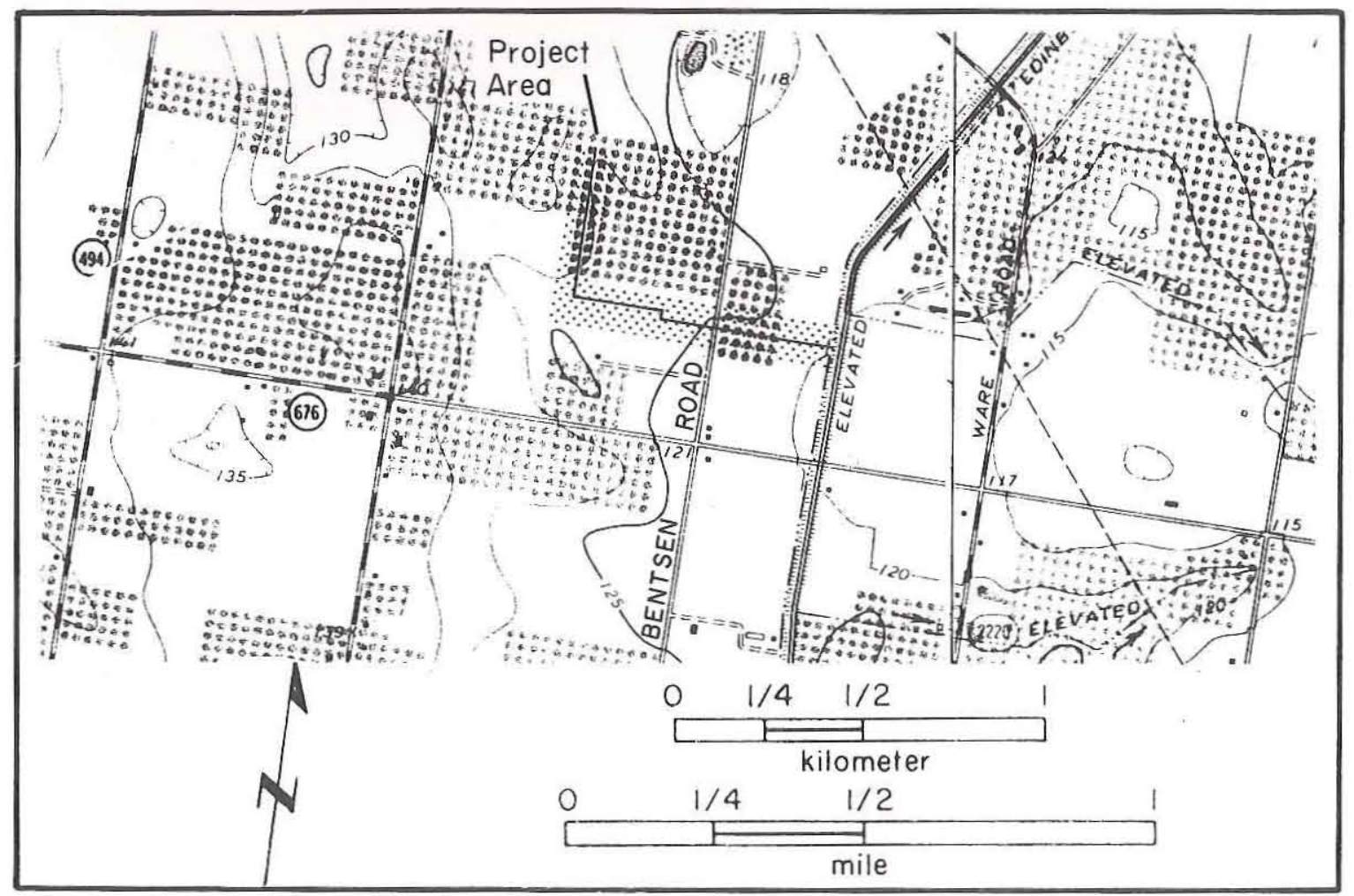

Figure 62. Section of USGS 7.5' Alton and Edinburg, Texas quadrangles showing survey areas. 


\section{REFERENCES CITED}

Day, D. William, Jane Laurens-Day, and Elton R. Prewitt

1981 Cultural Resources Surveys and Assessments in Portions of Hidalgo and Willacy Counties, Texas. Reports of Investigations No. 15. Prewitt and Associates, Inc., Austin.

Hall, Grant D., Michael B. Collins, and Elton R. Prewitt

1987 Cultural Resources Investigations Along Drainage Improvements, Hidalgo and Willacy Counties, Texas: 1986 Investigations. Reports of Investigations No. 59. Prewitt and Associates, Inc., Austin.

Mallouf, Robert J., Barbara J. Baskin, and Kay L. Killen

1977 A Predictive Assessment of Cultural Resources in Hidalgo and Willacy Counties, Texas. Survey Report 23. Office of the State Archeologist, Texas Historical Commission, Austin. 